\title{
Liberalismo y pragmatismo: una lectura de la justicia como imparcialidad desde el pragmatismo de John Dewey
}

\author{
TESIS \\ Para obtener el título de \\ Doctor en Filosofía
}

PRESENTA:

Diego Alejandro Otero Angelini 
Para ti papá, que ya no estás, que te extraño 


\section{Contenido}

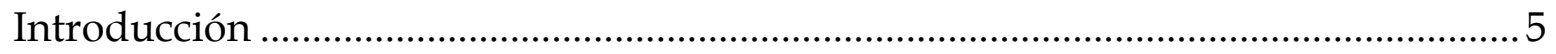

Democracia pragmática ...........................................................................................11

La justicia como imparcialidad ............................................................................ 16

Parte I. Democracia, liberalismo y pragmatismo en John Dewey ..................................24

Capítulo 1. Pragmatismo, verdad y razonamiento moral en John Dewey............. 25

Experiencia, verdad y método en John Dewey .........................................................28

Ética y razonamiento moral en John Dewey ............................................................ 41

Capítulo 2. Política pragmática y la justificación del liberalismo en John Dewey62

El origen de la comunidad y el surgimiento del Estado..........................................63

Cultura democrática liberal y cientificismo social................................................... 83

Parte II. El liberalismo antiperfeccionista de Teoría de la Justicia ...................................99

Capítulo 3. Una teoría de la justicia............................................................................ 100

Una teoría de la justicia o Teoría de la Justicia ......................................................104

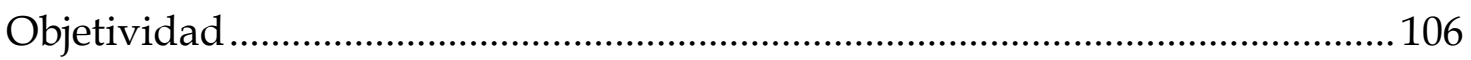

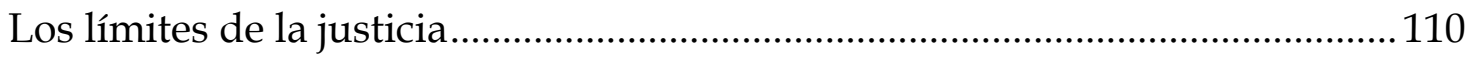

La elección entre las concepciones candidatas y el equilibrio reflexivo............123

El papel de la justicia en una sociedad liberal....................................................127

Capítulo 4. La Justicia como Imparcialidad en Teoría de la Justicia .........................139

Una concepción de la justicia procedimental .......................................................141

Los principios de la justicia..................................................................................... 164

Antiperfeccionismo y liberalismo político............................................................... 193

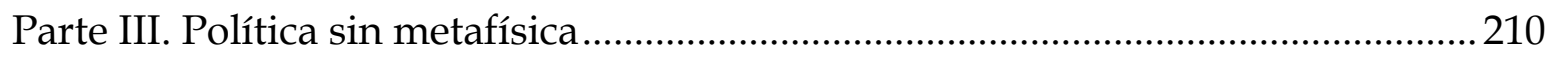

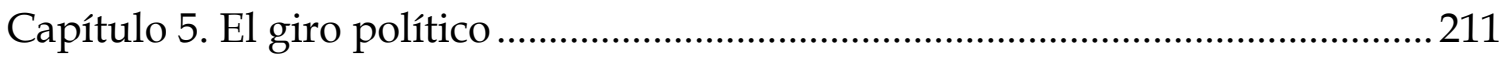

La nueva cuestión central de la justicia como imparcialidad ............................. 214

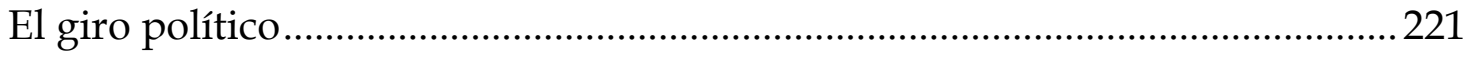

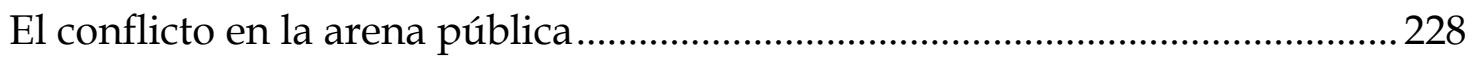

Capítulo 6. Liberalismo político y liberalismo moral ............................................... 251

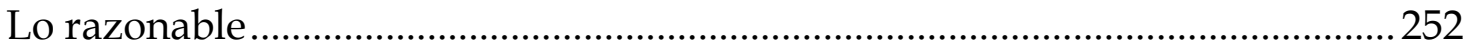




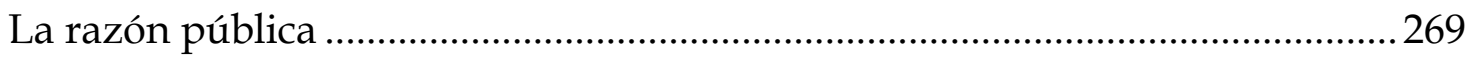

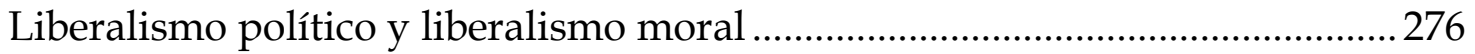

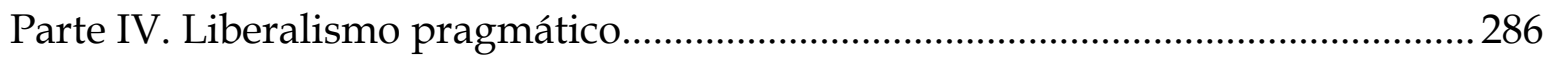

Capítulo 7. Una lectura pragmática de la justicia como imparcialidad .................287

La razón pública conforme al giro pragmático ......................................................307

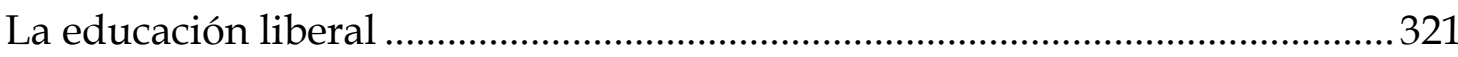

La justicia como imparcialidad, progreso y perfección ..........................................340

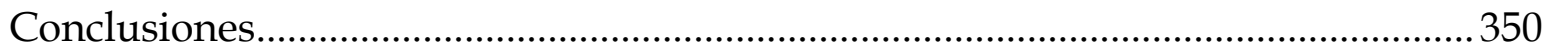

Las características moralmente relevantes para la justicia y el hecho del

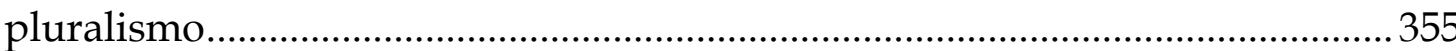

La relación entre democracia y liberalismo .........................................................360

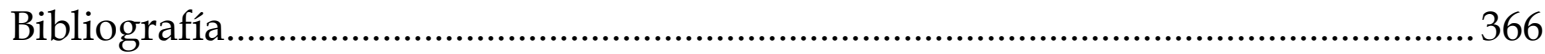




\section{Introducción}

Han pasado veintiocho años desde que Francis Fukuyama declaró que el fin de la historia estaba llegando. Los valores liberales, el desarrollo de la democracia y el cosmopolitismo estaban, de acuerdo con el análisis de Fukuyama, completamente seguros dada la falta de competencia ideológica:

Mientras que es imposible desechar la posibilidad de que aparecieran súbitamente nuevas ideologías o contradicciones previamente no reconocidas en las sociedades liberales, el mundo actual parece confirmar que los principios fundamentales de la organización socio-política no han avanzado terriblemente desde 1806. Muchas de las guerras y revoluciones peleadas desde ese tiempo han sido conducidas en el nombre de ideologías que declaraban ser más avanzadas que el liberalismo pero cuyas pretensiones fueron finalmente desenmascaradas por la historia. Mientras tanto, han ayudado a propagar el estado universal homogéneo al punto en que podría tener un efecto significativo en el carácter general de las relaciones internacionales. $^{1}$

Aunque parecería que, en caso de tener razón, Fukuyama debería celebrar este estado, concluye con una nota un tanto más sombría:

El fin de la historia será un tiempo muy triste. La lucha por el reconocimiento, la voluntad de arriesgar la vida por un objetivo puramente abstracto, la lucha mundial ideológica que invocó el arrojo, valor, imaginación e idealismo será reemplazada por los cálculos económicos, el infinito solucionar de problemas técnicos, preocupaciones ambientales y la satisfacción que el sofisticado consumidor demanda. En el periodo post-histórico no existirá arte ni filosofía, sólo el perpetuo cuidado del museo de la historia humana. Puedo sentir en mí, y en otros a mi alrededor, una nostalgia poderosa por el tiempo en que la historia existía. (...) Aunque reconozco su inminencia, tengo los sentimientos más ambivalentes por la civilización que fue creada en Europa desde 1945 con sus participantes en el norte del Atlántico y Asia. Tal vez este pronóstico de siglos de aburrimiento al fin de la historia sirva para llevar a la historia a iniciar una vez más. ${ }^{2}$

El tiempo del aburrimiento no llegó. Después de todos estos años a nadie le sorprendería saber que la historia, en los términos en que planteó Fukuyama, no ha terminado. Lo que es más, es posible afirmar que la democracia liberal, con todos los valores que la conforman, está hoy más en riesgo que en cualquier otro

\footnotetext{
${ }^{1}$ Francis Fukuyama, “The End of History?", The National Interest, no. 16 (1989): 15

${ }^{2}$ Ibid. 18
} 
momento en la última década. De acuerdo a un reporte de Freedom House, para el año 2017, un total de 67 países tuvieron una caída en sus índices de derechos políticos y libertades civiles, mientras que sólo 36 alcanzaron mejorar respecto al año anterior. ${ }^{3}$

Francis Fukuyama, quien después matizó su opinión, ${ }^{4}$ estaba claramente equivocado. El último par de años ha visto un resurgimiento de las políticas de tendencia antiliberal, profundamente conservadoras (en el peor sentido posible) y nacionalistas, en Europa y en Estados Unidos. Del mismo modo, la influencia de la democracia liberal no ha impedido que algunas naciones latinoamericanas tendieran a políticas represivas, normalmente consideradas de izquierda, que contradicen igualmente algunas de las aspiraciones del liberalismo que Fukuyama proclamaba vencedor de la guerra ideológica en la historia de la humanidad. La primavera árabe, que parecía ser un tiempo de esperanza para aquellos que sostienen la validez de la democracia liberal, fue corta y con resultados más bien limitados: inestabilidad en algunos casos, el fortalecimiento de regímenes dictatoriales en otros y, por supuesto, la llegada de políticas de corte teocrático, con alto contenido racial, en otros. Podríamos continuar con un análisis así por el resto de la geografía mundial y veríamos que, aun cuando la democracia liberal sigue siendo la opción preferida por naciones desarrolladas y en vías de desarrollo, su lugar en la historia no está claramente definido.

Quizá la dificultad principal para que la sociedad democrática liberal pueda establecerse y alcanzar el éxito que Fukuyama planteó está en su naturaleza misma. Los Estados actuales son muy grandes, en su mayoría albergan decenas de millones de ciudadanos y, contrario a lo que supone la sentencia del fin de la historia, no existe un consenso claro en los ideales de vida buena y en qué significa la justicia, esa virtud que tendemos a reconocer como necesaria para vivir en sociedad. Este hecho, que Rawls denominaba el del pluralismo, ${ }^{5}$ es un factor de inestabilidad natural irremediable si hemos de vivir en una sociedad donde se respeten las libertades de los individuos. Probablemente el modo más eficaz para anular ese pluralismo es mediante el uso de un Estado represor que, incluso en casos como el de Corea del Norte (que es criminal bajo cualquier estándar que no

\footnotetext{
${ }^{3}$ Cfr. https://freedomhouse.org/report/freedom-world/freedom-world-2017

${ }^{4}$ Habló de matiz porque, aunque reconoció que la historia no terminó en los términos en que supuso y la democracia liberal no se instauró (ni se instaurará) como el marco insitucional inamovible, sostiene la superioridad absoluta de la democracia liberal en términos racionales por lo que, la inestabilidad, tiende a ser más bien el producto de "debilidad tanto de la razón como de la política" (Francis Fukuyama: The end of History and the Last Man, (The Free Press: Nueva York, 1992), 212)

${ }^{5}$ John Rawls, Political Liberalism (Nueva York: Columbia University Press, 2005). xvii
} 
sea el de ellos mismos), no puede ser efectivo completamente. El mantenimiento de la democracia liberal claramente no está garantizado por su consistencia ideológica como parece presuponer Fukuyama. Sostener que es la opción mejor justificada no supone su consistencia ni, mucho menos, su realización.

La existencia de la sociedad liberal está condicionada por una tensión que la conduce a mantener su sobrevivencia en riesgo: la tolerancia a ideas del bien diversas, en algunos casos contrarias, que sostengan los ciudadanos y la necesidad de promover una concepción de la justicia (y quizá también una especie de ideal de bien liberal) lo suficientemente compartida como para que dichas ideas del bien puedan coexistir. ¿Cómo es posible alcanzar acuerdos sobre las normas fundamentales que gobiernen la sociedad si el desacuerdo entre los ciudadanos sobre algunas de las creencias más fundamentales puede ser irreconciliable y sobre algunos de sus valores más fundamentales? ¿Debemos respetar la autonomía y libertad de todos los ciudadanos dentro de la comunidad política a perseguir sus propios fines? ¿Qué responsabilidades tiene el Estado, entendiéndolo en este punto como sociedad organizada a través de oficiales, para facilitar el ejercicio de la libertad de los individuos?

Éstas y otras cuestiones se encuentran de fondo en los diversos planteamientos liberales. El modo de responderlos es sumamente diverso y, así como sucede con las ideas del bien de los ciudadanos, a veces incompatibles. En esta investigación me daré a la tarea de analizar dos de las que, en mi opinión, son de las mejores propuestas para pensar la sociedad liberal. Por un lado, estudiaré la democracia liberal y pragmática de John Dewey y, por otro, la teoría de la justicia, es decir, la justicia como imparcialidad, de John Rawls. Mi objetivo central será el de encontrar el modo en que estas dos elaboraciones del liberalismo pueden ser complementarias y, al mismo tiempo, hasta qué punto son críticas incompatibles entre ellas.

La cuestión sobre si el interés de ambos autores por la democracia liberal puede ser explicado por sus historias personales no puede escapar al mundo de la especulación, sin embargo es una que vale la pena hacer al menos brevemente. Después de todo, si estamos dispuestos a conceder a Dewey un punto, este podría ser que: "lo que llamamos motivos terminan siendo, después de un análisis crítico, un patrón complejo de actitudes formado bajo condiciones culturales más que simples elementos de la naturaleza humana." ${ }^{6}$

\footnotetext{
${ }^{6}$ John Dewey, Freedom and Culture (Nueva York: Prometheus Books, 1989), 86.
} 
Como si el cientificismo de su pensamiento, así como su cercanía con el pensamiento evolutivo de Darwin hubieran estado dictados por una especie de destino, cuya existencia él hubiera rechazado, Dewey nació en 1859, mismo año de la publicación de El Origen de las Especies, en una pequeña ciudad en el norte de los Estados Unidos (Burlington, en el estado de Vermont). Su niñez fue en el seno de una familia cristiana, en el norte de un país que acababa de terminar una Guerra Civil que confrontó visiones del mundo incompatibles (uno donde todos los individuos deberían ser considerados igualmente libres y otro en el que la esclavitud era una institución aceptable). De igual modo, una vez que Dewey ya había abandonado su cristianismo y se consagraba como uno de los principales exponentes del pragmatismo, vivió durante la Primera Guerra Mundial y criticó profundamente las actitudes imperialistas de algunas de las naciones europeas. Después de la crisis de 1929, una vez concluida esa guerra, reconoció en el capitalismo un sistema que, a pesar de haber traído grandes beneficios con el desarrollo de la industria, era capaz de generar inseguridad económica y atentar contra la libertad de los ciudadanos. Quizá fue por esa razón que fue un crítico del New Deal, al considerarlo una concesión a los grandes capitales de su época. ${ }^{7}$ Durante este mismo tiempo Dewey reconoció los peligros del totalitarismo en sus vertientes fascistas y nacionalsocialistas, las que criticó implacablemente. Igualmente, a pesar de sus objeciones al capitalismo, fue crítico del comunismo soviético $\mathrm{y}$, en particular, de la idea de sostener que la revolución era una condición necesaria para el desarrollo de las libertades. Las consecuencias de la Segunda Guerra Mundial y el uso del conocimiento científico con fines de destrucción fueron también realidades durante su vida. Dewey murió, en Nueva York, en 1952 habiendo sido un filósofo profundamente interesado en la crítica social y cultural de su tiempo. Al contrario de como sucede con otros pensadores, su pensamiento lo incapacitaba para la reflexión moral o política distanciada de los eventos del momento que le tocó vivir.

Por su parte, John Rawls nació en el año de 1921. Al igual que Dewey creció en un hogar cristiano. Al terminar sus primeros estudios en filosofía en la Universidad de Princeton decidió ingresar en el Ejército de los Estados Unidos y fue a pelear al Pacífico en el año de 1943. La guerra tuvo un gran impacto en el joven Rawls. Después concluido su servicio regresó para conseguir su doctorado en 1950 en Princeton donde pasó los siguientes dos años como instructor. A continuación Rawls fue a Oxford, a realizar estudios post doctorales, donde recibió la influencia de pensadores como H. L. A. Hart e Isaiah Berlin. A su regreso tuvo

${ }^{7}$ Cfr. Alan Ryan, John Dewey and the high tide of American Liberalism (Norton: Nueva York, 1997), 23. 
una estancia en la Universidad de Cornell y el Instituto Tecnológico de Massachusetts hasta llegar a Harvard, institución a la que pertenecería hasta su retiro en 1991. Quizá el evento que marcó de modo más importante la carrera intelectual de Rawls fue, como sería de esperar, la Guerra. La Segunda Guerra Mundial no sólo implicó las dificultades que vivió de primera mano, igualmente el Holocausto tuvo un impacto especial en él, como lo afirma Samuel Freeman:

La masacre en masa de la Segunda Guerra Mundial condujo a Rawls a preguntarse estas y otras cosas. ¿Por qué un Dios benevolente crearía humanos para que estuvieran naturalmente inclinados a aceptar, sin contar que a llevar a cabo, ese tipo de asesinatos en masa y destrucción de seres humanos? Al contrario de inspirar a Rawls a reafirmar su doctrina cristiana, el mal horrendo de la Segunda Guerra Mundial lo condujo a renunciarla. Abandonó el cristianismo porque la moralidad de Dios (al contrario de la moralidad humana) no tenía sentido para él. ${ }^{8}$

El siglo pasado fue el escenario de las dos guerras más devastadoras en la historia de la humanidad, de igual modo generó las condiciones para que, si existiera una tercera, sus repercusiones serían, en cierto sentido, inimaginables. La preocupación por desarrollar una teoría liberal funcional y que sea estable en el tiempo me parece, en el caso de ambos pensadores, una inquietud natural dadas sus circunstancias históricas.

Tanto Rawls como Dewey reconocieron que el pluralismo, el hecho que diversos grupos de individuos poseen lo que Rawls denomina diversas doctrinas comprehensivas, es una realidad en las sociedades democráticas actuales. Esta realidad hace que la justificación de una sociedad liberal dependa, en buena medida, de la capacidad de generar las condiciones que garanticen, no sólo su conveniencia o efectividad, sino también su estabilidad.

Las similitudes que pudieran existir en sus motivaciones no implican que no existan grandes diferencias en sus métodos. Todo lo contrario. A pesar de que en esta investigación haré un esfuerzo por demostrar que son compatibles, en especial por la tendencia pragmatista en el pensamiento de Rawls (que me parece que no ha sido suficientemente explorada por sus lectores al centrarse más bien en su kantismo y, posteriormente, el giro político), eso no significa que las propuestas sean naturalmente compatibles, como explica Daniel Savage:

Dewey ofreció una justificación del liberalismo basada en el desarrollo individual en oposición a las justificaciones dominantes basadas en derechos (o contractuales). De la concepción del liberalismo de Dewey también puede decirse que es un modelo basado en un ideal que justifica el liberalismo como el centro de una teoría

${ }^{8}$ Samuel Freeman, Rawls (Routledge: Nueva York, 2007), 9. 
particular de la vida buena. Las teorías basadas en derechos [rights-based theories], en contraste, normalmente buscan presentar una concepción de la justicia basada en la neutralidad entre concepciones de la justicia en competencia. La Teoría de la Justicia de John Rawls es un ejemplo de una justificación del liberalismo basado en la neutralidad. (...) Las justificaciones basadas en la neutralidad no interpretan los valores liberales como representantes de una concepción particular del bien. Al contrario, promueven el liberalismo como un marco de referencia neutral en el cual una pluralidad de concepciones del bien pueden coexistir pacíficamente. ${ }^{9}$

La influencia de ambos autores al debate contemporáneo no puede ser minimizada. Rawls es normalmente reconocido como el pensador que revivió la tradición contractualista en la segunda mitad del siglo XX. Esta revitalización del contractualismo no es, en absoluto, menor. Como menciona Daniel Savage en el fragmento anterior, este tipo de argumento se encuentra de fondo en el debate de la constitución política fundada en derechos, la cual es una de las tendencias principales de discusión en la actualidad. Esta tradición supone la idea de que la constitución justificada será aquella que, dadas ciertas condiciones contractuales, sería aceptada por individuos libres e iguales. Esta es la idea que estaba presente en las justificaciones de algunas de las revoluciones del siglo XVIII, como es claro en la Declaración de Independencia de los Estados Unidos y en la Declaración de los Derechos del Hombre de la Revolución Francesa.

Por su parte, las ideas de Dewey tuvieron su impacto principal en campos los campos de la educación y la crítica cultural. Ahora bien, reconocer que el mayor impacto de su pensamiento fue en esos ámbitos no supone que sus contribuciones en ética, teoría del conocimiento o filosofía política sean menores. Si bien es cierto que después de su muerte el pensamiento de Dewey dejó de tener el papel protagónico que tuvo durante su vida, en años recientes ha existido, en el campo de la filosofía, un renovado interés. Este retorno a algunas de las ideas de Dewey fue llevado a cabo principalmente por pensadores como Hilary Putnam, Richard Rorty, Molly Cochran, Daniel Savage o Steven Fesmire. Al contario de Rawls, que centró prácticamente la totalidad de su obra en la filosofía política y ética, Dewey fue un pensador que dedicó esfuerzos a múltiples disciplinas filosóficas, sociales y hasta científicas, todo eso con una consistencia conceptual admirable. Esta actividad obliga a quien quiera comprender su propuesta de democracia liberal a tener una visión, al menos general, de los supuestos políticos, éticos y antropológicos que sostiene.

\footnotetext{
${ }^{9}$ Daniel M. Savage, John Dewey's Liberalism (Southern Illinois University Press: Illinois 2002), 2.
} 
Antes de iniciar con la exposición de la estructura de esta investigación me parece importante decir algunas cosas sobre las ideas propuestas de ambos autores.

\section{Democracia pragmática}

El pensamiento político de John Dewey es bien conocido por su defensa de la democracia y el liberalismo. Que un filósofo norteamericano de principios del siglo pasado haya sido partidario de la democracia es difícilmente una rareza. Sin embargo, aun cuando no sea sorpresiva la tendencia de Dewey a favor de la democracia, la manera en que argumenta por ella sí es, en mi opinión, innovadora.

La innovación de Dewey proviene de su capacidad de justificar la relevancia de la democracia liberal mediante premisas pragmáticas. El pragmatismo de Dewey supone que todo el conocimiento humano es producto de nuestra experiencia empírica, que vivimos como somos seres orgánicos, que existen en un mundo. ${ }^{10}$ Como mencioné antes, el pensamiento de Dewey está profundamente influenciado por el pensamiento evolutivo de Darwin. Teniendo esto en mente, Dewey asume que los seres humanos interactúan, como todos los demás organismos, de acuerdo a las facultades que han desarrollado durante su proceso evolutivo. Esta noción implica un naturalismo en el desarrollo de las facultades humanas que permea todos sus modos de interacción con su medio. Es decir, Dewey no reconoce la existencia de facultades que no puedan ser explicadas por el mero desarrollo evolutivo, como podría ser algún tipo de Razón Pura o Intelecto Agente. $^{11}$

Este naturalismo genera ciertos problemas para poder explicar algunos de los objetos del conocimiento humano. No es extraño escuchar que en parte lo que nos diferencia de los animales es nuestra capacidad de conocer algunas "verdades" últimas o autoevidentes, Dewey no aceptaría esto. El pragmatismo deweyano sostendría, más bien, que lo que realmente nos diferencia de otros seres, en tanto a nuestras habilidades cognitivas, son las capacidades, más desarrolladas, de reconocer incertidumbre en nuestras situaciones y de plantear escenarios para prever como pueden ser alteradas a futuro. ${ }^{12}$ Así, cada individuo es capaz de

\footnotetext{
${ }^{10}$ Cfr. John Dewey, Logic (Nueva York: Saerchinger Press, 2007), 66-67.

${ }^{11}$ Cfr. Ibid. 46.

${ }^{12}$ Cfr. Ibid. 50.
} 
relacionarse con el mundo de acuerdo a sus necesidades. La indagación, el proceso de comprender una circunstancia incierta y el modo en que es posible interactuar con ella, está condicionada por la experiencia de cada ser humano, lo que no signifique que no pueda ser compartida entre todos.

La teoría del conocimiento pragmática que propone Dewey niega el representacionismo en la medida en que nuestras ideas no representan a la realidad en sí misma. Los seres humanos sólo pueden reconocer la realidad como es para ellos, del modo en que su existencia los afecta. Esto hace que podamos juzgar nuestras ideas de acuerdo a su funcionalidad respecto al entorno. Una mejor idea, compitiendo con el resto, es la que es considerada verdadera. Digamos que, desde las premisas deweyanas, cuando decimos que algo es verdad estamos afirmando que dicha idea o juicio es aquella que puede ser mejor verificada en el mundo y esto sólo puede ser así en función de su capacidad predictiva. ${ }^{13}$

Esta interpretación del conocimiento humano puede ser encontrada en su mejor manifestación, piensa Dewey, en el conocimiento científico. En el conocimiento científico alcanzamos un mayor nivel de abstracción pues somos capaces de pensar en cualidades de la realidad y pensarlas bajo diversas condiciones mínimas. La ciencia es el método indagatorio por excelencia en la medida en que se ha alejado de las discusiones metafísicas que no pueden ser realmente respondidas con el grado de certidumbre al que este tipo de indagación aspira y, por lo mismo, se mantiene en el campo de lo empíricamente justificable. Esto no significa que aquellos conocimientos que consideramos tradicionalmente parte del corpus científico sean verdaderos absolutamente. En la medida en que nuestro conocimiento del mundo está condicionado por nuestra circunstancia, piensa Dewey, siempre es posible desarrollar una nueva hipótesis del modo en que la realidad está constituida en función de nuestras necesidades. Esto hace que el pragmatismo sea una filosofía fundamentalmente falibilista; es decir, que siempre está abierta a la posibilidad de caer en el error y de poder encontrar mejores maneras de comprender una realidad.

El no reconocer el falibilismo en el conocimiento humano es una de las fuentes principales del error: "Los hombres piensan en modos en que no deberían cuando siguen métodos de indagación que la pasada experiencia nos muestra que no son competentes para alcanzar los fines buscados en las indagaciones en cuestión." ${ }^{14}$ De este modo, el criterio fundamental para analizar nuestros modos de

\footnotetext{
${ }^{13}$ Cfr. Ibid. 174.

${ }^{14}$ Dewey, Logic. 165
} 
indagar es el de la experiencia: mientras sirva es verdadero (pues está justificado), cuando deja de servir es falso. Este modo de proceder es claro en el campo científico, en donde las diversas teorías van siendo aceptadas y reconocidas sólo en la medida en que puedan ofrecer resultados. ${ }^{15}$ No hay razón para pensar que el mismo modo de proceder es incorrecto en otras áreas del pensamiento. Los criterios de justificación pueden cambiar dependiendo de qué ámbito del desarrollo humano estemos analizando, sin embargo el experimentalismo y el falibilismo tienen la misma validez: "A pesar de que Dewey repudia la búsqueda de certeza cuando el foco de una indagación es la esencia de una cosa en particular o un bien, no hay duda de que pensaba que existe un solo método general de indagación." 16

La ética pragmática, por supuesto, no es la excepción a esta aproximación al conocimiento. El pragmatismo de Dewey en ética está vinculado íntimamente a un escepticismo frente a la tradición como medio para encontrar respuestas a las preguntas morales de los individuos. Si las indagaciones están vinculadas al entorno de la persona que la realiza, es normal que los conceptos morales de la tradición tengan diversa importancia dependiendo de la circunstancia en la que nos encontremos: "Si la teoría intuitiva fuera verdad, toda la experiencia moral se reduciría a aplicar verdades morales a ciertos casos. No habría ningún tipo de responsabilidad del individuo por encontrar la verdad por sí mismo (...). La debilidad del intuicionismo es que no trata la experiencia como desarrolladora de verdad." ${ }^{17}$

La verdad en el ámbito de lo moral la encontramos, como en todos los demás, mediante un proceso de justificación de una hipótesis al enfrentarla a la realidad. La indagación moral es, fundamentalmente, aquella que ocurre en una situación en la que existen fines incompatibles y de los que es necesario evaluar su importancia para poder tomar una decisión. ${ }^{18}$ Esta indagación, como sucede en ciencia, en ocasiones nos conduce a evaluar ideas que dábamos por sentadas (en ciencia puede ocurrir con ciertas teorías o hipótesis fundamentales y en ética

\footnotetext{
15 Thomas Kuhn es quien probablemente desarrolla esta opinión hasta sus últimas consecuencias con la idea de la "ciencia normal" y el surgimiento de las revoluciones como cambios en los paradigmas dada la incapacidad de la "ciencia normal" para enfrentar los nuevos problemas que van surgiendo al intentar desarrollar teorías que respondan a la experimentación. [Thomas Kuhn, La estructura de las revoluciones científicas (Buenos Aires: Fondo de Cultura Económica, 2004)]

${ }^{16}$ Savage, John Dewey's Liberalism. 4

${ }^{17}$ Dewey, Principles of Instrumental Logic. 71

${ }^{18}$ Cfr. John Dewey, Ethics (Nueva York: Henry Holt, 1908). 209
} 
conceptos o ideas de bien que podemos considerar, igualmente, primeros) y en ocasiones simplemente indagamos aceptándolos.

El falsacionismo del pragmatismo de Dewey no supone que cada proceso indagatorio conduzca a una crisis completa de nuestro sistema de creencias; esto sólo ocurre cuando nuestro sistema no ofrece resultados o nos es presentado un sistema distinto que genere mejores resultados. Por ejemplo, en ética algunos conceptos sobre la sexualidad han sido parte de nuestra cultura y han dirigido la acción de modo claro durante cientos de años, ahora, desde hace algunos años, socialmente esos conceptos y principios han sido puestos en duda pues parecen no ser compatibles con otros valores a los que hoy les damos mucho más valor (como puede ser la igualdad y la libertad, por ejemplo).

Esta teoría del conocimiento humano tiene, por supuesto, implicaciones respecto de la cultura. La cultura en la que los seres humanos se desarrollan está compuesta por indagaciones individuales que, con el paso del tiempo, son compartidas y se convierten en parte de un "catálogo" común. En esta medida, las culturas son mejores o peores de acuerdo a ciertos objetivos o intenciones. Por ejemplo, si el objetivo de la organización social es la supervivencia en un ambiente hostil donde no se cumplan las "circunstancias de la justicia", ${ }^{19}$ sin duda hay modos de organizar que serán menos eficientes o eficaces para alcanzar este objetivo. Por ejemplo, es posible pensar que una sociedad profundamente igualitaria y liberal tendería a ser más ineficaz en un entorno donde no hubiera condiciones materiales para poder vivir en un estado de justicia (en una especie de escenario apocalíptico por ejemplo). Daniel Savage nos dice que "[L]a concepción de la cultura de Dewey es "funcional" En el sentido en que la cultura tiene funciones que desarrollar y puede ser juzgada por su capacidad para hacerlas mejor o peor que otras culturas." ${ }^{20}$

Ahora bien, si aceptamos que los contenidos de la cultura son hipótesis de acción, más o menos aceptados, es posible considerar que hay culturas que, dadas ciertas condiciones mínimas materiales, son mejores para promover el desarrollo de los individuos. Esta es la manera, fundamentalmente, en la que Dewey argumentará a favor de la democracia liberal. Según la propuesta deweyana la democracia es más que la distribución del poder político entre los ciudadanos. La democracia es una cultura en la que todos los individuos son libres de indagar y actuar de acuerdo a sus consideraciones morales. Es un sistema comprometido a

\footnotetext{
${ }^{19}$ Cfr. John Rawls, A Theory of Justice (Cambridge, Harvard University Press, 1999), 109.

${ }^{20}$ Savage, John Dewey's Liberalism. 3
} 
generar las condiciones en donde las personas sean capaces de encontrar las mejores maneras de vivir. Si la actividad que diferencia a los seres humanos de otros organismos es la capacidad de indagar, el sistema de organización social que mejor responda a nuestras necesidades, en tanto indagadores, será aquel que permita con mayor facilidad esta actividad: "el liberalismo que asume sus ideas del individuo sinceramente debe estar profundamente preocupado sobre la estructura de las asociaciones humanas. Pues éste opera de modo que afecta tanto positiva como negativamente el desarrollo de los individuos." 21

Ahora bien, alguien podría objetar que el falsacionismo, pieza fundamental del argumento, no nos permite hacer una afirmación como la de que la democracia liberal, como la que defiende Dewey, es un modo de organización adecuado a la naturaleza humana. Quien objetara así podría suponer que las consecuencias de una decisión como la elección de un modo de organización social son demasiado graves. A un argumento de este tipo es posible responder que, en efecto, es posible que exista una manera de organización social que, dadas nuestras condiciones, funcione mejor que la democracia liberal. No hay nada que lógicamente impida que sea así. Sin embargo, el falsacionismo de Dewey no implica que todas las hipótesis puedan ser verdaderas, sólo supone que cualquiera puede ser falsa (y podemos justificar verdaderamente que algunas lo son). Es decir, es posible afirmar que defender la tradición simplemente en términos conservadores es un error (pues niega las posibilidades de desarrollo posterior) y, al mismo tiempo, podría ser posible decir que hasta ahora no hay una mejor opción que la democracia liberal para plantear una sociedad que permita el desarrollo de los individuos.

La sociedad liberal de Dewey está pensada como un punto medio entre la anarquía improductiva y la sociedad totalitaria, completamente ordenada, que también genera condiciones de productividad limitada. Para tomar prestado un concepto, podríamos decir que la sociedad democrática deweyana es aquella en donde la organización está al servicio de la "destrucción creativa" de la que hablaba Shumpeter para explicar el capitalismo:

La apertura de nuevos mercados, externos o internos, y el desarrollo organizacional de los talleres y las fábricas a intereses como U. S. Steel ilustra el proceso de mutación industrial -si puedo usar el término biológico-que incesantemente revoluciona la estructura económica desde dentro de sí, incesantemente

${ }^{21}$ John Dewey, Liberalism and Social Action (Reno: Frederick Ellis), 48. 
destruyendo la vieja, incesantemente creando una nueva. Este proceso de Destrucción Creativa es el hecho esencial del capitalismo. ${ }^{22}$

Este proceso que Schumpeter reserva para los mercados y las industrias es similar al que Dewey considera para la moral y la política dentro de una sociedad liberal. Del mismo modo en que un economista liberal argumenta que una economía centralizada que no genera los incentivos adecuados para la innovación y tiende a desarrollar industrias anticuadas e ineficientes, un demócrata liberal, como Dewey, sostiene que una sociedad en donde los individuos no sean libres de indagar cuál es el mejor modo en que pueden vivir (respetando las condiciones necesarias para poder sostener este proceso) tiende a existir sobre principios morales anticuados que frustran la existencia misma de las personas bajo las condiciones cambiantes de la historia.

Las ideas de Dewey en los ámbitos de la teoría del conocimiento, ética, política y la democracia conducen a una comprensión del liberalismo que es indistinguible de la moralidad. A diferencia de los intentos de Rawls, como explicaré brevemente a continuación y mostraré en tercer apartado de esta investigación, de plantear un liberalismo que no dependa de una postura moral, la democracia liberal deweyana es moral en sí misma. Como mostraré esto generará límites a la cantidad de perspectivas morales que podrán existir dentro de una sociedad liberal más astringentes que lo que Rawls, por su parte, desea. Sin embargo, como también mostraré, puede servir como fundamento para una sociedad estable y funcional.

Por otra parte, la teoría de la justicia como imparcialidad, elaborada por John Rawls, amerita una muy breve presentación.

\section{La justicia como imparcialidad}

Cuando realizamos un análisis de la justicia como imparcialidad es posible identificar un supuesto fundamental, que está presente en el desarrollo de la teoría de Rawls completa, y que es el que garantiza el talante liberal de esta concepción de la justica: la igualdad moral de los individuos: “(...) la igualdad entre los seres humanos como personas morales, como criaturas que tienen una concepción del

${ }^{22}$ Joseph Shumpeter, Capitalism, Socialism and Democracy (Harper Perennial: Nueva York, 2008), 83. 
bien y capaces de un sentido de la justicia. La base de la igualdad es reconocida por la semejanza que encontramos en estos dos respectos." ${ }^{23}$

Este reconocimiento de la igualdad moral de los individuos conduce a Rawls a proponer una justificación de la justicia liberal haciendo uso del argumento contractual como un medio para explicar cómo, hipotéticamente, individuos iguales y libres se plantearían los principios fundamentales de su convivencia política. Este ejercicio, que recibió las mismas críticas que todos los contractualismos, que aluden al hecho de que el suceso no aconteció, y que me parece que están fuera de lugar, lo plantea Rawls de modo que aquellos que participen sólo tomen en cuenta los elementos moralmente relevantes. La discusión sobre el pacto original está enfocada en encontrar los principios que regirán las interacciones sociales, supuesto esto, podemos pensar que los participantes elegirían vivir bajo condiciones justas. La justicia no puede ser indiferente a la relevancia, es decir, a sólo tomar en cuenta los factores moralmente justificados. Estas condiciones, que Rawls considera de imparcialidad, en la Posición Original, la situación hipotética donde se lleva a cabo el acuerdo, están particularmente definidas por el velo de la ignorancia.

El velo de la ignorancia es una condición al conocimiento. Un límite a lo que pueden conocer las partes contratantes sobre sí mismos, su sociedad específica y el resto de los individuos que están en la posición original. ${ }^{24}$ En general, pues esto es algo que analizaré a detalle en la segunda parte de esta investigación, estos límites implican que las partes contratantes no saben cuál es la idea del bien que poseen fuera de la posición original, tampoco saben qué posición ocupan respecto a clases sociales o cuáles son sus motivaciones particulares. Estas condiciones conducen a una evaluación imparcial sobre los méritos de las distintas concepciones de la justicia que podrían ser adoptadas.

En estas condiciones Rawls confía en que las partes en la posición original elegirían la concepción que él denomina la justicia como imparcialidad. La propuesta rawlsiana de concepción de la justicia liberal está compuesta por dos principios:

Primer Principio

Cada persona debe tener el sistema más extenso de libertades básicas iguales que pueda ser compatible con un sistema de libertades similar para todos.

\footnotetext{
${ }^{23}$ Rawls, $A$ Theory of Justice. 17

${ }^{24}$ Cfr. Ibid. 118
} 
Segundo Principio

Las desigualdades sociales y económicas deben de ordenarse de modo que sean:

a. Para el mayor beneficio de los menos aventajados, consistentemente con el principio del ahorro justo, $y$

b. Referidas a posiciones o puestos abiertos a todos bajo condiciones de justa igualdad de oportunidades. ${ }^{25}$

Estos principios, piensa Rawls, serían elegidos en la posición original pues cumplen con las condiciones de imparcialidad, reconocen la igualdad de los individuos y garantizan las condiciones para que puedan perseguir su idea del bien específica. El primer principio garantiza las libertades básicas. Con este principio la libertad como imparcialidad garantiza ciertas condiciones para que todos los individuos se planteen la manera en la que perseguirán los bienes que ellos mismos definan a la vez que, si están en condiciones materiales para hacerlo, los busquen efectivamente.

Por otro lado, el segundo principio sirve como garantía para que las personas tengan los medios suficientes para perseguir los bienes que prefieran. Este principio es relevante pues establece las condiciones de un igualitarismo democrático que distancia a la justicia como imparcialidad de concepciones como el liberismo, que simplemente se interesa por ampliar las libertades en el sentido del primer principio.

Ahora bien, la argumentación por la justicia como imparcialidad se desarrolla, en Teoría de la Justicia, de dos modos: por un lado Rawls presenta una argumentación neokantiana, en la que pretende mostrar la competencia de sus argumentos apelando a una supuesta condición noumenal de los seres humanos, representada en los contratantes en la posición original que se encuentran bajo el velo de la ignorancia. Este argumento, como explico en el tercer capítulo, argumenta que la justicia como imparcialidad cumple con ciertos límites (condiciones) entre los que están la universalidad, finalidad y generalidad, todos estos atendiendo a argumentos de tipo kantiano.

Por otro lado, el otro modo de plantear la justificación de la justicia como imparcialidad, que por cierto ha sido menos atendido por la tradición, está desarrollado en función de un argumento de tipo pragmático. Es decir, Rawls presenta la conveniencia de la justicia como imparcialidad por su capacidad de

${ }^{25}$ Ibid. 266 
generar interacciones justas, siendo una concepción de justicia procedimental imperfecta, ${ }^{26}$ de modo estable en el tiempo, es decir que es capaz de desarrollar y mantener el suficiente consenso como para mantenerse como la concepción preferida en una sociedad democrático-constitucional.

Este modo de argumentación me parece superior al kantiano, como considero que reconoció el mismo Rawls después en el Liberalismo Político, al menos por su capacidad de funcionar como justificación para individuos que mantengan doctrinas comprehensivas diversas. Sin embargo, como también intentaré mostrar en la investigación, el argumento pragmático de Rawls es incapaz de coexistir con otra característica de la justicia como imparcialidad como el mismo Rawls la plantea: el antiperfeccionismo.

El antiperfecionismo está justificado en Teoría de la Justicia, piensa Rawls, por las condiciones mismas de la posición original. El presupuesto de la igualdad moral entre los participantes, así como el velo de la ignorancia como condición que genera el razonamiento imparcial, no permite tener los estándares o criterios para juzgar el valor entre las diversas ideas del bien. Si este argumento es correcto, el único criterio con el que podremos evaluar qué ideas del bien son aceptables para existir dentro de la sociedad gobernada por la justicia como imparcialidad es el de la estabilidad: cualquier idea del bien será aceptable en la medida en que no ponga en riesgo la estabilidad de la concepción. La labor del estado no debe ser la de evaluar los contenidos de las ideas del bien: "No debe preocuparse con doctrinas filosóficas y religiosas, sino regular la búsqueda de los individuos de sus intereses morales y espirituales de acuerdo con los principios con los que ellos mismos estarían de acuerdo en una posición inicial de igualdad." 27

La publicación de la Teoría de la Justicia, en la que realizó la primera presentación completa y sistemática de la justicia como imparcialidad, fue el lugar en que Rawls, como mencioné anteriormente, revitalizó el contractualismo. Las múltiples reacciones al texto condujeron a Rawls a repensar la presentación de la justicia como imparcialidad de modo que pudiera eliminar algunos de los elementos más controversiales. Este proyecto de innovación en la presentación tuvo como producto el Liberalismo Político, en el que, como afirma Rawls, la justicia como imparcialidad mantiene sus elementos esenciales pero evita cuestiones como la justificación kantiana, la que suponía que era innecesaria y polémica.

\footnotetext{
${ }^{26}$ Cfr. Ibid. 76-77

${ }^{27}$ Ibid. 190
} 
Esta nueva presentación condujo a lo que ha sido denominado el "giro político" en el pensamiento de Rawls. La intención de Rawls con este giro es lograr presentar la justicia como imparcialidad de modo que esté vacía de contenidos morales, metafísicos o filosóficos en general y se sostenga simplemente por premisas políticas que puedan ser aceptables para cualquier persona razonable. Este cambio acontece al ser Rawls sensible a la dificultad de aceptar, por ejemplo, la justificación kantiana para una persona que no reconozca algunos de los supuestos de dicha argumentación, como sucede con la comprensión de la autonomía, el individualismo que parece acompañarlo o la posibilidad de argumentar desde la naturaleza noumenal.

Esta nueva presentación pretende mostrar cómo la justicia como imparcialidad puede ser el centro de un consenso amplio entre diversos individuos y grupos de individuos que sostengan ideas del bien diversas. Esta posibilidad, sostiene Rawls, sólo puede ocurrir, con la amplitud suficiente para integrar a las diversas doctrinas comprehensivas razonables, si la justicia como imparcialidad pierde todo su contenido moral. Esto no significa que Rawls piense que la concepción de la justicia no requiere una justificación moral; más bien, al realizar el giro político, se genera una circunstancia en la que cada una de las doctrinas morales y filosóficas realice su propia justificación. Con estos cambios la justicia como imparcialidad, como es presentada en Liberalismo Político, mantiene, piensa Rawls, sus características liberales, igualitaristas y antiperfeccionistas haciéndose más incluyente a las doctrinas comprehensivas razonables.

No hay manera en que en una introducción pudiera incluir todos los conceptos relevantes para entender el pensamiento de autores como Dewey o Rawls. Incluso, si alguien pretendiera encontrar en la totalidad de esta investigación una exposición suficientemente detallada, terminaría insatisfecho. El objetivo fundamental que persigo no es el de realizar una exposición completa de las filosofías políticas de Dewey y de Rawls, lo que intento hacer, más bien, es una indagación sobre los elementos en que la democracia liberal de Dewey y la justicia como imparcialidad de Rawls pueden entablar un diálogo y, sobre todo, la cómo la aplicación pragmática en política de Dewey puede mejorar las que me parecen limitantes del argumento rawlsiano: el argumento kantiano en Teoría de la Justicia, el giro político, el rechazo al liberalismo moral y el antiperfeccionismo por sus implicaciones en la estabilidad de la concepción de la justicia. 
La estructura de la investigación está conformada por cuatro partes: (i) Democracia, liberalismo y pragmatismo en John Dewey, (ii) El liberalismo antiperfeccionista de Teoría de la Justicia, (iii) Política sin metafísica y (iv) Liberalismo pragmático. La primera está compuesta por dos capítulos, en el primero expongo brevemente la teoría del conocimiento y la verdad del pragmatismo de Dewey. Muestro cómo esos principios de conocimiento y verdad se aplican al campo de la ética pragmática y planteo modos en que influencian la política. En el segundo capítulo me dedico, ya con los presupuestos pragmáticos suficientemente expuestos, a analizar la concepción de la política de Dewey y, consecuentemente, de la democracia liberal. En esta parte intento mostrar cómo el argumento a favor de la democracia liberal en Dewey está fundamentado desde la antropología y la ética pragmática, lo que la identificaría con una doctrina comprehensiva, como las define Rawls en Liberalismo Político.

La segunda parte, en donde analizo el liberalismo antiperfeccionista que Rawls presenta en Teoría de la Justicia, está dividida, igualmente, en dos capítulos. En el primero (tercero de la investigación en general) analizo los dos métodos de justificación que Rawls usa para la justicia como imparcialidad. Muestro las fortalezas, debilidades y límites de los argumentos neokantianos y pragmáticos. El segundo capítulo de esta parte lo dedico a exponer algunos de los contenidos concretos de la justicia como imparcialidad. En particular analizo las ideas de la posición original, los bienes primarios y los principios de la justicia. Esta parte en general tiene la finalidad de ofrecer una comprensión general de la justicia como imparcialidad.

La tercera parte de esta investigación la dedico al análisis de los cambios en la presentación de la justicia como imparcialidad. Para esto me centro en la exposición que Rawls hace en el Liberalismo Político aunque, con la intención de presentar la mejor versión posible, cuando me parece adecuado acudo a la exposición que realiza en Justicia como Imparcialidad, una reformulación. Esta parte también está constituida por dos capítulos. En el primero de ellos analizo dos cuestiones íntimamente relacionadas: el giro político y el conflicto en el espacio público. El giro político es un esfuerzo, por parte de Rawls, para limitar el conflicto en la selección de la concepción de la justicia. Intento profundizar hasta qué punto los esfuerzos de Rawls pueden ser satisfactorios. El segundo capítulo, por su parte, está enfocado a analizar la relación entre el liberalismo político y el liberalismo moral. Exploro las posibilidades de plantear exitosamente una concepción de la justicia liberal que no dependa de una moral liberal. Esto lo hago profundizando en los conceptos de lo razonable y la razón pública. Estos conceptos están en el 
centro de la comprensión política del liberalismo y, como espero mostrar, generan condiciones que son difíciles de cumplir en las sociedades contemporáneas no ideales.

La última y cuarta parte de esta investigación consta de un solo capítulo. El capítulo final está dedicado a, siguiendo el método indagatorio de Dewey, plantear algunas de las consecuencias de realizar una lectura pragmática de la justicia como imparcialidad. Indago sobre tres temas en específico: la razón pública bajo un liberalismo pragmático (que no puede dejar de ser algún tipo de formulación moral), la importancia de la educación como mecanismo de estabilidad de una concepción de la justicia liberal y, por último, la importancia de un ideal perfeccionista, profundamente liberal y pragmático, como condición de estabilidad.

El final de la historia como lo planteó Fukuyama es, en la medida en que sea bajo las condiciones de una sociedad liberal, una contradicción que, además, me parece indeseable. En esta investigación, sin embargo, intento plantear, siguiendo dos de las propuestas liberales más relevantes del siglo pasado, cómo podríamos pensar una concepción de la democracia liberal que genere las condiciones para ser estable, con los resultados que imparcialmente deseamos y, cuando las circunstancias así lo demanden, sea capaz de reinventarse. Si este objetivo tiene algún futuro, la tradición norteamericana tiene mucho que decirnos y, en especial, aquella que busca argumentar la justificación de sus ideas en su capacidad de generar los resultados que deseamos. Para esto John Rawls y John Dewey son, sin duda, aliados invaluables. No dan respuestas a algunos de los problemas que aquejan a nuestras sociedades (lo que sin duda hacen y es importante), sino que, aún más valioso que las respuestas, nos ayudan a plantear mejores preguntas para que realicemos el proceso indagatorio por nosotros mismos.

Sin lugar a dudas las deudas que contraje para poder elaborar este trabajo son muchas. Cualquiera que haya llevado a cabo un proyecto de este estilo sabe que las contribuciones de individuos e instituciones al proceso creativo son tan variadas, y en momentos tan diversos, que es honestamente imposibles (al menos lo es para mí), mencionar a todos aquellos que merecerían unas palabras. Dicho esto, quisiera agradecer a todos los que, directa o indirectamente, contribuyen al programa de Doctorado en Humanidades de la Universidad Autónoma Metropolitana (unidad Iztapalapa). También tengo una deuda con el Consejo Nacional de Ciencia y Tecnología (CONACYT), de quien recibí la beca que me permitió dedicarme de 
tiempo completo al estudio y la elaboración de esta investigación. Igualmente quiero agradecer al Irving Ayala pues, sin su ayuda y paciencia, me hubiera sido imposible llevar a buen término el programa. Igualmente debo agradecer a muchas personas en la Universidad Panamericana, donde estudié mi licenciatura y maestría y donde, además de estimados colegas, tengo grandes amigos con los que discutí algunos de los temas que aquí trato hasta su cansancio. Por supuesto a pocas personas les puedo estar más agradecido que al doctor Jesús Rodríguez Zepeda, mi director durante el posgrado, quien supo exigirme más, cuando fue más necesario, y orientarme mejor, cuando estuve más perdido (que fue en más ocasiones de las que me imaginé antes de iniciar).

En lo personal le agradezco a mi familia: a mi hermano, mi madre y a mi padre, quien estaba muy orgulloso de mí cuando inició el programa y lamentablemente no está conmigo para verme concluir. La persona a la que más le debo es a Iliana Vetrano, mi esposa; nadie me ha apoyado tanto, a nadie he amado más. 


\section{Parte I. Democracia, liberalismo y pragmatismo en John Dewey}




\section{Capítulo 1. Pragmatismo, verdad y razonamiento moral en John Dewey}

No existe una teoría política que, al tiempo que busca explicar la naturaleza de la comunidad o simplemente enunciar las reglas que la informan, ya sea en el sentido de una teoría de la justicia o cualquier otro, pueda hacerlo al margen de una concepción particular del ser humano. Dicho supuesto antropológico es constitutivo de todas ellas, parte de su herencia genética por decirlo de algún modo. Esta realidad no es solamente propia de lo político, sino que cubre todos los ámbitos de la vida social. Como lo enuncia John Dewey:

Para toda filosofía política y social actualmente desarrollada se encontrará, después de un examen, que supone una cierta perspectiva sobre la constitución de la naturaleza humana: en sí misma y en relación con la naturaleza. Lo que es verdad sobre esto es verdad sobre todos los factores culturales. ${ }^{1}$

Este supuesto, de ser correcto, implica que la investigación y análisis de una filosofía política determinada exige analizar los conceptos subyacentes, o al menos hacerlos evidentes, de modo que sea posible considerarla adecuadamente. La obra política y moral de John Dewey es un claro ejemplo de consistencia conceptual. Como espero que quede claro durante el desarrollo de este capítulo, el pensador norteamericano no busca simplemente desarrollar una teoría política compatible con una comprensión del hombre; el objetivo de Dewey es ofrecer una comprensión de la política liberal democrática, que sostiene como la mejor organización posible, configurada en función de la naturaleza misma del hombre y su relación con el mundo. El liberalismo conforme a esta elaboración es un mecanismo de potencialización de las capacidades del ser humano.

La estructura de los apartados que conforman este capítulo dan testimonio de la importancia que considero debe tener la comprensión de lo que llamé los conceptos subyacentes. De otro modo, sería desconcertante reconocer el por qué un trabajo dedicado a la justificación de liberalismo político se preocupa por los temas que son analizados. Dicho de otro modo, ¿por qué una tesis enfocada en política, que claramente exige análisis de racionalidad moral, inicia con una exposición sobre la naturaleza del conocimiento humano?, ¿por qué un estudio dirigido a la

${ }^{1}$ John Dewey, Freedom and Culture (Nueva York: Prometheus Books, 1989), 18. 
democracia liberal requiere una exposición sobre la naturaleza de la verdad?, ¿es necesario llevar a cabo una indagación sobre el origen de las ideas en el pensamiento deweyano si nos interesa encontrar las razones que justifican una organización política determinada?

El análisis del liberalismo democrático de Dewey exige realizar una exposición, que enfoco sólo en sus aspectos más relevantes, de algunos de los supuestos pragmáticos del norteamericano. La importancia de llevar a cabo una exposición sobre conceptos tales como la realidad, el origen de las ideas, la experiencia y la verdad se encuentra en el hecho de que la labor filosófica de Dewey tiene la misión de mostrar la compatibilidad de la racionalidad científica (fundamentada en la experiencia pragmática de la realidad) con la experiencia moral y la organización política en beneficio del individuo.

El proyecto filosófico de Dewey, famoso por su tendencia cientificista, podría hacer pensar que su objetivo es homologar las ciencias humanas al proyecto de las ciencias exactas; esto sería una confusión. Contrario a lo que han procurado algunos pensadores durante los últimos siglos, como ocurrió con Comte antes y en la actualidad con el biólogo evolucionista Richard Dawkins, el pragmatismo de Dewey no asume que sea posible igualar los mecanismos de indagación entre disciplinas que tienen intenciones en la investigación distintas. Cada área del conocimiento, dadas sus intenciones y objetos, tiene métodos particulares; sin embargo sería un error, dada la distinción de objetos, suponer que existen áreas del conocimiento exentas de criterios de verificación y justificación. La intención de Dewey es demostrar que somos capaces de replicar los hábitos de indagación pragmática, experimentales y falsacionistas en todos los ámbitos de la experiencia humana. Es por esta razón que encuentro necesario, en una exposición sobre el liberalismo democrático, llevar a cabo una exposición de los principios cognitivos que, de acuerdo a Dewey, constituyen la única esperanza de progreso y libertad para los individuos así como el adecuado conocimiento del mundo. El riesgo de hacer una exposición apresurada de la política pragmática de Dewey, sin entender con claridad cuál es su idea del pragmatismo, la experiencia y la verdad, es presentar una concepción política que podría parecer en cierto sentido ajena a la realidad de las circunstancias políticas de la actualidad, lo que sería completamente contrario a los objetivos del mismo Dewey. Por ejemplo, la igualdad democrática necesaria para desarrollar nuestras libertades (idea presente también en Rawls, tanto en Teoría de la Justicia como en el Liberalismo Político) llevó a Dewey a abogar por la desaparición de la propiedad privada como mecanismo de producción, sin duda una opción poco viable en la actualidad. Sin un análisis 
cuidadoso del proyecto filosófico de Dewey, así como una comprensión de las circunstancias sociales en las que se encuentra, podríamos pensar que sus conclusiones son irrelevantes en nuestro contexto actual. Esta idea subestima seriamente la fuerza de sus argumentos limitando su verdadera utilidad en nuestro contexto. La vigencia de muchos de los conceptos y críticas sociales del norteamericano exigen más de nosotros.

Por esta razón, en el desarrollo del capítulo explico el pragmatismo de Dewey en diversas facetas (como explicación del conocimiento, en su dimensión moral y, por supuesto, en la política). Insisto, la aclaración de los conceptos supuestos en la teoría política de Dewey hace posible ofrecer una definición clara de su liberalismo y de los argumentos que lo justifican como un modo de ordenación adecuado para la comunidad política. Para lograr este objetivo estructuro el capítulo en dos partes. La primera es un análisis sobre el pragmatismo y el concepto de verdad para Dewey. La segunda se centra en la lógica del razonamiento moral, permitiéndome aclarar la naturaleza de la racionalidad práctica de modo que sea posible comprender las características que un buen argumento pragmático en el campo moral o político debería tener.

Al final del capítulo será claro que Dewey es un constructivista que, a partir de una comprensión de la naturaleza humana y su relación con el mundo, es capaz de proponer una metodología para estructurar las relaciones e instituciones sociales que tengan por objeto el desarrollo de las libertades de los individuos dentro de la comunidad. La coherencia del pensamiento en Dewey implica, mediante la afirmación del pragmatismo como el mecanismo del conocimiento humano, encontrar el criterio básico extra político para afirmar la conveniencia del liberalismo democrático como estructura de la sociedad. La afirmación del conocimiento válido, también llamado en algunos casos "verdadero", en el proceso de justificación pragmática hace patente la conveniencia de permitir el mayor número de hipótesis de acción y modos de vida en la comunidad con la finalidad de descubrir los mejores modos de ejercer la libertad, como sólo el liberalismo democrático puede hacer. Ahora bien, el desarrollo de una política pragmática lo reservo para el segundo capítulo, lo que significa que este primero sirve fundamentalmente para sentar las bases necesarias para justificar la democracia liberal como la organización política más adecuada dada la naturaleza humana que habré explicado. 


\section{Experiencia, verdad y método en John Dewey}

Una idea básica para comprender qué es el pragmatismo es la de su naturaleza empírica. Desde el pensamiento pragmatista de Dewey no hay conocimiento alguno en los individuos que no se refiera, o pueda ser rastreable, al mundo exterior empíricamente verificable. El pragmatismo deweyano, en tanto teoría de la realidad, niega categóricamente la existencia de esencias, o existencias nouménicas si se prefiere, que constituyen, al ser conocidas, el objeto mismo de la verdad. Dicho de otro modo, niega la posibilidad de acceder a estas esencias, aun si existieran, y deben ser descartadas como objetos de conocimiento válidas.

Lo anterior no significa lo mismo que afirmar que el hombre al nacer es tabula rasa, como Locke llegó a suponer. Si bien Dewey supone que todas nuestras ideas son fruto de nuestra relación directa con el mundo, ${ }^{2}$ existen ciertas condicionantes biológicas para conocer: estas condiciones incluyen, por supuesto, no sólo las estructuras físicas del cuerpo humano sino, del mismo modo, las respuestas psíquicas propias de nuestro proceso evolutivo. Decir lo anterior implica argumentar que nuestro conocimiento, que sólo existe en la realidad empírica, está condicionado por nuestra biología y, por lo mismo, por la cultura en tanto que es un fenómeno fruto de nuestra evolución. ${ }^{3}$ Una vez que aceptamos que no existe una división del conocimiento en un sentido similar al propuesto por Aristóteles cuando hablaba de la tecné, la phronesis, la epistéme y el nous, la totalidad de las ideas y creencias están en función de nuestra vida en el mundo y de nuestra capacidad de actuar en él.

La aplicación del postulado de continuidad a la discusión del objeto de la lógica significa, por tanto, negativamente, que para poder dar razón de las características distintivas y únicas de la lógica no debemos invocar abruptamente un poder nuevo o una facultad como la Razón o la Intuición Pura. Positiva y concretamente, significa que una explicación razonable será dada de modo en que sea posible para las características que diferencian la indagación deliberada para desarrollarse de las actividades biológicas que no son propias de ella. ${ }^{4}$

Esto no quiere decir que Dewey no tenga claridad respecto de las diferencias entre la investigación científica y la estética, por ejemplo. Lo que supone es que no existen diferencias más allá de cierta metodología e intereses; no hay una

\footnotetext{
${ }^{2}$ Cfr. John Dewey, Logic (Nueva York: Saerchinger Press, 2007), 66-67.

${ }^{3}$ Cfr. Ibid. 47

${ }^{4}$ Ibid. 46.
} 
diferencia en su naturaleza como sucedía en el pensamiento clásico, donde el tecné y la episteme eran de naturaleza radicalmente distintas.

Las consideraciones anteriores apuntan a una concepción de la naturaleza cognitiva humana como la de una agencia. En oposición a esta comprensión es posible pensar en una teoría del conocimiento que postula al ser humano como una especie de mero receptáculo, como intelecto paciente, del conocimiento que "está afuera" en el mundo (como postuló Tomás de Aquino por ejemplo). Asumir al hombre como un intelecto paciente, que recibe las "formas" exteriores es incorrecto. Todas nuestras ideas, hablando desde la perspectiva de la especie, son productos de individuos, dependientes y comprometidos con el mundo, con el que se relacionan empíricamente en tanto que actúan en él. Esta comprensión de la naturaleza nos permite, claramente, jerarquizar las ideas en función de su "utilidad" para referirse a las circunstancias de acción de los individuos:

Esta noción supone que las ideas son esencialmente intenciones (planes y métodos), y que lo que ellas, en tanto ideas, procuran es un cambio a futuro -un cambio en cosas previamente existentes. Esto contrasta con el racionalismo, con su teoría de las copias, en donde las ideas, en tanto ideas, son inefectivas e impotentes en tanto que buscan simplemente servir como un espejo de la realidad completa. ${ }^{5}$

El pragmatismo es una propuesta sobre el origen de las ideas sumamente innovadora debido al reconocimiento del papel activo del conocimiento. El pragmatismo como teoría del origen de las ideas se aleja de cualquier concepción del conocimiento, ya sea como representación directa o como reconstrucción mental (al modo de la epistemología de la modernidad) en función de un estado de cosas exterior, y más bien propone una nueva manera de comprender el origen de las ideas en nuestra intención de actuar en el mundo. Las ideas surgen a modo de proyecto y la reflexión sobre el mundo, así como la construcción de modelos explicativos, se explica por necesidad de encontrar maneras de desarrollar los actos en su entorno. ${ }^{6}$

El pragmatismo de Dewey constituye una propuesta subjetivista y antidualista conforme a la cual los individuos son capaces de generar modelos de la realidad, o de lo que comprenden por realidad, y están en condiciones de verificarlos materialmente. ${ }^{7}$ El proceso se inicia, en su desarrollo más simple, con el reconocimiento de un problema, el desarrollo de una idea que busque ayudarnos a

\footnotetext{
${ }^{5}$ Dewey, Freedom and Culture. 86

${ }^{6}$ Cfr. John Dewey, Principles of Instrumental Logic, editado por Donald Koch (Carbondale: Southern Illinois University Press, 1998), 54.

${ }^{7}$ Cfr. John Dewey, Logic. 4
} 
sobrepasar dicho problema y concluye con la verificación de sus consecuencias. El conocimiento del mundo es absolutamente subjetivo (aunque pueda ser compartido por diversos sujetos) en tanto que las creencias e ideas sobre el mundo no son extraídas directamente de la realidad:

Creer es suscribir valor, imputar significado, asignar significado. La colección e interacción de estas consideraciones es el mundo del hombre común. Por tanto las cosas siempre son personajes, no sólo entidades; se comportan, responden y provocan. En el comportamiento que ejemplifican las creencias y prueban su "personaje" son cosas que ayudan o se esconden; pacifican o causan conflicto; se resisten o someten (...) son mejores o peores. ${ }^{8}$

Podríamos decir que la realidad no tiene significado por sí misma o, como afirma Richard Rorty, no es "independientemente representativa". Afirmar la subjetividad como se ha hecho implica reconocer que la constitución actual de una idea es fruto del desarrollo de un individuo. Es tanto como decir que ninguna idea representa la realidad:

Que X sea representacionalmente independiente de nosotros significa que $X$ tiene un rasgo intrínseco (un rasgo que posee bajo todas y cada una de sus descripciones) tal que resulta mejor descrito por algunos de nuestros términos que por otros. Toda vez que no vemos la manera de decidir qué descripciones de un objeto llegan a lo que le es "intrínseco", por oposición a sus rasgos extrínsecos o meramente "relacionales", nosotros estamos dispuestos a desechar la distinción intrínsecoextrínseco, la tesis de que las creencias representan y, en su conjunto, toda la cuestión de la dependencia o independencia representacional. Esto quiere decir desechar la idea de "cómo son las cosas en cualquier caso" (expresión de Bernard Williams), más allá de si son descritas o cómo. ${ }^{9}$

Si la realidad fuera independientemente representativa o, dicho de otro modo, significativamente independiente, los cambios históricos en nuestra comprensión de un objeto, así como las nuevas descripciones que hacemos de los mismos, serían fruto de un conocimiento más profundo de él. Decir esto es tanto como aceptar que las nuevas maneras de describir los problemas no son fruto de la imaginación o la creatividad sino de nuestra capacidad para adentrarnos en la naturaleza o esencia de la realidad; este es básicamente el problema del realismo metafísico que supone que los seres humanos tenemos un acceso directo al conocimiento de la esencia del mundo. La realidad juega el papel verificador, de igual modo sirve como inspiración para pensar (sin la existencia de la realidad no habrían problemas); sin

\footnotetext{
${ }^{8}$ John Dewey, "Beliefs and Realities", The Philosophical Review vol. XV no. 2 (1906): 113.

${ }^{9}$ Richard Rorty, "Charles Taylor en torno a la verdad", en Verdad y progreso, trad. Ángel Faerna García (Barcelona: Paidós, 2000), 117-118.
} 
embargo, y es relevante mantener esto presente, es necesario recordar que la realidad no sirve como modelo de nuestras ideas en un sentido de representación.

En contra de la idea realista, el pragmatismo de Dewey nos lleva a reconocer que los significados, valores y creencias son fruto de planes de acción de individuos en la realidad concreta. Esos significados y creencias son parte de un catálogo constituido culturalmente en su mayoría o, cuando desarrollamos creencias nuevas en un esfuerzo incremental del conocimiento, son productos de ideas anteriores; los usos del momento y las construcciones culturales nos permiten construir un mundo de significados compartidos que nos permite actuar en una realidad que por sí misma no significa nada. Las creencias no sólo nos permiten desarrollar un mundo significativo, sino que, al mismo tiempo, nos permiten construir sobre ellas mismas el edificio del conocimiento humano en un sentido acumulativo. ${ }^{10}$

Este proceso acumulativo del conocimiento convierte a Dewey en un historicista respecto del contenido de nuestros conceptos. El mundo, dadas las conclusiones del pragmatismo de Dewey, no sólo está mediado por la cultura sino que está constituido por la herencia cultural y nuestra capacidad de proponer nuevas ideas en función de ella. ¿Qué preguntas nos parecen relevantes?, ¿cuáles son los métodos aceptables para alcanzar la verdad?, ¿qué términos utilizamos para describir la realidad?, ¿cómo nos entendemos en relación con el mundo? Estas son cuestiones a las que podemos responder sólo desde la parcialidad de una cultura y, radicalmente, sólo se pueden plantear como parte de una tradición. Esto, por supuesto, no implica que dicha cultura, la sociedad y su tradición no estén en un continuo cambio. De hecho, una evidencia clara que cambian continuamente es que los temas y preocupaciones de la humanidad van cambiando en el tiempo:

Toda indagación procede de una matriz cultural que es finalmente determinada por la naturaleza de las relaciones sociales. El objeto de las indagaciones físicas en cualquier momento caen en el campo social más amplio. Las técnicas disponibles en un momento dado dependen del estado material e intelectual de la cultura. Cuando vemos hacia atrás a periodos anteriores, es evidente que ciertos problemas no pudieron hacer sido evidenciados en el contexto de las instituciones, costumbres, ocupaciones e intereses que existían en ese momento y que, aun si, por imposible que sea, hubieran sido capaces de detectarlos y formularlos, no hubieran tenido los medios necesarios para resolverlos. ${ }^{11}$

\footnotetext{
${ }^{10} \mathrm{Cfr}$. Dewey, "Beliefs and realities". 114
}

${ }^{11}$ John Dewey, Logic. 762 
Así es como la tradición filosófica, que ha buscado mostrar la existencia de un conocimiento independiente de las creencias de la cultura determinada que las vio nacer, se equivoca. La naturaleza social del ser humano no sólo tiene implicaciones políticas y morales, como normalmente se asume; la naturaleza social del hombre termina condicionando su experiencia de la realidad absolutamente. Una vez que somos capaces de reconocer que las creencias surgen a causa de nuestro enfrentamiento con el mundo, como "intenciones" de acción, es necesario reconocer que todo el saber humano tiene una naturaleza hipotética ${ }^{12} \mathrm{y}$ dependiente de nuestro entorno cultural.

Esta primera aproximación podría hacer pensar que al no existir una facultad intrínseca para conocer la realidad (al modo del realismo clásico) el pragmatismo es una teoría del conocimiento que se justifica desde una perspectiva meramente coherentista; esto también sería un error. La naturaleza del pragmatismo, aun aceptando que no hay facultades humanas que ofrezcan un acceso directo a algo así como una esencia de la realidad, nos conduce a aceptar un tipo de realismo en tanto que las ideas responden a intenciones y a acción en la realidad. Todas las ideas deben ser contrastadas con la realidad para poder ser juzgadas como verdaderas o falsas. Como ya se puede ver, la única manera de ser verdaderamente realista, dado el origen de nuestras ideas y conceptos, es a través de un ejercicio de verificación o contraste de nuestras ideas con la realidad. La verdad, de este modo, debe ser comprendida como el nombre que damos a una "aseveración justificada". La verdad se dice, por tanto, de una hipótesis que ha sido puesta a prueba en la realidad (o frente a los datos extraídos de la realidad que nos permiten analizar su plausibilidad) y que ha sido capaz de ofrecer el resultado deseado con anticipación:

La verdad es la unión de los significados abstractos postulados y de los hechos concretos y brutos en una manera en que se utilizan los segundos como medios mientras los primeros se desarrollan como métodos en la experiencia personal activa. Al final todo se resume en la experiencia. ${ }^{13}$

El desarrollo de hipótesis, de esos métodos o intenciones de acción llevados a cabo en la experiencia personal, está vinculado a la curiosidad intelectual, curiosidad que sólo puede ser motivada por problemas. ${ }^{14}$ ¿Qué sentido tendría generar hipótesis o métodos para alcanzar objetivos si todo estuviera dado en el momento?

\footnotetext{
${ }^{12}$ Cfr. John Dewey, "What Does Pragmatism Mean by Practical?”, The Journal of Philosophy, Psychology and Scientfic Methods vol. 5 no. 4 (1908): 93.

${ }^{13}$ Dewey, "Beliefs and realities". 124

14 Dewey, Principles of Instrumental Logic. 54
} 
El interés intelectual que surge de la existencia de problemas, es decir complicaciones en los planes de acción, presupone que no tenemos un acceso privilegiado a la realidad. De existir esta capacidad aprehensiva del conocimiento no podríamos afirmar la existencia de problemas en un sentido sustantivo pues los problemas serían, de fondo, la incapacidad de conocer y no la circunstancia real. Con esto no se podría afirmar que los problemas sean simplemente estados mentales o psicológicos sin existencia real. Los problemas, para efectos de la comprensión pragmática de Dewey, surgen cuando las consecuencias de una indagación son inciertas, es decir, cuando la manera en que sucederán los eventos no puede ser predicha con seguridad. La mejor manera de resolver los problemas adecuadamente, por tanto, es comprendiendo las consecuencias de las hipótesis en el mundo; la mejor manera es la aplicación del pragmatismo como método experimental. ${ }^{15}$

El interés intelectual, fruto de la incertidumbre de las situaciones problemáticas, desemboca en la indagación. La indagación es el proceso de producir e investigar la veracidad de nuestras aseveraciones mediante la comprensión del problema en sus diversas partes constitutivas. La noción de indagación en la tradición filosófica no ha contado con la mejor recepción, considera Dewey. Recordemos que en la modernidad, y por supuesto en la antigüedad, la verdad se encontraba en modos que se considerarían representacionistas en el sentido que enuncia Rorty; las personas, al querer conocer, se daban a la tarea de entender el "libro de la naturaleza", en palabras de Galileo. Recordemos que el nous, el conocimiento más elevado dentro de la comprensión Aristotélica por ejemplo, no se investiga, se contempla. El proceso de indagar en la filosofía pragmatista tiene un papel creativo en el desarrollo de ideas y de métodos de evaluación de su corrección. Dentro del pensamiento pragmatista no existe una contemplación en sentido estricto. Esta nueva comprensión tiene consecuencias a futuro:

Una revisión de la teoría del pensamiento, de la indagación, parecería ser inevitable; una revisión que procuraría dejar de construir el conocimiento como un intento de reproducción de la realidad bajo condiciones que la condenan por adelantado; una revisión que debería iniciar francamente por el hecho del pensar cómo indagar y a las realidades externas como términos en la indagación, y que construya la validez, objetividad, verdad y la prueba y sistema de verdades en relación a lo que significan y hacen a la actividad de indagar. ${ }^{16}$

\footnotetext{
${ }^{15}$ Cfr. Dewey, Logic. 168-169

${ }^{16}$ Dewey, "Beliefs and realities". 123
} 
La teoría del conocimiento pragmática nos hace pensar en el conocer, a diferencia de como sucede con otras propuestas (como es el caso del realismo metafísico), en una actividad permanentemente constructiva:

Indagar es la transformación controlada o dirigida de una situación indeterminada a una que está determinada en sus distinciones y relaciones constitutivas de modo que convierte los elementos de la situación original en un todo unificado.

La situación indeterminada original no sólo está "abierta" a la indagación, sino que está abierta en el sentido en que sus constituyentes no se sostienen juntos. La situación determinada, por otra parte, en tanto producto de la indagación, está cerrada, como si fuera una situación terminada o "universo de experiencia". ${ }^{17}$

La indagación es una actividad en la que el intelecto humano, haciendo uso del conocimiento que posee (heredado culturalmente), intenta explicar las existencias en la realidad. Para hacerlo adecuadamente es necesario comprender cuáles son los elementos que forman parte de un fenómeno y el modo en que se relacionan. Esta tarea indagatoria, una vez que comprendemos nuestros límites biológicos, es condicionada en tanto que no es posible conocer el en sí de la realidad; siempre es realizada desde una perspectiva subjetiva que interactúa con la realidad para procurar comprender los alcances de las hipótesis.

La naturaleza histórica de la actividad indagatoria nos conduce a considerar el hecho que todos nuestros valores y conocimientos pueden ser inadecuados conforme las circunstancias exteriores, así como las descripciones de los diversos elementos integrantes de la indagación, cambian. Todas nuestras creencias deben estar sujetas a crítica, revisión e incluso eliminación cuando, al exponerlas al proceso de justificación o realización, de un modo inteligentemente dirigido, muestran ser inadecuadas; "porque la razón es un esquema de trabajo del significado de las creencias en términos comparables entre ellas y con las consecuencias que generan en las experiencias subsiguientes, las convicciones deben ser consideradas en mayor medida cambiables y responsables ante el ejercicio de la razón." ${ }^{18}$

El pragmatismo es una filosofía falibilista que asume que todas y cada una de las creencias que consideramos pueden ser falsas dadas las circunstancias cambiantes del mundo; dado que el conocimiento responde a intenciones de acción, y no a la aprehensión de esencias, siempre puede existir una hipótesis nueva que ofrezca resultados más convenientes. Si nuestras creencias están

\footnotetext{
${ }^{17}$ Dewey, Logic. 167

${ }^{18}$ Dewey, "Beliefs and realities". 128
} 
históricamente condicionadas (a los conocimientos e intereses propios de una cultura determinada) y constituyen hipótesis sobre nuestra acción en el mundo, es tan sólo normal considerar el hecho de que cambiando las condiciones históricas, o las condiciones del mundo, nuestras hipótesis puedan ser inadecuadas en un momento determinado. Las causas de esta inadecuación pueden ser históricas, culturales o materiales (un cambio en la realidad).

El reconocimiento de la relevancia cultural-histórica y de las realidades materiales como partes fundamentales en la construcción del conocimiento por la tradición pragmática ha derivado en grandes discusiones sobre el peso de estos elementos. Una de las controversias más famosas sobre la naturaleza del conocimiento y de la verdad en esta tesitura fue protagonizada por Richard Rorty y Hilary Putnam. Probablemente lo más interesante es que buena parte de los supuestos de ambos pensadores son compartidos, el más relevante probablemente sea la negación de las teorías del conocimiento representacionista; la diferencia, que es muy relevante por las consecuencias en lo práctico, es que mientras Rorty se interesa más por la naturaleza histórica de la verdad (acercándose a pensadores posmodernos continentales como Derridá y Foucault), Putnam se enfoca de modo más claro en la naturaleza verificacionista de la verdad, lo que lo mantiene más fiel a la tradición del pragmatismo clásico que incluye a Dewey. La consecuencia de esta diferencia termina siendo que, mientras Putnam no tiene ningún conflicto en hablar de conocimiento de la verdad como aseveración justificada, Rorty prefiere alejarse de cualquier tipo de consideración sobre la misma negando, incluso, la utilidad del concepto mismo de verdad. ${ }^{19}$ El equilibrio que debe existir entre la dicotomía historicista y verificacionista, en particular en el pragmatismo de Dewey, hace que no reconocer alguno de estos factores, o desdeñarlo en algún nivel, suponga diferencias teóricas relevantes, como es el cientificismo materialista por un lado o el historicismo relativista, por otro.

El pensamiento de Dewey reconoce la necesidad de un criterio de objetividad y de verdad que permita justificar una jerarquía entre las aseveraciones aunque, al mismo tiempo, obligue a un esfuerzo continuo por mejorar nuestras formulaciones e hipótesis sobre el mundo y nuestra actuación en él. Aun aceptando el historicismo en el ámbito de las ideas, la posibilidad de verificar las hipótesis en la realidad nos permite jerarquizarlas en función de criterios objetivos. Como se verá conforme continúa el capítulo, este criterio verificacionista es la

\footnotetext{
${ }^{19}$ Cfr. Richard Rorty, "Hilary Putnam y la amenaza del realtivismo", en Verdad y progreso, trad. Ángel Faerna García (Barcelona: Paidós, 2000), 63-88. y Cfr. Hilary Putnam, El Pragmatismo (Sevilla: Gedisa, 2006), 106108.
} 
condición necesaria para poder justificar el liberalismo democrático sin recurrir a una idea moral o política del bien. Si el único modo de justificar el liberalismo se encontrara en preferencias históricas arbitrarias, como puede ser una idea del bien determinada, el proyecto civilizatorio del liberalismo estaría en riesgo aun antes de iniciar. Por el contrario, si podemos integrar una hipótesis de la realidad política, aun desde una perspectiva histórica determinada, que pueda ser justificada por criterios pragmáticos, entonces, aun cuando aceptemos que nuestra justificación no es definitiva o final, podremos decir que es mejor que sus competidoras.

Si bien en todo momento es posible considerar que pudiera existir una nueva comprensión, lectura, creencia o hipótesis sobre el estado de la realidad, dadas ciertas intenciones, esto no quiere decir que las hipótesis ya existentes tengan la misma validez. Manteniéndonos en el campo científico, podríamos decir que aunque nuestra experiencia cultural histórica nos enseña que podrían existir nuevas teorías que explicaran de mejor modo la ordenación del cosmos (como nos muestra la historia de la astrofísica por ejemplo, que es un campo particularmente fértil y abierto a nuevas formulaciones), no podemos aceptar que todas las teorías existentes del orden del cosmos son aceptables hoy en día (como sucede con la teoría ptolemaica geocéntrica). Si bien no podemos estar seguros de que no existan mejores hipótesis posibles (sobre todo porque no las conocemos presentemente), sí sabemos que hay hipótesis peores que no sirven. Es cierto que la conceptualización de todas nuestras ideas y creencias como hipótesis supone siempre la existencia de la duda de poder realizar mejores descripciones e hipótesis, sin embargo no debemos confundir esto pensando cualquier aseveración puede ser correcta en un momento dado.

La verdad en el pragmatismo no debe ser comprendida en un sentido tradicional. Podríamos considerar que es de algún modo relativista, aunque no en el sentido que normalmente se entiende por el término como meramente dependiente de las consideraciones subjetivas, fruto de una voluntad arbitraria de los individuos. La verdad es relativa a las condiciones reales en las que aseveraciones o creencias sean postuladas; dentro de estas se encuentran la cultura, la realidad y las intenciones de quien postule la idea. Es cierto que desde el pragmatismo la idea de una verdad universal y atemporal carece de todo sentido (de entrada la verdad se dice de las ideas, no de los hechos, y las ideas son existencias, como ya vimos, históricas); sin embargo, esto no significa que cuando decimos de una creencia o aseveración que es verdadera estamos diciendo algo irrelevante de ella, lo que queremos decir es que es la más justificada entre sus "competidoras", o al menos constatamos sus consecuencias en la realidad en algún 
sentido. De este modo, cuando hablamos de una aseveración justificada estamos hablando de una hipótesis que se ha superado su prueba en la realidad (algunas hipótesis están mejor justificadas que otras). Debido a que dicho conocimiento ha sido probado puede ser utilizado posteriormente como "herramienta" para una indagación futura. ${ }^{20}$ Este hecho es evidente en la investigación científica donde ciertas hipótesis y leyes son consideradas como hechos sobre los que es posible construir conocimiento nuevo.

La naturaleza del conocimiento propuesta por Dewey nos permite no sólo explicar el desarrollo del conocimiento científico en su contexto histórico sino también el método de las ciencias. Dado que el conocimiento está constituido por la suma de las hipótesis confirmadas, el método científico es para Dewey la sistematización de los mecanismos de indagación que nos permitan probar nuestras hipótesis con mayor seguridad. En la medida en que reconocemos la naturaleza hipotética del conocimiento, estamos en condiciones de aceptar que dicho saber puede ser refutado en cualquier momento. Este hecho puede tener implicaciones graves en el cuerpo del conocimiento humano como lo muestra el ejemplo del darwinismo. Durante la mayor parte de la historia occidental se había considerado que las especies tenían una naturaleza inmutable; el hombre siempre había sido hombre del mismo modo, así como el resto de las especies de la naturaleza se habían mantenido iguales en el tiempo. La propuesta de una hipótesis nueva, la evolución por selección natural de Darwin, condujo al desarrollo de una nueva comprensión de la vida (desde el punto de vista de la biología) que tuvo un amplio impacto en el desarrollo del conocimiento de la humanidad. Gracias a la nueva hipótesis la idea de las especies inmutables fue desechada y una profunda reforma del campo biológico fue la consecuencia. Aun cuando en el campo de las ciencias este proceso indagatorio es especialmente claro, no hay una razón para pensar que es exclusivo de ellas. Los distintos ámbitos del conocimiento varían por sus intenciones, no por diferencias epistemológicas o metafísicas. $^{21}$

\section{$\underline{\text { Pragmatismo como método y actitud }}$}

La metodología de la indagación según Dewey es la del conocimiento válido en general, que es verificable y puede ser catalogable como verdadero, pues implica la

\footnotetext{
${ }^{20}$ John Dewey, Logic. 21

${ }^{21}$ Cfr. Ibid. 110
} 
búsqueda de la confirmación de nuestras hipótesis a través de pruebas en la realidad y en los datos previamente justificados. Si nuestras hipótesis no generan un cambio en la realidad, entonces nuestro postulado difícilmente constituye conocimiento válido: "El sentido práctico es, por tanto, el valor que le damos a las consecuencias: son buenas o malas; deseables o indeseables; o meramente nulo, indiferente, en cuyo caso la creencia es vana, la controversia es ociosa, convencional o verbal." ${ }^{22}$ En este sentido la comprensión de la verdad es mucho más amplia que la de los positivistas franceses por ejemplo.

Pensemos en una disputa intelectual particularmente famosa por su futilidad, ocurrida en el seno de la tradición escolástica: ¿cuántos ángeles caben en la cabeza de un alfiler? ¿Qué respuesta podríamos ofrecer que cumpliera con los requisitos deweyanos del conocimiento válido?, ¿es planteable el problema en algún sentido constatable?, ¿tiene algún objetivo práctico responder una pregunta de este estilo? La pregunta sobre la naturaleza de una entidad que no puede ser verificada, como son (al menos hasta el día de hoy) los ángeles, no tiene cabida dentro del pensamiento pragmático de Dewey; al menos en tanto tengamos por objetivo una discusión intelectual que procure ser algo más que una "controversia ociosa, convencional o verbal". El pragmatismo nos aleja de las disputas sobre las que no podemos ofrecer argumentos justificables y que, por lo mismo, no pueden ser realmente definidas. Si utilizamos el método pragmático de conocimiento, que es el de la indagación, seremos capaces de identificar desde un inicio las disputas o problemas que pueden ser solucionables y tener una respuesta. Al mismo tiempo, nos permite reconocer con claridad qué discusiones son francamente ociosas y sólo tienen sentido como un ejercicio mental inconsecuente, es decir pseudo problemas. ${ }^{23}$ La fuerza de la idea pragmática se centra en negar primacía a las ideas sobre el mundo impidiendo el extravío común de la mente en consideraciones alejadas de la realidad y sin aplicación o confirmación práctica. Esto es particularmente claro cuando observamos cómo las ciencias en la actualidad tienden a distanciarse de discusiones metafísicas que no pueden ser resueltas a través de la comprobación con la realidad (lo que no es lo mismo que negar el conocimiento eminentemente teórico). Es decir, aun cuando el

\footnotetext{
${ }^{22}$ Dewey, "What does pragmatism mean by practical?". 89

${ }^{23}$ En estos puntos se entiende con mucha claridad el por qué Hilary Putnam tiende a incluir a Wittgenstein dentro de la lista de pensadores pragmatistas (Cfr. PUTNAM, El Pragmatismo, 53-59.). La idea de un problema verbal en Dewey me parece que puede ser comprensible desde la noción de problemas de lenguaje en Wittgenstein en donde muchos de nuestros problemas, o al menos de lo que consideramos problemas, son malos usos del lenguaje en los que damos propiedades a los objetos reales que no les deberían de competer.
} 
conocimiento científico no es el único objeto de la indagación, Dewey considera que es el mejor ejemplo del que disponemos hasta la fecha. ${ }^{24}$

Al reconocer el límite de todas nuestras ideas en la realidad concreta, nunca al revés, la inducción pragmática nos ofrece la posibilidad de tratar los problemas y temas de interés intelectual, independientemente de su ámbito, bajo un criterio similar de consideración al de las ciencias naturales. La actitud que surge de este método frente a la totalidad del conocimiento es una perspectiva científica de la realidad:

(...) que los "principios" están últimamente sometidos a los hechos y no al revés; que las consecuencias empíricas más que lo a prioi son la base de sancionar y justificar las ideas. Pero todas estas ideas son fruto de la influencia dominante de las ciencias experimentales: el método de tratar las concepciones, teorías, etc. como hipótesis trabajando, como directores de un cierto experimento y observaciones experimentales. El pragmatismo como actitud representa lo que el Sr. Pierce ha felizmente determinado el "hábito del laboratorio mental" extendido a toda área en donde la indagación pueda ser llevada a cabo con éxito. ${ }^{25}$

La noción tradicional de la ciencia como un cúmulo de conocimientos, de un corpus de teorías que nos ofrecen la explicación de todo lo que pasa, queda prácticamente desvanecida. Podríamos decir que la ciencia pasa de ser un objeto a un método de confirmación de las verdades.

Los legos toman ciertas conclusiones que entran en circulación como ciencia. Pero el investigador científico sabe que constituye ciencia sólo en conexión con los métodos por los cuales son alcanzadas. Aun cuando fueran verdad, no son ciencia en función de su corrección, sino por los mecanismos que se emplean para alcanzarlos. (...) La ciencia, en otras palabras, es un lenguaje altamente especializado, más complicado de entender que cualquier otro lenguaje natural. ${ }^{26}$

Cuando los individuos reconocen que lo central de la ciencia no es el cuerpo de conocimientos acumulados, sino la actitud y metodología aplicadas para conseguir verdades, el proceso de identificación del conocimiento pseudocientífico es sencillo. El ejemplo típico para tratar este tema son algunas de las denominadas medicinas alternativas, que asumen que su habilidad terapéutica, aun cuando no es justificable mediante métodos científicos, está garantizada. Un tratamiento médico que no puede demostrar empíricamente su funcionalidad, no debería ser reconocido como ciencia (aunque asumamos que es de tipo alternativo); un individuo que sea capaz de reconocer la naturaleza del conocimiento científico no

${ }^{24}$ Cfr. John Dewey, Logic. 608

${ }^{25}$ Dewey, "What does pragmatism mean by practical?". 86

${ }^{26}$ John Dewey, The Public and its Problems (Atenas Ohio: Swallow Press y Ohio University Press, 1954), 163. 
debe tener problemas en rechazar las conclusiones no justificadas de un curandero charlatán. No intento decir que no existan algunos productos de las medicinas alternativas que funcionen. El punto es que los productos que demostrablemente funcionan tienden a ser reconocidos y agregados al cuerpo de medicina tradicional con el tiempo pues han superado los filtros de verificación.

Bajo esta nueva comprensión es necesario hacer el contraste con la comprensión de lo científico en la modernidad, en la que ciencia se podía entender en el descubrimiento y catalogación de los principios y conocimientos que describían el "lenguaje de la naturaleza". Como se ve desde la perspectiva pragmática de Dewey, el objetivo de la ciencia, o el conocimiento denominado como científico para el caso, no está en encontrar la verdad tanto en "construir" conocimientos-hipótesis sobre el mundo que pueda ser catalogado como verdadero. La actitud pragmática (iy por supuesto de la ciencia!) es la actitud anti dogmática por excelencia llevada todos los ámbitos de la vida que acepten ser juzgados por criterios de verificación claros.

La actitud pragmática es el llamado a comprender el mundo en categorías, para usar nomenclatura clásica, contingentes. Una vez que somos capaces de reconocer la naturaleza de las ideas y del mundo mental que construimos (reconociendo que mundo mental es el único mundo que existe fruto de una realidad que no tiene significado por sí), no nos queda más que aceptar la incertidumbre como un hecho normal que permea todo nuestro conocimiento de la realidad. La búsqueda de la verdad absoluta, como la ha procurado la tradición filosófica en distintos momentos de la historia, contradice las posibilidades fácticas de nuestro conocimiento.

El compromiso con la inevitabilidad es siempre el fruto del dogma; la inteligencia no pretende saber más allá del resultado de la experimentación, lo opuesto a las preconcepciones dogmáticas. ${ }^{27}$

La refutación de la idea de lo necesario como una característica constitutiva de algún tipo de realidad genera una igualación entre los distintos tipos de objetos del conocimiento. Aun cuando sea posible considerar diferencias entre la racionalidad práctica, la científica o la artística, considero relevante recalcar que la distinción entre cada ámbito se refiere del mismo modo a las intenciones del que conoce que a la naturaleza de los objetos mismos. Es fundamental recalcar, para comprender la comprensión política perfeccionista de Dewey, que la actitud pragmatista, que promueve una tendencia falsacionista y metódica para enfrentarse a la realidad, es

${ }^{27}$ John Dewey, Liberalism and Social Action (Reno: Frederick Ellis), 80. 
aplicable a ámbitos de la vida que tradicionalmente se consideraban alejados de la metodología indagatoria de las ciencias. La condición de posibilidad del mejoramiento del conocimiento está fundada, en cierto sentido, en la naturaleza parcial del conocimiento que siempre puede ser puesto a prueba y que, por las razones hasta ahora expuestas, puede estar equivocado en cualquier momento. El conocimiento humano está conformado por hipótesis que sólo pueden ser demostradas como justificadas si son puestas a prueba con la realidad; ningún tipo de conocimiento, por tanto, debería estar exento de demostración o de ser considerado falseable: "Pero en el momento en que la filosofía supone que puede encontrar una solución final y comprehensiva, deja de ser indagación y se convierte en apologías o propaganda." 28

El comportamiento humano, como es estudiado en la ética o la política, no está exento del examen racional aplicable a cualquier disciplina científica de las denominadas ciencias exactas. La actitud perfeccionista, tanto en moral como en política, está condicionada a nuestra capacidad de generar mejores descripciones e hipótesis de acción más efectivas. La actitud pragmática mantiene una confianza en la razón no sólo respecto a su capacidad de generar mejores ideas sino, debido a esto, de promover cambios en las circunstancias adecuados que en lo político y en lo moral refieren a la noción de perfeccionamiento.

\section{Ética y razonamiento moral en John Dewey}

Uno de los fenómenos más obvios de la vida es la aparente discontinuidad entre lo concreto y lo ideal. El punto de prueba de todo sistema ético es qué tan bien da sentido a la separación en la experiencia ética entre lo que es y lo que podría ser. ${ }^{29}$

Aun cuando la actitud pragmática es igualmente aplicable a la investigación científica como la moral, no debemos suponer que Dewey esperaría que los resultados de nuestras indagaciones fueran similares en lo que respecta a su capacidad predictiva. Dewey está perfectamente consciente de la cantidad de factores involucrados en nuestra racionalidad práctica son lo suficientemente complejos y cambiantes como para aceptar que el grado de incertidumbre entre ambas esferas del saber es distinta. Sin embargo, aceptar que el objeto de análisis que constituye la acción moral supone dificultades propias no significa, sin lugar a

\footnotetext{
${ }^{28}$ Dewey, Logic. 63

${ }^{29}$ Dewey, Principles of Instrumental Logic 76
} 
dudas, que no pueda o deba ser fruto y objeto de la indagación racional metódica. Después de todo, de no hacerlo así, surgen riesgos y problemas de los que hemos sido históricamente víctimas.

El ideal, por ejemplo, de la justicia no es una idea inútil. La mayoría de las personas asumirán que saben lo que es la justicia. Ese concepto tan vago de la justicia es peor que inservible, porque las personas actúan en función de él. Una persona que lo sostiene está a la merced de sus propios sentimientos o la tradición recibida de sus maestros. Primero debería existir una maestría en los hechos concretos para después discutir la tendencia de esos mismos hechos.

¿Cómo podría el ideal ordinario de justicia ayudar en la aplicación de justicia de nuestro mundo industrial? Uno debe primero entender la dinámica de las fuerzas industriales. Debe de existir algún tipo de teoría interpretativa, una teoría de la acción ética de la sociedad como un todo, como una organización ética. Debemos también ver la relación de esta acción respecto de todo el organismo. Esto requiere paciencia y por tanto parece ser más fácil actuar sin saber. ${ }^{30}$

La aplicación de conceptos y categorías morales que nos permiten generar más y mejores descripciones de la realidad moral de las personas, debe estar garantizada por criterios racionales de indagación. No es que conceptos como justo o valiente, por dar algunos ejemplos, no nos sirvan para decir algo de un estado de cosas, el punto es que estos conceptos, que tradicionalmente tienden a relacionarse con la categoría de valores, tienen que ser enfrentados con la realidad concreta para ayudarnos a comprobar la hipótesis. ${ }^{31}$

El trato de los ideales y valores morales, respecto a su relación con la realidad, ha sido muy diverso en la tradición. Una posición contrastante respecto a la racionalidad pragmatista de Dewey la podemos encontrar en las propuestas reduccionistas, como las denomina Hilary Putnam. ${ }^{32}$ Es interesante y relevante decir algunas palabras sobre ellas pues el contraste permite comprender de modo más claro los alcances de la actitud pragmática para referirse a la realidad desde una perspectiva moral.

La postura reduccionista, afirma Putnam, se plantea un problema cognitivo: sólo somos capaces de dar descripciones de la realidad en tanto que puedo describir hechos de la misma, las discusiones sobre valores no son sobre la realidad sino, más bien, sobre nuestras consideraciones o apreciaciones de la realidad; por otro lado, asumiendo que podemos dar descripciones de la realidad (sea sobre

${ }^{30}$ Ibid. 79

${ }^{31}$ Cfr. Dewey, Logic. 127

${ }^{32}$ Cfr. Hilary Putnam, El desplome de la dicotomía hecho-valor, trad. Francesc Forni Argimon (Barcelona: Paidós, 2004), 123. 
personas o circunstancias) pertinentes para el discurso moral, entonces es necesario considerar que esas descripciones se refieren directamente a hechos de la realidad, hechos morales de la realidad, si esto es así, ¿qué órganos sensorial poseemos para aprehender estos hechos-valores? El tema es sumamente complejo pues nos presenta dos posibilidades que podrían no ser aceptables: o bien los fenómenos morales existen en la realidad, en cuyo caso necesitaríamos de algún tipo de órgano que pueda percibir dichos fenómenos, o no poseemos dicho órgano (lo que parece ser la respuesta aceptable) y los fenómenos morales no existen en realidad sino sólo en nuestra imaginación.

El problema descrito por posturas reduccionistas como la esbozada arriba es correcto si suponemos una teoría del conocimiento empirista sumamente simplista, lo que no sucede con el pragmatismo de Dewey como ya mostré al examinar la noción de problema. El supuesto de una teoría de este estilo es que todas nuestras ideas y conceptos provienen directamente del contacto con la realidad sin ningún tipo de mediación. Como ya vimos en el apartado anterior, una concepción de este estilo falla en comprender la relación constructiva de las ideas y la realidad. Asumir que la realidad tiene descripciones propias nos podría conducir hacia la noción de cualidades primarias y secundarias elaborada por pensadores como Locke. El problema es el supuesto del representacionismo, como fue dicho, de que la realidad tiene un modo de ser representada, intrínsecamente adecuado, en sí. Si el reduccionismo que acabo de plantear fuera correcto, eso debería impactar todos los fenómenos existentes. Si aceptamos que existen los fenómenos morales en la realidad, diríamos que podrían ser juzgados en su dimensión moral independientemente de quién sea el actor moral y, del mismo modo, de quién sea el que lo esté juzgando.

Si el pragmatismo, como teoría de la verdad y explicación del origen de las ideas, es correcto, el representacionismo que acabo de retratar es necesariamente equivocado. Si no podemos garantizar, como afirmaría el pragmatismo de Dewey, la existencia de cualidades primarias y secundarias, por usar una hipótesis sobre una constitución del conocimiento representacionista, entonces no podríamos hacer una distinción cualitativa y objetiva de las descripciones de hecho y las de valor. Si el representacionismo estuviera en lo correcto diríamos que la realidad, si los fenómenos morales existen más allá de un mero delirio, tiene una naturaleza o dimensión moral independiente de nosotros.

Cuando una teoría representacionista exige que los argumentos científicos, que pueden ser realmente discutidos con pretensiones de verdad, deben referirse a 
las cualidades primarias, supone un nivel de objetividad del conocimiento que no existe en la realidad. ${ }^{33}$ Lo que es más, al desarrollar una pretensión tan elevada no reconoce que otro tipo de argumentos pueden estar sujetos de igual modo al análisis racional; tal es el caso de los argumentos morales. El representacionista parece dejarnos con pocas alternativas viables para poder realizar un análisis racional de la moral; una vez que desechamos la hipótesis de un mundo moral independiente de la existencia de agentes morales el pragmatismo de Dewey nos ofrece una alternativa:

Como John Dewey proclamó hace ya mucho tiempo, la objetividad requerida por las afirmaciones éticas no es del género de la que proporciona una fundamentación platónica o de otro índole que esté ahí previamente a nuestro entregarnos a la vida y reflexión éticas; es la capacidad para superar la clase de crítica que emerge en las situaciones problemáticas con las que nos enfrentamos en la vida real. ${ }^{34}$

Así como sucede en la ciencia, el criterio de objetividad que requiere el discurso ético es el de la justificación. Relacionado a este punto podríamos decir que, como veremos más adelante cuando analice el Liberalismo Político ${ }^{35}$ y el "giro político", el pensamiento de Rawls tiene una evolución que lo conduce a conclusiones similares a las de Dewey. Los límites al conocimiento que impone Rawls en el Liberalismo son altamente compatibles con la comprensión pragmática de la ética de Dewey. Rawls utiliza el concepto de las cargas del juicio, que explico con detalle durante mi análisis del Liberalismo Político, que le permite mostrar cómo es que el nivel de certidumbre y objetividad que esperan alcanzar algunas posturas filosóficas (como algunos modos de realismo representacionistas) son humanamente imposibles. Las cargas del juicio tienden a reconocer la incapacidad de ofrecer verdades completamente objetivas o últimas en la medida en que el análisis es siempre parcial (es decir, es decir desde la perspectiva de un individuo que valora de diversos modos la información a como lo hacen otros individuos) y los eventos son complejos. No deja de llamar la atención, sin embargo, las altas expectativas que tiene Rawls del conocimiento científico, que no parecen haber cambiado demasiado con el "giro político", al punto que le da un estatuto de objetividad e inmutabilidad irreconciliable con la propuesta de Dewey, lo que en su momento

\footnotetext{
${ }^{33}$ Quizá uno de los mejores ejemplos de este fenómeno lo encontramos en lo que se ha denominado la filosofía del primer Wittgenstein en su Tractatus. Recordemos que para Wittgenstein en este momento el lenguaje cumple la función de una fotografía del mundo en el que las proposiciones describen un "estado de cosas". La verdad y la falsedad sólo pueden decirse de "estados de cosas" que pueden ser contrastados con la realidad. De las preguntas morales, por dar una instancia de muchas en el pensamiento del austriaco en ese momento, no tienen siquiera sentido.

34 Ibid. 114

${ }^{35}$ John Rawls, Political Liberalism (Nueva York: Columbia University Press, 2005)
} 
criticaré (en especial al explicar la "posición original" al detallar la justificación de la justicia como imparcialidad en Teoría de la Justicia ${ }^{36}$ ).

En cualquier caso, la consecuencia del pragmatismo de Dewey en lo que se refiere a la argumentación moral es el volver innecesario un criterio trascendente para justificar la razón práctica. La acción moral es, fundamentalmente, una en la que los individuos deben de confrontar diversos valores e indagar la manera en que su acción les permite relacionarse con ellos. ${ }^{37}$ Dewey se aleja de tradiciones como la ética deontológica o una ética de fines como modelos de pensamiento ético objetivo. Son estas consecuencias del pensamiento de Dewey las que hacen que, como mostraré adelante, una comprensión pragmática-deweyana de la justicia como imparcialidad, la teoría de la justicia elaborada por Rawls, pueda superar algunas de las complicaciones derivadas por el neokantismo que el mismo Rawls terminó rechazando, prefiriendo un desarrollo político de su teoría.

Por un lado, continuando con el análisis de las consecuencias del pragmatismo de Dewey, la ética deontológica, que en términos muy generales supone la existencia de principios y deberes que orientan el comportamiento moral correcto de los individuos previos a la existencia de los fenómenos morales concretos que arbitran, pierde sustento en tanto reconozcamos que el único mecanismo racional de justificación es el pragmatista. Este tipo de éticas puede estar representado por una deontología kantiana, que en su fundamento busca desarrollar principios de acción completamente racionales. Otro tipo de ética deontológica es la de fundamento teológico como son algunas éticas protestantes, que tienden a sostener una especie de voluntarismo divino en el origen de los principios y deberes de los individuos. ${ }^{38} \mathrm{Si}$ asumimos la teoría del origen de las ideas del pragmatismo de Dewey, ambas propuestas, tanto una deontología racional como una de corte teológico voluntarista, deberían ser sujetas a la crítica racional todo el tiempo bajo el supuesto que dichos principios pueden ser incorrectos dado un contexto determinado. Claramente la deontología teológica no podría estar de acuerdo con una postura falsacionista de sus principios; la actitud pragmatista supone un antidogmatismo y antifundamentalismo de la verdad contrario a las pretensiones de una teología fundada en la revelación. Por su parte, la deontología racional de carácter kantiano presentaría un problema similar; el

\footnotetext{
${ }^{36}$ John Rawls, $A$ Theory of Justice (Cambridge: Harvard University Press, 1999).

${ }^{37}$ Cfr. John Dewey, Ethics (Nueva York: Henry Holt, 1908). 209.

${ }^{38}$ Un buen ejemplo de este tipo de moral es la luterana. Para un análisis de la relación autoritaria y voluntarista de la divinidad en la mentalidad luterana ver el estudio que hace Erich Fromm (Cfr. Erich Fromm, El miedo a la libertad (Barcelona: Paidós, 1964).
} 
falsacionismo en los principios, derivado de las condiciones cambiantes (recordemos que una de las razones para considerar el falsacionismo es que las descripciones del mundo, así como las condiciones, cambian continuamente y necesitamos adecuar nuestras hipótesis de acción), implicaría una primacía en lo que Kant denominaba la realidad fenoménica frente a la noumenica que sería inaceptable a todas luces. Esto nos conduce a renunciar a cualquier pretensión de desarrollar principios de comportamiento o conocimiento fijos o finales bajo condiciones cambiantes como se sostiene desde la deontología kantiana; podremos apostar por una cierta estabilidad, más no a la finalidad.

Por otra parte, en lo que se refiere a las éticas denominadas de fines, como pueden ser algunas lecturas de la ética aristotélica ${ }^{39}$ y ciertas éticas cristianas como la tomista, ${ }^{40}$ el pragmatismo de Dewey es irreconciliable. Una ética de fines que suponga un cierto catálogo de bienes y circunstancias individuales deseables independientemente del contexto cultural, material e histórico no está abierta al proceso de justificación racional al que cualquier aseveración debería estar sujeta. El liberalismo de Dewey, por ejemplo, se diferencia de algunos de sus similares al no considerar la libertad un valor que por sí sea relevante para la vida de los individuos. Dentro de la ética pragmática de Dewey la libertad es relevante siempre que nos permita desarrollar nuestras intenciones en un contexto determinado:

Para Dewey, las distinciones entre "medios" y "fines" también son dependientes de la perspectiva. Cuando valoramos algo como un medio, lo consideramos desde la

\footnotetext{
${ }^{39}$ Es importante mencionar que existen lecturas de la filosofía aristotélica que son mucho más compatibles con algunas de las ideas del pragmatismo deweyano. Hilary Putnam realiza un esfuerzo por revitalizar el aristotelismo en clave pragmática (Cfr. Hilary Putnam, Las mil caras del realismo, trad. Margarita Vázquez Campos y Antonio Liz Gutiérrez (Barcelona: Paidós, 1994), 41-68); del mismo modo Martha Nussbaum acentúa la importancia de la contingencia en la deliberación no científica que, en muchos aspectos, podría ser compatible con el pensamiento de Dewey (Cfr. Martha Nussbaum, The fragility of goodness (Nueva York: Cambridge University Press, 1986), 290-310.

${ }^{40}$ En este punto me siento obligado a hacer notar que la denominación aristotélico-tomista es, en el mejor de los casos, una caricaturización del desarrollo filosófico de Tomás de Aquino. Si bien es cierto que en textos como Suma Teológica una de las fuentes filosóficas de Tomás es Aristóteles, suponer que el estagirita estaría en condiciones de aceptar aseveraciones tomistas es un error pues ideas filosóficamente tan fundamentales para sus sistemas como la naturaleza de Dios son sumamente distintas (el primer motor inmóvil poco tiene de similar con un Dios personal). Del mismo modo, creer que el apoyo constante de Tomás en Aristóteles en la Suma Teológica o la Suma contra gentiles implica necesariamente una identificación de pensamiento es no tener un comprensión clara del argumento de autoridad en la escolástica medieval que tiende a usar el argumento de autoridad en buena medida sólo para mostrar que no hay contradicción con la tradición; es por demás relevante recordar que el primer texto fue elaborado para la preparación básica de futuros sacerdotes y la segunda es una respuesta a las filosofías no cristianas y, por lo mismo, procura dar respuesta a las inquietudes de las filosofías gentiles con diversos argumentos (el de autoridad es sólo uno de ellos). Asumir que la filosofía tomista es aristotélica limita el reconocimiento de originalidad en la obra de Tomás y probablemente genera una percepción equivocada respecto a su relevancia en el diálogo filosófico contemporáneo.
} 
perspectiva en que las consideraciones funcionales son prioritarias. Esto abre nuestra posibilidad para explicar cómo los fines, al igual que los medios, pueden ser evaluados instrumentalmente. Para Dewey, los medios definen los fines y los fines los medios. Fines de acción posibles - "fines" que podríamos adoptar "en perspectiva" de unas circunstancias concretas- son definidos pragmáticamente en términos de las operaciones requeridas para alcanzarlos. Pero la relación entre medios y fines es mucho más profunda que esto. Porque es como medios que valoramos los fines posibles cuando debemos elegir entre ellos. En cierto sentido, escribe Dewey, los fines posibles no son realmente "fines o término de la acción en lo absoluto. Son puntos finales en la deliberación e intersecciones en la acción." ${ }^{41}$

La diferencia irreconciliable de la ética pragmática con una ética de fines es que la categoría de fines en el pragmatismo de Dewey, como todas las ideas que poseemos, está sujeta a las intenciones y circunstancias del momento. Una ética de fines y bienes, que se precie de fundamentarse como tal, tiende a aceptar que hay circunstancias y objetos que son buenos dada la naturaleza humana (o una inteligencia trascendente) y las relaciones que surgen de ella. La ética pragmática de Dewey no puede garantizar la existencia de dichos fines y bienes por la naturaleza situada de nuestras ideas; si nuestras ideas y el interés intelectual surgen de situaciones problemáticas actuales, ¿cómo podemos concebir un bien o un fin más allá de las posibilidades cognitivas?, ¿podemos prever lo que querremos o necesitaremos si no sabemos cuál será nuestra condición?, aun si postulamos un bien trascendente (al modo de la filosofía cristiana de Tomás de Aquino), ¿tenemos las herramientas racionales para justificarlo? En este punto quiero recordar que la justificación racional en ética no tiene una razón para ser cualitativamente distinta de la justificación en otros ámbitos de la realidad. Los diversos mecanismos de justificación, dependiendo las áreas, varían según los "cánones" relevantes; sin embargo, los argumentos morales, al igual que los desarrollados por las ciencias naturales, deben estar sujetos a la justificación o verificación objetiva pragmática. Reconocer la importancia de la justificación pragmática en el ámbito moral nos permite comprender cómo es que pueden existir, así como sucede con las discusiones metafísicas como la disputa sobre la cantidad de ángeles en la cabeza de un alfiler, discusiones ociosas e irrelevantes en el campo de lo moral. ${ }^{42} \mathrm{Si}$ los criterios racionales de justificación requieren de comprobación de nuestras hipótesis en todos los ámbitos con la realidad, asumir

\footnotetext{
${ }^{41}$ Jennifer Welchman, “Dewey's Moral Philosophy” en The Cambridge Companion to John Dewey, ed. Molly Cochran (Nueva York: Cambridge University Press, 2010), 173.

42 Un argumento ocioso en este sentido sería la absolutización de las preguntas morales. Por ejemplo, "la homosexualidad es mala" es una cuestión irresoluble pues no hay un bueno o malo independiente de las circunstancias existentes. Los absolutos morales no tienen cabida en las discusiones racionales, al menos en tanto procuremos obtener una respuesta valiosa.
} 
que en ética no necesitamos herramientas racionales de justificación es un error. Desde este pragmatismo una ética que sostenga la idea del bien en sí o de principios universales es una que termina renunciando a la indagación moral:

La noción que el juicio moral simplemente aprehende y enuncia un fin en sí mismo predeterminado es, de hecho, un modo de negar la necesidad de y existencia de los genuinos juicios morales. Esto pues de acuerdo con esta noción no existe una situación problemática. Sólo existe una persona que está en un estado de incertidumbre o ignorancia moral subjetiva. ${ }^{43}$

El problema con las perspectivas filosóficas que tienden a negar la naturaleza empírica de la moral es la falta de comprensión del origen de la experiencia moral. La teoría de la ley natural, por ejemplo, supone que nuestras experiencias morales son juzgadas en función de ítems no naturales cuando es de corte teológico por ejemplo. ${ }^{44}$ Por otra parte, hay otra tradición de la ley natural que supondría que la realidad contiene, por sí misma, valores morales intrínsecos a su estructura. ${ }^{45}$ Como es de suponerse, en el pragmatismo de Dewey la comprensión y desarrollo de ideas morales es consecuencia natural de nuestra relación con el mundo concreto:

Cuando se dice que la experiencia moral evoluciona de lo no moral, no se quiere decir que la evolución implica el reconocimiento de valores morales en la experiencia no moral. Evolucionan en el sentido en que ciertas consecuencias externas se desarrollan de las experiencias no morales, y por referencia a ellas la experiencia se moraliza. ${ }^{46}$

Como vimos anteriormente, para Dewey las ideas son hipótesis de acción, intenciones. Podríamos decir, una vez que hemos aceptado ese origen de las ideas, que no hay eventos morales por sí mismos, del modo en que no hay sucesos químicos, biológicos o físicos por sí mismos; lo que existe en la realidad son fenómenos que son estudiados desde una perspectiva, con una cierta intencionalidad. Lo que existe, sin lugar a dudas, son interpretaciones químicas, biológicas, físicas $\mathrm{y}$, por supuesto, morales de los eventos. Al negar el

\footnotetext{
${ }^{43}$ Dewey, Logic, 266.

${ }^{44}$ En este punto entiendo lo natural como todas las entidades, en cualquiera de sus modalidades posibles, que se encuentran dentro de nuestro cosmos. En ciertos sentidos, la tradición de la ley natural supone que la ley tiene un legislador distinto de lo natural, superior y claramente diferenciable (recordemos la idea agustina de la divinidad viendo la totalidad de la creación, pasado, presente y futuro, desde un "punto" distinto (la eternidad). Esta comprensión de la ley natural es coincidente con posturas luteranas y calivinistas en particular.

${ }^{45}$ En esta tradición se encuentra la teoría, sobre todo medieval, de los trascendentales que, en su modo más simple, considera que la entidad, para poder existir dada la relación causal de Dios con el mundo, debe ser, en su totalidad y en cierta medida una, buena, bella y verdadera.

${ }^{46}$ Dewey, Principles of Instrumental Logic. 68
} 
representacionismo cognitivo en el campo científico, sin hacer una distinción tajante en el origen de las ideas morales o de otro ámbito, Dewey niega la existencia de verdades trascendentes en el campo de lo moral. Las posturas que suponen la existencia de entidades trascendentes fallan en reconocer la importancia de la experiencia empírica como mecanismo de descubrimiento y desarrollo de las ideas.

Si la teoría intuitiva fuera verdad, toda la experiencia moral se reduciría a aplicar verdades morales a ciertos casos. No habría ningún tipo de responsabilidad del individuo por encontrar la verdad por sí mismo (...). La debilidad del intuicionismo es que no trata la experiencia como desarrolladora de verdad.

La contención general del intuicionismo es que debe existir una verdad y universal, no particular y contingente. La experiencia muestra sólo lo particular. Debe de existir, por tanto, una potencialidad en la mente para darse cuenta de esas verdades universales que trascienden lo particular. Se dice que debe de existir un punto inicial definitivo, una verdad última a la que las demás se puedan ordenar. De otro modo no existe certeza. Por supuesto estas verdades deben de ser inmediatas, autoevidente. $^{47}$

El intuicionismo, para Dewey, es insostenible en la medida en que niegan la naturaleza contingente de la realidad moral de los individuos. Un problema de suponer que existen verdades universales y autoevidentes en ética es que la simplicidad requerida en las sentencias, para tener un cierto carácter axiomático, no responden en ninguna ocasión a las complicaciones reales del mundo contingente en el que vivimos. Supongamos uno de los grandes universales morales en la historia: "no matarás". La sentencia en contra de matar, que para ser una verdad universal debería ser aplicable en todas las ocasiones y reconocible para todas las personas, ha estado plagada de excepciones incluso por los defensores acérrimos de su universalidad. La teoría de la guerra justa, desarrollada con amplitud en la Edad Media y en la escolástica tardía española señala las ocasiones en que es legítimo iniciar hostilidades (aun cuando sea sólo en respuesta proporcional) entre naciones. La idea de la defensa propia como razón legítima para matar a alguien muestra cómo es que la aplicación de estas "verdades universales" depende seriamente de las condiciones materiales en las que las circunstancias se desarrollan. Aceptar que por principio reconocemos circunstancias particulares en las que matar puede ser aceptable y que esas circunstancias han cambiado con el paso del tiempo (pensemos que ha habido momentos en la historia en la que el honor era una razón suficiente para matar a alguien, aunque hoy en día, en nuestra cultura, esa noción tiende a no tener

${ }^{47}$ Ibid. 71 
sentido), dista mucho de reconocer una verdad moral que nos permite juzgar todos los eventos en los que una persona es responsable de la muerte de otra. Nuestra tarea no es deductiva, si queremos desarrollar un conocimiento útil para comprender la dimensión moral de nuestra acción la labor es inductiva. Los principios morales constituyen generalizaciones que deben ser puestas a prueba en las condiciones materiales predominantes.

Sólo con el análisis minucioso y cuidadoso de las implicaciones de nuestra hipótesis (en este caso el principio general), los medios y los fines que perseguimos con nuestra acción, ${ }^{48}$ podremos alcanzar los objetivos y fines que nos planteemos. "Las necesidades de una ciencia ética son, primero, una psicología adecuada que nos muestre el boceto, que nos ofrezca el esqueleto de cualquier experiencia como una de tipo ético. El conocimiento histórico pertinente y detallado es interpretado bajo la luz de las hipótesis que nos ofrece el análisis psicológico." ${ }^{49}$

El intuicionismo, con su obsesión por verdades universales y generales, tiende naturalmente al dogma y en ese sentido a un conservadurismo, o radicalismo en algunos casos, incapaz de responder a las necesidades y retos de un contexto cambiante. La ética pragmática de Dewey promueve por su parte una comprensión empírica de la moral que busca desarrollar los mejores mecanismos de acción en el mundo presente. Dewey es un progresista en temas de moral y lo es también en política. La clave del progreso está en la capacidad del individuo de desarrollar mejores mecanismos de indagación que le permiten enfrentar la realidad de mejor manera.

El problema de la toma de decisiones correcta, que es un tema recurrente en este trabajo al analizar el tema del progreso y la perfección, implica la complicación de tener las hipótesis de acción correctas para las condiciones cambiantes del mundo en que vivimos. Esa es la prueba básica de cualquier sistema de creencias morales: ¿cuál es su capacidad de explicar lo que es en función de lo que podría ser?, ¿es capaz de ofrecerme alternativas viables para alcanzar los fines que considero valiosos?, ¿en qué medida dichos fines son valiosos en realidad?

El modo de llevar a cabo este tipo de análisis moral no debería ser considerado como una especie de proceso casi matemático. El hecho de que Dewey sostenga que el proceso indagatorio de la ciencia debería de ser utilizado en el análisis moral no implica que los mecanismos específicos sean iguales:

\footnotetext{
${ }^{48}$ Cfr. Dewey, Ethics. 307

${ }^{49}$ Dewey, Principles of Instrumental Logic. 74
} 
La noción de que la deliberación sobre las distintas alternativas abiertas a nosotros es un proceso, a sangre fría, de enumerar los diversos elementos en nuestra ventaja y los que son desventajas (como Robinson Crusoe escribió al modo de contaduría sus miserias y bendiciones), para después hacer un balance algebraico, implica algo que nunca puede ser hecho. La deliberación es un proceso de ensayo activo y suprimido (...). Cuando vemos en la imaginación uno u otro cambio hay un sentido directo de cuánto y qué tipo de valor se le adjunta, tan real y directo, aunque no tan fuerte, como si el ato fuera realmente llevado a cabo y sus consecuencias realmente nos hubieran acontecido. ${ }^{50}$

Al desarrollo de la ética pragmática que niega la validez del intuicionismo moral, de una ética teleológica y en ciertos sentidos de la ética deontológica se le podría criticar por ser incompatible con un proyecto de vida fundamentado en la integridad moral como ésta es comprendida comúnmente. La crítica puede ser acertada en un sentido, aunque no en el que comúnmente se implica. En efecto una moral pragmática puede parecer incomprensible para una comprensión moral de la realidad estática. Si el criterio para decidir un camino de acción está profundamente vinculado con su viabilidad, eso implica que actuar por principio, aun reconociendo el fracaso inminente, lo que para algunas éticas es algo loable, carece de todo sentido desde una óptica pragmática. Si la integridad moral se considera como la capacidad u obligación de un individuo de apegarse a un canon de principios sin considerar los posibles resultados de sus acciones, la ética pragmática es carente de integridad. Sin embargo, el pragmatismo como alternativa no es, en modo alguno, una tendencia a hacer el mal o tomar ventajas indebidas para perseguir objetivos egoístas, como han intentado hacer algunos detractores del pragmatismo moral.

La deliberación moral, el acto de considerar y elegir entre las distintas posibilidades de acción, obliga a las personas a hacer planteamientos serios sobre sus opciones en función de un panorama complejo que supone no sólo las necesidades individuales sino, del mismo modo, de un ambiente mucho más amplio. Esto, que Steven Fesmire denomina un sistema "ecológico" que debe ser considerado en el proceso deliberativo, ${ }^{51}$ implica que un individuo que adoptara una actitud pragmática en temas de ética debe ejercer su razón de modo que pueda justificar sus creencias:

Una buena persona frecuentemente persigue malos fines, pero lo llamamos bueno si los persigue sin reservas porque al final actuará bien. La persona que toma

\footnotetext{
${ }^{50}$ Dewey, Ethics. 322-323

51 Steven Fesmire, "Dramatic Rehearsal and The Moral Artist: A Deweyan Theory of Moral Understanding", Transactions of the Charles S. Pierce Society, vol. XXXI no. 3 (1995): 581.
} 
ventaja de una nueva situación reconstruye sus ideales. Nunca es posible realizar un mal ideal porque las condiciones no lo permiten. ${ }^{52}$

En ciertos momentos el pensamiento moral de Dewey se asemeja a la phronesis aristotélica; después de todo, para Aristóteles el hombre prudente es capaz de evaluar las circunstancias contingentes en las que se encuentra de modo que puede actuar correctamente (recordemos que para Aristóteles la ética, más que una ciencia en su acepción clásica, se asemeja más al arte y debe aceptarse su naturaleza contingente y circunstancial excepto en los pocos casos, excepcionales, no sujetos a la deliberación prudencial como es el asesinato). La actitud pragmática nos lleva a considerar el impacto de las acciones en el amplio contexto de la sociedad, valores culturales e incluso el mundo natural.

Además de la naturaleza situada del conocimiento moral justificado, es importante enfatizar la influencia de nuestra cultura en informar qué objetos son o no deseables. La cultura funciona como vehículo de transmisión de ideas y principios que aprendemos para relacionarnos con el mundo. Lo que es más, incluso las motivaciones que consideramos primarias en nosotros son moldeadas y consideradas de acuerdo a la cultura y ambiente en general en el que nos encontramos. Si bien es cierto que existen tendencias naturales en el ser humano, la canalización de las mismas, que aparentemente no deberían responder a condicionamientos y herencia cultural por su naturaleza primitiva, son desarrollados a través del filtro de nuestro ambiente: "Lo que llamamos motivos terminan siendo, después de un análisis crítico, un patrón complejo de actitudes formado bajo condiciones culturales más que simples elementos de la naturaleza humana." ${ }^{53}$

Supongamos, en concreto, la competencia (que además sería una de las características del hombre que por antonomasia ha motivado la reflexión ética en el transcurso de la historia, aunque no siempre con el mismo enfoque) como una motivación relevante y perenne en la historia humana. Dewey contrasta dos hipótesis históricas sobre la competencia en el ser humano que generan comprensiones morales muy distintas de la motivación y, por tanto, traen consecuencias distintas en la teoría y, por supuesto, en la práctica.

Por un lado, Dewey retoma la preocupación de Hobbes por la competencia entre los seres humanos. Para Hobbes la competencia es un factor fundamental en el surgimiento de la violencia que nos obliga a "salir" del estado de naturaleza:

\footnotetext{
52 Dewey, Principles of Instrumental Logic. 92

${ }^{53}$ Dewey, Freedom and Culture. 86
} 
"Así hallamos en la naturaleza del hombre tres causas principales de discordia. Primera, la competencia; segunda, la desconfianza; tercera, la gloria." ${ }^{54}$ Hobbes, como es bien sabido, se enfrenta a los problemas que pueden surgir por la motivación del hombre a competir entre sí "obligándolo" a someterse a la autoridad del Estado; de este modo el individuo renuncia al ejercicio de sus motivaciones desenfrenadas asegurando su supervivencia. Sobre este punto Dewey nos dice que "las cualidades mencionadas por Hobbes realmente existen en la naturaleza humana y pueden generar "conflicto", esto es conflicto y guerra entre estados y guerra civil dentro de una nación -las circunstancias imperantes mientras Hobbes vivió- no se niega." ${ }^{55}$

Por otra parte, Dewey nos recuerda del trato que le dieron a la competencia algunos filósofos británicos en el siglo XIX. Para estos filósofos, parte de la escuela económica liberal, la competencia deja de ser considerada como el origen de la guerra y el conflicto y pasa a ser el motor del bienestar social. La competencia y la búsqueda de bienestar individual se convierten en la motivación que debe ser fomentada de modo que los individuos puedan desarrollarse con prosperidad. No sólo eso, nuestra naturaleza competitiva nos motiva a desarrollar nuestras capacidades y talentos de modo que las personas puedan alcanzar su potencial.

El modo de tratar este tipo de conflictos teóricos ha tendido a ser el anteponer ambas posturas intentando descifrar cuál de ellas es verdadera en un sentido más o menos trascendente. ${ }^{56}$ La estrategia de Dewey es diferente:

El objeto de referirnos a estas dos concepciones tan distintas de un componente de la naturaleza humana no es decidir o discutir cuál está bien. El punto es que ambos son culpables de la misma falacia. Por sí mismo, el impulso (o como prefiramos llamarlo) no es ni socialmente perjudicial ni beneficioso. Su significado depende de las consecuencias que de hecho produce; y estas dependen de las condiciones bajo las que opera y con las que interactúa. Las condiciones son puestas por la tradición, la costumbre, la ley, el tipo de juicios públicos; por todas las condiciones que constituyen nuestro ambiente. Estas condiciones son tan plurales aun en un mismo país, en un mismo momento histórico, que el amor por las ganancias (consideradas como un rasgo de la naturaleza humana) puede ser tanto socialmente útil como

\footnotetext{
54 Thomas Hobbes, Leviathan (Indianápolis: Hackett Publishing, 1994), capítulo 13.

55 Dewey, Freedom and Culture. 86

${ }^{56}$ Creo que es mejor decir trascendente que universal porque considero que toda postura que apunta a la universalidad suscribe la trascendencia de sus argumentos, aunque no toda postura que busque desarrollar argumentos trascendentales se refiere a la universalidad. Un argumento puede ser trascendente sólo en un sentido histórico determinado por ejemplo.
} 
dañina. (...) Ni la competencia ni la cooperación pueden ser juzgadas en tanto características de la naturaleza humana. ${ }^{57}$

Se puede ver cómo es que para que un individuo, siguiendo una actitud pragmática, renuncie al ejercicio de algún principio de acción previamente reconocido, lo que debería de hacer es un examen de las hipotéticas consecuencias de renunciar a dicho principio en las circunstancias competentes a dicha acción. Este modo de actuar se fundamenta en que nuestras ideas, principios e intuiciones morales, ya sea en su forma más general o específica, tienen una caducidad determinada por las condiciones "ecológicas" en las que se encuentren. Así, cuando nuestros ideales no están formulados para actuar con nuestra realidad presente, terminan exigiendo de nosotros acciones imposibles o inalcanzables dentro de lo razonable. Después de todo, una hipótesis de acción, o ideal, "elaborado lejos de los hechos presentes no tiene capacidad de actuar sobre la realidad y es impotente. Si el movimiento es incorrecto es imposible poder actuar para alcanzar el objetivo. Solo un milagro sobrenatural podría cambiar las cosas", por tanto, "cuando un ideal está aislado de la realidad, no sólo es impotente, sino dañino; nos lleva a intentar cosas imposibles y trae consigo males." ${ }^{58}$ Así, la falta de integridad en el actuar pragmático, si dicha falta implica el alejamiento del dogmatismo, representa una fortaleza de proyecto de Dewey.

Esta comprensión del pragmatismo, en la que las circunstancias y el falsacionismo juegan un papel protagónico dentro del razonamiento moral, tendrá implicaciones serias en la dimensión política también. Supongamos que fuéramos capaces de hacer una asamblea para elegir la mejor manera de organizar una sociedad políticamente, sin duda la aplicabilidad de los principios a la realidad sería uno de los criterios fundamentales a tomar en cuenta. Es decir, imaginando dicha asamblea, si alguien propusiera organizar a la sociedad en función del proyecto utópico de Tomas Moro, por ejemplo, una preocupación legítima sería la de entender qué tan posible es llevar a cabo dicho plan. En la medida en que no lo sea, sería considerado inestable y, por lo mismo, poco deseable. Esta preocupación estará presente en Rawls al plantear el tema de la estabilidad de su concepción de la justicia. Como mostraré en la segunda parte de esta investigación, uno de los pilares fundamentales para justificar el liberalismo igualitarista que propone Rawls (y que analizaré con cierto detalle después) es el de la capacidad de su concepción de la justicia de generar resultados justos en las disputas distributivas que se den

\footnotetext{
57 Ibid. 87-88

${ }^{58}$ Dewey, Principles of Instrumental Logic. 78
} 
en la sociedad. Este punto será central para comprender la vena pragmatista que está presente en toda la obra rawlsiana.

Por otro lado, regresando a la exposición de la ética pragmática de Dewey, en el mismo sentido que esperamos que una explicación científica o una aplicación tecnológica del conocimiento este fundamentada en hechos de la realidad adecuadamente justificados, deberíamos esperar que nuestros actos morales sean objeto de deliberación y consideraciones racionales que los justifiquen. Como en ciencia buscamos la verdad, en la moral buscamos el bien; términos relativos para las aseveraciones justificadas en cada uno de sus campos. El término verdad es utilizado en el ámbito de la ciencia, por ejemplo, para afirmar que una aseveración es la más justificada frente al resto de los competidores y, en ese sentido, podemos hablar de grados de verdad. Supongamos tres aseveraciones sobre la posición de la tierra en el universo: "la tierra es el centro del universo", "la tierra orbita alrededor del sol" y "la tierra se encuentra en el sistema solar que, a su vez, se encuentra dentro de la Vía Láctea". Dadas estas aseveraciones podríamos decir que cada una puede ser jerarquizada en función de su "grado" de verdad; la más verdadera sería la tercera. Del mismo modo, cuando nos encontramos en el ámbito de lo moral, es posible jerarquizar diversas aseveraciones dependiendo de qué tan justificadas se encuentren. Lo que buscaremos en esa jerarquización no es qué tanto nos permite describir el estado de cosas sino, por el contrario, qué tanto nos facilita lograr nuestras intenciones en el ámbito moral. Así como en ciencia hablamos de verdadero, en moral hablamos de bueno. ${ }^{59}$

La justificación de los conceptos morales depende, de modo muy similar a como ocurre en la ciencia, en reconocer la "correspondencia" de la hipótesis, idea o principio con el resultado esperado. El desarrollo de hipótesis está relacionado con la cultura en tanto que nuestros ideales, hipótesis y principios iniciales son elaborados colectivamente. Así como sucede con el desarrollo científico que implica la decisión del individuo de proponer una nueva alternativa para demostrar hipótesis establecidas o, cuando es el caso, para generar hipótesis nuevas, en el campo moral los principios, conducción de motivaciones e ideales, son postulados por individuos que, y esto es fundamental, participan y existen

\footnotetext{
${ }^{59}$ Estas distinciones no son exclusivas del pensamiento de Dewey de ninguna manera, están presentes con mucha claridad, por ejemplo, en Rawls: "La justicia es la primera virtud de las instituciones sociales, así como la verdad lo es de los sistemas de pensamiento. Una teoría, sin importar qué tan elegante o económica sea, debe ser rechazada o revisada si no es verdadera; del mismo modo las leyes y las instituciones, no importa que tan eficientes y bien ordenadas estén, deben ser reformadas o abolidas si son injustas." (John Ralws: $A$ Theory of Justice. 3)
} 
absolutamente inmersos en una tradición (misma que puede estar más o menos abierta al cambio y progreso).

Mientras que los seres individuales en su singularidad piensan, quieren y deciden, lo que piensan y desean, el contenido de sus creencias e intenciones es un objeto dado por la asociación. Por tanto el hombre no vive en sociedad de facto, sino que se hace un animal social en la elaboración de sus ideas, sentimientos y comportamiento deliberativo. Lo que cree, espera y procura es el producto de la asociación e interacción. ${ }^{60}$

De esta manera diversas culturas o tradiciones pueden asumir modos distintos de enfrentarse a la realidad desde una perspectiva moral. Todos nuestros conceptos morales, que sirven para analizar los problemas a los que nos enfrentamos y que no tienen una determinación moral por sí mismos, son productos culturales que se ven afectados por todo tipo de circunstancias que nos obligan a desarrollar nuevas hipótesis. Las nuevas hipótesis, en muchos casos, constituyen simplemente una relectura o cambio en la comprensión de conceptos morales ya existentes. Los matices que damos a nuestros conceptos e ideas implican que las distinciones pueden ser fruto de cambios en las condiciones ambientales que exigen ajustar la creencia para que se corresponda con la realidad.

\section{La actitud pragmática en ética}

Dada la similitud de la indagación ética a la que puede hacerse en otras áreas del conocimiento, la aplicación de la actitud pragmática a la ética se enfocaría en encontrar los mecanismos y métodos pertinentes para desarrollar mejores hipótesis de acción (creencias y principios morales, por ejemplo).

Una ética enfocada en principios normativos o fines establecidos, en muchos casos acríticamente aceptados, tiende a producir individuos que defiendan creencias propias de una clase, cultura o tiempo determinado, no en función de sus resultados sino por mero seguimiento a la tradición. Como se mencionó antes, la pertenencia a una cultura nos ayuda a formar los criterios para analizar nuestros problemas (morales o de cualquier índole), el respeto por la tradición y la cultura es importante pues constituye el cuerpo de creencias que nos han permitido llegar a donde estamos. Sin embargo, aceptar los criterios, principios y fines propuestos

\footnotetext{
${ }^{60}$ Dewey, The Public and its Problems. 25
} 
por la cultura acríticamente nos conducen invariablemente a contradicciones entre nuestros ideales y el "estado de las cosas".

Un ejemplo claro, aunque no suficientemente matizado en todas las ocasiones, es el conservadurismo estricto de la sociedad feudal en el Medievo. La sociedad medieval cristiana estaba organizada en función de criterios de autoridad y de tradición estrictos. En este punto es relevante recordar que dentro de la doctrina católica tradicional la tradición es considerada sagrada y parte de la revelación divina; es esta la razón de que la iglesia católica se define a sí misma como la comunidad de fieles y, en ese sentido, la pertenencia a esa comunidad exige la participación en el culto y en los principios y valores. En la Baja Edad Media europea la iglesia logró permear culturalmente casi todas las instancias e instituciones de la sociedad; su influencia era tan grande que la mera amenaza de excomunión se podía convertir en razón suficiente para que reyes y emperadores se "arrastraran" en actos de contricción. ${ }^{61}$ La sociedad medieval fue capaz, durante diez siglos, de mantener un orden social jerárquico estable mientras las condiciones materiales no cambiaron lo suficiente como para mostrar la incompatibilidad entre las ideas y la realidad. El final de la Edad Media, que fue un proceso sumamente complejo, integra fenómenos tan variados como el desarrollo técnico de la investigación astronómica, con Copérnico primero y el desarrollo del telescopio por parte de Galileo después (que es impulsado por la necesidad de mejores instrumentos de medición tanto para la navegación, con la creciente necesidad por los viajes al "nuevo mundo", como para un proceso agrícola cada vez más tecnificado), el desarrollo de una nueva clase burguesa (con origen en sus inicios en lo que hoy conocemos como Italia y que se dejan de entender dentro del sistema de clases feudal) $y$, aunque un tanto posterior, los diversos movimientos de reforma protestantes que dejan de encontrar en la tradición la respuesta a sus necesidades espirituales. La caída del paradigma del antropocentrismo cósmico, con la llegada del heliocentrismo, del surgimiento de nuevas clases sociales y el sentimiento de desolación generalizado por los cambios, a los que Lutero y otros grupos protestantes procuran ofrecer respuesta, ${ }^{62}$ entre otras circunstancias, hizo que valores tradicionalmente aceptados durante mil años terminaran siendo inadecuados.

\footnotetext{
${ }^{61}$ La honestidad de estos actos es discutible. La famosa disputa entre el papa Gregorio VII y el emperador Enrique IV, que condujo posteriormente a lo que se denominó la "querella de las investiduras" refleja la importancia del reconocimiento de la iglesia como factor de legitimidad ante la gran comunidad de los fieles. ${ }^{62}$ Erich Fromm ofrece una lectura sobre este proceso en: Erich Fromm, El miedo a la libertad (Barcelona: Paidós, 1964).
} 
Hoy en día los cambios sociales y en nuestra comprensión de la realidad se desarrollan con mucha mayor velocidad. El desarrollo del método científico en la modernidad es causa importante de esto. La posibilidad de encontrar una inmovilidad social como la de la Edad Media se ve cada vez más remota (siendo esto algo muy bueno para el progreso humano) por el proceso de liberación de los individuos que aconteció con el surgimiento del liberalismo y la ilustración en la modernidad. Sin embargo, aún dadas condiciones como las del Medievo, el argumento en favor de una actitud pragmática en ética (ser profundamente críticos y metódicos frente a las nociones de fines y principios por ejemplo) se sostiene. El desarrollo de la curiosidad intelectual, el reconocimiento de problemas y la búsqueda de soluciones es nuestra manera de relacionarnos con el mundo; no importa que tan alienados podamos estar, más tarde o más temprano nuestras ideas dejan de adecuarse a las circunstancias ya que estas son, irremediablemente, cambiantes. La actitud pragmática nos conduce a enfocarnos en el desarrollo de un método adecuado para mejorar nuestra comprensión del mundo e hipótesis:

El método es más importante que el fin porque el método correcto tenderá a corregir la ley equivocada. Lo normal es redefinir el ideal. (...) Los estándares morales son en su mayoría estándares de clase; a menos que hagamos esta distinción tendremos que identificar la bondad con la aceptación de una persona de los estándares de su clase en lugar de juzgarlo por su contribución al progreso mediante el uso de la experiencia. ${ }^{63}$

El método de la investigación ética no debe ser considerado como una serie de pasos determinados y absolutamente definidos. El método debe ser comprendido en relación con la actitud pragmática de libre pensamiento, intercambio de ideas y constatación con la realidad. De hecho, la noción de un método absolutamente definido es contrario a la comprensión deweyana de la investigación. La investigación se refiere a la búsqueda de verificación de hipótesis, construidas a partir de una tradición y cultura, enfrentadas a la realidad. La búsqueda de verificación en muchas ocasiones no lleva a "redefinir el ideal" operante en la investigación. El método pragmático conduce a considerar nuestros ideales en función de su éxito como herramienta para relacionarnos con la realidad y, en caso de no servir o de que postular una nueva herramienta sea posible, cambiarla.

Para él [Dewey] la 'investigación' en el sentido más amplio, es decir, el modo humano de enfrentarse a situaciones problemáticas, entraña una constante reconsideración de los medios y también de los fines; los objetivos de cada cual no están misteriosamente grabados en nuestra mente bajo la forma de una 'función de preferencia racional', ni todo lo que nos está permitido en tanto que seres

${ }^{63}$ Dewey, Principles of Instrumental Logic. 92 
'racionales' es buscar medios más eficientes para realizar esos inmutables aunque idiosincrásicos fines o valores. Toda investigación tiene tanto presuposiciones 'fácticas', incluidas las relativas a la eficiencia de ciertos medios para conseguir ciertos fines, como presuposiciones 'valorativas', y si nuestro problema es de difícil solución podemos muy bien replantearnos nuestros fines del mismo modo que nos replanteamos nuestros supuestos 'fácticos'. En resumen, cambiar los propios valores no es sólo un medio legítimo de resolver un problema; a menudo es el único modo de hacerlo. ${ }^{64}$

La finalidad de la ética pragmática es el desarrollo de las ideas e hipótesis que nos permitan, de mejor manera, conseguir los fines-medios que consideramos valiosos en un continuo proceso de construcción en comunidad. La correcta deliberación toma en consideración todos las circunstancias relevantes para la toma de decisión en un sentido "ecológico", un sentido que entiende nuestra dependencia respecto del ambiente social y físico que nos rodea. Por supuesto hay ambientes que facilitan la indagación; hay culturas más libres y menos dogmáticas, también las hay cerradas a la innovación en diversos ámbitos (dentro de los cuales el moral puede no ser la excepción). La ética y política pragmática desarrolla un ambiente positivo para la indagación.

El liberalismo político para Dewey sirve para optimizar las instancias materiales que promueven el desarrollo de la cultura y la consecución de los objetivos de los individuos en sociedad. Las sociedades conservadoras, como nos muestra con claridad el ejemplo de la Edad Media, limitan la libre indagación de los individuos de nuevas maneras de comprender, interpretar e interactuar con su entorno (este conservadurismo tiende a ser, para ser realmente efectivo, trascendente en diversos ámbitos de la cultura). El impulso conservador implica una negación ante la posibilidad de mejorar la relación de las personas con el mundo suponiendo que lo que hay es lo mejor que se puede tener. La actitud pragmática, en todas sus dimensiones, implica necesariamente la creencia en que los individuos son capaces de encontrar más y mejores maneras de lograr sus objetivos. La condición necesaria para alcanzar un estado en donde la actitud pragmática impere (que no es una circunstancia histórica terminada o final, sino que siempre está abierta al progreso) es necesariamente que los individuos puedan indagar con el método correcto para llevar a cabo la investigación, con completa libertad sobre cualquier problema que encontremos. Esto quiere decir que la investigación realizada por personas libres considera las implicaciones morales, físicas, políticas, económicas o cualquier otra que pudiera ser relevante dentro de

${ }^{64}$ Putnam, El desplome de la dicotomía hecho-valor. 118 
un proceso deliberativo ecológico. Para que la sociedad liberal merezca ese adjetivo necesita garantizar las condiciones para que los individuos puedan plantear y realizar sus proyectos de vida de acuerdo a límites que permitan esa misma oportunidad para todos. Es decir, la sociedad liberal, desde el proyecto político de Dewey, no puede simplemente mantenerse al margen y guardar distancia del individuo para dejarlo por sí solo, como el liberismo podría pretender. La sociedad liberal, por el contrario, debe generar las condiciones materiales para la libre indagación y eso, para que sea algo que todos los ciudadanos puedan experimentar, implica una sociedad sumamente activa e involucrada.

Este tema es central para comprender los objetivos del pragmatismo de Dewey en su dimensión ética y, posteriormente, política. La apertura del pensamiento, a la crítica y a la novedad es una condición necesaria de progreso y desarrollo. La única manera de saber si nuestras hipótesis de acción son correctas, es abriéndolas a la crítica que, en ocasiones, sólo puede ser elaborada desde "afuera". En un tono similar Judith Shklar, al plantear la importancia de que los ciudadanos sean capaces de analizar las prácticas del gobierno para evitar la crueldad (que es la preocupación esencial del Liberalism of Fear), resalta la importancia de una actitud abierta a la crítica como mecanismo para encontrar las mejores prácticas, algo muy parecido a la actitud pragmática que he expuesto:

Las prácticas santificadas y no tematizadas que se mantienen dentro de cada frontera tribal no pueden ser nunca analizadas o evaluadas abiertamente, pues están por definición establecidas permanentemente dentro de una conciencia comunitaria. A menos que exista una revisión pública y abierta de todas las prácticas alternativas, en especial de las nuevas y ajenas, no pueden existir elecciones responsables y modos de controlar a las autoridades que claman ser la voz y el espíritu del pueblo. ${ }^{65}$

La apertura falibilista de la ética pragmática de Dewey, como queda claro en el próximo capítulo, encuentra su continuación en el pensamiento político. Esta característica es particularmente relevante cuando procure hacer la lectura pragmática, al modo de Dewey, del pensamiento de Rawls. Como expongo en el tercer capítulo, Rawls dispone, para argumentar por su teoría de la justicia liberal que denomina la justicia como imparcialidad, de una representación contractualista que denomina la "posición original". Lo que argumenta es que, desde una posición de ese tipo, que supone importantes restricciones a la información, individuos racionales elegirían su concepción de la justicia. Dicho lo

\footnotetext{
${ }^{65}$ Judith Shklar, "Liberalism of Fear", en Political Thought \& Political Thinkers, ed. Stanley Hoffman (Chicago: The University of Chicago Press, 1998), 16
} 
anterior, parecería que la idea de la posición original es irreconciliable con la actitud pragmática en ética y en política. Mostraré en el trascurso de la investigación, en la medida en que Rawls estuviera abierto a rediseñar la posición original si la situación así o requiriera, así como que pudiera justificar que los límites al conocimiento que propone no conducen a una especie de dogmatismo (como me parece que lo hace, aunque haya restricciones con las que no estoy del todo de acuerdo), es posible proponer dicha posición consistentemente con una actitud pragmática. Sin embargo, antes de poder pasar a hacer una lectura comparada de ese estilo, es necesario entrar más a detalle al pensamiento político de Dewey, que por sí mismo implica una serie de desafíos que merecen atención por sí mismos. Por un lado analizo la comprensión del fenómeno político por sí mismo, es decir al margen de una organización particular (como es la democracia liberal) de sí, y, por otro, expongo la justificación de la democracia liberal. 


\section{Capítulo 2. Política pragmática y la justificación del liberalismo en John Dewey}

Antes de iniciar con el desarrollo de la teoría política de Dewey es necesario realizar una reflexión sobre el modo en que el pensador norteamericano utiliza los términos Estado y comunidad política de modo intercambiable; esto es importante porque yo haré lo mismo. Si bien es en muchos sentidos anacrónico referirse a la organización política de la antigüedad, ya sea clásica o medieval, con el término Estado, en el desarrollo del capítulo se ve cómo, dentro del pensamiento de Dewey, el uso del concepto es adecuado.

Una de las consecuencias de su comprensión pragmática de la política es el reconocimiento de que el ámbito político es tan sólo una perspectiva particular de un problema más grande: la vida en comunidad. La comunidad se puede analizar desde varias perspectivas, antropológica, sociológica, económica o psicológica; la política es sólo una más. De este modo, el objetivo del pensamiento político de Dewey es ofrecer una visión parcial de un problema sumamente complejo. Así, es relevante recordar la naturaleza de las ideas dentro del pensamiento pragmático en su dimensión de hipótesis. Las ideas de Dewey respecto al origen del Estado y de la comunidad política no están desarrolladas en función de encontrar su "sustancia" o naturaleza en un sentido representacionista. La explicación que ofrece Dewey del origen de la comunidad, así como de su dinámica interna, está orientada a explicar el funcionamiento de la comunidad y de la posibilidad de comprender la mejor manera de diseñar las instituciones que existen en ella.

Del mismo modo que la ética y la economía tienen objetos de estudio propios referidos a la dimensión social de la acción humana (el de la ética el análisis los fines e ideales que conducen la acción individual y son producto de la actividad social y el de la economía el estudio de los medios e instituciones de producción y distribución de bienes), la política tiene un objeto propio enfocado a la dimensión social de la vida humana:

La política se dedica a la anatomía de la estructura. La estructura está necesariamente supuesta en toda la economía, pero no debe ser dejada de lado. Las 
personas que controlan la economía son las instituciones políticas. El mismo hecho puede ser ético, económico o político dependiendo del punto de vista. ${ }^{1}$

Así, cuando Dewey analiza el fenómeno político no supone, como ha ocurrido en la tradición en muchas ocasiones, que la acción política es metafísicamente distinta de cualquier otro tipo de acto humano. Un ejemplo claro de esta distinción metafísica lo podemos encontrar en la obra de Hannah Arendt, en particular en su libro La condición humana, ${ }^{2}$ en el que la filósofa asume que la acción, es decir el acto político, es cualitativamente distinto y superior del mero trabajo y la labor (reservados para modos de agencia limitados en los que los individuos no pueden encontrar su realización última), muy al estilo del acto libre en el caso de Aristóteles. En lo que se refiere a lo político, Dewey procura distanciarse de esta tradición.

La investigación social, que implica la indagación de orden moral, político, económico, sociológico, antropológico, jurídico, etc. no está exenta de los mecanismos de indagación que he expuesto hasta ahora; en este sentido sus ideas deben de ser tratadas como hipótesis y estas hipótesis deben de estar abiertas a ser evaluadas en la realidad. ${ }^{3}$ Esta aproximación hace evidente, para Dewey, tres deficiencias o problemas comunes dentro de la indagación social: ${ }^{4}$ (i) teorías que sostienen fines en sí dentro del orden de la explicación, (ii) teorías que sostienen una especie de ley natural y (iii) teorías que sostienen intuiciones a priori que deben ser consideradas como verdaderas. Las teorías que operan de este modo están funcionando en contra de la lógica de la indagación misma y deben ser puestas a prueba como ocurre con cualquier otro tipo de hipótesis; en la medida en que no pudieran ser evaluadas (como sucedía con los ángeles en la punta de un alfiler) deben de ser simplemente desechadas como una aseveración prácticamente inservible.

\section{El origen de la comunidad y el surgimiento del Estado}

Desde las primeras formulaciones platónicas sobre el origen de la comunidad, ha sido reconocida la naturaleza política del hombre como un hecho constitutivo de éste. Decir que el ser humano es un zoon politikon, al modo que enunció Aristóteles,

${ }^{1}$ Ibid. 149

${ }^{2}$ Cfr. Hannah Arendt, La condición humana, trad. Manuel Cruz; (Barcelona: Paidós, 2007).

${ }^{3}$ Cfr. Dewey, Logic. 767

${ }^{4}$ Cfr. Ibid. 787 
equivale a ofrecer una descripción de un hecho justificable con la realidad. Preguntarse el por qué esto sucede así probablemente carezca de sentido en el orden de la explicación política. Es tan natural al hombre el vivir en comunidad como hablar, ser bípedo o cualquier otra característica constitutiva. El análisis del origen de la comunidad no es prometedor si está centrado en el análisis histórico como si fuera posible encontrar una causa históricamente determinable de la naturaleza social. Más bien debe enfocarse en la finalidad de generar conocimiento valioso respecto a la dinámica intrínseca de la comunidad. La existencia de la comunidad es testimonio de un hecho biológico en el hombre y, por tanto, intentar encontrar un momento en el tiempo para tratar su génesis es ocioso:

No tiene sentido preguntarse el cómo es que los individuos terminan asociándose. Existen y operan en asociación. Si existiera cualquier misterio sobre este hecho, es el misterio de por qué nuestro universo es como es. Este misterio no puede ser explicado sin salir del universo.

(...)

Existe, sin embargo, una pregunta inteligible sobre la asociación humana: no la pregunta de por qué los individuos o seres individuales terminan conectándose, sino por qué se asocian en los modos en que dan a las comunidades humanas características tan distintivas frente a las asociaciones de electrones, la unión de los árboles en el bosque, grupos de insectos y las constelaciones de las estrellas. ${ }^{5}$

La existencia del hombre en sociedad está marcada, como sucede con el conocimiento, por la constitución biológica del ser humano: la incapacidad de sobrevivir de las personas ante las inclemencias del entorno obligan a los individuos a vivir en sociedad para asegurar su sobrevivencia, la evolución condiciona nuestra existencia como seres sociales. Este condicionamiento, como hemos visto, es no sólo físico sino mental en tanto que el desarrollo de las creencias son productos sociales.

La dependencia del individuo respecto de la sociedad ha conducido en algunos casos a explicaciones del origen de las comunidades de tipo agencial, como las denomina Dewey. Este tipo de teorías suponen que es posible encontrar un agente, o grupo de ellos, responsable por el desarrollo de la vida en comunidad. Dewey, por el contrario, desarrolla una explicación que asume la existencia de la comunidad política como una consecuencia natural de la sociabilidad humana. Sin embargo, antes de comprender la propuesta deweyana, es relevante comprender a qué nos referimos por teorías agenciales y cuál es la crítica que hace de ellas por las

\footnotetext{
${ }^{5}$ Dewey, The Public and its Problems. 23-24
} 
implicaciones que tienen respecto a teorías del orden contractual y las implicaciones que tienen sobre la comprensión de la autonomía de los individuos en sociedades liberales. Esto será importante cuando inicie con el análisis del pensamiento de Rawls, un contractualista liberal. ${ }^{6}$

La existencia de una multitud de teorías del Estado contradictorias, que es sorprendente desde el punto de vista de las teorías mismas, es explicable en el momento en que vemos que todas las teorías, más allá de sus diferencias entre sí, se desarrollan a partir de un error compartido: el asumir la agencia como causa en lugar de las consecuencias de eventos como el corazón del problema.

Dadas estas actitudes y postulados algunos hombres en ocasiones encuentran la agencia causal en un acto metafísico de la naturaleza y el Estado se explica en términos de "esencia" de los hombres desarrollándose de acuerdo a una Sociedad perfecta. Otros, influidos por otras preconcepciones y otros deseos, encontrarán en la voluntad de Dios, que se reproduce a través de la humanidad, una imagen de orden y justicia divina. Otros encuentran la causa en el encuentro de las voluntades de los individuos que se acercan y mediante un contrato o acuerdo común dan existencia al Estado. ${ }^{7}$

El planteamiento de Dewey implica un distanciamiento de una teoría causal del surgimiento de la comunidad. La cita anterior hace referencia a tres de las tradiciones políticas más relevantes. Por un lado, una postura claramente identificable en su surgimiento con la antigüedad, de corte esencialista. La segunda mención hace referencia a una teocracia que implica que el origen de la sociedad se encuentra en la voluntad divina, una voluntad que define lo bueno y lo malo en sus propios términos. Por último la tercera mención hace referencia a las teorías contractualistas del Estado que, aun cuando históricamente han sido utilizadas por diversas tradiciones, tienden a ser la justificación del Estado constitucional. En cada una de estas posturas y teorizaciones del problema de la comunidad política existe una causa directa (la esencia, la divinidad o la voluntad popular) por la que se explica el origen de las comunidades. De este hecho en común se desarrollan errores comunes, uno de ellos, quizá el principal, que el Estado se convierte en una figura distinguible "esencialmente" de los individuos y en muchas ocasiones antagónica.

\footnotetext{
${ }^{6}$ Aprovecho para adelantar el hecho de que, contrario a lo que algunos críticos de Rawls han intentado sostener, su contractualismo no intenta servir como una explicación del origen de la comunidad política. Como explico más adelante, aunque queda especialmente claro con el análisis de Teoría de la Justicia y la idea de la posición original, la crítica de Dewey al contractualismo no funciona para el tipo del que Rawls propone para justificar la justicia como imparcialidad.

${ }^{7}$ Ibid. 20
} 
En el caso del primer tipo de postura, que podríamos denominar de corte esencialista, una de las principales tradiciones políticas que emanan de ella es el republicanismo. Este republicanismo, que en una de sus vertientes más difundidas tiende a ser de corte aristotélico al menos en su ordenación organicista, considera al individuo en su relación al Estado como una parte fundamental aunque claramente diferenciable. $Y$ es que aun dentro de una tradición republicana que se mantuviera dentro de los parámetros del organicismo aristotélico, reconociendo la importancia de la comunidad en la conformación del individuo, sigue existiendo el concepto de un Estado capaz de actuar al modo de un agente, que debe servir al individuo como vehículo de realización a través del ejercicio de la virtud cívica. Es relevante recordar que, dentro de la filosofía política aristotélica, la idea de que "el todo es mayor que la parte", con todas las implicaciones sustanciales que tiene para el hilemorfismo, implica, en el caso de la comunidad política, la existencia de dos entidades distintas y claramente diferenciables, el Estado y el individuo, que pueden tener intereses no siempre conciliables o identificables.

Sobre la teocracia, la presencia de una agencia constructora del Estado es muy clara. Sólo sería necesario agregar para el objeto de esta investigación que los intereses y la voluntad de la divinidad dentro de una postura como ésta tiende a ser asumida como justa y buena aun cuando las necesidades de los individuos puedan encontrar injustificados los mandatos de dicha voluntad. En un Estado teocrático es fácil reconocer al cuerpo del Estado como un agente informado por una voluntad distinta a la de los individuos y que, en ese sentido, responde a sus propias necesidades y principios de acción.

Por último, en lo que se refiere al contractualismo, la comprensión del origen del Estado, de naturaleza agencial, postula en la mayor parte de sus formulaciones relevantes un antagonismo claro entre los individuos y el Estado. Ya sea en la formulación de Thomas Hobbes, en la que la voluntad de los individuos termina reconociendo y generando un ser completamente distinto de la mera suma de voluntades en el Leviatán, quien se impone despóticamente sobre todos, o en el desarrollo del Estado liberal de John Locke, que se comporta y guía de acuerdo a la ley natural racional, o incluso el proyecto liberista del siglo XX, que encuentra en Robert Nozick uno de sus principales fundadores, el contractualismo parte de la premisa que las voluntades de los individuos ceden parte de su poder (en algunos casos casi todo, en otros casi nada) a otro ser que actúa en función de lo que dichas voluntades le permiten. Este tipo de antagonismo ha generado una comprensión negativa del Estado errónea según John Dewey: 
Al pensar aun en términos de fuerzas causales, la conclusión que se ha generado de esto ha sido que el Estado, lo público, es una ficción, una máscara para alcanzar los deseos privados de poder y posición. No sólo el Estado sino la sociedad misma ha sido pulverizada en un agregado de deseos y voluntades individuales y no relacionadas. Como una consecuencia lógica, el Estado se ha concebido como un opresor nacido del poder arbitrario y sostenido a través del fraude, o como un acumulador de la fuerza de los individuos a una fuerza masiva a la que las personas no pueden resistir, esta acumulación sirve como una medida desesperada ya que su única alternativa es el conflicto entre todos que genera una vida de desamparo y brutal. Por tanto, el Estado aparece como un monstruo que debe ser destruido o como un Leviatán que debe ser protegido. ${ }^{8}$

Este tipo de aproximaciones, que suponen el origen del Estado como el acto de un agente intencional, comparten un error derivado de una incomprensión de la relación real entre el individuo y la sociedad, según Dewey. Esta comprensión de la comunidad política como el producto de un acto, o acumulación de actos, voluntarios es propio de los modos de contractualismo a los que Dewey critica. Dado que la justicia como imparcialidad, de Rawls, es presentada como un contractualismo, me enfocaré en la crítica de Dewey, en especial a aquellos modos de contractualismo de corte liberal (que excluyen, por ejemplo, al de Hobbes), por las implicaciones que tendrá dicha crítica en el diálogo entre Dewey y Rawls.

El contractualismo supone, a ojos de Dewey, un equivocado antagonismo entre el individuo y la sociedad. No es que la distinción sea impensable, se puede hacer $\mathrm{y}$, dependiendo de nuestro interés en un momento dado, podría ser sumamente valiosa; el problema es, como diría Charles Taylor de la epistemología de la modernidad, no tanto su enunciación sino su ontologización. ${ }^{9}$ ¿Qué entidad, física o metafísica, es esa que llamamos sociedad? Si la sociedad y la cultura son fundamentales para la conformación de la persona al punto de que todos los contenido mentales son productos de nuestro enfrentamiento con la sociedad, ¿qué significa ser un individuo? El individuo y la sociedad, considera Dewey, son categorías de pensamiento que se refieren a modos de acción en el mundo y su impacto en la comunidad. ${ }^{10}$ Suponer que existe un antagonismo entre el individuo y la sociedad es asumir que la acción del hombre, o bien se debe mantener dentro del ámbito privado en todo momento, o bien impacta en todos los casos a la sociedad.

${ }^{8}$ Ibid. 21-22

${ }^{9}$ Cfr. Charles Taylor, "Paralelisms between Heidegger and Wittenstein"; Philosophical Arguments (Cambridge: Harvard University Press, 1995), 95.

${ }^{10}$ Dewey, Freedom and Culture. 32 
Antes de continuar, me parece oportuno mencionar que Rawls busca disolver el problema del antagonismo que acabo de plantear $\mathrm{y}$, en la medida en que el "giro político" fuera exitoso, lo volvería efectivamente inexistente. Como veremos en la tercera parte de esta investigación, Rawls, en el Liberalismo Político, defiende la importancia de desarrollar una teoría política que no esté constituida por una visión metafísica de la persona o de la sociedad. Se refiere a la elaboración de una concepción de la justicia libre de presupuestos metafísicos, morales y filosóficos en general y que, dado este hecho, se sostenga fundamentalmente por su razonabilidad política. Si es posible desarrollar una teoría libre de presupuestos de ese tipo, entonces el antagonismo que plantea Dewey se desvanece en tanto que su existencia, si persistiera en el debate público, sería más el fruto de un "juego del lenguaje" que cualquiera otra cosa.

Sin embargo, uno de los problemas prácticos que se derivan de estas teorías causales en general y del contractualismo que plantea Dewey, que antagoniza al individuo con la sociedad, en particular, está en que al "ontologizar" lo que son postulados hipotéticos que buscan ofrecer claridad sobre realidades que pueden ser pensadas de modo distinto dependiendo de las intenciones del observador, es que se postulan teorías políticas que no son capaces de reconocer la parcialidad de su enfoque respecto a un problema que abarca más disciplinas (como la economía, la sociología, la ética y el derecho por nombrar algunas). Esta falta de perspectiva lleva a proponer soluciones definitivas a un grupo de problemas que, como estipula el pragmatismo, no pueden ser solucionados de ese modo dada la naturaleza hipotética del conocimiento. Cuando definimos la dicotomía individuosociedad en los términos en que la tradición lo ha hecho, es fácil "escoger" un lado y suponer que, desde nuestra perspectiva, los problemas generados por la otra parte se solucionan limitándola cada vez más, como asume el proyecto liberista. Este es el conflicto, muy vivo en nuestros tiempos y de Dewey, entre quienes se diputan la prioridad entre el individuo y la sociedad:

En ausencia de una experiencia adecuada, la tendencia es desarrollar teorías generales en oposición una a otra; la expresión actual del problema humano como individualismo contra socialismo siendo ambos una expresión refleja de las divisiones de los factores económicos en la sociedad presente, y un ejemplo de la oposición general. En este tipo de oposición de ideas cada teoría ser fortalece con las debilidades de la otra; la confusión, por tanto, se incrementa.

(...) Mientras el conflicto se conduzca bajo la idea, en cada lado, de que ya existe una posesión de la verdad, una posición que implica negar la necesidad de cualquier tipo de examinación científica de las condiciones para poder determinar 
qué tipo de acciones deben de ser llevadas a cabo, la rivalidad entre las partes será una fuente de división y confusión. ${ }^{11}$

Como se puede empezar a ver, y era posible suponer, para Dewey la teoría política, la teoría de la anatomía de nuestras instituciones, no debe estar necesariamente comprometida con valores políticos del momento de modo independiente a las condiciones en las que nos encontremos. Las teorías agenciales tienden a suponer dogmáticamente (pues no están en condiciones de llevar a cabo un proceso de justificación en modo alguno) que la ordenación de lo político debe estar "alineada" a la "razón" causante de la comunidad. Como sucede con el ámbito de la ética, el análisis político debe estar consciente de que está completamente sujeto a la contingencia de la realidad. Este hecho nos lleva a aceptar que un régimen particular no puede ser juzgado más allá de sus condiciones "ecológicas". Lo más que podremos hacer dentro de los límites de la política pragmática de Dewey, si queremos desarrollar una hipótesis de la ordenación de la comunidad política, es un esquema general que nos permita evaluar la respuesta de un régimen concreto con sus necesidades y limitantes correspondientes. No es posible garantizar un orden político determinado como el mejor (aunque sea posible, como con cualquier orden del conocimiento como vimos en la primera parte del capítulo, determinar cuáles no cumplen con su función adecuadamente) pues las condiciones imperantes cambian continuamente. Lo que es posible afirmar es la dinámica general que explica la existencia de las distintas formas de Estado:

Sólo las exigencias de una filosofía rígida pueden llevarnos a suponer que existe una forma o idea del Estado paradigmática que los distintos Estados históricos han realizado en distintos grados de perfección. La única delimitación que puede hacerse es una de carácter completamente formal: el estado es la organización de lo público realizado a través de oficiales para la protección de los intereses compartidos por sus miembros. Pero qué pueda ser lo público, quiénes son los oficiales o cuál es la manera adecuada de llevar a cabo sus funciones son cosas que tenemos que dejar que la historia descubra. ${ }^{12}$

El desarrollo de una comunidad política determinada equivale, de este modo, a llevar a la práctica un grupo de creencias, ideales, hipótesis y principios compartidos en una cultura determinada sobre la mejor manera de coordinar e integrar los diversos intereses que surgen en la vida comunitaria. En contra del presupuesto agencial para explicar el origen de la comunidad política, Dewey nos dice que ésta y el espacio público surgen de un modo casi espontáneo en función

${ }^{11}$ Ibid. 60-61

${ }^{12}$ Dewey, The Public and its Problems. 32-33 
de las relaciones entre las personas. Cuando las relaciones e interacciones se estabilizan y se vuelven fuentes de preocupación y prevención social, empieza a surgir la esfera pública que responde a estas circunstancias. Supongamos una comunidad hipotética recién formada y sin autoridad formal, algo parecido a como pudo haber sucedido con algunos primeros colonizadores del Oeste durante las grandes migraciones en el siglo XIX en Estados Unidos. En esta comunidad, fundamentalmente agrícola y ganadera, sólo es posible encontrar un acceso al agua potable en un pozo. Al inicio del proceso de colonización del lugar no hay problemas para tener acceso al agua; sin embargo, conforme la población va en aumento, los nuevos habitantes encuentran el acceso cada vez más complicado pues el pozo está rodeado por la propiedad de los primeros colonizadores. En un escenario como este es normal prever que las relaciones entre los individuos que viven más cerca del acceso al agua (rodeando el pozo incluso con su propiedad) con aquellos que viven más alejados por el acceso al agua comenzarán a ser cada vez frecuentes y, en algunos casos, complejas. La teoría deweyana del surgimiento del espacio público y la comunidad política nos lleva a suponer que los individuos en conflicto, así como aquellos interesados en mantener cierto tipo de relaciones en la comunidad recién formada (y esperamos que las relaciones que quieran mantener sean pacíficas y razonables, aunque bien podrían ser relaciones jerárquicas de poder opresivas), comienzan a desarrollar los hábitos relacionales que poco a poco derivan en instituciones, mediante las cuales sea posible representar sus intereses de un modo más o menos eficiente. Si la comunidad reconoce como miembros legítimos a todos los nuevos colonizadores que lleguen, probablemente designarán lugares de paso o mecanismos de distribución del agua para todos. Si la comunidad, por otra parte, no reconoce a los nuevos colonizadores como miembros legítimos (y en ese sentido sus intereses no tienen lugar dentro de las relaciones de la comunidad), probablemente diseñarán instituciones que les permitan alejar a los nuevos colonos de acuerdo a como sea necesario para mantener el estado de cosas.

La comunidad política, dicho de otro modo, comienza a surgir por la búsqueda de objetivos, en unos casos comunes y en otros individuales, que implican una relación continua entre los individuos que la conforman. Dado que los fines que persiguen los individuos son desarrollados dentro de la comunidad, y en ese sentido reflejan que los intereses, más que ser de individuos son de grupos, es necesario que surjan representantes (no necesariamente elegidos democráticamente, claro está) de dichos intereses. A estos representantes Dewey les denomina oficiales: 
Las características de lo púbico surgen del hecho de que todos los modos de comportamiento producto de la asociación pueden tener consecuencias duraderas y de un alto impacto que involucran a otros más allá de aquellos directamente relacionados. (...) Las consecuencias deben ser atendidas. Esta supervisión y regulación no puede ser efectuada por los grupos involucrados directamente. Esto acontece así pues la esencia de las consecuencias que exigen el surgimiento de lo público es el hecho de que se expanden más allá de los directamente responsables de producirlas. Por tanto, agencias y medidas especiales deben de formarse si estas consecuencias han de ser atendidas; de otro modo algún otro grupo existente deberá asumir estas nuevas funciones. La marca distintiva evidente del surgimiento de una organización de lo público o de un Estado es, por tanto, el surgimiento de los oficiales. El gobierno no es el Estado, pues este incluye tanto la esfera pública como aquellos encargados del mando con poderes y deberes especiales. Lo público, sin embargo, se organiza a través de aquellos oficiales que actúan en función de los intereses de los demás. ${ }^{13}$

Así, la comunidad política es el producto que surge de la interrelación de individuos, que procuran fines socialmente elaborados y que exige a los individuos desarrollar las instancias necesarias para alcanzar la representación de sus intereses de modo más o menos eficiente. Esta interpretación del surgimiento del Estado permite comprender las diversas estructuras sociales en su tiempo y reconocer las instituciones que de ellas surgieron como el producto de las relaciones existentes en la comunidad. Por ejemplo, mientras no existieran las condiciones materiales para llevar a cabo relaciones capitalistas (la existencia de un mercado, la posibilidad de acumular capital, el surgimiento de la propiedad privada) no existían oficiales que representaran intereses de la que después sería una nueva clase burguesa. Una vez que las condiciones materiales estuvieron presentes y surgió en la comunidad la nueva clase requirió, debido al impacto de su actividad en el resto de la comunidad, que surgieran oficiales que fueran capaces de negociar y construir las instituciones necesarias para su desarrollo.

Del mismo modo, el marco conceptual nos permite comprender el surgimiento del movimiento obrero y su impacto en la formación del Estado actual. Conforme la clase industrial fue ganando fuerza y su posición en la esfera pública y el Estado se afianzó, el impacto del capital en la clase trabajadora fue cada vez mayor. El desarrollo de la industria desde una perspectiva tecnológica, ya sea por el surgimiento de la maquinaria o por el avance en lo que posteriormente se denominaría administración científica, ${ }^{14}$ generó un impacto profundo en la vida

${ }^{13}$ Ibid. 27-28

${ }^{14}$ Me parece razonable considerar que la primera versión refinada de la administración científica (y que realmente procuraba desarrollar una metodología y no sólo fundarse en conocimiento empírico sin sistematizar) es la que desarrolla Frederick Taylor (Cfr. Frederick Taylor, The Principles of Scientific 
de la clase trabajadora. Dadas las condiciones sociales, en donde la clase trabajadora contaba con un mínimo de libertad y capacidad de organizarse a principios del siglo XIX en lugares como Europa y Estados Unidos, la clase obrera fue capaz de desarrollar una resistencia que designó representantes (en general personificados en los sindicatos) que negociaron sus intereses (en este caso una mejor disposición de la jornada laboral, salario mínimo y en algunos casos límites en la edad de trabajo) dentro del espacio político. La relación obrero-patronal, en muchos casos adversaria, puede ser explicada con el marco conceptual que nos ofrece Dewey y, gracias a él, es posible comprender cuándo y por qué algunos miembros de dicha relación han tenido éxito en algunas ocasiones.

El desarrollo de las instituciones y el surgimiento de los oficiales que representan los intereses de los grupos están determinados por las condiciones sociales existentes. Dado lo cambiante de las condiciones sociales, es posible suponer que instituciones que en algún momento se consideraban inamovibles o necesarias sean entendidas en otro tiempo de un modo distinto. Un ejemplo de esto es la esclavitud. Pensemos en Estados Unidos a finales del siglo XVIII y principios del XIX. La guerra civil en este país está marcada por un discurso abolicionista por un lado y por otro de superioridad racial y conservadurismo social, político y moral. Sin embargo, en el fondo del conflicto, por supuesto marcado por principios e intuiciones morales, así como repercusiones económicas (recordemos que el análisis político es sólo una perspectiva particular de observar fenómenos sumamente complejos dentro del ideario pragmático de Dewey), se encuentra el reconocimiento pleno, al menos por parte del Lincoln, que no reconocer a la población negra como individuos libres, y que en ese sentido son sujetos de derecho y de algún tipo de representación, ${ }^{15}$ genera un conflicto aún mayor dentro de la Unión, poniendo en riesgo la estabilidad de todas las demás relaciones por el impacto y las consecuencias de la esclavitud. Sobre este mismo punto dijo Lincoln en una carta dirigida a Horace Greeley, director del Tribune de Nueva York:

Querido Señor... No ha sido mi intención dejar a nadie perplejo... Mi objetivo primordial en esta lucha es la salvación de la Unión, y no el salvar ni destruir la esclavitud. Si pudiera salvar la Unión sin liberar a ningún esclavo, lo haría; y si lo pudiera conseguir con la liberación de todos los esclavos, también... Aquí he expuesto mis intenciones según mi visión del deber oficial, y no cambiaré ni un

Management (Nueva York: Harper \& Brothers, 1919), 30), con lo que después sería denominado taylorismo, y que supone el desarrollo de lo que es la cadena de producción, después automatizada por Henry Ford.

${ }^{15}$ Recordando, por supuesto, que la ley que aseguraba el derecho al voto (Voting Rights Act) no es ratificada en el Congreso norteamericano hasta el año de 1965. 
ápice mi deseo personal -tantas veces expresado- de que todos los hombres, en todas partes, puedan ser libres. ${ }^{16}$

El texto de Lincoln es sumamente ilustrativo cuando lo leemos en clave del marco conceptual deweyano del surgimiento de la comunidad política. Si bien no es posible encontrar un punto en el tiempo en que podamos designar el nacimiento de la vida pública, sí lo es el determinar sucesos históricos que nos llevan a reformar o reconstruir Estados o comunidades políticas previamente existentes. La guerra civil norteamericana, como suele suceder con todas las guerras civiles que buscan reformar la estructura social para que la dinámica de representación de los grupos cambie, nos muestra el modo en que una sociedad determinada reconoce una relación, que durante mucho tiempo fue considerada un asunto privado, como un fenómeno perteneciente a la esfera pública. Este proceso, que asumiremos por un principio de economía que inició con la abolición de la esclavitud como suceso del ámbito privado y supuso el reconocimiento de un grupo de individuos (personas de color en Estados Unidos bajo el régimen de esclavitud) y sus relaciones con el resto de la sociedad, condujo a la elección del primer senador de color en la persona de Hiram Revels en el año de 1870. Si bien el proceso de representación de las personas de color en una sociedad como la norteamericana difícilmente se podría decir que ha sido logrado en una circunstancia de equidad, el hecho de que al día en que escribo este trabajo el primer presidente de color en la historia de Estado Unidos fuera electo en el 2009 es revelador del proceso de representación a través del surgimiento de oficiales que estabilizan e institucionalizan las relaciones como lo plantea Dewey. Podríamos decir que el actuar político, cuando se efectúa de acuerdo a sus fines, es siempre un acto de representación de intereses de grupo en la esfera pública.

Los ejemplos anteriores, que muestran cómo se integran nuevos grupos de intereses en el espacio público, sirven para dar luz a la formación de cualquier Estado o comunidad política organizada. Si bien los ejemplos son modernos, no hay razón clara para considerar que en la antigüedad ocurría de modo distinto. En la Edad Media, por ejemplo, el señor feudal representaba no sólo sus intereses ante el rey, sino que representaba los intereses de sus siervos en tanto que eran, para casi todos los efectos prácticos, su propiedad.

Antes de continuar con el análisis de la democracia liberal, es relevante retomar algunos puntos de la crítica de la agencia que realiza Dewey a las

\footnotetext{
${ }^{16}$ Abraham Lincoln apud ZINN, Howard, La otra historia de los Estados Unidos, trad. Toni Strubel; (México: Siglo xxi, 1999), 145-146.
} 
propuestas políticas tradicionales. En particular, quiero recuperar dos puntos. El primero es la fuerza de la crítica en tanto que las teorías agenciales son incapaces de ofrecer explicaciones útiles y, por lo mismo, generan expectativas incorrectas sobre el papel del poder político. Por otro lado, quisiera hacer un análisis de la crítica al contractualismo emanada de la crítica a las teorías de la agencia.

La crítica a las teorías de la agencia descansa en el supuesto de una causa intencional "responsable" de la existencia de una comunidad política determinada. De esta consideración varios pensadores han apreciado una distinción radical entre el Estado y los miembros integrantes (ya sea dentro de la analogía organicista, en donde el todo es mayor a la parte, o en la tradición contractualista, en donde el Estado es una entidad distinta de los individuos y debe de ser limitada en sus atribuciones). El análisis deweyano reconoce una debilidad del argumento que tiende a ser repetido continuamente en muy diversos ámbitos del conocimiento: hay ocasiones en que es un error asumir la agencia como causa en lugar de las consecuencias de diversos eventos, en muchas ocasiones no relacionados, y no intencionales.

Uno de los pensadores que han analizado de modo más completo este error conceptual ha sido el psicólogo, premio Nobel de economía, Daniel Kahneman. En su trabajo experimental, Kahneman ha buscado encontrar algunos de los errores más comunes en la toma de decisión de las personas causados por una acción heurística de la mente que procura encontrar las mejores explicaciones del modo más rápido posible. Dentro del trabajo de Kahneman, que se encuentra en buena medida sintetizado en su libro Thinking Fast and Slow, una fuente continua de errores ocurre cuando la mente ofrece explicaciones "causales" en lugar de probabilísticas. Es decir, considera Kahneman, "nuestra preferencia por el pensamiento causal nos expone a serios errores en la evaluación la aleatoriedad de eventos verdaderamente aleatorios." ${ }^{17}$

Dewey se anticipa a la investigación de Kahneman en el sentido de que reconoce la existencia de hechos no explicables en un sentido causal; la comunidad es un hecho no explicable en un sentido causal. Ofrecer una explicación causal de la naturaleza social, o del origen de la comunidad para el caso, es fruto de la incomprensión del proceso evolutivo y de la selección natural como uno fortuito de desarrollo del ser humano. Al igual que cualquier característica humana, como el habla, el ser bípedo o la posesión de un pulgar, la existencia de las comunidades y de la naturaleza social es producto de una serie de eventos indeterminables (al

\footnotetext{
${ }^{17}$ Daniel Kahneman, Thinking Fast and Slow (Nueva York: Farrar, Straus and Giroux, 2011), 115.
} 
menos con los recursos de investigación actuales). El gran problema de buscar una causa, en particular una intencional, es que las consecuencias de ese pensamiento no nos ofrece una explicación válida o justificable, por un lado, y al mismo tiempo nos puede llevar a pensar en la comunidad como un "ser" con una finalidad intrínseca o esencial distinta de su utilidad en el desarrollo de los individuos. Al enfatizar la relevancia de la justificación y de la verificación, Dewey está en condición de reconocer la conveniencia de una teoría que se asume incapaz de explicar causalmente un fenómeno pero que puede, al mismo tiempo, proporcionar una estructura razonable y justificable para comprender su funcionamiento; esto frente a teorías que intentan explicar causalmente pero que son incapaces de justificar sus aseveraciones $y$, al mismo tiempo, no ofrecen una estructura razonable del funcionamiento de la comunidad política (al menos de acuerdo con Dewey y su teoría de la representación de intereses en la comunidad política).

Respecto al segundo tema que me interesa tocar, referente a la crítica a las teorías de agencia de Dewey, el foco de esta discusión es la crítica a la teoría contractual del pensador norteamericano. El fundamento de la crítica al contractualismo en Dewey se funda, al igual que los otros modos de teorías de agencia (organicistas o providencialistas), en la imposibilidad de justificar una causa original de la vida en comunidad política. Del mismo modo, piensa Dewey, el contractualismo termina derivando en una comprensión del Estado antagónica a los intereses de los individuos que es equivocada.

La crítica de Dewey es, como explico a continuación, imprecisa. Aunque es posible considerar que existan contractualismos que sostienen que el pacto original es la causa de origen de la existencia de la sociedad en un sentido histórico, dicho contractualismo, en efecto, sería empíricamente falso. Sin embargo, en algunos de los modos de contractualismo más logrados (como son el de Rawls, Kant o Hobbes) la idea fundamental del pacto original tiene una función representativa para justificar las condiciones adecuadas de organización social. Esta justificación del orden social no busca dar una explicación histórica o causal de la existencia de la sociedad, simplemente es un mecanismo para pensar las condiciones de organización social de modo que puedan ser comprendidas y justificadas de un modo racional. En este punto, por tanto, encuentro una imprecisión grave en el desarrollo teórico de Dewey; el pensador norteamericano omite hacer una distinción, que considero fundamental, entre la comunidad en un sentido general y la comunidad política o Estado (lo que no significa, por lo que explico a continuación, que no esté supuesta en su justificación de la democracia liberal). 
El contractualismo no se refiere necesariamente, y me parece que en sus formulaciones más logradas es así, a una propuesta metafísica de la constitución de la sociedad o de la comunidad. El relato del pacto y el estado de naturaleza en los que así lo implican no busca justificarse como un argumento fáctico en sentido alguno (aun cuando hubiera casos en que así fueran pensados). El poder del argumento contractualista no se halla en que esté elaborado desde una postura de agencia, como parece suponer Dewey. La fuerza del argumento contractual se encuentra en el reconocimiento de la distinción entre la sociedad en general y la comunidad política en particular y que, más específicamente, esta segunda adopta sus formas históricas particulares en función del consentimiento de los grupos o individuos que participan en ella.

La insistencia de Dewey en las circunstancias como elemento de verificación de una hipótesis debería llevar al norteamericano a una plena conciencia de que, con el surgimiento de los denominados oficiales, surgen también reglas que permiten la mejor representación de los intereses de los individuos. La diferencia entre la vida social en general y la comunidad política parece encontrarse justamente en el surgimiento de estas reglas y los oficiales. El contrato, una vez que negamos su intención de explicar el origen de la comunidad en un sentido causal, se establece como el mecanismo para justificar racionalmente las reglas mediante las cuales los oficiales pueden representar los intereses como les corresponde. Sobre esto habla John Searle: "Todo poder político es cuestión de funciones de estatuto, razón por la cual todo poder político es un poder deóntico. Los poderes deónticos tienen que ver con los derechos, los deberes, las obligaciones, las autorizaciones, los permisos, la autoridad, etc." ${ }^{18}$

Para comprender esto con más claridad es necesario regresar al problema del antagonismo del poder político frente a los intereses individuales y su relación con el contractualismo. Una posibilidad a la que nos enfrentamos al tratar este antagonismo es que sea una realidad política a la que el contractualismo intenta dar respuesta y no, como Dewey intenta defender, una consecuencia del planteamiento contractual. No existe "la sociedad" como una entidad con voluntad e intereses propios; eso no implica, sin embargo, que no puedan existir conflictos de intereses entre la clase política (que podrían ser desde intereses egoístas y corruptos hasta aquellos inspirados por sentimientos como el patriotismo que en ocasiones no refleja los intereses de los individuos), que está constituida por los oficiales que Dewey postula, y los individuos a quienes representan. El

\footnotetext{
${ }^{18}$ John Searle, Libertad y neurobiología, trad. Miguel Candel (Barcelona: Paidós, 2005), 107.
} 
contractualismo, al proponer las condiciones del contrato, establece condiciones mínimas de convivencia. El ejercicio del poder político termina encontrando sus límites en las circunstancias hipotéticas del contrato en tanto representan los mínimos que se exigen al Estado para prevenir su reconocimiento como uno fallido $\mathrm{y}$, por tanto, injustificable.

No deja de llamar la atención la relevancia de la teorización sobre la democracia en el pensamiento de Dewey como un mecanismo legítimo para determinar los mecanismos justificables de atribución del poder político. Pues, aun cuando estos desarrollos toman en cuenta las condiciones históricas contingentes, parecen tener la misma intención que algunos modelos de contractualismo:

\begin{abstract}
Las teorías y las prácticas concernientes a la selección y el comportamiento de los oficiales públicos que constituyen la democracia política han sido desarrollados tomando en cuenta un trasfondo histórico. Éstas representan un esfuerzo para, en primer lugar, contrarrestar las fuerzas que han determinado generalmente quién posee las facultades de mando por factores accidentales e irrelevantes, en segundo lugar son un esfuerzo para contrarrestar la tendencia de emplear el poder político al servicio de intereses privados en lugar de fines públicos. Discutir el gobierno democrático al margen de un trasfondo histórico es un error y una claudicación de los medios para una crítica inteligente de la misma. ${ }^{19}$
\end{abstract}

Lo que Dewey parece no reconocer es la intención del contractualismo de "aislar" los factores relevantes para la toma de decisión concreta de los principios que determinan la organización política de la comunidad. Como veremos en los capítulos siguientes, Rawls procura mostrar cómo es posible generar un contractualismo que reconozca las contingencias históricas $\mathrm{y}$, al mismo tiempo, aísle los factores relevantes que permitirían una deliberación entre individuos libres, iguales y racionales.

Dentro de esta comprensión de la tradición contractual, así como sus similitudes con la comprensión deweyana de la teorización democrática, queda la duda sobre qué tan procedente es la crítica al contractualismo desarrollada por Dewey. Me parece que, por las razones ya explicadas, la crítica se disuelve cuando negamos al contractualismo como una teoría metafísica o histórica del origen de la comunidad política o social. El contractualismo, si queremos evadir la crítica de Dewey y ser capaces de rescatar algunos de los valores más importantes en la tradición del Estado constitucional, tiene una función de justificación de principios si no la entendemos como un análisis histórico o metafísico.

\footnotetext{
${ }^{19}$ Dewey, The Public and its Problems. 83
} 
Por otra parte, Dewey considera que su explicación es superior al contractualismo pues funciona para juzgar el funcionamiento de una sociedad política sin la necesidad de una deontología, fines en sí o conceptos de ley natural que parecen suponer la mayoría de los contractualismos. Al considerar la comunidad política como la institucionalización de los hábitos de relacionales y la representación de intereses de grupo por parte de oficiales, nos otorga un criterio para juzgar la eficiencia de un Estado concreto, independientemente de su forma determinada.

Nuestra concepción nos ofrece un criterio para determinar qué tan bueno un Estado
particular es: principalmente, el grado de organización de lo público que es
alcanzado, y el grado en que sus oficiales están constituidos para desempeñar sus
funciones en tanto que procuran los intereses públicos. Sin embargo, no existen
reglas a priori que puedan ser desarrolladas mediante las cuales se pueda crear un
buen Estado. En ninguna época o lugar ha existido la dimensión pública del mismo
modo. Las condiciones hacen las consecuencias de la acción fruto de la asociación y
el conocimiento de ellas distintos. Adicionalmente, los medios mediante los cuales
la dimensión pública puede establecer un gobierno para que cumpla sus cometidos
varían. $^{20}$ La explicación de Dewey del origen de la comunidad política es incapaz, por diseño, de ofrecernos una receta de la conformación del Estado que sea correcta en todos los casos pues las condiciones materiales en las que las comunidades políticas surgen son muy variables en el tiempo. Aun cuando esto es así, el análisis de la funcionalidad del Estado nos ofrece herramientas cognitivas para analizar las instituciones sociales (trabajo propio del pensamiento político) en función de un mejor cumplimiento de los objetivos naturales que dan pie a la existencia de la comunidad política. Dicho de otra manera, con el uso de esta propuesta somos capaces de analizar y criticar el orden político en la historia en función de progreso y retroceso, de mejores y peores ordenamientos políticos, no porque sepamos cuál es la ordenación correcta del Estado, como presumirían las teorías agenciales del origen de la comunidad política, sino porque somos capaces de reconocer cuáles no logran su cometido y en qué medida, independientemente de sus condiciones contingentes. Ahora bien, esto no equivale a afirmar que las disputas concretas dentro de la comunidad pueden ser evaluadas en función de esta teoría sobre la representación. Por el contrario, el modo concreto en que resuelvan los conflictos las sociedades no está a discusión en este punto; lo que la teoría de Dewey nos obliga a mantener presente es, sin embargo, la relevancia de analizar el éxito de la sociedad política en función de la representación de intereses.

${ }^{20}$ Ibid. 33 
Así, es posible perfilar dentro del pensamiento de Dewey una tendencia hacia la democracia liberal en función de que ésta, como defiendo más adelante, cumple de mejor modo los objetivos generales del Estado pues garantiza de mejor modo que los individuos puedan representar sus intereses en la comunidad. La aplicación del pragmatismo a la política, con esta consecuencia, permite hacer un contraste con algunos modos de liberalismo neutrales. Rawls, como veremos en la tercera parte, busca justificar el liberalismo no en función de su éxito para mejorar la vida de los ciudadanos (como el proyecto indagatorio democrático de Dewey sí hace), sino debido a su capacidad de mantenerse neutral frente a creencias contrarias de los ciudadanos, aparentemente irreconciliables entre ellas, sirviendo de ese modo como un terreno neutral de convivencia pacífica. Espero dejar claro, al final de esta investigación, que la justificación del liberalismo en función de su neutralidad genera problemas de estabilidad a largo plazo. Esto es mucho más claro cuando expongo el pensamiento de Rawls en los apartados posteriores.

La aplicación de la actitud pragmática a la política, que ya vimos cómo ocurre en el conocimiento científico y el ético, conduce a plantear los mecanismos y métodos generales que permitan la función del Estado, que es el espacio público en donde se representan los intereses de los grupos y se institucionalizan las relaciones entre individuos, en las circunstancias contingentes de la existencia humana. La idea del progreso contenida en un mejoramiento de los sistemas de representación e institucionalización, conduce a la posibilidad de plantear los mecanismos básicos y generales de operación que permitan el perfeccionamiento de la operación del Estado en función de sus objetivos "naturales". En las palabras de Dewey:

Concretamente, en lo que se refiere a una estructura actual y concreta no hay modo de decir cuál es la mejor: al menos no hasta que la historia haya terminado, y sea posible estudiar todas las que existieron. La formación de los Estados es un proceso experimental. El proceso de prueba puede conducirse, sin embargo, bajo distintos niveles de incertidumbre y accidente, $\mathrm{y}$ es posible que con altos costos por procedimientos no regulados, de ensayo y error, de constantes equivocaciones sin tener algún grado de conciencia de lo que las personas persiguen o un conocimiento claro de lo que implicaría lo que es un buen estado. (...) No es asunto de la filosofía y ciencia política determinar qué Estado debería existir. Lo que pueden hacer es ayudar en la creación de métodos tales que la experimentación pueda conducirse de un modo menos ciego, menos a la merced del accidente, de manera más inteligente para que las personas aprendan de sus errores y se beneficien con sus aciertos. ${ }^{21}$

${ }^{21}$ Ibid. 34 
La indagación pragmática en política implica, del mismo modo como sucedió en su dimensión científica y ética, una visión antidogmática de la realidad y objetiva en su verificacionismo empírico. Si bien es imposible saber de antemano cuál es la mejor organización concreta de lo público, sí somos capaces de juzgar las hipótesis concretas en función de un criterio general (el fin general del Estado). Es importante tener presente, cuando asumimos una teoría del conocimiento pragmática aplicada a cualquier área del conocimiento humano, que para poder postular hipótesis o ideas concretas para solucionar problemas, es necesario tener ideas y creencias previas que nos ayuden a formular hipótesis funcionales. Las teorías agenciales del surgimiento del Estado son ejemplos de esas creencias previas que nos sirven como criterios de juicio. El ejemplo claro es una teoría teocrática del Estado inspirada por la revelación. En una propuesta como ésta se supone que el orden social está condicionado por una ley divina revelada (independientemente de si la revelación es accesible para todos, para unos pocos o sólo para una persona). Si asumimos que la existencia del Estado está determinada por un agente voluntarioso externo al orden natural y contingente, entonces todas las medidas políticas concretas que llevemos a cabo deben ordenarse a la tradición que mejor personifique dicha revelación. Juzgaremos todas las iniciativas sociales, económicas y morales relevantes para el análisis político en función de la ley revelada. Las consecuencias de esas iniciativas, ideas o hipótesis concretas, se analizan a la luz del criterio fijo y dogmático de la ley divina.

La propuesta del origen de la comunidad política de Dewey conduce a una hipótesis funcional del Estado. No intenta determinar una causa original sino que, como se ha visto, asume su existencia como un hecho de la realidad. La comunidad política es una manifestación necesaria de la vida en sociedad y la vida en sociedad es una condición necesaria de la existencia humana. Intentar justificar su existencia en un acto causal particular falla en reconocer la espontaneidad con la que surge. La teoría funcional de Dewey, en este caso, ofrece la alternativa que, sin pretender dar una explicación agencial del origen, garantiza los parámetros para interpretar los distintos modos de manifestarse de la comunidad política en función de sus instituciones, ideales y oficiales en circunstancias concretas determinadas.

Una ventaja adicional de la teoría del origen de la comunidad política de Dewey, como una existencia natural y necesaria frente a las teorías agenciales, es que permita que podamos abordar el problema de los límites del poder político (problema fundamental de la modernidad). Históricamente el tema ha sido tratado de diversos modos, en algunos casos se ha supuesto que la relación antagónica entre el gobierno y el individuo debe garantizar prioridad (en algunos casos 
absoluta) al soberano, en otros se ha argumentado por limitar el ámbito del gobierno a los espacios absolutamente indispensables para permitir el desarrollo de la iniciativa privada individual. Del primer caso, el ejemplo clásico es la propuesta hobbesiana del poder político del gobierno, que para todos los sentidos prácticos es ilimitado. Del otro lado de la balanza podemos encontrar los desarrollos liberistas, como el caso de Robert Nozick, que asume que todo ejercicio del poder político por parte del gobierno que limite la iniciativa privada es ilegítima. La similitud de ambas teorías, al menos la relevante para este punto, se encuentra en que Hobbes y Nozick, igualmente, consideran al gobierno un ente con intenciones y objetivos propios a su naturaleza, como actor. Una interpretación del gobierno en esta clave supone la pregunta de cuánto poder es legítimo otorgar a un agente tan potencialmente peligroso para el individuo. Para Dewey esta noción es fruto de una comprensión equivocada que, al llevarse a la práctica, genera las tendencias corruptas del ejercicio de los puestos oficiales al promover la idea de que el gobierno es un agente con intereses propios y distintos de su misión de representar intereses de los miembros de la comunidad. Dentro del marco conceptual deweyano la pregunta por los límites del poder político deja de lado la presunción de antagonismo entre el individuo y el gobierno permitiendo plantear la cuestión de un modo distinto. La pregunta ahora, en estos nuevos términos, está centrada en la finalidad misma del surgimiento del Estado, con sus instituciones y oficiales que son el cuerpo mismo del gobierno y su carácter de medio para garantizar a los grupos e individuos la consecución de sus legítimos intereses:

El Estado es sólo un órgano entre muchos que componen el Espíritu y la Voluntad que mantienen la sociedad unida y que hace a los seres humanos miembros de una comunidad. De éste no se originan las exigencias morales a los individuos para llevar a cabo la plena realización de sus potencialidades de pensamiento y propósito. Lo que es más, los motivos a los que el Estado puede apelar no son los más elevados. Es el trabajo del Estado proteger y promover todas las formas de asociación humana en que las exigencias morales que puedan surgir de los miembros de una sociedad como medios para la plena autorealización. ${ }^{22}$

La cuestión no es hasta qué punto otorgamos facultades a otro ser antagónico (gobierno) para entrometerse en nuestra vida sino, más bien, qué tantas facultades necesitan los oficiales para garantizar la adecuada representación de nuestros intereses así como la existencia de las instituciones que garanticen los hábitos relacionales óptimos para el desarrollo de nuestros ideales. El proceso deliberativo cambia de una argumentación del tipo del "mal menor" a un argumento desarrollado en función de disposición de medios para alcanzar un fin. Dicho de

${ }^{22}$ Dewey, Liberalism and Social Action. 34 
otro modo, en el caso de Hobbes podríamos decir que otorgar al gobierno las facultades necesarias para ser de tipo absolutista es un "mal menor" al riesgo de perder la vida; por su parte, para Nozick la existencia de un Estado mínimo es un "mal menor" ante la posibilidad de no tener garantía absoluta a conservar los derechos individuales y de propiedad que considera propios y naturales en el hombre, un gobierno mayor, en este caso, deja de ser el "mal menor" y se convierte en uno mayor. Dewey no piensa el gobierno en este modo, su existencia no es un mal en modo alguno debido a que no representa una limitación a mis potencialidades presociales (recordemos que la vida en sociedad para el hombre es una constante en nuestro universo como es la fuerza de gravedad); el gobierno es una manifestación y condición necesaria para poder desarrollar mis objetivos y fines creados dentro de la vida social. Sin embargo, como queda claro con la cita anterior, la comunidad política, el Estado y el gobierno con sus instituciones y oficiales, no puede considerarse como la fuente de donde emanan los ideales morales fundamentales del desarrollo de los individuos. La existencia de la comunidad política, que implica un grado de organización mayor que la mera vida social, está regida por su condición de medio. Aun cuando el mantenimiento de un Estado funcional y que cumpla sus objetivos pueda exigir un esfuerzo grande por parte de los miembros de la comunidad, no hay que olvidar que existe sólo para permitir el pleno desarrollo de los hábitos relacionales de los individuos y como mecanismo para garantizar a los grupos e individuos el espacio adecuado para alcanzar sus legítimos intereses. La cuestión no es cuánto limitamos al gobierno sino cuánto debemos empoderarlo para cumplir su trabajo.

Hasta este punto es posible anticipar la existencia de una relación entre la cultura y las formas determinadas que el Estado adopta con el tiempo; los fines y objetivos están históricamente condicionados. Una cultura permeada por creencias e ideales autoritarios, tradicionales y dogmáticos por ejemplo, tiende a aceptar y desarrollar mecanismos de gobierno que representen esas creencias y los hábitos que ellos desarrollan. Si consideramos que la filosofía y el análisis político implican una perspectiva parcial de un "problema" aun mayor, que es la vida del ser humano en sus diversas dimensiones y modos de actuar, es fácil considerar la importancia de la coherencia de los valores y aplicación de los mismos en los diversos ámbitos de la vida para las personas. Esta interrelación de los distintos ámbitos de la vida de los individuos y su relación con el establecimiento y mantenimiento de un entramado político institucional fue entendido, antes de Dewey, con mucha claridad por Alexis de Toqueville. Cuando Toqueville lleva a cabo su análisis sobre las causas que mantienen la democracia, no se contenta con 
hablar de las leyes, las condiciones geográficas o las condiciones materiales en general, incluye, del mismo modo, las costumbres o mores: "No solamente la aplico a las costumbres propiamente dichas, que se podrían llamar los hábitos del corazón, sino a las diferentes nociones que poseen los hombres, a las diversas opiniones que tienen crédito entre ellos, y al conjunto de las ideas de que se forman los hábitos del espíritu." 23

El objetivo de Dewey, por su parte, es desarrollar un mejor y más amplio conocimiento de la comunidad política para sea posible plantear su existencia de modo que podamos planificarla de manera que nuestras ideas de lo político se correspondan mejor con las circunstancias en las que se desarrolla. Una teoría política inspirada en la actitud pragmática frente al conocimiento y desarrollo de teorías procura "ayudar en la creación de métodos tales que la experimentación pueda conducirse de un modo menos ciego, menos a la merced del accidente y de manera más inteligente para que las personas aprendan de sus errores y se beneficien con sus aciertos." El método es el de la libre indagación en un sistema sin jerarquías determinadas mediante criterios arbitrarios, dogmáticos e injustificados. El método para conseguir una ordenación política que alcance sus fines adecuadamente es la instauración de la democracia liberal.

\section{Cultura democrática liberal y cientificismo social}

Antes de continuar con el desarrollo de la democracia liberal en Dewey, explicando el por qué se justifica como el modo de organización política (no como una forma de comunidad política definida) óptimo dada la naturaleza del Estado, es necesario retomar el tema de la naturaleza social del conocimiento humano.

Nuestras aproximaciones a la realidad están siempre mediadas por esquemas conceptuales. Como expliqué anteriormente, una de las premisas del pragmatismo es que no existe un acceso directo y privilegiado a la realidad metafísica del mundo (suponiendo que dicho ámbito siquiera existe). Del mismo modo, suponer que cada idea que surge de nosotros es original, asumiendo que la originalidad fuera algo como una creación desde la nada, es ingenuo y equivocado. Nuestras ideas son productos de un conjunto de factores, principalmente un contexto intelectual dado (aprendido de nuestra cultura), el estado de cosas en el mundo y la identificación de un problema (que es reconocido como tal en función

${ }^{23}$ Alexis de Toqueville, La democracia en América (México: FCE, 2009), 287. 
de nuestro contexto intelectual por supuesto); así, las ideas y creencias que desarrollemos para solucionar la circunstancia problemática determinada es un producto de la realidad y el contexto cultural en el que nos desarrollamos. La originalidad, en ese sentido, se puede entender más bien como la capacidad del individuo de desarrollar hipótesis-creencias nuevas que puedan revolucionar nuestra comprensión de la realidad en mayor o menor medida, a partir de ideas previas, no asumiendo que surgen del vacío, dentro de una realidad que le permite verificar la validez de la creencia.

Los productos del conocimiento, aun cuando puedan ser elaborados de modo individual, son en su fundamento productos sociales. El reconocimiento de este hecho permite explicar por qué algunas civilizaciones son intelectualmente prolijas mientras que otras, en otro extremo, se hunden en el oscurantismo. Las condiciones sociales para el desarrollo del conocimiento son fundamentales; una comunidad que no permita el libre intercambio de ideas, así como que censure el desarrollo de nuevas hipótesis de solución de los problemas (en todos los ámbitos), se mantiene anclada a creencias que podrían ser perfeccionadas en algunos casos y superadas en otros. Esto sucede así tanto con el conocimiento de las ciencias naturales como con el de la ética, la economía y, por supuesto, la política. Un ejemplo para mostrar el efecto de las condiciones sociales en el desarrollo del conocimiento es la Edad Media. Si bien asumir que el medievo fue un momento de absoluto oscurantismo es impreciso, ${ }^{24}$ es innegable que al menos en el ámbito del saber político, legal y moral ocurre un estancamiento (con sus meritorias excepciones) siempre que la mayor parte de los teóricos procuran justificar las relaciones de poder existente. Las estrictas y jerárquicas relaciones sociales de la época tendían a asumir que la tradición era un producto valioso de la cultura en donde los individuos encontraban su razón para existir; los remanentes de esta idea sobre la tradición continúan existiendo en la fe católica que la considera parte de la revelación.

\footnotetext{
${ }^{24}$ Es impreciso porque asumir que no hubo avance en el conocimiento científico, por ejemplo, en la Edad Media, implicaría que la sociedad medieval censuraba o limitaba el desarrollo de un conocimiento sobre el que no tenían noticia. Es importante recordar que en este contexto las ciencias experimentales no existen, del mismo modo en que no existen en la antigüedad clásica. Quizá una de las diferencias radicales entre la antigüedad clásica y la Edad Media en el avance del conocimiento se encuentra en que en la antigüedad no existía el consenso, que sí se dio durante todo el medievo, sobre cuál era la causa de la existencia del mundo, así como su orden. El éxito del cristianismo (con su explicación causal del surgimiento y ordenación del mundo), aunado a la falta de algún desarrollo tecnológico, como sería después el telescopio, limitó el interés intelectual que podía existir en intentar explicar el origen de todo. Sin embargo, en lo que se refiere a la ética, política y derecho (aun con los desarrollos en derecho canónico) considero que sí ocurre un conservadurismo fruto de las condiciones sociales, como intento defender.
} 
La justificación de la democracia liberal se encuentra fundada radicalmente en la actitud pragmática que reconoce la importancia de hacer de la investigación de la realidad una circunstancia permanente, dadas las condiciones cambiantes y la posibilidad de desarrollar mejores aproximaciones a nuestros problemas. La democracia liberal es el sistema antiautoritario y antidogmático que genera las condiciones sociales para el desarrollo del conocimiento de las mejores aproximaciones a nuestra ordenación social, nuestro conocimiento del mundo y, por supuesto, de formulaciones morales que nos permitan hacer frente de mejor manera a la realidad desde la visión ética de los fenómenos.

Es evidente que mientras existen estructuras biológicas y orgánicas que se mantienen por lo general constantes, las "leyes" de la naturaleza humana son leyes de los individuos viviendo en asociación, no de ser en una condición mítica alejada de la asociación. En otras palabras, el liberalismo que asume sus ideas del individuo sinceramente debe estar profundamente preocupado sobre la estructura de las asociaciones humanas. Pues éste opera de modo que afecta tanto positiva como negativamente el desarrollo de los individuos. ${ }^{25}$

El liberalismo de Dewey se diferencia de las doctrinas liberales clásicas que asumen que el adecuado desarrollo del individuo se encuentra fundado en la laboriosidad humana en el ámbito privado y, cuando esto ocurre así, el gobierno debe limitar su intervención en la vida de los individuos. Para Dewey el liberalismo en la actualidad (su actualidad por supuesto), exige del gobierno hacerse responsable de sus funciones como medio instituido para facilitar el desarrollo.

Gradualmente un cambio sobre el espíritu y el significado del liberalismo ha ocurrido. Este tendió a distanciarse, gradualmente, de las creencias del laissez faire para asociarse con el uso de la acción gubernamental en ayuda a aquellos con desventajas económicas para aliviar sus condiciones. En este país, excepto por un pequeño grupo de adherentes al viejo liberalismo, las ideas y las políticas de este tipo han venido a definir el significado del credo liberal. El liberalismo americano, como lo ilustra el progresismo de inicios del siglo, tiene tan poco en común con el liberalismo ingles de la primera parte del siglo pasado que se manifiesta en oposición a él. ${ }^{26}$

No es de sorprender que un concepto como el del liberalismo haya sufrido cambios con el paso del tiempo y el cambio de circunstancias. De hecho es muestra de la viveza y actualidad del principio liberal como método de desarrollo del individuo el ser capaz de ajustarse a sus condiciones. Los cambios históricos en el concepto

\footnotetext{
25 Dewey, Liberalism and Social Action. 48

${ }^{26}$ Ibid. $30-31$
} 
del liberalismo son síntomas de un hecho fundamental que debería afectar nuestras consideraciones sobre el mismo: la idea de una tendencia natural en el hombre a buscar su libertad y desarrollar naturalmente sus capacidades sin la colaboración de la sociedad en su conjunto, como algunos prominentes liberales de la modernidad suponían, es una creencia injustificada.

Al mismo tiempo, considero relevante hacer mención del momento histórico en el que Dewey se encuentra al escribir buena parte de su obra política. El texto Freedom and Culture, por ejemplo, fue publicado en el año de 1939, mismo año en que inicia la Segunda Guerra Mundial con la invasión alemana a Polonia. Una preocupación constante en el pensamiento político de Dewey es el surgimiento de los Estados totalitarios en Europa, en particular el fascismo italiano y el nacionalsocialismo alemán. El supuesto del liberalismo lockeano, de que los individuos "fundan" la comunidad política con la finalidad de asegurar un estado de libertades prepolíticas y que el cumplimiento de esta exigencia es factor para garantizar la justificación y legitimación del ejercicio del poder político, no reconoce la importancia de la cultura en la consideración de la libertad como un principio valioso en la vida de las personas. Como veremos en capítulos posteriores, este es un tema relevante en el pensamiento político de Rawls. En el análisis de Teoría de la Justicia, el trato de Rawls a la libertad como un valor prepolítico parecería estar justificado en un planteamiento neokantiano de la justicia como imparcialidad; sin embargo, conforme avance en el análisis de su obra, podremos ver cómo, con el "giro político", Rawls abandona la idea de los valores prepolíticos, incluyendo entre ellos a la libertad, apostando a la posibilidad de fundar una concepción liberal de la justicia alejada de cualquier concepción de ley natural existente (para mantenerse en el ámbito de la ley política). El objetivo de Rawls es compatible con la preocupación de Dewey: garantizar la justificación de la libertad en una sociedad frente concepciones de la justicia opresoras, como es el caso del fascismo o el nacionalsocialismo, cuando existe la posibilidad de mostrar que la libertad como valor prepolítico no se justifica en la naturaleza al modo de ley o tendencia natural. La premisa sobre la tendencia natural en el hombre hacia la libertad, piensa Dewey, se encuentra también en el pensamiento de los "padres fundadores" de la nación norteamericana; las condiciones históricas en el tiempo de Dewey parecen mostrar que esta tendencia puede no ser tan necesaria:

La idea de que el amor a la libertad es inherente al hombre, al punto en que de tener la oportunidad de la abolición de la opresión ejercida por la iglesia y el Estado producirá y mantendrá instituciones libres no es actualmente adecuada. La idea 
surgió naturalmente cuando los colonos del nuevo país sintieron que la distancia que habían puesto entre ellos y las fuerzas que los oprimían simbolizaba lo lejano que se encontraban las amenazas a su libertad. Hoy en día estamos forzados a ver que las condiciones, que conforman el estado actual de la cultura, son relevantes para mantener la posibilidad de verdad. La liberación de la opresión y la represión que existió marcó una transición necesaria, pero las transiciones son simplemente puentes hacia algo más. ${ }^{27}$

Los estados totalitarios procuran convertir el gobierno y la vida pública en el fin de la vida de los individuos ejerciendo un control absoluto sobre sus vidas. ${ }^{28} \mathrm{El}$ éxito en el desarrollo de estos proyectos políticos es una de las preocupaciones de Dewey. Si consideramos, como sucede con el liberalismo clásico, que existe una tendencia natural del hombre a vivir en libertad, a buscar su bienestar y ampliar el ámbito de la vida privada como campo de desarrollo individual y no como una ordenación social fruto de una cultura determinada, el desarrollo del Estado Nazi es sumamente complejo de explicar dado que Alemania, previa al desarrollo del nacionalsocialismo, era una nación ilustrada, tendiente incluso a la socialdemocracia (con la fundación de la República de Weimar), con una industria creciente y respeto por la propiedad privada. El totalitarismo nos muestra como algunos de los valores del liberalismo clásico que mejor se han mantenido a través del tiempo, como son "la libertad, el desarrollo de las capacidades inherentes de los individuos a través del ejercicio de su libertad y el rol central del uso libre de la inteligencia en la investigación, la discusión y la expresión", ${ }^{29}$ son valores construidos socialmente, que exigen de una disposición cultural y de un esfuerzo deliberado si queremos mantenerlos vigentes, para mantener en las instituciones liberales. Dado que la comunidad política concreta y las formas de gobierno que esta adopta son manifestaciones institucionales de eventos sociales más complejos, asumir que la comunidad política se justifica o legitima por valores no condicionados culturalmente, anteriores a la vida social concreta que informa la comunidad política actual, es un error. El florecimiento de un Estado liberal exige el desarrollo de una cultura liberal y, de acuerdo con Dewey, necesariamente democrática.

La desconfianza de Dewey hacia los principios dogmáticamente sostenidos lo conduce a dudar de la eficacia del mero constitucionalismo como mecanismo eficiente para sostener un Estado democrático y liberal. Pueden existir instituciones democráticamente concebidas, sin embargo, sin las condiciones materialmente

\footnotetext{
27 Dewey, Freedom and Culture. 14

${ }^{28}$ Cfr. Ibid. 16

${ }^{29}$ Dewey, Liberalism and Social Action. 40
} 
apropiadas, dichas democracias liberales están destinadas al fracaso. El papel protagónico otorgado por Dewey a las condiciones sociales responde a su filosofía pragmática que supone la profunda relación entre la generación de intenciones e ideas y las condiciones materiales existentes: "Si queremos que los individuos sean libres debemos darnos a la tarea de que las condiciones apropiadas existan." ${ }^{30}$

Dewey parece tener una comprensión más o menos clara de una distinción tratada por algunos teóricos contemporáneos de la democracia, como es el caso de Robert Dahl: la distinción entre la democracia como sistema de instituciones y la democracia como el conjunto de las condiciones sociales necesarias para la participación (aunque limitada) dentro de un gobierno poliárquico. En Dewey la democracia es más que un arreglo institucional, pues supone necesariamente una cultura abierta de igualdad. Las palabras de Dahl resuenan con fuerza en el pensamiento político pragmatista:

Porque nos han enseñado a creer en la necesidad de sistemas de rendición de cuentas y balance de poder constitucionales, ponemos poca fe en sistemas de rendición de cuentas y balance de poder sociales. Admiramos la eficacia de la separación de poderes constitucional para administrar mayorías y minorías, pero continuamente olvidamos la importancia de los límites impuestos por la separación social de poderes. Aun así, si la teoría de la poliarquía es en algún sentido adecuada, se sigue que en la ausencia de ciertos prerrequisitos sociales, ningún arreglo constitucional puede producir una república no tiránica. La historia de numerosos estados latinoamericanos es, creo yo, prueba suficiente. Por el contrario, un incremento en la medida en que los prerrequisitos sociales están presentes puede ser por mucho más importante en el fortalecimiento de la democracia que cualquier diseño constitucional. Ya sea que estemos preocupados por la tiranía de la minoría o la de la mayoría, la teoría de la poliarquía sugiere que las primeras y más cruciales variables en las que los científicos políticos deben centrar su atención son sociales y no constitucionales. ${ }^{31}$

Elementos como la educación y lo que Rawls llama en Teoría de la Justicia "igualdad democrática" ${ }^{32}$ son condiciones sociales de la existencia del proyecto democrático y liberal. Un sistema liberal, desde una formulación pragmatista al menos, debe funcionar más que como un mero garante de la privacidad de sus miembros; la sociedad liberal democrática tiene la "misión" de garantizar el ejercicio de la libertad en función de los medios y mecanismos existentes. La falta de garantía de ciertos medios necesarios para desarrollar las facultades y capacidades humanas (como son posibles dadas las condiciones sociales y técnicas del momento), aun

\footnotetext{
${ }^{30}$ Dewey, Freedom and Culture. 33

${ }^{31}$ Robert Dahl, A preface to democratic theory (Chicago: The university of Chicago press, 2005), 83.

32 En el siguiente capítulo analizo con cierto detalle este concepto.
} 
cuando no existiera una prohibición expresa en su posesión, supondría un mal uso del poder político si este existe para garantizar la persecución libre y legítima de los intereses de los individuos y los grupos. Dicho con otras palabras, un Estado liberal que no garantice los medios mínimos, que estén a su disposición, para que los individuos configuren y persigan libremente sus intereses legítimos, falla en su alcanzar su finalidad.

El Estado totalitario, que como mencioné es central en las preocupaciones de Dewey, desarrolla una dinámica de solidaridad y colaboración absoluta. Al someter los intereses de grupos a los fines designados por el Estado, sustituye la pluralidad de intereses que obligan al surgimiento de la comunidad, en un sentido político a través de la designación de oficiales, mediante la imposición dogmática de fines comunes que afectan la totalidad de la vida de los individuos. Uno de los problemas que surgen de una postura como ésta es que la imposición efectiva de fines en los individuos deshace una de las condiciones básicas del progreso y desarrollo de las capacidades investigativas de las personas: el conflicto y la tensión.

Las posturas conservadoras y radicales que no son capaces de reconocer la incompatibilidad de sus ideales con las circunstancias concretas, tienden naturalmente a distanciarse del liberalismo, así sea de modo gradual, porque éste pretende respetar la pluralidad de intenciones y opiniones en los distintos ámbitos de la vida. La pluralidad, que puede ser interpretada en un sentido político como el estado de competencia ente diversas creencias para responder a las condiciones materiales en las que se encuentran, es el factor que históricamente ha permitido el desarrollo evolutivo de las comunidad políticas. Los gobiernos totalitarios buscan, de modo similar al liberalismo aunque con fines diametralmente opuestos, tomar control del proceso evolutivo de la sociedad que busca adecuar sus creencias y sus acciones lo mejor posible a las condiciones existentes. Un gobierno totalitario supone poseer la verdad sobre el modo adecuado de organización en todos sus niveles y procura limitar la libertad en la sociedad para evitar los movimientos que pudieran alejarla de esa verdad. El Estado liberal, por su parte, reconoce la importancia del conflicto y busca encaminarlo en su modo más productivo; de nuevo el liberalismo se tiene que entender como el método que facilite el desarrollo de creencias y aproximaciones a la realidad más convenientes y mejores para los individuos. A la vez que en el Estado liberal existe un reconocimiento de la importancia del conflicto, también está presente la conciencia de los riesgos cuando no existen los mecanismos para controlarlo y llevarlo a cabo de modo productivo; dentro de estos controles podríamos contar la división de poderes, los mecanismos 
legislativos concretos, el interés en el procedimentalismo como estrategia para contener arbitrariedades, etcétera. La comunidad liberal representa un punto medio entre el conflicto desordenado e improductivo, anárquico, y el orden perfectamente cooperativo y solidario ausente de conflicto, también improductivo.

En tanto que el proceso es uno de tipo evolutivo -el proceso de desarrollo de comunidades políticas determinadas-, es un proceso continuo de superar estados anteriores. Cuando la competencia se convierte en un rasgo demasiado prominente de la existencia deja de existir evolución y el proceso se detiene; degenera en un congestionamiento. (...) La competencia tiene este aspecto riesgoso en los puntos críticos, justo antes de que alguna variación favorable ocurra. Aquellos que consideran la competencia como esencialmente mala y la cooperación como un ideal absoluto, respondan esto: ¿Cuál es el motivo para que ocurran variaciones? ¿Cuál es el estímulo del progreso en un régimen que se ha deshecho de la competencia? ${ }^{33}$

En el tema del conflicto, la competencia y la evolución social, Dewey nos deja ver la influencia del pensamiento de Darwin en la filosofía pragmática. Así como en la naturaleza sobrevive el ser que esté mejor equipado para adaptarse a su medio, del mismo modo las creencias, hábitos e instituciones sociales que estén mejor equipadas para responder a las condiciones existentes tienden a mantenerse de mejor modo. Al igual que ocurre en el mundo natural con el proceso evolutivo darwiniano, el proceso de selección está fundamentado en la lucha por la sobrevivencia. Es posible considerar que Dewey está realizando una gran apuesta por el liberalismo dado el relativamente corto tiempo que tiene existiendo, que es todavía menor en el modo que él lo entiende como un proyecto de potencialización de capacidades. La apuesta está en la creencia, aparentemente justificada por las implicaciones que ha tenido en el progreso científico, de que los procesos competitivos pueden ser conducidos por la razón, mediante una actitud pragmática, de modo que sea posible obtener los mejores resultados en el menor tiempo posible. La democracia y el liberalismo son los mecanismos para limitar el dogmatismo y la arbitrariedad en la vida social de modo que puedan surgir nuevas interpretaciones, mejor adaptadas a la realidad. Siguiendo la lógica pragmática de Dewey, podríamos decir que lo que hace que la democracia liberal sea el mejor modo de ordenar la comunidad política (al menos hasta no encontrar uno todavía mejor), es que tiene como consecuencia permitir el desarrollo de los individuos y de los mejores modos de acción en ese sentido darwiniano. De este modo la libertad tiene un valor meramente instrumental, aunque sea una condición necesaria para el desarrollo de los individuos; no puede ser entendida como un fin

\footnotetext{
${ }^{33}$ Dewey, Principles of Instrumental Logic. 141
} 
en sí: las personas son libres para o de. Aun cuando podemos decir, con actitud pragmática, que es posible anticipar mejores y peores modos de ejercer la libertad, no estamos en condición para describir un estado final al que debamos apuntar con el ejercicio de la misma, esto está supuesto en el falibilismo de la postura deweyana. La libertad así entendida es la condición de posibilidad para que los individuos desarrollen nuevas hipótesis de acción en su vida ordinaria y, teniendo como escenario una sociedad democrática y liberal, puedan ponerlas a prueba.

Probablemente la mejor aplicación de la libertad es viviéndola en todos nuestros ámbitos de acción. El supuesto liberal de que el hombre está capacitado para, mediante el ejercicio de su libertad, encontrar las mejores maneras de desarrollarse, nos conduce a reconocer lo preferible de vivir una vida sin ataduras a una autoridad exterior pues es el medio más eficiente de desarrollar nuestras capacidades y nuestras hipótesis de acción en función de nuestras condiciones y circunstancias contingentes. Reproducir el método de la razón y la inteligencia, que supone necesariamente la libertad de indagación, en todos los ámbitos de la vida exige la implementación de una comunidad política de carácter liberal. El objetivo es reproducir las condiciones del surgimiento de nuestra comprensión científica de la realidad en el ámbito social de modo que la competencia sea lo más fructífera posible para el desarrollo de los individuos.

La necesidad esencial, en otras palabras, es el mejoramiento de los métodos y las condiciones del debate, la discusión y la persuasión. Ese es el problema de la esfera pública. Hemos dicho que este mejoramiento depende esencialmente de la liberación y el perfeccionamiento del proceso de indagación y publicidad de las conclusiones. $^{34}$

La existencia de los mecanismos de indagación adecuados, que nos permitan enfrentar distintas hipótesis sobre las diversas áreas de conflicto en el espacio público, es la condición de posibilidad de planear racionalmente el desarrollo de las políticas en la comunidad que permitan la consecución de sus fines. El mecanismo para desarrollar mejores métodos de indagación en la comunidad no puede estar ser pensado en un sentido definitivo al modo de principios determinados que sirven en todos los casos necesariamente; mucho menos en un sentido de instituciones atemporales. Tampoco es una posibilidad real suponer que todos y cada uno de los individuos en la comunidad se convertirán en científicos sociales, económicos, políticos y morales; la cantidad de tiempo requerido para desarrollar los talentos necesarios para serlo es incompatible con la posibilidad de una sociedad que en su totalidad esté constituida por individuos con ese nivel de

\footnotetext{
${ }^{34}$ Dewey, The Public and its Problems. 188
} 
preparación. El mecanismo se refiere, más bien, a la instauración y promoción de una actitud en la ciudadanía. No es necesario que cualquier ciudadano pueda desarrollar una propuesta concreta para lidiar con un problema complejo determinado, lo que debemos de buscar es que cualquier ciudadano sea capaz de reconocer la importancia del proceso racional en el análisis de los problemas y que, en caso de desear informarse para poder juzgar sobre alguna creencia o hipótesis de acción, sea capaz de indagar de un modo productivo al respecto:

Aunque es absurdo creer que sería posible o deseable hacer de todos un científico cuando la ciencia se define en función de una materia específica, el futuro de la democracia -y por tanto del liberalismo, que en el pensamiento de Dewey están definitivamente vinculados- está relacionado con la propagación de la actitud científica. Ésta es la única garantía en contra de la propaganda que confunde. Aun más relevante, es la única garantía de poder desarrollar una opinión pública lo suficientemente inteligente como para hacer frente a los problemas sociales de nuestros días.

El problema es también educativo. Un libro, en lugar de un párrafo, podría ser escrito sobre este tema. Que las escuelas se han dedicado sobre todo a impartir información preanalizada, al tiempo que enseña las herramientas básicas del conocimiento, no puede ser negado. Los métodos utilizados para adquirir esa información no son los que desarrollan habilidades en la indagación y en el análisis de las opiniones. Al contrario, son hostiles a estos fines. Tienden a limitar la curiosidad natural y a sobrecargar los poderes de observación y experimentación con una cantidad tal de material inconexo que tienden a trabajar como si fueran los de una persona sin educación. El problema de las escuelas comunes en la democracia ha alcanzado tan sólo su primer estadio cuando se han asegurado para todos. Hasta que lo que se enseña y cómo se enseña esté definido en función de la formación de la actitud científica, la función formativa de las escuelas estará garantizada por golpes de suerte en lo que a sus contribuciones a la democracia se refiere. $^{35}$

Las alternativas a un Estado liberal como el que plantea Dewey no son, por lo general, muy alentadoras en el largo plazo. Una comunidad política que busca desarrollar los mejores mecanismos para permitir que los intereses de los individuos puedan ser alcanzados $\mathrm{y}$, por tanto, puedan ejercer efectivamente su libertad como medio para procurar fines racionalmente elaborados, exige la generalización de la actitud falibilista-pragmática pues, de lo contrario, estaríamos aceptando, en cualquier otro modelo, el sometimiento a fines, creencias, valores y principios no sujetos a revisión y producción racional.

\footnotetext{
${ }^{35}$ Dewey, Freedom and Culture. 114-115
} 
Si no aceptamos la democracia liberal, antidogmática y cientificista (en un sentido pragmatista del término) como un método organizativo adecuado, tendremos que contentarnos con una de dos opciones: ${ }^{36}$ por un lado tendríamos que aceptar una ordenación dogmáticamente elaborada y sostenida (en general con el uso de la fuerza al margen del manejo racional) que aun cuando, en el mejor caso posible, pueda ser eficiente y efectiva para alcanzar sus fines se cierra ante la posibilidad (latente y probable) de considerar opciones mejor adecuadas a las condiciones cambiantes o, por otro, la resignación que el proceso de desarrollar ordenaciones sociales debe estar regido por la arbitrariedad de la improvisación difícilmente inteligente que en cualquier momento puede terminar generando resultados negativos respecto a los fines del Estado. Así, "lo que se utiliza como alternativa al conocimiento en la regulación de la sociedad es la ignorancia, el prejuicio, el interés de clase y el accidente." ${ }^{37}$

Dejar al azar el cumplimiento de la finalidad de la comunidad política (la efectiva representación de los intereses de miembros de la misma y promover el desarrollo de sus capacidades mediante el ejercicio de su libertad) existiendo un método adecuado es una opción poco razonable. La ampliación de los marcos de libertades para la población de una comunidad permite construir una comunidad de "investigadores" más amplia y capaz de desarrollar nuevas hipótesis de acción en todos los ámbitos de la realidad. Hacer de la actitud pragmática un estado generalizado es generar las condiciones culturales de propagación de la libertad y la garantía de perpetuar la búsqueda de nuevos modos de actuar que enriquezcan la vida de las personas; esto sólo se puede hacer confiando en la capacidad de los individuos de llevar a cabo la libre indagación de sus fines y circunstancias de modo racional.

De igual modo, garantizar la libertad efectiva de los individuos permitiendo el adecuado desarrollo de sus capacidades racionales supone generar las condiciones materiales adecuadas para estos fines. La aplicación del intelecto humano en el mejoramiento de los estándares de vida, conforme se encuentren disponibles, es una exigencia de acuerdo a los fines mismos del Estado cuando reconozca la igualdad moral de todos los individuos. Limitar el acceso de la ciudadanía a una formación científica y a los productos del intelecto humano sin una razón justificada implicaría un vacío en la representación de los intereses de un grupo en el Estado, ya sea que dicho grupo no se encuentre representado, que

\footnotetext{
${ }^{36}$ Cfr. Dewey, Liberalism and Social Action. 56

${ }^{37}$ Dewey, The Public and its Problems. 174
} 
no exista una representación equitativa o que la operación de los oficiales sea corrupta y alejada de su finalidad.

Queda claro que para vivir en un Estado liberal, ya que hemos comprendido la naturaleza de la comunidad política en el pensamiento de Dewey, el antagonismo entre bienestar social e individual, así como sucede con el del gobierno con el del individuo, responde más a una distinción mental que a un hecho de la realidad. Es claro que existen circunstancias concretas y determinadas en las que el interés de un individuo existe en oposición directa al de la sociedad, sin embargo la sociedad como abstracción no la debemos comprender como una entidad antagónica al individuo absolutamente, pues eso nos llevaría a no comprender la interdependencia del bienestar individual con el desarrollo de su comunidad. Recordemos que la vida en sociedad es un hecho del mundo; si recordamos también que somos productos de esa vida en sociedad, el desarrollo social y el ejercicio de nuestra libertad están naturalmente vinculados: “La libertad es el desarrollo de las potencialidades personales que ocurren sólo en una compleja y rica asociación con los demás: el poder de ser un ser individualizado haciendo una contribución distintiva mientras disfruta a su modo de los frutos de la vida en asociación." ${ }^{38}$

Garantizar las condiciones materiales para el desarrollo de la comunidad política conforme las posibilidades existentes es un imperativo político si se busca vivir en un Estado liberal. No es suficiente promulgar garantías que limiten la intervención del Estado para que los individuos puedan alcanzar sus propios fines. Confiar en que la libertad existe únicamente por decreto, manteniendo las fuerzas opresoras al margen, no sólo es ingenuo, pues implica que no se entiende la relevancia del contexto material y cultural para la acción del individuo, sino contraproducente. Este punto lo analiza Dewey al enfocarse a la libertad de pensamiento y expresión. Su reflexión no tiene desperdicio:

La creencia de que el pensamiento y su comunicación son libres hoy simplemente porque las restricciones legales que alguna vez existían han sido eliminadas es absurdo. Su existencia perpetúa el estado infantil del conocimiento social. Esta creencia ensombrece el reconocimiento de nuestra necesidad de poseer concepciones que son usadas como herramientas para la indagación dirigida que son puestas a prueba, rectificadas y que crecen a través del uso. Ningún hombre o mente se ha vuelto libre simplemente al dejarse por sí solo. Retirar limitaciones formales es sólo una condición negativa; la libertad positiva no es un estado sino un acto que involucra métodos y mecanismos para controlar las condiciones. La

\footnotetext{
${ }^{38}$ Ibid. 150
} 
experiencia nos muestra que algunas veces la sensación de opresión externa, como sucede con la censura, actúa como un reto promoviendo la energía intelectual y motivando el valor. Pero una creencia en la libertad intelectual donde ésta no existe contribuye sólo a una esclavización a la torpeza y la superficialidad direccionándonos a las sensaciones como sustitutos de las ideas: una característica clara sobre nuestro estado presente al respecto del conocimiento social. ${ }^{39}$

El análisis de la libertad de pensamiento y de expresión nos permite comprender la importancia del papel activo de la comunidad en el desarrollo de las libertades y nos lleva a resaltar su liberalismo sustantivo. En sociedades que asuman una separación absoluta de la acción social y el bienestar individual como un principio normativo, como sucede con el proyecto liberista, el desarrollo de las aptitudes y capacidades necesarias para el ejercicio y ampliación de las libertades es imposible de alcanzar. El mecanismo de la libertad nos exige permitir a todos los grupos de la comunidad el participar en la indagación política, social, moral, económica y cualquiera otra relevante para el bienestar de la comunidad no sólo adoptando una postura negativa no intervencionista. El camino de la libertad, la libertad racional inspirada por la actitud científica-pragmática (que dentro del pensamiento de Dewey es la única que nos puede garantizar la adopción de creencias justificadas) es el de la participación activa que promueve la igualdad en sentido moral y de oportunidades, la del mejoramiento de la comunidad y de las condiciones de los distintos grupos que la componen a través del uso de la razón.

La justificación del liberalismo en Dewey, consecuencialista por su naturaleza pragmática, está afirmada en dos puntos principalmente: un argumento moral y uno argumento político. El primer argumento, el moral, supone que el liberalismo político permite establecer un método que garantice el desarrollo de una indagación moral de acuerdo a las necesidades del momento, desde una perspectiva histórica y material. Esta dimensión moral de la justificación del liberalismo depende de la idea de progreso y de perfeccionamiento en sentido práctico (que abordo a detalle en el cuarto capítulo). La actitud pragmatista está abierta al progreso y a la mejor adecuación de las creencias respecto de las circunstancias concretas.

Del mismo modo, el argumento moral asume que el liberalismo responde al modo en que los seres humanos construimos el conocimiento y nos aproximamos a los problemas. La justificación del Estado liberal desde esta perspectiva garantiza generar las condiciones en que la naturaleza humana pueda expandir sus capacidades cognitivas mediante el uso de la actitud científica frente a la realidad.

${ }^{39}$ Ibid. 168 
El Estado liberal nos permite desarrollar nuestras facultades no sólo limitando los obstáculos sino generando las condiciones positivas de desarrollo.

El segundo argumento, que defino como político, está elaborado a partir de la teoría deweyana de la política como la anatomía de las instituciones y la finalidad de la comunidad política como el espacio de representación de intereses e institucionalización de hábitos. El liberalismo se justifica desde un argumento político una vez que observamos que el Estado cumple una finalidad determinada y que, dada esta finalidad, la sociedad liberal está constituida de modo que permite su correcto funcionamiento de modo que genera las mejores condiciones para que cumpla su fin.

Este modo de justificar el liberalismo es típicamente "comprehensivo", para usar la categoría de Rawls. La idea de doctrina comprehensiva, que Rawls desarrolla en el Liberalismo Político a la luz del "giro político", supone que una doctrina es de ese tipo cuando "incluye concepciones de lo que es valioso en la vida humana $(. .)^{\prime \prime} \cdot{ }^{40}$ Aun cuando analizo a detalle este concepto en partes posteriores de este trabajo, además del contraste entre el pensamiento de Dewey y de Rawls en este respecto del liberalismo, es importante recalcar que la democracia liberal de Dewey es mucho más que una idea organizadora del poder político, como el concepto de doctrina comprehensiva nos da a entender. Sin importar que desde el pensamiento de Dewey no sea posible definir objetos concretos como bienes últimos o valiosos para la vida humana, sí podemos definir la actividad de indagación del mundo como un bien, instrumental si se quiere, para poder alcanzar una vida satisfactoria. Este modo de comprender la indagación afecta la vida de los individuos en muy diversos ámbitos.

Si asumimos la corrección en la justificación de la democracia liberal de Dewey, entonces tendríamos que reconocer la falta de justificación de otras explicaciones de la democracia liberal (que pudieran materializarse de modo distinto) o de cualquier otra organización social para los casos que pudieran ser comparables. Como ya he afirmado antes, el pragmatismo de Dewey no nos permite asegurar que poseemos la verdad (ahí radica su falibilismo), aunque sí nos permite saber cuáles opciones (las menos justificadas) son equivocadas. Para Rawls, la naturaleza comprehensiva del liberalismo de Dewey sería una "desventaja" aun cuando sea una doctrina comprehensiva razonable (en la medida en que el pragmatismo, como lo mencioné de pasada el capítulo anterior y analizo con detalle más adelante, es compatible con la idea de las cargas del juicio

\footnotetext{
${ }^{40}$ Rawls, Political Liberalism. 13
} 
rawlsianas). El problema desde una perspectiva rawlsiana es que, asumiendo que en las sociedades actuales existe, como condición irrenunciable, el pluralismo, una comprensión comprehensiva del liberalismo se convertiría en una imposición injusta sobre ciudadanos razonables (es decir que son capaces de vivir en una sociedad liberal como miembros plenamente cooperadores); en tanto propone una ideal de vida (sin importar qué tan abierto sea este), tiende a ser más excluyente que una comprensión del liberalismo que exija compromisos más débiles (como intenta hacer el mismo Rawls con el "giro político" que expongo en la tercera parte de esta investigación). El balance de las presuntas debilidades y fortalezas de la naturaleza comprehensiva del liberalismo, ya sea del de Dewey o del de Rawls (pues intentaré mostrar que no puede abandonar un cierto grado de comprehensividad), es uno de los principales temas de análisis en las páginas por venir.

Para Dewey la democracia liberal es un medio que promueve una idea comprehensiva del bien (una idea del bien profundamente indeterminada aunque vinculada al ideal de indagación pragmático). El liberalismo pragmático tiene la función de permitir a los individuos encontrar mejores modos de vivir y desarrollarse de manera que la caracterización de adecuada o incorrecta de la ordenación política depende de su capacidad de facilitar la representación de intereses legítimos por parte de los oficiales. Sin embargo, la consideración del liberalismo pragmático, así como sus instituciones y criterios o principios de ordenación, como un medio para fines posteriores es compleja en tanto que se acepta que los diversos fines y bienes que la justifican están, por sí mismos, indeterminados. Aun cuando el liberalismo se sostiene porque maximiza el bienestar, lo hace distanciándose de formulaciones concretas y particulares del bien, aunque mantenga un ideal general; en ese sentido se sostiene por una ordenación que es independiente de los contenidos concretos de las ideas del bien. Dicho de otro modo, la democracia liberal del Dewey supone una idea comprehensiva del liberalismo pero, al mismo tiempo, permite pensar una ordenación social al margen de ideas del bien concretas, lo que en cierto sentido podría hacerlo aceptable, al menos en un mayor grado, para Rawls frente a otras opciones de organización que buscaran la ordenación política en función de un ideal de bien particular.

Dada la pluralidad de fines legítimos que pueden surgir en una comunidad democrática y liberal, se vuelve necesario generar un criterio distinto de un bien particular como el rector de la organización misma, al menos si queremos aspirar al mejor criterio posible de organización política. La propuesta deweyana nos 
ofrece, a través de la epistemología y la indagación pragmática, los principios para justificar un liberalismo que reconoce la inconveniencia de fundamentar las instituciones en visiones del bien particulares. Aun cuando el pensamiento de Dewey reconoce que el origen de las comprensiones del bien y de la justicia concretas surgen a partir del devenir cultural de la comunidad, la comprensión pragmática del conocimiento humano le permite afirmar la democracia liberal al margen de una sociedad específica como el tipo de organización social óptima para el desarrollo de los miembros de la comunidad. La propuesta de Dewey se fundamenta en que, aun cuando las ideas del bien y de lo justo específicas que surjan en las comunidades puedan ser irreductibles entre sí, las circunstancias antropológicas son iguales independientemente de la cultura en la que nos encontremos. La democracia liberal es, simplemente, la organización política mejor ordenada a la naturaleza humana que, pensaría Dewey, hemos sido capaces de elaborar al menos hasta ahora. Es de este modo que la democracia liberal puede pretender ser justificable en sociedades eminentemente plurales.

El compromiso de Dewey justificar su democracia liberal en la naturaleza indagatoria del ser humano está evidenciado en su interés por generar las condiciones materiales necesarias para que los individuos puedan actuar con libertad. Como intenté mostrar, para Dewey las distribuciones e instituciones sociales, así como culturales, son necesarias para que la democracia liberal pueda sostenerse. En Dewey existe la convicción de desarrollar las condiciones materiales necesarias de la libertad así como, igual de importante, una cultura pública, a través del proceso educativo, en donde la actitud pragmática se convierta en parte del ethos de la comunidad. Dado que la justificación del liberalismo no está en principios indemostrables, sino, por el contrario, en una hipótesis funcional de la naturaleza humana y del conocimiento, el pragmatismo sostendría que, así como se ha hecho con la enseñanza de la ciencia, es posible generar una cultura abierta a la indagación que reconozca la importancia de las condiciones ecológicas para el surgimiento de nuevo y mejor conocimiento. Las implicaciones distribucionistas y colectivistas de la democracia liberal de Dewey son amplias en este punto. Como mostraré en la siguiente parte de la investigación, Dewey comparte con Rawls la preocupación de que la sociedad permita el ejercicio de la libertad garantizando los medios necesarios para su experiencia y, al igual que hace Rawls, esto sólo puede ser satisfaciendo las necesidades biológicas y sociales al menos en un grado mínimo garantizado para todos. 
Parte II. El liberalismo antiperfeccionista de Teoría de la Justicia 


\section{Capítulo 3. Una teoría de la justicia}

El primer capítulo inició con una cita de John Dewey sobre la necesidad de supuestos antropológicos para cualquier teoría política; considero relevante retomarla para iniciar este capítulo, en el que me dedicaré a la exposición, análisis y crítica del liberalismo de John Rawls como lo expone en Teoría de la Justicia. Antes, unas palabras preliminares son necesarias.

John Rawls es el filósofo político norteamericano más relevante del siglo pasado. Su relevancia estriba de su capacidad de revivir la discusión política desde una vertiente contractualista y anti utilitarista, por cierto dos esquemas de pensamiento poco vigentes en el año 1971, mismo de publicación de Teoría de la Justicia, hasta esa fecha su obra más importante. La labor filosófica de Rawls es de una importancia tal que dio lugar a una oleada de reacciones a su pensamiento tan grande que, en su momento, hubiera sido imposible definirla como positiva o negativa en términos generales. Hay quienes piensen que el liberalismo rawlsiano, que como veremos además de ser un contractualista tiende a ser kantiano en muchas de sus consideraciones, representa una defensa del capitalismo; otros lo consideran socialista. Para unos es una muestra del universalismo ilustrado en uno de sus mejores desarrollos, para otros un imperialismo cultural que banaliza las creencias de las personas. En cualquier caso, Rawls representa una voz original en la discusión política como pocas y, en 1971, fue profundamente innovadora y prolífica. En Teoría de la Justicia presenta una amplia elaboración de un sistema liberal que incluye temas como la racionalidad, el bienestar y la justicia entre muchos otros (que abordo después). Cada uno de ellos es expuesto con profundidad y a detalle por Rawls, por lo mismo Teoría de la Justicia no admite ser leído con ligereza.

Algunas de las lecturas e interpretaciones a Teoría de la Justicia merecieron, por parte de Rawls, respuesta de distinto tipo. El Liberalismo Político, publicado en 1993, representa la forma más desarrollada de esa respuesta. En su segunda gran obra, John Rawls muestra la improcedencia de muchas de las críticas, que en algunos casos considera como injustas y provenientes de una mala comprensión del texto anterior. En esta segunda parte de la investigación, sin embargo, asumiré provisionalmente que Teoría de la Justicia representa la presentación preferida por Rawls de su pensamiento. En la tercera y cuarta parte integro al análisis del 
pensamiento de Rawls el Liberalismo Político para entender con mayor claridad los cambios sustanciales, donde lo hubiera, entre las dos obras. Este modo de proceder, además de parecerme más ordenado, permitirá entender los cambios en el pensamiento de Rawls con mayor claridad.

Como mencioné, Teoría de la Justicia mereció una atención poco común desde el momento de su publicación; vale la pena recordar que Brian Barry, al inicio de su reseña del texto, en la "Apología", hace hincapié en que la amplitud del análisis responde a su consideración de Teoría de la Justicia como un texto que se convertiría, con el tiempo, en una obra profundamente relevante:

Estoy, en efecto, anticipando el paso del tiempo al asumir, y actuar conforme esa presunción, que Teoría de la Justicia es un trabajo de la mayor importancia y que valdrá la cuidadosa atención que aquí he procurado dedicarle. Creo que será así, y todas las reseñas que he visto están de acuerdo en señalar a Teoría de la Justicia como un trabajo de gran importancia para la filosofía moral y política. ${ }^{1}$

Dada la extensión de la obra, así como la cantidad de temas que en ella se tratan, es imposible hacer en la presente investigación un análisis detallado de cada una de sus partes y conceptos. En este y el próximo capítulo busco explicar en términos generales los objetivos y argumentos de Rawls. De igual modo, trato algunos de los elementos de la teoría que considero más problemáticos. Todo este análisis lo llevo a cabo teniendo en mente el pragmatismo deweyano con la intención de, al reconocer algunos de los temas problemáticos, comprender hasta qué punto el pragmatismo puede servir como una herramienta útil a la propuesta liberal rawlsiana.

Es de llamar la atención, como se ve cuando analizo el Liberalismo Político en la parte siguiente, que una estrategia de Rawls para escapar a algunas de las críticas recurrentes a Teoría de la Justicia fue la de afirmar un "giro político" a su pensamiento. Corriendo el riesgo de adelantarme, cabe mencionar que este giro implica un cambio en la argumentación del liberalismo para Rawls. Dicho giro ha sido interpretado como un acercamiento al pragmatismo, así como un distanciamiento de su kantismo. El análisis de ese giro es central en mi investigación por las implicaciones en la estabilidad a la que aspira el liberalismo rawlsiano.

En este capítulo muestro cómo la argumentación acerca de la justicia procedimental, de carácter liberal, que presenta Rawls, podría presentar problemas de estabilidad ya que las concepciones del bien a las que intenta dar cabida pueden

${ }^{1}$ Brian Barry, The liberal Theory of Justice (Londres: Oxford University Press, 1973), ix. 
tender (y si Dewey está en lo correcto en general sucede así) a negar los principios de la justicia derivados de "la justicia como imparcialidad", el nombre de la concepción que desarrolla, y Rawls no genera los mecanismos para lidiar con esta dificultad. Esto ocurre así en tanto los principios suponen una doctrina comprehensiva del individuo y la comunidad política liberales que puede ser irreconciliable con doctrinas comprehensivas que sostengan algunos de los ciudadanos dentro de la sociedad. Hasta cierto punto el comunitarismo asume esta dificultad, de conciliar una concepción de la justicia particular con todas las distintas doctrinas comprehensivas que mantienen los ciudadanos, y la hace central en su comprensión de la realidad; esto es el foco a su crítica del pensamiento de Rawls.

Así, realizando una lectura de Teoría de la Justicia desde una perspectiva pragmática, en particular desde el pragmatismo de Dewey, es posible reconocer que una de las debilidades del argumento de Rawls (que intenta solucionar en el Liberalismo Político) es la relación entre la formación de la identidad de los individuos y los alcances de una teoría de la justicia distanciada de las contingencias de la vida social regular (recordemos su naturaleza kantiana). La formación de una concepción del bien está íntimamente relacionada con la cultura y sociedad en la que viven las personas (eso sin tomar en cuenta los hechos concretos de su vida que afectan la interpretación de la cultura y el modo en que esta les ayuda a comprender lo que les acontece día a día) y su comprensión de la justicia está siempre en relación dinámica respecto con estos y otros factores. Intentaré mostrar que el antiperfeccionismo rawlsiano es una consecuencia de la comprensión limitada de Rawls, en particular en Teoría de la Justicia, de estos hechos e influye directamente en la estabilidad de la concepción de la justicia en una sociedad determinada. Para hacerlo, por supuesto, trato el tema el antiperfeccionismo con cierto detalle.

Ahora quisiera regresar a la idea del primer párrafo de este capítulo. La cita de Dewey que utilicé para abrir el primer capítulo, y que es útil para tratar la discusión de Teoría de la Justicia, es:

Para toda filosofía política y social actualmente desarrollada se encontrará, después de un examen, que supone una cierta perspectiva sobre la constitución de la naturaleza humana: en sí misma y en relación con la naturaleza. Lo que es verdad sobre esto es verdad sobre todos los factores culturales. ${ }^{2}$

\footnotetext{
${ }^{2}$ Dewey, Freedom and Culture. 18.
} 
La cita anterior aplica bien para el pensamiento de Rawls (y no tendría por qué ser de otro modo). Rawls busca desarrollar una teoría del liberalismo que le permita, desde una perspectiva particular de la naturaleza humana (que, veremos, es heredera principalmente del ideal de persona autónoma kantiano, aunque con conceptos de racionalidad hobbesianos y algunos elementos de orden pragmatista), servir de ideal ordenador aceptable para perspectivas distintas de la naturaleza del hombre y la sociedad. Este esfuerzo no queda resuelto, tampoco es claro que sea siquiera posible absolutamente, pues las objeciones que se le hacen a Rawls al respecto son en algunos casos persuasivas. La búsqueda de dicho ideal, que sea capaz de servir como justificación para perspectivas de la naturaleza humana diversas, es una de las contribuciones de Rawls al debate político asumiendo que pueda plantearlo en términos racionales y que pueda traducirse en políticas concretas. Rawls recuerda la obligación, en todo aquel que quiera pensar la política, de plantear la relevancia de la normatividad y la justicia entre personas con ideas del bien distintas, ya sea para afirmarlas o para negarlas.

Este capítulo inicia con el análisis de Teoría de la Justicia aclarando, antes que todo, algunos conceptos relevantes previo al estudio de la "posición original", el recurso argumentativo de Rawls para la derivación de los principios de la justicia. Inicio con un análisis de los alcances y objetivos mismos del texto, tanto según Rawls como lo que al respecto podría contribuir Dewey. Es primordial comprender, por ejemplo, a qué se refiere John Rawls cuando plantea la objetividad o cualquiera de los límites de la justicia en relación a sus principios. Sin hacer los matices adecuados, podríamos caer en el error de creer que Rawls intenta descubrir verdades autoevidentes. Eso sería un error respecto a los alcances de la teoría. Siguiendo esta idea, es ilustrativo reconocer que el texto de Rawls, en su título original en inglés, lleva el título A Theory of Justice, es decir, Una Teoría de la Justicia. El hecho de que el artículo "una" sea indeterminado, implica que Rawls no considera su teoría como la única o final. La teoría que propone Rawls es una más en "competencia" por la aceptación social (lo que no deja de ser una comprensión pragmática de la argumentación; en particular cuando se refiere a las consecuencias de la adopción de los principios como argumentos para seleccionarla entre sus competidores).

La segunda sección del capítulo se centra en la idea de la justicia como el criterio de organización dentro de la sociedad. La cuestión fundamental a tratar en esta sección, aunque no la única por supuesto, es la relación que existe entre la justicia y el bien. Buena parte de tradición filosófica ha tratado la finalidad de la sociedad como la consecución del bien común. Si Rawls está en lo correcto, la 
finalidad de la sociedad no puede ser configurada en términos de un bien determinado, si queremos que sea, al mismo tiempo, justa. El problema de asumir el bien como el criterio rector de la organización social es que, de acuerdo a Rawls, corremos el riesgo de tratar injustamente a individuos que pudieran no compartir nuestra concepción del mismo. Así, si el bien no es el criterio adecuado, ¿cómo debemos organizar la sociedad?, ¿cómo opera la justicia si no está relacionada con el bien?

Como un comentario adicional es relevante aclarar que la edición que utilizo de Teoría de la Justicia es la revisada de 1990 y publicada por Harvard University Press. ${ }^{3}$ Si bien el mismo Rawls asume que los cambios son múltiples respecto de la edición original, en particular en el trato de los bienes primarios y en el desarrollo de los poderes morales de los individuos, la edición revisada mantiene la misma estructura y formula los problemas esenciales de la original de 1971.

\section{Una teoría de la justicia o Teoría de la Justicia}

Como mencioné anteriormente, el título original de la obra que analizo en este capítulo es $A$ Theory of Justice. Si cambiáramos el artículo indeterminado, por uno determinado, es decir por "la" (o, en inglés, "the"), tendríamos un significado muy distinto y, si ese fuera el espíritu de la obra, la elaboración de Rawls hubiera sido distinta. El objetivo de la teoría no es servir como una demostración infalible o definitiva (aunque la derivación de los principios por momentos aspira a esto más que a servir como un argumento de razonabilidad, como también lo hace); por el contrario, Teoría de la Justicia busca, más bien, construir argumentaciones que garanticen la plausibilidad de la teoría de diversos modos. Como dice el mismo Rawls en el prefacio a la edición revisada:

Mi esperanza es que la justicia como imparcialidad aparezca como razonable y útil, si no es que completamente convincente, a un amplio rango de opiniones políticas reflexivas $\mathrm{y}$, de este modo, exprese una parte esencial del centro común a la tradición democrática. ${ }^{4}$

Como es claro con su declaración de intenciones, Rawls tiene, incluso desde su primera gran obra, una tendencia pragmatista, aunque en el Liberalismo Político haga un giro aparentemente más pronunciado en esa dirección. En Teoría de la

\footnotetext{
3 John Rawls: A Theory of Justice (Cambridge, Harvard University Press, 1999)

${ }^{4}$ John Rawls, $A$ Theory of Justice (Cambridge, Harvard University Press, 1999), xi.
} 
Justicia Rawls analiza y evalúa algunas de las creencias fundamentales dentro de la tradición norteamericana en el contexto de la democracia liberal respecto a su operación y efectos en la vida ordinaria de los ciudadanos; esta estrategia la realiza en especial en la segunda parte del texto, llamado "Instituciones", y en buena parte de la tercera, "Fines". La razón por la que Rawls no es interpretado como un autor de carácter pragmático dentro del contexto de Teoría de la Justicia es que el pragmatismo convive con un "compañero" que tiende a ser mucho más polarizante en su recepción y, al mismo tiempo, mucho más protagonista: el kantismo de la derivación de los principios de la justicia en la posición original y el mantenimiento del ideal de autonomía. No deja de ser sorprendente para el lector que, poco después de la referencia anterior, en el prefacio a la edición revisada, encontramos, en el de la edición original, el siguiente fragmento: "La teoría resultante es en la mayor parte de naturaleza kantiana. En efecto, debo rechazar toda originalidad por las ideas que presento. Las ideas principales son clásicas y bien conocidas." ${ }^{5}$

¿Qué intenta decirnos Rawls con lo anterior?, ¿qué partes de la teoría son las kantianas?, ¿debemos asumir que los conceptos, como el ideal de autonomía o libertad, son kantianos en su contenido?, ¿también debemos considerar que su derivación tiene la misma caracterización veritativa que, por ejemplo, el imperativo categórico en Kant? En Teoría de la Justicia, Rawls aboga por su concepción haciendo uso de dos modos distintos de argumentar. Como menciona Onora Nell, ${ }^{6}$ Rawls intenta, por un lado, desarrollar argumentos desde la posición original (una especie de reformulación del "estado de naturaleza" del contractualismo clásico, que considero como un esfuerzo por aplicar, como muestro más adelante en este capítulo, categorías kantianas en la discusión) y, por otro, con el uso del equilibrio reflexivo, que explico más adelante, que correspondería a un mecanismo de argumentación fundamentado en el análisis de la adecuación de nuestros juicios considerados (lo que se corresponde más como una estrategia de carácter pragmático que kantiana).

Existen ciertos conceptos fundamentales, sin embargo, que nos permiten comprender con claridad en qué sentido Rawls es un autor kantiano, al menos en Teoría de la Justicia, y hasta qué punto podríamos decir que es un pensador pragmático. Estos conceptos, que analizo a continuación, son el de objetividad y los límites de la justicia y el equilibrio reflexivo. Antes de hacer esto, es importante afirmar la utilidad de hacer este tipo de generalizaciones, como es la afirmación de

${ }^{5}$ Ibid. xviii.

${ }^{6}$ Cfr. Onora Nell, "A Theory of Justice”, Journal of Economic Issues vol. 7 no. 4 (1973): 665. 
que el pensamiento rawlsiano es de carácter kantiano o pragmatista, es grande porque nos permite generar expectativas sobre algunas de las consecuencias del pensamiento de un autor, reconociendo por supuesto que en ningún sentido son determinantes en la valoración final de su pensamiento. Por ejemplo, cuando decimos que un pensador que es kantiano intentamos resaltar el papel predominante de la razón y de la deontología en su comprensión de la moralidad. Por otro lado, cuando nos referimos un pensador como pragmatista, queremos resaltar su falsacionismo y contextualismo. Suponiendo estas etiquetas, a continuación analizo algunos conceptos fundamentales en Teoría de la Justicia que me permiten aclarar en cuál de estas categorías es más fácil clasificar el pensamiento de Rawls. Esto sólo en la medida en que hacerlo favorezca una lectura más productiva pues, un autor tan relevante y versátil como Rawls, debe ser estudiado, en la medida de lo posible, bajo su propia categoría.

\section{Objetividad}

Como vimos en el capítulo anterior, el pragmatismo se caracteriza en parte por su férreo antifundamentalismo y, por decirlo de algún modo, por un particularismo normativo. Dewey deduce estas condiciones cognitivas de una teoría que niega que la categoría de verdad se refiera a una cualidad de las aseveraciones, más allá de calificarlas como las más aceptables dadas ciertas condiciones, y que implica de igual modo a términos como justo, bueno o bello de acuerdo a sus propios parámetros. Esta actitud conduce a una desconfianza en el desarrollo de principios de acción que intentan ser permanentes en el tiempo. Pudimos ver cómo es que Dewey desconfía de la utilidad de un texto constitucional por la inaplicabilidad que tendría en un contexto histórico cambiante y promueve una apertura al cambio de leyes, principios y ordenamientos continuo con el paso del tiempo. ${ }^{7}$

Teniendo esta comprensión falibilista del pragmatismo de Dewey, parecería que la idea de que detrás de Teoría de la Justicia hay un pensador de carácter

\footnotetext{
${ }^{7}$ Vale la pena recordar que en los Estados Unidos existe una amplia tradición jurídica que aboga por una especie de originalismo constitucional. Este plantea la importancia de analizar la intención de los fundadores de la república (los Founding Fathers) al plantear el texto constitucional como si, independientemente del momento histórico en que elaboraron la constitución, sus intenciones fueran igualmente válidas hoy que en ese momento. Si bien dicho originalismo puede ser analizado en muy diversas vertientes, queda claro que dentro de él existe un conservadurismo del texto constitucional que se enfrenta a teorías interpretativas de las normas que entienden el texto constitucional como uno "vivo" que debe ajustarse y cambiar conforme los tiempos lo demanden (Cfr. Thomas Colby y Peterr Smith, "Living Originalism", Duke Law Journal, vol. 59 no. 2 )2009): 262-263.)
} 
pragmatista, en tanto Rawls busca fundar su teoría en la universalidad, es un sinsentido; mostraré cómo esto no es así. Al analizar con detenimiento la idea de la teoría presentada como una más que compite con otras propuestas como principios o esquemas organizadores, más la comprensión de objetividad rawlsiana, que abordo inmediatamente, nos daremos cuenta que pensar al "primer Rawls" (es decir al de Teoría de la Justicia) en términos pragmáticos no es del todo descabellado, aunque es importante hacerlo con cautela.

El concepto de objetividad en el pragmatismo deweyano es complicado. Podemos entenderlo, como expuse en el primer capítulo, en relación al conocimiento con la realidad objetiva, desconocida en un sentido realistametafísico, en tanto que una teoría o esquema mental actúa sobre la realidad; en tanto sea capaz de resolver problemas, decimos que la realidad objetiva nos permite evaluar nuestro conocimiento. Así, asumimos que la objetividad sirve como criterio de evaluación de una propuesta. En este sentido es en el que Dewey asume el conocimiento objetivo.

La objetividad de acuerdo a Rawls, sin embargo, nos lleva a considerar el asunto desde una perspectiva distinta, aunque compatible con un cierto pragmatismo. Como veremos a detalle más adelante, una condición básica para la derivación de los principios es la aplicación de lo que Rawls llama el velo de la ignorancia. Este velo constituye, dentro de la representación que es la posición original, los límites al conocimiento que tienen cada uno de los sujetos hipotéticos que deciden sobre los principios de la justicia que regirán la estructura básica de la sociedad.

Rawls es consciente de que el acuerdo sobre conclusiones a problemas particulares es un objetivo complicado de obtener si nos planteemos el problema desde perspectivas radicalmente distintas $\mathrm{y}$, en ciertos casos, irreconciliables. Partamos de la definición clásica de justicia acuñada por Ulpiano ("Justicia es la constante y perpetua voluntad de dar a cada quien lo que le corresponde"); desde una perspectiva pragmatista nos encontramos con que la aplicación del concepto a la práctica es sumamente compleja. La definición de lo que a cada quien le corresponde está irremediablemente vinculada con contingencias históricas, políticas, sociales, económicas, psicológicas, naturales, etc. ¿Deberíamos renunciar a la justicia si definir lo que a cada quien le corresponde por sí mismo, sin recursos adicionales de medición o comparación, es imposible?

En las sociedades actuales el problema se exacerba más allá de lo que Dewey consideraba, recordemos como él pensaba que la aplicación del concepto de 
justicia está vinculada al conocimiento de las circunstancias concretas, cuando asumía la industrialización como uno de los factores más importantes a considerar en el contenido de lo que es la justicia. Rawls agudiza el problema con un factor adicional, que no está tematizado con claridad en Dewey, que es el pluralismo y la multiplicidad de concepciones del bien y de lo justo en la sociedad. No sólo es un problema definir lo justo con el cambio de las relaciones productivas, como es una preocupación central en Dewey, es de igual modo un problema definir el contenido de lo justo cuando nos damos cuenta de que nuestras consideraciones están vinculadas estrechamente a nuestra posición social, predisposiciones psicológicas y culturales o nuestras dotes naturales.

Para plantear el problema de la justicia, de modo que sirva a las condiciones del pluralismo contemporáneo, diría Rawls, necesitamos encontrar criterios compartidos de juicio. Esos criterios compartidos, que nos alejan del subjetivismo aislacionista (que no del subjetivismo absolutamente), son los que garantizan la objetividad y son condición de posibilidad de la justicia:

Una consecuencia de querer ser objetivo, o intentar enmarcar nuestras concepciones morales y juicios desde un punto de vista compartido, es que hacemos más probable el que podamos alcanzar acuerdos. En efecto, todo lo demás constante, la descripción preferida de la situación inicial es aquella que introduce la mayor convergencia de opiniones. Es en parte por esta razón que aceptamos las limitantes de la posición desde una perspectiva común, dado que no podemos razonablemente esperar que nuestras perspectivas se alineen cuando están siendo afectadas por las contingencias de nuestras distintas circunstancias. ${ }^{8}$

Rawls está muy consciente, contrario a como sucedería con algunas concepciones realistas por ejemplo, de que para poder llegar a acuerdos entre personas con ideas de lo que es el bien distintas no es suficiente suponer que nuestra demostración, por sí misma, es capaz de convencer a cualquier individuo independientemente de la perspectiva. La posición original responde en parte a la necesidad de hacer de la justicia un concepto aplicable para diversas personas con diversas perspectivas; esto sólo puede suceder si hacemos homogéneas las condiciones de razonamiento para las partes involucradas. Si Rawls no es capaz de elaborar una circunstancia compartida donde los acuerdos puedan surgir entre personas (reales o hipotéticas), es decir en donde sea posible estar definir con claridad cuáles son los elementos relevantes para tomar en cuenta en la deliberación, entonces tendría que confiar en ser capaz de desarrollar un argumento que cambie la opinión (convenza o de

\footnotetext{
${ }^{8}$ Rawls, $A$ Theory of Justice. 78.
} 
cualquier otro modo genere un acuerdo) de personas inmersas en su subjetividad absoluta; esto me es prácticamente imposible.

Este criterio de objetividad es, desde una lectura pragmatista, una alternativa para hacer que el concepto de justicia tenga sentido, de un modo sustantivo y aplicable, para sociedades plurales donde distintos individuos tienen ideas del bien radicalmente distintas. En este sentido, si Rawls es capaz de lograr su objetivo (afirmar objetivamente una concepción de la justicia), justifica un concepto de justicia que, de no existir, nos obliga a confiar simplemente en la buena voluntad de los ciudadanos, o quizá en la fuerza arbitraria del Estado, para mantener el orden y la funcionalidad dentro de la sociedad. ${ }^{9}$

El tema es de fondo y afecta a la teoría en su totalidad. Esto es claro cuando lo relacionamos con un concepto fundamental en la obra como es el caso de la estabilidad de la concepción para ordenar una sociedad. Ese criterio es, asumiendo que es uno que permite justificar la concepción de la justicia que debería ordenar a la sociedad, pragmático. Una condición para elegir la teoría rectora de la vida en sociedad está en su capacidad de ser estable a través del tiempo, de ofrecer el resultado esperado por la mayor cantidad de tiempo posible. Sobre la estabilidad, Rawls afirma que ésta es la capacidad de un sistema de permanecer en equilibrio una vez que fuerzas ajenas afectan su funcionalidad. ${ }^{10}$ Una sociedad es más estable en la medida en que el funcionamiento interno esté en equilibrio; por tanto, llega a un estado interno tal que, sin influenza de fuerzas externas, continuaría funcionando de igual modo mientras no sea abatido por fuerzas externas. Para poner un ejemplo muy simple, un motor mecánico es un sistema que opera en equilibrio para controlar una fuerza y desencadenar un movimiento, el motor es estable siempre que pueda seguir operando del mismo modo (tendríamos que considerar al desgaste de las piezas fruto de la fricción, por ejemplo, como una fuerza externa que afecta el equilibrio). La justicia sirve para mantener el funcionamiento ordenado de la sociedad sirviendo como límite de las acciones aceptables dentro del sistema social. $\mathrm{Si}$ no es objetiva (en un sentido de compartida), no es claro por qué sería respetada más allá de que fuera forzada, lo que levantaría dudas de su legitimidad, en especial si fueran pocos quienes aceptaran dicha concepción.

Por ejemplo, la determinación de la distribución adecuada de bienes, que puede implicar una limitante en el ejercicio de derechos u obtención de riqueza

\footnotetext{
${ }^{9}$ Cfr. Idem.

${ }^{10}$ Cfr. Ibid. 400.
} 
material, requiere de un criterio compartido por la comunidad. Si no existe dicho criterio, es decir un concepto funcional de justicia, entonces confiamos, como menciona Rawls, en la buena voluntad de los integrantes de la comunidad para garantizar la estabilidad del funcionamiento social. Esto hace de la argumentación acerca de la objetividad del concepto de justicia una prioridad, a la vez de ser un criterio fundamentalmente pragmático.

Aun cuando seamos capaces de dar una lectura pragmática del criterio de objetividad rawlsiano, como considero que debe ser hecho, se mantiene la cuestión del kantismo en la teoría, que se refleja, en uno de sus aspectos, en el criterio de universalidad. A continuación profundizo en este tema para comprender cuáles son algunas de las características con las que debe contar la concepción de la justicia que ordene la sociedad, además de la objetividad pragmática, según Rawls. Algunos de estas, como se verá, son claramente requisitos planteados desde el pensamiento kantiano de Rawls.

\section{Los límites de la justicia}

En Teoría de la Justicia, Rawls analiza el concepto de universalidad en dos lugares principalmente. Primero en la sección 23, donde analiza las limitantes formales del concepto de lo justo. El segundo es, al menos de modo indirecto, cuando realiza, en la sección 40, la interpretación kantiana de su concepción de la justicia, la justicia como imparcialidad.

En la sección 23 Rawls enumera cinco limitantes para las alternativas a escoger en la posición original. Esta es una especie de lista de características con las que considera debe contar cualquier teoría candidata a informar los principios de organización y de justicia en la comunidad. La lista es: (i) los principios deben ser generales, (ii) universales en su aplicación, (iii) públicamente reconocidos, (iv) deben jerarquizar los distintos reclamos en conflicto y (v) deben ser finales, es decir que no puede existir un estándar más alto para argumentar.

La generalidad, como límite de la justicia, implica que, en su formulación, la teoría o principios de la justicia que deben ordenar la comunidad no deben postularse con nombres propios, es decir referirse a individuos o grupos particulares. ${ }^{11}$ Esta característica tiende a garantizar la imparcialidad. Si

\footnotetext{
${ }^{11}$ Cfr. Ibid. 113
} 
estuviéramos en una posición hipotética de elaborar los principios que regirán nuestra sociedad, como la que Rawls desarrolla en la posición original, sería claramente parcial escoger unos que trataran de modo desigual a seres por definición iguales. En este límite hay un supuesto claro de la igualdad moral de las personas, independientemente de cualquier característica contingente al hecho mismo de ser persona. Si bien este supuesto es típico dentro del pensamiento liberal, dadas las condiciones que impone Rawls en la posición original (de la que hablo más adelante a detalle) no hay muchas razones para negar esta igualdad entre seres humanos que cumplan con un mínimo de poderes morales (la capacidad de poseer una idea del bien y sostener una concepción de la justicia). Negar la generalidad equivale a negar la imparcialidad de la justicia y la igualdad moral entre las personas, que por supuesto no supone una especie de homogeneidad absoluta.

Supongamos que, si estuviéramos en la situación de poder elegir una concepción de la justicia, y alguien postulara que todas las personas que profesan una religión determinada merecen una mayor tolerancia en el ejercicio de su culto sin una razón que pueda ser formulada de modo general, tendríamos que decir que la elección de los principios es parcial en beneficio de un grupo particular. Dicho principio realizaría una excepción imposible de justificar si aceptamos la igualdad moral de las personas y, por tanto, podemos suponer que no sería elegido en una circunstancia "prepolítica" (como el contractualismo suele usar como mecanismo de representación) por parte de individuos que profesaran un culto, o que no profesaran culto alguno para el caso, distinto al del beneficiado (esto sin suponer que podría haber individuos dentro del grupo beneficiado que valoraran lo suficiente la imparcialidad como para rechazar un principio que les garantiza ventajas inmerecidas). La generalidad, por tanto, tiene la función de garantizar la imparcialidad en la medida en que reconoce un grado de igualdad entre los individuos pues las reglas aplican a todos por igual.

Una vez presentada la generalidad, podemos continuar con el siguiente límite de la justicia, la universalidad:

(...) los principios deben ser universales en su aplicación. Deben mantenerse para todas las personas en virtud de ser seres morales. Por tanto asumo que cada individuo puede entender estos principios y utilizarlos en sus deliberaciones. Esto impone un límite en qué tan complejos pueden ser y en el número de distinciones que pueden hacer. Lo que es más, un principio debe de ser rechazado si su aplicación conlleva acciones contradictorias, o que simplemente muestren su inaplicabilidad, si todos los individuos actúan en función de él. Del mismo modo, si 
un principio es razonable de seguir sólo cuando los demás actúan en función de uno distintos es, de igual modo, inadmisible. Los principios deben de ser elegidos en función de las consecuencias de que todos actúan en conformidad con ellos.

La definición de universalidad de Rawls muestra su vena deontológica pues implica que la búsqueda de principios que normen la sociedad esté al margen de circunstancias contingentes. Creo que es posible confundir los límites de generalidad y el de universalidad, sin embargo tienen consecuencias muy distintas: el de generalidad no niega que se elaboren principios para una sociedad concreta y que tengan límites en su aplicación (su cualidad de perpetuidad, como la enuncia Rawls, ${ }^{12}$ se refiere a la aplicación de una sociedad en particular por tiempo indefinido, no para cualquier sociedad necesariamente), el de universalidad sí. El límite de universalidad es parte de la herencia kantiana de Rawls ya que condiciona a que cualquier teoría de la justicia que busque ser elegida en la situación hipotética contractual a estar fundamentada en la naturaleza noumenal de los seres humanos. En la sección 40, al hacer una interpretación kantiana de su teoría de la justicia, Rawls declara sobre sus principios, elegidos en parte por cumplir en mayor medida los límites impuestos a las consideraciones de lo justo, lo siguiente:

Las partes en tanto seres noumenales -como veremos para Rawls las partes manifiestan esta condición dadas las condiciones impuestas por el velo de la ignorancia, que limita su conocimiento y motivación hasta alcanzar el mayor grado de imparcialidad posible para la articulación de los principios- tienen completa libertad de escoger los principios que prefieran; pero también tienen el deseo de expresar su naturaleza como seres racionales y miembros iguales del reino de lo inteligible precisamente con esta libertad de elegir $(\ldots)^{13}$

Los principios que se elijan son análogos al imperativo categórico dado que se aplican a las personas en tanto los consideramos "esencialmente" libres e iguales. En palabras de Rawls, "la posición original puede ser vista, por tanto, como una interpretación procedimental de la concepción de autonomía de Kant y del imperativo categórico dentro del marco conceptual de una teoría empírica." ${ }^{14}$

La aplicación de la universalidad en la obra de Rawls implica una limitante clara para quien busque hacer una lectura eminentemente pragmática de su pensamiento. Como veremos en la tercera parte, Rawls, en el Liberalismo Político, se distancia de esta línea de argumentación, en particular aquella que considere que la justificación de los principios proviene de la realidad noumenal de los individuos.

\footnotetext{
${ }^{12}$ Cfr. Ibid. 114

${ }^{13}$ Ibid. 225

${ }^{14}$ Ibid. 226
} 
Es importante recalcar que en Teoría de la Justicia, Rawls, aun cuando suponga que el contrato en una situación hipotética tiene una naturaleza meramente representativa, afirma que las conclusiones a las que llega tienen la justificación suficiente para hacerlas contar como los principios que ordenarán la comunidad en su totalidad (lo que se denomina estructura básica). Es decir, supone que las condiciones de la posición original permiten llegar a conclusiones que están justificadas en el nivel de argumentación noumenal. De este modo, Rawls es parte de una tradición contractualista en la que el contrato, en cualquiera de sus formulaciones razonables, no supone que cada individuo otorgue su consentimiento en algún momento determinado de su vida, sino que obtiene su fuerza argumentativa en función de su capacidad de justificarse como racional o razonable; si el consentimiento de cada ciudadano fuera una condición de aceptabilidad el contractualismo sería inservible. Como expliqué en el capítulo anterior, al analizar la crítica de Dewey al contractualismo, es un error considerar que existe un ejercicio actual de la voluntad de cada individuo para aceptar o rechazar las condiciones fundacionales de la sociedad. Lo que Rawls debe mostrar, si quiere que su empresa surta efecto, es que las condiciones de su contrato son no sólo razonables sino que, en caso de que un individuo estuviera en la situación (asumiendo que las condiciones de la posición original son realmente aceptables), elegiría esos mismos principios. De esto se deriva su obligatoriedad. Como veremos en la tercera sección de este capítulo Rawls busca desarrollar este argumento a partir de la tradición kantiana y, por momentos, negando la epistemología pragmática que acepta al exponer el concepto de objetividad.

Sobre el resto de los límites para cualquier candidato en la situación hipotética para escoger principios ordenadores de la sociedad, falta comentar respecto de otros tres. Adicionalmente a la generalidad y la universalidad, Rawls enumera la publicidad, la capacidad de jerarquizar reclamos en conflicto y su carácter superior o final. Sobre el límite de publicidad podríamos decir que es un criterio fundamental dentro de la lógica del Estado constitucional. En la medida en que la operación de un Estado está limitado por una constitución, las leyes, con sus derechos y responsabilidades, deben ser del conocimiento público. Como menciona Miguel Carbonell al respecto:

El constitucionalismo como filosofía política aspira en lo fundamental a una sola cosa: controlar el poder con el fin de preservar la libertad, si recurrimos a la conocida formulación de Montesquieu. Para ello es necesario que cada Estado se dote de una regulación básica de carácter unitario: la Constitución escrita. El tener un texto supremo de carácter escrito es una novedad histórica que aporta el siglo 
XVIII y que no existía durante el feudalismo, que se regía más bien por normas consuetudinarias. ${ }^{15}$

La publicidad es necesaria desde el punto de vista del Estado moderno por la importancia del control del ejercicio del poder público. Desde el punto de vista contractual de Rawls, la publicidad de la concepción de la justicia no puede estar exenta de este límite ya que dicha concepción sirve para controlar, de igual modo, el ejercicio del poder y, más aún, la formación de la constitución y la estructura básica misma. Si asumiéramos que en la situación original se seleccionan efectivamente los principios, sería razonable, considera Rawls, desear que las partes conozcan cuáles son estos para que puedan servir objetivamente como criterios y guías de justicia. ${ }^{16}$

El cuarto límite es en el que Rawls asume que cualquier candidata a ser la concepción de justicia de la sociedad debe ser capaz de jerarquizar reclamos. Podríamos decir que, asumiendo un punto de vista pragmatista, lo que esta condición hace es procurar desarrollar un estándar de medición, que podríamos llamar artificial. El problema de la medición y comparación de reclamos es fundamental dentro de una sociedad en donde existen conflictos por reclamos contrarios entre individuos merecedores de satisfacción, es este uno de los objetivos de poseer una concepción de la justicia. Si nuestra concepción de justicia no es capaz de ordenar reclamos, reconociendo que hay unos más relevantes de atender por algún criterio determinado, entonces nuestra concepción es inservible. Lo que Rawls procura hacer, y por lo que es fuertemente criticado incluso dentro de la misma tradición liberal, fue proponer que en la justicia como imparcialidad los reclamos de libertad son siempre prioritarios frente a reclamos de otros bienes. El problema de esta limitante, cuando la entendemos como compañera de la de universalidad, es que Rawls se deshace de un plumazo de una buena cantidad de concepciones de la justicia (entre ellas ciertas comprensiones del aristotelismo centrado en la phronesis y, por supuesto, de propuestas pragmatistas como la de Dewey) que plantean la importancia de las condiciones y circunstancias concretas para determinar prioridades y jerarquías.

Si la concepción de la justicia permite jerarquizar los reclamos de los individuos, respetando los límites de generalidad y universalidad que propone Rawls, esto puede ocurrir por dos posibilidades: por un lado porque la concepción prevé todos los posibles reclamos que han sido hechos o serán hechos en un futuro

\footnotetext{
${ }_{15}$ Miguel Carbonell, Una historia de los derechos fundamentales (México: Porrúa 2010), 35

${ }^{16}$ Cfr. Rawls, A Theory of Justice. 115
} 
de modo justo o, por otro lado, porque la concepción informa los reclamos a futuro de modo que los ciudadanos no puedan legítimamente imaginar reclamos que no estén en consonancia con la concepción (a un modo de control político, mental o coercitivo, de los deseos y reclamos de los ciudadanos), lo que atenta contra la autonomía de los individuos. La segunda opción la considero indeseable para cualquier concepción de la justicia, pues estaría poniendo un límite no justificado, pues aún no sabemos cómo se podría manifestar, a la experiencia legítima de la libertad de los individuos. La primera opción es implausible por dos razones: por un lado por la naturaleza falible del conocimiento que plantea el pragmatismo que considero fundamentalmente correcta; por otro lado porque eso significaría que la política, en tanto es justa, es meramente administración, lo que es contrario a nuestra experiencia histórica. En buena medida la comprensión del valor de los reclamos e intereses de los individuos y los grupos, en relación con una jerarquía de valores políticos, ha cambiado durante el tiempo de modo importante; decimos que ha cambiado, no que estaba mal o que era, de hecho, injusta (aun cuando pueda haber ciertas instituciones o acciones que hoy en día consideramos tan aberrantes como para pensar que fueron injustas cuando se llevaron a cabo igualmente que lo son hoy en día, como sucede con la esclavitud, no todos los ejemplos históricos tienen esta naturaleza).

Si la concepción de la justicia de Rawls cumple con los límites que él mismo propone, y se demuestra como la que sería elegida en la posición original, tendríamos que aceptar que los valores e intereses no pueden ser juzgados de modo distinto independientemente de las circunstancias históricas (recordemos los límites de generalidad y universalidad). Esto supone que la acción política de los individuos, cuando se encuentran en una sociedad ordenada por una concepción de la justicia adecuada, según los límites de Rawls, se corresponde con una mera tarea de administración de justicia. Los límites de la justicia de Rawls limitan la experiencia política de un modo que históricamente no ha sido: "La política es en ocasiones (al menos en ocasiones) sobre encontrar cómo cambiar las reglas de juego, y en cualquier caso, las reglas sin poder -el poder de alguien que pueden forzarlasestán vacías. (...) ¿es toda la política administración? ¿Puede existir administración sin poder?"17

Las implicaciones anteriores son graves en la medida en que hacen de la propuesta de concepción de la justicia rawlsiana una excepción inexplicable en la historia de la humanidad (en la medida en que funciona como un estándar exento

\footnotetext{
${ }^{17}$ Raymond Geuss. Philosophy and Real Politics (Princeton: Princeton University Press, 2008), 93.
} 
del devenir histórico). Por ejemplo, asumamos que, como afirma Rawls (y veremos más adelante la justificación), las libertades básicas de los individuos son anteriores a cualquier reclamo centrado en un bien. Asumiendo los límites de la justicia en los términos que plantea Rawls, el análisis sobre el origen y justificación de algunos (probablemente todos) de los derechos que existen en la sociedad conduce a argumentos alejados de los hechos históricos, lo que es, por decir lo menos, polémico. Pensemos, por ejemplo en el salario mínimo como un derecho de los ciudadanos a no ser explotados. Las justificaciones sobre la necesidad o rechazo al salario mínimo son complejas y supone posiciones polarizantes, que van desde la negación de su utilidad por economistas liberistas como Milton Friedman, a propuestas que resaltan la importancia del salario mínimo como herramienta necesaria para el desarrollo de los individuos y, a largo plazo, de la economía en general, como lo defiende Joseph Stiglitz en la actualidad. No hay duda que Rawls no es un pensador liberista, después de todo nos dice que:

En el sistema de libertad natural la distribución inicial está regulada por los acuerdos implícitos en la concepción de carreras abiertas al talento. Estos acuerdos presuponen un trasfondo de igual libertad (como se especifica por el primer principio) y una economía de mercado libre. Requiere de una igualdad de oportunidades formal en tanto que todos tengan al menos los mismos derechos legales para accesar a las posiciones sociales más aventajadas. Pero dado que no existe un esfuerzo por preservar la igualdad, o similarmente, las condiciones sociales, excepto en la medida en que es necesario preservar las instituciones necesarias, la distribución inicial bienes por un periodo de tiempo determinado está influenciada fuertemente por las contingencias naturales y sociales (...).

La interpretación liberal, como yo me referiré a ella, intenta corregir esto al añadir a los requisitos de carreras abiertas a los talentos la condición adicional de la igualdad de oportunidades. ${ }^{18}$

Según Rawls, por tanto, el liberismo presenta dos problemas: (i) permite la distribución inicial injusta de bienes en función criterios moralmente irrelevantes (por ejemplo la posición social en la que nacimos o los dones naturales que no nos ganamos) y (ii) perpetúa la injusticia en la distribución por un periodo de tiempo más o menos prolongado que puede afectar a grandes grupos de individuos a través de las generaciones.

Rawls, en Teoría de la Justicia, exalta la necesidad de un Estado que genere condiciones de igualdad a través de distintos medios (uno de ellos, por ejemplo, a través de una carga fiscal a los grupos más beneficiados que garanticen las

\footnotetext{
${ }^{18}$ Rawls, $A$ Theory of Justice. 62-63
} 
condiciones mínimas para los peor situados), sin embargo impone la condición de la libertad, como se enmarcan de acuerdo a las libertades básicas, ${ }^{19}$ como anterior, lexicográficamente apunta él mismo, frente a cualquier otro reclamo de distribución. Nunca es justificable limitar las libertades básicas de un individuo para garantizar una mayor o mejor distribución de otro bien, piensa. Ahora bien, aunque podríamos pensar que la consecuencia de dicha anterioridad es la inaceptabilidad de limitar la libertad del empleador a pagar la cantidad que prefiera por un trabajo dado, al tiempo que es inaceptable limitar la libertad del trabajador a laborar por la cantidad que él considere aceptable, esto no sería correcto. Como menciona Samuel Freeman al hablar de la postura de Rawls en este tema: "La libertad real no es un simple formalismo; más bien requiere que las personas tengan poderes, oportunidades y recursos que les permitan actuar con libertad." ${ }^{20}$ De fondo lo que supone Rawls es que las libertades económicas, para que pudieran existir en un modo que complaciera a los liberistas, sería necesario que existieran en una sociedad que tuviera satisfechas ciertas condiciones de justicia previas y, por lo tanto, el salario mínimo sería innecesario en la medida en que se cumplirían los requisitos de competencia perfecta que suponen (bajo el supuesto, que no sostiene Rawls, que dicho estado se conservara en el tiempo). ${ }^{21}$

Dicho esto, es posible afirmar que existen argumentos en favor del salario mínimo que tienden a estar en línea con algunas de las preocupaciones de Rawls respecto del liberismo; es decir la preocupación de permitir una distribución injusta de los recursos. Estos argumentos también tienden a vincularse al buen funcionamiento económico en sí mismo, pues la tendencia a la desigualdad en un mercado imperfecto (donde no existen condiciones de competencia efectiva por el desnivel de los competidores, así como la asimetría de información que dichos desniveles generan) tiende a generar ineficiencia, con el surgimiento de "jugadores" monopólicos o preponderantes por ejemplo. ${ }^{22}$

Si bien es cierto que existen múltiples medios para garantizar condiciones de igualdad de oportunidades en el mercado, el salario mínimo es un mecanismo eficiente y que, al mismo tiempo, garantiza limitar problemas de justicia adicionales, como la llamada esclavitud salarial, en la cual los trabajadores en circunstancias muy precarias aceptan libremente trabajar en condiciones que se pensarían como inaceptables y que violan, en muchos casos, los que se consideran

\footnotetext{
${ }^{19}$ Ibid. 53

${ }^{20}$ Samuel Freeman, Rawls (Routlege: Londres, 2007), 59.

${ }^{21} \mathrm{Cfr}$. Rawls, A Theory of Justice. 269

22 Cfr. Joseph Stiglitz, El precio de la desigualdad, trad. Alejandro Pradera (México: Taurus 2012), 306
} 
mínimos razonables de subsistencia. El asumir que una concepción de la justicia debe de servir para jerarquizar reclamos, al tiempo que sus criterios son universales, al modo que pretende Rawls, nos obliga a negar la importancia radical de las circunstancias en la definición del contenido de lo justo que, como he dicho ya, es una premisa pragmática fundamental. De alguna manera la justificación desde el pensamiento de Rawls del salario mínimo, por ejemplo, proviene del reconocimiento de la preeminencia de las libertades básicas, entre ellas las políticas, frente a las libertades económicas; sin embargo, no queda de ningún modo claro cómo sería posible derivar esa anterioridad al margen de las condiciones históricas concretas. La gran preocupación de Dewey por la existencia de principios e instituciones sociales que busquen perpetuarse a través de las circunstancias cambiantes es la prerrogativa de Rawls; a este respecto son incompatibles. El tema del salario mínimo es uno que nos muestra cómo, a través del uso del poder político (de los trabajadores en este caso) fue posible comprender la importancia de los intereses de un grupo aun cuando en cierto momento histórico no fuera tomados en cuenta. La existencia de dicho salario es el resultado del conflicto de interés y negociaciones que suponen más la lucha por el ejercicio del poder por ciertos intereses que la distribución justa de un Estado administrador funcionando en base a un principio derivado de la razón. Aceptar los límites de la justicia, en especial los de orden kantiano, nos conducen a afirmar que las sociedades en donde existiera la explotación económica, y no hubiera un salario mínimo u otra alternativa para contrarrestarla, son intrínsecamente injustas, no injustas de acuerdo a nuestro criterio o estándar. ¿Qué significa ser intrínsecamente injusto? Como expuse en el primer capítulo, la teoría del conocimiento pragmatista nos conduce a negar cualidades intrínsecas a los hechos, como injusto o verdadero, al margen de una perspectiva y circunstancias particulares que nos permitan contextualizar la realidad.

El último límite a las concepciones de la justicia asume que nuestra concepción de la justicia debe de ser final. Este límite tiene implicaciones epistémicas y culturales y, de nuevo, ejemplifica el kantismo en el pensamiento de Rawls. Sobre la concepción de la justicia que se elegirá en la situación hipotética Rawls afirma que:

Estos -los principios que se elijan- están por encima de las demandas de la ley y la costumbre y de las normas sociales en general. Debemos desarrollar y respetar las instituciones sociales como los principios de la justicia nos dirijan. Las conclusiones de estos principios están por encima, de igual modo, de las consideraciones de la prudencia y el interés propio. Esto no significa que estos principios insistan en el auto sacrificio; pues al plantear su concepción de lo justo las partes toman sus 
intereses en consideración del mejor modo posible. Las exigencias de la prudencia personal ya están tomadas en cuenta con su peso apropiado dentro el sistema total de principios. El esquema es final en tanto que el desarrollo del razonamiento práctico que define ha alcanzado sus conclusiones, la cuestión está definida. Los reclamos de los acuerdos sociales existentes y del interés propio han sido debidamente reconocidos. No podemos al final tomarlos en cuenta de nuevo porque no nos gusta el resultado. ${ }^{23}$

Rawls asume que la concepción de la justicia es el último criterio de apelación en la sociedad. Es probable que esta idea se derive de los límites de objetividad y universalidad en tanto que la concepción de justicia, y los principios que ella enuncie, son los criterios compartidos (objetivos) y aplicables a todos por igual (universales). ¿Por qué asumo que este límite es particularmente kantiano? El supuesto en este límite es que, una vez asumiendo la universalidad, la determinación de lo correcto o incorrecto (justo o injusto) no puede estar limitado, en ningún caso, a las contingencias temporales. El criterio último es aquel al que hemos llegado a través del uso de la razón postulando seres noumenales, no empíricos.

Encuentro controversial asumir que es razonable que individuos empíricos, con una visión del bien particular y una formación cultural determinada con todo lo que eso implica respecto al desarrollo de sus alianzas, elegirán los principios de la justicia derivados frente a una comprensión completa la realidad, en los casos en que dichos principios y juicios se contrapongan a ésta. Esta expectativa es francamente poco razonable por parte de Rawls. Supongamos, de nuevo, que la libertad individual es anterior a cualquier otra consideración de justicia. Adicionalmente aceptemos, siguiendo a Rawls, que reconocemos la "personalidad" de los individuos en la posesión de las facultades morales (la capacidad de tener una idea del bien y de desarrollar una concepción de la justicia). ${ }^{24}$ Dados esos supuestos, podemos afirmar con sencillez que la idea de que un cigoto es persona, y por tanto sujeto y objeto de la concepción de justicia derivada en una situación hipotética, es insostenible y no existe algo así como un atentado contra la vida humana en el caso de conducir un aborto (o en el caso de la fertilización in vitro con la pérdida de óvulos fecundados como se espera en el procedimiento). Dado este razonamiento básico, ¿es correcto suponer que un grupo religioso que reconozca la vida humana a partir de la fecundación (porque piensen que existe algo así como el alma y que esta es la que da la "personalidad"

\footnotetext{
${ }^{23}$ Rawls, $A$ Theory of Justice. 116-117

${ }^{24}$ Cfr. Ibid. 17
} 
y se encuentra en el óvulo recién fecundado por ejemplo) acepte como justa una legislación que permita el aborto (o la fertilización in vitro para el caso)?

Pienso que es razonable suponer, como lo hace el mismo Rawls, que esos grupos pueden tolerar, aunque en ocasiones no lo hagan pues recordemos que en Estados Unidos han existido atentados violentos contra clínicas donde se practican abortos legales por ejemplo, ${ }^{25}$ de mejor o peor manera la existencia de normas o instituciones injustas independientemente de qué tanto se apeguen a la concepción de justicia dominante. Si suponemos que debemos desarrollar una concepción de la justicia que debe ser el último criterio de argumentación social, estamos comprendiendo mal, o al menos de modo incompleto, las motivaciones reales de los individuos empíricos al definir los temas de justicia. Cuando Rawls trata el tema de la tolerancia, en particular respecto de los grupos intolerantes, supone que los límites de la tolerancia están enmarcados en el mantenimiento de la constitución justa; debemos tolerar al intolerante cuando su intolerancia no ponga en riesgo la estabilidad de la constitución y de la concepción de la justicia reconocida en la situación hipotética. ${ }^{26} \mathrm{El}$ problema de la tolerancia y la intolerancia es relevante respecto de los límites de la justicia que hemos estado analizando en referencia a la finalidad. Teoría de la Justicia es un texto que parece por momentos no tomar en serio el pluralismo de concepciones del bien en la medida en que tiende a menospreciar la importancia de la idea de bien como el elemento que orienta la acción humana. De otro modo, la prioridad de lo justo sobre lo bueno, es decir la consideración que la primera virtud social es la justicia y que es el recurso final de apelación, hace dos suposiciones muy importantes: (i) considera que las distintas concepciones del bien pueden convivir bajo una concepción de justicia que le dé cabida a todas y (ii) en caso de que los individuos encuentren que su idea del bien los lleva a un juicio contrario a las consideraciones de la justicia, da prioridad a la segunda.

Sobre el primer supuesto hablaré al tratar el tema de la posición original y los principios de la justicia a fondo, sin embargo vale dejar planteado uno de los problemas fundamentales. Asumir que es posible plantear una confluencia de las distintas ideas del bien en una concepción de la justicia, que como veremos es liberal, puede implicar una de dos cosas: (1) o bien los principios de la justicia

25 Jill Fillipovic, "How the right plays with murder: The antiabortion movement's cycle of violence" Salon, consultado 1 de octubre 2014,

http://www.salon.com/2013/09/10/how the right plays with murder the anti abortion movements cycle of violence/

${ }^{26}$ Cfr. Rawls, A Theory of Justice. 193 
liberales no implican una idea del bien determinada y, por lo tanto, pueden albergar diversas ideas del bien tradicionalmente no liberales, o bien (2) los principios de la justicia liberales sí implican una idea del bien liberal y, si es así, hay a su vez dos posibilidades: (2.1) la concepción liberal del bien es compatible con ideas del bien no liberales o (2.2) la concepción liberal del bien no es compatible con ideas del bien no liberales y no pueden coexistir. Si esto es así nos encontramos frente a un serio riesgo a la estabilidad de la comunidad política.

La primera opción (1) es históricamente refutable. Desde que Locke inaugurara la tradición liberal (como el reflejo teórico de condiciones históricas que comenzaban a surgir) existe una bien establecida comprensión de la importancia del espacio privado, la tolerancia como un valor social relevante y la promoción de las libertades para la realización de las capacidades personales; es decir una idea de bien liberal en términos generales. Sólo es necesario revisar el discurso de Benjamín Constant de "Sobre la libertad de los antiguos comparada a la de los modernos" para encontrarnos con que el liberalismo implica una idea de la vida lograda, aun cuando sea una idea amplia y que permita diferencias en su ejecución. Aun cuando Rawls procure realizar una argumentación del bien a través de una teoría débil, que busca sólo "esquematizar" el desarrollo y existencia de teorías del bien completas, el uso de conceptos tales como "el principio Aristotélico" en la tercera parte de Teoría de la Justicia, nos deja ver una idea del bien particular, no general ni reconciliable con cualquier idea del bien. El desarrollo de una concepción de la justicia liberal que estuviera verdaderamente alejada de un ideal de bien liberal supone la renuncia a la causa misma de la existencia de dicha tradición: la promoción de la autonomía y el desarrollo de las capacidades individuales de los ciudadanos; sin esas ideas, constitutivas del ideal del bien liberal, no queda claro qué queda del liberalismo. De igual modo, una teoría de la justicia que estuviera desvinculada absolutamente de una idea del bien, al menos de una muy general, idealmente podría servir como una concepción igualmente adecuada para un fundamentalista religioso en cierto grado intolerante que para un liberista pacifista; una posibilidad así sería ilusoria. Este tema es recurrente en esta investigación, en especial cuando analice el "giro político" de Rawls en las partes siguientes.

Dado que parecería insostenible una concepción de la justicia completamente desligada de una idea del bien, aunque sea una general, debemos analizar la segunda posibilidad. Aceptando que principios de la justicia liberales suponen una idea del bien liberal, entonces tendríamos que decir que hay al menos dos posibilidades para considerar respecto a los principios en relación con la 
limitante de la finalidad: o bien la idea del bien liberal es compatible con ideas no liberales o la concepción liberal del bien es incompatible con ideas del bien no liberales.

Si una concepción de la justicia liberal implica una idea del bien liberal, es complicado suponer que podría ser al mismo tiempo compatible con ideas no liberales, al menos desde una perspectiva general. Las ideas del bien contrarias, no simplemente distintas, tenderían a ser excluyentes en tanto que el objeto que una de ellas considera valioso puede ser un mal para la otra. Por ejemplo, para una concepción liberal del bien, la idea de que un grupo religioso coopte el ejercicio del poder político es un mal, en cambio, para ciertos grupos conservadores la participación de la religión en el ejercicio del poder político puede ser algo bueno. El liberalismo tiende a permitir que ideas distintas del bien coexistan en tanto estas sepan aceptar el ideal liberal de desarrollo individual libre y el ejercicio limitado del poder político (que no niega la posibilidad de que dicho poder sea usado para mejorar las condiciones para el ejercicio de las libertades de los individuos, como algunos liberistas podrían sostener). Tal vez debería reconocerse que la concepción de la justicia liberal exige una idea del bien compatible con esa concepción. Cualquier concepción del bien compatible con la concepción de justicia liberal es intrínsecamente una concepción del bien liberal.

El límite de finalidad a las concepciones de justicia nos remite a la necesidad de que las comprensiones del bien de los individuos deben ser intrínsecamente congruentes con dicha concepción para que puedan existir en una sociedad gobernada por ella. Lo que quiero decir, y es una pregunta constante durante el resto del capítulo, es que no es claro que Teoría de la Justicia de Rawls sea un texto que efectivamente pueda argumentar en favor de una concepción de la justicia liberal incluso ante concepciones del bien antiliberales. Si es necesaria una sociedad liberal para mantener una concepción de la justicia liberal, entonces los alcances del kantismo en Rawls son mucho más modestos de lo que en primera instancia parecerían ser (¿cómo podría ser universal en ese caso?). No es sorprendente que en Liberalismo Político Rawls abandone las pretensiones universalistas por una aproximación mucho más modesta y con miras a una argumentación más pragmática.

A continuación me centro en la idea rawlsiana de considerar que la fortaleza del argumento, o más bien la argumentación definitiva en favor de una concepción de la justicia, se encuentra no es una demostración apodíctica, sino, más bien, en su capacidad de mostrarse como más plausible que sus competidoras. Este tema es el 
del equilibrio reflexivo y es uno de los que acercan más a Rawls a una lectura pragmatista desde Teoría de la Justicia.

\section{La elección entre las concepciones candidatas y el equilibrio reflexivo}

Para que la elección en la posición original pueda ser llevada a cabo adecuadamente, considera Rawls, es necesario garantizar condiciones de imparcialidad que produzcan un resultado justo y objetivo. Supongamos que estamos intentando determinar cómo debe ser llevada a cabo la distribución del un bien X; para hacer un juicio al respecto es fundamental considerar qué cualidades deben poseer las partes involucradas en la distribución de $X$ para merecer una mayor o menor cantidad. Si el bien a distribuir fuera el acceso a un estado de derecho, podríamos decir que la determinación de quién tiene acceso a este bien y en qué "cantidad" no tiene relación, por ejemplo, con una característica como el color de la piel de las personas. Las variaciones genéticas que producen la pigmentación de la piel son características o cualidades irrelevantes respecto a la distribución del bien de la protección de un estado de derecho, en la medida en que las diferencias derivadas del color de piel son irrelevantes respecto a su vida en tanto que ciudadanos; de ahí la injusticia de los regímenes que condicionan el acceso a la justicia en función del color de piel de los individuos. La tarea de Rawls es encontrar cuáles son las características relevantes para la formulación de principios de justicia que ordenen la sociedad, para que sea objetiva y cumpla con los límites de la justica.

Para garantizar las condiciones de imparcialidad en la posición original, el "lugar" donde se elige la concepción de la justicia, Rawls postula el velo de la ignorancia. A reserva de que adelante en el capítulo analizo a profundidad este concepto, podemos decir que el velo de la ignorancia busca condicionar el conocimiento de los individuos, que están en la posición de elegir una concepción de la justicia, a los factores básicos para la toma de decisión (las condiciones generales de la civilización humana, leyes básicas de la psicología y la economía y el hecho que los individuos poseen una idea del bien, aunque no tengan conocimiento sobre la suya en particular). "La justicia como imparcialidad", el nombre de la concepción de la justicia que desarrolla y presenta John Rawls, proviene de esta idea: un juicio sobre lo justo es aceptable en un grado mayor 
cuando toma en cuenta únicamente los factores relevantes y no aquellos que podríamos considerar como parciales y arbitrarios. ${ }^{27}$ La determinación de qué es relevante está intrínsecamente vinculada a las circunstancias en la que la decisión es llevada a cabo.

La importancia de la posición original es que ésta sirve, o al menos eso piensa Rawls, para decidir entre diversas consideraciones de justicia que podrían servir para ordenar la sociedad (entre ellas el utilitarismo, el perfeccionismo y el intuicionismo). Si la posición original está estructurada de modo que impide estrategias de elección racionales o impone condiciones al conocimiento innecesarias sólo para garantizar la elección de la justicia como imparcialidad, entonces tendremos que concluir que Rawls no está intentando mostrar que su concepción es más convincente de modo imparcial. Dado que Rawls menciona que su teoría "parece ofrecer un desarrollo sistemático alternativo de la justicia que es superior, o al menos eso argumento, que el dominante utilitarismo de la tradición," ${ }^{28}$ todo apunta a que las condiciones impuestas en la posición original (posición de la que se derivan los principios) tienen la finalidad de servir como un campo de argumentación donde las premisas deben de ser aceptables para las concepciones en contienda, de ahí la importancia de garantizar la imparcialidad.

\begin{abstract}
Se debe argumentar desde premisas muy aceptadas pero débiles hasta conclusiones más específicas. Cada uno de los presupuestos deben de ser naturales y plausibles; algunos incluso puede parecer inocuos o incluso triviales. El objetivo de enfoque contractual es establecer que tomadas en su totalidad imponen límites significativos en los principios de justicia aceptables. El resultado ideal sería que esas condiciones determinan un grupo único de principios; pero quedaré satisfecho si permiten jerarquizar los conceptos tradicionales principales de las concepciones de la justicia social. ${ }^{29}$
\end{abstract}

Dadas las condiciones de imparcialidad, lo que se busca es que las concepciones de justicia que se sostienen por presupuestos inaceptables en la posición original sean desechadas debido a que esos presupuestos son irrelevantes desde la perspectiva de la justicia. En este sentido podemos afirmar que todos los individuos son considerados iguales dentro de la posición original, ya que las causas para discriminar entre personas y reclamos, previo a la postulación de principios de la justicia que sirvan justamente para ello, requieren de premisas difícilmente aceptables por todas las partes. Dicho de otro modo, sería inaceptable elegir ser discriminado sin que exista un status quo determinado que genere las condiciones

\footnotetext{
${ }^{27}$ Cfr. Rawls, $A$ Theory of Justice, 16

${ }^{28}$ Ibid. xviii

${ }^{29}$ Ibid. 16
} 
psicológicas, sociales y materiales de la discriminación. En la medida en que dicho status no existe en la posición original, las partes son efectivamente iguales entre sí, "todas tienen los mismos derechos en el proceso de elegir principios; cada uno puede hacer propuestas, someter razones para su aceptación y demás." ${ }^{30}$

El procedimiento a seguir, una vez que las condiciones de imparcialidad han sido establecidas, es a través de lo que Rawls denomina equilibrio reflexivo. Como se explica a continuación:

Iniciamos describiéndola -la posición original- de modo que represente condiciones generalmente compartidas y preferentemente débiles. Después veremos si estas condiciones son lo suficientemente fuertes para producir un grupo de principios significativo. Si no es así, buscamos más premisas igualmente razonables. Si es así, y los principios están en concordancia con nuestras convicciones consideradas de justicia, entonces hasta ese punto estaremos bien. Sin embargo, presumiblemente tendremos diferencias. En este caso tenemos una opción. Bien podríamos modificar la ordenación de la situación inicial o podemos revisar nuestros juicios preexistentes, pues aun los juicios que hemos aceptado provisionalmente como directrices fijas son sujetos a ser revisados. Mediante la continua revisión, algunas veces alterando las condiciones de las circunstancias contractuales, y otras retirando nuestros juicios y haciéndolos conformarse a los principios, asumo que eventualmente encontraremos una descripción de la posición inicial que exprese tanto a las condiciones razonables y que produzca principios que estén en concordancia con nuestros juicios considerados debidamente modificados y ajustados. A este estado de cosas es al que me refiero como equilibrio reflexivo. Es un equilibrio porque al fin nuestros principios y juicios coinciden; y es reflexivo porque sabemos a qué principios nuestros juicios se conforman y las premisas de las que se derivan. ${ }^{31}$

El procedimiento es claro e implica que debemos desarrollar un método de investigación que no sólo debe cuestionar las condiciones mediante las cuales llegamos a nuestros juicios sino que, al mismo tiempo, nos obliga a considerar los juicios que poseemos en función de las circunstancias. El equilibrio reflexivo promueve un pensamiento crítico abierto a objeciones y reconsideraciones continuas. Es de algún modo es un método falsacionista. El resultado es estable, si lo aplicamos a la situación original, ya que las consideraciones de las circunstancias no cambian. Sin embargo, si asumimos que una nueva lectura de las condiciones es un cambio de las mismas (una aproximación o intención nueva a un mismo problema o contexto, como vimos en el capítulo anterior, implica una nueva perspectiva y una nueva conformación del mismo) podemos decir que en la

\footnotetext{
${ }^{30}$ Ibid. 17

31 Ibid. 18
} 
medida que busquemos poseer más o mejor información, alteraremos posiblemente los principios y juicios considerados. Eso hace que el ejercicio de la posición original esté abierta al cambio en función de las circunstancias que se incluyan en ella (a sabiendas, de nuevo, que un cambio en el conocimiento de las circunstancias es, en cierta medida, un cambio en las circunstancias mismas).

Es interesante la inestabilidad intrínseca al método del equilibrio reflexivo y lo que esto implicaría respecto a los límites de finalidad y universalidad. Si la universalidad y la finalidad de la concepción de justicia están sujetas a nuevas reinterpretaciones de las condiciones de la posición original, dicha universalidad y finalidad son intrínsecamente contingentes a la comprensión de las condiciones dentro de dicha posición. Si esto es así, el acercamiento de Rawls al pensamiento pragmatista es mayor al que inicialmente consideramos. Pongamos un ejemplo, Rawls asume que los individuos dentro de la posición original tienen conocimiento de los hechos generales sobre la sociedad humana, entienden los asuntos políticos, los principios de la teoría económica y las bases de la organización social y las leyes de la psicología humana. ${ }^{32} \mathrm{Si}$ el pragmatismo deweyano tiene méritos en la explicación del conocimiento humano, y asumo que los tiene, entonces estos conocimientos, que para Rawls son incontrovertibles (pues considera que es el tipo de conocimiento que todos necesitarían y reconocerían como aceptables en la situación original), están no sólo compuestos de supuestos controversiales sino que son falseables. Desde una perspectiva pragmática el equilibrio reflexivo funciona espléndidamente como un método de revisión para nuestras consideraciones de justicia; nos permite contrastar nuestros juicios con las condiciones que les dan origen permitiendo anticipar algunos de los resultados de los mismos. El método, sin embargo, está condenado al fracaso si las pretensiones son realmente la universalidad y la finalidad. ${ }^{33}$ Las leyes de la psicología humana cambian continuamente, diariamente podríamos decir, gracias a que la ciencia psicológica ha mejorado sus mecanismos de indagación; las leyes de las ciencias sociales (intentando incluir en este segmento la política, sociología y la economía) no están libres de disputas razonables y, al contrario, son un hervidero de creación de nuevos métodos y comprensiones de su objeto. ¿Hasta qué punto el equilibrio reflexivo permite la estabilidad que Rawls pretende?, ¿en qué modo es posible

\footnotetext{
${ }^{32}$ Cfr. Ibid. 119

${ }^{33}$ Esta aparente tensión la hace evidente Jesús Rodríguez Zepeda, al tratar el positivismo rawlsiano en relación a la posición original: “(...) creo que una visión restringida del pluralismo científico en el caso de la posición originaria hace un flaco favor a la efectiva racionalidad dialógica que es lo que, si mi lectura de Rawls no es incorrecta, se intenta fundamentar mediante la estrategia contractualista." [Jesús Rodríguez Zepeda, El igualitarismo liberal de John Rawls (México: Miguel Ángel Porrúa, 2010). 123]
} 
postular principios que jerarquicen nuestros reclamos a través de un tiempo y un contexto relativamente indefinido si son formulados en función del conocimiento que sabemos puede ser, y con un alto grado de certeza podemos decir que será, falseado?

Independientemente de hasta qué nivel de generalidad (si es que es posible hablar de niveles) es capaz de llevarnos el equilibrio reflexivo, es importante recalcar que en el proceso de alcanzarlo es necesario contrastar las conclusiones que obtengamos con nuestros juicios considerados. Este modo de proceder permite contrastar los juicios elaborados en la posición original con las concepciones dominantes dentro de la tradición filosófica, las instituciones y hábitos enraizados en la comunidad. La concepción de la justicia dominante será aquella que logre demostrar que, dadas ciertas condiciones de arranque que se consideran adecuadas, puede ofrecer los principios que armonizan de mejor modo nuestros juicios considerados y las condiciones en la posición original. Aquellas concepciones que no logren hacerlo, ya sea porque no aceptan las condiciones de imparcialidad en la posición original, o porque sus principios no pueden ser compatibles con nuestros juicios considerados (algunas de nuestras ideas centrales sobre la justicia), serán desechadas.

Antes de entrar a detalle a la argumentación de la justicia como imparcialidad, así como de los principios de la justicia y cómo se derivan en la que Rawls denomina la posición original, trataré en el final de este capítulo el tema del objeto y el papel de la justicia, entendida como la justicia como imparcialidad, dentro de una sociedad liberal.

\section{El papel de la justicia en una sociedad liberal}

El desarrollo histórico de una concepción de la justicia, en particular una de corte liberal, implica necesariamente la convicción de su importancia fundamental dentro de la comunidad política. Es relevante recalcar este supuesto pues es posible plantear una sociedad sin pensar en términos de relaciones de justicia. Un ejemplo claro de esto es Thomas Hobbes.

El contractualismo hobbesiano no cumple la función de establecer condiciones de justicia para la interacción entre los integrantes de la comunidad. Como es bien sabido, la fundamentación de la comunidad política en Hobbes está íntimamente relacionada con la preocupación por el conflicto total que supone la 
guerra civil y el olvido de la ley y el orden, ${ }^{34}$ que evidentemente no es lo mismo que el mantenimiento de un orden justo, en especial si entendemos la justicia en relación con el concepto de imparcialidad. Dada esta preocupación, asumiendo un criterio de racionalidad enfocada en la eficiencia de los medios, que cabe señalar que es el criterio de racionalidad que emplea Rawls, Hobbes llega a la conclusión de la justificación de un cuerpo gobernante sin límites en el poder ni en el ejercicio del mismo (más allá de cumplir el objetivo de orden y aseguramiento de la vida de los ciudadanos):

Lo que es cierto es que una vez que, con Hobbes, hemos asumido este acercamiento a la naturaleza humana secular, mecánica y naturalista, nos quedamos con que no existen acciones absolutamente prohibidas, no hay comportamiento intrínsecamente maligno. Los límites de la política, aun cuando son perseguidos por aquellos innegablemente benevolentes, se imponen por la tecnología psicológica más que por estándares independientes de la dignidad humana o algo parecido.

Pero si la naturaleza humana es así de manipulable, una de las funciones de la noción de naturaleza humana queda prácticamente inhabilitada, pues juega un papel mucho más reducido en el establecimiento de límites a las posibilidades políticas. $^{35}$

Lo que Rawls busca, a diferencia del proceder de Hobbes, es no sólo mostrar cómo desde su comprensión de la naturaleza humana se derivan ciertos límites al poder político, sino, del mismo modo, que la justicia es necesaria para el adecuado funcionamiento de la sociedad. Este tipo de argumentación requiere mostrar cómo es que la justicia es el fundamento central de comunidad, como menciona el mismo Rawls:

La justicia es la virtud primera de las instituciones sociales, como lo es la verdad de los sistemas de pensamiento. Una teoría, sin importar que tan elegante o económica, debe de ser rechazada o revisada si es falsa. Del mismo modo las leyes y las instituciones, no importa que tan eficientes o bien organizadas, deben ser reformadas o abolidas si son injustas. Cada persona posee una inviolabilidad fundada en la justicia que ni siquiera una sociedad de bienestar puede atropellar. ${ }^{36}$

Esta postura es antitética a la comprensión de la sociedad de Hobbes, como se ve cuando enfrentamos las dos últimas citas. Para Rawls una sociedad desinteresada de la justicia es una de carácter vicioso, si asumimos que el vicio efectivamente se contrapone a la virtud. Una diferencia ente Rawls y posturas como la de Hobbes,

\footnotetext{
${ }^{34}$ Cfr. Alan Ryan, The Making of Modern Liberalism (Princeton: Princeton University Press 2012), 222

35 Ibid. 227

${ }^{36}$ Rawls, $A$ Theory of Justice. 3
} 
que no consideran la primacía de la justicia en la conformación de las instituciones sociales como una condición necesaria, se encuentra en el concepto mismo de sociedad:

Asumamos, para aclarar las ideas, que la sociedad es más o menos una asociación auto suficiente de personas que en sus relaciones ente sí reconocen ciertas reglas de conducta como vinculantes y que en la mayor parte actúan en función de ellas. Supongamos, aún más, que esas reglas especifican un sistema de cooperación diseñado para avanzar el bien de aquellos que forman parte de él. Así, aunque una sociedad es una empresa cooperativa para la ventaja mutua, está típicamente marcada por el conflicto tanto como por la identidad de intereses. ${ }^{37}$

En este sentido, la sociedad en Rawls es, en su origen, distinta a lo que Dewey había considerado. En Rawls hay un marcado acento en la cooperación, el cual en el caso de Dewey prácticamente no existe aun cuando ésta parece ser una condición necesaria para poder mediar con el conflicto cuando surjan los intereses convergentes. El conflicto, según Rawls, es el producto de la falta de consenso en los mecanismos y medidas de distribución de los bienes: "Existe el conflicto de interés ya que las personas no son indiferentes sobre el cómo la mayor parte de los beneficios producidos por la colaboración deben ser distribuidos, pues para perseguir sus fines cada uno prefiere una mayor cantidad que una menor." ${ }^{38} \mathrm{La}$ comprensión misma de la naturaleza del conflicto en Rawls nos remite a un problema que exige una solución pragmática. Las diferencias en las expectativas distributivas pueden surgir por dos circunstancias distintas: (i) por un lado puede suceder por lo difícil de realizar juicios imparciales cuando mi bienestar está de algún modo, directo o indirecto, involucrado; por otro lado, (ii) el conflicto en las consideraciones de distribución puede ser fruto de la inexistencia de criterios compartidos para determinar las medidas adecuadas para cada una de las partes. La primera razón por la que surge el conflicto exige que los individuos procuren actuar con imparcialidad. Como he dicho, cualquier concepción de la justicia que pueda ser aceptable debe de ser, de origen, imparcial. Del mismo modo, una vez que hemos elegido los principios en la situación original, el ejercicio de los principios exige que busquemos la aplicación imparcial de los mismos.

La segunda razón por la que surge el conflicto es que, mientras distintos individuos tengan comprensiones distintas de la justicia, lo que es muy común en las sociedades contemporáneas, es prácticamente imposible garantizar la existencia de juicios compartidos. La importancia de desarrollar una concepción de la justicia

\footnotetext{
${ }^{37}$ Ibid. 4

38 Idem.
} 
como imparcialidad se deriva justamente de este hecho. Como vimos con la exposición del pragmatismo de Dewey, principios o creencias distintas producen acciones y juicios distintos y, en lo que se refiere al contenido de la justicia, es un concepto hasta cierto punto histórico que no siempre ha significado lo mismo. Del mismo modo, Rawls reconoce este hecho y le da su justa importancia en lo que a la organización social se refiere.

Un juego de principios se requiere para elegir entre los distintos arreglos sociales que determinan la división de ventajas y para tener un acuerdo sobre el modo adecuado de garantizar las porciones distributivas. Estos principios son los de la justicia social: ellos ofrecen un modo de asignar derechos y deberes en las instituciones básicas de la sociedad y definen la distribución apropiada de los beneficios así como las cargas de la cooperación social. ${ }^{39}$

En caso de no existir una concepción compartida de justicia, nos enfrentamos a un muy serio problema, pues el conflicto se vuelve, conforme a las consideraciones de Rawls, insoluble de un modo razonable y aceptable al menos en la mayoría de los casos. Como veremos más adelante, este hecho genera una gran dificultad dentro del sistema rawlsiano. Una característica del liberalismo de Rawls es su marcado antiperfeccionismo. Sostiene firmemente la creencia que una sociedad liberal, que asuma la imparcialidad con seriedad, tiende naturalmente a tomar una posición que niega cualquier ideal de perfección para sí o los ciudadanos, debido a que no puede preferir una idea del bien como ideal regulativo o aspiracional. La imparcialidad implica que no tengamos preferencias y considera, como lo comenté anteriormente, todas las ideas del bien como igualmente aceptables. El problema con esto es que la concepción de la justicia difícilmente puede ser entendida al margen de una idea del bien determinada. La aceptación de la importancia y prioridad de encontrar una concepción de la justicia liberal compartida implica, necesariamente, un riesgo a las concepciones del bien que no son liberales, o al menos altamente compatibles con un ideal del bien liberal. Si Rawls quiere conservar el antiperfeccionismo y la imparcialidad total, a la vez que busca resolver el conflicto mediante la adopción de una concepción de la justicia compartida, creo que quiere más de lo que puede razonablemente obtener. Considero fundamental recalcar que, sin la concepción compartida, difícilmente tendremos una solución estable al problema del conflicto:

Digamos que una sociedad está bien ordenada no sólo cuando está diseñada para avanzar el bien de sus miembros sino cuando está, del mismo modo, efectivamente regulada por una concepción pública de la justica. Esto es, es una sociedad en la

${ }^{39}$ Idem. 
que (1) todos aceptan y saben que los demás aceptan los mismos principios de la justicia, y (2) las instituciones sociales fundamentales generalmente satisfacen y la generalidad sabe que satisfacen estos principios. En este caso mientras los hombres pueden generar demandas excesivas los unos a los otros, reconocen, sin embargo, un punto de vista en común desde el que saben que sus reclamos pueden ser enjuiciados. $^{40}$

Por supuesto, el ideal de ordenación no se cumple materialmente en ninguna sociedad actualmente existente. Podríamos decir que hay dos razones para que esto sea así. Por una lado es muy difícil imaginar que exista una concepción dominante al modo en que Rawls desearía: “Los hombres están en desacuerdo sobre qué principios deberían definir los términos básicos de su asociación. Aun así podemos decir, asumiendo el desacuerdo, que cada uno de ellos tiene una concepción de la justicia. Esto es, entienden la necesidad para, y están preparados para afirmar, una serie de principios determinados para asignar los derechos y deberes básicos $(\ldots)^{\prime \prime} \cdot{ }^{41} \mathrm{Al}$ menos hasta la década de los setentas no existía, según Rawls, ningún Estado con una concepción de la justicia compartida al modo que él hubiera deseado para poder limitar el conflicto entre los ciudadanos. El planteamiento rawlsiano termina siendo ideal y una referencia regulativa que sirve para guiar sociedades imperfectas más que un plan o proyecto de sociedades existentes y perfectas.

Una segunda razón por la que es complicado que el ideal de una sociedad bien ordenada sea alcanzable es que siempre hay disputas sobre lo que es justo o injusto en la medida en que la aplicación de los principios a la realidad siempre puede ser imaginada de modos distintos. Un ejemplo de esto es la primera razón por la que surge el conflicto al que aludí arriba. El conflicto en concreto aparece ya que la distribución de bienes en la sociedad es sumamente compleja y, como en cualquier caso de justicia imperfecta, aun cuando "existe un criterio independiente para obtener un resultado correcto, no existe un procedimiento posible que nos lleve con seguridad al resultado." ${ }^{42}$ El conflicto se mantiene como una constante en la comunidad, por tanto, ya que aun cuando exista un criterio independiente para juzgar, la distribución de modo incontrovertible y que funcione en todas las circunstancias no existe, pues no tenemos un método infalible de asignación de bienes que garantice un resultado correcto. Sin embargo, sostiene Rawls, la existencia de una concepción de la justicia compartida por los individuos de la comunidad permitiría, de ser posible, tener un sistema, aunque imperfecto, estable.

\footnotetext{
40 Idem.

${ }^{41}$ Ibid. 5

42 Ibid. 14
} 
El objeto primordial de la concepción de la justicia que elegiremos en la posición original, ya sea la justicia como imparcialidad o algún otro candidato, es lo que Rawls denomina la estructura básica de la sociedad: las instituciones fundamentales de la sociedad, la constitución y el ordenamiento económico y social fundamental. ${ }^{43}$ ¿Por qué el objeto de la concepción de la justicia es la estructura básica? La razón para elegir la estructura básica como el objeto de la concepción de justicia es que estas instituciones son fundamentales para determinar la distribución de bienes esenciales (derechos, obligaciones y demás bienes posibles) en sociedad. Una teoría de la justicia que apuntara únicamente a regir sobre reglamentos secundarios o algún área del derecho en particular, no nos serviría para definir los conflictos que, como vimos, surgen naturalmente en la comunidad de acuerdo a los límites de generalidad y universalidad. Del mismo modo, sin embargo, no podemos esperar que los principios de la justicia resuelvan todos los conflictos y disputas que surjan en la sociedad. Hay, en general, dos circunstancias en las que los principios no operan: en las relaciones entre naciones (“Las condiciones para la ley entre naciones puede requerir de principios distintos a lo que llegamos de un modo diferente" ${ }^{44}$ ) y en las relaciones intragrupales reguladas por la tradición o convenciones informales. ${ }^{45}$ La concepción de la justicia que busca Rawls no es un sustituto de todo tipo de reglamentación de la conducta social. Algunas de las relaciones sociales más importantes que tenemos, piensa Rawls, no están medidas por relaciones de justicia, por ejemplo la familia ${ }^{46} \mathrm{o}$ algunos grupos religiosos; aunque, como argumento más adelante, no debemos descartar la intervención gubernamental incluso en esos ámbitos si queremos garantizar la estabilidad de la comunidad. En estos casos especiales, aunque no limitados por supuesto, podemos reconocer los límites de la concepción de la justicia. El límite en la aplicación de los principios de justicia reconoce que las relaciones sociales tienden a ordenarse tanto por la idea de la justicia como por concepciones del bien determinadas. Una vez que entendemos la concepción de la justicia como el criterio unificado para juzgar los reclamos entre los individuos, es importante recalcar las implicaciones que tiene en la dinámica de la sociedad.

\footnotetext{
${ }^{43}$ Cfr. Ibid. 7

${ }^{44}$ Ibid. 7

${ }^{45}$ Cfr. Idem.

${ }^{46}$ Respecto a si la familia debe estar sujeta a la concepción de la justicia o no, Rawls parece descartarlo con cierta prisa. Es decir, aun cuando los niños no puedan ser parte de la posición original, en la medida en que no tienen sus poderes morales plenamente desarrollados, no es claro que dejarlos fuera de su "jurisdicción" sea una solución aceptable. No sólo los niños son los ciudadanos del futuro (tema que trato a fondo cunado planteo algunos problemas de estabilidad que se pueden derivar de la negligencia en su cuidado) sino que tiende a ser plenamente aceptado que son sujetos legítimos de derechos, no sólo por una extensión al modo que se hace con otros sujetos.
} 
Si volvemos a las consideraciones políticas de Dewey, como analicé en el capítulo anterior, podemos recordar cómo es que el desarrollo consuetudinario de las interacciones sociales esta dictado por un sistema competitivo de intereses. $\mathrm{Si}$ bien es posible, dentro del liberalismo deweyano, hacer convergentes los intereses de los ciudadanos, en particular mediante el desarrollo de la democracia como un ethos completo que informa sus intereses, la cooperación está fundada en la mera convergencia. Esto quiere decir que la actividad política de los oficiales (que incluyen dentro del grupo a los legisladores) se basa en la representación de los intereses de grupo y la "negociación" de condiciones. El sistema de partidos es el ejemplo por excelencia de este proyecto. Cada partido tiene una plataforma que representa intereses de grupos e individuos; por lo tanto, cuando un partido que no cuenta con una mayoría suficiente de acuerdo al proceso, y busca obtener legislación que beneficie a su grupo, por ejemplo, está en la obligación de generar alianzas mediante la negociación política. Como podemos recordar, para Dewey la democracia liberal es el mejor sistema, en buena medida, porque garantiza el mejor, por ser el más equitativo y amplio, mecanismo de representación de intereses para los ciudadanos. El mantenimiento de libertades e igualdad dentro de la concepción de Dewey tiene la finalidad de garantizar que los ciudadanos puedan alcanzar sus propios intereses y, en esa medida, los oficiales están en la obligación de buscar que las condiciones de libertad y de igualdad se mantengan pues, de perderse, no podrían garantizar las condiciones óptimas para que cada quien procure su bienestar. El mantenimiento de la libertad y la igualdad es en este sentido instrumental.

La persecución de la igualdad y la libertad por parte de los oficiales está enfocada en los intereses de su grupo, no de la totalidad de la sociedad por sí misma. Si bien un oficial podría estar interesado en garantizar las condiciones de libertad de otro grupo, o de la totalidad de la sociedad para el caso, esto es en función, desde una perspectiva sistémica, de generar las mejores condiciones para el grupo que representa. Las razones podrían ser varias, sin embargo podríamos decir que garantizar la existencia de una sociedad liberal genera las condiciones óptimas para que los individuos puedan desarrollar sus proyectos de vida pero, al mismo tiempo, que puedan comparar su proyecto con el de otros actores para, de este modo, perfeccionar su propio modelo. La libertad en la sociedad es benéfica porque permite hacer del método pragmático falsacionista, considera Dewey, la ordenación social que genera mayores beneficios.

En el caso de Rawls la dinámica dentro de la posición original es distinta: 
Los legisladores no son, con seguridad, meros agentes de sus constituyentes, que poseen una cierta discreción y se espera que ejerzan su juicio al desarrollar legislación. En una sociedad bien ordenada deben, sin embargo, representar los intereses de sus constituyentes de un modo sustantivo: deben buscar primero el pasar legislación justa y efectiva, dado que es este uno de los intereses primordiales del gobierno, y segundo deben buscar maximizar los otros intereses de sus constituyentes en la medida en que sean consistentes con la justicia. Los principios de la justicia están entre los criterios principales a ser usados para juzgar el record de un legislador y las razones que da para defenderlo. ${ }^{47}$

Recordemos que encontrar una sociedad en la que todos los ciudadanos acepten una concepción de la justicia es probablemente imposible; después de todo el mismo Rawls menciona que no existen actualmente sociedades bien ordenadas con las características que él supone. Rawls reserva una tarea muy especial para los representantes en la posición original primero y los legisladores después, el conocer los principios y actuar conforme a ellos aun cuando los grupos que representa no los acepten como justos en primera instancia. Parece ser que el legislador es más bien una especie de iluminado que está por encima de sus conciudadanos, al menos en los casos en que los ciudadanos contemplan una idea del bien distinta. Los principios sirven para informar la ley y enmarcar el comportamiento de los legisladores aun cuando esto pudiera suponer un desvinculamiento con los intereses del grupo que representa.

No sólo podría ser considerado irresponsable con los votantes que un legislador dejara de lado sus intereses porque contradicen los principios sino que, al mismo tiempo y por cómo funcionan las democracias actuales, pone en riesgo su trabajo como representante ya que puede no ser elegido en un futuro. Este segundo hecho hace de facto improbable que pueda sostenerse un sistema político en el que los representados no sienten confianza en sus representantes; el movimiento natural de cualquier representante es el de mantenerse como tal y por tanto darle prioridad a los intereses de su grupo. Sobre este punto, John Harsanyi desarrolla una crítica aguda en función de los riesgos a la estabilidad de la comunidad si debemos confiar en una teoría con supuestos altamente improbables. Creo que, para comprender la fuerza del argumento, bien vale una cita extensa:

La sociedad justa que describe, sin embargo, no es simplemente una versión mejorada de las mejores sociedades existentes hoy; es como ninguna otra sociedad conocida por científicos políticos, historiadores o cualquier otro observador competente. Es una sociedad donde los ciudadanos y los legisladores nunca son motivados por su propio interés o (en el caso del legislador) por el interés de sus

${ }^{47}$ Ibid. 200 
constituyentes, sino que siempre están motivados, más bien, por su fuerte sentido de la justicia. Así, esta sociedad es prácticamente lo apuesto de la sociedad retratada en An Economic Theory of Democracy de Anthony Downs.

Por supuesto, Rawls está en lo correcto al rechazar que los supuestos motivacionales de Downs representan una imagen realista y completa de la motivación humana. Sin duda es falso que los ciudadanos ordinarios nunca se interesan por algo más que su interés propio en un sentido económico simple, o que los políticos nunca se interesan por algo más que sus oportunidades para una elección o reelección. (...) Es claro que Downs no asume que sus presupuestos motivacionales simplificados son literalmente verdaderos; todo lo que afirma es que nuestro sistema político opera la mayor parte del tiempo como s estos supuestos motivacionales fueran correctos.

Sin embargo, el hecho de que los supuestos motivacionales de Downs se acerquen tanto a la verdad debería obligarnos a pensar antes de aceptar la teoría de la estabilidad de Rawls. (...) De hecho, nuestra experiencia histórica parece mostrar que las sociedades como un todo pueden alcanzar dichos estados motivacionales como los planteados por Rawls para los legisladores- sólo por periodos más bien cortos de tiempo (por ejemplo durante revoluciones o algunas guerras sumamente populares). La misma experiencia muestra también que estos estados motivacionales altamente idealistas - $u$ continuamente fanáticos e intolerantes- de la sociedad están lejos de ser una simple bendición. ${ }^{48}$

La crítica de Harsanyi es sólida y atendible ya que el esquema de racionalidad preferido por Rawls para la posición original es el de la racionalidad económica. El esquema racional usado en la posición original debería ser, según Rawls, aquel que nos garantice la selección de los mejores medios. No deja de ser criticable, como sostiene Harsanyi, la decisión de Rawls de negar, posteriormente, este tipo de racionalidad al legislador para llevar a cabo su trabajo dentro de la comunidad. En ese sentido Dewey nos sirve, de mejor manera, para explicar el comportamiento real de los oficiales en el gobierno.

Tendríamos que decir que cuando Rawls asume que las personas desean una legislación justa como objetivo primario parece, de nuevo, no estar tomando en serio el problema del pluralismo. Si asumimos que la población sostiene ideas del bien realmente distintas y que de hecho mantienen una concepción de justicia diversa, pues la unanimidad en la concepción de la justicia necesaria para una sociedad bien ordenada no ocurre ordinariamente, no suena razonable suponer que la justicia, en particular una concepción que podría no ser compartida del todo, o que podría ser debatible que aceptaran respecto a su finalidad, será la

\footnotetext{
48 John Harsanyi: "Can the Maximin Principle Serve as a Basis for Morality? A Critique of John Rawls Theory"; The American Political Science Review vol. 69 no 2 (1975). 603-604
} 
prioridad de los ciudadanos. Aun cuando el argumento por una concepción de la justicia determinada, la justicia como imparcialidad si fuera el caso, fuera el mejor candidato para una concepción pública de la justicia, ¿en qué medida es razonable exigir a los oficiales guiarse por dicha concepción si puede estar en conflicto con la concepción de sus representados y si pone en riesgo su continuidad como representante? Como bien menciona Harsanyi, podemos esperar ese tipo de conducta "iluminada" solo mientras estemos conscientes de que es excepcional.

Este tema presenta un problema central de la propuesta rawlsiana. A continuación veremos la derivación de los principios de la justicia como imparcialidad. Como se verá, dicha derivación se realiza en un evento hipotético, la posición original, que busca servir sólo como un ejemplo de condiciones hipotéticas de imparcialidad de las que se pueden derivar principios de justicia. Una teoría de la justicia es funcional, como hemos visto hasta ahora, incluso bajo los criterios de Rawls, cuando ofrece las bases de estabilidad del sistema social. ${ }^{49}$ Algunas de las exigencias que plantea Rawls, incluso sin haber profundizado en los contenidos de la justicia como imparcialidad, generan condiciones de inestabilidad en la comunidad. Si vamos a esperar que la concepción de la justicia derivada de la posición original, que es equivalente a la concepción de la justicia derivada de la dimensión noumenal de los individuos, se imponga en la comunidad independientemente del consenso que hay en ella, el proyecto puede estar condenado al fracaso.

Si bien es cierto que Rawls supone que los ciudadanos tienden a reconocer los principios con el paso del tiempo ${ }^{50}$ nos queda la pregunta sobre cómo lidiar con el problema del consenso mientras no ha permeado la concepción de la justicia en la sociedad. En tanto que no exista consenso queda la cuestión de si tendremos que obligar una concepción de la justicia a un grupo más o menos amplio de la sociedad. El proceso de "homogenizar" concepciones de la justicia puede no ser tan pacífico como Rawls supone $\mathrm{y}$, al mismo tiempo, puede exigir un involucramiento activo por parte de los oficiales para garantizar su implementación de modo que podría ser restrictivo de algunas de las libertades de los individuos; un ejemplo de esto serían las restricciones a miembros de grupos

\footnotetext{
${ }^{49}$ En partes por venir en esta investigación profundizaré en este tema. Vale la pena mencionar que, en el contexto de la relación entre el kantismo y el pragmatismo en el pensamiento de Rawls, en la última presentación de la justicia como imparcialidad, en Justicia como imparcialidad, una reformulación (Cfr. John Rawls, Justice as Fairness, a restatement, ed. Erin Kelly (Estados Unidos de América: Harvard University Press, 2001).), Rawls se dedica a justificar la justicia como imparcialidad desde el consecuencialismo.

${ }^{50}$ Este tema lo desarrollo al final del capítulo cuando trate la psicología moral según Rawls.
} 
religiosos, por ejemplo sacerdotes, a cumplir funciones de servicio público. Si este modo de actuar es inaceptable, pues podría implicar el violentar los principios con el pretexto de su implementación, surge la pregunta de en qué sentido el liberalismo de Rawls puede funcionar para una sociedad que no sea previamente liberal del modo en que él mismo propone. Si el liberalismo de Rawls exige en su implementación la violación de sus mismas restricciones (lo que sería inaceptable para el mismo Rawls) y él considera que es un proyecto que habla de una sociedad que puede de hecho existir, entonces la opción que nos queda es que el liberalismo de Rawls, incluso desde Teoría de la Justicia, se refiere únicamente a sociedades que de hecho son ya liberales bajo un consenso amplio.

Más allá de este problema, que sin duda es complejo en tanto la justicia como imparcialidad busque mostrarse como una opción viable para un marco amplio de sociedades posibles, es razonable revisar cómo los principios que propone Rawls podrían generar estabilidad en la comunidad. Si la justicia como imparcialidad puede ser una concepción compartida, o al menos no controvertida, implicaría que los ciudadanos tienen expectativas del comportamiento de los oficiales, para usar el término deweyano, consistentes con lo que Rawls propone. De este modo el sistema legal debe estar en sintonía con los principios elegidos en la posición original. Si el sistema legal opera de este modo, siguiendo la limitante de publicidad, todos los ciudadanos tendrán claridad respecto a las expectativas razonables que podrán tener de sus interacciones, ya sea mediante el conflicto o la cooperación:

Un sistema legal es un orden coercitivo de reglas públicas dirigidas a personas racionales con el propósito de regular su conducta y proveer el marco para la cooperación social. Cuando estas reglas son justas establecen las bases para las expectativas legítimas. Constituyen las bases sobre las que las personas pueden depender unas de otras y objetivamente demandar cuando sus expectativas no son satisfechas. Si las bases de estos reclamos no son ciertas, lo mismo sucede con las libertades de los hombres. ${ }^{51}$

Si consideráramos al sistema legal únicamente como "las reglas del juego", sin hacer énfasis en la justicia, tendríamos que reconocer que la condición de la legitimidad de la ley y del poder político en general, es su capacidad de imposición. La argumentación de Rawls sobre la relevancia de la justicia resuena con la lógica política que supone que el poder no se justifica por sí mismo, en palabras de Jesús Rodríguez Zepeda, podríamos comprender el talante liberal de Rawls en función de "una intuición moral perfectamente defendible: la idea de que

${ }^{51}$ Rawls, $A$ Theory of Justice. 207 
una teoría de la justicia sólo puede justificarse como una apelación a la igualdad moral constitutiva del género humano y formularse como una teoría distributiva." $^{52}$

Recordemos la breve discusión con Hobbes revisada antes en el capítulo, incluso para un autor que permite el establecimiento de regímenes autoritarios, la justificación última del poder está en su capacidad de salvaguardar la vida y el mantenimiento del orden. La existencia de un criterio independiente de justificación para el orden social se contrapone al ejercicio del elitismo y la violencia irracional. Lo que Rawls busca es mostrar cómo es que dicho criterio de justificación emana del juicio imparcial entre seres esencialmente iguales (con capacidades morales del mismo tipo). Si la sociedad tiende a la construcción de instituciones parciales, y por tanto injustas, una reforma sería necesaria. Aunque de nuevo, ¿cómo podríamos llevar a cabo esta reforma aplicando un principio de imparcialidad? Si la justicia como imparcialidad supone que no debemos limitar los derechos de los demás simplemente por diferencias en las ideas del bien, ¿cómo se institucionaliza dicha concepción de la justicia? Por momentos parece que estamos atrapados en un laberinto sin salida.

Una vez discutidos estos temas daré paso a la exposición, ahora sistemática, de los contenidos concretos de la justicia como imparcialidad. Explicaré el concepto de la posición original, de los principios de la justicia, los dos principales, y los principios adicionales que son postulados en la situación hipotética en el próximo

capítulo.

\footnotetext{
${ }^{52}$ Rodríguez, El igualitarismo liberal de John Rawls. 129
} 


\section{Capítulo 4. La Justicia como Imparcialidad en Teoría de la Justicia}

Este cuarto capítulo sirve como una continuación del análisis que inicié sobre la justicia como imparcialidad en el capítulo anterior. La primera sección del capítulo se centra en la naturaleza procedimental de la justicia como imparcialidad. En ésta se ve cómo es que, al plantear la concepción de la justicia de este modo, Rawls se ve en la necesidad de generar límites a las contingencias, para garantizar la imparcialidad del producto de la posición original. Es necesario comprender las condiciones bajo las que ocurre el acuerdo en tanto que, como establece el mismo Rawls, si las condiciones cambian el resultado puede variar. La importancia de la composición de la posición original es evidente, si las condiciones son cuestionables los resultados se hacen, en cuanto la posición sirva efectivamente como un mecanismo para justificar los principios, también cuestionables. El trabajo de Rawls en este sentido es exhaustivo, el detalle de las circunstancias en la posición es amplio; las condiciones de conocimiento y motivación son variadas y no todas sencillas de aceptar. De igual modo, la postulación de los bienes primarios, aquellos que todos los individuos, en condiciones normales, desean en la mayor cantidad posible, permiten plantear la justicia como imparcialidad cumpliendo los límites de la justicia, u condición de imparcialidad y su naturaleza procedimental.

Después de haber realizado este análisis, comenzaré con la exposición de los contenidos de la justicia como imparcialidad como se materializan en los principios de la justicia. Los principios son dos: el principio de libertad y el de igualdad. Sobre el principio de igual libertad, o el primer principio de la justicia, analizaré la derivación del mismo y el tema de su prioridad. En su tratamiento Rawls asume que la prioridad de la libertad en la posición original no es algo problemático, me parece que es mucho más complicado que eso. Como veremos hay ocasiones en las que la libertad podría no ser prioritaria en el sentido en que Rawls parece asumir; el problema se puede plantear en términos de lo incomparable que son los denominados bienes primarios (los bienes que Rawls asume se distribuirían en la posición original y que todos los individuos desearían independientemente de cual sea su concepción del bien particular), dentro de los que se encuentran bienes como la libertad, los derechos políticos, la riqueza, el 
ingreso, el autoestima, etc. Las preguntas que nos quedan al plantearnos estos bienes son: ¿cómo podríamos compararlos entre sí, si no conocemos nuestras circunstancias particulares (como nos exige la posición original)?, ¿es imposible considerar una circunstancia en la que nuestras prioridades puedan cambiar? En este punto la naturaleza hipotética del pragmatismo de Dewey nos permite hacer contrastes relevantes con el pensamiento de Rawls.

El segundo principio es también parte del análisis de esta sección. En particular me concentro en la aplicación del principio de la diferencia como criterio de distribución de bienes (el principio de diferencia, que es una variante política del maximin, asume que las desigualdades que se promuevan en la sociedad son para maximizar las circunstancias de aquellos que se encuentren en la peor posición). Analizo el principio en dos vertientes. Por un lado planteo algunas de las consecuencias negativas de la aplicación del principio, lo que podría ser suficiente para que, dadas las condiciones de Rawls, lo dejáramos de lado. Por otro lado analizo las limitantes a la racionalidad probabilística que impone Rawls para evitar que se elija el principio de utilidad media como segundo principio de la justicia. En particular me interesa ese problema en su relación a la idea del riesgo pues es una limitante en cierto modo arbitrario en el proceso de selección de la posición original y que obliga a las partes a tomar una decisión irracional. Veremos que Rawls asume que al no conocer las probabilidades objetivas la selección, al no tener evidencia empírica de qué tan probable es estar en una posición determinada en la sociedad (o en qué sociedad estemos para el caso), debe hacerse de un modo conservador. Lo que muestro es que, dadas las condiciones de la posición original, parece ser que el único mecanismo razonable para tomar una decisión es en función de un cálculo de probabilidades, aun cuando el margen de error pueda ser relativamente amplio.

En la última sección analizo la idea del antiperfeccionismo y las complicaciones que su defensa genera en la estabilidad de la concepción de la justicia. Este estudio sirve como vínculo para lo que viene en esta investigación. Lo que hago es, ya con una comprensión de los argumentos y desarrollos de Teoría de la Justicia, utilizar la preocupación por la estabilidad, que se refiere a las consecuencias de la aplicación de los principios, para hacer una lectura pragmática de los principios mostrando que el antiperfeccionismo de Rawls, que lo lleva a asumir que se debe tolerar la intolerancia siempre y cuando no represente un riesgo inmediato para el mantenimiento de la concepción de la justicia, tiende a ser un factor de inestabilidad sistémica. En este mismo sentido abogo por la importancia de que Rawls reconozca ampliamente la importancia de un ideal 
regulativo de la persona (que tiene, de hecho, en el ideal de autonomía), pero que se extiende también al de la cultura y la sociedad liberal, así como la necesidad de que el gobierno lleve a cabo acciones positivas para desarrollar estos ideales (que puede ser mediante una educación cívica por ejemplo) y no sólo mediante la aplicación de los principios a lo que Rawls denomina estructura básica.

\section{Una concepción de la justicia procedimental}

Uno de los conceptos fundamentales dentro de la justicia como imparcialidad, la teoría de justicia desarrollada por Rawls que busca presentar como la mejor opción dentro de la posición original, es el de justicia procedimental. Como ya he mostrado hasta ahora, Rawls busca presentar una concepción de la justicia que sea general, pública, universal y final. La posibilidad de presentar una concepción que cumpla con estos límites exige que seamos capaces de desarrollar una comprensión de la justicia que no se fundamente en las contingencias presentes.

Una teoría de la justicia teleológica, como las denomina Rawls, no es capaz de cumplir con los criterios de generalidad y universalidad pues impone un ideal de perfección anterior a la libertad de cada individuo. ${ }^{1}$ El problema con esto es que, además de no cumplir con los límites a la justicia antes explicados, no trata con imparcialidad a los demás miembros de la sociedad en tanto que se discriminan ideas del bien que podrían no significar un perjuicio a alguna de las partes en la posición original. Una teoría de la justicia teleológica podría asumir que si un ateo no reconoce la participación en alguna tradición como un bien, el ateísmo debe de estar prohibido y, por tanto, la libertad de conciencia sería inexistente aun cuando el ateo no representara (si fuera ese el caso) un riesgo a las prácticas tradicionales de una comunidad particular. Rawls considera que esto es inaceptable pues niega la facultad natural de los individuos a desarrollar y adoptar una idea del bien de su preferencia y a tener una concepción de la justicia propia.

La alternativa a una teoría de la justicia teleológica es el desarrollo de una concepción que por sí misma no elija una idea del bien determinada como la rectora de la concepción de la justicia. Lo que nos queda es una concepción de la justicia procedimental y anterior a cualquier idea del bien concreta. Si evocáramos una comprensión de la justicia intrínsecamente vinculada con, por ejemplo, la idea

${ }^{1}$ Cfr. Rawls, A Theory of Justice. 285-286 
de la prudencia aristotélica, ${ }^{2}$ con su interés por la contingencia de los juicios, tendríamos una teoría que difícilmente serviría para resolver los reclamos entre individuos que interpretan sus hechos y sus circunstancias de modo distinto; violaríamos, por tanto, la universalidad como límite de la justicia.

Si quisiéramos determinar la justicia de cada disputa asumiendo que cada caso es único y es necesario juzgarlo en función de sus propias circunstancias absolutamente, de acuerdo a un criterio exclusivamente prudencial, probablemente generaríamos más problemas de los que solucionaríamos. ${ }^{3}$ Por un lado existiría absoluta incertidumbre jurídica pues es muy difícil, si no imposible, conocer las circunstancias de todas las partes involucradas en conflicto (esto haría que no pudiéramos estar del todo conscientes en qué modo perjudicamos o beneficiamos a los demás con nuestras interacciones). De igual modo, habría incertidumbre en tanto que las consecuencias jurídicas de nuestros actos estarían a consideración de quien nos juzga sin un parámetro determinado. Por último, un sistema exclusivamente prudencial exigiría que los jueces fueran individuos muy prudentes, pues un juez con capacidades de juicio limitadas impartiría una justicia limitada en tanto que un juez akolastos o akrático para el caso, usando la terminología aristotélica, simplemente no impartiría justicia en lo absoluto; un requisito inviable para cualquier concepción de la justicia.

Ante estas dificultades la opción de la justicia procedimental rawlsiana adquiere fuerza, ya que es una opción mucho más estable. La concepción de la justicia que propone, dados los límites a las concepciones mismas, sirve no sólo para plantear las instituciones de la estructura básica sino que, al mismo tiempo, permite canalizar los reclamos que surjan posteriormente a causa de su ordenación:

Por tanto, en este tipo de justicia procedimental la corrección de la distribución está fundada en la justicia del esquema de cooperación de la que esta surge y en la respuesta que se le da a los reclamos de los agentes en la misma. Una distribución no puede ser juzgada en el aislamiento del sistema del que es producto o del que

\footnotetext{
${ }^{2}$ Es pertinente recordar que Aristóteles prefería una polis regida por leyes antes que confiar en encontrar gobernantes virtuosos que pudieran ser la última palabra dentro de la ciudad. La inestabilidad de la vida humana, pensaba, no ofrece las garantías suficientes para eso. ${ }^{3}$ De hecho no me parece una posibilidad real el establecimiento de un sistema jurídico de este tipo. Como se vio en la parte anterior parece imposible realizar un juicio sin un esquema desde el que podamos llevar un análisis. Las comunidades que fundamentan la impartición de la justicia en los usos y costumbres, aun cuando no tengan una ley escrita, claramente dependen de las normas no escritas que les permiten tener un criterio de juicio.
} 
los individuos han usado como base para sus acciones en buena fe para establecer sus expectativas. ${ }^{4}$

Una de las implicaciones del fragmento anterior es que el criterio mediante el cual juzgamos el estado de las distribuciones en la sociedad debería estar en conformidad, no con un mero juicio prudencial, sino con la concepción de justicia desarrollada anteriormente a la distribución concreta. Lo que la justicia procedimental argumenta es que debemos desarrollar las reglas de acción para que el producto que obtengamos sea siempre justo, o al menos lo más justo posible: "La idea intuitiva es la de diseñar el sistema social de modo que su producto sea justo como sea que fuere, al menos dentro de un cierto rango." ${ }^{5}$

Rawls busca generar una concepción de la justicia que sea aceptable independientemente de las condiciones concretas de un individuo o, para decirlo de otro modo más adecuado, que sea aceptable para cualquier individuo capaz de pensar con imparcialidad. Si este es el objetivo de la justicia como imparcialidad entonces, piensa Rawls, la concepción no se puede derivar de condiciones que no puedan ser aceptables por individuos que se encuentren en condiciones materialmente distintas; para hacerlo debe actuar de modo distinto a la tradición. Como afirma David Lewis:

En lugar de inferir los principios del contrato de lo que los hombres, dada su naturaleza, probablemente elegirían dada la existencia de un gobierno y leyes existente, libremente construye el personaje de las partes en una "puramente hipotética" "posición original" en orden a "alcanzar una cierta concepción de la justicia". (...)

El hecho de que los principios no deban ser derivados de una situación concreta que se asuma es dada por la naturaleza, significa que Rawls es libre para alterar cualquiera de las circunstancias de la posición original en la que los principios serían elegidos, en caso de que no quede satisfecho con los principios a los que llegaríamos en la situación particular. ${ }^{6}$

La naturaleza procedimental del proyecto de Rawls, que intenta no formular una concepción parcial de la justicia que pueda beneficiar a cualquiera de los individuos que habitan dentro de una comunidad política determinada, le permite plantear la naturaleza de las circunstancias del acuerdo de modo que generen las condiciones idóneas para desarrollar la concepción de la justicia.

\footnotetext{
${ }^{4}$ Ibid. 76

${ }^{5}$ Ibid. 74

${ }^{6}$ David Lewis, Justice or Tyranny (Londres: Kennikat press 1979). 25-26
} 
Para entender lo que dicho sistema procedimental podría ser, Rawls realiza la comparación entre un sistema procedimental perfecto y uno imperfecto (ya he hablado atrás un poco del sistema imperfecto). El sistema perfecto se ilustra de mejor modo con el caso más simple de distribución justo: la repartición de un pastel. ${ }^{7}$ Supongamos un número $\mathrm{X}$ de personas que quieren distribuir un pastel en partes iguales, debido a que sólo será justa una repartición igual en tanto no tengamos más información de cada uno de las partes, ¿qué procedimiento deberíamos elegir?, ¿de qué regla podríamos disponer para esta repartición justa? La solución obvia, piensa Rawls, es la de escoger un individuo que parta el pastel y sea él la última persona en tomar un pedazo. Esta regla, bajo el supuesto de que todas las partes quieren la mayor cantidad de pastel posible (pues los individuos siempre querrán más bienes que menos en condiciones normales ${ }^{8}$ ), obliga que quien parta el pastel lo haga en rebanadas iguales. Si cortara las rebanadas de tamaños distintos corre el riesgo, y si asumimos que todos quieren la mayor cantidad posible de pastel puede tener la certeza, de quedarse con la rebanada más pequeña del pastel; la única solución para quedarse con la mayor cantidad posible es que todos tengan lo mismo. Este ejemplo simple nos muestra las características de la justicia procedimental en su modo perfecto:

Primero, existe un criterio independiente para lo que será una división justa, un criterio definido de modo separado y anterior al procedimiento que debe ser seguido. Y segundo, es posible desarrollar un procedimiento que nos asegure la conclusión deseada. Por supuesto existen ciertos supuestos que se han realizado aquí, por ejemplo que el hombre elegido podrá dividir el pastel en partes iguales, quiere una rebanada tan grande como pueda obtener y más. Sin embargo podemos ignorar estos detalles. El tema esencial es que existe un estándar independiente para decidir que conclusión es justa y un procedimiento que garantice que la alcancemos. Es claro que la justicia procedimental perfecta es rara, si no imposible, en casos donde existen más intereses prácticos involucrados. ${ }^{9}$

Este es el ideal que tiene en mente Rawls. La justicia procesal en su modo perfecto es un ideal que muestra cómo un criterio independiente, que en ese sentido puede llegar a ser objetivo, puede servir en todos los casos ofreciendo un resultado que se considere justo. La justicia como imparcialidad busca cumplir ese cometido al menos en su modo imperfecto. Su imperfección deriva, como vimos antes, en que aun cuando la justicia como imparcialidad pueda ofrecer un criterio

\footnotetext{
${ }^{7}$ Cfr. Rawls, A Theory of Justice. 74

${ }^{8}$ Este es un supuesto constante dentro de la argumentación por los principios de la justicia. Como veremos más adelante no es en lo absoluto un principio autoevidente o una condición necesariamente aceptable para todo individuo empírico.

${ }^{9}$ Idem.
} 
independiente, ciertamente con la pretensión de ser objetivo, no presenta un procedimiento que garantice la obtención del mismo resultado en todas las ocasiones. En buena medida esto ocurre porque existe una pluralidad de ideas del bien, perspectivas distintas para juzgar (como vimos en el capítulo anterior una perspectiva diferente genera juicios sustancialmente distintos) o capacidades de juicio variantes, por sólo nombrar algunas de las posibilidades.

\section{$\underline{\text { Los límites a las motivaciones y al conocimiento en la Posición Original }}$}

Más allá de estos retos, queda una cuestión por resolver: ¿cómo es posible obtener el criterio independiente de juicio? Y una vez conseguido, ¿cómo podríamos garantizar su objetividad? La respuesta a estas interrogantes están en lo que Rawls denomina el velo de la ignorancia. Antes de tratar de fondo el velo de la ignorancia y los límites al conocimiento que supone, es importante hablar de las otras condiciones que impone Rawls dentro de la posición original: límites a las motivaciones de los individuos. En palabras de uno de los lectores y críticos más relevantes de Rawls, Brian Barry: "Los postulados motivacionales son, primero, que los actores en la posición original son racionales $\mathrm{y}$, segundo, que no son altruistas. Más precisamente, la segunda condición significa que cada uno de ellos desea alcanzar sus propias "concepciones del bien", aunque no -dadas las limitaciones al conocimiento- saben cuál es el contenido de dicha concepción." ${ }^{10}$

Las limitantes en las motivaciones son un tema fundamental por la cantidad de críticas que se pueden desprender de ellas. Por un lado, podemos encontrar desarrollos de corte comunitarista, como el de Michael Sandel, que supondría que asumir al hombre como un sujeto no altruista, o desinteresado, tiende a reflejar una antropología que es inadecuada para muchas expresiones culturales existentes, dentro de las cuales el papel del altruismo es fundamental, y que nos obligaría a desatender problemas sociales que requieren la cooperación de los individuos. ${ }^{11}$ Esta crítica resuena en el pensamiento comunitarista que supone la importancia del desarrollo de intereses comunes como condición de posibilidad de una sociedad justa y funcional. Una crítica comunitarista al pensamiento rawlsiano es que la

\footnotetext{
${ }^{10}$ Barry, The Liberal Theory of Justice. 10-11

11 Sobre este punto Sandel tiene una interesante discusión de los límites de la justicia sobre la justificación de los programas de acción afirmativa y cómo, desde la teoría de la justicia rawlsiana, parecería imposible de justificar. La crítica, aun cuando tiene méritos, es en su mayor parte desafortunada en tanto que tiende a suponer que los sujetos noumenales de Rawls, aquellos en la posición original, representan un ideal antropológico. Esto no es del todo correcto para Rawls.
} 
elaboración de su concepción de la justicia implica, irremediablemente, condiciones que vuelven la existencia real del Estado imposible ya que exige condiciones irrealizables.

Por otro lado, Benjamin Barber sugiere la complicación de promover la idea de un ser desinteresado eligiendo principios que gobernarán sus elecciones cuando efectivamente deseen algo: "Tengo una gran duda sobre si es posible concebir personas como poseedoras de un conocimiento hipotético de lo que significa tener un interés y deseos sin tener intereses y deseos particulares. Hombres mutuamente desinteresados terminan siendo hombres sin intereses, hombres incapaces de comprender el significado de interés." ${ }^{12}$ Este problema se agrava con la existencia del velo de la ignorancia.

Otra posible vertiente para criticar los límites a la motivación en la posición original de Rawls es la desarrollada por Rodríguez Zepeda:

Ciertamente, Rawls, al excluir las actitudes altamente competitivas de la situación originaria, está garantizando que los principios alcanzados mantengan un perfil igualitario, pero con ello no sólo elimina un rasgo distintivo del desarrollo de las sociedades modernas -la disposición a asumir riesgos y a entrar en condiciones de incertidumbre si es factible esperar la optimización del beneficio personal- sino que anula uno de los atractivos de la propia estrategia contractualista, a saber, su consideración como un mecanismo de juego (gambling) que permitiría la asunción moderada y racional de riesgo en el marco de un sistema aceptado por todos sus participantes. ${ }^{13}$

Si bien Rodríguez considera este problema como "comprensible del todo si consideramos el objetivo moral que persigue, ${ }^{14}$ me parece que responde desde un inicio a la búsqueda de conformar una concepción puramente procedimental y que pueda ser aplicable a cualquier individuo. La crítica de Barber y la de Rodríguez están profundamente relacionadas: si Rawls despoja al individuo de intereses, probablemente al punto de hacer que deje de ser propiamente un individuo, la posibilidad de negociación dentro del contrato queda completamente desairada. La naturaleza hipotética de la posición original es forzada más allá de lo que sería razonable en tanto que Rawls no plantea un escenario dialógico. Aboga no por un proyecto de racionalidad dialógica sino, por el contrario, por una especie de necesidad conceptual derivada de la naturaleza de seres noumenales. Para poder

\footnotetext{
12 Benjamin Barber: "Justifying Justice: Problems of Psychology, Measurement, and Politics in Rawls", The American Political Science Review vol 69 no 2 (1975). 664

${ }^{13}$ Rodríguez, El Igualitarismo Liberal de John Rawls. 119

${ }^{14}$ Idem.
} 
aclarar aún más esta idea, a continuación explico el concepto del velo de la ignorancia.

Para poder alcanzar una concepción de la justicia procedimental, que en una de sus características supone que las circunstancias en las que se encuentren los individuos no pueden ser determinantes en la distribución de bienes, en tanto podrían tomar en cuenta al emitir un juicio características irrelevantes, Rawls recurre al velo de la ignorancia:

La idea de la posición original es el establecimiento de un procedimiento justo para que cualquier principio que sea elegido sea justo. El objetivo es el uso de la noción de justicia procedimental pura como la base de la teoría. De algún modo debemos nulificar los efectos de las contingencias específicas que contraponen a los hombres y los tientan a explotar las circunstancias sociales y naturales en su propia ventaja. En orden para poder lograr esto asumo que las partes están situadas bajo un velo de la ignorancia. ${ }^{15}$

El velo de la ignorancia es una condición donde se restringe la información de las partes en la posición original, de modo que las circunstancias sociales y ambientales no influyan en su elección de principios. Las restricciones son las siguientes: ${ }^{16}$

a. Nadie conoce su lugar en la sociedad, su clase, posición o estatus.

b. Nadie conoce su fortuna en la distribución de bienes ni, del mismo modo, habilidades naturales.

c. Nadie sabe las circunstancias particulares de su propia sociedad, ni la situación política, económica o el nivel de cultura y civilización que poseen.

Estas restricciones impiden a los individuos llevar a cabo una elección que dependa de, o que calcule, la posibilidad de ocupar una posición social determinada. Si tuviéramos el conocimiento de en qué sociedad habitamos (condición particulares de la sociedad en la que vivimos), nuestros principios podrían perder imparcialidad en tanto que elegiríamos una concepción que nos beneficiaría (siempre y cuando asumamos que los individuos efectivamente tienden a perseguir sus intereses). Difícilmente elegiríamos los mismos principios que regirán la vida económica de una sociedad con altos índices de desigualdad y una mayoría pobre que una con una clase media predominante y bajos niveles de pobreza. ¿Por qué elegiríamos distinto? Bajo el supuesto de que en la posición original buscaremos mejorar nuestra circunstancia, es posible que si sabemos que

\footnotetext{
${ }^{15}$ Rawls, $A$ Theory of Justice. 118

${ }^{16}$ Cfr. Ibid. $118-120$
} 
viviremos en una sociedad muy desigual, en donde probablemente seríamos pobres, razonablemente podríamos exigir que todos los bienes del grupo más rico fueran expropiados y repartidos entre los que menos tienen. Del mismo modo, si sabemos que la probabilidad de que pertenezcamos a la clase menos favorecida es prácticamente inexistente, es posible que decidiéramos favorecer principios que limitaran la transferencia de bienes del grupo social más rico al menos rico en la mayor medida posible (aunque en general los Estados que tienen índices de pobreza muy bajos tienden a alcanzarlos a través de políticas de bienestar que justamente hacen esto).

Ahora bien, ¿por qué este tipo de razonamiento es inaceptable para Rawls? El problema es que, contrario al objetivo de imparcialidad y de justicia procedimental, estaríamos desarrollando principios de justicia en función de circunstancias irrelevantes y contingentes. Si los principios que desarrollemos en lo posición original dependen de la sociedad en la que vivimos, entonces los límites de generalidad y universalidad son inaplicables, eso sin contar con que no serían imparciales.

Teniendo claros los límites al conocimiento en la posición original, ¿qué se le permite a las partes conocer? Los individuos en la posición original, que es importante recalcar que es hipotética, conocerían los hechos generales sobre la sociedad humana, los asuntos políticos y la teoría económica, las bases de la sociedad, las leyes de la psicología humana y cualquier otro conocimiento de teorías generales que no remitan a condiciones particulares para el juicio. Este conocimiento nos ofrece, piensa Rawls, los elementos necesarios mínimos para poder elaborar una concepción de la justicia imparcial, con información suficiente, que garantice la aplicabilidad de los principios universalmente.

Es relevante recalcar cómo es que la racionalidad, dentro de una perspectiva como ésta, parecería ser equivalente a la capacidad de computar datos e información de modo que garantice siempre un resultado similar. El propósito del ejercicio de la posición original es mostrar, al modo de ejemplo, como dada la información adecuada cualquier individuo llegaría a conclusiones iguales. Si esta idea es incorrecta, entonces el valor de la posición original, incluso en su dimensión hipotética, es cuestionable para los objetivos de Rawls. La única manera en la que podríamos argumentar por una concepción de la justicia, en tanto su derivación sea de carácter kantiano, es que sea aceptable para cualquier individuo; de lo contrario el objetivo está comprometido. La objetividad de la justicia como imparcialidad implica que los individuos reconocen las premisas de las que la 
concepción se deriva como aceptables y que, al mismo tiempo, sus conclusiones se derivan incontrovertiblemente. Este modo de comprender la racionalidad humana nos remite a una especie de ordenador en el que la racionalidad se convierte en un proceso de cálculo: "el concepto de racionalidad debe ser interpretado en la medida de lo posible en el sentido limitado, de la teoría económica estándar, de tomar los medio más efectivos para ciertos fines. ${ }^{17}$ Este concepto de racionalidad, y la seguridad que tiene Rawls para asumir que su concepción de la justicia (o para el caso una similar que diera un valor alto a la imparcialidad $\mathrm{y}$, por tanto, a la igualdad) sería elegida en la posición original, nos debería llevar a preguntarnos si es realmente posible que la derivación del liberalismo sea prácticamente una necesidad. En palabras de Bernard Williams: “ ¿Realmente podemos suponer, como Kant suponía, que la razón es en sí misma una razón liberal, y que una práctica ética que sea distinta de la moral de la autonomía implica un rechazo a querer escuchar razones en lo absoluto, el equivalente a taparse los oídos? Seguramente no." ${ }^{18}$

Dado que el liberalismo es históricamente reciente y que no asumo que las sociedades no liberales, tanto anteriores como actuales, carecen de razón, una respuesta que Rawls podría ofrecer es que, mientras que las leyes de la psicología no sean conocidas, las personas no tienen las mismas herramientas conceptuales para poder juzgar, como sucede con las que sí las conocen, con verdad. A una respuesta de este tipo podríamos decir que, aun cuando las leyes de la psicología hayan sido mejor postuladas y nuestro conocimiento al respecto esté mejor justificado y sea más profundo que en cualquier otro momento de la historia, si la selección de la concepción de la justicia depende del estado de la ciencia (reconociendo que la comprensión de Rawls de lo que es el conocimiento científico es bastante deficiente), entonces la concepción de la justicia tiene simplemente un carácter hipotético (como podría ser postulado desde el pragmatismo deweyano dada la naturaleza hipotética del conocimiento científico). Sobre esta naturaleza hipotética de la concepción de la justicia hablo más en el cuarto capítulo, en donde realizo una lectura eminentemente pragmática de la justicia como imparcialidad.

Por otro lado, continuando con la exposición del velo de la ignorancia, es necesario afirmar que hay un problema con la restricción del conocimiento que es cercano a la crítica antes citada, de Benjamin Barber, sobre los límites a la motivación de las partes en la posición original. Aun cuando aceptáramos que

\footnotetext{
17 Ibid. 12

${ }^{18}$ Bernard Williams: "In the Beginning Was the Deed", en In the Beginning Was the Deed (Princeton: Princeton University Press, 2005). 22-23
} 
Rawls no está intentando realizar una descripción metafísica o antropológica del individuo ideal en la posición original, y que sólo intenta desarrollar una instancia que permita persuadir de lo adecuado de su concepción de la justicia, es por demás urgente resolver el problema de si tal nivel de imparcialidad es razonablemente asequible e incluso deseable pues, como afirma Lewis: "No es en lo absoluto evidente que existan leyes universales significativas que determinen el comportamiento humano, individual o colectivo, con la misma regularidad que las leyes de la física que gobiernan el mundo material. No parece ser posible el desarrollo de los principios más generales para la regulación de una sociedad particular sin saber nada de las características distintivas de dicha sociedad." ${ }^{19} \mathrm{La}$ realidad es que no es del todo claro que el objetivo de universalidad al que apunta Rawls sea posible. Una cuestión que vale la pena cuestionarse es si los individuos hipotéticos que propone Rawls realmente sirven para ejemplificar modos de racionalidad humana real. A Barber le interesa la cuestión de si es posible pensar en un ser preocupado por intereses sin tener intereses propios, en ese mismo tenor podemos preguntarnos si es razonable que existan individuos preocupados por la justicia (y la libertad) que no tengan conocimiento "personal" de lo que son la injusticia, la justicia, la tiranía y la libertad.

Aun cuando lo que Rawls busca con este concepto de racionalidad es "evitar introducir elementos éticos controversiales" ${ }^{20}$, es menester mencionar que no deja de ser controversial el limitar el concepto de racionalidad al mero cálculo de posibilidades. El problema de la definición de lo que es la razón es complejo y asumir una definición proveniente de la modernidad, en particular de Thomas Hobbes y después apropiado por la tradición económica, es todo menos poco controversial. Uno de los problemas comúnmente asociados a este modelo de racionalidad es que tiende a despojar la evaluación de los fines del análisis racional. Así, decimos que un individuo como Adolfo Eichmann actuó racionalmente al planificar la deportación de judíos durante la Segunda Guerra Mundial, debido a que su selección de medios fue altamente eficaz. Por el contrario, por ejemplo, un criterio para evaluar la racionalidad anterior sería el que Charles Taylor denomina como "logos óntico" en Las Fuentes del Yo, donde asume que en la antigüedad existía una convicción de que el ejercicio de la razón está en la capacidad de los individuos de descubrir la naturaleza de la realidad y actuar conforme a ella. ${ }^{21}$ Aun cuando el criterio de racionalidad antiguo es difícilmente

\footnotetext{
${ }^{19}$ Cfr. Lewis, Justice or Tyranny. 29

${ }^{20}$ Idem. Rawls, $A$ Theory of Justice.

${ }^{21}$ Cfr. Charles Taylor, Sources of the Self (Cambridge: Harvard University Press, 1989). 186-192
} 
justificable bajo estándares actuales, es importante recalcar cómo es que Rawls introduce de contrabando un concepto de racionalidad que no es, en modo alguno, simple o neutral. Esto no quiere decir que el concepto de racionalidad rawlsiano no esté justificado frente a otras opciones, sin embargo, de ningún modo es un concepto poco controvertido. La racionalidad moderna presenta una ventaja para la empresa de Rawls, frente a otras opciones, ya que es una racionalidad imparcial en que los fines no son cuestionados. En cualquier caso, la introducción de un concepto como este pone en duda la universalidad de la concepción.

Volviendo al velo de la ignorancia, teniendo claro lo que la racionalidad implica en el contexto de la filosofía de Rawls, aparentemente lo que está de fondo en la idea de la posibilidad del consenso, es decir, de la idea que asume que con la misma información se obtienen los mismos principios, es la existencia de un mismo fin para todos los individuos. Si la racionalidad es la capacidad de seleccionar los mejores medios para alcanzar un fin, y los individuos de la posición original buscan desarrollar principios de justicia que gobiernen la estructura básica y las instituciones y ejercicios de poder que se deriven de ella, para que concluyan los mismos principios deberían tener los mismos objetivos en mente.

Si el velo de la ignorancia prohíbe el conocimiento del yo empírico a los seres noumenales, ¿cómo podrían tener fines?, si las partes no tienen fines determinados, ¿qué reclamos estarían intentando jerarquizar los principios que se elaboran?, ¿qué forma podrían tener dichos principios? Si los seres noumenales no desean nada, pues no tienen noticia de sus intereses o preferencias, ¿cómo podría surgir el conflicto? Si no hay conflicto, ¿para qué necesitamos principios de la justicia? La necesidad de los principios surge porque somos seres empíricos, seres con intereses, preferencias y necesidades. ¿Por qué confiaríamos en los acuerdos y conclusiones de seres que posiblemente no entiendan la necesidad y urgencia de tener una concepción de la justicia?

Una de las críticas más comunes a Rawls y la derivación de los principios de la justicia, justamente proviene de la duda sobre cómo es que individuos condicionados por el velo de la ignorancia estarían en posibilidades de determinar principios de acción. El problema, sin duda complejo, se refiere a si los participantes pueden ser capaces de tener una visión, como diría Dewey, ecológica de su contexto; y por tanto de estar en posibilidades de realizar juicios morales vinculantes. Si la decisión de elección de principios no satisface algunos requisitos cognitivos mínimos (como podría ser el conocimiento de las circunstancias en el caso del juicio moral y político), no es tan claro de qué modo se justificaría dicha 
decisión. Esta crítica también está presente en la lectura de Thomas Nagel de Teoría de la Justicia. Nagel reconoce, como muestro con mucha más claridad adelante en el capítulo, que las limitaciones en el conocimiento y las motivaciones en el pensamiento de Rawls terminan implicando una idea del bien determinada; contrario al objetivo de imparcialidad total que procura alcanzar Rawls, Nagel piensa que, de fondo, existe una idea del bien supuesta en la justicia como imparcialidad:

El modelo tiene una tendencia fuertemente individualista que está, además, reforzada por los supuestos motivacionales del desinterés mutuo y la ausencia de envidia. Estos supuestos tienen el efecto de excluir las pretensiones de las concepciones del bien que dependen fuertemente de la relación entre la propia posición y la de los demás (...). La posición original no parece presuponer una teoría neutral del bien, sino una concepción liberal, individualista, según la cual lo mejor que podemos desearle a alguien es la prosecución sin obstáculos de su propio camino, siempre que no interfiera con los derechos de los demás. ${ }^{22}$

Encuentro muy atinado el comentario de Nagel. Como muestro al final del capítulo, el liberalismo, incluso el de Rawls, es mucho más incompatible con diversas ideas del bien de lo que la neutralidad rawlsiana reconoce. Lo que es más, mostraré, de igual modo, que es la obligación del gobierno, quien debe encarnar la concepción de la justicia, promover la idea de bien que está de fondo dentro de la concepción de la justicia rawlsiana. Antes de hacer esto continúo con la exposición del pensamiento de Rawls, en particular con los bienes primarios y los principios de la justicia.

Los bienes primarios en Rawls tienen la finalidad de garantizar la imparcialidad entre las distintas ideas del bien que puedan tener los participantes dentro de la posición original. Rawls intenta, contrario a la crítica de Nagel, ofrecer un mecanismo para desarrollar una concepción de la justicia que permita la búsqueda de las más diversas concepciones del bien. Rawls necesita generar una instancia adecuada para argumentar por los fines que, si bien las partes no tendrían dentro de la posición original, sí tendrán en el momento en que salgan de ella. Por esto es que es necesaria la convicción de que los bienes primarios son, efectivamente, de un tipo que todos los individuos pensarían que desearán en la mayor medida posible una vez que salgan de la posición original. En la medida en que los bienes primarios son deseados por todos, por lo general en la mayor cantidad posible, y que son escasos, es que tiene sentido discutir su distribución en la posición original; si nadie los quisiera, o no fueran escasos y todos pudieran

${ }^{22}$ Thomas Nagel: "Rawls: sobre la justicia” en Otras mentes (Barcelona: Gedisa 2000). 164-165 
tener acceso a ellos, no tendría sentido plantearnos si existe una manera justa de distribuirlos en la posición original. A continuación me centro en ellos.

\section{$\underline{\text { Los bienes primarios }}$}

El problema de la justicia, su determinación y concepción, es para Rawls básicamente el problema de la distribución. El tema de la posición original es, por tanto, la determinación, como vimos al tratar el tema de la justicia procedimental perfecta, de los mecanismos de distribución. La cuestión que sigue es responder la pregunta: ¿qué vamos a distribuir?

El problema se perfila una vez que reconocemos, como es implícito dada la necesidad del velo de la ignorancia como recurso para garantizar la imparcialidad, que el pluralismo de concepciones del bien es la norma y no la excepción dentro de una sociedad. El velo de la ignorancia tiene por función, al menos en parte, limitar el conocimiento de las ideas del bien debido a que, considera Rawls, la formulación de principios de justicia tomando en cuenta nuestra idea del bien tiende a la parcialidad y, por lo mismo, a generar condiciones injustas para los principios escogidos. Ahí donde no hay imparcialidad difícilmente podría haber justicia, pues los juicios responden a características irrelevantes para la justicia. El problema con el que se encuentra Rawls es que, aceptando que los individuos sostienen concepciones del bien diversas, al postular el velo de la ignorancia queda la pregunta: ¿bajo qué estándares podrían los individuos decretar principios de justicia si no tienen idea de qué bienes quieren distribuir? Este tema, que no es otro que el de los bienes primarios, lo trata Rawls en Teoría de la Justicia en dos lugares fundamentalmente: en la primera parte, en la sección 15 y en la tercera parte, en el capítulo 7. En la primera parte lo hace en el contexto del planteamiento de los principios de la justicia, después de haber analizado la justicia procedimental. La siguiente ocasión en que Rawls se centra en los bienes primarios dentro de la Teoría de la Justicia es en la tercera parte, en donde expone el concepto del bien como racionalidad. Esta segunda aproximación a los bienes es particularmente relevante pues, como expongo en este apartado, asume en cierta medida un modelo de racionalidad (del que ya he dicho algunas cosas) para definir la composición del bien; lo problemático de este hecho es que implica que las ideas de bien que sean consideradas desde otro modelo de racionalidad serían inaceptables, o al menos inadecuadas, dentro de la sociedad rawlsiana. 
Los bienes que se pretende repartir dentro de la posición original, estando cubiertos por el velo de la ignorancia, deben de ser de un tipo que todos deseen. Recordemos el ejemplo de justicia procedimental perfecta, lo adecuado del ejemplo supone que todos los individuos a los que se les reparte el pastel quieren la mayor cantidad posible. Supongamos que todos desearan tamaños, o porciones distributivas, distintas: pensemos que vamos a distribuir el pastel entre cuatro personas, dos que quieren la mayor cantidad posible (una de ellas distribuirá el pastel), otra que está a dieta (y por lo mismo sólo comerá un poco) y una cuarta que es intolerante a la lactosa (y por ser un pastel de queso puede comer muy poco pastel); si esta fuera la condición, y quien reparte tiene conciencia de esto, la distribución sería claramente distinta e indisputada. El problema se agrava si una parte cree que merece más pastel que los demás por su color de piel o cualquier otra característica moralmente irrelevante para la distribución misma. El velo de la ignorancia permite sortear este problema ya que estamos argumentando en favor de una distribución inicial imparcial; esto quiere decir que posteriormente podrían desarrollarse los ajustes en la distribución según fueran necesarios dadas las circunstancias contingentes que se presentaran.

El problema por el que es necesario desarrollar una concepción de los bienes primarios es el que surge de imaginar que hay quienes simplemente no quieren pastel. Imaginemos que estamos en la posición original, considerando qué principios de la justicia escogeremos para regir las relaciones sociales y definir las partes distributivas, y nos enfrentamos con que buena parte de los principios no atienden a las necesidades o deseos de las partes. Un ejemplo de esto podría ser el desarrollo del contrato en función del establecimiento y protección de la propiedad privada como mecanismo de producción exclusivamente. ¿Qué problemas surgirían si cuando estamos en el proceso de establecer los límites y obligaciones del poder político reconocemos que una parte importante de los contratantes creen en la propiedad comunitaria como forma deseable de propiedad? Parece no haber nada en la naturaleza noumenal del hombre que impida que la propiedad comunal pueda ser considerada razonablemente un bien. Hay ocasiones en que las ideas del bien son tan distintas que su diferencia no es de grado, sino que son radicalmente opuestas. Por lo tanto, Rawls está en la obligación de proponer bienes que sean de un tipo que todo individuo racional desee, independientemente de su idea del bien particular: "Sin importar cuál sea el plan racional de un individuo en particular, se 
asume que existen varias cosas que los individuos preferirían en mayor que en menor cantidad." 23

Cuando Rawls dice que existen cosas que son deseables siempre en la mayor medida posible, independientemente del plan racional de vida, nos da una pista clara sobre la naturaleza de los bienes primarios. ${ }^{24}$ La idea anterior nos ofrece dos posibilidades. La primera es que los bienes primarios son bienes compatibles, aunque independientes, con todos los planes racionales de vida. Esta opción significaría que existen una serie de bienes (que aún no hemos definido) que pueden ser entendidos como fines y que pueden ser compatibles con ideas de bien hipotéticamente contradictorias y de las que todos los individuos pueden gozar igualmente sin contradicción. Sin duda no hay evidencia de que exista un bien de este tipo.

La segunda opción, que es la que Rawls asume como adecuada y es la que supone que los bienes primarios son medios necesarios para alcanzar los fines planteados en los diversos planes racionales: "Con más de estos bienes las personas pueden generalmente asegurar un mayor éxito para alcanzar sus intenciones y lograr sus fines, cualesquiera que estos sean." ${ }^{25}$ Todo individuo racional, o que tenga un plan racional de vida, deseará más bienes primarios por la razón de que dichos bienes son los medios necesarios para alcanzar dicho fin. Esto significa que todos los planes de vida exigen, en cierta medida, los mismos medios básicos; ésta también es una idea controversial.

Este modo de proceder es innovador. Asumiendo que hablaré sobre cuáles son los bienes primarios en concreto y el modelo de racionalidad que Rawls

\footnotetext{
${ }^{23}$ Rawls, $A$ Theory of Justice. 79

${ }^{24}$ Asumiendo que los bienes primarios implican una especie de neutralidad respecto a los planes racionales de vida (que incluyen la búsqueda racional del bien), no deja de ser curioso el planteamiento de Rawls sobre el principio aristotélico. Con este principio Rawls asume que las personas tienden a disfrutar más, naturalmente, las actividades que los llevan a desarrollar sus capacidades en mayor medida o que tienden a ser más complejas (Cfr. A Theory of Justice. 374).

Si el principio aristotélico conduce a las personas a perseguir actividades y proyectos más complejos y es un principio que opera en todos los seres humanos racionales, como supone Rawls, la distribución de bienes primarios tendería a beneficiar de modo injustificado un tipo de proyecto de vida, los racionales al modo que entiende Rawls. Esto implica una parcialidad hacia cierto tipo de proyectos que Rawls, probablemente, no aceptaría por negar la relevancia de la neutralidad y el antiperfeccionismo. Esta paradoja, al introducir Rawls dicho principio, la explica con claridad Brian Barry:

(...) un hombre cuya decisión fuera contraria a él -es decir al principio aristotélico- diríamos que no tiene un "plan racional". Por ejemplo, alguien con un paladar moderadamente desarrollado para el vino que prefiriera tomar cerveza la mayor parte del tiempo tendría que ser llamado irracional, ya que hay menos discriminación involucrada en el beber cerveza que en beber vino. Deberíamos decir que, contrario a las intenciones declaradas por Rawls, que una idea de la excelencia humana está siendo propuesta bajo la cubierta de un aparente racionalidad neutral. (Barry, The Liberal Theory of Justice. 28)

${ }^{25}$ Rawls, $A$ Theory of Justice. 79
} 
supone para los planes racionales de vida que desearán dichos bienes, es un buen momento para evidenciar cómo es que Rawls se distancia de buena parte de la tradición filosófica en este punto, al menos de cualquier teoría utilitarista, teleológica o perfeccionista en cualquiera de sus modalidades. Cuando Rawls propone que los bienes a distribuir en la posición original son aquellos que sirven como medios para diversos planes de vida racionales, y asumimos que la primera virtud social es la justicia, estaría afirmando que la virtud fundamental de la comunidad política es garantizar la distribución de medios para alcanzar proyectos personales del vida. La separación con la tradición se encuentra en que la finalidad política, en particular una del tipo moral como lo es la concepción de la justicia de Rawls, no tiene un fin determinado "independiente" de los fines particulares. Con esto Rawls conduce a que el bien común sólo se entienda como la ordenación social (en función de cómo los principios afectan la estructura básica) para de garantizar la justa distribución de medios, nada más que eso. El contraste con el organicismo aristotélico, por ejemplo, es claro. Para Aristóteles el fin de la comunidad política es el bien común. Si bien la definición del bien común siempre ha sido complicada, la analogía organicista lo plantea en términos del bienestar del organismo político completo. Esta perspectiva política tendería a asumir que hay sectores de la población que en ocasiones tienden que padecer dificultades en favor del bienestar de la comunidad en tanto que el todo es más importante que la parte, de este modo se podría justificar, por ejemplo, la esclavitud (como lo hizo el mismo Aristóteles).

En el caso de Rawls se puede empezar a ver que una explicación en el orden del bien común es inadecuada. La definición de un bien objetivo públicamente reconocido por todos pero que, al mismo tiempo, no es un bien para cada uno en lo particular carece de sentido. Dado que los individuos en la posición original no conocen los detalles y circunstancias históricas en las que se encuentran, así como la posición que ocuparán en la sociedad (ni siquiera en un sentido genérico de clase privilegiada o sin privilegios), asumir que es posible un consenso dadas esas circunstancias es una mera ilusión. No es posible determinar un bien común en la posición original dadas las limitantes impuestas por el velo de la ignorancia, por tanto queda la pregunta de si podríamos definir el bien común fuera de la posición original. El problema con una teoría política fundada en la idea del bien común, desde las premisas rawlsianas, es que definir dicho bien implicaría, posterior a las determinaciones de la posición original, que es posible descubrir, o construir para el caso, un bien que trasciende la racionalidad y los acuerdos de los sujetos noumenales. Sería tanto como decir que los fines de los individuos, aun cuando estuvieran en consonancia con la concepción de la justicia públicamente 
reconocida, son secundarios por un fin o bien distinto $\mathrm{y}$, en esa medida, la autonomía de las personas está sujeta a las condiciones particulares contingentes históricamente analizables. Desde una comprensión kantiana de las personas esto es inaceptable.

Dicho lo anterior, es importante volver al análisis del problema de los bienes primarios como medios necesarios para alcanzar cualquier ideal del bien razonable (sin duda hay ideas del bien inaceptables que no serían reconocidas como válidas en la posición original, por ejemplo la idea del bien que pueda tener un asesino serial). Una idea fundamental dentro del concepto de bienes primarios, en tanto que son medios necesarios, es la idea de una aproximación al bien racional, en particular una idea de la racionalidad en un sentido instrumental o enfocada en los medios:

Debemos suponer, por tanto, que cada individuo tiene un plan racional de vida sujeto a las condiciones en las que éste se encuentra. Este plan está diseñado para permitir la armoniosa satisfacción de sus intereses. Programa las actividades de modo que varios deseos puedan ser satisfechos sin interferencia. Llegamos a él rechazando otros planes que son menos probables de tener éxito o que no proveen una obtención inclusiva de objetivos. Dadas las alternativas disponibles, un plan racional es aquel que no puede ser mejorado; aquel del que no hay otro, tomando todo en consideración, que sería preferible. ${ }^{26}$

Esto quiere decir que los planes racionales de vida implican una preferencia por uno o más bienes que no se poseen actualmente y que para obtenerlos es necesario contar con ciertos medios necesarios. La apuesta de Rawls es que existen ciertos medios mínimos necesarios, que por sí no excluyen la existencia de otro tipo de bienes, para que, independientemente del plan de vida racional, podamos ser exitosos: ${ }^{27}$ derechos, libertades, oportunidades, ingreso, riqueza y una buena auto estima (o una idea positiva de uno mismo). ${ }^{28}$

\footnotetext{
${ }^{26}$ Ibid. 80

${ }^{27}$ Este punto ha sido uno de los más contendidos de Teoría de la Justicia. ¿Son realmente los bienes primarios neutrales ante todas las ideas del bien? Una crítica clásica es la de Joseph Raz: "Todas las concepciones que implican el cultivo y satisfacción de los llamados gustos caros son más difíciles de satisfacer, y la teoría rawlsiana puede ser acusada de discriminar contra ellos.

"Las concepciones no individualistas probablemente se encuentren dentro de los gustos caros dado que su realización depende en la cooperación de otros, y para lograrlos se tendrán que convencer a los agentes de que vale la pena. (...) Esta consideración apunta al hecho de que las restricciones mismas impuestas por los principios de la justicia de Rawls hacen la implementación de algunas concepciones del bien más difícil y su búsqueda menos atractiva que otras para los individuos." (Joseph Raz, Morality of Freedom (Oxford: Oxford University Press, 1988) 119-120)

${ }^{28} \mathrm{Cfr}$. Rawls, $A$ Theory of Justice. 79
} 
Esta teoría de los bienes primarios exige un desarrollo mayor de una teoría del bien en general. Diremos que algo es un bien siguiendo una fórmula muy simple: ${ }^{29}$ " $\mathrm{A}$ " es un bien " $\mathrm{X}$ " para " $\mathrm{P}$ " (persona con un plan racional de vida) si, y sólo si, " $\mathrm{A}$ " tiene las propiedades deseadas, al menos en un estándar normal, de " $X$ ", en tanto que se espera que " $X$ " sea usado o sirva para algo. Esta fórmula nos permite comprender la necesidad de entender el bien, o los bienes si fuera el caso, bajo dos supuestos. Por un lado el bien siempre está en función de algún objetivo trascendente al bien mismo; decir esto es tanto como afirmar que cuando queremos algo, o cuando percibimos un objeto como un bien, siempre está en función de su cualidad de medio. Esto ocurre de modo evidente cuando, por ejemplo, entendemos que un martillo es un bien cuando tengo como fin clavar algo a la pared o, del mismo modo, cuando entiendo que el agua es un bien en tanto necesito consumirla para seguir vivo. Incluso en algunos otros bienes que se han conceptualizado como bienes en sí mismos tendríamos que afirmar que son, del mismo modo, medios, aun cuando no los deseemos para obtener un objeto posterior concreto, en tanto que deseamos su efecto; del desarrollo espiritual, que en buena medida tiende a ser entendido como el bien por excelencia (ya sea en su modo del valor del conocimiento por sí mismo o de la iluminación espiritual, si algo así existe, en su sentido religioso tradicional), buscamos el cambio en el espíritu y la sensación (o percepción, que no siempre son lo mismo) de realización.

La comprensión del bien que nos presenta Rawls en la Teoría de la Justicia tiene otro supuesto, que también responde a categorías pragmáticas, que implica que un bien es tal en función de cómo se compara con las opciones que contienden con él. De nuevo este supuesto nos lleva a comprender el bien siempre en un sentido instrumental en tanto que lo que hoy se considera un bien puede dejar de serlo en tanto se descubran mejores medios que compitan. Un ejemplo muy simple de esta realidad está en el desarrollo histórico de la medicina: en la antigüedad, antes del descubrimiento de los antibióticos, existía una gama de opciones médicas limitadas para tratar, por ejemplo, una infección en el pie. Si estuviéramos viviendo en Europa medieval y por un accidente tuviéramos una seria infección en el pie, es probable que la amputación del miembro fuera un bien en la obtención del bien preferible de la salud. Con la existencia de antibióticos es probable que pensemos, en términos actuales, en la amputación de un pie por una infección más como un mal que un bien. Si la amputación es un medio para recobrar la salud, será un mal medio que cumple con este fin en un grado menor (¡nos quedamos sin pie!) que sus posibles competidores.

${ }^{29}$ Cfr. Ibid. 350-351 
Con estas consideraciones podemos desechar, con la ayuda de Rawls, la idea de un bien en sí y nos mantenemos en el orden del bien para. El calificativo de bien no se refiere a una propiedad intrínseca de las cosas sino a las intenciones del agente y en las posibles comparaciones con otros bienes: "Un punto trascendente es que no existe algo necesariamente justo, o moralmente correcto, sobre el punto de vista desde el que las cosas son juzgadas como un bien o un mal." ${ }^{30}$ Este punto es importante dentro del liberalismo de Rawls debido a que representa un ataque a las teorías del bien teleológicas que asumen que existen bienes que deben de ser perseguidos independientemente de las condiciones históricas de los individuos. Al mismo tiempo, dentro de la posición original, garantiza a las partes que los principios que elijan deben ser respetados y sirvan como límites efectivos a la búsqueda del bien de los individuos en tanto que nadie puede afirmar la existencia de un bien metafísico que todos deban perseguir. Al desarrollar principios de justicia fundamentados en la dimensión noumenal de los individuos es posible afirmar que todas las consideraciones de bien posteriores, empíricamente determinadas, se tienen que sujetar a dicha concepción de justicia en tanto que ninguna tiene una naturaleza metafísicamente vinculante o anterior para todos los seres.

Esta aproximación pragmática a la naturaleza del bien, que nos remite al pensamiento de Dewey para quien la calificación de bien está históricamente (y por tanto "ecológicamente") determinada, tiene sus detractores. El pensamiento político y antropológico de Charles Taylor es una de las respuestas más acreditadas. Para el canadiense una afirmación de que todos los bienes son tales en un sentido pragmático implicaría la inexistencia de lo que él llama los hyperbienes, ${ }^{31}$ que son el tipo que nos sirven como base para juzgar todos los demás tipos de bienes independientemente de las circunstancias contingentes concretas. Por su parte, Rawls desarrolla un instrumento funcional para, mediante el desarrollo "posterior" de la concepción de la justicia liberal de Teoría de la Justicia, afirmar la improcedencia de permitir que ideas del bien determinadas puedan afirmarse en el poder político argumentando por el Bien de la comunidad o de la humanidad. Si Rawls es capaz de formular la justicia como imparcialidad como una concepción de lo justo independiente de lo bueno y que niega la existencia del bien en sí, entonces habrá logrado formular una teoría de la justicia secular y, en su aplicación, secularizante de la sociedad. El contraste con el pensamiento de autores como Charles Taylor en este punto es especialmente

\footnotetext{
${ }^{30}$ Ibid. 357

31 Taylor, Sources of the Self. 63-73
} 
importante. Para ver con claridad el impacto que esto puede tener es necesario profundizar un poco en la idea de los hyperbienes. Como ya mencioné, los hyperbienes según Taylor nos sirven para juzgar el valor del resto de bienes a los que tenemos acceso en la sociedad. Es decir, deben ser perseguidos por el valor de que en sí mismos presentan (pues son bienes después de todo) y, al mismo tiempo, nos sirven como estándares para evaluar distintos otros bienes en la medida que representan un estadio de conciencia moral más elevado; ${ }^{32}$ el ejemplo que usa Taylor es la noción del trato justo e igual a las personas. ${ }^{33}$

El ejemplo de hyperbien de Taylor parecería conducir a un tipo de liberalismo imparcial como el que Rawls desarrolla, eso, sin embargo, no es así. El problema, desde una perspectiva liberal-imparcial, con la teoría de los hyperbienes es que no termina con la postulación de la justicia y la imparcialidad, simplemente es uno de los ejemplos. Los hyperbienes son múltiples y su origen se encuentra en la historia de la humanidad. Es decir, a diferencia de suponer que los bienes están históricamente determinados (lo que significa que hay bienes que son tales en un momento pero no lo son en otro), Taylor supone que los bienes se desarrollan durante la historia y se van "perfeccionando" con el paso del tiempo: "Los más importantes -se refiere a los hyperbienes-, aquellos que están más vinculados a nuestra civilización, han surgido a través de una superación de visiones antiguas y menos adecuadas -análoga a la superación crítica de la ciencia premoderna a la moderna $(. . .)^{\prime 34}$ Esta idea es problemática en al menos dos sentidos, una de carácter práctico (por no llamar directamente de estabilidad) y otro de carácter cognitivo. Por un lado, en tanto haya una característica en los bienes morales que los hace ser "verdaderamente" buenos, independientemente de sus circunstancias históricas, la necesidad de un planteamiento de justicia independiente de la idea de bien es una idea equivocada (pues no se justifica permitir la existencia de ideas del bien que contradigan una idea de lo justo fundamentada en un hyperbien); si esto es así, sería razonable justificar la imposición de ciertos bienes provenientes de ciertas tradiciones independientemente de que podamos dar una justificación pragmática a quienes queremos imponérselos. Por otro lado, si los hyperbienes no se justifican pragmáticamente, no tenemos ningún otro modo para justificarlos que no sea a través de la tradición, lo que por sí mismo no nos ofrece un mecanismo de justificación válido frente a quienes no compartan nuestra tradición. Estas dos dificultades son, de fondo, las inquietudes que justifican la existencia de la

\footnotetext{
${ }^{32}$ Cfr. Ibid. 64

${ }^{33}$ Idem.

${ }^{34}$ Idem.
} 
sociedad liberal misma, contra la que atentaría una idea del bien como la propone Charles Taylor. Dicho de otro modo, si seguimos una idea como la de los hyperbienes a una de sus posible conclusiones, diríamos que es legítimo que la sociedad imponga una idea de lo justo intrínsecamente vinculada a una idea de lo bueno particular a pesar de que pueda ser incapaz de justificarla más allá de ser parte de su tradición. Esto nos podría conducir rápidamente a un conservadurismo social y cultural del tipo más hermético.

Ahora bien, regresando a la idea del bien rawlsiana, así como su presunta neutralidad, lo que queda claro es que la naturaleza de los bienes primarios es menos neutral, como ya había mencionado antes citando a Nagel, de lo que Rawls desearía. El problema de los bienes primarios y su desarrollo en Rawls es problemático pues asume que el modo correcto de disfrutarlos-poseerlos-desearlos es en su dimensión de medios en una medida similar o igual por parte de todas las personas; es posible, como se puede anticipar, que distintas personas los procuren sobre la base de una comprensión radicalmente distinta, como afirma Barber: "Sin embargo, bienes primarios tan distintivos como la libertad, el poder, la riqueza y el autorespeto pueden difícilmente considerarse como satisfactorios en un modo unitario excepto desde la perspectiva de un hedonismo rudimentario al cual Rawls no parece suscribirse. (...) Algún cristiano asceta podría quejarse de que el estándar rawlsiano los priva de la austeridad y la lucha por sobrevivir que asumen como necesaria para alcanzar sus demás creencias mundanas." ${ }^{35}$ De nuevo este problema conduce a un contenido moral robusto en el liberalismo de Rawls. Aun cuando procura generar las condiciones adecuadas para justificar un liberalismo que dé cabida a otras concepciones del bien, el ethos liberal genera condiciones astringentes relativamente incompatibles con concepciones del bien distintas.

La formulación del bien y de los bienes primarios en Rawls termina implicando, de algún modo, la obligación de todos los integrantes de la comunidad política de reconocer los límites de sus ideas del bien respecto de una concepción de lo justo elaborada con pretensiones noumenales. La cuestión de esta aproximación no es si una sociedad liberal y democrática aceptaría dicha formulación del bien y de los bienes que se distribuirán en la posición original, la pregunta interesante es si una persona que no es liberal, asumiendo que acepta las formulaciones de la posición original en primera instancia, pues está sujeta al velo de la ignorancia, mantendrá su alianza con una concepción de la justicia que no reconoce la naturaleza de sus bienes del mismo modo. Dicho de otro modo, parece

\footnotetext{
35 Barber: "Justifying Justice: Problems of Psychology, Measurement, and Politics in Rawls". 665-666
} 
fácil construir una concepción liberal estable para una sociedad liberal, ¿es igual de fácil construirla para una sociedad que no es previamente liberal?, ¿tiene alguna responsabilidad la comunidad política de desarrollar una cultura liberal activamente en perjuicio de concepciones no liberales? Como veremos más adelante, el antiperfeccionismo de Rawls asume que es ilegítimo que el Estado lleve a cabo acciones para imponer una concepción liberal del bien (que es una concepción compleja e irreconciliable con muchas de sus competidoras); Rawls parece no tomar en serio las diferencias en las ideas del bien que pueden surgir entre los individuos y el impacto que pueden tener en la estabilidad de la comunidad. ${ }^{36}$

Una defensa sustantiva, que pudiera dar cuenta de las diferencias culturales y las diversas comprensiones del bien, de los bienes primarios y de la comprensión pragmática del bien, en tanto que la adjetivación de bueno se otorga en función de intenciones y comparaciones con otros medios disponibles, necesitaría de una teorización más completa de la racionalidad. Rawls desarrolla dicho argumento en las secciones 62 a 64 de Teoría de la Justicia.

La racionalidad en Rawls está íntimamente vinculada, como había dicho antes, con la comprensión de la racionalidad de medios hobbesiana. Este modo de racionalidad moderna ha conducido al desarrollo del modelo de elección racional que es sumamente popular dentro del ámbito económico. Podríamos decir que la racionalidad se dice de los procesos cognitivos que cumplen con ciertas características básicas: no toda decisión-elección es racional. La elección racional se sostiene, considera Rawls, bajo tres principios: ${ }^{37}$

1. La elección racional debe tomar en cuenta la eficacia de los medios: debemos escoger los medios que garanticen de mejor modo nuestros objetivos.

2. Cuando desarrollamos un plan al corto plazo elegiremos el que, entre sus competidores, sea capaz de alcanzar la mayor cantidad de objetivos deseables.

3. Cuando debemos elegir entre una variedad de planes (2 o más) debemos elegir aquel que ofrece las mayores probabilidades de éxito en el alcance de nuestros objetivos.

\footnotetext{
${ }^{36}$ Como muestro en la siguiente parte de esta investigación, Rawls intenta solucionar el problema en el Liberalismo Político a través del concepto de razonabilidad.

${ }^{37}$ Cfr. Rawls, $A$ Theory of Justice. 358-362
} 
No debemos pensar que estos principios representan una versión completamente acabada de la racionalidad. Si bien se presentan como su sustento fundamental, están abiertos a un análisis posterior. Por ejemplo, una variante del segundo principio respecto al largo plazo nos obligaría a considerar los estados intermedios dentro del plan y el modo en que cada un afecta nuestra posibilidad de acceder a más bienes: una persona podría pensar que robar un banco en el corto plazo es un buen proyecto pues la obtención de dinero le permite alcanzar la mayor cantidad de recursos en el menor tiempo; sin embargo, utilizando el mismo principio, en referencia al largo plazo, podríamos pensar que, aun cuando en el corto plazo pudiéramos quedarnos con el dinero, eso no implica que no seremos atrapados después, terminemos en la cárcel y debamos renunciar al resto de nuestros objetivos a futuro.

Uno de los retos de la teoría de elección racional consiste en que, al negar la existencia de un conocimiento sustantivo del bien (un bien en sí mismo), la definición y búsqueda del bien está limitada por la información realmente disponible. Decir esto es tanto como afirmar que no hay garantías sobre el éxito de nuestros planes (por tanto el tercer principio de probabilidad) pero, al mismo tiempo, sobre la satisfacción de la obtención de nuestros deseos. Este punto es importante pues puede servir, al mismo tiempo y aun cuando Rawls no lo hace directamente, para defender la existencia y repartición de los bienes primarios dentro de la posición original. Como mencioné anteriormente, los bienes primarios se refieren a libertades, derechos, ingresos, riqueza y a la autoestima de los individuos. Siempre que Rawls sostenga un modelo de racionalidad instrumental como ha hecho hasta ahora, y que lo haga afirmándolo sustantivamente como parte de una comprensión liberal del individuo, podría ser capaz de argumentar por la importancia de las libertades, derechos y el resto de los bienes primarios ya que dichos bienes facilitan la obtención de mejor información y de mejores elecciones a futuro. Si esta defensa es viable desde la perspectiva de Rawls, y creo que así es, Dewey y Rawls reconocerán en la sociedad liberal no sólo el medio para que cada quien pueda perseguir sus propios deseos o intereses sino que, del mismo modo, es un ambiente propicio para el mejoramiento social en que se permite un mejor desarrollo de la racionalidad y la elección que de ella emana. Es posible reconocer que el liberalismo fundado en la justicia como imparcialidad, en tanto la elección racional como una condición antropológica está supuesta, es un liberalismo que exalta la responsabilidad personal de los individuos pues los bienes primarios garantizan los medios mínimo necesarios para que ellos se hagan responsables de la obtención de sus deseos. Del mismo modo, es un liberalismo 
que hace responsable a los individuos de los fines e ideas del bien que desarrolla en libertad en tanto que está en condiciones de considerarlos en función de un plan de vida amplio.

La justicia como imparcialidad no sólo reconoce la importancia de la responsabilidad personal en la toma de decisión de los principios de justicia. Del mismo modo que asume que cada individuo es legítimamente un ser capaz de determinar sus fines (deseos, ideas del bien) y la concepción de la justicia que lo gobierna, asume, al menos implícitamente en la garantía de los bienes primarios como medios necesarios para la deliberación racional, que los individuos deben de ser capaces de comparar distintos medios y bienes libremente para identificar cuáles cumplen mejor con sus objetivos. Desde el pensamiento de Rawls es posible afirmar una especie de falsacionismo político y moral que apunte a la distribución de los bienes primarios con la finalidad de permitir a los ciudadanos hacerse responsables de sus propias vidas en un ambiente antidogmático, pues garantiza la libertad.

Con lo dicho hasta ahora hay suficientes antecedentes para poder comprender a fondo la justicia como imparcialidad. A continuación explico sus contenidos concretos como se detallan en los principios de la justicia.

\section{Los principios de la justicia}

Una vez que he expuesto la posición original como el planteamiento básico para desarrollar un esquema de justicia procedimental, la naturaleza del velo de la ignorancia, los límites de la justicia, el objeto de la justicia y otros de los temas sobre los que he hablado hasta ahora, lo que sigue es enunciar los principios de la justicia. La formulación concreta de la concepción de la justicia rawlsiana, la justicia como imparcialidad, está fundamentada en dos principios de la justicia. Estos principios son los criterios fundamentales que serían elegidos en la posición original bajo el velo de la ignorancia, que gobernarán la estructura básica de la sociedad. Estos principios, que gobiernan la estructura básica, influencian a la totalidad de la sociedad en la medida en que determinan el procedimiento de distribución de los bienes básicos necesarios para alcanzar los fines determinados que cada ciudadano persiga.

La formulación concreta de la justicia como imparcialidad, materializada en los principios de la justicia, es la pieza clave en la formación de las instituciones de 
una sociedad democrática y liberal. Las instituciones que se formarán derivadas de los principios de la justicia son la materialización de la conducta de los individuos durante todo el tiempo que se apegan a los principios. ${ }^{38}$ Cuando hablemos de instituciones o acciones justas o injustas, nos referiremos a aquellas que se apegan a los principios de la justicia.

Los principios, como vimos al respecto de los límites de la justicia, deben de cumplir ciertas características y la finalidad, que significa que no hay un criterio posterior para juzgar una acción, es una de ellas. Asumir la finalidad de los principios implica que no hay razones válidas por encima de la concepción de la justicia que propone Rawls para justificar una acción como justa o injusta. Cuando una acción pueda estar sujeta a ser nombrada como justa o injusta, pues existen instituciones y actos que no están sujetos a esta calificación (como puede suceder con algunas tradiciones), tiene que ser juzgada en función de los mismos principios, los principios de la concepción de la justicia elegida en la posición original. De este modo, los principios de la justicia suponen la igualdad de las personas, pues el criterio final de juicio para sus instituciones fundamentales es la concepción de la justicia elegida en la posición original.

A lo largo del texto de Teoría de la Justicia Rawls propone distintas enunciaciones de los principios que conforman la justicia como imparcialidad. Su forma final, que es la que cito a continuación, la expresa en el apartado 46 del texto. En esta sección la enunciación de los principios es acompañada por dos reglas de prioridad. Los dos principios son:

Primer Principio

Cada persona debe tener el sistema más extenso de libertades básicas iguales que pueda ser compatible con un sistema de libertades similar para todos.

Segundo Principio

Las desigualdades sociales y económicas deben de ordenarse de modo que sean:

c. Para el mayor beneficio de los menos aventajados, consistentemente con el principio del ahorro justo, $y$

d. Referidas a posiciones o puestos abiertos a todos bajo condiciones de justa igualdad de oportunidades.

Primera regla de prioridad (la prioridad de la libertad)

${ }^{38}$ Cfr. Ibid. 47 
Los principios de la justicia deben de ser ordenados de acuerdo a un orden lexical y por tanto las libertades básicas sólo pueden ser restringidas por las libertades mismas. Existen dos casos:

a. Una libertad menos extensiva debe fortalecer la totalidad del sistema de libertades que comparten todos;

b. Una libertad no igualitaria debe ser aceptable para aquellos con menor libertad.

Segunda regla de prioridad (la prioridad de la justicia sobre la eficiencia y el bienestar)

El segundo principio de la justicia es lexicalmente anterior al principio de eficiencia y el de la maximización de la suma de ventajas; la justa oportunidad es anterior al principio de diferencia:

a. La desigualdad de oportunidad debe aumentar las oportunidades de aquellos con menos oportunidades.

b. Una tasa de ahorro excesiva debe, en un balance final, mitigar la carga de aquellos que sobrellevan esta carga.

Los principios de la justicia, como se puede ver, enuncian las condiciones de convivencia para una sociedad en la que se considera que los individuos tienen la misma capacidad de perseguir su propio bien. Si bien es claro que la libertad es el bien fundamental a distribuir, como se ve con la primera regla de prioridad, es de llamar la atención el papel predominante de la igualdad, otro de los grandes valores liberales a través de la historia, dentro de la concepción de la justicia.

Por un lado podríamos identificar el igualitarismo rawlsiano en el contexto de la antropología liberal. Rawls es un representante típico de la tradición liberal en su comprensión de los seres humanos como individuos moralmente iguales. En otro sentido podríamos plantear el igualitarismo en Rawls no como la condición noumenal de los individuos, que está implicada siempre por supuesto, sino como el balance del poder que se debe garantizar en la comunidad, como el medio para garantizar la libertad de los individuos. Primero diré algunas cosas sobre la primera consideración de la igualdad en Rawls; para empezar cito un fragmento de Teoría de la Justicia:

Las personas morales se distinguen por dos características: primero son capaces de tener (y se asume que así la tienen) una concepción del bien (como se expresa por un plan racional de vida); segundo, son capaces de tener (y se asume que poseen) un sentido de la justicia, un deseo normal y efectivo de aplicar y actuar en función 
de principios de la justicia, al menos en un grado mínimo. (...) Por tanto, la justicia igual es debida a aquellos que poseen la capacidad de tomar parte y de actuar en función de una comprensión pública de la situación inicial. Se debe hacer notar que la personalidad moral se define aquí como una potencialidad que se realiza ordinariamente en el tiempo. ${ }^{39}$

La correcta aplicación de los principios de la justicia está en función del descubrimiento de los criterios relevantes para la distribución de los bienes. Recordemos el tema de la justicia procedimental perfecta y la relevancia de reconocer a las distintas partes dentro del proceso de repartición. Cuando Rawls plantea las distintas partes en que se distribuirán el pastel, es importante tener en mente que no fue enunciado el color de piel, coeficiente intelectual, formación académica, pertenencia social o linaje familiar de las distintas partes; en el caso de la distribución del pastel lo único que importa es que hay un número determinado de individuos interesados, todos con disposición a obtener la mayor cantidad posible $\mathrm{y}$, dado el resultado, inferimos que todos igualmente legitimados para obtenerlas. En el ejemplo de justicia procedimental perfecta que ofrece Rawls, las características mencionadas antes (color de piel, coeficiente intelectual, formación académica, etc.) no son relevantes para determinar la distribución del pastel, en ese caso en particular. Dentro de la posición original la aplicación del velo de la ignorancia, y por tanto la búsqueda de la imparcialidad en la formación o adopción de una concepción de la justicia, hace que características como el color de la piel, la formación académica o el linaje familiar se vuelvan irrelevantes del mismo modo. Las características relevantes de los individuos son, en último término, las dos características morales de las personas: las capacidades de tener una idea del bien y una concepción de la justicia.

La igualdad moral de los individuos es uno de los argumentos fundamentales para sostener una concepción liberal de la vida política de la comunidad. Si la distribución de bienes primarios, que como vimos son los medios necesarios para obtener bienes posteriores adicionales, está determinada en función de la igualdad moral, y asumiendo que las libertades básicas son el bien primario más fundamental, ésta es la garantía de la libertad para todos los individuos con capacidades morales básicas. A diferencia de concepciones de la justicia enfocadas en el desarrollo de la comunidad, que podrían comprender su misión en función del bien común, y por tanto justificarían una distribución de bienes de acuerdo a la consecución de dicho bien, el liberalismo rawlsiano asume que los factores determinantes para la distribución de los bienes equivalen a la

${ }^{39}$ Ibid. 442 
posesión de facultades mínimas presentes en la gran mayoría de las personas adultas. Por ejemplo, los nacionalismos del siglo pasado, dentro de los que se encuentra el nacionalsocialismo por ejemplo, consideraban que la gloria y bienestar de la nación justificaba una distribución de ventajas sociales en función de la variación de los individuos; alguien más inteligente, con mejores disposiciones físicas y perteneciente a algún grupo étnico o social particular tenía derecho, con supuesta justicia, a ventajas sociales frente al resto de la población. La garantía de la libertad como bien primario para conseguir objetivos personales y sociales, en regímenes de este tipo, se encontraba en factores que, dentro de la posición original, serían absolutamente arbitrarios e inaceptables.

El primer principio de la justicia, de este modo, es el principio que reconoce la igualdad moral de todos los individuos y sus implicaciones con la libertad. En la medida en que distribuye el bien primario más relevante, el medio necesario para conseguir cualquier otra cosa que es la libertad por sí misma, en condiciones de imparcialidad, reconoce la igualdad de todos los individuos en función de su capacidad de tener una idea del bien y una concepción de la justicia, independientemente de cualquier otra característica. El primer principio es anterior a cualquier otra norma o distribución en tanto que relegarlo supondría negar la igualdad moral de las personas. Supongamos que limitamos la libertad de un individuo por obtener beneficios materiales para un tercero, hacerlo representa una negación en su igualdad moral y, por tanto, una pérdida de la imparcialidad. La única manera en la que podríamos legítimamente limitar las libertades de un individuo por beneficio de alguien más es si pudiéramos garantizar que la idea de bien de uno es necesariamente correcta y la del otro incorrecta, aun antes de verlas operar en el mundo real. Este tipo de justificaciones son las que se encontraban detrás de los argumentos en favor de la desigualdad de género de Aristóteles, por ejemplo: es natural en la mujer la incapacidad de controlar y ordenar su vida como sólo lo puede hacer un hombre libre; debido a que una mujer es una especie de hombre incompleto, es justificable limitar su libertad y acceso a bienes (por su propio bien). Este argumento es inaceptable desde una consideración de imparcialidad.

Esta primera comprensión de la igualdad en Rawls es la que determina la prioridad de la libertad frente a la distribución de otros bienes. Suponiendo que diéramos preferencia a otros bienes antes que a la libertad, estaríamos negando la igualdad de los individuos respecto a su capacidad de formar una idea del bien o una concepción de la justicia particular. Es importante tener en mente que el resto de los bienes primarios, como es el ingreso por ejemplo, es secundario pues un 
mayor ingreso sin libertad implicaría que la riqueza no puede ser utilizada como prefiera el que la detenta. ${ }^{40}$ Lo que es más, el igualitarismo rawlsiano asume que sólo es necesaria la igualdad en la libertad aun cuando el ingreso, la riqueza y las oportunidades tenderán a ser distribuidas de modo desigual (siempre en función del bienestar de todos). ${ }^{41}$ La libertad es anterior y siempre debe ser cumplida debido a que la diferencia en las garantías de libertades (libertades políticas, de expresión, de reunión, conciencia, etc.) implican una desigualdad de trato injustificable en la posición original (en una posición de equidad que reconozca las capacidades morales de los individuos). Si se limitan las libertades en función de la repartición, creación o adquisición de otros bienes, habremos actuado fuera del marco de lo razonable (más allá de los límites de la justicia que ya he analizado) negando la igualdad moral de los ciudadanos. Por tanto, habremos actuado injustamente.

Existe otro sentido de igualdad en la justicia como imparcialidad que es igualmente relevante. Como vimos, los principios de la justicia asumen la igualdad moral de los individuos y, por lo mismo, asumen que la distribución del bien primario fundamental (la libertad en sus diversas formas) debe ser igual entre todos. Al mismo tiempo, como se ve con el segundo principio, la distribución del resto de los bienes (riqueza, ingreso y oportunidades) debe ser hecha de modo desigual para que traiga beneficios a los que están más necesitados de dicha distribución.

Es relevante asumir que la distribución de los bienes supuestos en el segundo principio siempre tiende a ser desigual en la medida en que las condiciones sociales e históricas tienden siempre a la desigualdad por sí mismas. Si asumimos la crítica de Rawls al principio de libertad natural, en la que afirma que

\footnotetext{
${ }^{40}$ Brian Barry reconoce que si aceptamos la prioridad de la libertad frente a la distribución del ingreso Rawls requiere, de igual modo, de otro presupuesto adicional: que el valor de la riqueza sea "infinitesimalmente más pequeño en relación a la libertad, de modo que sería juzgado apropiado el renunciar a la afluencia económica y caer en la pobreza sólo para obtener una ínfima ganancia en el criterio de libertad, si esta opción fuera presentada a la sociedad." (Barry, The Liberal Theory of Justice. 60)

El argumento es sugerente ya que supone que, en ocasiones, una ganancia en mayor libertad tiene un costo de oportunidad que se refleja en la capacidad de acumular-generar riqueza. Si quiero más libertad, entonces tendré menos prosperidad económica; por el contrario, si quiero una mayor prosperidad, deberé renunciar a cierta libertad. Asumiendo que este costo de oportunidad sucede en ocasiones, Rawls difícilmente puede plantear que en todos los casos sería preferible una mayor libertad y, en esa medida, el velo de la ignorancia, al no permitirnos saber exactamente cuál es la circunstancia de nuestra sociedad, nos obliga a pensar en términos inadecuados para muchas sociedades y problemas concretos (algunos mecanismos de redistribución de la riqueza de las democracias contemporáneas presuponen que ciertos mínimos en la distribución de bienes justifican límites a las libertades). ${ }^{41}$ Cfr. Ibid. 53
} 
el problema con una política y economía fundamentada en el principio de libertad natural, como ocurre con el liberismo, es que las condiciones de convivencia y competencia perfectas que se requieren para asumir la no intervención del Estado tienden a desaparecer con el paso del tiempo conforme se acumulan las desigualdades ${ }^{42}$ tendremos que asumir que el segundo principio siempre está actuando en algún ámbito de la sociedad de modo que las instituciones promuevan siempre el trato desigual en favor de los menos aventajados.

La promoción del trato desigual, que explico con más detalle adelante en un apartado específico sobre el segundo principio, cumple la función de garantizar las condiciones que aseguren el mantenimiento del respeto a la igualdad moral de los individuos. El segundo principio de la justicia cumple una doble función: por un lado es claro que Rawls intenta garantizar los medios de vida necesarios para que los individuos puedan perseguir sus ideas del bien. De poco sirve tener garantizado un esquema de justicia amplio si los medios de vida necesarios para actuar en función de ideas del bien determinadas son negadas a los individuos, esto es lo que Rawls denomina el valor de la libertad. ${ }^{43}$ Sin embargo, considero que hay otra función del segundo principio de la justicia que no es tan evidente en primera instancia.

El reconocimiento de la institucionalización del trato desigual, como mencioné antes, es de que las circunstancias óptimas de convivencia son insostenibles en el tiempo por sí mismas. Por esto, el contenido del segundo principio de la justicia reconoce no sólo que las personas requieren un mínimo de bienes para poder ejercer sus poderes morales sino que, al mismo tiempo, (al asumir que las desigualdades sólo son permitidas para beneficiar a todos, y en última instancia, como veremos, a los más desfavorecidos) es el papel de las instituciones de la estructura básica de la sociedad el promover, a través del trato desigual, un cierto nivel de igualdad (igualdad democrática) que garantice que las diferencias nunca sean de una magnitud tal que los menos aventajados queden excluidos del proceso político (es decir de ocupar puestos abiertos a todos). La concepción de la justicia debe ser capaz de gobernar las distribuciones dentro de la comunidad siempre que estas puedan afectar las condiciones que acordamos como justas en la posición original.

\footnotetext{
${ }^{42}$ Cfr Ibid. 62-63

${ }^{43}$ Cfr. Ibid. 179
} 
El segundo principio de la justicia

El segundo principio de la justicia establece en qué situaciones es aceptable el trato desigual en los ámbitos sociales y económicos. En su última elaboración, Rawls postula el segundo principio del siguiente modo:

Segundo Principio

Las desigualdades sociales y económicas deben de ordenarse de modo que sean:

a. Para el mayor beneficio de los menos aventajados, consistentemente con el principio del ahorro justo, $y$

b. Referidas a posiciones o puestos abiertos a todos bajo condiciones de justa igualdad de oportunidades.

El segundo principio, como mencioné antes, asume que las desigualdades sociales y económicas son circunstancias normales dentro de la comunidad política. Esta característica de la justicia como imparcialidad es particularmente atractiva; contrario a lo ocurre con otras propuestas de filosofía política, que buscan plantear las condiciones para que la sociedad se desarrolle óptimamente, como puede verse en La República del Platón, por ejemplo, Rawls asume que la labor de la teoría política es plantear un sistema funcional en el tiempo, asumiendo que de hecho el tiempo genera contingencias independientemente de la conformación de la estructura básica que tengamos. Como mencioné antes, la idea de una justicia procedimental imperfecta como la que plantea Rawls supone que el conflicto es un hecho normal dentro de nuestras comunidades $y$, justamente por eso, necesitamos una concepción de justicia que los individuos puedan encontrar apropiada en una circunstancia de imparcialidad. En este punto la preocupación de Rawls por una teoría que nos sirva como hipótesis de acción muestra una clara orientación pragmatista. Al proponer una concepción de justicia procedimental imperfecta, Rawls está suponiendo al menos dos cosas que nos muestran dicha vena pragmatista: por un lado, al centrarse en el procedimiento, evidencia que la medida de corrección para una concepción de la justicia está en su capacidad de generar condiciones justas aun cuando las circunstancias cambien en el tiempo, lo que no son capaces de hacer las concepciones teleológicas por ejemplo; ese es el criterio de corrección fundamental en el pensamiento pragmatista de Dewey. Por otra parte, al asumir que es imperfecta, está haciendo una consideración sobre la perfectibilidad de dicha concepción y, en la medida en que hace eso, reconoce un falibilismo intrínseco a su propuesta. El segundo principio de la justicia encarna estas preocupaciones procurando generar las condiciones necesarias para que el 
procedimiento imperfecto de la concepción de la justicia como imparcialidad consiga su cometido.

La estructura del segundo principio, que inicia con el reconocimiento de las desigualdades en la comunidad, está integrado, como se ve en su enunciación, por dos principios secundarios: el principio de diferencia y el principio de justa igualdad de oportunidades. Cada uno de ellos merece ser, al menos brevemente, analizado por separado.

\section{La interpretación democrática del segundo principio}

El principio de diferencia, que estipula que las desigualdades deben servir para "el mayor beneficio de los menos aventajados", es uno de los contenidos de la justicia como imparcialidad más contendidos. La primera enunciación de los principios de la justicia en Teoría de la Justicia no contenía el principio de diferencia (al menos no de manera explícita):

Segundo: las desigualdades sociales y económicas deben establecerse de modo que ambas (a) se esperen razonablemente como una ventaja para todos y (b) estén sujetas a posiciones y puestos abiertos a todos. ${ }^{44}$

Esta primera enunciación es distinta a la que expuse antes, que es la que ofrece la forma final del principio. Recordemos que Rawls propone una concepción de la justicia que pueda ser elegida en la posición original. Esta primera formulación nos permite, evidentemente, comprender los principios como una concepción conveniente para el gobierno de la estructura básica mientras estamos cubiertos por el velo de la ignorancia. El velo, como vimos, es un "artificio" que nos permite pensar en una situación de igualdad total de modo que podamos plantear principios imparciales. Con esa limitante en mente, la primera elaboración del segundo principio de la justicia es sumamente sugerente desde la perspectiva de la imparcialidad: por un lado garantiza que todos tengamos acceso a las diversas posiciones y puestos existentes en la comunidad y, por otro, nos intenta garantizar que cuando existan desigualdades, estas deben existir para beneficiar a todos.

El segundo principio de la justicia, en su primera elaboración, es fácilmente aceptable en el contexto de la posición original, sobre todo una vez que recordamos que existe un principio, el primer principio de la justicia, que garantiza el esquema más amplio de libertades posible para todos por igual. Sin embargo,

${ }^{44}$ Ibid. 53 
¿por qué sería necesario realizar elaboraciones subsecuentes?, ¿por qué Rawls postula el principio de diferencia en sustitución del inciso (a) de la primera elaboración? En buena medida es porque el principio como es presentado en esa primera elaboración, se presta a múltiples interpretaciones.

La expresión "ventaja para todos" es ambigua del mismo modo que lo es la de "abierto para todos". La primera formulación del principio nos obliga a preguntarnos: ¿qué constituye una ventaja para todos?, ¿en qué sentido los puestos están abiertos para todos? El principio, en su primera enunciación, puede ser entendido según Rawls de cuatro modos fundamentalmente: como un principio que funda un sistema de libertad natural, un igualitarismo liberal, una aristocracia natural o un igualitarismo democrático. La interpretación del principio depende del sentido que demos a dos expresiones contenidas en el principio, "abiertos a todos" y "ventajas para todos". Para aclarar estas interpretaciones Rawls realiza un diagrama que reproduzco a continuación: ${ }^{45}$

\begin{tabular}{|l|l|l|}
\cline { 2 - 3 } \multicolumn{1}{c|}{} & \multicolumn{2}{c|}{ "Ventaja para todos" } \\
\hline $\begin{array}{l}\text { "Abierto a todos" } \\
\text { abiertas al talento }\end{array}$ & Principio de eficiencia & Principio de diferencia \\
\hline $\begin{array}{l}\text { Igualdad como igualdad de } \\
\text { oportunidades }\end{array}$ & $\begin{array}{l}\text { Sistema de libertad } \\
\text { natural }\end{array}$ & Aristocracia natural \\
\hline
\end{tabular}

Si asumimos, por ejemplo, que "abierto para todos" significa "igualdad como carreras abiertas al talento", es decir que todos pueden acceder a cualquier puesto en función de sus talentos no limitados por otro tipo de circunstancias contingentes, y que "ventaja para todos" significa actuar en función del principio de eficiencia", dado que una mayor eficiencia implica un mejor uso de los bienes disponibles y que cualquier distribución eficiente es igualmente aceptable, entonces el segundo principio de la justicia, en su enunciación inicial, implica la promoción de un "sistema de libertad natural" ${ }^{46}$

\footnotetext{
45 Ibid. 57

${ }^{46}$ Cuando Rawls hace referencia al "sistema de libertad natural" tiene en mente la tradición inaugurada por Adam Smith en la que las obligaciones del "soberano" son muy limitadas: "De acuerdo al sistema de libertad natural, el soberano tiene sólo tres deberes que atender; tres deberes de gran importancia, sin
} 
La ambigüedad del principio en su primera formulación es imprecisa si queremos que la justicia como imparcialidad pueda determinar, con sus principios, el mejor modo de conducir la comunidad política de un modo justo. Si no estamos seguros qué significan los principios, difícilmente pueden ser útiles para juzgar la estructura básica $\mathrm{y}$, en ese sentido, no son mejor opción que una especie de intuicionismo que, como afirma Rawls, es incapaz de garantizarnos reglas de prioridad claras. ¿De qué sirve saber que el primer principio es siempre anterior al segundo si no sabemos, de cualquier modo, cuál es el contenido de los principios?

La estrategia de Rawls para definir el contenido del segundo principio, que lo conduce a la última formulación que ya he citado atrás, es en dos "pasos": primero analiza la interpretación de las ideas "ventaja para todos" y "abierto a todos" afirmando que la primera no debe de ser pensada en función del principio de eficiencia y la segunda no debe estar fundada en la igualdad de acceso en función del talento. Segundo, Rawls hace una defensa del principio de diferencia y del igualitarismo democrático. Es importante tener en mente que una de las estrategias para justificar la justicia como imparcialidad, al menos en su dimensión más pragmática, es la de mostrar su conveniencia superior frente a las demás opciones existentes.

Cuando Rawls analiza la comprensión del segundo principio en función del principio de eficiencia, la plantea en términos del óptimo de Pareto, que se refiere básicamente a cualquier uso o distribución de recursos que no permite que queden bienes sin usar o distribuir. Supongamos que tenemos que distribuir eficientemente 10 pedazos de pastel entre 10 personas; la distribución será óptima, y por tanto eficiente, tan pronto como se distribuyan los 10 pedazos, no importa si damos 10 pedazos a una persona, 1 pedazo a cada una de las 10 o cualquier otra distribución posible siempre y cuando se distribuyan los 10 pedazos. El principio de eficiencia no se interesa por ordenar la distribución o uso de los bienes en función de criterios adicionales (como podrían ser el mérito, la equidad, la igualdad o, por supuesto, la justicia); en esta medida, la eficiencia difícilmente puede ser parte definitoria, por sí, de nuestra concepción de la justicia. Tendríamos

duda, pero simples y comprensibles para el sentido común: primero, el deber de proteger la sociedad de la violencia y la invasión de otras sociedades independientes; segundo, el deber de proteger, en la medida de lo posible, a cada miembro de la sociedad de la injusticia y la opresión de cualquier otro miembro de ella, o el deber de e3satblecer una administración de justicia; $y$, tercero, el deber de levantar y mantener ciertas obras públicas y ciertas instituciones públicas que no pueden ser intereses de ningún individuo, o un número reducido de individuos, levantar y mantener (...)" (Adam Smith, An Inquiry into the Nature and Causes of Wealth of Nations (Chicago: University of Chicago Press, 1977). 914-915 
que reconocer que, si bien el principio de eficiencia puede ser un criterio relevante para plantear nuestros principios de la justicia debido a que es poco razonable desear que los bienes se distribuyan ineficientemente, no es suficiente como único criterio de distribución de bienes. ${ }^{47}$ Esto queda mucho más claro cuando Rawls combina el principio de eficiencia con las dos comprensiones de "abierto para todos" como las vimos anteriormente: "igualdad como carreras abiertas al talento" y la "igualdad como igualdad de oportunidades".

Como vimos en el diagrama anterior, la combinación del principio de eficiencia con la idea de la igualdad como carreras y puestos abiertos en función del talento deriva en el sistema de libertad natural. El problema con el sistema de libertad natural es que permite la existencia de desigualdades en función de características moralmente arbitrarias desde la perspectiva de la justicia: los talentos naturales y las condiciones contingentes que permiten su desarrollo (medios materiales como la riqueza heredada, la educación, la pertenencia a una clase social, etc.). La apertura de todos los puestos en función del talento, si el criterio de distribución es el de eficiencia, corre el riesgo, con el tiempo con una probabilidad bastante alta, de mantenerse en tanto que no hay manera de impedir la acumulación de desigualdades en el tiempo que hagan del talento una característica insuficiente. Asumiendo que el sistema de libertad natural es indiferente a cualquier tipo de distribución en tanto sea eficiente, es incapaz de generar las condiciones para que un individuo que obtuvo una cantidad menor de bienes en la distribución, pueda efectivamente acceder al puesto que desee en tanto que el desarrollo del talento tiende a estar vinculado a esos bienes primarios que no posee. En tanto no existan principios adicionales que regulen la distribución de los bienes, el principio de eficiencia tiende, con el tiempo, a generar desigualdades sociales que terminan considerándose injustas en tanto que, al ser éstas cada vez mayores, impiden el derecho al acceso libre a los puestos para todos los individuos. $^{48}$

Por su parte, la interpretación del segundo principio como uno de igualdad liberal, interpreta la "ventaja para todos" desde el principio de eficiencia y la condición de que los puestos estén "abiertos a todos" como una condición de igualdad de oportunidades. Esta interpretación presenta ventajas claras frente al sistema de libertad natural pues busca limitar la influencia de la distribución previa de los bienes al acceso a los puestos de los individuos; dentro del igualitarismo liberal se busca que una persona, independientemente de cuántos

\footnotetext{
${ }^{47}$ Cfr. Ibid. 61-62
}

${ }^{48}$ Cfr. Ibid. 63 
bienes posea, sea capaz de acceder a cualquier puesto en tanto tenga la capacidad natural de alcanzarlo:

La idea es que las posiciones deben estar abiertas no sólo en un sentido formal, sino que todos deberían de tener una oportunidad justa de llegar a ellas. En principio no es claro lo que esto significa, pero podríamos decir que aquellos con habilidades y talentos similares deberían de tener oportunidades en la vida similares. Más específicamente, asumiendo que hay una distribución de bienes natural, aquellos con un nivel de talento y habilidad igual y que tienen la misma voluntad de utilizarla, deberían de tener las mismas posibilidades de tener éxito sin importar su posición inicial en el sistema social. En todos los sectores de la sociedad debería existir aproximadamente el mismo acercamiento a la cultura y al éxito para todos los que se encuentran similarmente dotados y motivados. ${ }^{49}$

Esta interpretación del segundo principio de la justicia tiene un contenido de justicia mucho más robusto. Cuando nos planteamos la interpretación en función del sistema de libertad natural, en donde lo único que interesaba era cumplir con el principio de eficiencia y un criterio de acceso a los puestos que, con el paso del tiempo y gracias a la aplicación del principio de eficiencia, concluimos que termina siendo únicamente una condición formal difícilmente materializable. Por su parte, la interpretación liberal, o de igualitarismo liberal, toma más en serio el papel de la justicia como la virtud que debe permitirnos distribuir los bienes en sociedad en función de las características moralmente relevantes: esta segunda interpretación reconoce que la posición social no es una característica moralmente relevante para determinar las posibilidades de éxito de un plan de vida y, por tanto, debe ser minimizada o anulada como criterio de distribución de ser posible.

Si la interpretación liberal igualitaria del segundo principio de la justicia busca limitar el efecto injusto de la posición social y los beneficios materiales que ella implica, ¿por qué no es la interpretación adecuada según Rawls?

Mientras que la concepción liberal parece ser claramente preferible al sistema de libertad natural, intuitivamente sigue pareciendo defectuosa. Por un lado, aun si trabaja a la perfección en eliminar la influencia de las contingencias sociales, de cualquier manera permite que la distribución de la riqueza y el ingreso se determine por la distribución natural de habilidades y talentos. Dentro de los límites establecidos por los acuerdos fundamentales, las porciones distributivas se deciden por el resultado de la lotería natural; este resultado es arbitrario desde una perspectiva moral. No hay más razones para permitir que la distribución de ingreso

${ }^{49}$ Idem. 
y riqueza se acuerde por la distribución de bienes naturales que por la fortuna histórica y social. ${ }^{50}$

La cuestión que plantea Rawls en este punto es por demás interesante. Es moralmente irrelevante si alguien nace naturalmente con un talento mayor que otro. Si la distribución de bienes va a ser justa, debe de responder a razones moralmente relevantes. Haber nacido con ciertas características naturales, por las que ningún ser humano beneficiado puede declararse responsable, no puede ser una causa suficiente para garantizar bienes primarios en cantidad suficiente para poder desarrollar sus poderes morales. Aquellos que nacen con menos dones en la sociedad no deben ser "castigados" con menos bienes de los necesarios para desarrollar sus capacidades morales, al menos si nos mantenemos en el ámbito de lo justo, pues no son responsables de sus carencias. Con lo que ha sido dicho hasta ahora es evidente que en la posición original los individuos tienden a elegir la interpretación de los principios en función de que la justicia opere tomando en cuenta las características moralmente relevantes; en buena medida esto está garantizado por el velo de la ignorancia, que nos obliga a asumir una postura de imparcialidad. Si seguimos este razonamiento la interpretación liberal igualitarista del principio es incorrecta.

En lo que respecta a la aristocracia natural es sencillo entender por qué Rawls la considera una comprensión inadecuada para nuestra concepción de la justicia: asumiendo que la aristocracia natural reconoce la diferencia en los talentos naturales y ofrece la estructura básica necesaria para "premiar" con mayores porciones distributivas a dicha aristocracia, encarna una concepción de la justicia injusta donde los criterios para la distribución son moralmente arbitrarios y no cumplen con el criterio de imparcialidad e igualdad necesarios.

En la medida en que rechazamos el sistema de libertad natural como una concepción de la justicia adecuada por la arbitrariedad de los factores que ordenan la distribución, tendremos que rechazar el igualitarismo liberal y la aristocracia natural pues sólo se diferencian del sistema de libertad natural en una cuestión de grado.

La interpretación democrática, la mejor de ellas según Rawls, es aquella que obtenemos al combinar el principio de igualdad de oportunidades y el principio de diferencia. Hasta este punto el primero de ellos es claro, en tanto que el igualitarismo liberal ya lo he explicado. Ahora es importante explicar el principio de diferencia

50 Idem. 


\section{El principio de diferencia}

El principio de diferencia, como es expuesto por Rawls, es un principio igualitarista. Suponiendo en que fuera posible hacer una distribución igual a todos los individuos de la comunidad, manteniendo un criterio de eficiencia, dicha distribución sería la elección preferida en todos los casos dentro de la posición original. Si fuéramos a distribuir 10 rebanadas de pastel entre 10 personas, siempre será preferible repartir una rebanada para cada quien; si fuéramos a repartir entre 5 personas, lo mejor sería repartir dos rebanadas por persona. Esta primera consideración igualitarista es una buena candidata en la posición original en tanto que un individuo cubierto por el velo de la ignorancia, y que por lo mismo no sabe cuáles son sus talentos, aptitudes o posición social, probablemente preferirá, como se demuestra en el caso de justicia procedimental perfecta que mostré anteriormente, una distribución lo más igualitaria posible. El problema es que es muy difícil que se den casos perfectos.

Supongamos que vamos a distribuir 10 piezas de pastel (que no pueden a su vez ser divididas pues cada una representa un pastel individual y, al cortarlo, perdería frescura y lo haría poco apetecible) entre 7 personas. En primera instancia podríamos distribuir, siguiendo un criterio igualitario, una pieza a cada individuo, la pregunta que nos queda es, ¿qué hacemos con las tres rebanadas sobrantes? Si no las repartimos, para evitar problemas de envidia, entonces romperíamos con una condición de eficiencia que es a todas luces razonable, dejar que se desperdicien no representa un beneficio material para nadie y sí es un perjuicio para aquel que pudiera haber sido beneficiado. ${ }^{51} \mathrm{Si}$ siguiéramos una comprensión

\footnotetext{
${ }^{51}$ Un problema adicional que es relevante exponer sobre la distribución de los bienes primarios como lo plantea Rawls con el segundo principio es el desarrollado por Onora Nell sobre las complicaciones de medición. Rawls supone que los bienes primarios son medios fundamentales para conseguir otros fines, por tanto procura una distribución igualitarista, en el mayor grado posible, de modo que los individuos puedan efectivamente perseguir dichos bienes. El problema que identifica Nell es la necesidad de aclarar el objetivo de la distribución de bienes pues garantizar riqueza por sí puede no ser suficiente si lo que queremos es apoyar la autonomía de los individuos: "Las unidades en que el ingreso y las oportunidades se miden son heterogéneas, y la teoría de Rawls no parece tener un método para explicar si un aumento en el ingreso de los peor situados o en el control de su vida es justo. (...) ¿Es justo buscar el crecimiento económico y los prospectos de acumulación material para los peor situados con costo a incrementar sus posibilidades de controlar sus propias vidas? La pregunta no es artificial, y una teoría de justicia institucional debería indicar un método para su solución." (Nell, $A$ Theory of Justice. 666-667)

De nuevo nos enfrentamos a lo que entiendo como un problema recurrente en Teoría de la Justicia. En la medida en que Rawls renuncia a una idea del bien liberal como rectora dentro de la posición original, genera incertidumbre sobre los alcances de la concepción de la justicia elegida. Tomemos la disyuntiva que plantear Nell, dentro de una lógica liberal progresista, como la que desarrolla Dewey, lo
} 
de aristocracia natural, tendríamos que decir que hay que entregarlos a aquellos que tengan los dones naturales más desarrollados para aprovecharlos, por ejemplo el sentido del gusto más refinado. Este criterio, como vimos, no es adecuado para Rawls; al final del día el sentido del gusto se puede desarrollar y si no es posible y es más bien un talento nato, no parece ser un criterio moralmente razonable para garantizar una mayor cantidad de pastel para los 3 mejores catadores de postre. ${ }^{52}$

Asumiendo que nos encontremos en una circunstancia de imparcialidad, como sucede con el velo de la ignorancia, Rawls supone que sería insatisfactorio un principio de justicia que facilitara beneficios en función de características arbitrarias, como es la "lotería" genética. De este modo, la interpretación de "ventaja para todos" no puede mantenerse al margen de un criterio más elaborado que el mero principio de eficiencia. La opción que nos queda, según Rawls, es la aplicación del principio de diferencia.

El principio de diferencia estipula que cuando existan desigualdades sociales y económicas estas deben de ser "para el mayor beneficio de los menos aventajados". Por tanto, en los casos en que sea necesario el trato desigual, dado que no podemos juzgar la distribución desigual en función de ideas del bien, sólo sería justificable si sirve para beneficiar a quien tenga menos bienes. El razonamiento para justificar el principio de diferencia en la posición original podría ser enunciado del siguiente modo: dado que no tenemos información concreta de quiénes somos o qué posición ocupamos en nuestra sociedad, y aceptamos que hay ocasiones en que la distribución de los bienes tiende a ser desigual, la única manera en que una distribución particular será aceptable para todos es si beneficia a los menos aventajados. Dado que la concepción de la justicia como imparcialidad niega la posibilidad de cambiar los principios de la justicia dependiendo de las circunstancias concretas (en tanto que eso implicaría la falta de imparcialidad), el único criterio razonable es garantizar el beneficio de quien tenga menos oportunidades para alcanzar su idea del bien.

fundamental es garantizar las capacidades de los individuos de controlar su vida y desarrollarla de un modo productivo, lo que en efecto dista mucho de simplemente garantizar una distribución equitativa de los recursos (¿no tendrían que aceptar las partes en la posición original que hay mejores y peores maneras para disponer de los recursos?, en esa medida, ¿no deberían razonablemente aceptar un criterio liberal para hacerlo?).

52 Vale tener presenta la discusión en la nota 72 de este trabajo, en donde expongo la crítica de Brian Barry a la idea del principio aristotélico presente en el pensamiento de Rawls. Parecería que en este punto la aceptación del principio aristotélico nos obligaría no tanto a garantizar una distribución lo más igualitaria posible sino, por el contrario, procurar que todos terminaran siendo catadores. Al mismo tiempo esto está en contra del espíritu antiperfeccionista de Rawls. 
La elección del principio de diferencia en buena medida está fundamentada en una actitud conservadora ante el riesgo. Si bien es cierto que el mero principio de eficiencia no ofrece una comprensión del principio fundada en una idea de lo justo, considero que es evidente que la preferencia en el trato desigual por el menos beneficiado supone una especie de seguro en caso de que, una vez que salga de la posición original y me enfrente con mi yo empírico, me encuentre en el grupo de los menos beneficiados. En este sentido debemos pensar en la justicia como imparcialidad como la aplicación misma de la regla maximin al problema de la justicia mismo:

Hay una relación entre los dos principios y la regla maximin para la elección bajo incertidumbre. Esto es evidente desde el punto de vista de que los dos principios son aquellos que elegiría una persona para el diseño de una sociedad en la que sus enemigos asignarán su posición. La regla maximin nos dice que debemos clasificar nuestras alternativas en función de los peores resultados posibles: debemos adoptar la alternativa cuyo peor resultado es superior al peor resultado de todas las otras opciones existentes. ${ }^{53}$

Aun cuando no necesitemos asumir que nuestra posición en la sociedad la eligen nuestros enemigos, Rawls sostiene que es razonable elegir los principios, tomando en cuenta la comprensión del segundo desde el principio de la diferencia, pues la posibilidad de estar en la peor posición social es una constante desde la perspectiva de la posición original.

Recordemos que hay dos formas de argumentar en favor de una concepción de la justicia determinada dentro de la teoría rawlsiana. Estas dos estrategias, como mencioné al principio del capítulo, dan cuenta de dos grandes tradiciones que están en juego en Teoría de la Justicia, por un lado el neokantismo y por otro el pragmatismo. El neokantismo se refiere a los argumentos que se derivan de la posición original por la naturaleza noumenal de las partes contratantes; por su parte, el pragmatismo rawlsiano se funda en argumentos, como sucede con la aplicación de la regla maximin, que intentan dar cuenta de las posibles consecuencias de la aplicación de la teoría de la justicia elegida.

El principio de diferencia, que se justifica por ser una ventaja para todos pues implica que el beneficio a los menos aventajados genera beneficios para todas las partes, es parte de la interpretación de la justicia como imparcialidad desde la regla maximin. El principio de diferencia ofrece el contenido a la justicia como imparcialidad que garantiza el mejor peor resultado posible; el trato desigual debe en

${ }^{53}$ Rawls, A Theory of Justice. 132-144 
todos los casos beneficiar a los peor posicionados, al tiempo que todas las libertades están igualmente garantizadas independientemente de la posición social concreta. Implica que en la justicia como imparcialidad aquellos que se encuentran en la peor posición posible (como si sus enemigos hubieran designado su lugar) recibirán un trato preferencial por parte de la sociedad y sus instituciones como lo determina la estructura básica.

Dicho lo anterior, parecería evidente la superioridad de la interpretación igualitarista democrática de la justicia como imparcialidad. Lo que debe preocuparnos en este momento, más bien, es si la regla maximin es una buena herramienta heurística para determinar la conveniencia de una concepción de la justicia dados los parámetros de la posición original, es decir los parámetros de igualdad y ausencia de información impuestos por el velo de la ignorancia. John Harsanyi argumenta que esto no es así. Si la toma de decisión que supone Rawls es una que debe hacerse bajo incertidumbre, la aplicación de la regla maximin es una alternativa en desuso, piensa Harsanyi, debido a las consecuencias indeseables que produce: "Si tomamos el principio maximin con seriedad entonces uno no podría siquiera cruzar la calle (después de todo, podríamos ser atropellados); no podría manejar sobre un puente (después de todo, podría colapsar); no podría casarse (después de todo, podría acabar en desastre). Si alguien actuara de este modo tendría que ser llevado a una institución psiquiátrica." ${ }^{54}$

La respuesta rawlsiana a este respecto es que la incertidumbre es tal, dadas las condiciones en la posición original, que la aplicación de la regla maximin es justificable. Si alguien no saliera de su casa por el miedo a ser atropellado sería una conducta en cierto sentido demente porque, como argumentaría Rawls dadas las condiciones, podemos hacer un cálculo razonable que no requiere de la aplicación del maximin.

El tema de fondo es si la actitud respecto al riesgo que tiene Rawls es realmente razonable dadas las condiciones de elección en la posición original. Hay tres razones por las que Rawls piensa que sí: ${ }^{55}$

1. El cálculo probabilístico en la posición original es complicado dados los altos niveles de incertidumbre por el velo de la ignorancia.

2. Los sujetos noumenales no deben preocuparse demasiado más allá del mínimo que puedan conseguir pues lo que se reparte son bienes primarios

\footnotetext{
${ }^{54}$ Harsanyi: "Can the Maximin Principle Serve as a Basis for Morality? A Critique of John Rawls Theory". 595

${ }^{55}$ Cfr. Rawls, A Theory of Justice. 133-135
} 
y, una vez que se tiene un mínimo asegurado, todos están en condiciones de concretar su idea del bien particular.

3. Todas las opciones rechazadas implican, en mayor o menor medida, condiciones inaceptables para ser concepciones de la justicia legítimas.

Respecto de la primera razón, podríamos decir que este es uno de los puntos más debatidos. Harsanyi no está del todo de acuerdo pues, aunque Rawls piense que el cálculo probabilístico debería de ser un recurso no usado en la posición original por las complicaciones de calcular las probabilidades, este argumenta que "si los que toman la decisión siguen el principio maximin, entonces no están evitando una elección en base a las probabilidades subjetivas, al menos implícitamente. Por supuesto, puede ser que él no esté pensando en términos de probabilidad explícitamente. Sin embargo, lo quiera o no, este comportamiento implica la asignación de probabilidad uno (o cercana a uno) al peor resultado posible." ${ }^{56} \mathrm{Si}$ evitar el cálculo probabilístico es imposible, como argumenta Harsanyi, entonces la actitud de Rawls frente al riesgo es excesivamente conservadora. Si la actitud frente al riesgo es particularmente adversa, como argumenta Harsanyi, entonces la aplicación de la regla maximin como criterio adecuado tiene implicaciones psicológicas no aceptables dadas las condiciones de la posición original. ${ }^{57}$

En este punto es relevante tocar el tema de las condiciones de la justicia; al respecto Rawls asume, siguiendo la tradición filosófica inaugurada principalmente por Hume, que para que la justicia pueda ser la virtud que guíe las relaciones sociales es necesario que se den ciertas condiciones mínimas: unas objetivas y otras subjetivas ${ }^{58}$ Las condiciones objetivas son aquellas que hacen posible y necesaria la cooperación, como son la escasez moderada, una cierta igualdad ente las partes, la vulnerabilidad a ser atacado por amenazas externas, etc. Las condiciones subjetivas, por su parte, se refieren a las ideas del bien compartidas o compatibles entre los distintos sujetos que viven en comunidad.

La razón para introducir en este momento las circunstancias de la justicia es que considero plausible argumentar que, dadas las condiciones de la justicia, el principio maximin refleja una aversión al riesgo, probablemente irracional, para justificar el principio de diferencia. Asumamos que estamos en la posición original, con todas las limitaciones a la información que impone Rawls, y nos presentan una comprensión del segundo principio en función de una comprensión liberal

\footnotetext{
${ }^{56}$ Harsanyi: "Can the Maximin Principle Serve as a Basis for Morality? A Critique of John Rawls Theory". 599

${ }^{57}$ Cfr. Barber: "Justifying Justice: Problems of Psychology, Measurement, and Politics in Rawls". pg 664

${ }^{58}$ Cfr. Rawls. A Theory of Justice. 109-110
} 
igualitarista y otra en función del principio de diferencia. Rawls cree que si razonamos tomando en cuenta la posibilidad de estar en la peor condición posible, la aplicación de la regla maximin es natural y aplicable. Sin embargo, Rawls parece olvidar que las condiciones en las que se lleva de acuerdo el "pacto" son las de las circunstancias de la justicia, lo que nos obliga a pensar, según los propios criterios de Rawls, que todas las partes son relativamente iguales y que viven en un estado de escasez moderada. Dicho de otra manera, Rawls piensa razonable comprender el principio de justicia, referido a la distribución de la riqueza y bienes primarios no referidos a las libertades políticas fundamentales, en función de la posibilidad de estar en la peor situación posible, lo que de por sí implica una posibilidad pequeña. Esta pequeña posibilidad, que sin duda sería una probabilidad real dentro del razonamiento de un individuo en la posición original, se da en el contexto de una sociedad en la que la escasez es moderada y que todos los individuos son considerados, al menos moralmente, iguales. Al mismo tiempo, si recordamos la definición de sociedad, el hecho de estar en la posición original implica que estamos en condición de cooperar y de llevar una vida más o menos productiva.

El planteamiento rawlsiano supone que es injusto que la distribución desigual de algunos bienes primarios pueda responder al desarrollo de las clases medias, por ejemplo. Este punto es particularmente interesante pues implicaría, de ser cierto, que el velo de la ignorancia conduciría a los participantes en la posición original a negar "la inversión" en bienes sociales como el desarrollo de la cultura, la ciencia, la tecnología o las humanidades, ya que estos tienden a estar vinculados con la clase media; el desarrollo e inversión de la cultura es una preocupación de dichas clases porque el que está en condición de pobreza tiende a no preocuparse por estos dada su condición de emergencia y, los que más tienen, de cualquier manera tienen su acceso garantizado a dichos bienes en caso de preferirlos. La aplicación de la regla maximin, en este caso, no reconoce la importancia de ciertos bienes públicos para la existencia de una sociedad liberal dirigidos a miembros de la comunidad que no están en las condiciones más precarias. ¿Es poco razonable asumir que las desigualdades distributivas puedan incluir, además del beneficio de los menos aventajados, el desarrollo de valores y productos propios del talente liberal? La aplicación de la regla maximin, para forzar el principio de diferencia como la interpretación adecuada de la concepción general de la justicia, nos lleva a la renuncia de la comunidad del reconocimiento de fines sociales más allá de la tendencia igualitarista de la justicia como imparcialidad. En este punto Rawls y Dewey rompen irremediablemente. 
Si bien es cierto que para Dewey es de primordial importancia garantizar el justo valor de las libertades, en tanto que, como vimos, los meros acuerdos constitucionales son insuficientes para garantizar las condiciones de libertad en una sociedad en continua evolución, asumir que el único trato desigual justo es aquel que está enfocado en paliar las desventajas de los peor situados, es una simplificación del espíritu liberal. Recordemos que la política liberal para Dewey implica la posibilidad de representar los diversos intereses de los miembros de la comunidad de un modo que permita los cauces para su consecución. La aplicación del principio de diferencia en los términos que ha planteado Rawls en Teoría de la Justicia hace que los únicos intereses que merecen ser apoyados socialmente (que deben ser relevantes, aunque no lo únicos) sean los de los peor situados en la sociedad. Dewey reconocería que las necesidades de los peor situados son prioritarias siempre que, dependiendo de las carencias, pueden implicar una limitante material al ejercicio de sus libertades; sin embargo Rawls rechaza la dimensión adversativa de la política y niega la posibilidad de pensar en términos distintos al de la urgencia como el de la relevancia o legitimidad (en la medida en que ciertos intereses o búsquedas de otras clases puedan ser menos urgentes pero igualmente legítimos y más relevantes para la sociedad en su conjunto).

Si asumimos, como Rawls lo hace explícitamente, que el liberalismo es una teoría moral con sus propios valores y objetivos, queda la pregunta de si la realización de algunos de esos valores (que está materialmente condicionada por el uso de recursos económicos) debe estar sujeta a la aplicación del principio de diferencia. Aun aceptando que tiende a ser más urgente el trato desigual en beneficio de los menos aventajados, Rawls no deja muchas opciones abiertas para que la sociedad debata si otros intereses pueden ser preferibles en ciertas circunstancias. Niega la posibilidad a la sociedad de dialogar sobre los méritos del trato desigual con la finalidad de desarrollar intereses igualmente relevantes aunque no satisfagan las condiciones de la regla maximin. En este sentido Dewey presenta una idea mucho más comprehensiva de los bienes que se espera que la sociedad sea capaz de producir en la medida en que el mantenimiento de una sociedad liberal en el tiempo requiere del desarrollo de una cultura liberal compartida. El desarrollo de la cultura, el arte y la tecnología permite a los individuos ampliar el ejercicio de su libertad en lo privado; a la sociedad le facilita las condiciones culturales para el mantenimiento estable de la democracia y el régimen de libertad. Lo que intento afirmar es que, la aplicación del principio de diferencia, haciendo uso de la regla maximin, pone en riesgo el desarrollo de las libertades de amplios sectores de la población (todos aquellos que no son los peor 
situados pero tampoco tienen los suficientes medios como para conseguir algunos bienes como la cultura, arte o tecnología a través de un mercado privado) y falla en promover las condiciones culturales y sociales que solidifiquen su estabilidad en el tiempo.

De este modo, asumiendo las condiciones de la justicia, la aplicación de la regla maximin es un ejercicio de juicio irracional frente al riesgo. En palabras de Harsanyi:

Conceptualmente, el problema básico con el principio maximin es que viola un requisito de continuidad importante: es extremadamente irracional hacer el comportamiento completamente dependiente de contingencias poco favorables altamente improbables sin importar que tan poco probabilidad se está dispuesto a asignar.

Por supuesto, Rawls está en lo correcto cuando argumenta que en algunas situaciones el principio maximin conducirá a decisiones razonables. Pero una mirada más cercana mostrará que esto sucederá sólo en aquellas situaciones en las que el principio maximin es esencialmente equivalente al principio de maximización de utilidad esperada. ${ }^{59}$

Por la preocupación de estar en la peor posición, que insisto que es una probabilidad materialmente menor, Rawls renuncia a todos los objetivos y bienes sociales que requieran del esfuerzo coordinado por la comunidad política que no están incluidos en el segundo principio. Sin duda si actuáramos en función de la regla maximin para tomar decisiones con regularidad, tenderíamos a la inactividad o, por otro lado, tendríamos que renunciar a bienes que, quizá, preferiríamos no hacerlo.

Hay otras dos maneras en las que Rawls intenta justificar la aplicación del principio de diferencia y, por lo mismo, de la interpretación democrática igualitaria para el segundo principio de la justicia. Por un lado desarrolla el argumento de la conexión en cadena y, por otro, hace uso del principio de fraternidad.

Por parte de la conexión en cadena podríamos decir que, retomando la enunciación original del segundo principio, con la que se asume que las desigualdades sociales y económicas se ordenan de modo que generen una ventaja para todos, Rawls asume que la manera de garantizar esa ventaja para todos es mediante la aplicación del principio de diferencia. La idea del principio de conexión en cadena es que conforme los menos aventajados reciban un trato

\footnotetext{
${ }^{59}$ Harsanyi: "Can the Maximin Principle Serve as a Basis for Morality? A Critique of John Rawls Theory". 595
} 
desigual que los beneficie, todos en la comunidad se benefician (lo que no significa que las clases medias, por ejemplo, no se pudieran beneficiar más si el trato desigual fuera en su beneficio, por supuesto). ${ }^{60}$ La idea que parece encontrarse de fondo es que siempre que todas las clases e individuos tengan la posibilidad de ser productivas todas se benefician de dicha productividad.

La fuerza de este argumento es endeble. La demostración del éxito de la conexión en cadena está sujeta a modos de producción definidos y, en la posición original, no hay garantías de que la producción se ordenaría en función de esos modos determinados. En general, los argumentos de conexión en cadena, como podría entenderse el planteamiento del fortalecimiento de la demanda de Keynes mediante la búsqueda del pleno empleo (aunque una comprensión simplista), implican una sociedad capitalista.

La conexión en cadena, incluso en una sociedad de pequeños propietarios capitalista, como la considera Rawls, no funciona. Tenemos que reconocer que por naturaleza una economía de mercado capitalista implica que gracias a la competencia algunos individuos pierden y otros ganan. La defensa del capitalismo como sistema productivo no está en que dadas ciertas condiciones todos los individuos ganan; para el caso se podría argumentar que un sistema capitalista deja abierta la posibilidad de que todos ganen en algún momento determinado (nunca en el mismo, pues esto es contrario a la competencia) y que, al mismo tiempo, permite el desarrollo de la productividad (y supuestamente del bienestar) promedio. El supuesto de la conexión en cadena es falso dentro de una sociedad capitalista, en tanto que niega la naturaleza misma de la competencia y el mercado, y es inaplicable a una estructura socialista, en tanto que el ciclo productivo no responde necesariamente a la demanda en el mercado que pudiera tener los menos favorecidos beneficiados por el principio de diferencia. Considero que parte del atractivo del capitalismo para los menos beneficiados (por decirlo de algún modo) no es que mediante este sistema se terminen las desigualdades, sino que, aun cuando sea una sociedad más desigual, las condiciones de vida de los menos beneficiados son objetivamente mejores de lo que lo eran con sistemas con mayor igualdad. Pensemos en un siervo en la Edad Media y el tipo de bienes a los que podría aspirar frente a una persona pobre viviendo en una sociedad capitalista contemporánea (el medioevo es un periodo de la historia con una gran igualdad económica); una persona pobre (en especial una en una sociedad como la que Rawls tiene en mente) en la actualidad cuenta con bienes que mejoran su calidad

${ }^{60}$ Cfr Rawls, $A$ Theory of Justice. 71-72 
de vida y tiene objetivamente más bienes de lo que, en comparación, podría haber soñado un siervo en la edad media (como es acceso a la cultura, entretenimiento, en muchos casos educación y servicios básicos) aunque viva en una condición de mayor desigualdad. En pocas palabras, la desigualdad puede no sólo traer crecimiento económico sino que, al mismo tiempo, mejorar las condiciones materiales de vida de los menos beneficiados, incluso mientras la desigualdad se hace más pronunciada. Aunque esto no debe asumirse como una apología de la desigualdad, creo que es suficiente para reconocer que el argumento de conexión en cadena es inoperante.

Por otra parte, Rawls desarrolla una argumentación por el principio de diferencia desde el principio de fraternidad:

El ideal de la fraternidad en ciertas ocasiones se piensa que involucra lazos sentimentales y sentimientos que es poco realista esperar que existan entre miembros de la sociedad amplia. Esta es sin duda una razón ulterior para su relativo alejamiento de la teoría democrática. Muchos piensan que no tiene un lugar apropiado en los asuntos políticos. Sin embargo, si es interpretado de modo que incorpore los requisitos del principio de diferencia, no es una concepción impracticable. En realidad parece que las instituciones y políticas que consideramos justas satisfacen estas demandas, al menos en el sentido de que las inequidades permitidas contribuyen para el bienestar de los menos favorecidos. (...) Una vez que lo hemos aceptado podemos asociar las ideas tradicionales de la libertad, igualdad y fraternidad con la interpretación democrática de los dos principios de la justicia del siguiente modo: la libertad corresponde al primer principio, la igualdad con la idea de igualdad del primer principio junto con la igualdad de oportunidades justa, la fraternidad con el principio de diferencia. ${ }^{61}$

Antes de tratar la idea de la fraternidad, Rawls había mostrado dos maneras de intentar justificar el principio de diferencia y la interpretación democrática igualitaria de la justicia como imparcialidad. La primera, la idea de la aplicación del maximin deja mucho que desear: Rawls intenta argumentar usando la regla maximin como si, desde la posición original, fuera la mejor opción la interpretación democrática igualitaria usando el principio de diferencia. Como vimos, esta estrategia fracasa desde el inicio. La aplicación de la regla maximin a la toma de decisión bajo incertidumbre apunta a una comprensión del riesgo probablemente irracional por parte de Rawls; en la vida real, no en el planteamiento hipotético de la posición original, las personas corren riesgos aun cuando la peor consecuencia posible de su decisión sea la peor posible (un buen ejemplo de esto es salir de vacaciones viajando en carretera, en donde las probabilidades de tener un

${ }^{61}$ Rawls, $A$ Theory of Justice. 90-91 
accidente son relativamente altas comparadas con el volar o, simplemente, no salir de vacaciones), la toma de decisión sin una actitud frente al riesgo tan adversa como la plantea Rawls es la normalidad en la vida de prácticamente la totalidad de la humanidad.

La segunda manera en que Rawls buscaba argumentar en favor de la aplicación del principio de diferencia, como vimos, se funda en la idea de conexión en cadena. Argumento más endeble que la idea de la aplicación de la regla maximin. En este caso Rawls tiene confianza en la aplicación de "leyes económicas" a las cuales los individuos en la posición original sí podrían tener acceso. Este argumento es muestra de las complicaciones de asumir que existe algo así como una teoría económica lo suficientemente estable y empíricamente demostrable como para que pudiera ser razonable que la conocieran en la posición original. Rawls, en este sentido, tiene una comprensión pobre de lo que es la ciencia. Dewey, que en este contexto nos ofrece una explicación mucho más enriquecedora, asume la ciencia más como una serie de estrategias, conocimientos y mecanismos de indagación intrínsecamente abiertos a la falsación (lo que implica la imposibilidad de demostrarlos como verdaderos más allá de los mecanismos de justificación existentes). Dado que Rawls considera la teoría económica una especie de ley científica lo suficientemente estable como para servir en la posición original, es incapaz de reconocer que la ciencia está en profunda relación con la sociedad concreta en la que existe. ${ }^{62}$ Esto lo lleva a cometer el error de pensar que la conexión en cadena sirve como un argumento dentro de la posición original sin advertir que dicho argumento es inaplicable en un contexto en el que la información está tan limitada (esto asumiendo que la conexión en cadena de hecho es una realidad económica justificable dentro de un modelo económico particular). El conocimiento científico, con mayor claridad en las ciencias sociales, no es un catálogo de información universalmente válida; el conocimiento científico es más una aproximación a la realidad socialmente condicionada que tiende a reconocer la falibilidad de nuestras aseveraciones en función del contexto en el que nuestras ideas fueron postuladas. Reconocer esto no es acceder a la idea del relativismo o el subjetivismo absoluto, como lo discutí en el capítulo anterior.

\footnotetext{
62 Barry trata el tema de la conexión en cadena, en particular de su inadecuación, del siguiente modo: "Hay dos preguntas que deben responderse en este punto. La relativamente sencilla es si la "conexión en cadena" se mantiene en todas las sociedades. La respuesta es no. Aun si esto se piensa como una desestimación demasiado brusca uno debe con seguridad, al menos, decir que es demasiado controversial para ser tratado como un axioma en el que la elección de los principios fundamentales e pueden basar." (Barry, The Liberal Theory of Justice. 111)
} 
El argumento en favor de la interpretación democrática igualitarista de la justicia como imparcialidad, que implica la igualdad de oportunidades como lo entiende el liberalismo igualitarista y la aplicación del principio de diferencia, fundado en la idea de la fraternidad, es el más consistente. En el largo fragmento anterior se puede ver cómo es que el argumento en favor del principio de diferencia es de naturaleza pragmatista en su mejor estructura. Es llamativo que la argumentación desde la fraternidad sea tan breve en Teoría de la Justicia, su trato no es mucho mayor a lo que cité anteriormente y un par de párrafos más. Rawls, en el momento en que escribe su Teoría, lo hace con la convicción, que se debilita después hasta llegar al Liberalismo Político, como muestro en capítulos posteriores, de que los argumentos más estables y justificables son aquellos derivados de su constructivismo neokantiano; aquellos que se construyen desde la idea de la posición original como una representación hipotética de igualdad e imparcialidad en donde sujetos noumenales buscan establecer una concepción de la justicia adecuada para gobernar la estructura básica de la sociedad. En muchos casos esta convicción es una debilidad, en especial en el caso del argumento en favor del principio de diferencia.

La diferencia ente los argumentos de la regla maximin y la conexión en cadena frente a la aplicación del ideal de fraternidad en favor del principio de diferencia es fundamental. Rawls no estima que la fraternidad pueda servir dentro de la posición original en el mismo sentido que funciona la aplicación de la regla maximin; el argumento mismo, como se ve en la cita anterior implica, más bien, la experiencia histórica de los individuos en sociedades democráticas y liberales que han existido después de la Revolución Francesa de finales del XVIII. Rawls considera que es razonable sostener el principio de diferencia ya que nos permite integrar el ideal de fraternidad a la vivencia institucional de la sociedad; esto en tanto la fraternidad ha sido, tradicionalmente, considerada un valor o ideal inaplicable en la estructura básica de la sociedad pues se refiere a sentimientos empáticos que difícilmente se traducen en acciones o tendencias institucionales impersonales.

Rawls reconoce la validez de un argumento que descansa, no en la demostración bajo condiciones ideales, sino en la pertinencia de nuestros hábitos sociales y el mejoramiento de intenciones que consideramos adecuadas para la vida social. La conformación de la sociedad a la fraternidad, que no es un valor o ideal presente en todas las ideas del bien o concepciones de la justicia imaginables en una circunstancia como sería la posición original, como ideal regulativo, dadas las instituciones y condiciones existentes en las sociedades liberales, es adecuado 
en la formación de una concepción de la justicia. Llama la atención que algunos comentadores de Rawls han reconocido que este argumento en favor del principio de diferencia, como es el caso de Rodríguez Zepeda, es el más convincente pues se sostiene en el contenido moral del liberalismo y no tanto en la expectativa demostrativa kantiana:

Las ventajas de este argumento son varias. Una de las más importantes es la de no tener que suponer una improbable conexión causal entre todas las posiciones sociales y un movimiento ascendente de la optimización de expectativas. Pero la ventaja de mayor relevancia residiría en el hecho de que el principio de diferencia aparecería más como un principio moral de compromiso con los peor situados que como una mera regulación sociológica de la distribución de los excedentes de la riqueza y el ingreso. En esta línea, la conexión entre la posición más débil y el resto no aparecería como un juego de mera distribución de beneficios sino como la expresión de un verdadero compromiso moral, fraternal en definitiva, de evitar que las posiciones superiores puedan tener alguna ventaja a costa de las posiciones inferiores. ${ }^{63}$

La adopción de la fraternidad como ideal regulador de las instituciones, como afirma el mismo Rawls, está relacionada con los aparentes resultados de su aplicación en los juicios referidos a la justicia. Como afirma en uno de los pasajes anteriormente citados: "En realidad parece que las instituciones y políticas que consideramos justas satisfacen estas demandas -las de la fraternidad-, al menos en el sentido que las inequidades permitidas contribuyen para el bienestar de los menos favorecidos." Nuestra comprensión de lo justo está íntimamente vinculado a la aplicación del ideal de la fraternidad en las instituciones públicas, que implica la igualdad de los individuos. En este argumento el argumento rawlsiano en favor del principio de diferencia resuena al argumento rortiano sobre la naturaleza de la justicia como lealtad ampliada. ${ }^{64} \mathrm{Si}$ bien el artículo de Rorty "La justicia como lealtad ampliada" se centra en la comprensión de la razonabilidad en Rawls, a partir de la publicación del "Derecho de Gentes", comparada con la idea de la acción comunicativa de Habermas y el comunitarismo de Walzer, es relevante tenerlo presente pues, en lo que se refiere a la aplicación de la fraternidad como herramienta argumentativa, muestra cierta cercanía entre Rawls y el neopragmatista, confeso deudor de Dewey, Rorty. Para mostrarlo creo que sirve revisar parte de las conclusiones:

\footnotetext{
${ }^{63}$ Rodríguez, El igualitarismo liberal de John Rawls. 213

${ }^{64}$ Cfr. Richard Rorty: "La justicia como lealtad ampliada" en Filosofía y Futuro (Barcelona: Gedisa 2002) 79-97
} 
Si nos deshiciéramos de la idea de las obligaciones morales universales, que nos impone nuestra pertenencia a la especie humana y en su lugar pusiéramos la idea de construir una comunidad de confianza entre nosotros y los demás, tal vez estaríamos en una mejor posición para convencer a los miembros de sociedades nooccidentales de las ventajas que acarrea la integración en una tal comunidad. (...) Con esta propuesta, como ya en anteriores ocasiones, quiero insistir en que deberíamos separar el liberalismo ilustrado de su racionalismo. ${ }^{65}$

Una de las conclusiones de la obra de Rorty es la de reconocer la importancia de los hábitos sociales en la construcción de comunidades y, al mismo tiempo, de desarrollar consideraciones de justicia adecuadas para la realidad social. ${ }^{66}$ Rorty y Rawls se encuentran en el argumento que justifica el principio de diferencia desde la fraternidad y su desencuentro, particularmente marcado en Teoría de la Justicia (aunque es uno que se irá disolviendo conforme la obra de Rawls se desarrolla), es en el peso que cada uno le otorga a los argumentos de orden pragmático. Si bien, como he mostrado hasta ahora, dos de los argumentos para justificar el principio de diferencia en Teoría son del tipo de Rorty llamaría racionalistas (la aplicación de la regla maximin y la conexión en cadena dentro de la posición original o, de otro modo, en condiciones de absoluta imparcialidad con sujetos noumenales), el reconocimiento de la fraternidad en la tesitura de un ideal presente, históricamente desarrollado y moralmente relevante dentro del liberalismo garantiza otro modo de defender la igualdad democrática y, considero, mucho más poderosa que las otras dos opciones. Una pregunta que vale la pena hacerse es, si el argumento que mejor funciona es el de la fraternidad, ¿podríamos seguir afirmando que el principio de diferencia cumple con los límites de la justicia? No veo cómo podría ser así. Me parece fácil comprender por qué Rawls no se centra más en el argumento en la medida en que la fraternidad no es suficiente para cumplir con los límites de universalidad o finalidad de la concepción de la justicia.

Como he mostrado, la aceptación y aplicación del principio de diferencia es controversial en tanto que los argumentos que intentan justificarlo desde la perspectiva de la posición original son criticables y, en el caso de la conexión en cadena, equivocados. Por su parte, el argumento que sostiene el principio de

\footnotetext{
${ }^{65}$ Ibid. $96-97$

${ }^{66}$ Antes de continuar con la relevancia del pasaje para la discusión sobre la fraternidad y el principio de diferencia, es importante recalcar el contexto en el que Rorty está hablando. El artículo de "La justicia como lealtad ampliada" se refiere a la posibilidad de que las democracias liberales occidentales se vuelvan capaces de establecer lazos fundados en la justicia con sociedades no occidentales; en ese contexto la intención de Rorty es mostrar que es posible establecer prácticas y consensos sociales que promuevan relaciones fundadas en la justicia entre individuos y sociedades que tengan definiciones previas de lo que es la justicia y el bien diversas. Rorty apuesta por la posibilidad a desarrollar un concepto de razón que pueda trascender las comprensiones particulares de lo racional.
} 
diferencia desde premisas pragmáticas, como es su justificación en función del ideal de fraternidad, es someramente desarrollado en el texto y tiende a pasar desapercibido debido a que es complicado centrar la atención en tres párrafos dentro de un libro de más de 500 páginas.

Hay un problema en Teoría de la Justicia bastante claro: en la medida en que Rawls tiende a la justificación de su concepción de la justicia de acuerdo a argumentos de naturaleza pragmática, y por tanto reconozca la historicidad de los conceptos y la importancia de los hábitos, instituciones e intenciones empíricas en la conformación de nuestra concepción de lo justo, surgen ciertas contradicciones con otras partes de la teoría, en particular con algunas de sus ideas fundadas en su neokantismo como la universalidad y los límites de la justicia. La tensión presente en Teoría de la Justicia sobre la naturaleza de la argumentación en favor del liberalismo está más que presente en uno de los elementos de la justicia como imparcialidad: la interpretación democrática igualitarista de la concepción de la justicia.

Rawls busca la tranquilidad que traería consigo la certeza de la verdad de su concepción, de ahí la búsqueda de una argumentación neokantiana; si fuera capaz de mostrar que los argumentos que sostienen su concepción de la justicia se desarrollan desde un punto arquimédico, y por lo mismo son finales (recordemos el límite de la justicia que es la finalidad), Rawls podría descansar en la confianza del saber "imperturbable". En el texto, al mismo tiempo, está continuamente la conciencia de que dicha confianza es inalcanzable de modo absoluto (es importante recordar como Rawls afirma que su concepción de la justicia es una más que compite con otras candidatas, que al mismo tiempo podría surgir una nueva concepción que tome su lugar, que en parte los argumentos deben estar enfocados a predecir resultados convenientes y favorables, etc.). Creo que, dicho lo anterior, queda la siguiente pregunta, a la que responde con el tiempo y el llamado "giro político" Rawls: si la argumentación de la justicia como imparcialidad, y en particular de su interpretación democrática igualitarista, no puede ser hecha satisfactoriamente desde la certeza del racionalismo kantiano, ¿está dispuesto Rawls a reconocer la primacía de los argumentos pragmáticos? Si así fuera, ¿reconoce la importancia de desarrollar un liberalismo perfeccionista al menos en un sentido deweyano? Como veremos en capítulos posteriores, considero que Rawls sí reconoce la primacía de los argumentos de carácter pragmático. Por otra parte, mantiene su postura antiperfeccionista aun cuando esto implique negar el carácter civilizatorio del proyecto liberal. 
Si aceptamos que la concepción de la justicia se justifica por la existencia de ciertos ideales y valores, como es el de fraternidad, que se construyen históricamente y que responden a intenciones y hábitos sociales, la negación del carácter perfeccionista del liberalismo implicaría que éste se desarrolló por circunstancias de algún modo externas a la lógica liberal misma. El antiperfeccionismo sólo tiene sentido y es sostenible si la justicia como imparcialidad, así como su interpretación democrática igualitarista, pueden ser justificados en función de argumentos del tipo de la regla maximin o la conexión en cadena para justificar el principio de diferencia. Una vez que reconozcamos que la concepción de la justicia, o al menos elementos sustantivos de ella, sólo son comprensibles desde una perspectiva pragmática de la cultura (pragmático en el sentido de Dewey), el antiperfeccionismo que propone Rawls es una incomprensión de la naturaleza del liberalismo mismo. Este problema, que expondré a continuación con mayor claridad, lo abordo en las siguientes partes de esta investigación con la finalidad de reconocer hasta dónde el antiperfeccionismo y los elementos más pragmáticos del pensamiento de Rawls pueden coexistir sin generar condiciones de inestabilidad.

A continuación, una vez que he expuesto algunos de los elementos esenciales de la justicia como imparcialidad, me centro en el análisis de la propuesta antiperfeccionista de Rawls en este texto. Dicho antiperfeccionismo está relacionado con la idea de la tolerancia y la estabilidad. Para concluir, busco hacer un balance entre la importancia de la tolerancia y la necesidad de garantizar la estabilidad de la concepción de la justicia. Al hacerlo muestro cómo es que, para que Rawls pueda garantizar la estabilidad de la justicia como imparcialidad, es necesario adoptar algún tipo de perfeccionismo en función de una idea del bien liberal.

\section{Antiperfeccionismo y liberalismo político}

El antiperfeccionismo en Teoría de la Justicia está fundamentado en la idea de que ideas del bien distintas, en un estado de imparcialidad, son incomparables. La imposición del velo de la ignorancia, junto con los límites a la motivación, obliga a las partes a considerar las distintas concepciones del bien de modo imparcial ya que no pueden saber cuál será la que ellas tendrán. Rawls espera que el velo de la ignorancia, que implica la imposición de la imparcialidad como criterio fundamental, obligue a las partes que "deciden" sobre la concepción de la justicia a 
considerar las distintas ideas del bien con indiferencia. Debido a que no hay una idea del bien trascendente que nos sirva como criterio para comparar y juzgar distintas comprensiones del bien es necesario reconocer que todas las ideas son igualmente aceptables.

Recordemos que la justicia, como primera virtud social, está encargada primordialmente de la distribución de bienes, en particular de los bienes primarios. En virtud de que la justicia distribuye bienes primarios, como hemos visto hasta ahora, es su labor garantizar los medios adecuados para que los individuos sean capaces de alcanzar la realización de sus ideas del bien. El criterio de imparcialidad en la posición original, que es la idea clave dentro de la justicia como imparcialidad, supone que cada idea del bien está igualmente legitimada a ser perseguible. Históricamente la comprensión de una sociedad justa ha estado relacionada con aquella que garantiza la distribución adecuada de los bienes en función del valor moral de los individuos y las ideas del bien que forman sus actos. En el caso del liberalismo de Rawls, al no procurar desarrollar una idea del bien que ordene cuáles concepciones son, a su vez, aceptables, nos encontramos con la necesidad de aceptarlas todas, dando igual respeto y "apoyo" (cuando necesiten dicho apoyo de acuerdo con lo estipulado por el segundo principio) siempre y cuando su existencia no represente un riesgo inminente para la existencia de la concepción de la justicia.

El ejercicio de la tolerancia dentro de la comunidad política está enmarcado por los límites de la conservación del orden y la seguridad. El principio de tolerancia supone que el gobierno, o mejor dicho la estructura básica de la sociedad, no está en condiciones de afirmar qué idea del bien es mejor, por el contrario:

(...) dados los principios de la justicia, el Estado debe ser entendido como la asociación que consistente en ciudadanos iguales. No debe preocuparse con doctrinas filosóficas y religiosas, sino regular la búsqueda de los individuos de sus intereses morales y espirituales de acuerdo con los principios con los que ellos mismos estarían de acuerdo en una posición inicial de igualdad. (...) Por tanto la noción de un Estado laicista omnicompetente también es rechazada, esto dado que de los principios de la justicia se sigue que el gobierno no tiene ni el derecho ni el deber a hacer lo que él o la mayoría (o quién sea) quiera hacer en cuestiones de moralidad y religión. Su deber está limitado a garantizar las condiciones de igualdad moral y libertad religiosa. ${ }^{67}$

${ }^{67}$ Rawls, A Theory of Justice. 190 
La idea de que el Estado pueda asumir el papel de árbitro sobre qué ideas del bien son correctas es, a todas luces, un peligro constante por el cual, en buena medida, vino a existir la tradición liberal (con su búsqueda de la defensa de la privacidad). Lo que es más, Rawls formula un argumento importante cuando sostiene que “donde la supresión de la libertad está basada en principios teológicos o asuntos de fe, ninguna discusión racional es posible." ${ }^{68}$ Rawls busca garantizar la estabilidad de la comunidad política mediante los principios de la justicia: en tanto las distintas ideas del bien (fundamentadas en principios teológicos o en asuntos de fe) no contradigan directamente la concepción de la justicia que sería elegida por los individuos en una circunstancia de imparcialidad donde se reconozca su absoluta autonomía, deben de ser respetadas y toleradas. Lo que es más, de acuerdo con Rawls, el trato tolerante debe ser garantizado incluso con aquellos que no son tolerantes con los demás siempre que la constitución, y por tanto la estructura básica gobernada por una concepción de la justicia razonable como son los principios de la justicia como imparcialidad, no corra ningún riesgo: "Cuando la constitución está por sí misma segura, no hay ninguna razón para negar la libertad al intolerante." ${ }^{\prime 9}$

Un ejemplo claro de la actitud liberal frente a este problema es el de permitir la existencia de grupos como la asociación religiosa norteamericana llamada Westboro Baptist Church (Iglesia Bautista de Westboro). Esta es una iglesia familiar, fundada, por el fallecido en el 2014, Fred Phelps. La característica fundamental de esta organización es la de su visión radical y discriminatoria contra grupos minoritarios, en particular contra la comunidad homosexual. La Iglesia Bautista de Westboro ganó popularidad en Estados Unidos por sus manifestaciones públicas en funerales de soldados norteamericanos y otras celebridades, desde el año 1991, en donde pisotean la bandera y sostienen carteles con leyendas ofensivas en contra de la comunidad homosexual, culpándolos de guerras, terrorismo y catástrofes naturales y sociales al ser responsables de desatar la ira de Dios. Aun cuando no existan políticos que apoyen la agenda de este grupo, al menos no abiertamente, y su aceptación dentro de los Estados Unidos sea prácticamente inexistente (quizá más por su obsesión con manifestarse en funerales de soldados muertos en batalla que por su visión discriminatoria e intolerante), podríamos afirmar, siguiendo a Rawls, que no es competencia del Estado el actuar en contra suya. Por otro lado, si dicho grupo tuviera la posibilidad de poner en riesgo la estabilidad nacional, el caso sería distinto. Podríamos decir que en el caso en que la Iglesia Bautista de

\footnotetext{
${ }^{68}$ Ibid. 190

${ }^{69}$ Ibid. 192
} 
Westboro pudiera poner en riesgo la constitución y la estructura básica, sería posible, usando un argumento de razón de Estado, suprimir la existencia de dicho grupo. Suponiendo que las libertades de los demás estén garantizadas, no hay una razón justa para limitar incluso a grupos así de dañinos para la sociedad según Rawls.

En este punto Dewey no seguiría a Rawls. Una deficiencia dentro del planteamiento del liberalismo rawlsiano se encuentra en que no termina de asumir del todo el impacto social de las diversas ideas del bien. Por su parte Dewey, como vimos, asume una idea del ethos liberal más robusta; al menos respecto del alcance de dicho ethos. Considero que este problema se mantendrá en obras posteriores de Rawls. En el sexto capítulo mostraré algunas de las implicaciones de esta actitud en el pensamiento de Rawls al exponer el tema de "lo razonable" y cómo éste parece no dar la importancia debida a las diferencias en ideas del bien por las implicaciones que pueden tener.

Aun cuando cualquier liberal sea capaz de aceptar y reconocer la importancia de limitar el acceso del poder político al ámbito privado, la cuestión sobre el impacto de las ideas del bien de los individuos en aquellos que los rodean debería de ser central para una concepción de la justicia que busca ser estable en el tiempo, esto está ausente en Rawls. Esta falta de comprensión de la naturaleza social de la formación del yo y del impacto de las ideas del bien de terceros en los individuos, desemboca en una falla dentro del liberalismo rawlsiano pues descarta la responsabilidad de la concepción de una justicia liberal respecto a su papel civilizatorio y perfeccionista de la población. Este problema es evidente cuando Rawls toca someramente, en Teoría de la Justicia, la existencia de la familia como una de las fuentes originarias de desigualdad social:

Parece que aun cuando la igualdad de oportunidades (como ha sido definida) es satisfecha, la familia conducirá a oportunidades desiguales entre individuos. ¿Deberíamos deshacernos de la familia por tanto? Si la tomamos por sí misma y le damos prioridad, la idea de la igualdad de oportunidades se inclina en esta dirección. Sin embargo dentro del contexto de la teoría de la justicia como un todo, existe mucha menor urgencia para hacerlo. El reconocimiento del principio de diferencia redefine el terreno para las desigualdades sociales como son comprendidas dentro de un sistema liberal igualitario; y cuando los principios de fraternidad y de compensación se permiten en su justo valor, la distribución natural de bienes y las contingencias de circunstancias sociales pueden ser aceptadas con mayor facilidad. ${ }^{70}$

${ }^{70}$ Ibid. 448 
En la cita anterior es claro que Rawls reconoce la centralidad de la familia como una institución que, independientemente del bienestar que pueda generar, es un catalizador de desigualdad social. El lugar en el que nacemos es sin lugar a dudas determinante para comprender nuestras posibilidades y oportunidades a futuro; nacer en una familia con una mayor riqueza, mejor posición social o, incluso, que herede a su prole características genéticas socialmente deseables (como puede ser la inteligencia, el talentos físicos-atléticos $\mathrm{o}$, incluso, un fenotipo físico ${ }^{71}$ ) puede significar una gran ventaja. Si la única manera en que la familia puede generar desigualdad fuera a través de la repartición de bienes primarios a sus integrantes, la justicia como imparcialidad estaría en condición de paliar dichas desigualdades. El efecto de la familia es, sin embargo, mucho más profundo; esto es más claro en el caso de los hijos, aunque no exclusivo de ellos. Aun cuando Rawls reconoce que la familia forma las aspiraciones de los menores, no vislumbra el impacto de la educación en la formación del individuo al suponer que la justicia como imparcialidad es capaz de paliar las desigualdades más relevantes. ${ }^{72}$ La familia es normalmente, aunque siempre existan excepciones, el lugar en el que los individuos construyen parte relevante de sus aspiraciones y comprensión del mundo. La familia no es la institución exclusiva en la que sucede esto, la realidad es que durante toda nuestra vida, aunque probablemente en la niñez esto es más evidente y tiene un mayor impacto, nuestras relaciones con otros individuos influyen en nuestra conformación como personas y ciudadanos.

Regresemos al ejemplo de la Iglesia Bautista de Westboro. Esta comunidad religiosa, catalogada como un "grupo de odio" por la Liga Antidifamatoria de América, ${ }^{73}$ está localizada en la pequeña ciudad de Topeka en Kansas, que cuenta con poco más de 122 mil habitantes según el censo del 2006. Debido a su naturaleza radical, los miembros de este grupo religioso viven en una comunidad residencial pequeña y aislada. Su mala fama es bien merecida y, como había comentado antes, son un grupo con amplio reconocimiento; aun cuando es pequeña (los miembros de dicho grupo son los integrantes de la familia del fundador de la organización), la iglesia ha logrado tener presencia en medios de

\footnotetext{
${ }^{71}$ Recordemos que Aristóteles afirma que las personas muy feas tienen una mayor dificultad para ser felices.

Angélica Enciso, "En pobreza, 53.3 millones de mexicanos, informa el Coneval," La Jornada, 30 de julio 2013, consultado 1 de septiembre 2014, http://www.jornada.unam.mx/2013/07/30/politica/007n1pol

${ }^{72}$ Cfr. Ibid. 265

${ }^{73} \mathrm{Cfr}$. Anti discrimination League, "Extremism in America" consultado 4 de noviembre 2014, http://archive.adl.org/learn/ext_us/wbc/wbc-onamerica.html?LEARN_Cat=Extremism\&LEARN_SubCat=Extremism_in_America\&xpicked=3\&item=WBC
} 
difusión internacional como son la BBC, Huffington Post o CNN, entre otros. Una vez dicho lo anterior, y bajo el supuesto de que no representan un peligro para la constitución norteamericana, ¿es razonable suponer que la imparcialidad de gobierno en este caso, al menos en lo que se refiere a la educación de los hijos de los miembros, es algo adecuado? Es importante comentar que este grupo de odio siempre se mantiene dentro de los márgenes de la ley. Si Rawls está en lo correcto, dado su respeto por la ley, deberíamos ser tolerantes con la existencia de dicha institución en tanto que el gobierno no está en condición de determinar si las perspectivas de dicho grupo son correctas o incorrectas, después de todo procuran sustentar sus creencias en afirmaciones de carácter teológico (la discriminación a homosexuales no es un hecho excepcional dentro de diversos grupos religiosos). El problema se puede abordar desde dos perspectivas distintas: (i) la responsabilidad de gobierno en una democracia liberal con aquellos cuyas ideas del bien están en plena formación y que no tienen sus poderes morales completamente desarrollados (suponiendo que juzgamos la responsabilidad de un niño de un tipo o grado distinto a la de un adulto) y (ii) si la existencia misma del liberalismo exige un cierto ethos para poder mantenerse en el tiempo y en esa medida debe procurar un ideal liberal en los ciudadanos y debe encontrar modos adecuados (la educación, por ejemplo, es uno de los mejores métodos según Dewey) de limitar y desaparecer grupos que pongan en riesgo dicho ethos.

Aun cuando abordo ambas cuestiones por separado, y en esa medida la segunda es más relevante para esta investigación, me parece importante mencionar cómo es que ambas están íntimamente relacionadas. La responsabilidad del gobierno en una democracia liberal con los niños, bajo el supuesto que un niño está en proceso de desarrollar su idea del bien y, en caso de tenerla, no puede ser considerado responsable al modo de un adulto por las acciones que lleve a cabo para alcanzarla, está relacionada con el contenido moral del liberalismo; es decir, con promover ciertas ideas y creencias fundamentales para que dichos niños puedan desarrollar ideas del bien compatibles con una democracia liberal, así como garantizar los bienes primarios que requerirá cuando tenga la edad para hacerse responsable de su búsqueda de un proyecto de vida determinado (garantizando una educación que le permita acceder a ciertos bienes materiales). El gobierno de una democracia liberal sólo podría tener cierta responsabilidad por las ideas del bien de aquellos que no son actualmente ciudadanos en la medida en que el mantenimiento de la democracia liberal supone un contenido moral determinado (lo que es tanto como decir una serie de ideas del bien determinadas). Dicho de otro modo, es necesario preguntarnos si el liberalismo exige la existencia 
de ideas del bien determinadas que, en caso de no existir, puedan poner en riesgo la estabilidad de la comunidad. Si esto es así, que el gobierno tendría la responsabilidad de promover esos ideales y eso equivaldría a un cierto modo de perfeccionismo (al menos perfeccionismo en un sentido práctico, como lo conceptualiza John Dewey).

El problema de la responsabilidad del gobierno frente al impacto de las ideas del bien de terceros en individuos que no pueden considerarse responsables es clave dentro del contractualismo. En de la posición original, o cualquier circunstancia contractual hipotética para el caso, todas las partes contratantes, asumiendo que estén en una posición de igualdad, suponen que están legitimados para poseer una idea del bien determinada. Lo que es más, si agregamos el velo de la ignorancia, como sucede en la posición original rawlsiana, como método de garantizar la imparcialidad entre las partes contratantes, no existe razón alguna, más allá de la defensa de la constitución (que es tanto como decir que en defensa de la concepción de la justicia acordada para la estructura básica), para limitar la posesión y ejercicio implícito de una concepción del bien. Supuesto esto, ¿cuál es el problema con los niños?

La cuestión fundamental cuando hablamos del derecho de los niños de poseer una idea del bien determinada, o a ser influenciados libremente por quien quiera que esté alrededor de ellos (idealmente bajo el consentimiento de quien tenga la tutela legal), es que los niños no son, en caso alguno, partes en el pacto original. Cuando se asume que las capacidades morales de los menores de edad no están completamente definidas, reconocemos que no pueden ser parte del contrato y que no pueden ser sujetos de los mismos derechos, del mismo modo, que quienes sí lo son. Las preguntas que se siguen son las siguientes: ¿Tiene la comunidad una responsabilidad especial con los menores de edad? ¿El derecho de un adulto, que se asume que sería una parte contratante en la posición original, a poseer una idea del bien determinada, puede suponer el derecho de influenciar del modo que prefiera a un menor, con la limitante de no romper alguna ley determinada? Si así fuera, ¿este derecho implica la transmisión de valores e ideas del bien contrarias a los principios del liberalismo como los de la Iglesia Bautista de Westboro?

En Teoría de la Justicia el problema no tiene una clara solución. Por un lado Rawls parece abordar el problema de la familia como uno de mera desigualdad de oportunidades, como vimos atrás. Por otro lado, difícilmente podríamos decir que existe una teoría, al menos esbozada con cierta claridad, sobre los derechos de los menores o aquellos que no son candidatos a contratantes en la posición original. 
Aun cuando hay una intención de hacer la concepción de la justicia lo más posible, los límites impuestos por Rawls tienden a ser restrictivos: "La capacidad mínima para tener un sentido de la justicia asegura que todos tengan los mismos derechos. La igualdad se afirma por los hechos generales de la naturaleza y no simplemente por una regla procedimental sin fuerza sustantiva." ${ }^{74}$ La idea anterior es clara: es en la capacidad de poseer un sentido de la justicia (una capacidad que exista actualmente $)^{75}$ donde se pueden afirmar los derechos implicados en los principios de la justicia. Dicho esto, Rawls termina dividendo el mundo en dos grandes grupos: aquellos seres capaces de pertenecer actualmente a la comunidad política en tanto pueden desarrollar una concepción de la justicia y una idea del bien y, por otro lado, el resto de los seres del mundo con los cuales tendremos, en mayor o menor medida según sea el caso, algunas obligaciones y responsabilidades:

Aunque no he sostenido que la posesión de la capacidad del sentido de la justicia es necesaria para que los deberes de la justicia sean debidos, sí parece que no estamos obligados a garantizar justicia estricta a creaturas que carezcan de esta capacidad. Sin embargo no se sigue que no existan ciertos requerimientos en lo absoluto al respecto de ellos, ni sobre nuestras relaciones con el orden natural. ${ }^{76}$

Es importante hacer notar que en este pasaje Rawls se refiere específicamente al mundo natural y los animales. Sin embargo, como espero que haya quedado claro, no hay certidumbre dentro de la teoría de hasta qué punto este fragmento se puede referir, del mismo modo, a menores de edad sin la capacidad de desarrollar una concepción de la justicia e ideas del bien de un modo que puedan hacerse responsables por ellas. Dicho esto, la determinación de qué deberes y obligaciones tiene el gobierno, como garante del acuerdo que sería llevado a cabo en la posición original, con los menores incapaces de desarrollar una concepción de la justicia e ideas del bien adecuadas, está abierta a discusión. La posibilidad de plantear las responsabilidades del gobierno con los menores es fundamental pues termina dejando abierta la posibilidad de un proyecto perfeccionista como lo hubiera vislumbrado John Dewey. El proceso educativo, como argumento más adelante en

\footnotetext{
${ }^{74}$ Rawls, $A$ Theory of Justice. 446

${ }^{75}$ Esta aclaración es pertinente ya que, si comenzamos a plantear el problema en términos de una capacidad en potencia, nos adentramos a un debate insoluble. Es por la aceptación de la discusión sobre la potencialidad de las capacidades que debates como el del el aborto (si el embrión es un ser humano en potencia y, por lo mismo, un sujeto de derecho) han llegado a un estancamiento en la medida en que las distintas partes sostienen presupuestos filosóficos diversos. El tema sobre la potencia puede ser de interés filosófico, quizá teológico, pero si reconocemos que su solución no es competencia adecuada del ámbito político, como me parece que lo haría Rawls, podríamos afirmar que sólo las capacidades que actualmente existen pueden ser tomadas en cuenta dentro de la concepción de la justicia elegida en la posición original.

${ }^{76}$ Ibid. 448
} 
esta investigación, es una de las herramientas para construir un proyecto perfeccionista liberal en tanto que, por su naturaleza, el liberalismo tiende a alejarse de la coerción y, más bien, se relaciona con la persuasión.

Esta posibilidad en Teoría de la Justicia podría parecer una contradicción directa con los objetivos mismos del texto; después de todo Rawls afirma, continua y consistentemente, que el perfeccionismo no podría ser una concepción de la justicia aceptable dadas las condiciones de imparcialidad en la posición original. Sin embargo, la aceptación de la tarea del gobierno de educador, o al menos moderador en la educación de los menores de edad, que tiende a imponer un ideal liberal en la población, es condición necesaria para la estabilidad de la comunidad. Del mismo modo, sólo aceptando el papel rector del gobierno se reconocen las obligaciones de justicia de la comunidad con los menores de edad, que suponen que no pueden ser considerados propiedad de sus padres o tutores directos y, por lo mismo, no están necesariamente en libertad de enseñarles lo que quieran como idea del bien aun cuando se mantengan dentro de la estricta legalidad. Este problema es radicalmente importante $\mathrm{y}$, con excepción de casos como el de la Iglesia Bautista de Westoboro, tiende a pasar relativamente desapercibido.

México es un ejemplo claro de la problemática social y el impacto a corto, mediano y largo plazos que puede significar la libertad de enseñanzas antiliberales en una sociedad que se supone garantiza los mismos derechos a sus ciudadanos. Tres casos claros son la discriminación de género, que termina significando una desigualdad en los ingresos, la falta de apoyo al desarrollo y autonomía de grupos indígenas, en buena medida fundamentado en prejuicios sobre su capacidad intelectual para gobernarse y la discriminación a grupos con preferencias sexuales minoritarias, que terminan implicando menos oportunidades y límites en sus derechos.

Sin duda Rawls reprobaría estos y muchos otros hechos discriminatorios que suceden continuamente en las sociedades. Lo que es más, Teoría de la Justicia ofrece los argumentos suficientes para demostrar que dichos actos de intolerancia deben estar prohibidos. El problema, sin embargo, es que la existencia de estos argumentos difícilmente es suficiente para individuos que no reconozcan la primacía del argumento contractual, el valor de la igualdad y la importancia del respeto de la autonomía. En la medida en que la sociedad no cuente con los mecanismos (aquellos que fueran razonables y congruentes con los contenidos de la moral liberal) para detener la propagación de ideas contrarias al liberalismo, no hay garantías que no transite a una cultura de intolerancia. En ese escenario 
podríamos anticipar que, aceptando que los oficiales ocupan sus puestos en parte porque representan los intereses de los ciudadanos, los puestos en el gobierno tenderán a ser ocupados por personas que compartan ideas del bien contrarias a los objetivos de una sociedad liberal. Esto me lleva al segundo punto que quería tratar en este apartado: (ii) si la existencia misma del liberalismo exige un cierto ethos para poder mantenerse en el tiempo y en esa medida debe procurar un ideal liberal en los ciudadanos.

Cuando nos planteamos, como lo hace Rawls, qué es necesario para garantizar la estabilidad de una concepción de la justicia que gobierne la estructura básica de la sociedad, parecería que es algo más allá de los meros controles constitucionales. Recordemos, como vimos el capítulo anterior, que Dewey reconocía con claridad que "si queremos que los individuos sean libres debemos darnos a la tarea de que las condiciones apropiadas existan." ${ }^{77}$ Dado que la concepción de la justicia que Rawls considera apropiada, en función en que sería aquella elegida en la posición original, es una liberal, es necesario que las condiciones adecuadas existan. Una de las condiciones para que las personas puedan ser libres es que las personas que integran la comunidad, en especial aquellos encargados de ejercer el poder político, acepten la concepción de la justicia y, por lo mismo, ordenen sus actos en función de ella. El problema grave de permitir la intolerancia en la sociedad es que tendremos que confiar en que individuos intolerantes trabajen en función de instituciones tolerantes; esto es poco razonable. En los capítulos quinto y sexto muestro como el planteamiento rawlsiano, aun después de los cambios (de fondo y de presentación) que realizó posterior a las reacciones a Teoría, establece un liberalismo sobre un fundamento inestable por la reticencia de Rawls de promover una cultura, más allá de la estructura básica, que sea compatible con la concepción de la justicia.

En Teoría de la Justicia hay dos maneras de explicar por qué Rawls considera que, con el paso del tiempo, la justicia como imparcialidad sería una concepción estable si suponemos que sería aceptada y ejercida por los ciudadanos. Por un lado se encuentra el principio de imparcialidad, que es el que informa los deberes y obligaciones y, por otro, está el funcionamiento de nuestra psicología moral, con la que Rawls piensa que los principios terminarían siendo aceptados por la gran mayoría de los individuos.

Sobre el principio de imparcialidad podemos decir que, de acuerdo con Rawls, supone que las personas están obligadas a hacer lo que les corresponde

77 Dewey, Freedom and Culture, 33 
según las reglas de una institución siempre que hayan aceptado voluntariamente los beneficios de dicho esquema y cumpla con los criterios de justicia. ${ }^{78}$ Dicho de otra manera, Rawls asume que existe un principio moral, derivado de una idea intuitiva, que estipula que "no debemos ganar del esfuerzo cooperativo de otros sin haber hecho lo que nos correspondía con justicia hacer." ${ }^{79}$ El principio de imparcialidad sirve como fundamento de las relaciones de justicia en tanto los miembros participantes reconocen la naturaleza del esfuerzo cooperativo que implica que las partes sólo pueden beneficiarse en tanto en que de hecho cooperen con los objetivos.

Dicho lo anterior, se puede ver una condición necesaria para que el principio de imparcialidad pueda operar: cada uno de los participantes deben tener una cierta confianza en que sus contrapartes están en condición de reconocer el principio de imparcialidad y están en disposición de cumplir con su parte del esfuerzo cooperativo. ${ }^{80} \mathrm{Si}$ pensamos en la posibilidad de que el esfuerzo cooperativo lo lleven a cabo personas intolerantes y con prejuicios, como pueden ser los miembros de la Iglesia Bautista de Westboro, es posible encontrar un primer problema. Cuando una de las partes no piensa que sus contrapartes son igualmente dignos, el cumplimiento del principio de imparcialidad se ve seriamente comprometido; del mismo modo la víctima de la discriminación probablemente duda de que su contraparte, es decir aquel que sea intolerante, esté en disposición de cumplir con el principio. Si la existencia de intolerancia y grupos de odio fuera algo más o menos común en la comunidad política, el cumplimiento de los principios derivados de la posición original estaría sujeta a una continua negociación que más parecería un perpetuo dilema del prisionero. El principio de imparcialidad requiere, para que podamos considerar su aplicación razonablemente, que las partes cuenten con una moralidad con rasgos democráticos y liberales ya que todos deben pensarse como individuos iguales.

De este modo, el principio de imparcialidad es insuficiente para garantizar la aplicación de los principios de la justicia como imparcialidad. Por supuesto, si nos imaginamos estar en la posición original, en donde todos los individuos están cubiertos por el velo de la ignorancia y, por lo mismo, se consideran iguales en tanto no tienen conocimiento de sus yoes "empíricos", por decirlo de algún modo, el principio de imparcialidad sería elegido y considerado una necesidad. El problema de la teoría, en este caso, es que el principio de imparcialidad, como ya

\footnotetext{
${ }^{78}$ Cfr. Rawls, $A$ Theory of Justice. 301

${ }^{79}$ Idem.

${ }^{80}$ Cfr. Ibid. 305
} 
he afirmado, exige que las partes que se encuentran en el esfuerzo cooperativo consideren iguales, al menos en sus características relevantes para la circunstancia concreta a sus pares, y, en realidad, fuera de la posición original existen ideas del bien que contradicen esta creencia.

Una vez dicho esto, como había mencionado antes, Rawls fundamenta la estabilidad de la justicia como imparcialidad en la psicología moral. Al tratar la psicología moral, Rawls reconoce la importancia de que la concepción de la justicia sea compartida por todos. Esto es particularmente claro cuando dice que:

Para asegurar la estabilidad los hombres deben de poseer un sentido de la justicia o una preocupación por aquellos que estarían en desventaja por su mala acción, preferiblemente ambos. Cuando estos sentimientos son suficientemente fuertes para imponerse a la tentación de violar las reglas, el esquema justo es estable. ${ }^{81}$

El modo en que las personas desarrollan estos sentimientos y adoptan la concepción de la justicia, está plasmado en tres leyes o tendencias de la psicología moral: ${ }^{82}$

1. Dada la existencia de la familia y que ésta es una institución justa en donde los padres aman a sus hijos, los menores reconocen el amor de sus padres y los aman en reciprocidad.

2. Dado que las personas desarrollan la capacidad de tener sentimientos hacia sus iguales, inicialmente del modo que se estipula en la primera ley, y que un ordenamiento social es justo y públicamente reconocido, entonces las personas desarrollan los sentimientos afectivos hacia aquellos que viven en dicho ordenamiento en cuanto los otros cumplen con sus deberes y obligaciones de acuerdo a su posición.

3. Dado que la capacidad de una persona de desarrollar sentimientos hacia sus iguales se ha realizado mediante la formación de lazos como se establece en las primeras dos leyes, y dado que las instituciones sociales son justas y públicamente reconocidas por todos, entonces esta persona adquiere el correspondiente sentido de la justicia pues reconoce que él y aquellos que le importan son beneficiarios de dicha ordenación.

Los principios de la psicología moral de Rawls intentan ofrecen una generalización sobre cómo los individuos tienden a desarrollar sentimientos morales hacia otros individuos y por las instituciones. Aun cuando estas leyes representan una simplificación excesiva por parte de Rawls, asumiré que son correctas; $^{83} \sin$

\footnotetext{
81 Ibid. 435

${ }^{82}$ Cfr. Ibid. 429-430

${ }^{83}$ Asumir que son correctas es bastante generoso con Rawls en tanto que asumir que se cumplen (como se cumpliría una ley) es imposible. Por ejemplo, ¿en realidad es una ley que los padres aman a los hijos?, ¿es un hecho excepcional cuando no sucede así?
} 
embargo, en este sentido es posible encontrar mejores desarrollos al respecto, como sucede con Dewey quien ofrece, como se vio someramente en el primer capítulo, una construcción de la moralidad humana sumamente rica. En cualquier caso, estos principios son, según el mismo Rawls, los que informan la moralidad de todas las personas.

Rawls confía en que los principios de la psicología moral garantizan la estabilidad de la justicia como imparcialidad en función de que las personas terminan generando los sentimientos morales apropiados para que la estructura básica se conduzca con los principios de la justicia y sean estos los que gobiernen las relaciones de los individuos. Para que esto sea correcto tenemos que suponer que la justicia como imparcialidad tiende a ocupar un papel central en las relaciones sociales de la comunidad, mucho más allá de la estructura básica, que es su objeto.

Rawls está equivocado al suponer que el impacto de la concepción de la justicia, de orden político, en la formación de los sentimientos morales, es suficiente como para convertirse en una de las condiciones de estabilidad en la comunidad por sí misma. Esta idea está desarrollada por Barber en su crítica a los problemas de justificación en Rawls:

Rawls es incapaz de citar evidencia psicológica o histórica que sugiera que la tolerancia del intolerante lo vuelve más tolerante y consciente de la libertad. El tipo de datos exigidos por aquellos interesados en la evidencia indican que el intolerante está, en la mayor parte, más allá de la racionalidad y por tanto es incapaz de comprender lo que está de fondo en la misma idea de la tolerancia. El intolerante normalmente se refiere a superiores imaginarios con la misma falta de racionalidad con la que tiranizan a sus inferiores imaginarios. Los creyentes fanáticos continuamente parecen comprender la tolerancia por los demás más como un halago que como una reprimenda a su intolerancia. Sin embargo, no debemos falsificar la intención de Rawls para dejar en claro que, en la falta de una sociología política, no sólo se mantiene sin probar sino, igualmente, sin siquiera examinar. ${ }^{84}$

La necesidad social de desarrollar legislación contra la discriminación en el mundo debería de comprenderse como una consecuencia clara de este hecho. Considero sorprendente que Rawls, quien en su juventud vivió en un Estados Unidos que en buena parte mantenía una sociedad intolerante, no plantee el tema con mayor claridad.

El ejemplo de Estados Unidos es particularmente ilustrativo. Después de la guerra civil norteamericana los congresos locales de los estados del sur, los

${ }^{84}$ Barber: "Justifying Justice: Problems of Psychology, Measurement, and Politics in Rawls". 671 
Confederados que habían perdido, se dieron a la tarea de elaborar legislación segregacionista. Ésta entraría en vigor a finales del XIX y estaría vigente hasta 1965; sería conocida con el nombre de leyes Jim Crow. Estas leyes suponían que las personas de color y las personas blancas deberían de contar con instalaciones separadas en servicios tales como el transporte público, escuelas, baños y restaurantes. Estas leyes estaban fundadas en la doctrina legal, sostenida largamente por la Suprema Corte de Justicia, "iguales, pero separados". Formalmente la consideración de "iguales, pero separados" no suponía la desigualdad en la distribución de bienes, de hecho la doctrina estipulaba que, como la discriminación era ilegal, el Estado estaba obligado a garantizar el mismo acceso a servicios a las personas de color que a las blancas.

En la posición original, el establecimiento de leyes segregacionistas como las de Jim Crow sería inaceptable. Aun cuando la doctrina de "iguales, pero separados" podría ser pensada como consecuente con el segundo principio de la justicia, en tanto se garanticen ingreso y oportunidades equivalentes, claramente implica una violación al primer principio ya que tanto personas de color como blancas tienen libertades distintas $\mathrm{y}$, aceptando que las libertades básicas son limitadas en número y la distribución era desigual, es posible prever que un grupo tendría menos, en este caso las personas de color. Sin embargo, asumiendo lo inadecuado del establecimiento de la segregación por parte del gobierno, queda la pregunta de si pueden ser prohibidas por el gobierno, dadas las condiciones antiperfeccionistas de Rawls, haciendo uso de los principios de la justicia, las conductas discriminatorias de los individuos en el ámbito privado.

Uno de los efectos de la legislación Jim Crow fue la promoción (el visto bueno por decirlo de algún modo) de discriminación en espacios privados: espacios educativos como escuelas y universidades, prestación de servicios (como sucedía con restaurantes, bares, eventos sociales, etc.) y ofertas de trabajo en empresas privadas. No veo claro hasta qué punto Rawls nos ofrece herramientas para detener este tipo de conducta en Teoría de la Justicia. ${ }^{85}$ Por el contrario, como

\footnotetext{
${ }^{85}$ Este punto lo analiza directamente Rawls en Justice as Fairness, a restatment. El análisis del problema del racismo y, como se analiza en el texto del sexismo, desde la perspectiva de la justicia como imparcialidad conduce a pensar esos problemas sociales como cualquier otra situación de desventaja en relación a los bienes primarios. Es decir, el trato injusto en función de la raza o al sexo no es, al menos en tanto seamos capaces de pensar desde la imparcialidad, distinto de cualquier otro tipo de trato injusto y, por lo mismo, no merece un planteamiento distinto a cualquier otro problema de injusticia: "Por tanto, si los hombres tienen una mayor cantidad de derechos o mejores oportunidades que las mujeres, estas desigualdades se pueden justificar únicamente si están presentes para la ventaja de las mujeres y son aceptables desde su punto de vista. Sucede lo mismo para los derechos básicos y
} 
espero haber podido mostrar hasta ahora, dada la precaución de Rawls frente a un gobierno que intervenga en el desarrollo del plan de vida de los ciudadanos, creo que la justicia como imparcialidad genera los espacios para que este tipo de conducta pueda existir; lo que no significa, en modo alguno, que la promueva. Este es un efecto no deseado del antiperfeccionismo rawlsiano que, al tiempo que puede ser para muchos lamentable, en el largo plazo pone en riesgo la estabilidad de la comunidad. La promulgación de leyes contra la discriminación, inicialmente con la Ley de los derechos civiles (Civil Rights Act) de 1964, apunta a la desaparición de actos de segregación y discriminación por razones moralmente arbitrarias. Desde esta primera ley quedó prohibida la discriminación laboral por razones de sexo, raza o religión. Hay diversas razones para argumentar que la justicia como imparcialidad, como es desarrollada en Teoría de la Justicia, no nos ofrece los instrumentos necesarios para llevar a cabo este tipo de acciones que busquen corregir esas injusticias sociales. Por un lado podríamos decir que al limitar la tarea de la concepción de la justicia a la distribución de bienes primarios, Rawls termina haciendo del ámbito privado un espacio absolutamente aislado de la acción de los oficiales de modo que niega su derecho a limitar (de cualquier modo) las concepciones del bien antiliberales siempre y cuando se mantengan dentro del marco estrictamente legal (en tanto la ley es congruente con la concepción de la justicia). El planteamiento de Rawls mantiene, de este modo, que es injusto que el gobierno limite la existencia de ciertas ideas o comprensiones del bien dentro de ciertos amplios parámetros (mantenerse respetuosos de la ley). Como he explicado ya, esta idea se encuentra fundada en el criterio de imparcialidad de la posición original y asume que es injusto imponer una concepción de la justicia a individuos que no la podrían aceptar razonablemente dadas las condiciones que impone el velo de la ignorancia y las condicionantes a la motivación en dicha posición. Sobre este punto, David Lewis hace la pregunta que buena parte del progresismo contemporáneo hace a autores liberales como Rawls:

\footnotetext{
¿Es realmente injusto organizar la sociedad de modo que se promuevan los modos de vida más valiosos sobre aquellos modos de vida menos valiosos? Si lo que está en disputa es la ordenación inicial de la sociedad -antes de que sus miembros escojan un estilo de vida particular o una concepción del buen- ¿en qué sentido puede una persona tratar de modo injusto a cualquiera de esos miembros al motivarlos a perseguir algún modo de vida antes que otro? ${ }^{86}$
}

\footnotetext{
oportunidades desiguales fundados en la raza." (John Rawls: Justice as Fairness a Restatement (Cambridge: Harvard University Press, 2001), 65.

${ }^{86}$ David Lewis, Iliberal Justice (Columbia: University of Missouri Press 2007). 66
} 
Se puede decir mucho del comentario anterior. Por un lado, en defensa de Rawls, podríamos afirmar que la posición original es un estado en el que la determinación de qué es más o menos valioso es, prácticamente, imposible. Quizá valdría la pena preguntarnos si podríamos considerar una circunstancia hipotética en la que razonemos con imparcialidad, como con el velo dela ignorancia, que conduzca a que los que participan reconozcan la legitimidad de que una concepción de la justicia limite, oriente y ayude a formar en los ciudadanos ideas del bien que sean compatibles con ella misma (aun sabiendo que hay algunas que no son, en el momento en que hacemos el experimento, compatibles y que existen en la sociedad). Es decir, si hiciéramos los ajustes adecuados (aceptables) a la posición origina, podría ser aceptable afirmar que cualquier persona razonable, razonando desde la imparcialidad, podría seleccionar una concepción de la justicia que limitara las ideas del bien en función de su adecuación a dicha concepción y a avanzar el desarrollo de los individuos; ¿sería posible que eso se considerara, propiamente, justo? Si esto es injusto e inaceptable en todos los casos, la justicia como imparcialidad tiene problemas de estabilidad (por tanto de falta de justificación pragmática) que me parecen serios.

¿Cómo podríamos garantizar la estabilidad de una sociedad democrática liberal sin leyes como la Ley de los derechos civiles en Estados Unidos o la Ley Federal para Prevenir y Eliminar la Discriminación en México? La falta de acciones positivas y concretas del gobierno para prohibir conductas que considera contrarias al liberalismo como una postura política y moral ponen en riesgo la estabilidad de la constitución, si bien podría no ser en el corto, sí en el largo plazo. La cuestión sobre los derechos de los individuos a ser intolerantes, pero sobre todo el derecho de los individuos de educar a sus hijos en la intolerancia, es central en cualquier teoría política liberal. Rawls reconoce esto pero, tal vez por prevención a los riesgos del gobierno intervencionista, rehúye a las exigencias concretas necesarias para garantizar una sociedad liberal.

El intento de ofrecer una concepción de la justicia liberal, sin fundamentarla necesariamente en el ethos liberal para poder hacerla incluyente, es un proyecto inestable a futuro. El liberalismo y la democracia, para el caso, como bien lo identificó Dewey, es más que una mera organización política y acuerdos constitucionales, es todo un proyecto de vida. En palabras de Barry:

El liberalismo descansa en una visión de la vida: una visión fáustica. Exalta la autoexpresión, el autocontrol y el control sobre el ambiente natural y social; la activa búsqueda del conocimiento y el choque de ideas; la aceptación de la responsabilidad personal por las decisiones que moldean nuestras vidas. Para 
aquellos que no pueden con la libertad provee alcohol, tranquilizantes, lucha libre en la televisión, astrología, psicoanálisis y demás, sin fin, pero no puede por su naturaleza proveer de ciertas seguridades psicológicas. Como cualquier credo no puede ser justificado o condenado en términos ajenos a él. Es él mismo una respuesta a la pregunta insoluble pero inescapable: ¿¿Cuál es el significado de la vida? $?^{\prime \prime 87}$

A lo anterior me atrevería a agregar que el liberalismo, en comparación con la gran mayoría de los credos y concepciones de la justicia existentes, es capaz de coexistir con una mayor cantidad de ideas del bien distintas, algunas de ellas incompatibles entre sí. Sin embargo, al igual que todos los credos y concepciones de la justicia existentes, es incompatible con algunas otras irremediablemente. No puede existir una concepción de la justicia que reconozca la validez de todas las ideas del bien pues, en último término, eso significaría que no tiene una postura en lo absoluto. La expectativa rawlsiana de desarrollar un liberalismo antiperfeccionista, que no suponga una idea (o al menos una familia de ideas) del bien, es contraria al hecho de que hay en el liberalismo (o en los liberalismos si se quiere) ciertos ideales de vida en cierto sentido arquetípicos (sin importar que por su naturaleza se puedan materializar de muy diversos modos), ideales que se encuentran en autores como Constant, Mill, Barry o el mismo Dewey por dar sólo unos ejemplos. Estos ideales, que suponen una comprensión moral del liberalismo, son irrenunciables al menos porque, de no existir, la estabilidad de la sociedad liberal estaría comprometida.

Como muestro más adelante, la actitud perfeccionista pragmática de Dewey le permitiría a Rawls garantizar las condiciones de estabilidad que Teoría de la Justicia simplemente no ofrece. Del mismo modo se ve como la adecuación de la idea de perfección en un sentido práctico, desarrollada por Dewey, se hace aún más adecuada una vez que Rawls lleva a cabo su giro político en el Liberalismo Político. En la siguiente parte, por lo tanto, profundizo en la segunda gran obra de Rawls para entenderlos alcances de la justicia como imparcialidad una vez que su autor se dio a la tarea de responder algunas de las críticas que surgieron tras la publicación de Teoría de la Justicia.

${ }^{87}$ Barry, The Liberal Theory of Justice. 127 


\section{Parte III. Política sin metafísica}




\section{Capítulo 5. El giro político}

La importancia de Teoría de la Justicia en el pensamiento político del siglo XX no puede ser eludida. Como ya he mencionado, el texto fue automáticamente reconocido como un parteaguas, en especial dentro de la filosofía política liberal (particularmente en su modelo contractualista), que es una de las corrientes de pensamiento protagónicas en el escenario político occidental desde la publicación del Segundo Tratado del Gobierno Civil de John Locke, a finales del XVII. Dada su importancia, no debe sorprender a nadie que el texto de Rawls condujera a una enérgica reacción, tanto positiva como negativa, por parte de sus lectores. Por lo que a las críticas positivas se refiere, las palabras del expresidente de los Estados Unidos, Bill Clinton, en la entrega de la Medalla de las Artes y las Humanidades, resumen el sentir de parte de una generación de liberales igualitaristas profundamente influenciados por las ideas contenidas en Teoría:

John Rawls es quizá el más importante filósofo político del siglo XX. En 1971, cuando Hillary y yo estábamos en la escuela de derecho, nos encontrábamos entre los millones que fueron movidos por un notable libro que escribió, Teoría de la Justicia, que justificó nuestros derechos a la libertad y la justicia con una nueva y brillante justificación racional.

Casi por sí mismo, John Rawls revivió las disciplinas de la filosofía política y ética con su argumento de que una sociedad en la que los más afortunados ayuden a los menos afortunados no sólo es una sociedad moral, sino también una lógica. Igualmente impresionante, ha ayudado a toda una generación de americanos educados a revivir su fe en la democracia por sí misma. ${ }^{1}$

Por otra parte, las ideas contenidas en Teoría de la Justicia fueron ampliamente criticadas. Las críticas provinieron de diversos ámbitos; sin embargo, una de las corrientes de pensamiento que reaccionaron de modo más "radical" fue la del comunitarismo. Considero justo decir que, sin la existencia de John Rawls y Teoría de la Justicia, el comunitarismo no hubiera tenido la amplia difusión que tuvo. Dos de los textos más representativos de la reacción comunitarista, igualmente fundamentales dentro de dicha tradición de pensamiento, son Las esferas de la justicia de Michael Walzer y El liberalismo y los límites de la justicia de Michael Sandel. Ambos surgen como una reacción al pensamiento de Rawls dentro de las líneas de la supuesta incomprensión rawlsiana de la relevancia de la cultura y la

\footnotetext{
${ }^{1}$ Bill Clinton: "Remarks by the President at Presentation of the National Medal of the Arts and the National Humanities Medal" (Washington, D.C., September 29, 1999).

http://clinton4.nara.gov/WH/New/html/19990929.html
} 
importancia de la comunidad, así como un rechazo directo a la idea de una política deontológica que, como vimos, Rawls sostiene en buena parte de Teoría de la Justicia. Desde la perspectiva de algunos autores comunitaristas, dentro de los que además de Walzer y Sandel podríamos incluir a Charles Taylor y Alasdair McIntyre, el liberalismo de Rawls tiende a, debido a su comprensión del individuo como un ser autónomo, no entender el papel de la cultura en la formación del individuo $\mathrm{y}$, en ese sentido, es parcial (contrario a las expectativas del mismo Rawls como mostré en el capítulo anterior) y da prioridad a ciertos modos de ser individualistas y liberales que atomizan la sociedad.

Como ha sucedido a lo largo la historia de la filosofía, los textos destinados a convertirse en clásicos sufren un cuidadoso escrutinio, tanto por simpatizantes como por detractores. Teoría de la Justicia no podía ser la excepción. Al ser un texto prolífico capaz de evocar la reflexión y la crítica, no sólo sobre la sociedad en la que vivimos sino en la que queremos construir en un futuro, fue analizado con el paso de los años desde su primera letra hasta su último punto. Para algunos, como fueron ciertos comunitaristas y conservadores, el texto representó la última elaboración del hubris moderno que busca controlar la naturaleza misma del ser humano subyugándolo a la razón calculadora; para otros, como el expresidente Clinton o liberales como Brian Barry, representó una de las formas de liberalismo más acabadas y una verdadera fuente de inspiración.

Algunas de las críticas ya mencionadas llevaron a Rawls a replantear algunos de los temas centrales y a repensar la justicia como imparcialidad. Los cambios dentro del liberalismo de Rawls, posterior a este proceso, son por momentos fundamentales y obligan a un análisis de los mismos. En esta parte muestro algunos de los cambios principales en el pensamiento de Rawls, así como las ventajas y deficiencias que presentan en relación con la formulación anterior de la justicia como imparcialidad, que para efectos prácticos de este estudio considero en Teoría de la Justicia. Este análisis me servirá para que, en la parte final, pueda realizar una lectura del pensamiento liberal de Rawls desde una perspectiva pragmática, en particular desde el pragmatismo de Dewey, para intentar solucionar algunos de los problemas que permanecen o, en su caso, se desarrollan en la presentación de la justicia como imparcialidad posterior a Teoría de la Justicia.

La exposición se centrará en el que es quizá el cambio más importante, al menos desde la perspectiva del mismo Rawls, en el planteamiento de la justicia como imparcialidad posterior a la publicación de Teoría: me refiero en particular al trato del problema de la "estabilidad" como una de las cuestiones centrales de la 
obra intelectual de Rawls. En esta sección muestro también algunos de los conceptos que permiten a Rawls desarrollar un planteamiento de su liberalismo estable, dentro de los que se encuentran la idea del consenso traslapado, el cambio a una concepción política del liberalismo y la naturaleza de lo razonable. Estos conceptos, a su vez, me llevarán a tratar algunos de los problemas dentro del desarrollo de la justicia como imparcialidad en esta nueva etapa en el pensamiento de Rawls. Entre estos está el problema de la verdad y la obligatoriedad de la concepción de justicia, el escepticismo rawlsiano, el problema del conservadurismo del liberalismo político, la política sin conflicto, lo limitado de la idea de lo razonable y, lo que intentaré justificar al final, un fracaso de la distinción entre liberalismo político y liberalismo moral (es importante adelantar que buena parte del proyecto rawlsiano posterior a la publicación de Teoría descansa en poder sostener esta distinción como mecanismo para garantizar la estabilidad a la vez que el Estado mantiene la neutralidad respecto a diversos grupos y comunidades dentro de sí).

En la parte final trato de resolver algunos de los problemas presentados mediante una lectura pragmática-deweyana de algunos de los temas fundamentales en Rawls. Una vez realizado el análisis al pensamiento de Dewey en el primer par de capítulos, así como una revisión profunda, aunque no completa, de Teoría de la Justicia en la segunda parte, será posible plantear algunos de los problemas que complican la estabilidad política manteniendo el espíritu de la justicia como imparcialidad, es decir el liberalismo igualitarista, como Rawls lo propuso en Teoría de la Justicia. Me parece oportuno mencionar que considero que dicha obra incorpora todas aquellas virtudes de las que Bill Clinton habló.

Antes de iniciar con la exposición vale la pena hacer algunos comentarios preliminares. Cuando me refiero al pensamiento de Rawls posterior a Teoría de la Justicia me refiero, particularmente, al publicado en El Liberalismo Político ${ }^{2}$ y en Justicia como imparcialidad, una reformulación ${ }^{3}$ (que no debe de ser confundida con el artículo de 1957 titulado, simplemente, "Justicia como imparcialidad" ${ }^{4}$ y al que no hago referencia en este capítulo; por lo mismo, todas las referencias al título Justicia como imparcialidad son al libro publicado en el 2001). Reconociendo el poder de

\footnotetext{
2 En este capítulo utilizo la versión expandida de Liberalismo Político, que incluye dos artículos, no incluídos en su edición original de 1993 ("Reply to Habermas" y "The Idea of Pubic Reason Revisited", así como la introducción la edición paperback: John Rawls, Political Liberalism (Nueva York: Columbia University Press, 2005).

${ }^{3}$ John Rawls, Justice as Fairness, a restatement, ed. Erin Kelly (Estados Unidos de América: Harvard University Press, 2001).

${ }^{4}$ John Rawls: "Justice as Fairness"; The Philosophical Review, vol. 67 no. 2 (1958).
} 
síntesis y de repetición de Rawls, puedo anticipar que la mayoría de las referencias su pensamiento en este capítulo serán al Liberalismo Político. Por otra parte, Justicia como imparcialidad es un texto que hace hincapié en algunos de los temas ya desarrollados con anterioridad con afán de aclarar algunos puntos que Rawls pensaba que no lo estaban suficientemente. Cuando en esta investigación me refiera a temas que se encuentran en ambos textos, me refiero a aquel en el que considere que su desarrollo se presenta de modo más completo; las referencias tenderán a ser, en mayor medida, al Liberalismo Político pues es la obra donde la exposición es más desarrollada. Sin embargo, hay temas que se tratan en Justicia como imparcialidad (al menos así sucede con temas como la familia y la educación en una sociedad liberal, aunque, en cualquier caso, fueron poco tratados por Rawls, en especial en relación a su importancia) de un modo más completo y, en aquellos casos, me refiero a ese texto preferentemente. Lo que intento es exponer la mejor versión posible de Rawls a mi juicio.

\section{La nueva cuestión central de la justicia como imparcialidad}

Antes de continuar se vuelve relevante ofrecer una definición de un concepto que será fundamental dentro de la filosofía política de Rawls, posterior al giro político, y que utiliza continuamente en Liberalismo Político: el de "doctrina comprehensiva". El concepto de doctrina comprehensiva es aquel que le permitirá referirse a las diferencias culturales supuestas en la crítica comunitarista. Decimos que una doctrina es comprehensiva cuando "incluye concepciones de lo que es valioso en la vida humana, los ideales de carácter personal, del mismo modo los ideales de amistad y de las relaciones familiares y asociativas, también aquello que informa nuestra conducta y limita nuestra vida como un todo. Una concepción es completamente comprehensiva si cubre todos los valores y virtudes reconocidos dentro de un sistema bien articulado (...)." ${ }^{5}$ Dicho de otro modo, una doctrina comprehensiva equivale a un grupo de creencias sistematizadas que permiten al individuo valorar y dar sentido del mundo y de la conducta, propia y ajena. El concepto de doctrina comprehensiva está presente de modo importante en la obra de Rawls posterior al giro político y es, al mismo tiempo, una especie de reconocimiento de la relevancia de la cultura en la formación de los individuos; reconocimiento fuertemente exigido por el pensamiento comunitarista. Es

\footnotetext{
${ }^{5}$ Rawls, Political Liberalism. 13
} 
importante tener en mente, sin embargo, que para Rawls la cultura puede ser conceptualmente separada entre una social y otra política. Esta división le permitirá plantear la posibilidad de justificar una concepción política de la justicia que no requiera una argumentación desde conceptos no políticos (pues el desarrollo de argumentos desde ese tipo de conceptos son, piensa Rawls, los que dificultan los acuerdos entre individuos que sostienen doctrinas comprehensivas distintas, que no comparten algunos de los presupuestos sociales necesarios). Esta distinción, sin embargo, no está presente en el pensamiento comunitarista. Así, Rawls considera que en las sociedades contemporáneas, en particular las democráticas y de talante liberal, están presentes una multiplicidad de doctrinas comprehensivas que, en ocasiones, tienen comprensiones del mundo contradictorias entre sí.

Un hecho que quiero resaltar, aunque hablo de él con más detalle en las próximas páginas, es un defecto en la comprensión rawlsiana del devenir social y cultural que afecta el concepto de doctrina comprehensiva. Éste es relevante para el liberalismo de Rawls porque la estabilidad social, en particular de una sociedad gobernada en su estructura básica por una concepción de la justicia liberal, depende de la posibilidad de que dichas doctrinas sean capaces de compartir una concepción de la justicia. En la medida en que las doctrinas comprehensivas no compartan la concepción de la justicia, la única manera en que podrían coexistir dentro de un marco social ordenado es si un grupo, con una doctrina particular, impone a aquellos que no la comparten su concepción de la justicia y eso, a ojos de Rawls, es inaceptable ya que violenta el principio de legitimidad democrática aplicable a las doctrinas comprehensivas razonables (más adelante profundizo en la idea de lo razonable, que en Rawls es un concepto que merece un tratamiento preciso).

En el Liberalismo Político, Rawls renuncia a la posibilidad de desarrollar una concepción de la justicia que sea justificable frente a cada uno de los ciudadanos sin importar cuál sea su doctrina comprehensiva, como lo intentó en Teoría desde su neokantismo. Por el contrario, y de nuevo puede conjeturarse que es una respuesta a las críticas comunitaristas, Rawls busca presentar una concepción de la justicia que pueda ser justificada desde las premisas de cada una de las doctrinas comprehensivas, lo que parece en primera instancia una tarea complicada. Parecería que Rawls asume que hay una diferencia entre justificar la concepción de la justicia a cada uno de los ciudadanos y justificar la concepción de la justicia a las doctrinas comprehensivas. En Teoría asumía que la justicia como imparcialidad era justificable para cada una de las personas que habitan la sociedad ya que era 
razonada desde una perspectiva de imparcialidad; parecía que Rawls confiaba que, usando los recursos racionales naturales y mínimos con los que cuenta una persona, sería posible justificar la justicia como imparcialidad. Ahora, en el Liberalismo Político, la preocupación de Rawls es elaborar una concepción que pueda ser justificada por las doctrinas mismas, las cuales razonan en función de contenidos culturalmente determinados. El problema con este proyecto me parece que es doble y debemos tenerlo en mente durante todo el capítulo: (i) las doctrinas comprehensivas no son sujetos de derechos y (ii) el concepto de doctrina comprehensiva rawlsiana corresponde con una generalización, útil para la reflexión, pero inexistente en la realidad social y cultural

Según Rawls, el primer punto es relevante pues que la estabilidad de la comunidad política depende de ser capaz de desarrollar un consenso entre las diversas doctrinas comprehensivas razonables que existen en una sociedad plural. Si la justificación debe ser en el ámbito de las doctrinas comprehensivas, Rawls podría terminar abriendo la puerta a los llamados derechos de grupo, que son tan complicados de justificar y que tienden a contrariar los derechos de los individuos (el derecho preferencial de un grupo frente a individuos que no pertenecen a él o, de igual modo, derechos del grupo preferentes al de los miembros individuales). El problema con estos derechos de grupo es que podrían terminar legitimando prácticas antiliberales que limiten las libertades de individuos. Rawls no es un autor que estuviera dispuesto a anteponer derechos de grupo a los derechos de los individuos; basta con tener presente el primer principio de la justicia, de la justicia como imparcialidad, y su clara carga individualista en la distribución de libertades. El punto que intento hacer es que Rawls, al reconocer la importancia de las comunidades culturales en la formación de los individuos (la falta de éste es central en las críticas comunitaristas a Teoría de la Justicia), abre una ventana a la idea, que considero inaceptable, de que la justificación de la concepción de la justicia debe satisfacer criterios de grupos culturalmente homogéneos y no, como ha tendido a hacer la tradición liberal históricamente, de individuos. En este capítulo profundizo, más adelante, en algunas de las dificultades que esta idea presenta para una sociedad liberal, aunque puedo adelantar, de la mano de Russell Hardin, que: “En general, el consenso de grupo más allá de algunos compromisos es una quimera. La historia de las ortodoxias es la historia de las fracturas. El ideal comunitario del consenso en las normas es romántico y falso. Esto es un pronunciamiento empírico, no uno normativo." ${ }^{6}$ En la medida en que esto es así, y

\footnotetext{
${ }^{6}$ Russell Hardin, Liberalism, Constitutionalism, and Democracy (Oxford: Oxford University Press, 1999).
} 303 
que para lograr dicho consenso es probablemente necesario el uso de la violencia, al plantear Rawls la importancia de los grupos culturales en la formación de los individuos, en los términos que lo hace, puede terminar generando las condiciones para justificar (aunque el mismo Rawls no lo hace directamente) derechos de grupo como contrapuestos a los derechos de los individuos. Esto en la medida en que, al menos en Liberalismo Político, parece que la aceptación de la concepción de la justicia corre a cuenta de las doctrinas comprehensivas.

El segundo tema a discutir con el concepto de doctrina comprehensiva de Rawls es que termina generando una idea de las comunidades, tradiciones, cosmovisiones, es decir de todo aquello que Rawls parece comprender con el concepto de doctrina comprehensiva, de un producto en cierta medida consistente y estático. Si bien es cierto que ciertos grupos, en general pequeños, son capaces de dicho conservadurismo doctrinal (los Amish, así como algunas comunidades menonitas en México, representan buenos ejemplos), la realidad es que son más la excepción que la regla; lo que es más, cuando dichos grupos tienden a abrirse a otros grupos sociales, como suele suceder en una sociedad liberal, más bien tienden a adecuar sus tradiciones e instituciones a las circunstancias cambiantes. Esta comprensión de la cultura como producto terminado conduce a Rawls a sostener una especie de conservadurismo liberal. Como explico más adelante, una de las maneras en las que Rawls intentará justificar el giro político será aceptando las instituciones de la sociedad democrática liberal como un hecho existente, en cierto sentido estático y en general aceptado por los distintos grupos que viven en la comunidad. El problema, como ocurre con su idea de las doctrinas comprehensivas, es que no existe el tipo de consenso sobre el contenido, historia y permanencia de las instituciones de la sociedad democrática y liberal. Para usar una analogía, el concepto de doctrina comprehensiva hay que considerarlo como una foto, estática, de los grupos culturales y no como un concepto que nos ayude a comprender el dinamismo cultural.

Ahora bien, asumiendo la existencia de las doctrinas comprehensivas del modo en que Rawls considera, la diversidad y diferencias entre ellas, con comprensiones del mundo diversas y a veces contrarias dentro de una misma comunidad política, es un problema perenne dentro de la sociedad democrática y liberal. Este hecho conduce a una nueva pregunta central para el liberalismo: si nos encontramos en una sociedad plural, ¿cómo podría ser posible coexistir de un modo adecuado?, o, como lo pregunta el mismo Rawls: “¿Cómo es posible para que exista en el tiempo una sociedad justa y estable de ciudadanos libres e iguales, que se encentran profundamente divididos por doctrinas morales, filosóficas y 
religiosas razonables?"7 Hay que tener presente que cuando Rawls habla de una sociedad justa se refiere a un "sistema justo de cooperación en el tiempo, de una generación a la siguiente ${ }^{\prime \prime}$ en donde hay un estado de reciprocidad, pues hay genuina cooperación, ${ }^{9}$ y que, cuando habla de ciudadanos, se refiere a individuos plenamente cooperadores y poseedores de los dos poderes morales (una capacidad para un sentido de la justicia y para desarrollar una idea del bien.) ${ }^{10}$

El cambio frente a la presentación en Teoría es sustancial; en el primer gran texto de Rawls el objetivo se refería a desarrollar una concepción de la justicia adecuada que cumpliera con todos los límites competentes y que, dadas las condiciones de equidad adecuadas, sería elegida por cualquier persona racional. En el Liberalismo Político, por su parte, la pregunta central de la reflexión política ya no se refiere a la composición de una concepción de justicia que cumpla con los límites (la publicidad, universalidad, generalidad, finalidad y jerarquía) y, por tanto, sea obligatoria su observación. Más bien Rawls se pregunta por una concepción de la justicia que simplemente permita la cooperación entre diversas doctrinas comprehensivas de modo estable de una generación a la siguiente. Parecería que en su formulación inicial, en Teoría de la Justicia, Rawls intentaba mostrar cómo dadas las condiciones argumentativas explicadas por la posición original, el velo de la ignorancia, las características necesarias de una concepción de la justicia, el neokantismo y ciertos sentidos de pragmatismo que ya analizamos, la justicia como imparcialidad representaba la opción racional y razonable ${ }^{11}$ que serviría para juzgar la corrección de las distintas ideas del bien en la medida que fueran capaces de ordenarse a dicha concepción de la justicia. Ahora Rawls genera un problema complicado de solucionar dado que parecería posible afirmar la razonabilidad de una doctrina comprehensiva, como lo hace en el Liberalismo Político, independientemente de si acepta o no la justicia como imparcialidad. Antes, la aceptación de la concepción de la justicia era la regla de lo razonable en tanto que, si era verdad que Rawls estaba en posibilidad, como lo buscaba hacer en Teoría, de desarrollar el mejor candidato frente a las concepciones de justicia existentes, aquellas doctrinas que no la aceptaran en función de los argumentos ahí desarrollados (sin negar que cada una pudiera agregar argumentos adicionales) serían poco racionales y razonables.

\footnotetext{
${ }^{7}$ Rawls, Political Liberalism. 4

8 Ibid. 15

${ }^{9}$ Cfr. Ibid. 16

${ }^{10}$ Cfr. Ibid. 18-19

${ }^{11}$ La distinción entre racional y razonable la analizo con detalle adelante. En cualquier caso es oportuno adelantar que la razonabilidad implica, además de características epistémicas, algunas que permiten el diálogo y la generación de acuerdos como un cierto grado de tolerancia, cooperación y responsabilidad.
} 
En Teoría parecería que la justicia como imparcialidad establecía el estándar de lo aceptable en la comunidad; en Liberalismo Político, si las doctrinas son previamente razonables, más bien tendremos que encontrar una concepción que satisfaga las necesidades de todas las doctrinas comprehensivas razonables, aunque puedan ser, como afirma Rawls, contrarias entre ellas. Si no podemos presentar una concepción que lo haga, tendríamos que decir que la justicia es poco razonable. Si no todas las doctrinas comprehensivas razonables pueden alcanzar un consenso en la concepción de la justicia, parecería una posibilidad real que una persona razonable puede ser injusta, al menos en función de la concepción política de la justicia. Una complicación adicional para poder encontrar una concepción de la justicia aceptable es que Rawls exige que dicha concepción, que él espera que sea la justicia como imparcialidad, sea aceptable en los términos mismo de las doctrinas comprehensivas:

El problema de la estabilidad no es el de llevar a aquellos que rechazan la concepción a compartirla, o a actuar en función de ella, mediante sanciones adecuadas, si fuera necesario, como si la tarea fuera la de encontrar maneras para imponer la concepción una vez que estamos convencidos que es correcta. Más bien, como una concepción política liberal, la justicia como imparcialidad no es razonable en primer lugar a menos que genere su propio apoyo de modo adecuado al referirse a la razón de cada ciudadano y es explicado dentro de su propio esquema. ${ }^{12}$

Esta búsqueda de estabilidad consensual (que como veremos un poco más adelante está basada en lo que Rawls llama un consenso traslapado), que procura encontrar una concepción de la justicia que toda doctrina comprehensiva razonable pueda justificar, está justificada en el hecho, reconocido ampliamente por la tradición liberal en sus distintas vertientes, de que “(...) una continua y compartida comprensión de una doctrina comprehensiva moral, filosófica o religiosa puede ser mantenida sólo con el uso opresivo del poder estatal." ${ }^{13}$ Debido a que la tradición liberal ha estado en contra del uso opresivo del Estado para forzar una idea del bien, Rawls se mantiene fiel a dicha tradición. Sin embargo, la tradición liberal en general, incluyendo en esa tradición a Teoría de la Justicia, contrario a las expectativas que aparentemente tendrá Rawls en Liberalismo Político, ha tendido a reconocer que la medida de lo que puede ser obligado mediante el uso de la fuerza del Estado se encuentra en los límites constitucionales justos; lo justo, por su parte, ha sido conceptualizado de modo que puede ser justificado racionalmente al punto de considerarse aceptable el forzar a alguien, aun cuando su doctrina

\footnotetext{
12 Rawls, Justice as fairness. 186

${ }^{13}$ Rawls, Political Liberalism. 37
} 
comprehensiva no le permita entender la "verdadera" justicia. En este punto Rawls parece ser inconsistente con sus expectativas: supongamos que una doctrina comprehensiva razonable acepta la venta de hijos dentro de su comprensión del mundo (lo que considero una posibilidad real), no hay modo que eso fuera compatible con la justicia como imparcialidad y, por lo mismo, sería prohibido mediante el uso de la fuerza. ¿Quién pensaría que es ilegítimo prohibir la venta de menores en esos casos? Si es posible que una persona razonable quisiera vender a sus hijos y, simplemente, no está de acuerdo con la justicia como imparcialidad (asumiendo que la justicia como imparcialidad de hecho prohibiría la venta de hijos), diríamos que su concepción de la justicia es injusta y, aun cuando sea razonables, es legítimo prohibir, con el uso de la fuerza si es necesario, su mal comportamiento. Si ese tipo de actos nos parece justo y adecuado dentro de una sociedad liberal, por qué sería distinto con cualquier otro acto que consideremos incorrecto. Es decir, ¿estaría injustificado obligar a una persona que viva en una sociedad ordenada por la justicia como imparcialidad a cumplir con sus instituciones (ordenadas por dicha concepción de la justicia) aun cuando no las aceptara su doctrina comprehensiva razonable?

Encuentro problemático el planteamiento rawlsiano pues no es claro si todas las doctrinas comprehensivas razonables tendrían que elegir la justicia como imparcialidad como la concepción preferida. Cuando el argumento por la concepción de la justicia venía acompañado de una comprensión de la verdad (ya fuera kantiana o pragmática), el problema desaparecía pues, cuando suceda que un individuo no pueda entender las razones de por qué la concepción de la justicia es la elegida, obligarlo a cumplir con los lineamientos de dicha concepción es una conclusión aceptable pues estaría rechazando las condiciones justas de cooperación. Ahora bien, en tanto no podamos responder la cuestión si todas las doctrinas comprehensivas razonables tendrán que aceptar la concepción de la justicia (lo que no parece ser una condición necesaria), no queda del todo claro cómo podríamos abordar el problema justificadamente. En la medida en que la justificación de la concepción de la justicia está en función de ser aceptada por las doctrinas comprehensivas razonables, deja de ser claro qué argumentos nos quedan para defenderla como la concepción que debe gobernar las instituciones.

Este problema no se encontraba en Teoría porque la concepción era la medida misma de la razón en términos de justicia. A lo que nos enfrentamos ahora es a la cuestión de si la justicia como imparcialidad puede ser defendida en términos racionales incluso frente a aquellos que no la acepten, aun cuando sean personas razonables, o si, por el contrario, tenemos que reconocer los límites de la 
razón como las fronteras que existen entre las doctrinas comprehensivas. Considero que en este punto se debate el legado de la obra de Rawls en los términos en los que trataba el expresidente Clinton. Para intentar aclarar el punto anterior, en lo que resta del capítulo analizo algunos de los cambios que el giro político representó para el pensamiento de Rawls. Este análisis se enfocará en analizar la idea del giro político, el papel del conflicto en la arena pública Será en el próximo que analizo las ideas de lo razonable y la razón pública. Para terminar con esta parte hago un balance sobre el éxito del giro político en distanciar la justicia como imparcialidad de una formulación del liberalismo de tipo moral.

\section{El giro político}

El problema de la estabilidad, que en parte se deriva de la existencia del pluralismo dentro de la sociedad (pues la estabilidad puede estar comprometida por cuestiones ajenas al sistema social, como la intervención extranjera o algún tipo de desastre), condujo a Rawls a reformular la justicia como imparcialidad como una concepción política de la justicia. Cuando dice que la justicia como imparcialidad es ahora una concepción política, lo que Rawls afirma es que ya no depende de una doctrina comprehensiva, o es parte de una para el caso, para poder justificarse. Por esto desarrolla una concepción de la justicia que sea completamente política y no metafísica; una especie de módulo común que pueda ser usado por las distintas doctrinas comprehensivas razonables en la medida en que, al no tener una justificación "doctrinal", aceptarla no implica necesariamente una contradicción con la metafísica de cada una de ellas. Frente a esto, la elaboración de la justicia como imparcialidad dentro de Teoría era claramente una que dependía de una idea del liberalismo, si no completamente comprehensiva, sí parcial en lo que respecta a su neokantismo y pragmatismo.

La aparente necesidad del giro político proviene, en mi opinión, de un cambio en las preocupaciones de Rawls posterior a la publicación de Teoría. Como comenté líneas atrás, las reacciones al texto clave de la justicia como imparcialidad fueron variadas $\mathrm{y}$, en muchos casos, de rechazo amplio. Si bien Rawls en Liberalismo Político prácticamente no mencionó a sus críticos comunitaristas, ${ }^{14}$ en el texto es claro el "acuse de recibo" de algunas de las críticas del pensamiento

\footnotetext{
14 A Sandel lo menciona en una nota (Rawls, Political Liberalism, 27 n.29), a Taylor también en una nota (206 n.38). Con Walzer fue más generoso, lo menciona en una nota ( 46 n.49) y una mención adicional en el texto principal (44). MacIntyre ni siquiera mereció una mención.
} 
comunitarista y afines. Una idea que parece ser una respuesta a críticas, y que termina implicando en el caso de Rawls el giro político, es la del "hecho del pluralismo" y sus implicaciones con una teoría de la justicia de orden kantiano: "El hecho de una pluralidad de razonables pero incompatibles doctrinas comprehensivas -el hecho del pluralismo razonable- muestra que, como es usada en Teoría, la idea de una sociedad bien ordenada por la justicia como imparcialidad es irreal."15 El neokantismo, como mostré desde el capítulo anterior, termina generando condiciones de obligatoriedad que son complicadas de cumplir dada la naturaleza deontológica de su argumentación y la dificultad de afirmar su verdad desde distintas perspectivas culturales. Sin embargo, adelantándome a la que será mi exposición de los problemas en los cambios en su filosofía, me parece que Rawls, como espero mostrar más adelante, podría ser capaz de sostener parte del argumento en favor de la justicia como imparcialidad, como fue realizado en Teoría, en sus bases pragmáticas. Esa posibilidad generaría mayor estabilidad que la opción que Rawls desarrolla en el Liberalismo Político.

El giro político conduce, irremediablemente, a hacer varios ajustes en la justicia como imparcialidad a la vez que precisa de incorporar nuevos conceptos e ideas:

La justicia como imparcialidad ahora se presenta como una concepción política de la justicia. Para llevar a cabo este cambio en cómo debe ser entendida la justicia como imparcialidad es necesario hacer otros cambios y requiere una familia de ideas adicional que no se encontraban en Teoría, o al menos no con el mismo significado y relevancia. Además de la introducción de la idea de una concepción política por sí, es necesaria la idea de un consenso traslapado de doctrinas religiosas, filosóficas y morales comprehensivas, o parcialmente comprehensivas para poder formular una concepción de la sociedad bien ordenada más realista, dado el hecho del pluralismo de dichas doctrinas en una democracia liberal. De igual modo necesitamos de las ideas de las bases públicas de justificación y de la razón pública, así como ciertos hechos generales del sentido común de la sociología política, algunos de los cuales se cuentan por lo que llamo las cargas del juicio, de nuevo una idea no utilizada en Teoría. ${ }^{16}$

A diferencia del proceder constructivista de Teoría, en Liberalismo Político Rawls, al buscar generar una concepción política aceptable para las doctrinas comprehensivas, se refiere a la cultura política de una sociedad democrática como el fundamento de la concepción en cuestión. Con el giro político la argumentación contractual de Teoría, que si las críticas comunitaristas tienen mérito, presupone

\footnotetext{
${ }^{15}$ Rawls, Political Liberalism. xvii

${ }^{16}$ Rawls, Justice as Fairness. xvii
} 
una antropología individualista, es inaceptable pues depende de una doctrina comprehensiva particular y, por lo tanto, no podría ser objeto de un consenso traslapado, una de las ideas que Rawls menciona dentro de las añadidas en la nueva presentación de la justicia como imparcialidad. Es importante tener en mente, en cualquier caso, que la justicia como imparcialidad será justificable sólo para aquellos individuos y sus doctrinas comprehensivas que acepten las instituciones democráticas: “Debemos empezar, por tanto, buscando en la cultura política en sí como el fondo de ideas y principios básicos, implícitos y compartidos." ${ }^{17}$

En la medida en que Rawls reconoce la importancia de desarrollar una concepción política de la justicia que sea aceptable para un número indefinido de doctrinas comprehensivas razonables a partir de elementos de la cultura política existente, termina negando la posibilidad de que dicha concepción pueda ser justificable ante individuos que no comparten, ex ante, una cultura política liberal y democrática. Como se puede ver, la idea del giro político es sumamente problemática en este sentido. El giro parece buscar internalizar instituciones en las que ya se vive (de modo que las doctrinas comprehensivas puedan aceptarlo sin dificultad), limitando su aceptación a aquellos grupos e individuos razonables que hayan vivido bajo dichas instituciones. ${ }^{18} \mathrm{Si}$ bien parecería que esta estrategia argumentativa implica un giro no sólo político sino, más bien, pragmático, con lo dicho sobre el pensamiento pragmático en el primer capítulo, al menos desde el enfoque del pragmatismo de Dewey, sería impreciso, pues el pragmatismo no sólo se refiere a la formación de nuestros estándares sino, al mismo tiempo, al mecanismo de superación de estos estándares dada la aplicación de la inteligencia a nuestras circunstancias cambiantes.

La idea rawlsiana de "encontrar un modo de organizar ideas familiares y principios en una concepción política de la justicia que exprese esos ideales y principios en un modo distinto al anterior", ${ }^{19}$ es distinta del ideal argumentativo de Dewey. Dewey es un pensador que, aunque reconoce la importancia de las "ideas familiares y los principios" para la construcción de nuevas ideas-hipótesis, difícilmente aceptaría que los contenidos de nuestra cultura deberían de ser el

\footnotetext{
${ }^{17}$ Rawls, Political liberalism. 8

${ }^{18}$ Este hecho conduce a Habermas a criticar duramente el giro político pues parece implicar que Rawls renuncia a la facultad emancipadora de la razón, en tanto que el único modo de garantizar la estabilidad del Estado liberal es a través de las instituciones preexistentes. (Jurgen Habermas: "Reconciliation Through the Public use of Reason: Remarks on John Rawls's Political Liberalism"; The Journal of Philosophy, vol. 92 no. 3 (1995).)

${ }^{19}$ Ibid. 9
} 
fundamento para nuestra concepción de la justicia. Una comprensión deweyana de la concepción de la justicia, por ejemplo, no sólo se interesaría por el estado presente de la cultura, ya que Dewey siempre se mantiene abierto a la posibilidad que nuestras ideas y principios pueden ser inadecuados para enfrentarnos a la realidad presente; desde la perspectiva pragmática de Dewey la cultura sería sólo uno de los múltiples factores relevantes para poder plantear una concepción de la justicia adecuada (de igual modo considero que incluiría las condiciones materiales y los méritos de la justificación dadas esas condiciones).

El giro político termina llevando a Rawls a acercarse a tradiciones con las que, quizá, no comparta objetivos en lo fundamental. La búsqueda del fundamento de la concepción política en la tradición resuena más con el conservadurismo que con la democracia liberal e igualitarista, que siempre ha tendido mucho más a ser progresista que meramente conservadora de libertades; el liberalismo igualitario ha tendido más a la ampliación de las libertades humanas que a su "petrificación". En la medida en la que Rawls habla de lo ideal que era la justicia como imparcialidad en Teoría y el modo en que la estabilidad se volvió una prioridad de su pensamiento con el desarrollo de un giro político, resuena con las palabras de Russell Kirk en La mente conservadora:

A los principios generales en la política -que se distinguen de la ideología fanática y dogmatizada- se suscribe el conservador. Estos son los principios a los que se llegan mediante la convención y el compromiso, ${ }^{20}$ en su mayor parte, y pueden ser probados a lo largo de la experiencia. En cualquier caso estos principios generales deben de ser aplicados de modo variado y con prudencia, las circunstancias de la humanidad varían mucho de lugar a lugar y de época a época. Los conservadores se rehúsan a aceptar las políticas utópicas como un sustituto a la religión." ${ }^{21}$

Si bien es claro que Rawls difícilmente puede ser llamado un conservador (después de todo sería un conservador que justificó una agenda abiertamente liberal y de libertades progresistas como el matrimonio entre personas del mismo sexo y el derecho al aborto por ejemplo), el fragmento anterior me parece relevante para mostrar cómo la idea del giro político llevó a Rawls a proponer un pensamiento en cierto sentido conservador. En Teoría de la Justicia Rawls considera la opción que su concepción de la justicia podría ser justificada por sus méritos racionales; en el Liberalismo Político Rawls termina concediendo que la justicia como imparcialidad sólo se puede justificar si afirma parte de la "convención" de la que habla Kirk.

\footnotetext{
${ }^{20}$ Es curioso que, como veremos más adelante en el capítulo, para Rawls también es un paso anterior a la concepción de la justicia, con sus dos principios al ser justicia como imparcialidad, la convención y el compromiso.

${ }^{21}$ Russell Kirk, The Conservative Mind, From Burke to Eliot (Washington: Regnery Publishing, 1985), xvi.
} 
Considero que este pensamiento conservador en Rawls se deriva de una comprensión deficiente de las ideas y principios contenidos en la cultura política de la que está hablando, así como de su comprensión del fenómeno de la cultura misma. Al igual que con la idea de las doctrinas comprehensivas, Rawls considera que los contenidos de la cultura política son estables en el tiempo y, por decirlo de algún modo, unívocos, ¿quién podría razonablemente sostener que la interpretación de las libertades y los derechos contenidos en la cultura política en las sociedades liberales y democráticas, incluso si sólo pensáramos en Estados Unidos de América, es una y compartida entre todos los ciudadanos y las diversas doctrinas comprehensivas? Al final, este supuesto básico en el giro político de Rawls implica un hecho demostrablemente falso, que es la idea de la existencia de una cultura política unívoca y estática, y parecería que justificar que habrá una sola concepción de la justicia fruto de dicha cultura política es un error. Sobre esto afirma Rodríguez Zepeda:

En efecto, el problema de la visión rawlsiana de la cultura política es que supone que los elementos latentes en ella (y que habrían de constituirse en la base de la concepción política aceptable por todas las visiones comprehensivas razonables) tienen una interpretación homogénea y, en ese sentido, no son contestables ni están sujetos a un debate radical y constante. La consecuencia paradójica de este supuesto es que, si tal tipo de acuerdo interpretativo fuera posible, el proceso de formación de un consenso traslapado se haría irrelevante, pues las doctrinas comprehensivas ya estarían, de hecho, instaladas en él. ${ }^{22}$

La interpretación homogénea de la cultura política parece ser una ilusión, una imposibilidad dada una de las condiciones mencionada por Rawls: el pluralismo. La idea misma del pluralismo razonable supone, para que ese pluralismo sea tal, que no exista una interpretación homogénea de la cultura ya que esto sólo puede suceder, como es bien sabido por la tradición liberal y ampliamente reconocido por Rawls, con el ejercicio opresivo del poder del Estado. Esto supondría que para que dicha interpretación homogénea ocurra tendrían que suceder una de dos cosas $(0$, probablemente, las dos): o el Estado utiliza opresivamente su poder y desaparece efectivamente el pluralismo ( $\mathrm{y}$ claramente no hay una cultura de libertades democrática con todos los ciudadanos, en tanto que los miembros de la clase gobernante, que usan el poder político, son parte de los ciudadanos) o, segundo, que no existe el pluralismo porque hay un consenso natural entre todos. Esta segunda es la opción que se encuentra evidenciada en el fragmento recién citado de Rodríguez.

\footnotetext{
22 Jesús Rodríguez Zepeda, La política del consenso, Una lectura crítica de El liberalismo político de John Rawls (Barcelona: Anthropos, 2003), 68
} 
Rawls parece encontrarse con una aporía: o bien reconoce el hecho de que existe el pluralismo razonable y, por tanto, "se tendrá que aceptar también una pluralidad en la interpretación de esos principios", ${ }^{23}$ es decir de aquellos que conforman la cultura política, o, como segunda opción, se queda con la posibilidad de reconocer principios políticos derivados de la cultura política compartida y homogénea pero, al mismo tiempo, termina negando la existencia del pluralismo razonable como el hecho que había postulado.

El pluralismo parece ser un hecho incontrovertible en las sociedades humanas actuales. Cuando se exponen a la novedad (que puede provenir por el avance tecnológico, cambios demográficos, climáticos o de cualquier otra índole, sin considerar las limitantes y diferencias relativas a la materia del conocimiento humano), los diversos grupos sociales han reinterpretado los contenidos de la cultura que hoy en día conforman las democracias liberales y cada grupo lo ha hecho de un modo diverso. Cuando Rawls espera poder elaborar una concepción de la justicia en función de la cultura política parece obviar el hecho que incluso algunos de los conceptos más fundamentales de dicha cultura política son altamente controvertidos, como afirma R. Dahl:

Los veinticinco siglos durante los cuales la democracia ha sido discutida, debatida, apoyada, atacada, ignorada, establecida, practicada, destruida $\mathrm{y}$, algunas veces, reestablecida no ha, al parecer, producido un acuerdo en algunas de las preguntas fundamentales sobre la democracia. ${ }^{24}$

Si el proyecto constructivista político rawlsiano, posterior a Teoría de la Justica, depende de dichos conceptos, entonces el proyecto completo está en grave riesgo. El problema proviene de la precaución de Rawls a comprometerse con una metafísica para, después, poder obtener los conceptos con los cuales construirá el resto de la concepción. Con la intención de poder afirmar que su concepción política de la justicia no requiere justificación de una doctrina comprehensiva particular, Rawls se ve en la necesidad de generar condiciones de construcción que son simplemente irreales.

Considero que el objetivo de desarrollar una concepción libre de toda metafísica, o como el mismo Rawls la denomina, freestanding, fracasa dada la naturaleza de la cultura y el hecho del pluralismo. Vale la pena recordar la cita de Dewey que he analizado para comenzar los capítulos primero y tercero de esta investigación que estipula cómo toda teoría política implica una antropología, tal

\footnotetext{
${ }^{23}$ Ibid. 66

${ }^{24}$ Robert Dahl, On Democracy (Londres: Yale University Press, 2000), 3.
} 
como la que Rawls parece querer negar ahora. Por tanto, como explica Ryan Davis, al no poder justificarse en valores e ideas no comprehensivos o morales, en cualquier caso requerirá una justificación más allá de su mera enunciación: “Si la justicia es construida con materiales libres de las razones morales usuales, tendrá que ser hecha de otro tipo de consideraciones que al final responden a los mismos estándares. La investigación sobre la justicia o la legitimidad no ocurre en un dominio distinto del de otro tipo de investigaciones sobre la normatividad." 25

Aun cuando fuera cierto que puede construir una concepción de la justicia sin elementos controversiales por su contenido moral o comprehensivo ( $\mathrm{y}$ sostengo que eso, por la naturaleza de las ideas de la cultura política, es imposible en cualquier caso), eso no quiere decir que su concepción de la justicia estaría exenta de justificarse. De algún modo Rawls busca que cada doctrina pueda justificar la concepción en sus propios términos y al mismo tiempo, asumiendo que esto fuera posible (cosa que espero quede claro que, siempre que exista el pluralismo, es imposible pues la concepción de la justicia sería en sí misma distinta y no solamente su justificación), darle el mismo valor relevante en sus vidas; para que la concepción sirva, para gobernar una sociedad bien ordenada, todas las doctrinas tendrían que ser capaces de justificar el mismo objeto, de modo diferente, dándole prioridad en los diversos asuntos de la vida política. Lo que Rawls olvida es que incluso el conservadurismo más tradicionalista y estatista requiere de justificación y esa, irremediablemente, es una justificación que se refiere al nivel argumentativo del que Rawls busca escapar.

Dicho esto, la concepción de la justicia, más bien, debería de ser capaz de justificarse frente a otras doctrinas comprehensivas y lograr el consenso que Rawls desea. Este objetivo hubiera estado al alcance de Rawls si hubiera sido capaz de dar un giro, no político, sino genuinamente pragmático. En la medida en que Rawls hubiera reconocido que la justificación de un acto está en función del objetivo deseado, habría justificado la justicia como imparcialidad bajo premisas altamente compartibles por otras doctrinas comprehensivas (pues la eficacia de los medios, por ejemplo, parece ser un criterio razonablemente transversal entre muchas doctrinas comprehensivas razonables). De ese modo podría haber reconocido que la formación de su concepción de la justicia no podía divorciarse, como de hecho terminó sucediendo, de la argumentación moral ya que, como afirma John Dewey, "la situación distintivamente moral es, por tanto, aquella en la

${ }^{25}$ Ryan Davis: “Justice: Metaphysical, After All?”; Ethical Theory and Moral Practice vol. 14 no. 2 (2011). 221 
que elementos de valor y control se juntan con la del proceso de deliberación y deseo (...)." ${ }^{26}$ En este sentido deweyano y pragmático, la selección de la concepción de la justicia se haría sobre bases morales.

Si el giro político fuera pragmático no habría problema para reconocer, mediar y probablemente conducir productivamente el conflicto en la sociedad entre doctrinas comprehensivas razonables. Recordemos que para Dewey una de las tareas de la política, si no es que la principal, es la de permitir solucionar los conflictos que surgen de las intenciones encontradas, la escasez y la convivencia para que sea conductor del progreso social. Sin embargo, como explico a continuación, desde la óptica del Liberalismo Político y en la medida en que el giro político de Rawls no implica un giro pragmático en un sentido deweyano y se basa sólo en consenso, parece que Rawls busca eliminar de la política su naturaleza conflictiva, permitiéndole conservar un valor muy apreciado por el conservadurismo político: el orden. En Teoría de la Justicia Rawls asumía que la cooperación es la circunstancia política fundamental, dejando el conflicto (que, según Dewey, es el origen de la política) a un lado. En el Liberalismo Político Rawls mantiene a la cooperación en el centro pero, a diferencia de antes, simplemente olvida la existencia del conflicto como un hecho continuo dentro de la sociedad con lo dicho hasta ahora.

A continuación profundizo en esto. Para hacerlo expongo el concepto del consenso traslapado, central en el pensamiento de Rawls en especial en el Liberalismo Político por su papel en la resolución del conflicto fruto del pluralismo existente en la sociedad. En este análisis se verá con claridad cómo es que, en la medida en que el proyecto tenga éxito, el conflicto debería desaparecer de la arena política aunque, como intenté justificar antes, esto sólo puede suceder si Rawls justifica la idea, que considero refutada, de poder fundar una concepción de la justicia en función de los contenidos propios de la cultura política liberal y democrática imperante en la sociedad, en particular la sociedad norteamericana.

\section{El conflicto en la arena pública}

Teniendo en mente que la concepción de la justicia política preferida por una sociedad con una cultura democrática y liberal, que Rawls sostiene que sería la justicia como imparcialidad, tiene por objeto la estructura básica, debemos aclarar

${ }^{26}$ John Dewey, Ethics (Nueva York: Henry Holt and Company, 1908), 210. 
los alcances de dicha concepción. Antes de continuar es menester recordar que cuando habla de la estructura básica, Rawls se refiere a "las principales instituciones políticas sociales y el modo en que se hilvanan en un sistema de cooperación" ${ }^{27}$ Asumir que la concepción de la justicia política sirve para ordenar la estructura básica de una sociedad bien ordenada implica aceptar que la concepción de la justicia debe de ser capaz de servir como criterio para juzgar algunos de los hechos más importantes en la vida de los individuos; es decir, las exigencias y actos políticos. Siempre que esto ocurre así, lo que Rawls propone es la presentación de una concepción de la justicia que sirva para ordenar la estructura básica de la sociedad (y hasta este punto es consistente con lo dicho en Teoría) y que, al mismo tiempo, aun cuando no pueda ser justificada a los individuos en función de su derivación, forme parte de la cultura política compartida que se encuentra en sus instituciones y sea aceptada por todas las doctrinas comprehensivas razonables que habiten en la sociedad en función de su propia justificación.

La conclusión es que los ciudadanos generarán expectativas y deseos alineados a una concepción de justicia que incorpora su cultura política (aunque cada quien la pudiera justificar de un modo distinto). Esto nos conduce a pensar que sus reclamos no deberían generar un conflicto con los de los demás ya que dicha concepción, que es la justicia como imparcialidad, estipula los términos concretos de cooperación y reciprocidad; al menos no debería generar conflicto respecto a ideas fundamentales de lo justo o lo injusto. Esta es la idea central dentro del concepto del consenso traslapado: "un consenso en el que la misma concepción política es sostenida por las doctrinas comprehensivas razonables opuestas que gana un cuerpo significativo de adherentes y perdura de una generación a la siguiente." 28

Antes de continuar con el análisis del consenso traslapado recordemos la definición de doctrina comprehensiva. Rawls asume que una doctrina comprehensiva cubre "todos los valores y virtudes reconocidos dentro de un sistema bien articulado". Esta definición implica que la doctrina comprehensiva permite a un individuo dar sentido a su realidad pues permite valorarla completa; es a través de los contenidos de las doctrinas comprehensivas que los individuos desarrollan gustos e intereses y, por tanto, sus intenciones terminan estando gobernadas por las doctrinas comprehensivas a las que se adhieren. Si la concepción política de la justicia es justificada desde cada una de las doctrinas

\footnotetext{
${ }^{27}$ Rawls, Political Liberalism. 35

${ }^{28}$ Rawls, Justice as Fairness. 184
} 
comprehensivas razonables, podríamos decir que todos los deseos en el ámbito político de todos los ciudadanos, independientemente de su doctrina comprehensiva, se desarrollan originariamente en función de la misma concepción de justicia. Si esto es así, entonces el conflicto radical en la arena política no debería de existir en la medida en que todas las disputas consisten sólo en "ponerse de acuerdo" sobre la base de los principios contenidos en la concepción de la justicia que todos comparten desde su doctrina comprehensiva independientemente de que se justifique de un modo distinto. Esto implicaría que algunas luchas dentro de los Estados democráticos contemporáneos, como el derecho a la no discriminación (en sus distintas manifestaciones), a la seguridad social, al aborto, a la libertad e igualdad sexual y la distribución del gasto público, entre otras, se deberían resolver, si el proyecto rawlsiano es acertado, con la convicción de las partes de que, independientemente de cuál sea su resolución concreta en cada caso, es "intrínsecamente" justa y compatible con su doctrina comprehensiva y no es, simplemente, una concesión o fruto de una negociación como tantas veces ocurre. Ese parece ser el objetivo final del consenso traslapado como la herramienta para garantizar la estabilidad. ${ }^{29}$

La sociedad en la que piensa Rawls, donde los individuos cooperan y comparten la misma concepción de la justicia, deja de ser el espacio en el que los individuos se presentan como sujetos de intereses, en algunos casos convergentes pero, en muchos otros, excluyentes; así, deja de lado la naturaleza adversarial de la vida política. Los ciudadanos rawlsianos, que normalmente buscan maximizar su bienestar mediante la selección de los mejores medios, lo que implica intereses conflictivos siempre que exista la escasez moderada que Rawls reconocía en las circunstancias de la justicia (en Teoría de la Justicia), parecen tener ahora intereses complementarios, en especial si suponemos que mantener una concepción de la justicia es una prioridad. El ámbito político es un campo fértil para alcanzar algunos de los objetivos que poseen los individuos. En tanto reconozcamos la racionalidad económica (o moderna-hobbesiana en general) de medios y fines, que por cierto no deja de tener semejanzas con una racionalidad auténticamente pragmática en algunos sentidos, es claro ver que el ámbito político será un campo de "juego" para satisfacer mis deseos, que en muchos casos serán contrarios y, en

\footnotetext{
${ }^{29}$ Relacionado a este punto, el filósofo conservador Robert P. George afirma: “Por supuesto, defensores pro-vida y por la libertad de elegir pueden, por sus propias razones partisanas, o como parte de un modus vivendi, aceptar un requerimiento constitucional que la política pública sobre el aborto se resuelva mediante procedimientos democráticos. Pero este tipo de acuerdo no es un acuerdo en los principios básicos de justicia." (Robert P. George: "Public Reason and Political Conflict: Abortion and Homosexuality"; The Yale Law Journal, vol. 106 no. 8 (1997). 2476.)
} 
otros, excluyentes de los de los demás. Al final del día Rawls termina asumiendo, de un modo históricamente indemostrable, que las distintas doctrinas comprehensivas en una sociedad plural comparten intereses en lo fundamental; el interés, por ejemplo, de mantener una concepción de la justicia igual para todos. Esto es muy difícil de aceptar pues ni siquiera es claro hasta qué punto sería posible afirmar que, incluso en una sociedad predominantemente liberal, la idea misma de la libertad es entendida de igual modo por los ciudadanos; tiendo a pensar que no es, de ninguna manera, una idea tan compartida como Rawls parece considerar. En elación a esto, Russell Hardin afirma que: "Los movimientos nacionalistas normalmente se enfocan en una identidad supuestamente compartida de algún tipo, pero pocas democracias liberales contemporáneas pueden ser caracterizadas de este modo a menos que su identidad compartida esté relativamente vacía." ${ }^{30}$

Dado que, como bien enuncia el mismo Rawls en el Liberalismo Político, la sociedad democrática no es una comunidad en donde todos comparten una doctrina comprehensiva ${ }^{31}$ (en esa medida, reconociendo el pluralismo), ¿no sería normal reconocer que los individuos tendrán ideas distintas de cómo avanzar el bienestar de la sociedad, que intentarán plasmar en la concepción de la justicia, como Rawls aceptaba en Teoría (y era por eso que asumía la importancia de justificar racionalmente una concepción que fuera mejor justificada que las otras opciones)? Es curioso como Rawls, intentando agregar plausibilidad a la justicia como imparcialidad, desarrolla en el Liberalismo Político un argumento en favor a la estabilidad en función del consenso traslapado, que parece obviar un hecho tan fundamental de la experiencia histórica, en palabras de Brian Barry:

Finalmente, donde miembros de distintos credos religiosos tienen ideas incompatibles en el modo en que una ciudad o una sociedad debe de ser organizada, y al menos uno de estos grupos busca imponer sus ideas en un territorio conteniendo con otros grupos, eso está destinado a resultar en conflicto. Dado que éstas son las condiciones para el conflicto, es poco sorprendente que las dos religiones monoteístas proselitistas, Cristianismo e Islam, hayan estado implicadas en tanto de éste. ${ }^{32}$

Parece que Rawls asume que las doctrinas comprehensivas razonables, para poder coexistir en una sociedad liberal de un modo bien ordenado, tendrán la misma comprensión del "modo en que una ciudad o sociedad debe de ser organizada"

\footnotetext{
${ }^{30}$ Hardin, Liberalism, Constitutionalism, and Democracy. 315

${ }^{31}$ Cfr. Rawls, Political Liberalism. 42

${ }^{32}$ Brian Barry, Culture and Equality (Cambridge: Harvard University Press, 2001). 25
} 
con la misma concepción de justicia bajo un consenso. De lo contrario, parecería que el mecanismo con el que terminaríamos para contener el conflicto, mediante concesiones por parte de las doctrinas, es una especie de negociación donde las concesiones tienden a estar más relacionadas a un tema de capacidad o incapacidad de imponerse mediante los procesos democráticos.

Una preocupación que podría existir de organizar una sociedad liberal primordialmente en función de la negociación y las concesiones, es que parecería que con el tiempo éstas son un fundamento endeble para la estabilidad social: cuando las condiciones materiales cambien podrían abrir paso a que una doctrina comprehensiva no tuviera que conceder, pues podría estar en posición de imponer. La contrapropuesta rawlsiana reconoce el peligro de una sociedad que se mantiene ordenada únicamente bajo un criterio de capital político. Si la estabilidad está basada en un consenso, en particular uno del tipo que prefiere Rawls, las distintas doctrinas sostendrán el orden social pues éste materializará la idea de justicia que sustenta su propia doctrina comprehensiva; esta opción garantizaría más estabilidad.

La plausibilidad del argumento rawlsiano para la falta del conflicto, aceptada su comprensión de doctrina comprehensiva y la cultura política como realidades estáticas (lo que francamente no es fácil hacer), descansa en buena medida en la distinción entre doctrinas comprehensivas razonables y doctrinas comprehensivas no razonables. Si bien analizo con más detalle la idea de la razonabilidad más adelante, basta con decir por ahora que, como hemos visto, Rawls asume que el pluralismo en una sociedad democrática y liberal es de doctrinas comprehensivas razonables. Si asumimos que la idea de la razonabilidad implica una serie de características determinadas (entre ellas la tolerancia, la honorabilidad de cumplir con los acuerdos y la búsqueda de la cooperación en lugar del conflicto), parecería ser que la exigencia de la razonabilidad como condición de la adopción de la justicia como imparcialidad nos conduce a un pluralismo mucho más limitado de lo que pensamos inicialmente. Chantal Mouffe, por ejemplo, asume que la distinción entre razonable y no razonable en el pensamiento rawlsiano conduce a una sociedad homogénea ya que, al final, sólo los razonables pueden ser parte de la sociedad: "Lo que Rawls está realmente indicando con esa distinción es que no puede existir pluralismo en lo que a los principios de las asociación política se refiere y que la concepción que se rehúse a 
los principios del liberalismo deben de ser excluidos." ${ }^{33}$ De este modo, cuando de democracia liberal se trata, existe un pluralismo más bien limitado en el que los individuos comparten la misma concepción de la justicia.

La realidad es que siempre que Rawls asuma que es ilegítimo en cualquier caso imponer un orden social determinado, sin importar que tan racionalmente justificado esté (como lo estaba en Teoría de la Justicia), la única opción viable es la del consenso traslapado que, si Mouffe está en lo correcto, terminaría negando la pertenencia a cualquier persona que no comparta completamente la concepción de la justicia. Este proceder difícilmente puede ser justificado dada la evidencia real de las sociedades plurales actuales: aun cuando los individuos tienden a estar de acuerdo en algunos de los elementos de la cultura política, es imposible afirmar que están acuerdo sobre los mismos factores y, por lo mismo, la ciudadanía actual tiende a reconocer que algunos de los mecanismos de operación de la sociedad le parecen injustos. Suponer que las personas obedecen todas las leyes porque les parecen justas sería ingenuo; suponer que algunas leyes les parecen justas y otras las obedecen simplemente porque, de no hacerlo, las consecuencias son peores que la obediencia, y otras simplemente les son indiferentes, considero algo más razonable de creer. Esta segunda perspectiva la tomaba en cuenta Rawls en Teoría de la Justicia. En el Liberalismo Político no es claro cómo podría hacerlo pues la concepción de la justicia se justifica desde cada doctrina comprehensiva.

No deja de ser curioso que el consenso traslapado, que supone la aceptación de todos los ciudadanos que poseen una doctrina comprehensiva distinta de la misma concepción de la justicia es, para Rawls, la posibilidad realista de que la comunidad pueda ser estable:

(...) la idea del consenso traslapado es utilizada para permitirnos pensar en la sociedad bien ordenada de la justicia como imparcialidad en un modo más realista. Dadas las instituciones libres que la concepción implica, no podemos seguir asumiendo que los ciudadanos en lo general, aun si aceptan la justicia como imparcialidad como una concepción política, también aceptarán la perspectiva comprehensiva particular a la que parecía pertenecer en Teoría.

Ahora asumimos que los ciudadanos mantienen dos visiones distintas; o más bien, su visión completa tiene partes: una parte puede ser vista como, o coincidente con, una concepción política de la justicia; la otra parte es una (completa o parcial) doctrina comprehensiva con la que la concepción política esta de algún modo relacionada. La concepción política puede ser simplemente una parte, o un adjunto, de una visión comprehensiva parcial; o puede ser sostenida

\footnotetext{
${ }^{33}$ Chantal Mouffe: "The Limits of John Rawls' Pluralism"; Theoria: A Journal of Social and Political Theory, vol. 56 no. 118 (2009), 4.
} 
porque puede ser derivada desde una doctrina comprehensiva completamente articulada. Es tarea de los ciudadanos individualmente decidir por sí mismos en qué modo sus concepciones políticas compartida están relacionadas con sus visiones comprehensivas. ${ }^{34}$

El argumento de Rawls es en esta instancia engañoso. Si nos enfrentamos ante la cuestión de qué es más realista, si el que la sociedad tenga un consenso traslapado sobre su concepción política de la justicia o un consenso traslapado sobre la totalidad de sus doctrinas (como para poder hacer aceptable un argumento moral como el que desarrollaba en Teoría) la posibilidad del consenso sobre la concepción política es más factible. El problema con este argumento está en la idea de que el fundamento de legitimidad y estabilidad de una concepción de la justicia sólo puede encontrarse en la idea misma del consenso traslapado. La cuestión que Rawls debería haber respondido es por qué es razonable la idea misma del consenso frente a la posibilidad de una justificación racional como la que realizó en Teoría, dentro de la cual se suponía que, aun cuando una persona pudiera no estar de acuerdo con la justicia como imparcialidad, dada la manera en que fue derivada, era legítimo imponer sus consecuencias. Sostengo que la posibilidad de desarrollar un consenso en el modo que Rawls lo plantea es nula. Es como si nos preguntamos qué es más realista, que los humanos viajen a Saturno a que viajen al Sol mañana; sin duda la opción de Saturno suena más realista, ya que el Sol es una imposibilidad absoluta, sin embargo, al menos hasta hoy, viajar a Saturno es igualmente imposible. El hecho de que algo nos parezca más posible que otra opción no implica que de hecho lo sea por sí; este problema se encuentra en la idea del consenso traslapado en una sociedad plural en las condiciones que propone Rawls.

Usando esta inferencia incorrecta, sobre la posibilidad de la existencia de un consenso traslapado que aparentemente se justifica por la imposibilidad de un consenso moral más profundo entre doctrinas comprehensivas, Rawls procura ofrecer una justificación de carácter "empírico" para su existencia. Esta justificación asume que para llegar a un consenso traslapado adecuado, primero es necesario tener un consenso constitucional. Dicho consenso constitucional, que para Rawls es un paso anterior, es fruto de circunstancias históricas en las que los individuos se vieron forzados a hacer concesiones inicialmente. El ejemplo para esto es, en Liberalismo Político, las guerras de religión. ${ }^{35}$

\footnotetext{
${ }^{34}$ Rawls, Justice as Fairness. 187

${ }^{35}$ Cfr. Rawls, Political Liberalism. xxxix y 159-160
} 
Rawls asume que en un inicio, después del surgimiento de la Reforma protestante, los distintos grupos, abiertamente hostiles entre ellos, se vieron en la necesidad de aceptar, inicialmente con reticencia, algunos acuerdos para poder vivir en paz. De esto se derivó un modus vivendi en el que los individuos fueron capaces de reconocer la importancia de conceder algunos de sus objetivos con la finalidad de obtener un beneficio aún mayor. El denominado consenso constitucional es el producto de "una cierta soltura de nuestras visiones comprehensivas, así como el que no son completamente comprehensivas" ${ }^{36}$ que, después de un cierto tiempo, cumple tres requisitos mediante el desarrollo de principios liberales: ${ }^{37}$ (i) los principios liberales dan respuesta a circunstancias políticas que exigen respuesta pronta (por ejemplo la determinación de la libertad de culto), (ii) los principios pueden ser aplicados haciendo uso de métodos de investigación pública y reglas para analizar la evidencia, y por último, (iii) las instituciones políticas que encarnan estos principios tienden a motivar la cooperación de las virtudes políticas cooperativas (la virtud de lo razonable, un sentido de la justicia y una voluntad para la cooperación).

Así, "en la primera etapa del consenso constitucional los principios liberales de justicia, inicialmente aceptados con reticencia como un modus vivendi y adoptados en una constitución, tienden a cambiar las doctrinas comprehensivas de los ciudadanos para que ellos puedan al menos aceptar los principios de una constitución liberal." ${ }^{38}$ Una vez que tenemos el consenso constitucional, el paso siguiente es alcanzar un consenso traslapado, que sería uno más amplio (sobre una concepción de la justicia política completa y no sólo sobre los principios constitucionales) y que formaría parte de las doctrinas comprehensivas ya que estaría fundado en la cultura política de las que éstas participan. Algunos de los factores, sostiene Rawls, que conducen a dicho consenso, es la participación en los foros de discusión públicos y el hecho que es racional para los ciudadanos el querer acercarse de modo que sea más fácil desarrollar acuerdos. ${ }^{39}$

Si bien es cierto que el diálogo y la discusión públicas son las condiciones de los acuerdos y consensos, no es del todo claro por qué el diálogo tendría que conducir, en una sociedad plural de personas libres (en la medida en que ya aceptaron el consenso constitucional), al tipo de consenso que Rawls desea. Pareciera ser que, dentro de la lógica rawlsiana, no cabe la posibilidad de que el

\footnotetext{
${ }^{36}$ Ibid. 159

${ }^{37}$ Cfr. Ibid. 161

${ }^{38}$ Ibid. 163

${ }^{39}$ Cfr. Ibid. 165
} 
producto del diálogo y la discusión pueda ser distinto de la aceptación de la concepción de la justicia (la justicia como imparcialidad) teniendo como su origen el consenso constitucional; es como si Rawls fuera capaz de predecir el resultado del diálogo libre entre personas razonables que poseen perspectivas de la vida distintas, lo que encuentro posible pero poco probable. En Teoría de la Justicia Rawls argumentaba, por ejemplo, que, dadas ciertas condiciones argumentativas, los individuos tendrían que aceptar la justicia como imparcialidad como la concepción de la justicia adecuada (las condiciones siendo la posición original, el velo de la ignorancia y la racionalidad económica-modera); es importante aclarar que, dentro de la lógica de Teoría, el supuesto era aceptable solo si existían restricciones al diálogo que permitían poner a prueba los argumentos de un modo "controlado". El problema es que no se ve como puede ser así en el Liberalismo Político; en palabras de Rodríguez Zepeda:

En efecto, mientras que, en tanto doctrina comprehensiva, la justicia como
imparcialidad garantizaba que la absoluta inclusividad de su diseño ideal
conduciría a un conjunto de normas aceptables de manera directa y sin necesidad
de un consenso ulterior, ahora, en tanto que doctrina política, lo único que puede
hacer es apelar a la razonabilidad de las visiones comprehensivas razonables y al
cumplimiento de las condiciones políticas establecidas por la historia y la cultura
políticas de una sociedad democrática. ${ }^{40}$ El giro político termina debilitando el proyecto de la justicia como imparcialidad pues, en tanto se justifica únicamente en el consenso, es incapaz de ofrecer razones más allá de la aceptación de la mayoría. Aun cuando desde una perspectiva pragmática sea imposible ofrecer una justificación final de todos nuestros conceptos (no sólo por el falsacionismo sino por qué, en la construcción de cualquier idea compleja, estamos presuponiendo conceptos todo el tiempo ${ }^{41}$ ), la posibilidad de justificar la concepción de la justicia en términos de ser la mejor candidata (como lo hacía, en parte, en Teoría) ofrece un mejor sustento que simplemente el que cuente con el apoyo de la mayoría (pues las mayorías son, como lo ha mostrado la historia continuamente, volubles). Este proceso me parece que debilita su obligatoriedad pues en último término justifica su existencia (de modo radical y más allá de las justificaciones particulares de cada una de las

\footnotetext{
40 Rodríguez, La política del consenso. 45

41 Un ejemplo de estos conceptos presupuestos desde una perspectiva pragmática puede ser que la vida en paz es mejor que la vida en guerra continua o, del mismo modo, que vivir es mejor que morir. No es claro que desde bases pragmáticas podamos dar un argumento definitivo a por qué es mejor vivir que morir, pues cualquier respuesta supondrá, nuevamente, conceptos sostenidos con bases en aseveraciones justificadas que no tienen un carácter de verdad final o absoluta.
} 
doctrinas comprehensivas) en la cultura política y, como he insistido, la cultura política es un objeto inestable.

En buena medida la complicación se encuentra en la insistencia de Rawls en pensar la cultura de modo unívoco y muy poco cambiante. Quizá si todos los ciudadanos de una sociedad en la que sólo existe el consenso constitucional estuvieran perfectamente de acuerdo en el significado de conceptos tales como democracia, libertad, derechos (y cada uno de ellos), obligaciones, tolerancia y demás valores políticos relevantes, al tiempo en que los individuos aplican el principio de caridad ${ }^{42}$ en el diálogo $\mathrm{y}$, al mismo tiempo, participan con absoluta honestidad y son igualmente capaces de participar, podría ser posible (¿al menos mínimamente?) el tipo de consenso que busca Rawls, aunque lo encuentro poco probable. Sin embargo, en una sociedad plural en donde los ciudadanos buscan alcanzar sus propios beneficios, como lo mencionaba Barry en el pasaje citado, y donde no hay un acuerdo claro en el significado y valor de los distintos valores políticos por la naturaleza cambiante de la cultura, la idea del consenso se vuelve un ideal realmente inalcanzable.

El problema del planteamiento rawlsiano sobre la posibilidad de alcanzar un consenso traslapado no concluye en este punto. Todavía es posible decir algo sobre la importancia de la justificación de un concepto como el de la justicia para comprender sus implicaciones. Cuando Rawls asume que la concepción de la justicia se elabora con las ideas contenidas en la cultura política pero que, al mismo tiempo, puede ser justificada de modo distinto dependiendo de cada doctrina comprehensiva, parece no reconocer que el contenido de la justificación es parte esencial de la idea misma. Recordemos el fragmento citado de Dewey en el primer capítulo sobre el tema: “La mayoría de las personas asumirán que saben lo que es la justicia. Ese concepto tan vago de la justicia es peor que inservible, porque las personas actúan en función de él. Una persona que lo sostiene está a la merced de sus propios sentimientos o la tradición recibida de sus maestros. Primero debería existir una maestría en los hechos concretos para después discutir la tendencia de esos mismos hechos." ${ }^{43}$

Rawls no reconoce que, dependiendo del modo en que la justicia como imparcialidad sea justificada, podría tomar un sentido distinto. Es decir, si una doctrina comprehensiva justifica la justicia como imparcialidad en función de una

\footnotetext{
${ }^{42}$ El principio de caridad se refiere a la condición del diálogo, postulada por Donald Davidson, que implica que, para poder tener un diálogo productivo, es necesario realizar la mejor y más fuerte interpretación de los argumentos de las personas con las que entablamos un diálogo.

${ }^{43}$ DEWEY, Principles of Instrumental Logic. 79
} 
perspectiva teológica (por ejemplo, asumiendo que las libertades básicas son derechos otorgados por Dios) esa justificación tendrá implicaciones distintas a que una persona piense que las libertades básicas son simplemente condiciones mínimas para la existencia de una sociedad democrática. Una concepción de la justicia como imparcialidad justificada de modo distinto, dependiendo de la doctrina comprehensiva que la justifique, puede equivaler, en cierto modo, a una concepción de justicia distinta (pues estas diferencias dictarán la manera en que el ideal se aplique concretamente). En tanto que no hay un criterio de justificación aceptable para las distintas doctrinas comprehensivas (al menos según Rawls en el Liberalismo Político), no queda claro hasta qué punto podríamos hablar de una misma concepción de la justicia, aun si las palabras que la definen fueran iguales para todos.

Rawls, en Teoría, estaba consciente de este problema, es por esto que la idea de la posición original como mecanismo que permite una justificación y articulación de la justicia como imparcialidad me parece más adecuada, aunque no sea perfecta. En el Liberalismo Político, Rawls renuncia a una derivación racional de la concepción de la justicia y deja a la justicia como imparcialidad a la libre justificación de cada una de las doctrinas comprehensivas; si es verdad que características relevantes de la idea de justicia están vinculadas, como presumo que así ocurre, del modo en que está justificada la concepción, Rawls se terminaría enfrentando con un probable conflicto sobre la materia misma de la justicia (es decir, qué bienes se resguardarán gracias a dicha concepción). Si vivimos en una sociedad plural como aquella que considera Rawls para ser ordenada por la justicia como imparcialidad, ¿cómo podemos estar seguros de qué corresponde al ámbito público que debería regular la concepción de la justicia que buscamos sea la materia del consenso? La aparente solución de este problema, que no reconozco que esté del todo justificada en la cultura política de una sociedad democrática y liberal, al menos no libre de polémica, es para Rawls la reafirmación de los bienes primarios como aquellos que deberán de ser distribuidos por parte de la concepción de la justicia.

Dada la naturaleza política del ciudadano, como miembro colaborador de una sociedad bien ordenada y poseedor de sus dos poderes morales, Rawls precisa que la concepción política de la justicia se limite al ámbito público. Contrario a lo que denomina concepciones de la justicia perfeccionistas o utilitaristas, que reconocen desde su perspectiva la importancia y legitimidad del uso del poder público para generar un mayor bienestar, o lo que entiendan por tal (por ejemplo con una educación "ilustrada"), el liberalismo político debe mantenerse alejado de 
dichas ideas pues, como ya se ha mencionado antes, eso implicaría un perjuicio a individuos que sostienen doctrinas comprehensivas contrarias a, digamos, dicha educación ilustrada. Los bienes primarios son el mecanismo preferido para postular una solución a este problema ya que se fundamentan en la idea de que "las concepciones del bien, sin importar que sean distintas en su contenido y que sus doctrinas religiosas y filosóficas, requieren para su desarrollo generalmente los mismos bienes primarios, esto es, los mismos derechos básicos, libertades y oportunidades, y los mismos medios multipropósito como ingreso y riqueza, con todos estos apoyados por las mismas bases del auto respeto" ${ }^{\prime 4} \mathrm{y}$, por lo mismo, no es necesario justificar su necesidad desde una doctrina comprehensiva en particular. Lo que es más, Rawls considera que podemos justificar su existencia en términos puramente políticos. El intento de Rawls de plantear una concepción de la justicia política, que no se sostenga por una idea moral o metafísica y que, por lo mismo, pueda ser justificada desde diversas doctrinas comprehensivas, se enfrenta a algunos problemas respecto a la identificación de los bienes públicos como muestro a continuación.

El problema es que Rawls, con el liberalismo político, cierra la puerta a la argumentación moral del espacio público, negando por adelantado la posibilidad de que la distribución de ciertos bienes pueda estar condicionada por valores extra políticos en el sentido que Rawls da de lo político. Para esto creo que servirá un ejemplo respecto de un bien particular.

Pensemos en la prohibición de ciertos tipos de discursos que pudieran incitar odio. Recordemos el ejemplo en el capítulo anterior sobre la Iglesia Bautista de Westboro, en donde un pequeño grupo lleva a cabo manifestaciones públicas donde los mensajes de odio se encuentran presentes en contra de homosexuales, militares y cualquier otro individuo que el grupo considere pecador. En Estados Unidos, la democracia liberal en la que piensa Rawls al escribir Liberalismo Político, la libertad de expresión puede ser limitada sólo cuando su ejercicio genere condiciones de peligro para otros o que sea un llamado inminente a la violencia contra un individuo o grupo de individuos. Esto quiere decir que si la Iglesia Bautista de Westboro no genera un riesgo inminente, no puede ser censurada. ${ }^{45}$

La interpretación norteamericana del derecho a la libertad de expresión, que se encuentra dentro de los bienes primarios postulados por Rawls, parecería ser

\footnotetext{
${ }^{44}$ Rawls, Political Liberalism. 180

45 Un ejemplo típico de lenguaje no protegido es el de la prohibición a gritar "fuego" dentro de una sala de cine (concierto, teatro o cualquiera similar) llena de gente, sin que realmente haya un incendio, generando caos, violencia y lesiones entre los asistentes.
} 
consistente con el pensamiento de Liberalismo Político: todos tienen el mismo derecho a la libertad de expresión, del modo más completo posible, en la medida en que el ejercicio de ese derecho no transgreda directamente los derechos o integridad física de los demás de un modo injustificable; es decir que sea un ejercicio de derechos compatible con el de los demás. En cualquier caso, es cuestionable que la interpretación norteamericana a la libertad de expresión, y por tanto la interpretación de Rawls, sea necesariamente correcta dentro de una sociedad liberal y democrática.

Probablemente el momento más oscuro en la historia de la humanidad, hasta ahora, fue la Segunda Guerra Mundial, acontecida a mediados del siglo XX principalmente en Europa, aunque una buena parte de la guerra se llevó a cabo en Asia (en China, Indochina y por supuesto Japón), África y, en mucho menor medida, en América. Fue el momento histórico en el que millones perdieron la vida en los campos de batalla y, de igual modo (y relevante para mi punto), en campos de concentración. La memoria de lo acontecido en campos de concentración y de exterminio ha estado presente en buena parte del mundo (en particular en aquellas naciones más directamente involucradas) como un recordatorio de los peligros en los que la especie humana puede ponerse a sí misma. La importancia de estos hechos es tal que en algunas naciones existen restricciones a la libertad de expresión; restricciones que se refieren a la negación de los hechos históricos, demostrables, ocurridos en ese tiempo. La negación del Holocausto judío puede conducir a la prisión, en algunos casos, en algunas naciones. Algunas de las naciones con leyes que limitan o prohíben la negación del Holocausto, son: Alemania, Austria, Francia y Suiza entre otras. Aun cuando pueda haber razones de peso para mantener una interpretación "americana" del derecho a la libertad de expresión, es comprensible que el volksverhetzung, o incitación al odio, pueda ser un hecho lo suficientemente negativo en Alemania para justificar la prohibición de un modo de expresión particular. En la medida en que lo político, al menos para Rawls, puede ser separado de lo moral (no sólo conceptualmente), la condena pública en contra de los mensajes de odio se dificulta pues el argumento en contra de éstos se construye en términos morales, aun cuando sea una moral liberal.

Alguien podría responder, a favor de Rawls, que en cualquier caso el tipo de expresión implicada en la volksverhetzung no es propia de individuos o doctrinas comprehensivas razonables; cuando eso es así las personas no razonables pueden ser obligadas a someterse a estándares razonables. Este argumento, desde el liberalismo político, carece de todo mérito. En la medida en que una persona que 
niegue el Holocausto respete la ley (como hacen los miembros de la Iglesia Bautista de Westboro respecto a sus afirmaciones de odio) y sea parte del consenso traslapado, no hay argumentos para justificar que debería tener prohibido hacerlo si la argumentación moral está prohibida aun cuando fuera una idea o intuición moral ampliamente compartida (como la prohibición de volksverhetzung en una nación como Alemania). Es probable que los ciudadanos y legisladores de un país decidieran que el derecho a la libertad de expresión es más importante que la prohibición de las expresiones de odio sin importar la historia; de cierto modo en Estados Unidos es lo que ha ocurrido. Sin embargo, ese debate sólo puede ser llevado a cabo mediante un proceso conflictivo en el que los ciudadanos deben decidir cómo se deben de distribuir los bienes desde una perspectiva moral. En el Liberalismo Político Rawls parece querer disolver la cuestión, exterminando el diálogo y el conflicto, decidiendo, en cualquier caso, que los bienes primarios son necesariamente preponderantes ante cualquier otro reclamo. ${ }^{46}$

Dado que es una posibilidad real, constatablemente así, que en una sociedad democrática y liberal donde el pluralismo sea un hecho, existirán doctrinas que mantengan ideas que los demás consideren reprobables (que por motivos poco claros, por ejemplo, buscan negar uno de los hechos históricos más oscuros de la humanidad, como fue el Holocausto durante la Segunda Guerra Mundial, o aquellos que discriminan por razones que pensamos moralmente irrelevantes), la pregunta es si el consenso traslapado de una concepción política de la justicia, que busca distribuir bienes primarios bajo las condiciones que mencioné antes, puede existir en esa circunstancia de modo que el conflicto, efectivamente, desaparezca de la arena pública. Nadie niega que seamos capaces de vivir en sociedad con personas con las que estamos en profundo desacuerdo, la pregunta interesante es si es posible alcanzar algo más que un modus vivendi con individuos cuya doctrina comprehensiva nos es ofensiva (aunque no hagan algo para ofendernos directamente). Como afirma Andrew Lister:

El Estado en el que Rawls quiere que vivamos es un Estado en el que sabemos o pensamos que los demás están mal pero, como son razonables y aceptan la vida bajo la misma concepción de la justicia, podemos vivir con ellos. Esto es un tipo de

\footnotetext{
${ }^{46}$ Es de llamar la atención que, cuando de hecho existe el conflicto, dadas las condiciones que propone Rawls, este se da de modo que las que la doctrina comprehensiva que esté en conflicto deba ser considerada no-razonable y, por lo mismo, prohibida totalmente. Lo que considero particularmente interesante es que, cuando esto sucede, no es porque dicha doctrina sea falsa o contraria a ciertas consideraciones morales (liberales o de cualquier otro tipo), sino porque es poco razonable. Esto nos conduce a pensar, de nuevo, que si las doctrinas comprehensivas son razonables, del modo que supone Rawls, el conflicto simplemente no existe en la esfera pública (Cfr. Rawls, Political Liberalism. 138) de la sociedad liberal.
} 
compromiso pues sabríamos que sería mejor que los equivocados aceptaran nuestra concepción verdadera. ${ }^{47}$

Parecería que la única manera en la que es posible el consenso es si los individuos consideran que los contenidos morales de su doctrina comprehensiva no tienen implicaciones políticas (asumiendo que la concepción de la justicia puede existir del modo que Rawls supone). La existencia del pluralismo como un hecho implica que distintas doctrinas comprehensivas podrían considerar la importancia de sus ideas morales respecto a la arena pública de modo distinto; parecería que el liberalismo político termina exigiendo a las personas no tomar demasiado en serio a sus doctrinas en los casos que sus contenidos no los lleven a hacer una distinción tan clara, como la que hace Rawls, entre lo político y lo moral.

Evidentemente Rawls no afirma que el liberalismo político promueve que los individuos no tomen en serio sus doctrinas comprehensivas: "Las luchas más intricadas, el liberalismo político asume, son confesadamente por el bien de las cosas más valoradas: las religiones, visiones filosóficas del mundo y por diferentes concepciones morales del bien." ${ }^{\prime 8} \mathrm{Si}$ Rawls cree que la concepción política de la justicia, en su caso la justicia como imparcialidad, puede ser aceptada por las distintas doctrinas comprehensivas (aunque espero haber mostrado lo improbable que es esto), queda la pregunta de cómo podría ser esto posible. Asumiendo que distintas doctrinas comprehensivas pueden de hecho tener una comprensión diversa del papel de la concepción de la justicia y de su ideal moral sobre ella, Rawls parece requerir, como condición del establecimiento de su liberalismo, de una herramienta para "convencer", aunque no necesariamente justificar, pues la justificación depende de cada doctrina, de la plausibilidad de la justicia como imparcialidad.

La filosofía política juega un papel relevante en este punto para Rawls. Contrario a lo que sucedía en Teoría, donde la argumentación filosófica en favor de la justicia como imparcialidad era el tema central del texto, con el giro político la filosofía perdió la responsabilidad de justificar la justicia como imparcialidad por las razones que ya hemos visto hasta ahora. La filosofía política tiene más bien una función secundaria: su finalidad es facilitar el consenso. En Justicia como

\footnotetext{
${ }^{47}$ Andrew Lister: "Public Reason and Moral Compromise"; Canadian Journal of Philosophy, vol. 37 no. 1 (2007). 22

48 Rawls, Political Liberalism. 4
} 
Imparcialidad, a restatement Rawls afirma que la filosofía política cumple cuatro funciones: ${ }^{49}$

1. Una función práctica en la que busque indagar sobre, en los casos en que las doctrinas comprehensivas están en desacuerdo, las bases para un acuerdo entre los grupos en función de perspectivas filosóficas o morales. La filosofía política como herramienta de relación.

2. Contribuir a que las personas piensen sus instituciones políticas y sociales de un modo sistemático y que entiendan de qué modo se relacionan con sus objetivos y propósitos como individuos, miembros de familia o de cualquier otra asociación a la que, de hecho, pertenezcan.

3. Como conciliación con nuestras instituciones. La filosofía política puede servirnos para aliviar nuestra molestia o frustración con nuestra sociedad, cuando esto suceda pues muestra cómo es que nuestras instituciones son el producto racional, desarrollado en el tiempo.

4. Para permitirnos imaginar cómo, dadas las condiciones adecuadas, podría existir una sociedad democrática y liberal bien ordenada en el futuro.

Con el giro político, como se puede ver, la filosofía es un instrumento sin una función justificativa vinculante y no tiene una función normativa en lo absoluto. Con el giro político la filosofía deja de cumplir la función "constructora" que tenía en Teoría, independientemente de si lo hacía con bases kantianas o pragmáticas, a ser una herramienta de convencimiento, dilucidación y terapéutica.

El cambio en la comprensión de la tarea de la filosofía política es por demás relevante. Cuando Rawls afirma que cada doctrina comprehensiva, suponiendo que sea razonable, debe de ser capaz de justificar la concepción de la justicia desde sus propios principios, lo que implica es que la verdad de una justificación determinada es indiferente para los efectos de la justicia como imparcialidad. Si un católico diera una justificación a la justicia como imparcialidad en función de los principios de la doctrina social de la iglesia, un musulmán en función de una interpretación del Corán y un ateo por una convicción puramente liberal, todo nos conduce a pensar que Rawls afirmaría que es indiferente el contenido de dichas justificaciones en cuanto a su verdad. Esta faceta del giro político tiende a ser una respuesta a la naturaleza conflictiva de un diálogo cuando las partes involucradas afirman la verdad de sus aseveraciones; en particular este hecho en la política es relevante dado que, como el mismo Rawls asume, algunas de las luchas más enconadas son por este tipo de creencias, en palabras de Rodríguez:

${ }^{49}$ Rawls, Justice as Fairness. 1-4 
(...) la idea de que nada se avanza en la fundamentación moral de los argumentos del dominio político con su calificación como verdaderos es un punto a favor de Rawls. Su idea de que una teoría normativa de la política ha de estar vinculada con lo que denomina "el arte de lo posible" (the art of the posible) no hace más que confirmar lo que ha sido un rasgo característico de la historia de las sociedades democráticas, a saber, que la pretensión de verdad en el dominio político ha sido siempre más un factor de desequilibrio que una forma razonable de garantizar soluciones a los conflictos de principios y valores. ${ }^{50}$

El claro que dentro de las sociedades democráticas, en las cuales existe el pluralismo (que históricamente no ha sido, normalmente, sólo del tipo razonable), afirmar la verdad de las consideraciones de justicia de algunos frente a las de los demás es más una fuente de conflicto que de soluciones dialogadas. De cualquier manera considero que la negativa a Rawls de utilizar la filosofía política como fuente de una concepción de justicia, en el sentido en que sea desde la filosofía política que se justifique y se analice si dicha justificación posee validez (según los parámetros mismos de su justificación) independientemente de doctrinas comprehensivas, al modo en que sí lo había hecho en Teoría, y que, como vimos, hacía que la justicia como imparcialidad cumpliera con los límites de la justicia (que implican condiciones bastante exigentes), es un error. Darle la espalda a un problema no es, en modo alguno, solucionarlo.

El problema en buena medida se deriva de que Rawls tiene un concepto de la verdad limitado. En esto difiero con la lectura de Rodríguez Zepeda, quien asume como un acierto el que Rawls deje de lado la "verdad o validez para los juicios que la constituyen" y que además para hacerlo desarrolla un "procedimiento pragmático sin consecuencias epistémicas." ${ }^{51}$ Como vimos en el primer capítulo, el pragmatismo no se deshace del concepto de verdad, mucho menos del de validez; de igual modo el pragmatismo tiene claras consecuencias epistémicas. El hecho de que el pragmatismo sea falsacionista no supone que todas las aseveraciones tienen la misma validez; por el contrario, la única manera en que el pragmatismo puede tener utilidad como filosofía y tendencia para el desarrollo del conocimiento humano, es si reconoce que es posible calificar y ordenar las aseveraciones en función de su validez, es decir a su justificación, y hablar en este sentido de verdad. Si bien es cierto que desde una postura pragmática nos deshacernos de la idea de verdad como una cualidad metafísica de las aseveraciones que se consideran así, podemos mantener la idea de verdad como el

\footnotetext{
${ }^{50}$ Rodríguez, La política del consenso. 145

${ }^{51}$ Ibid. 143
} 
adjetivo que damos a las aseveraciones mejor justificadas que tengamos disponibles.

El abandono de la idea de la verdad implica un costo alto respecto a la justificación de la concepción de la justicia y su estabilidad. Si bien es cierto que tener la concepción mejor justificada (verdadera en un sentido pragmático) no supone que será considerada legítima y aceptada por toda la población, en la medida en que aceptemos que las personas son seres racionales y que pueden comprender el papel de la inteligencia en sus vidas, tenderán a aceptar en mayor medida, de forma consensual si se quiere, la concepción de la justicia que verdaderamente encarne la racionalidad y razonabilidad de las personas. Recordemos que razón y justificación van de la mano según Dewey.

Un problema adicional derivado del abandono de la noción de verdad o validez en la filosofía política (incluso una de carácter pragmática) por parte de Rawls es que termina desarmando a la sociedad para poder vincularse con otras áreas del conocimiento que podrían llegar a ser "útiles" para resolver cuestiones tradicionalmente públicas. Dado que el liberalismo político no se relaciona con las doctrinas comprehensivas en función de su verdad, se desentiende no sólo de la filosofía política como disciplina de la que se pueden afirmar verdades sobre la concepción de la justicia sino, aún más, de cualquier otro conocimiento que afirme verdades (ya sea desde un punto de vista pragmático o de cualquier otro). Si es posible hablar de avances en áreas de conocimiento como biología, psicología, sociología, economía, neurociencia o cualquier otra que puedan ser analizadas en función de su verdad, eso terminará siendo irrelevante para quien razone tomando como referencia la concepción política de la justicia. Rawls deshace el liberalismo de su contenido filosófico y, al hacerlo, limita sus contribuciones a debates tan relevantes como la libertad sexual, el derecho de las mujeres a abortar o, igualmente, sobre la educación y la promoción de actividades artísticas y culturales para los ciudadanos. Como ya habíamos mencionado antes, siempre que el liberalismo político delimita su discusión del modo en que lo hace (con una concepción política de la justicia, que se refiere a la distribución de bienes primarios y es objeto de un consenso traslapado), no está facultado a tener una postura clara sobre cualquiera de los temas atrás mencionados, ya que parecen escapar a sus límites argumentativos. Esto representa una gran pérdida para el liberalismo en general si el proyecto del liberalismo político es adecuado pues: “La importancia de estos ejemplos reside en que, más que ser una excepción en la pauta de discusiones y conflictos del espacio público norteamericano y, en general, 
del de las naciones democráticas, son ejercicios de un modelo de argumentación ampliamente extendido, incluso para el restringido espacio del foro político." ${ }^{52}$

El liberal rawlsiano, ante la pregunta de la promoción de la cultura por parte del Estado, por ejemplo, tendría que responder que dicha promoción no corresponde al ámbito de la política pues la cultura se refiere a contenidos de doctrinas comprehensivas y, ante esas, la política no tiene manera de valorarlas. El liberal rawlsiano debería suponer que la oferta cultural debe mantenerse en el ámbito de lo privado y funcionar con una lógica de mercado (oferta y demanda). Contrastemos este tipo de razonamiento con, por ejemplo, la idea de un liberal como Brian Barry sobre la responsabilidad del Estado con la educación de los menores de edad en función de contenidos culturales no políticos: "la comprensión del mundo alrededor de nosotros y ser capaz de apreciar las más altas creaciones de la mente y el espíritu humano son, directamente, beneficios. Y son beneficios que los padres no deben estar facultados para privar a sus hijos." ${ }^{53}$

¿Es responsabilidad de una sociedad bien ordenada, democrática y liberal, garantizar el acceso a elementos culturales no políticos a los ciudadanos (al menos a aquellos individuos que, por su edad o condición no pueden hacer uso pleno de sus derechos)? La respuesta es, sin duda, relevante para el futuro de dicha sociedad. En la medida en que Rawls desvincula la filosofía política de la verdad y la validez, y la separa del resto de la tradición liberal y del conocimiento humano en general, niega que la pregunta anterior sea de naturaleza política $\mathrm{y}$, al mismo tiempo, que la respuesta que podamos obtener implique una responsabilidad moral de dicha sociedad. En este punto no intento afirmar que la sociedad debería garantizar el acceso a la cultura o no, lo relevante es mostrar cómo, desde el liberalismo político, la cuestión no debería ser siquiera discutida. La sociedad bien ordenada de Rawls es una en la que la concepción de la justicia no reconoce la importancia política de la búsqueda de ampliación de las capacidades de los individuos, del progreso y del mejoramiento de los estándares de vida sociales más allá de la mera distribución de los bienes primarios previamente existentes. Si la cultura y el conocimiento no son áreas de debate político, parecería que la sociedad ordenada no estaría justificada para hacer esfuerzos coordinados por el desarrollo de su cultura (pensemos en este ámbito en la pérdida que implicaría que la sociedad dejara de beneficiar la investigación hecha por universidades y centros de investigación en áreas como la medicina y la tecnología y cómo eso afectaría el desarrollo de bienes que han mejorado la calidad de vida de incontables seres

52 Ibid. 90

${ }^{53}$ Barry, Culture and Equality. 221 
humanos gracias a la participación, según el liberalismo político, injustificada de la sociedad). Esto se contrasta de modo importante con Brian Barry, a quien acabo de citar, y por supuesto con John Dewey. ${ }^{54}$ Si alienamos el liberalismo de todo tipo de verdad, nos quedamos con un liberalismo político que difícilmente nos servirá para solucionar algunos de los conflictos dentro de las sociedades liberales reales, de las cuales, irónicamente, se deriva el liberalismo político (de su cultura pública).

Del mismo modo, la comprensión de la verdad limitada con la que trabaja Rawls termina por dañar, a mi parecer, incluso los ámbitos en los que la justicia como imparcialidad debería de operar. En el Liberalismo Político la idea de la posición original, que en Teoría fue utilizada como mecanismo de representación, sufre una adecuación a la nueva función de la filosofía política, que la vuelve normativamente inservible:

Como mecanismo de representación la idea de la posición original sirve como un medio de reflexión pública y auto clarificación. Nos ayuda a comprender mejor lo que ahora pensamos, una vez que somos capaces de tener una idea clara y sin confusiones de la tarea de la justicia cuando una sociedad está concebida como un esquema de cooperación entre ciudadanos libres e iguales de una generación a la siguiente. La posición original sirve como una idea mediadora entre nuestras convicciones consideradas, cualquiera que sea su nivel de generalidad -ya sea que se refieran a condiciones justas para situar a las partes o los límites razonables a la razón, o los primeros principios y preceptos, o los juicios sobre instituciones y acciones particulares- que pude ser traída para sopesar una con otra. Esto nos permite establecer una mayor coherencia entre todos nuestros juicios; y con esta auto comprensión más profunda podemos obtener un acuerdo más amplio entre nosotros. $^{55}$

En la medida en que la filosofía política se convierte en una herramienta cuasi terapéutica, la posición original, que en Teoría de la Justicia generaba una responsabilidad moral aun siendo un mero mecanismo de representación, ya que se aceptaban las condiciones del acuerdo, pierde cualquier utilidad normativa. Supongamos que la sociedad bien ordenada que propone Rawls en el Liberalismo Político existe, esta sociedad tiene un consenso traslapado sobre la concepción de la justicia, la misma que ha sido derivada de la cultura política democrática y liberal. Una vez que reconocemos que nuestra sociedad bien ordenada depende de una concepción política construida, presentada y reconocida del modo que Rawls prefiere, debemos pensar en el hecho que dicha sociedad, por definición, debe de

\footnotetext{
${ }^{54}$ Por nombrar sólo dos pensadores liberales, aunque podríamos incluir más, como Joseph Raz, por ejemplo.

55 Rawls, Political Liberalism. 26
} 
existir de una generación a la siguiente. Aun aceptando que los conceptos constitutivos de la democracia liberal son tan homogéneos como los quiere Rawls (cosa que no se puede hacer), es imposible aceptar que han estado presentes en las sociedades humanas por mucho tiempo (cuatrocientos años, asumiendo que fueran así de antiguos, lo que sería en el mejor de los casos una gran exageración, difícilmente se puede considerar mucho tiempo dentro del contexto de la historia humana). Si a lo anterior sumamos la existencia del pluralismo, aunque sea razonable, podemos considerar la posibilidad de que, dada la libertad de las sociedades democráticas y liberales, las personas tenderán a cambiar sus ideas y concepciones del bien con el paso del tiempo. Si es razonable aceptar que la civilización humana tenderá a cambiar sus ideas del bien en el tiempo, ¿qué impide que cambien su concepción de la justicia? En particular una que está basada, únicamente, en la tradición. Creo que la filosofía política, como la entiende Rawls, poco puede hacer al respecto.

Rawls, con el giro político, se convierte en un conservador que quiere, por un lado, establecer una sociedad liberal (que por su naturaleza se mantiene abierta siempre al cambio) y, por otro, afirmar su existencia fundamentalmente en las tradiciones (como si estas no fueran a cambiar); por tanto, se queda sin las herramientas adecuadas para proteger aquello que quiere conservar. El contraste con algunas de las tradiciones conservadoras por excelencia tiende a ser llamativo en la medida en que las sociedades más conservadoras, que tienden a ser las que asumen algún tipo de teocracia, no dudan de la verdad de sus tradiciones. Por otro lado, si Rawls considerara la opción de la filosofía política como fuente de aseveraciones verdaderas, $\mathrm{o}$ al menos justificables independientemente de que provengan de una doctrina comprehensiva particular (al modo que podría hacer si realmente hubiera realizado un giro pragmático o si al menos mantuviera la validez de su kantismo), podría justificar que la justicia como imparcialidad puede ser defendida ante concepciones de la justicia no liberales siempre que sea la mejor justificada dadas las condiciones, por ejemplo, de la posición original (que buscaba mostrar los hechos moralmente relevantes para una distribución de los bienes justa en Teoría).

En el pensamiento político de Rawls posterior al giro político, conviven tendencias que están en continua y fuerte tensión. A la vez que considera la tradición, la cultura y las instituciones políticas que se derivan de ella la fuente única de la concepción de la justicia que debe gobernar sobre una sociedad bien ordenada, rechaza que dicha concepción tenga una derivación moral o filosófica propia que le permita ser enunciada como verdadera. Dado que es imposible que 
todas las doctrinas comprehensivas sean verdaderas, en especial con el concepto de verdad unívoco que parece encontrarse en el pensamiento de Rawls, es claro que las justificaciones que harán las doctrinas comprehensivas razonables de la concepción de la justicia serán, en algunos casos (y probablemente la mayoría de ellos) falsas. La cuestión es, si en nuestra sociedad no existe la doctrina comprehensiva que desarrolle la justificación verdadera de la concepción de la justicia, ¿cómo podemos saber que es verdaderamente la concepción de la justicia correcta para una sociedad bien ordenada? Una característica relativamente común del pensamiento conservador es que tiende a suponer que las costumbres, tradiciones e instituciones que busca respetar son correctas (lo que implica una aceptación de su adecuación). Rawls se convierte después del giro político en un conservador que, dadas las condiciones que él mismo se impone, no puede afirmar la corrección de su concepción de la justicia política de un modo convincente; sólo puede asegurar que es conveniente. Ya que no hay un plan o proyecto salvífico dentro de la tradición, así como que existe una negativa a ofrecer una justificación filosófica o moral de la corrección de dicha concepción, es complicado entender por qué dicha tradición podría ser objeto de un consenso traslapado con el paso del tiempo. Sin un criterio de corrección independiente, parece que debemos elegir la justicia como imparcialidad como la concepción de la justicia porque "es lo que hay" y, dada la falta de garantías, probablemente existirá hasta que "haya algo más".

Una duda que queda ahora es si Rawls, después de todo, dejaría desaparecer su liberalismo político dada la falta de justificación que puede dar de él una vez que las condiciones del consenso desaparecieran o si, al final, buscaría afirmar que la corrección de su liberalismo está justificada por más que el mero consenso. Chantal Mouffe resume esta cuestión del siguiente modo para la democracia liberal en general:

Lo específico de la democracia plural no se encuentra en la ausencia de dominación o de violencia, sino en el establecimiento de ciertas instituciones a través de las cuales sea posible que se limiten y se resuelvan. Esto requiere renunciar a la idea de que podría existir algo así como un consenso político racional, un consenso que no esté basado en modo alguno de exclusión. ${ }^{56}$

Para poder llevar a cabo esta exclusión, que de otro modo puede implicar una obligación de imponer una concepción liberal a las instituciones, sólo se puede hacer manteniendo un principio de legitimidad si somos capaces de justificar,

\footnotetext{
${ }^{56}$ Mouffe, "The limits of John Rawls' Pluralism". 9
} 
como Rawls hacía en Teoría de la Justicia (cuando reconocía que de la posición original se seguía una cierta obligación argumentando que dadas las condiciones de la posición cualquier persona elegiría la justicia como imparcialidad), que nuestra concepción es correcta en algún sentido.

Aun cuando en el siguiente capítulo seguiré profundizando en algunos de los cambios principales dentro de la presentación de la justicia como imparcialidad, en su exposición posterior a Teoría, así como algunos de los conceptos e ideas adicionales que presenta Rawls a partir de la elaboración del giro político, vale la pena insistir que dicho giro no es necesariamente consistente con el pragmatismo que estaba presente en Teoría y, por el contrario, representa un acercamiento a un modo de conservadurismo muy particular. El conservadurismo tiende a limitar las acciones de los individuos de modo que las instituciones sociales, políticas y económicas no corran el riesgo de ser desplazadas por nuevos modos de actuar. Las razones últimas para limitar dichas libertades pueden ser diversas para cada individuo, aunque, como lo mostré antes retomando el conservadurismo de Russell Kirk, la convención y el compromiso son las piezas fundamentales que sostienen esta comprensión de la política que es, fundamentalmente, antiprogresista. El liberalismo político de Rawls, por su parte, procura, como lo implica el primer principio de la justicia, mantener el esquema de libertades lo más amplio posible. Parecería, por tanto, que el liberalismo político y el conservadurismo son incompatibles.

Creo que esa incompatibilidad es real y está presente en el Liberalismo Político; sostener una sociedad liberal en la convención (pues, como lo cité antes: “Debemos empezar, por tanto, buscando en la cultura política en sí como el fondo de ideas y principios básicos, implícitos y compartidos.." ${ }^{57}$ ) es la causa, en mi lectura, de algunos de los problemas de estabilidad fundamental del liberalismo político. Independientemente de esto, sin embargo, me parece que el distanciamiento que hace Rawls, con el giro político, de las justificaciones neokantianas es correcto en tanto que es una doctrina comprehensiva inútil para formar un consenso traslapado amplio. Ahora bien, mantengo la convicción que un giro pragmático (desarrollando las intuiciones presentes en Teoría) permitiría hacer ese consenso, aunque quizá no tan amplio como el mismo Rawls desearía, de modo que pudiera presentar una concepción estable. Este será un planteamiento que exploraré, al menos de modo inicial, en la última parte de esta investigación.

${ }^{57}$ Rawls, Political liberalism. 8 


\section{Capítulo 6. Liberalismo político y liberalismo moral}

El giro político que hace Rawls en el Liberalismo Político viene acompañado de una reformulación de algunos conceptos. En el capítulo anterior abordé algunos de ellos, como lo es, por ejemplo, el concepto de doctrina comprehensiva. En este capítulo me enfoco, en un primer momento, al concepto de lo razonable. La razonabilidad dentro del liberalismo político de Rawls tiene una importancia fundamental. La característica necesaria que deben cumplir todas las doctrinas comprehensivas que existan en una sociedad bien ordenada, es decir una en donde la cooperación es una de sus características más importantes, es la de ser razonables. Como muestro, la razonabilidad es la condición de posibilidad para que las doctrinas comprehensivas, y por tanto los individuos, sean capaces de reconocer la importancia de vivir en función de una concepción de la justicia compartida y, en especial, de comprometerse a cumplir con ella incluso cuando no fuera conveniente hacerlo por razones de ventaja. El consenso traslapado, como expliqué antes, requiere de individuos que aceptan la concepción de la justicia como parte fundamental de su doctrina comprehensiva, estos individuos sólo serán capaces de hacer esto en la medida en que sean razonables y, por tanto, la razonabilidad es la clave para afirmar el consenso mismo.

Como es de esperar, un concepto así de importante dentro del sistema que es el del liberalismo político no puede estar alejado de controversias y críticas. En este capítulo muestro algunas de las más relevantes para evidenciar cómo el criterio de razonabilidad es mucho más constringente de lo que Rawls hace parecer en un primer momento. Cuando afirma que la razonabilidad es un criterio necesario para poder vivir en una sociedad como un sistema de cooperación, parecería que Rawls dice algo poco complicado; empero, en este capítulo explico como el concepto que tiene de razonabilidad terminaría dejando de lado doctrinas, y por tanto individuos, que podrían ser considerados razonables normalmente. Es

decir, busco mostrar que el concepto de lo razonable en Rawls es mucho más limitante de lo que comúnmente se piensa.

El tema de lo razonable me conduce a, en el segundo apartado del capítulo, analizar los alcances del giro político. Expongo que, una vez que analizamos algunos de los conceptos centrales del liberalismo político, como habré hecho en 
ese punto, el giro político termina fracasando en su intento de diferenciar el liberalismo político del moral. Ese tema da pie a poder analizar, en la cuarta parte de esta investigación, el modo en que podría proponer una lectura de la justicia como imparcialidad desde una visión pragmática al modo de John Dewey.

\section{Lo razonable}

Una distinción que no había sido tratada o especificada en Teoría de la Justicia es la de lo razonable frente a lo meramente racional. Rawls consideraba en Teoría la posesión de una capacidad racional que permitiera a los individuos reconocer la pertinencia de la justicia como imparcialidad como la concepción de la justicia correcta dadas las condiciones de la posición original. En tanto Rawls fuera capaz de aceptar que la afirmación de la justicia como imparcialidad era racionalmente justificada, asumiendo que las personas son razonables, parecía haber generado las condiciones de obligatoriedad suficientes. Con el giro político y el abandono de la filosofía política como herramienta constructiva de una justificación racional y correcta, la racionalidad termina perdiendo su papel regulador y, por lo mismo, su obligatoriedad. Una vez que Rawls renuncia a la filosofía como mecanismo para justificar su concepción de la justicia, dependiendo entonces del consenso, es necesario establecer condiciones para que este se pueda dar; hasta este punto ya hemos tratado algunas de las que propone Rawls, entre ellas el que la concepción sea de un tipo político, es decir que no se argumente desde una doctrina comprehensiva particular. La razonabilidad, en cualquier caso, es la condición fundamental.

Cuando Rawls se plantea la existencia del pluralismo dentro de una sociedad democrática y liberal no está pensando en un pluralismo cualquiera, sino en uno de carácter razonable. Rawls, que abandona la categoría de verdad como una herramienta para identificar las doctrinas comprehensivas que pueden formar parte de una sociedad liberal, asume que existen comprensiones del mundo, doctrinas comprehensivas, que no pueden coexistir. Actualmente uno de los ejemplos más evidentes sería el grupo terrorista Estado Islámico, que busca la imposición de un califato en medio oriente por medio del uso de la fuerza y la violencia irracional y desmedida. ¿Cómo podríamos esperar que un miembro de dicha organización acepte vivir en una sociedad bien ordenada basada en el consenso si mantiene su doctrina comprehensiva? La respuesta es que, 
simplemente, no podemos. Es dada esta imposibilidad de incluir a todos los individuos, sin importar cuál sea su doctrina comprehensiva, que Rawls propone la razonabilidad como criterio de identificación de las doctrinas apropiadas.

Es interesante cómo este criterio parece darle la oportunidad a Rawls, aunque considero por razones que explico después que es un intento más bien fallido, de incluir dentro de una sociedad liberal a doctrinas comprehensivas (y a las organizaciones e individuos que viven de acuerdo a sus preceptos) no necesariamente liberales. La manera en la que Rawls podría asumir que esto es posible es que una doctrina comprehensiva no liberal, como puede suceder con algunos modos de cristianismo, pueda reconocer la concepción de la justicia como adecuada para la realidad política, aunque inadecuada para el ámbito privado. Podría aceptar, por ejemplo, que las mujeres que pertenezcan a su fe tienen la obligación natural y exclusiva de atender las labores domésticas y, al mismo tiempo, reconocer sus derechos políticos en tanto ciudadanos cooperadores. Lo razonable, dentro de este contexto, se refiere más bien a la capacidad de las doctrinas comprehensivas (y de las personas que las aceptan por supuesto) de encontrar mecanismos de cooperación adecuados para el ámbito político en lugar de que posean ciertos contenidos determinados:

Las personas son razonables en un aspecto básico cuando, entre iguales, están listas para proponer principios y estándares como términos justos de cooperación y a actuar conforme a ellos voluntariamente, dada la seguridad de que otros lo harán igual. Esas normas las identifican como razonables para todos de aceptar y por tanto como justificables para ellos; y están listos a discutir los términos justos de cooperación que otros propongan. ${ }^{1}$

Una doctrina comprehensiva razonable, aparentemente, sería aquella que dentro de su contenido doctrinal está abierta al diálogo para establecer mecanismos justos de cooperación para todos. Por su parte, cuando decimos que una persona es poco razonable decimos que es así cuando "planean entrar en un esquema de cooperación pero carecen de la voluntad de cumplir, o siquiera proponer, excepto como una falsificación pública, cualquier principio o estándar general para especificar los términos de cooperación. Están listos para violar cualquiera de dichos términos en tanto se ajuste a sus intereses cuando las circunstancias lo permiten." ${ }^{2}$

Una doctrina comprehensiva no razonable, diríamos, es aquella que no está en disposición honesta de encontrar los términos, principios o estándares generales

\footnotetext{
${ }^{1}$ Rawls, Political Liberalism. 49

${ }^{2}$ Ibid. 50
} 
de cooperación y, al mismo tiempo, dentro de su contenido doctrinal supone que puede aprovechar cualquier ocasión para intentar avanzar sus objetivos violentando los términos de cooperación.

Esta categoría de lo razonable parece que dejaría campo abierto para un número amplio de individuos con doctrinas comprehensivas que normalmente no pensaríamos en términos de razonables. Por ejemplo, cuando Vito Corleone, en la primera película de El Padrino, se consideraba una persona razonable, parecía hacer referencia a una capacidad de entender los intercambios y la interacción humana, un hombre que entiende que las personas pueden llegar a acuerdos que los beneficien pero que deben de ser justos y deben de ser cumplidos. Cuando el mafioso Tattaglia, que había organizado el asesinato de uno de los hijos de Vito, pide garantías de que Corleone no lo atacará después, durante un consejo con los jefes de las distintas mafias de Nueva York, don Barzini, jefe de la familia Barzini, le responde: "Mira, todos somos hombres razonables aquí. No tenemos que darnos garantías como si fuéramos abogados." Parece ser que, incluso para los jefes de la mafia, ser razonable implica ser de algún modo honorable respetando los términos de cooperación. ${ }^{3}$

Una vez que reconocemos el pluralismo como un hecho, y suponemos que el tipo de pluralismo que puede existir en una sociedad liberal y democrática es de carácter razonable, nos enfrentamos al problema de cómo justificar una concepción de la justicia. En Teoría de la Justicia Rawls intentaba construir un argumento, desde líneas kantianas pero también algunas pragmáticas, que mostraba la justificación de la justicia como imparcialidad de modo que se convirtiera en la mejor opción y, siendo así, en la más razonable (la mejor manera de cooperar). Si la filosofía está incapacitada a ofrecer una justificación de la concepción de la justicia que pueda ser considerada verdadera (incluso en el sentido de verdad como aseveración justificada), sostener la opción que nos quede, de modo estable, parece ser imposible a no ser que pueda ser sostenida, simplemente, en función de un criterio de beneficio propio en el momento en que nos encontremos. Usemos el ejemplo del derecho al aborto: supongamos que en nuestra sociedad un católico razonable está dispuesto, dadas sus circunstancias (entiéndase que no tiene la capacidad de imponer su voluntad de forma estable en el tiempo y sin un muy alto costo), a considerar que debe buscar principios de cooperación con personas que no están

\footnotetext{
${ }^{3}$ Me parece que Rawls no les concedería el título de razonables a estos mafiosos en la medida en que no tienen dicha capacidad respecto a las reglas de la sociedad en general; no se consideran parte de la sociedad en la medida en que buscan beneficiarse de sus bienes a la vez que no intentan cumplir con las normas básicas de respeto a la ley.
} 
de acuerdo con su postura respecto del aborto. Así, este individuo termina aceptando un orden social en el que, posteriormente, se acepta que sea legal la interrupción del embarazo dadas ciertas circunstancias (por razones de conservar la salud de la madre, en caso de que sea producto de una violación o simplemente en función de un criterio de tiempo, por ejemplo durante el primer trimestre). Supongamos que, por efectos de la migración, la tasa de natalidad, el cambio climático o su tarea evangélica, lo que sea, este mismo católico se encuentra con que las condiciones sociales le permiten cambiar la legislación de modo que el aborto quede prohibido sin importar las circunstancias, aunque implica faltar a su compromiso con los principios reconocidos inicialmente. Alguien podría pensar que una persona razonable, como aparentemente Rawls cree, debería de abstenerse de cambiar la legislación en la medida en que eso demuestra que no cumple sus acuerdos independientemente de las circunstancias. Sin embargo, si aceptamos que para este católico el aborto representa un homicidio, al menos desde su doctrina comprehensiva, aunque no pueda demostrarlo a otras que, cabe pensar, no aceptan esa idea, ¿no es predecible que buscará cambiar las condiciones del acuerdo?, ¿no es racional que lo haga?

Si alguien supusiera que, de hecho, es correcto cambiar el acuerdo en el caso del aborto, la pregunta para él sería si no sería igualmente válido cambiar el acuerdo para, por ejemplo, restituir leyes discriminatorias en el caso de que su doctrina comprehensiva sostuviera que dicha discriminación es necesaria, buena y obligatoria. ${ }^{4}$ Parecería ser que Rawls considera razonable aceptar una circunstancia política indeseable (que podría mejorar) pues es necesario honrar los acuerdos aunque fuera factible alcanzar un estado mejor según el contenido de una doctrina comprehensiva.

La idea del consenso traslapado implica algo distinto a la simple razonabilidad. Una persona razonable es aquella que está dispuesta a construir un acuerdo para organizar las diferencias; por su parte, una sociedad que funciona bajo el consenso no parecería que lo alcanzó en función de su razonabilidad sino que, como ha mantenido Rawls con la idea de la cultura de fondo aceptada por todos, el consenso es el producto de la tradición y la costumbre. La diferencia se encuentra en que nada negaría la posibilidad de que una persona razonable

\footnotetext{
${ }^{4}$ No hay que olvidar que, por ejemplo, la Iglesia de Jesucristo de los Santos de los Últimos Días (mormones) mantuvo, abiertamente, políticas discriminatorias contra personas de color hasta 1978. Con estas les impidieron ocupar posiciones de prestigio dentro de su comunidad cerrándoles la posibilidad de participar en el sacerdocio (asumiendo que buena parte de los miembros de la iglesia pueden buscar el sacerdocio y la edad más joven para ordenarse es de 12 años, sin duda es una medida restrictiva).
} 
cambiara las reglas cuando las circunstancias cambiaran de modo significativo. Rawls propone, con la idea del consenso traslapado, que las personas mantendrán el acuerdo porque consideran que es justo (independientemente de cómo lo justifiquen desde su doctrina comprehensiva). En otras palabras, no es tanto que sea necesaria la razonabilidad como condición para el consenso traslapado (ya que dicho consenso supera las posibilidades mismas de la razonabilidad), sino que exista una cierta homogeneidad cultural (lo que nos obligaría a repensar el papel del pluralismo del que habla Rawls como un hecho en la sociedad).

La posibilidad de que personas razonables puedan, con el paso del tiempo y el cambio de circunstancias, realizar cambios a los acuerdos sociales que ordenan la estructura básica, pone sobre la mesa un problema distinto para la estabilidad de la justicia como imparcialidad que Rawls no aborda con suficiente claridad: ¿sólo se puede ser razonable y ser parte del consenso si se es liberal? Recordemos que para Rawls no es suficiente con que la concepción de la justicia se mantenga por un mero modus vivendi; la justicia como imparcialidad debe, en última instancia, ser aceptada en un consenso traslapado. El consenso traslapado supone que cada ciudadano razonable, y por tanto cada doctrina comprehensiva razonable, debe de ser capaz de justificar la justicia como imparcialidad desde su propia doctrina y, en esa medida, buscar su mantenimiento si desea que sea la concepción de la justicia. Si los casos del aborto o de la discriminación pueden ser considerados plausibles en las sociedades democráticas y liberales contemporáneas, nos queda la pregunta de si un católico, que cree en su misión evangelizadora y en la posibilidad de construir una "ciudad de Dios", puede alcanzar un consenso traslapado respecto a una concepción política de la justicia liberal que pudiera garantizar el derecho a interrumpir el embarazo. Si no es capaz de hacerlo, y Rawls asume que la razonabilidad es una característica necesaria para alcanzar dicho consenso, ¿tendríamos que decir que el católico no es razonable? En la nota 29 del capítulo anterior cité a Robert P. George que enuncia que el consenso sobre los principios fundamentales es inexistente en temas como el del aborto, entre las posiciones pro vida y por la libertad de elegir; eso significaría, desde las premisas de Rawls, que George es poco razonable. Aunque no tengo ningún problema en considerar que el conservadurismo de George cae en esa categoría, el problema es que si él lo es, también lo son millones de fieles de muy diversas doctrinas comprehensivas que, de hecho, son ciudadanos en sociedades liberales y democráticas. Eso, sin duda, es un problema para la estabilidad de la concepción de la justicia.

Supongamos por un momento que estamos en una sociedad en donde sólo hubiera una doctrina comprehensiva, compartida por todos los ciudadanos. En 
una sociedad de este tipo, la razonabilidad sería una virtud muy poco necesaria puesto que todos sabrían, en función de los dictámenes de su doctrina, cuáles son las reglas de convivencia (aunque no sean necesariamente cooperativas). En la sociedad feudal medieval era mucho más valorada la templanza, por ejemplo, que la razonabilidad; más que pedir a las partes que aceptaran el acuerdo, se les exigía esa otra virtud moral para soportar aquello que, en cualquier caso, no estaban en condiciones de rechazar. Así, la existencia del pluralismo, tanto como la búsqueda de una concepción de la justicia que permita alcanzar aquello que Rawls denomina una sociedad bien ordenada, conducen a que la razonabilidad juegue un papel fundamental.

En el inicio de este apartado afirmé que Rawls introduce la noción como un mecanismo para incluir a grupos con doctrinas comprehensivas no necesariamente liberales. Afirmé esta idea basándome en que, hipotéticamente, un individuo podría aceptar dentro de su comunidad (no política) prácticas no liberales (como la desigualdad entre hombre y mujer) y, al mismo tiempo, alcanzar un consenso sobre la concepción de la justicia, lo que implicaría que es razonable según Rawls. El resultado concreto del planteamiento de Rawls conduce a un resultado distinto, pues termina haciendo una cierta equivalencia entre razonable y liberal.

¿Cómo es posible, se podría preguntar, que la intención y el resultado sean tan distintos? Considero que la respuesta a esto se da en la idea rawlsiana de que la importancia de la razonabilidad para la justicia como imparcialidad proviene de una especie de falsacionismo cognitivo. El liberalismo político asume que todos los individuos reconocerán las cargas del juicio, que explico a continuación, y, por tanto, reconocen un cierto nivel de falsacionismo. Sin embargo, al mismo tiempo que los ciudadanos hacen esta concesión en el campo político, Rawls asume que podrían, simultáneamente, reconocer un estándar de verdad distinto $\mathrm{y}$, en cierto sentido, irreconciliable (como podría ser un realismo metafísico-teológico). Para entender por qué Rawls sostiene esto, y sobre todo por qué es un error, es necesario comprender el concepto de las cargas del juicio y el papel que juegan en el pensamiento de Rawls posterior al giro político.

Las cargas del juicio son, según Rawls, las causantes de los desacuerdos entre personas razonables. ${ }^{5}$ Es claro que entre personas razonables existen desacuerdos, algunos más fácilmente conciliables que otros, pero, en cualquier caso, si son razonables pueden ser mediados mediante reglas y principios de argumentación. Las diferencias entre estas personas provienen, según Rawls, de la

${ }^{5}$ Cfr. Ibid. 55 
naturaleza humana que está condicionada a un cierto tipo de perspectivismo. Para entender a lo que me refiero será útil enunciar las cargas del juicio que enumera Rawls, dejando en claro que no pretende ser una lista exhaustiva: ${ }^{6}$

- La evidencia que se utiliza para hacer un juicio sobre una situación tiende a ser conflictiva y compleja: es difícil evaluarla adecuadamente.

- Aun cuando al revisar una circunstancia nos ponemos de acuerdo en cuáles son los factores relevantes a evaluar, podríamos no estar de acuerdo en el peso que deberíamos darle a cada uno.

- En cierto sentido todos nuestros conceptos son vagos y pueden ser puestos a prueba por casos concretos. Este hecho nos hace dependientes en la interpretación de nuestros conceptos.

- Hasta cierto punto, la manera en que consideramos la evidencia y le damos consideración moral y política a los valores está informada por la totalidad de nuestra experiencia.

- Normalmente cuando estamos discutiendo un hecho, hay consideraciones de peso en las diversas perspectivas de la cuestión; esto dificulta hacer una evaluación general.

- Por último, todo sistema social está limitado en la cantidad de valores que puede admitir, lo que implica que valores que pueden ser relevantes para alguien queden excluidos dentro de una concepción de la justicia.

Lo que Rawls muestra con el concepto de las cargas del juicio es cómo dos o más individuos, teniendo la misma información, aplicando el principio de caridad y actuando con completa honestidad y razonabilidad, pueden llegar a concepciones distintas de la justicia y del bien. De ese modo, la justicia como imparcialidad permitiría un cierto rango de interpretaciones razonables una vez que fuera elegida por individuos que cumplan la condición de ciudadanos razonables. Esta situación conduce a la garantía, piensa Rawls, de derechos de libertad de expresión y de conciencia si reconoce la imposibilidad de desaparecer el pluralismo razonable:

Para concluir: personas razonables ven que las cargas del juicio imponen límites a lo que puede ser razonablemente justificado a los demás y así prefieren apoyar algún tipo de libertad de conciencia y libertad de pensamiento. Es no razonable para nosotros usar el poder político, si fuera nuestro para eso, o compartirlo con otros, para reprimir visiones comprehensivas que son razonables. ${ }^{7}$

\footnotetext{
${ }^{6}$ Cfr. Ibid. 56-57
}

${ }^{7}$ Ibid. 61 
El tema de las cargas del juicio permite tender un lazo con el pensamiento pragmatista de Dewey. Para John Dewey el conocimiento humano está profundamente condicionado por nuestras circunstancias y por nuestras experiencias y las de los demás (a través de la cultura). La manera en que nos enfrentamos y comprendemos la evidencia, por ejemplo, está filtrada por nuestras intenciones de acción y, al mismo tiempo, por experiencias anteriores, tanto de la misma persona evaluando como de otras personas, que los transmiten a través de la cultura. Aceptar las cargas del juicio para un pragmatista es simple; lo inaceptable sería pensar que no existen y que tenemos algún tipo de acceso privilegiado a las circunstancias y a los eventos que nos permiten llegar a respuestas perfectas.

Rawls reconoce la imposibilidad de desarrollar un punto de vista arquimédico como había intentado en Teoría de la Justicia, que en ese caso estaba constituido por la posición original y que le permitiría desarrollar una concepción que cumpliera con los límites de la justicia y sus expectativas neokantianas. Las cargas del juicio incorporan una refutación misma a la posibilidad de dicho punto arquimédico. Si el liberalismo cumple con la característica de ser razonable, entonces es un ejemplo de cierto escepticismo; esto debería de ocurrir con todas las doctrinas comprehensivas razonables en último término:

En este sentido, más allá de los requisitos de razonabilidad para las doctrinas comprehensivas que he revisado arriba, parecería necesario incluir un requisito explícito de "escepticismo" que precisara la disposición del orden discursivo de cada doctrina razonable (que, por supuesto, orienta la conducta de las personas) a aceptar la existencia de las demás. ${ }^{8}$

El fragmento anterior de Rodríguez Zepeda captura la nueva perspectiva escéptica de Rawls. En efecto, descansa en la opción escéptica y perspectivista para sostener la posibilidad de la tolerancia: tolero la diferencia razonable (que no la no razonable, por supuesto) ya que reconozco que no estoy en condiciones de probar la verdad de mi propia doctrina a los demás. Dado que el giro político conduce a un cierto escepticismo, Rawls tiene que abandonar cualquier resabio de neokantismo para afirmar qué es aquello que es razonable. Esto lo obliga a refinar nociones tan fundamentales como la de objetividad del siguiente modo:

Las convicciones políticas (que son también, por supuesto, convicciones morales) son objetivas -realmente fundadas en un orden de razones- si personas razonables racionales, quienes son suficientemente inteligentes y diligentes en el ejercicio de su razón práctica, y cuyos razonamientos no exhiben ninguno de los defectos

${ }^{8}$ Rodríguez, La política del consenso. 119 
familiares del razonamiento, pudieran aceptar eventualmente esas convicciones, o significativamente limitar su desacuerdo sobre ellas, suponiendo que esa personas conozcan los hechos relevantes y hayan investigado lo suficiente el terreno sobre el que tratan bajo condiciones favorables para la correcta reflexión. (...) Decir que una convicción política es objetiva es decir que hay razones, especificadas por una concepción política razonable y reconocida mutuamente, suficientes para convencer a todas las personas razonables de que es razonable. ${ }^{9}$

Podría conjeturarse que cuando Richard Rorty leyó Liberalismo Político y se topó con el fragmento quedó contento. Rawls, quien en Teoría parecía sostener el hecho que el liberalismo implicaba una concepción de la justicia perfectamente defendible, incluso ante aquellos que fueran poco razonables pero que, al menos, aceptaran la igualdad moral de las personas como lo postuló en la posición original, terminó renunciando a esta posibilidad sometiéndose al criterio del consenso, no sólo como un mecanismo para garantizar la estabilidad, sino como método para justificar la objetividad y validez misma del liberalismo. Es cierto que Rawls hace mención a los hechos relevantes como parte importante de la información necesaria para la correcta reflexión, sin embargo, mientras no profundice en cómo es que se define qué es un hecho relevante y cuál es la manera adecuada de analizarlos, no queda claro hasta qué punto ese análisis no termina remitiéndonos a un nuevo consenso, muy al modo que Rorty hubiera deseado. La cuestión, que Rawls no desarrolla en Liberalismo Político, y que hubiera dado especial satisfacción a un pensador como Rorty es la siguiente: ¿es posible afirmar un escepticismo en el espacio político como condición de ser razonable (aceptándolo como una condición real del conocimiento humano) y que dicho escepticismo no se transfiera a otros ámbitos de la vida?

Me parece que no. Cuando Rawls supone que una condición de ser razonable, que aparentemente sería una virtud, es ser escéptico, no tiene las herramientas suficientes para considerar que ser un escéptico en lo político no implica serlo en lo privado. Sobre esto Eamonn Callan menciona:

El hecho de que debamos interpretar nuestras doctrinas comprehensivas, o parcialmente comprehensivas, de un modo que nos permita reconocer las cargas del juicio revela una seria erosión en la distinción de Rawls ente las esferas públicas y no públicas porque como interpretamos estas doctrinas es central a las vidas que llevamos fuera de lo político. Después de todo, sería absurdo enseñar a los ciudadanos a adoptar esta interpretación de sus doctrinas éticas cuando ellos piensan sobre las preguntas políticas fundamentales mientras insistimos que están en posición de rechazarlas una vez que su atención se centra en otro lugar. Eso sería

\footnotetext{
${ }^{9}$ Rawls, Political Liberalism. 119
} 
una invitación para que oscilen entre creencias contradictorias sobre el estatus racional de sus creencias éticas, y eso es difícilmente un destino atractivo para quien sea. ${ }^{10}$

Estoy en este punto plenamente de acuerdo con Callan. Si Rawls asume que las personas reconocerán la verdad de sus creencias (la verdad entendida como una especie de correspondencia, que es la que parece encontrarse en el pensamiento rawlsianoo continuamente) en parte de sus doctrinas comprehensivas en lo privado pero no en lo público, está pensando en un ciudadano esquizofrénico. Por supuesto que habrán quienes piensen en sus creencias en términos de razonables independientemente del ámbito en el que estén (Dewey sería un caso de estos), pero, ¿podemos esperar que haya quienes hagan la distinción que Rawls parece suponer? Imaginemos a un católico razonable. ¿Rawls supone que ese católico cree que la vida humana comienza desde la concepción como una verdad en lo privado pero que es razonable permitir el aborto en lo público? ¿Un católico que está de acuerdo y encuentra razonable hacer leyes que, supongamos, permitan el aborto en ciertas circunstancias, tendrá que sostener que el "producto" es un ser humano dependiendo de dónde discuta el tema? No dudo que haya personas que puedan aceptar esta inconsistencia sin mayores problemas, como afirma Raymond Geuss:

Cualquier intento de pensar seriamente sobre la relación entre política y ética debe permanecer cognitivamente sensible al hecho que las creencias, valores, deseos, concepciones morales, etc. de las personas están usualmente a medio cocer (en todos sentidos) y son casi siempre tanto indeterminadas como, en la medida en que estén determinadas, ampliamente inconsistentes en todos menos los contextos más locales y altamente formalizados y están constantemente cambiando. ${ }^{11}$

Aun cuando podamos aceptar que los individuos pueden, y de hecho viven con dichas inconsistencias, es menester recordar que Rawls está pensando en términos de doctrinas comprehensivas y, por lo mismo, parece suponer que dichas inconsistencias son propias de las doctrinas comprehensivas mismas. Por tanto Rawls, siempre que asuma su escepticismo en lo público, termina exigiendo que algunas de las doctrinas comprehensivas más difundidas (buena parte de las religiosas que pretenden una posesión de la verdad, así como muchas otras filosóficas) sean intrínsecamente inconsistentes para poder considerarlas razonables: ¡una exigencia bastante grande!

\footnotetext{
${ }^{10}$ Eamonn Callan: "Political Liberalism and Political Education"; The Review of Politics, vol. 58 no. 1 (1996). 12

${ }^{11}$ Geuss, Philosophy and Real Politics. 3-4
} 
Dado que Rawls piensa que todas las doctrinas comprehensivas razonables deben de ser escépticas al respecto de su posibilidad de enunciar la verdad, al menos en el ámbito de lo público y en lo que a la concepción de la justicia se refiere, debería afirmar el escepticismo. Si aceptamos la existencia de las cargas del juicio como un hecho que condiciona la experiencia humana del conocimiento como tal, terminaría reconociendo que no es razonable ser dogmático, lo que implicaría que doctrinas comprehensivas dogmáticas son incapaces de alcanzar un consenso traslapado.

Al final Rawls termina relacionando tres conceptos de modo inadvertido: razonable-escéptico-liberal. Con lo dicho hasta ahora parecería acertado afirmar que sólo las doctrinas comprehensivas razonables están es condición de alcanzar un consenso traslapado; el consenso traslapado de la justicia como imparcialidad es uno liberal y su necesidad se encuentra en que, dada la inoperancia de la verdad en el ámbito político, es necesario establecer reglas liberales que sean razonables. Dado que los ciudadanos son escépticos, son razonables (pues parecería ser el criterio restante para afirmar algún tipo de concepción de la justicia una vez que desapareció la verdad), dado que son razonables terminarán eligiendo una concepción liberal.

Un matiz me parece importante: es que no intento afirmar que se siga del pensamiento de Rawls que todos los liberales son escépticos o, incluso, razonables; tampoco que todos los escépticos son liberales ni razonables. Lo que parece seguirse, es que todos los razonables son escépticos y todos los razonables (según lo que Rawls entiende por razonables) son, de igual modo, liberales. Si mi comprensión del giro político es correcta hasta este punto, podríamos decir que no hay ciudadanos razonables que no sean liberales y escépticos, aunque haya escépticos y liberales que no sean razonables. Esta afirmación no sería aceptable para Rawls, como se puede ver en la introducción a la edición paperback de Liberalismo:

El punto es que no todas las doctrinas comprehensivas razonables son doctrinas comprehensivas liberales; así la cuestión, es si pueden ser compatibles por las razones correctas con una concepción política liberal. Para hacer esto, sostengo, no es suficiente que estas doctrinas acepten el régimen democrático como un simple modus vivendi. Más bien, deben aceptarlo como miembros de un consenso traslapado razonable. El referirse a los ciudadanos que mantienen una doctrina religiosa como ciudadanos de fe, preguntamos: ¿Cómo es posible que los ciudadanos de fe puedan ser miembros de una sociedad democrática convencidos cuando ellos apoyen una estructura institucional que satisfaga una concepción política liberal de la justicia con sus ideales y valores políticos propios, y cuando 
ellos no están simplemente conviviendo con ella dado el balance de las fuerzas sociales y políticas? ${ }^{12}$

La respuesta que podríamos darle a Rawls es que, si la fe de aquellos ciudadanos no tiene en sí un talante liberal y razonable, no parece ser posible. Analicemos el ejemplo, más o menos a modo, que escribe Rawls de un consenso traslapado en donde participa un ciudadano de fe en Liberalismo Político: supongamos un caso modelo entre tres individuos, un liberal moral que defienda un liberalismo como el de Kant o Mill, una persona que no tenga creencias bien sistematizadas, es decir que no suscriba una doctrina comprehensiva pero que, podemos suponer, es una persona razonable y, por último, una que "afirma la concepción política porque su doctrina religiosa y comprensión de la fe libre lo conducen a un principio de la tolerancia y a sostener libertades fundamentales de un régimen constitucional." ${ }^{13}$

Creo que si alguna vez Rawls debería ser critivado por "cargar los dados" esta debería de ser esa ocasión. En una nota Rawls nos explica algunas de las características de la fe libre (que obtiene de algunas ideas provenientes, ni más ni menos, del padre del liberalismo John Locke): ${ }^{14}$

- Debe reconocer que Dios no ha dado autoridad a ningún hombre sobre otro hombre.

- Nadie puede confiar la salvación de sí a otro hombre.

- La comprensión no puede ser obligada por fuerza.

- La salvación del alma de un hombre no está dada a un magistrado, pues eso haría que la de se determine en función de un lugar de nacimiento.

- La iglesia es una unión voluntaria que no puede ser impuesta a nadie.

- La excomunión no afecta la relación civil.

- Sólo la fe y la sinceridad personal pueden ganar la salvación de las personas.

Parece que Rawls supone, en un caso modelo, que la posibilidad de un consenso traslapado con un ciudadano de fe depende de la posibilidad de encontrar uno que entienda la salvación como un acto completamente individual, que no tiene una responsabilidad evangelizadora, que no crea que existan individuos con la misión de imponer un orden divino (algunos dirían natural) ya que la salvación es un acto completamente voluntario y que sólo es necesaria la fe y la honestidad en su creencia para la salvación, lo que en modo alguno implica una imposibilidad de

\footnotetext{
12 Ibid. xxxvii-xxxviii

${ }^{13}$ Ibid. 145

${ }^{14}$ Cfr. Ibid. 145 n.12
} 
cambiar el contenido de las creencias siempre y cuando se haga con fe y honestidad. Si esta evaluación es correcta, Rawls deja de lado a buena parte del mundo religioso y se queda con algunas iglesias protestantes y quizá alguna manifestación religiosa oriental que no responda a una organización vertical.

Cuando Rawls plantea el hombre religioso capaz de llevar a cabo un consenso traslapado está pensando en personas como Roger Williams, pastor protestante que fundó la colonia de Rhode Island en el siglo XVII. Un modelo de tolerancia religiosa y respeto a la ley quien, como resume Martha Nussbaum en Libertad de Conciencia, pensaba respecto a la relación entre religión y gobierno que "la paz sólo se pone en peligro en la medida en que las iglesias sobrepasan sus límites y empiecen a dictar la ley civil, o a interferir en la propiedad, los medios de vida y la libertad de las personas." 15

Alguien podría afirmar que el caso del ciudadano que acepta la fe libre claramente no es el de un escéptico y, en esa medida, asumir que todas las doctrinas comprehensivas razonables son escépticas es, por demás, falso. Esto querría decir, además, que es posible tener un consenso traslapado del tipo que Rawls asume sin tener que ser escéptico. Afirmar algo así sería adelantarnos a las conclusiones que he intentado mostrar hasta ahora.

Como mencioné anteriormente no todos los liberales son escépticos y no todo los liberales serían razonables como entiende la razonabilidad Rawls. Creo que es posible considerar individuos liberales que no estén dispuestos a cumplir con las características de lo razonable que propone Rawls, como podría ser algún liberal de corte kantiano que no reconociera las cargas del juicio y que tuviera la convicción de la imposición de un régimen liberal aunque no estuviera fundamentado en el consenso (bajo el supuesto de que pudiera considerar que si una persona está en contra del liberalismo está atentando contra su propia humanidad). El caso de Roger Williams, sostengo, correspondería a esta categoría de un liberal no razonable; es importante tener en mente que lo razonable, en este punto, es un concepto con un contenido muy preciso dentro de la filosofía de Rawls. Como sucede continuamente dentro del pensamiento de Rawls los conceptos no nos dan demasiada libertad de movimiento. La defensa de Williams por la fe libre corresponde a una comprensión antropológica y metafísica que es contraria al espíritu de lo razonable en Rawls:

\footnotetext{
${ }_{15}$ Martha C. Nussbaum, Libertad de conciencia, trad. Alberto Álvarez y Araceli Benítez (México: Tusquetes Editores, 2009), 69.
} 
A fin de ser más precisos, Williams tiene dos imágenes diferenciadas para la persecución, la violación y el encarcelamiento, que corresponden a géneros distintos de menoscabo de la conciencia. La persecución es como el encarcelamiento en el sentido de que la persona cuya conciencia no ha sufrido un daño interior necesita, no obstante, espacio para respirar a fin de actuar según el dictado de su conciencia, para buscar significado a las cosas a través de la forma de oración, culto, o expresión escrita o verbal que elija. Pero la persecución también es como la violación, porque penetra en el interior de la persona e inflige un daño terrible. ${ }^{16}$

Es claro que Williams, de acuerdo a la lectura que de él hace Nussbaum, es un liberal que sostiene los derechos de libertad de conciencia, de expresión y de reunión no en función del escepticismo propio de lo razonable, que está implícito en las cargas del juicio, sino, más bien, en función de la creencia, empíricamente indemostrable y políticamente injustificable, de que en cada persona existe un alma que no debe de ser sujeto de persecución pues eso equivale a una violación y un encarcelamiento. Dado que es esa la razón, es claro que no es un liberalismo político y, mucho menos, razonable. Asumiendo el contenido de la idea de lo razonable para Rawls, no veo como Williams podría legítimamente ser considerado así. En el momento en que Rawls introduce las cargas del juicio y el escepticismo para lo razonable, y hace de lo razonable una de las características de las doctrinas comprehensivas que pueden existir bajo la justicia como imparcialidad, termina imponiendo serios límites a las justificaciones mismas que las doctrinas comprehensivas harían de la justicia como imparcialidad. Recordemos que para Rawls cada doctrina debe de ser capaz de justificar la justicia como imparcialidad desde sus propios contenidos; el problema es que, si son verdaderamente razonables saben que es imposible de demostrar la verdad de su justificación a aquellos que no comparten su doctrina comprehensiva (sin importar el modo en que justifiquen la concepción). Este hecho condice a pensar que las diversas doctrinas comprehensivas, una vez que renuncian a cualquier aspiración de verdad (incluso una pragmática), tendrían que conformarse por apelar a la mera tradición (al conservadursimo, vacío de contenido, al que aludí en el capítulo anterior). Al reconocer el escepticismo de todas las doctrinas comprehensivas razonables (y en todos los individuos razonables), parece que Rawls desaparece la posibilidad de justificar la concepción de la justicia en función de la verdad pues, si los ciudadanos piensan que tienen los argumentos suficientes, eso implicaría que ignoran las cargas del juicio y por eso mismo dejarían de ser razonables. El contenido del concepto de lo razonable termina jugando en contra, al menos en casos como este, de la posibilidad de las doctrinas comprehensivas justifiquen la

16 Ibid. 64 
justicia como imparcialidad de un modo adecuado según los requisitos del mismo Rawls entre ellas.

Al punto anterior, viendo el problema en el que nos encontramos, alguien podría responder: “¿qué más da si el liberal no es uno razonable mientras sea liberal?" En el liberalismo político que Rawls quiere sostener es muy importante. Siempre que un individuo sea un liberal no razonable, podría no estar en la disposición de reconocer que la concepción de la justicia es algo que se construye en función de un esquema de cooperación y que la justicia como imparcialidad es su mejor presentación disponible. Un liberal no razonable podría suponer, en última instancia, que la concepción responde a un derecho divino-natural que sólo se refiera a algún derecho, no todos, de los incluidos en la justicia como imparcialidad o podría suponer que el liberalismo no debe ser de carácter igualitarista (el cual es el talante de la justicia como imparcialidad desde Teoría de la Justicia). De ser eso así hay un posible problema, serio además, si consideramos que la estabilidad es, como Rawls lo piensa, uno de los temas centrales para el liberalismo político y sólo puede estar garantizada por el consenso traslapado. Para explicar el posible problema, o riesgo, cito con cierta extensión a Brian Barry:

Asumamos, en cualquier caso, que Rawls está preparado para aceptar la participación en el "consenso traslapado" sólo para aquellas posiciones religiosas que incorporan la "fe libre". El caso por la compatibilidad con los principios de la justicia me parece bastante débil. Sin duda "una propuesta de la fe libre" puede ser mostrada hasta que sostenga el primer principio de la justicia de Rawls, y este proceso ha sido desarrollado significativamente con las libertades civiles. Pero no hay nada que garantice esto. La "fe libre" asume que Dios es un liberal sólo hasta este punto: en que no valora la profesión de la creencia religiosa que sea coaccionada. Pero no elimina la supresión de los credos heterodoxos debido a que pueden tentar a los fieles del verdadero camino. Tampoco elimina la conversión forzada de una generación con la esperanza (que la historia justificaría enormemente) de que las siguientes generaciones aceptaran voluntariamente la religión dominante. Aun peor, la "fe libre" no hace nada para defender la acción libre: Dios podría en cualquier caso valorar la prohibición de lo que la religión dominante define como actos pecaminosos. Además, las religiones naturalmente tienden a apoyar la teocracia más que la democracia, dado que la implementación de las demandas religiosas serían llevadas a término con mayor cuidado por la jerarquía religiosa. Por tanto, no hay razón en general para esperar que las religiones, aun si aceptaran la doctrina de la "fe libre", apoyarían las igualdades civiles y los derechos políticos que constituyen el primer principio de la justicia de Rawls. En lo que se refiere al segundo principio de la justicia, es significativo que 
Rawls ni siquiera intenta mostrar que las ideas religiosas que incorporan la "fe libre" deben suscribirse a él. ${ }^{17}$

La lectura de Barry sobre la fe libre en este pasaje es mucho menos "generosa" de la que yo he realizado hasta ahora. Si bien yo he supuesto que la fe libre, como Rawls hace también, implica un cierto respeto de la libertad de conciencia, la realidad es que, como analiza Barry, esto no es necesariamente cierto. Si bien Williams parecería ser un ejemplo oportuno para las intenciones de Rawls, en la medida en que es uno de los constructores de la separación de la iglesia y el Estado en la tradición norteamericana, la realidad es que simplemente ejemplifica una manifestación abiertamente liberal del principio de la fe libre. Si asumimos una definición de la fe libre un poco más estricta, como lo hace Barry, podríamos considerar fe libre cualquier religión que reconozca la necesidad de la libertad en la experiencia de la fe (que no se puede obligar a nadie a creer); si asumimos esa definición la crítica de Barry es completamente acertada. Si nos preocupa el consenso traslapado como mecanismo de estabilidad, y Rawls busca dicho consenso sobre la justicia como imparcialidad, parece complicado que individuos y doctrinas comprehensivas puedan llegar a él si no reconocen, antes incluso de comenzar el "diálogo", que sus concepciones y principios políticos están abiertos a negociación. Esa apertura a la negociación, parece ser intrínseca a la razonabilidad.

El problema con las cargas del juicio es que no son fácilmente aceptables por todas las doctrinas comprehensivas que, hoy en día, habitan sociedades democráticas y liberales. Antes mencioné que la postulación de las cargas del juicio constituyen un giro pragmático por sí. En efecto, el presunto escepticismo que termina suponiendo el mismo Rawls para las personas razonables puede constituir, si hacemos una lectura deweyana de las cargas, una apertura al falsacionismo. Con estaríamos abriendo la puerta a un auténtico liberalismo pragmático (siempre y cuando hiciéramos los ajustes apropiados a la justicia como imparcialidad, como haré posteriormente en esta investigación) que, lamentablemente para la causa de Rawls, tenderá a ser de una naturaleza moral, contrario a las pretensiones del giro político.

Rawls no reconoce en su giro político el hecho de que las cargas del juicio son conceptos cargados de contenido filosófico y que, al mismo tiempo, aplican para todo el conocimiento, no sólo para el político:

En este sentido, la noción rawlsiana de persona razonable parece destinada a contener una verdadera paradoja: por un lado está formulada para justificar la

${ }_{17}$ Brian Barry: "John Rawls and the Search for Stability"; Ethics, vol. 105 no. 4 (1995). 909-910. 
comunicación entre las distintas visiones comprehensivas y, para ello, requiere que cada una de ellas se haga cargo de condiciones o requisitos cognitivos; por otro, el contenido de estas condiciones está asociado con la tradición crítica e incluso científica del pensamiento occidental, por lo que impone a visiones comprehensivas como las religiosas o metafísicas criterios de pertinencia argumental que chocan con su propia racionalidad, discursividad o narratividad. Por ejemplo, visiones comprehensivas como la de la iglesia católica se negarían a aceptar que sus argumentos públicos tuvieran que ajustarse a las cargas del juicio, es decir, al reconocimiento de la existencia de ciertas fuentes de desacuerdo en los juicios y enunciados morales y teóricos que no dependen de la mera ignorancia, los prejuicios o la mala fe sino de la naturaleza misma del ejercicio de las capacidades de pensamiento y juicio. ${ }^{18}$

En este punto es de llamar la atención lo que es una deficiencia en el pensamiento de Rawls, presente desde Teoría de la Justicia, que hice notar desde el capítulo anterior: Rawls parece tener un concepto de las ciencias antiguo. Cuando hablaba de la ciencia en Teoría, y del acceso que se podía tener a ella en la posición original, parecía remitirse a una idea de la ciencia prácticamente aristotélica: la ciencia como el conocimiento de las primeras causas, universal y necesario de la naturaleza. Como hace notar Rodríguez en el fragmento anterior, el concepto de ciencia contemporáneo es el del falsacionismo, si se quiere cierto escepticismo para el caso, presente en el pensamiento de autores como Kuhn, Popper o, por supuesto, Dewey. Rawls caracteriza al ciudadano de una sociedad bien ordenada abierto al cambio, renunciando a cualquier tipo de dogmatismo y buscando mejorar sus circunstancias de cooperación (dada su idea de lo razonable y la búsqueda de bienestar personal pues, recordemos, la cooperación implica ganancia para las partes). Si esto es así, parece que el conservadurismo, que termina siendo una de las apuestas principales, aunque quizá inconsciente del giro político, está en un serio riesgo pues nada impediría que los ciudadanos revisaran el contenido de su consenso continuamente y, en esa medida, la justicia como imparcialidad tendería a cambiar de forma en tanto las circunstancias de su aplicación cambiaran. Esto se termina asemejando más a la actitud deweyana respecto a la elaboración de principios políticos permanentes, es decir a la inconveniencia de mantenerlos.

Esta comprensión de la concepción de justicia, así como de las implicaciones de la razonabilidad en los ciudadanos, conducen al concepto de razón pública. La razón pública juega un papel relevante en el giro político de Rawls en la medida en que, una vez que poseemos una concepción política de la justicia que no está

\footnotetext{
${ }^{18}$ Rodríguez, La política del consenso. 109
} 
construida a partir de una doctrina comprehensiva particular, requerimos de una delimitación de las razones que pueden ser válidas en el espacio público.

\section{La razón pública}

Si asumimos la razonabilidad de las personas, piensa Rawls, y aceptamos las cargas del juicio, es posible reconocer con cierta facilidad que los argumentos desarrollados desde las doctrinas comprehensivas de los individuos son inaceptables en la esfera pública. Si la razonabilidad implica un cierto escepticismo, o falsacionismo en su mejor expresión, es claro que si un individuo fuera incapaz de dar razones que pudieran ser compartidas por todos los ciudadanos, sus argumentos serían considerados inválidos. Por ejemplo, si una persona argumentara por la defensa de la vida humana en función de su dignidad, que se refiere según una doctrina comprehensiva al valor que tiene cada vida humana en virtud de haber sido creada a imagen y semejanza de dios, ese argumento sería inaceptable dentro del espacio público dado que la evidencia que sobre esa creencia es un hecho valorado y aceptado de modo distinto por distintas personas.

Las razones aceptables en el espacio público deben de ser comprensibles por todos los individuos. Cuando todos los ciudadanos aceptan, a través del consenso traslapado, la concepción política de la justicia, las razones deben de ajustarse a dicha concepción; es decir, ser razones públicas:

No todas las razones son razones públicas, como ocurre que hay razones no públicas de iglesias y universidades y de otras muchas asociaciones en la sociedad civil. En regímenes aristocráticos y autocráticos, cuando el bien de una sociedad está siendo considerado, esto no se hace por el público, si existe en lo absoluto, sino por los encargados de mandar, quienes sean estos. La razón pública es característica de un pueblo democrático: es la razón de los ciudadanos, de esos que comparten el estatus de igual ciudadanía. El sujeto de su razón es el bien del público: lo que la concepción de la justicia requiere de la estructura básica institucional de la sociedad, y de los propósitos y fines que estas sirven. La razón pública, por tanto, es pública de tres modos: como la razón de los ciudadanos en tanto tales, es la razón del público; su objeto es el bien del público y los temas de la más fundamental justicia; y su naturaleza y contenido es público, siendo dadas por los ideales y principios expresados por la concepción política de la justicia de la sociedad, y conducida abiertamente en base a ella. ${ }^{19}$

\footnotetext{
${ }^{19}$ Rawls, Political Liberalism. 213
} 
Para los temas que se refieren a las instituciones esenciales de una sociedad, donde apuntamos a alcanzar un consenso traslapado sobre la concepción de la justicia política y su aplicación para cuestiones constitucionales esenciales, no es posible usar cualquier tipo de argumento; en estos casos sólo un argumento público es capaz de alcanzar dicho consenso. Se sigue, de acuerdo con Rawls, que el contenido de la razón pública está dictado por la concepción política de la justicia (que a esta altura debería ser claro que será una de carácter liberal). Esto implica que la razón pública está compuesta por dos partes: ${ }^{20}$ (i) principios sustantivos de la justicia para la estructura básica (los dos principios de la justicia, de "libertad" y de "igualdad democrática" en el caso de la justicia como imparcialidad) y (ii) guías de investigación: principios de razonamientos, reglas del evidencia mediante los cuales los ciudadanos puedan decidir los principios que se consideran propios para identificar leyes y políticas adecuadas.

Podemos resumir que existen dos tipos de valores dentro de una concepción política como la justicia como imparcialidad y, por tanto, dentro de la razón pública liberal: ${ }^{21}$ los principios de la justicia (que implican los valores de igualdad política y civil, igualdad de oportunidad e igualdad social y económica) y valores que se refieren a la investigación (que hacen que la investigación sea libre y pública como el deber a la civilidad y el uso de conceptos aceptables para todos).

El ideal de razón pública es un mecanismo que facilita el acuerdo pues genera condiciones óptimas para el diálogo. El liberalismo político de Rawls parece estar diseñado para hacer desaparecer el conflicto y, en esto, la razón pública juega un papel importante. Con la postulación de ésta, Rawls termina delimitando qué podemos pensar y cómo lo hacemos en la esfera pública. Por ejemplo, si queremos justificar la igualdad entre parejas del mismo sexo y su derecho al matrimonio civil, deberíamos de poder construir un argumento desde las premisas de la razón pública. Un ejemplo, que no representa una versión completa o final de un argumento podría tener una forma como la siguiente: si el reconocimiento público del matrimonio cumple una función política, esta debe de ser la de permitir a dos individuos adultos decidir crear una familia que sea consistente con su idea del bien personal, que no es en sí misma objeto de escrutinio público. Dado que la preferencia por el matrimonio heterosexual $u$ homosexual se refiere al contenido de las doctrinas comprehensivas particulares que poseen los ciudadanos, no compete al Estado hacer un juicio de ellos siempre y cuando no violenten los derechos de otros individuos; dicho esto, no parece ser responsabilidad del Estado

\footnotetext{
${ }^{20}$ Cfr. Ibid. 224

${ }^{21} \mathrm{Cfr}$. Idem
} 
favorecer o privilegiar algún tipo de unión en particular. ${ }^{22}$ Sólo si se acepta que el acceso a la institución matrimonial corresponde a un tema de fundamentos constitucionales, compete a la concepción política de la justicia regularlo (es relevante el reconocimiento del matrimonio así como en la protección de derechos y responsabilidades que los individuos puedan adquirir al formar dicha familia) y la sociedad no puede limitar la posibilidad de casarse a cierto tipo de parejas ya que hacerlo sería injustificable de acuerdo a los principios de la razón pública (ya que los argumentos para defender que un tipo de familia particular violenta el orden público estructurado por la concepción política de la justicia deberían de provenir de una doctrina comprehensiva).

Un argumento como el anterior, asumiendo que su estructura fuera la adecuada, debería de ser capaz de alcanzar un consenso relativamente fácil. Sin embargo, hasta ahora, no existe un consenso de ese tipo en la sociedad norteamericana, que es en la que Rawls está pensando. Incluso después de más de 10 años de la publicación del Liberalismo Político, el 26 de junio del 2015, cuando la Suprema Corte de Justicia dio su fallo al respecto del matrimonio entre personas del mismo sexo en Norteamérica, declarando inconstitucional su prohibición, nos enfrentamos con que la opinión del juez Anthony Kennedy, quien redactó la sentencia para la mayoría, cierra con el siguiente párrafo:

Ninguna unión es más profunda que el matrimonio, pues incorpora los ideales más altos de amor, fidelidad, devoción, sacrificio y familia. Al formar una unión marital, dos personas se convierten en algo más grande de lo que alguna vez fueron. Como algunos de los demandantes en este caso demuestran, el matrimonio incorpora un amor que puede durar aún más de la muerte. Sería una mala comprensión de estos hombres y mujeres decir que no respetan la idea del matrimonio. Su declaración es que ellos lo respetan, lo respetan tanto que desean encontrar su desarrollo en ellos mismos. Su esperanza es no estar condenados a vivir en soledad, excluidos de una de las instituciones más antiguas de la civilización. Piden por igual dignidad a los ojos de la ley. La constitución les garantiza ese derecho.

La sentencia de la Corte del Sexto Circuito de Apelaciones queda revertida.

Así queda ordenado. ${ }^{23}$

El argumento anterior, aunque bien podría ser convincente para muchos, difícilmente cumple con los requisitos de la razón pública que Rawls desarrolla para la comunidad. La idea de que el Estado tiene algún tipo de competencia en

\footnotetext{
${ }^{22}$ Cabe decir que este argumento se podría utilizar para argumentar por matrimonios polígamos de igual modo.

${ }^{23}$ Anthony Kennedy: "Opinion of the court: Obergeflel v. Hodges" (26 junio, 2015). 33. http://www.supremecourt.gov/opinions/14pdf/14-556_3204.pdf
} 
reconocer y distribuir (siempre que sea el Estado el que decide quién puede contraer nupcias) dicho bien porque "al formar una unión marital, dos personas se convierten en algo más grande de lo que alguna vez fueron", parecería ser un sinsentido desde la postura del liberalismo político. El contenido de premisas como tales difícilmente cumplen con principios de investigación y, si asumimos eso, deberíamos de aceptar que son argumentos derivados de una doctrina comprehensiva, total o parcial, del juez.

Alguien podría argumentar que los recursos que nos ofrece la razón pública no han sido suficientes, al día de hoy, para solucionar el problema del estatus del matrimonio entre personas del mismo sexo. En esa medida, es necesario desarrollar argumentos no disponibles a meras razones públicas. Para Rawls esta idea es un error, si el proyecto político de Rawls pudiera ser fructífero, y en efecto fuera capaz de desaparecer el conflicto de la arena política gracias al consenso traslapado logrado por ciudadanos razonables, las razones públicas deberían de ser suficientes. ${ }^{24}$

En caso de que las circunstancias del liberalismo político existieran, los temas de justicia básica, o fundamentos constitucionales como les llama Rawls, tenderían a solucionarse con bastante rapidez. Dados los límites a los argumentos aceptables, es posible afirmar que, en caso de entablar una discusión como el matrimonio entre personas del mismo sexo, haciendo uso de la razón pública, las causas del desacuerdo estarían más bien vinculadas a la capacidad de procesar la información adecuadamente. Aparentemente sería un proceso más parecido, aunque no idéntico, al de resolver un problema matemático que a elaborar un canon de grandes clásicos de la música, que tendería a ser mucho más polémico.

No es problemático suponer que, haciendo uso de la razón pública en el contexto de una sociedad donde existe un consenso traslapado, es posible alcanzar un acuerdo sobre temas de justicia fundamentales. Sin embargo, lo que es necesario preguntarnos, es si podemos esperar encontrar esas condiciones de razonabilidad y consenso en una sociedad liberal. Considero posible enunciar dos problemas distintos al respecto: por un lado, se encuentra el hecho de que la aceptación de las cargas del juicio y de la importancia de tener una razón pública compartida relevante tiende a ser escasa ya que las doctrinas comprehensivas regularmente afirman que su contenido es verdad (algo así como metafísicamente verdadero); el segundo problema, que se encuentra relacionado, es que con el giro político, Rawls termina desapareciendo la política de ámbitos en los que

${ }^{24}$ Cfr. Rawls, Political Liberalism. 241 
tradicionalmente se ha encontrado, negando su labor civilizatoria, en la medida en que hace una separación tajante entre lo político y todo lo demás (moral, metafísico, científico, etc.).

El primer problema es por demás claro. Si los ciudadanos están convencidos de la verdad de su doctrina comprehensiva, la petición rawlsiana de que suspendan su juicio sobre la verdad en la arena política es posiblemente inalcanzable. Como ya he intentado argumentar, la posibilidad de que un individuo sea escéptico o falsacionista en lo político (al punto de pertenecer a un consenso traslapado), pero un realista metafísico en lo privado parece no tener muchos méritos. La posibilidad de que las cargas del juicio sean reconocidas por los ciudadanos, al menos por una mayoría, depende de la capacidad de la sociedad de formar ciudadanos escépticos o falsacionistas, lo que tendría implicaciones sobre la existencia del pluralismo y sobre todo sobre la naturaleza política y no metafísica de la concepción de la justicia.

El segundo problema, por su parte, no es necesariamente uno de carácter negativo. Uno de los objetivos centrales de la filosofía de Rawls, en especial con el giro político aunque estaba presente desde Teoría (con su insistencia en contra del perfeccionismo), es el de desaparecer, o al menos restringir seriamente, la labor civilizatoria de la política. Este problema, que como mencioné ya estaba esbozado en Teoría de la Justicia, ${ }^{25}$ se acrecienta con el giro político y temas tan relevantes como derechos de los niños y generaciones futuras, personas con discapacidad incapaces de ser ciudadanos cooperadores, derechos de los animales y la relación del hombre con el medio ambiente, que son temas centrales dentro de la agenda liberal norteamericana y del mundo liberal en general, dejan de ser preocupación central de la sociedad.

El trato que Rawls puede ofrecer a temas como los anteriores, que incluye las relaciones entre pueblos, de carácter internacional, es francamente insatisfactorio desde una visión moral del liberalismo. El tema lo define simplemente como uno de extensión y básicamente implica que la justicia como imparcialidad puede ser razonablemente interpretada para extenderse a estos otros ámbitos que no son, naturalmente, de su competencia. El proceso de extensión lo menciona, brevemente, del siguiente modo:

Algunas ideas que se obtienen de la tradición del contrato social, y la justicia como imparcialidad es una, inician tomando como un hecho el estatus completo de

\footnotetext{
25 Para la relación de la concepción de la justicia con animales y medio ambiente revisar: Rawls, $A$ Theory of Justice, 441 y 448.
} 
ciudadanía de personas adultas en una sociedad particular (los miembros de su cuerpo de ciudadanos) y procede desde ese punto: adelante hacia otras generaciones, afuera hacia otras sociedades, y hacia adentro con aquellos que requieren cuidados de salud normales. En cada caso iniciamos desde el estatus del ciudadano adulto y procedemos sujetos a ciertas limitantes para obtener una ley razonable. Podemos hacer lo mismo con las exigencias de los animales y el resto de la naturaleza; esta ha sido la idea tradicional de la era cristiana. ${ }^{26}$

El fragmento anterior presenta algunos problemas desde este análisis. En primer lugar, una preocupación que se puede plantear desde el giro político es que, ya que la concepción de la justicia política no está fundada en una derivación filosófica, (como es el contractualismo), sino en las instituciones derivadas de la cultura política, y que para alcanzar un consenso traslapado debe de ser justificada desde las premisas de cada doctrina comprehensiva razonable, el procedimiento de extensión desde la idea del ciudadano del contractualismo es inoperante. La fundamentación de instituciones democráticas y liberales, parece olvidar Rawls, puede ser coexistente, en los hechos históricamente constatables, con una cultura profundamente segregacionista. Recordemos que este tipo de políticas parciales tienden a estar vinculadas con ciertos tipos de conservadurismo existente en buena parte de las naciones democráticas y liberales. Sólo basta recordar que el sufragio universal en Estados Unidos no sucede, al menos en el sur, hasta la promulgación de la Ley de Derecho al Voto de 1965, que refutaba las llamadas leyes Jim Crow, de las que hablé en la parte anterior. El problema es que, en la medida en que Rawls sólo funda su concepción política en las instituciones de la cultura política, no parecería imposible pensar que la extensión de derechos a grupos de personas vulnerables, así como otros seres no humanos (animales y medio ambiente en general), sea inexistente en tanto algunos individuos podrían considerar que dicha extensión es una afrenta directa a esa misma tradición e instituciones. Rawls, en este caso y sin intentar justificar demasiado, parece querer lo mejor de todos los mundos: una concepción política que no requiera de argumentación filosófica y, al mismo tiempo, sostener una agenda liberal y progresista más cercana al liberalismo moral.

Un segundo problema del fragmento es la idea de una ley razonable. Si fuera aceptable utilizar un ideal de ciudadanía derivado del contractualismo, ¿en qué modo la ley propuesta cumpliría con las características de razonabilidad de propone Rawls? No es claro cómo es que la postulación de una ley de extensión de derechos, que no está necesariamente implicada en las instituciones políticas

\footnotetext{
${ }^{26}$ Rawls, Political Liberalism. 245
} 
existentes, podría cumplir con el criterio de razonabilidad política de Rawls. Supongamos el caso respecto a los derechos de los animales. En Teoría de la Justicia Rawls nos dice que: "Ciertamente está mal ser cruel con los animales y la destrucción de toda una especie puede ser un gran mal. La capacidad para sentir placer y dolor y para los modos de vivir que los animales son claramente capaces de vivir impone deberes de compasión y humanidad a favor de su caso. No intentaré explicar esas creencias consideradas. Están por afuera del enfoque de la teoría de la justicia, y no parece ser posible extender la doctrina del contrato para incluirlas de una manera natural. ${ }^{27} \mathrm{Al}$ igual que con la idea de la extensión de derechos a individuos que no son normalmente miembros cooperadores de la sociedad, en función de una idea del ciudadano extraída del contractualismo, la creencia de los deberes hacia los animales, desde la justicia como imparcialidad (en especial ahora con el giro político), es completamente inservible. ¿Cómo podría existir una ley que prohíba las peleas de perros, gallos, la tauromaquia, la ganadería sin cuidado a las condiciones de los animales (más allá de un tema de salubridad), la cacería indiscriminada o, incluso, la destrucción del medio ambiente (siempre y cuando esta destrucción no ponga en riesgo el futuro de generaciones futuras)? Desde el punto de vista de la concepción política de la justicia matar a un animal, así como la manera en que se hace, ya sea por alimento, razones religiosas o entretenimiento es indiferenciable respecto a las razones. No es posible elaborar una ley que ordene el trato a los animales ya que las instituciones políticas, sobre las que se construye la justicia como imparcialidad, no tienen nada que regular al respecto (pues la protección por ley de animales o medio ambiente no tiene implicaciones en la distribución de bienes primarios ${ }^{28}$ ).

Estos problemas, que Rawls llama de extensión y que están presentes desde Teoría, pero que se agudizan con el giro político, ponen en evidencia deficiencias importantes dentro de la concepción política del liberalismo. La denominada extensión de derechos, por el contrario, desde una perspectiva moral del liberalismo no es problemática en su justificación (siempre y cuando la moral liberal que se use para argumentar dé para eso), aunque puede ser problemática respecto a su estabilidad. Como muestro en la siguiente parte, el problema de la estabilidad desde un liberalismo moral puede ser abordado desde un proyecto

\footnotetext{
${ }^{27}$ Rawls, $A$ Theory of Justice. 448

${ }^{28}$ Es posible pensar casos en que sí los tenga, claramente. Un caso puede ser la protección de un depósito de agua en la medida en que es un medio material necesario para que los ciudadanos puedan ejercer sus poderes morales. La idea conservacionista, que implica que hay que mantener todo el medio ambiente porque más tarde o más temprano eso implicará un daño irreparable a la tierra y, al mismo tiempo, un daño a generaciones futuras, tiene el mismo problema de extensión que he estado discutiendo hasta ahora.
} 
educativo (entendiendo educativo al modo de Dewey, no como mera escolaridad, aunque por supuesto ésta queda incluida), aunque, como Rawls prevé correctamente, probablemente no pueda ser del todo resuelto.

Sin embargo, antes de llevar a cabo ese desarrollo, analizaré, para terminar con el examen del giro político de Rawls, hasta qué punto, asumiendo que pudiéramos aceptar el giro político con todas las condiciones que he considerado críticamente, el liberalismo político y el moral quedan irremediablemente vinculados. Este ejercicio me parece relevante para comprender el pensamiento de Rawls posterior al giro político en la medida en que puede abrir la puerta a elaboraciones de la justicia como imparcialidad que sean más fecundas en sus posibilidades de realización, tanto por su capacidad de enarbolar cierto liberalismo igualitario y progresista como, al mismo tiempo, por la mayor estabilidad, al menos a mediano y largo plazo, dentro de la sociedad.

\section{Liberalismo político y liberalismo moral}

En la introducción al Liberalismo Político Rawls plantea algunos de los temas fundamentales que los fundadores del proyecto liberal moderno, a partir de la Reforma, intentaron responder. Estos son de carácter moral, en especial de psicología moral, y son base del desarrollo del liberalismo posterior: ${ }^{29}$

1. Si el conocimiento del bien y la justicia es accesible sólo a algunos pocos elegidos o a todos por igual.

2. Si el orden moral proviene de una autoridad exterior o, por el contrario, proviene del hombre mismo.

3. Si el cumplimiento con el orden moral debería de provenir de motivación exterior (por ejemplo por castigo divino o político) o la naturaleza humana nos da motivos suficientes sin necesidad de amenazas.

Ante estos temas el liberalismo político no puede adoptar una postura definitiva. En tanto es político, la respuesta a los tres corresponde a las doctrinas comprehensivas de responder:

El liberalismo político no es liberalismo comprehensivo. No toma una postura general sobre las tres cuestiones de arriba, sino que deja que las responda a su modo cada doctrina comprehensiva. Sin embargo, el liberalismo político sí afirma la

${ }^{29}$ Cfr. Rawls, Political Liberalism. xxvi-xxvii 
segunda alternativa en cada caso con respecto a la concepción política de la justicia para un régimen democrático constitucional. ${ }^{30}$

Cuando Rawls habla de afirmar la segunda alternativa, lo que quiere decir es que, con respecto a la concepción política de la justicia, el liberalismo político sostiene que todos los individuos tienen acceso a una concepción política de la justicia, el orden moral proviene de ellos mismos y, al mismo tiempo, es capaz de encontrar en su naturaleza como ciudadanos la motivación para cumplir con dicha concepción. La cuestión sobre la separación entre el liberalismo comprehensivo, o moral, frente al liberalismo político radica en si es posible afirmar lo que Rawls acepta respecto a las tres cuestiones en referencia a la concepción política de la justicia y, al mismo tiempo, poder suspender el juicio al respecto de una psicología moral más amplia, como pretende hacer.

Ya he tratado el punto cuando he puesto en duda la posibilidad de mantener las cargas del juicio en lo político pero no en lo privado. Esa imposibilidad parece abrir la puerta a la ulterior asimilación del liberalismo político al moral. Si mi lectura es correcta sería posible defender la idea de que la sociedad bien ordenada que considera Rawls no podría albergar todas las doctrinas comprehensivas razonables, a menos que ser razonable fuera ser moralmente liberal. La alternativa que nos queda es la de una sociedad que promueva un cierto tipo de moral liberal frente a otros candidatos a concepción de la justicia e ideas del bien. ${ }^{31}$ Sin embargo, esta situación es contraria a los objetivos del giro político y, por tanto, de Rawls.

Rawls considera que la justicia como imparcialidad debe ser neutral respecto de los ideales morales de los ciudadanos y las doctrinas comprehensivas. Esta expectativa es difícil de cumplir ya que los principios que constituyen la justicia como imparcialidad responden a principios que no son neutrales de ese modo, dado que promueven un conjunto de virtudes políticas determinados, que, para formar parte de la cultura política de una sociedad democrática, alguna vez respondieron a intereses de individuos en función de alguna moral determinada. El intento rawlsiano es hacer que el giro político garantice, con la idea de evitar la justificación metafísica y moral, que no se beneficiará a ninguna doctrina comprehensiva en particular. En la medida en que Rawls desarrolla una

\footnotetext{
30 Idem.

${ }^{31}$ De esto es importante mencionar que no se sigue, necesariamente, el uso del poder opresor del Estado contra los individuos. De hecho, me parece que el poder del Estado tiende a ser proteccionista de las libertades y derechos de los individuos aunque pueda tener una relación de enfrentamiento con doctrinas comprehensivas no liberales.
} 
concepción de la justicia que no se fundamenta en ningún principio moral o metafísico puede sostener una neutralidad de trato frente a otras doctrinas comprehensivas, pues todas estas son igualmente válidas, siempre que sean parte del consenso traslapado. La pregunta central es si Rawls puede, verdaderamente, lograr un consenso traslapado con una concepción de la justicia carente de justificaciones morales o metafísicas.

Pensemos en las virtudes que el liberalismo político promueve: cooperación, civilidad, tolerancia, razonabilidad y un sentido de justicia. ${ }^{32}$ Todas estas, considera Rawls, son virtudes meramente políticas y son neutrales respecto a las diversas doctrinas comprehensivas. Lo que propone Rawls es que la cooperación, tolerancia, razonabilidad y el sentido de la justicia son virtudes necesarias para poder tener una concepción de la justicia como la justicia como imparcialidad, es decir democrática y liberal, pero que, al mismo tiempo, pueden ser virtudes que no sean necesariamente reconocidas en el ámbito privado. En esa medida, desde las premisas de Rawls, sería pensable considerar que un grupo podría ser tolerante políticamente pero, al mismo tiempo, intolerante dentro de su doctrina comprehensiva. Así es posible hacerlo con la cooperación, la civilidad y la capacidad de tener un sentido de la justicia.

Esto nos conduce, de nuevo, al problema que analicé antes: ¿es posible ser razonable en lo público pero no en lo privado? La diferencia ahora, que en cierto sentido agrava el problema, es que tendríamos que hacer el mismo ejercicio con todos los valores políticos pues Rawls parece suponer que es posible poseerlos como ciudadanos pero no tenerlos como individuo y que, además, eso es normal y consistente. Un hecho muy importante a recordar ahora es que Rawls afirma que las doctrinas comprehensivas no sólo son un cúmulo de creencias sobre todos los ámbitos de la vida, sino que son creencias que están articuladas y sistematizadas de modo que poseen, en mayor o menor grado, cierta consistencia.

Sobre la posibilidad de la neutralidad de la sociedad liberal, Brian Barry está en desacuerdo con Rawls. Si bien es cierto que el liberalismo tiende a permitir un número mayor de modos de vida que cualquier otra opción que tenga una idea del bien y de la justicia perfectamente definida, la realidad es que el liberalismo no puede ser neutral frente a doctrinas comprehensivas diversas: "Parecería ser que para que el liberalismo -o cualquier otra doctrina para el caso- pudiera ser culturalmente neutral, no debería existir una idea del mundo con la que esté en conflicto. Dado que esto es manifiestamente absurdo, la aserción de que el

${ }^{32}$ Cfr. Ibid. 194 
liberalismo no es culturalmente neutral sostiene algo que no podría ser concebiblemente negado." ${ }^{33}$

Si por neutralidad intentamos afirmar que el liberalismo político es capaz de no entrar en conflicto con cualquier doctrina comprehensiva en tanto sea razonable (si asumimos, con Rawls, que se puede ser razonable y no liberal en un sentido moral), parece que estamos diciendo una de dos cosas: o que existen doctrinas comprehensivas razonables que no hacen suyas las virtudes políticas de las que hablamos antes, dentro de su contenido comprehensivo y, en cualquier caso, son perfectamente compatibles con el liberalismo, o, segundo, que todas las doctrinas comprehensivas razonables, para ser razonables, deben de reconocer las virtudes políticas dentro de su contenido doctrinal en mayor o menor medida. Al respecto de la primera opción Barry diría que es una esperanza banal. Sobre la posibilidad de que existan religiones que coexistan en la sociedad liberal sin tener que renunciar a las virtudes políticas dentro de su contenido doctrinario, afirma:

Los principios liberales no son un tipo de "bala mágica" que puede de algún modo crear armonía sin la necesidad de sacrificios por las partes. Si deseamos hacer una analogía médica, podríamos hacer la comparación menos agradable con el tratamiento de quimioterapia: está mantiene la esperanza de destruir las características malignas de la religión, pero esto sólo ocurre con efectos secundarios que pueden ser experimentadas como debilitadoras por los fieles. ${ }^{34}$

Lo que Barry propone es la idea de la fe libre y cómo aun cuando pueda no ser del todo compatible con el liberalismo, implica un gran ajuste en la experiencia religiosa de los fieles. Pensemos en que muchas de las características de la fe libre que analizamos antes eran causa suficiente, durante la Edad Media, pero sobre todo con la Reforma, de terribles castigos para quien hubiera apoyado tales ideas.

La opción que nos quedaría es que todas las doctrinas comprehensivas razonables son liberales. Si esto fuera así, entonces el esfuerzo completo del giro político sería un fracaso desde la óptica de la crítica comunitarista pues, al final del día, el liberalismo terminaría conduciendo a una antropología individualista y que valora la autonomía sobre otros valores culturales a otras doctrinas comprehensivas. Esta opción, sin embargo, es inaceptable para Rawls:

(...) la justicia como imparcialidad no busca cultivar las virtudes distintivas y valores de autonomía e individualidad del liberalismo, o de cualquier otra doctrina comprehensiva. Pues en ese caso deja de ser una forma de liberalismo político. La justicia como imparcialidad honra, tanto como sea posible, la demanda de aquellos

\footnotetext{
${ }^{33}$ Barry, Culture and Equality. 27

${ }^{34}$ Barry, Culture and Equality. 25
} 
que desean retirarse del mundo moderno de acuerdo con los mandatos de su religión, supuesto que reconocer los principios de la concepción política de la justicia y aprecian sus ideales políticos de persona y sociedad. ${ }^{35}$

Lo que una sociedad bien ordenada debería buscar es enseñar a todos los ciudadanos, y cabe decir que a aquellos que serán ciudadanos en el futuro, la concepción política de la justicia, incluyendo sus valores y usos de la razón pública, de modo que sean capaces de integrarla a su doctrina comprehensiva razonable. Rawls elige la posibilidad de una sociedad en donde las doctrinas comprehensivas pueden no hacer suyas las virtudes políticas dentro de su contenido moral doctrinario y, en cualquier caso, ser compatibles con el liberalismo político (y recordemos que la compatibilidad está dada, ni más ni menos, que por el consenso traslapado). Esta opción, como ya sabemos, no podría ser aceptable ya que el acuerdo sería más bien un modus vivendi y no parte de un consenso traslapado. Todo parecería apuntar que las expectativas de Rawls son inalcanzables.

En el debate de esta cuestión es en donde podremos reconocer hasta qué punto el liberalismo político está en condiciones de afirmar una neutralidad como la que busca Rawls. Penny Enslin, por ejemplo, afirma que el tipo de neutralidad que Rawls busca sostener en la sociedad es imposible. El problema, sostiene Enslin, es que en el caso de algunas comunidades con doctrinas comprehensivas no liberales es imposible que se desarrollen las virtudes políticas necesarias para mantener una sociedad basada en el consenso traslapado de una concepción política de la justicia como imparcialidad. ${ }^{36}$ Supongamos una doctrina comprehensiva que no reconoce igual autonomía e individualidad de las mujeres al interior de la comunidad. Supongamos que dicha comunidad está en disposición de aceptar la igual participación de las mujeres en el ámbito político siempre que eso exija la concepción política de la justicia, pero no está en disposición de garantizar igualdad de trato hacia las mujeres al interior de la comunidad. ¿Cómo podría ser posible que una mujer que pertenece a una comunidad que promueve su discriminación y trato desigual, pueda adquirir los valores políticos necesarios para participar en la arena pública $\mathrm{y}$, al mismo tiempo, razonablemente identificarse como un sujeto de derechos y reclamos válidos? Del mismo modo podríamos preguntarnos cómo un hombre de dicha comunidad podría aceptar que las cargas del juicio aplican por igual a hombres y mujeres si cree, como

\footnotetext{
35 Rawls, Political Liberalism. 200

${ }^{36}$ Cfr. Penny Enslin: "Education and the Limits of Political Liberalism"; Theoria: A Journal of Social and Political Theory, no. 90 (1997). 74.
} 
probablemente lo haría, que las mujeres no tienen la constitución natural para participar en política.

Del mismo modo, supongamos una doctrina comprehensiva que considera que las tradiciones e instituciones de su comunidad, que son de clases jerarquizadas, responden a una ordenación divina y que deben de someterse absolutamente a ellas. Un miembro de esa comunidad, que ha aprendido que, por ejemplo, la tradición en la que vive representa parte de la revelación divina, ¿en qué modo será capaz de desarrollar las virtudes políticas? Concedamos a Rawls que su doctrina comprehensiva es compatible con la justicia como imparcialidad y por tanto podría ser parte de un consenso traslapado; incluso en ese caso la situación es compleja dadas las condiciones que Rawls supone con el giro político pues, aun cuando la jerarquía de dicha comunidad alcanzara un consenso traslapado y ordenara al resto de la comunidad a honrar dicho consenso, esto no es suficiente desde el liberalismo político: el consenso lo deben alcanzar cada uno de los individuos razonables. Si un individuo aprende a venerar la tradición por ser manifestación de la verdad revelada, ¿en qué modo se podría justificar que su aceptación de la concepción de la justicia, que dentro del contenido de su doctrina comprehensiva forma parte de la tradición, es parte de un consenso traslapado si, sin duda, no sería razonable (dado el concepto de razonabilidad de Rawls, que implica las cargas del juicio)? Recordemos que para el liberalismo político no se trata sólo de ser estable, sino ser estable por las razones correctas; así como un mero modus vivendi no es suficiente, parecería que la aceptación ciega de la concepción política tampoco lo sería.

Ahora es el momento en que el análisis de Amy Gutmann al respecto de la educación cívica cobra especial relevancia. En su estudio sobre las diferencias educativas entre la educación necesaria para llevar a cabo un proyecto de liberalismo político frente a un liberalismo democrático moral, Gutmann concluye que las diferencias entre uno y otro proyecto son, más bien, inexistentes:

Es, por tanto, comprensible que exista en el liberalismo político, en la práctica, poca diferencia entre educar para la ciudadanía y educar para la individualidad o la autonomía. No sólo son las virtudes y aptitudes similares, sino que existen puntos en común entre esas características de nuestras vidas contemporáneas que son políticamente relevantes y aquellas que son relevantes en la elección de nuestra vida buena (no política). ${ }^{37}$

${ }^{37}$ Amy Gutmann: “Civic Education and Social Diversity"; Ethics, vol. 105 no. 3 (1995). 573. 
Si la educación ciudadana que requiere el liberalismo político incluye aprender a ser tolerante con aquellos que son diferentes a mí, a reconocer la importancia de la cooperación (la reciprocidad), a entender lo fundamental de tener un sentido de la justicia (y dada la naturaleza de la concepción de la justicia, de un sentido de imparcialidad como justicia) y a formar una mentalidad razonable (que implica, como ya he explicado, una suerte de escepticismo y falsacionismo), ¿cómo podría mantenerse inmune una comunidad que sostenga una doctrina comprehensiva, que rechace una moral razonable, sea intolerante y no reconozca la importancia de la justicia dentro de ella misma? Si los ciudadanos son educados para sostener esas virtudes políticas, ¿tendremos que educarlos, de igual modo, para desarrollar algún tipo de síndrome de doble personalidad? Después de todo, como afirma Gutmann: "Una educación compatible con el estilo de vida Amish es también incompatible con una educación por la individualidad o la autonomía." ${ }^{38}$ Aun cuando Rawls afirme que el liberalismo político no favorece el individualismo, la realidad es que la condición de que cada individuo forme parte del consenso, y en esa medida que se requiera su consentimiento reflexivo y autónomo de la concepción política de la justicia, es una que exige la individualidad y la autonomía en la esfera pública.

La preocupación por no establecer una concepción de la justicia política que tienda a homogenizar a la sociedad, que parece encontrarse dentro del Liberalismo Político y que considero que es una concesión de Rawls a la crítica comunitarista que mencioné al principio de esta parte, parece no ser capaz de reconocer que la enseñanza enfocada a la individualidad y a la autonomía, si bien no es compatible con todas las doctrinas comprehensivas, sí es la que, al menos hasta ahora, permite una mayor libertad a los individuos para que ejerzan sus poderes morales:

Enseñar tolerancia, respeto mutuo y deliberación no homogeniza a los niños ni niega el valor de las diferencias genuinas asociadas con diversos modos de vida individual y comunal. Por el contrario, enseñar esas virtudes cívicas apoya el rango más amplio de diversidad social consistente con la búsqueda continua de justicia liberal democrática. ${ }^{39}$

Es claro que sostener una sociedad liberal implica un costo más alto para algunos grupos frente a otros. Una ley laboral que garantice derechos como un salario mínimo, una jornada laboral de 8 horas y otras prestaciones a los trabajadores, supone un costo mayor a aquellos que creen que deberían tener el derecho de pagar la menor cantidad posible por un trabajo (aun si este está por debajo del

\footnotetext{
${ }^{38}$ Ibid. 568

${ }^{39}$ Ibid. 579
} 
salario mínimo) y que los límites a la jornada laboral deberían estar en función de las necesidades de la empresa que a aquellos que heredaron sus bienes y no tienen necesidad de trabajar o de contratar empleados. De ese mismo modo, si el mantenimiento de una sociedad liberal bien ordenada es nuestro objetivo, no debe de sorprendernos el hecho de que las leyes (y en este sentido la concepción de la justicia que informa la estructura básica y ayuda a resolver problemas constitucionales) tengan un costo mayor para ciertos grupos. La cuestión, más bien, es si este costo es injusto.

En Teoría de la Justicia, Rawls había desarrollado una concepción de la justicia, con fundamentos neokantianos y pragmáticos, que era capaz de ofrecernos criterios generales para reconocer en qué casos sería legítimo que cierta doctrina comprehensiva padezca los costos más elevados. Como intenté hacer ver, la justicia como imparcialidad en esa primera formulación presentaba algunos problemas de estabilidad pues no daba cuenta directamente del hecho del pluralismo y, por lo mismo, desarrollaba una teoría de la tolerancia que considero insostenible sin hacer matices y cambios relevantes. Sin embargo tengo la convicción que dichos problemas de estabilidad simplemente se hicieron más graves con el giro político.

La identificación del liberalismo de Teoría con uno de carácter comprehensivo llevó a Rawls a considerar su naturaleza como represiva. Concuerdo con Brian Barry en que esa comprensión de la formulación anterior de la justicia como imparcialidad es equivocada: "La razón crucial para decir que Teoría de la Justicia no era "comprehensiva" es que dejaba abierto a las personas el determinar y perseguir sus propias concepciones del bien. Ofrecía términos justos de cooperación bajo los cuales las personas con diferentes concepciones del bien pueden vivir juntas." 40

Al realizar Rawls el giro político, renunció a reconocer la importancia de la justicia y la esfera pública dentro de la vida comunitaria de las personas, permitiéndoles enriquecer su vida privada sin, en el caso de una sociedad liberal, renunciar a ese mismo carácter privado. La separación absoluta entre lo político y lo no político en el pensamiento de Rawls conduce a la justicia como imparcialidad a constituirse como un proyecto irrealizable sostenido sobre premisas fuertemente conservadoras, en algunos casos, y, en otros, simplemente inadecuadas para sus objetivos sobre la naturaleza del conocimiento y la verdad, la psicología moral y las instituciones.

\footnotetext{
${ }^{40}$ Barry, "John Rawls and the Search for Stability". 880
} 
El proyecto del giro político, como espero haber mostrado, está condenado a derrotarse así mismo por las condiciones que ya expuse en este capítulo. Amy Gutmann desarrolla un argumento sólido para mostrar cómo, en sus efectos prácticos, el liberalismo político y el liberalismo moral terminan siendo indistinguibles. Esa misma línea de argumentación persigue, pienso que satisfactoriamente, Eamonn Callan:

El contraste que desarrolla Rawls es falso porque las virtudes políticas que implementan los términos justos de cooperación imponen requisitos educativos que traen la autonomía por la puerta de atrás del liberalismo político. Esto se hace obvio una vez que reflexionamos sobre la tarea educacional de asegurar la aceptación activa de las cargas del juicio. (...) La autoridad moral de la familia y de las varias asociaciones en las que crece el niño deben de ser cuestionadas en la medida en que la sociedad contiene alternativas razonables para lo que sea que la autoridad prescribe. Todo esto parece ser una descripción muy familiar de los elementos centrales en una educación para la autonomía porque los atributos psicológicos que constituyen una aceptación de las cargas de la razón, como la capacidad e inclinación de los sujetos de analizar críticamente las ideas éticas reconocidas, también constituye un ideal reconocible de la autonomía ética. ${ }^{41}$

A continuación procuraré, una vez analizado el giro político de Rawls, que, como espero haber podido mostrar, aun cuando hace algunos matices, difícilmente puede ser justificadamente considerado pragmático, realizar una propuesta de lectura de la justicia como imparcialidad que sea capaz de lidiar con algunos de los problemas de estabilidad. Argumento que una lectura de la justicia como imparcialidad con un giro auténticamente pragmático permite abordar la preocupación por la estabilidad que se encuentra en la obra del giro político en Rawls de un modo satisfactorio aunque, como quedará en evidencia, este giro implica un abandono de una de las preocupaciones fundamentales dentro del giro político en tanto que debe afirmar un criterio pragmatista de verdad, o al menos de justificación suficiente, que termina deslegitimando la neutralidad que Rawls quiere sostener. Esto hace que la justicia como imparcialidad tenga que ser ampliamente reconocida como un modo de liberalismo moral pero, al mismo tiempo, capaz de vincular la mayor cantidad posible de doctrinas comprehensivas.

${ }^{41}$ Callan, "Political Liberalism and Political Education". 21 



\section{Parte IV. Liberalismo pragmático}




\section{Capítulo 7. Una lectura pragmática de la justicia como imparcialidad}

Una de las primeras tareas para poder realizar un proyecto liberal, que cumpla con las expectativas de estabilidad que preocupan a Rawls en el Liberalismo Político, es la de reconocer la importancia del conflicto en el espacio público. Parte importante del capítulo anterior la he dedicado a reconocer cómo es que el giro político, más que reconocer la realidad del conflicto (que tiende a ser mayor una vez que estamos en una sociedad democrática y liberal y que es, como menciona el mismo Rawls, plural) busca desaparecerlo a la vez que se mantenga la pluralidad; esta tarea es imposible. En la sociedad democrática y liberal que esboza Dewey, por su parte, el conflicto es una constante, la causa misma de la política como la representación de intereses entre individuos que se encuentran el espacio público, por lo que ni siquiera se plantea si debemos intentar desaparecerlo; debe ser encausado de modo que sirva como un factor de progreso: el conflicto constituye una condición de posibilidad de que las personas puedan desarrollar sus capacidades ya que, si está bien delimitado por reglas de convivencia, promueve la examinación de las propias creencias de los individuos y el desarrollo en su vida personal de modo que, en consecuencia, impliquen mejoras en la vida social. El desarrollo y el progreso en el liberalismo democrático de Dewey supone que los individuos puedan libremente comparar ideas del bien y de desarrollo, eso implica la existencia continua de conflicto pues las intenciones y expectativas en el espacio público son diversas y en muchos casos adversos.

Es posible identificar una segunda diferencia entre el pensamiento político de Dewey y el de Rawls: para Dewey la sociedad liberal tiene, dentro de sus fines, la "vocación" de garantizar los medios necesarios para el progreso y el bienestar de los ciudadanos (lo que no necesariamente implica la imposición de una moral particular), aunque no tengo razones para pensar que aceptaría la idea de la imparcialidad rawlsiana. Para Rawls, por el contrario, en la medida en que termina negando la verdad en el ámbito político, así como la afirmación de su constante antiperfeccionismo (que está desde Teoría de la Justicia y persiste durante toda su obra), no reconoce fin o vocación alguna en la comunidad que no sea la de mantener el orden en función de la cultura política dominante de su sociedad y garantizar los bienes primarios. Como ya he mencionado, Rawls termina convirtiéndose, con el giro político, en un conservador, Dewey, por su parte, 
podría ser identificado, siguiendo algunas de las etiquetas más populares hoy en día, como un liberal progresista. Esta diferencia tiene como una de sus causas, considero, la comprensión que tienen del conflicto: para Rawls es algo que debe desaparecer (o al menos minimizarlo al máximo en la esfera pública) pues es la única manera de conservar las instituciones políticas que permiten la distribución de bienes primarios adecuada y permite la plena cooperación; para Dewey, por su parte, debe ser utilizado para promover el progreso y desarrollo, tanto de individuos como de la sociedad en su conjunto. ${ }^{1}$

Detrás de la idea del conflicto de cada uno de estos pensadores se encuentra una comprensión del pluralismo y la libertad. La libertad para Rawls se ejerce principalmente en el espacio privado, después de todo el liberalismo, como ya he mencionado siguiendo al mismo Rawls, fue la respuesta histórica ante las intromisiones políticas de diversos grupos que buscaban imponer sus doctrinas comprehensivas sobre los demás; aunque esto no implica que la libertad no tenga lugar en el espacio público, las libertades básicas, en Rawls, son muestra de esto. Recordemos que el hecho del pluralismo supone de que los individuos en una sociedad liberal y democrática tienden a usar libremente sus poderes morales (la capacidad de tener una idea del bien y una concepción de la justicia), la diferencia entre las diversas ideas del bien supone, si asumimos la razonabilidad de los

\footnotetext{
${ }^{1}$ Incluso cuando Rawls discute los niveles de publicidad para la concepción de la justicia nos encontramos con este problema. Cuando iniciamos con una lectura del apartado (John Rawls, Political Liberalism. 77-77) dedicado a este tema en el Liberalismo Político parece que los distintos niveles de publicidad apuntan a niveles de justificación que acercan a Rawls al pragmatismo. Sin embargo, dicha lectura se complica, a mi entender, en la medida en que plantea la justificación de los principios en función del sentido común e ideas generales de la naturaleza humana. Como dije antes, los conceptos de Rawls de naturaleza y conocimiento científico, que utiliza para justificar la justicia como imparcialidad en la posición original, son, en el mejor de los casos, insensibles ante la realidad falsacionista y pragmática del conocimiento humano. En la medida en que la justificación de la concepción de la justicia se lleve a cabo de acuerdo a esas ideas de sentido común, con el grado de generalidad al que parece apuntar (como si no existiera pluralismo en esa dimensión del saber humano en las sociedades contemporáneas), termina siendo, a pesar de desarrollar condiciones de justificación en tres etapas, un proyecto conservador de origen.

Este problema está presente, considero, incluso en obras posteriores, como sucede en su "Réplica a Habermas", donde afirma: "Si podemos exponer argumentadamente que hay razones adecuadas para que diferentes personas razonables afirmen conjuntamente la justicia como equidad en tanto que su concepción política efectiva, entonces están satisfechas las condiciones para ejercer legítimamente el poder político coercitivo sobre otros, lo cual es algo que inevitablemente hacemos mediante el voto o de otras maneras." (John Rawls, "Réplica a Habermas", en Debate sobre el Liberalismo Político, traducción Gerard Vilar Roca (Paidós: Barcelona, 1998). 94-95). En este punto Rawls parece insensible ante el problema de las condiciones de la razonabilidad que traté en la sección anterior y al hecho que, dado el concepto de "razones adecuadas" con el que ha trabajado, en tanto están justificadas en los conceptos de naturaleza, ciencia y sentido común con los que justifica la justicia como imparcialidad, termina atrapado en un argumento conservador por la naturaleza política de justicia como imparcialidad a partir del Liberalismo Político.
} 
individuos, aunadas a la libertad y las circunstancias particulares, que diversos individuos tendrán ideas del bien distintas. No deja de ser sorprendente que desde el pensamiento de Rawls esas mismas personas, dadas sus condiciones, su razonabilidad y su libertad harán uso de la razón pública y aceptarán (al modo que supone el consenso traslapado) la misma concepción de la justicia. Si bien la idea de que un individuo puede sostener concepciones del bien y de la justicia contrarias, como intenté justificar en la parte anterior, en función de si hablamos del ámbito político o el ámbito privado parece suponer una especie de personalidad múltiple, si ésta fuera así aceptaríamos una disminución radical de las diferencias en el ámbito público, aunque no su desaparición completa. Este estrechamiento, cabe decir, terminaría implicando que en la sociedad de Rawls no habría espacio para individuos con una cultura política distinta a la predominante, la cultura que justifica el giro político.

Una sociedad en la que existiera el tipo de consenso traslapado que propone Rawls, bajo las condiciones que impone dicho consenso (por ejemplo no limitarse a un mero modus vivendi), me parece que sería una en la que el pluralismo sería sumamente limitado. Considero que no estaría abierta a modos de liberalismo que no fueran específicamente del tipo de igualdad democrática fundamentados en la razonabilidad (del cual la justicia como imparcialidad es un ejemplo); por ejemplo, el liberalismo progresista de Dewey o el liberismo de la escuela austriaca tendrían "prohibida" la entrada a la esfera pública pues sus contenidos no están determinados por la cultura pública de la sociedad democrática de Rawls. En la medida en que la libertad es una de las circunstancias de las diferencias, el tipo de consenso que busca Rawls sólo podría existir si la libertad en el ámbito político $\mathrm{Si}$ la libertad es la causa de las diferencias, las condiciones no están dadas para el tipo de consenso que busca Rawls para una sociedad bien ordenada. En resumen, Rawls reconoce la importancia y los efectos de la libertad en el ámbito privado (por eso reconoce el pluralismo respecto a las ideas del bien), pero parece ignorar que el pluralismo estará igualmente presente en el ámbito político haciendo, en la medida en que mantenga el giro político con todas sus implicaciones, imposible sostener el consenso traslapado con todo lo que eso implica.

Por otra parte, el concepto de libertad en John Dewey parece llevarnos a reconocer que en una sociedad realmente libre, en donde se permita a los individuos decidir el modo en que desean conducir sus vidas en función de su propio juicio moral, el tipo de consenso que busca Rawls, un consenso fundamentado en la idea de la tradición, es imposible. Si el pluralismo razonable es un hecho, como estipula Rawls, no tenemos razón para pensar que el pluralismo 
en lo privado no se traducirá en un pluralismo en lo público; no queda claro por qué una persona razonable podría tener ideas del bien distintas de otras personas razonables pero no concepciones de la justicia. La razonabilidad en esos casos nos da para un modus vivendi, un tipo de acuerdo más bien fundamentado en la idea de que es mejor aceptar un orden que no refleje necesariamente mis convicciones pero nos permita vivir en paz, en lugar de imponer por la fuerza una concepción, arriesgando empezar un estado de inestabilidad y posible violencia.

El hecho de que las doctrinas comprehensivas, para mantenernos con la nomenclatura rawlsiana, tiendan a sistematizar las creencias de los individuos en su totalidad (en las distintas facetas de su vida), supone que esas doctrinas ordenarán la concepción de la justicia de los individuos. Si esto es realmente así, es considerable que el anhelo de Rawls, que pretende que todas las doctrinas comprehensivas razonables acepten la justicia como imparcialidad como si ese consenso fuera la medida misma de razonabilidad, es un deseo inalcanzable. Siempre que exista el pluralismo y la sociedad garantice la libertad, la existencia de un consenso traslapado como el que pretende alcanzar Rawls, que se desharía del conflicto, es imposible. La libertad tiende a generar diferencias irremediablemente; y libertades políticas generarán diferencias políticas con el tiempo.

Si queremos sostener que la sociedad liberal del Liberalismo Político es estable, tendremos que asumir que, en el largo plazo, el consenso traslapado sólo sería posible si todas las personas fueran liberales del tipo igualitarista democrático; la experiencia histórica, sin embargo, parece no estar muy de acuerdo con Rawls. Dicho esto, asumiendo que el problema de la estabilidad es central en el desarrollo de la justicia como imparcialidad, tendríamos que preguntarnos cómo una sociedad liberal puede de hecho lidiar con el conflicto de un modo que realmente le permita existir en el tiempo. Lo que haré será retomar la pregunta fundamental del Liberalismo Político perfilando una posible respuesta que responda a las complicaciones que conlleva el pluralismo.

Como he intentado mostrar repetidamente, la idea de un consenso que cumpla todas las condiciones del consenso traslapado y que, por tanto, no dependa en cierta medida en un modus vivendi parece injustificable en una sociedad plural y libre, en especial reconociendo los méritos de la idea comunitarista que supone la imposibilidad de ofrecer razones y justificaciones trascendentes para todas las doctrinas comprehensivas independientemente de sus ideas del bien $o$ concepciones de la justicia. Por tanto, considero que lo que restaría, para que la justicia como imparcialidad pueda ser estable en los términos políticos que 
propone Rawls, es esperar que la mayoría comparta la misma concepción (de inicio) y que, con el tiempo, no cambien de opinión pues, si por alguna razón la mayoría de un grupo con capital político lo suficientemente grande cambiara de opinión, parece que no tendríamos argumentos suficientes para justificar que un régimen liberal como la justicia como imparcialidad es, efectivamente, justo. Hay una preocupación de este tipo en las siguientes palabras de Robert Dahl, quien parece que, ante la posibilidad de que la sociedad pueda cometer actos injustos, asume la educación como el mecanismo para garantizar su buen funcionamiento:

Nada de lo que he dicho busca implicar que la mayoría de los ciudadanos no cometen errores. Pueden y lo hacen. Esto es precisamente el por qué aquellos que apoyan la democracia siempre han puesto un alto valor en la educación. Y la educación cívica requiere no sólo formación escolar formal, sino discusión pública, deliberación, debate, controversia, la pronta accesibilidad a información confiable y otras instituciones de una sociedad libre. ${ }^{2}$

Dado que Rawls, con el giro político, despoja a la sociedad de las herramientas necesarias para lidiar con el pluralismo de concepciones de la justicia que surgen con el tiempo, parece condenar el proceso democrático a uno en el que se impone la mayoría (esperando que la mayoría sustente la justicia como imparcialidad como concepción de la justicia política) en el procedimiento sin un criterio de justificación distinto al consenso mismo. Contra esto, la razón pública tiene una capacidad de acción limitada pues, para que funcione realmente, es necesario que los miembros de la comunidad acepten la concepción de la justicia y su naturaleza meramente política; sin embargo, ¿qué pasa cuando un grupo de ciudadanos niega la naturaleza política de la concepción de la justicia?, ¿podemos esperar que ese grupo reconozca la razón pública como medio para debatir los conflictos?, ¿puede existir una razón como la que postula Rawls sin una educación como la que plantea Dahl?

Estas preguntas nos sirven para buscar puntos de encuentro entre el pensamiento de Rawls y Dewey ya que, el segundo puede ofrecernos las herramientas necesarias para responderlas. Creo que si es posible encontrar una manera de integrar el pensamiento pragmático de Dewey con la justicia como imparcialidad debe de hacerse a partir de Teoría de la Justicia, antes de que Rawls hiciera el giro político. Dicha compatibilidad puede encontrarse en la intención de Rawls, en Teoría, de desarrollar una concepción de la justicia que, aun si no se pudiera afirmar su verdad en términos metafísicos (algo así como sostener que es la verdadera justicia independientemente de quién la mire), se sostenga por ser

${ }^{2}$ Robert Dahl, On Democracy (Londres: Yale University Press, 2000), 79. 
justificable dados criterios pragmáticos. Como afirma el siguiente fragmento que cité en el segundo capítulo de esta investigación:

Mi esperanza es que la justicia como imparcialidad aparezca como razonable y útil, si no es que completamente convincente, a un amplio rango de opiniones políticas reflexivas y, de este modo, exprese una parte esencial del centro común a la tradición democrática. ${ }^{3}$

Las palabras clave del fragmento anterior son "razonable" y "útil". Si mantenemos la idea de lo razonable como la planteó Rawls en el Liberalismo (que Rawls afirma que ya se encontraba en Teoría), así como algún concepto de la utilidad como criterio de efectividad, una de las razones para justificar la justicia como imparcialidad en Teoría se refería a valores pragmáticos de desarrollar acuerdos entre personas con concepciones distintas en buena medida por su eficacia. Considero que el pensamiento de Rawls, como fue plasmado en Teoría, y el de Dewey son más cercanos de lo que podría ser con el Rawls posterior al giro político, pues la idea de que la concepción de la justicia elegida debe ser aquella que se encuentre más y mejor justificada es compatible entre ambos. Si bien es cierto que en el Liberalismo Político Rawls asume que la concepción política de la justicia se debería de justificar desde cada una de las doctrinas comprehensivas, esto es insuficiente en tanto Rawls presupone que las justificaciones difícilmente servirán para doctrinas comprehensivas que no sean liberales por sí. Como ya analicé en el capítulo anterior, lo que Rawls asume es que no existen justificaciones que puedan trascender una doctrina comprehensiva particular (o quizá una familia de doctrinas comprehensivas que compartieran algunos rasgos, como podría suceder con algunos modos de cristianismo o con algunos de judaísmo); eso es un error. La justificación de la justicia como imparcialidad que realizó Rawls en Teoría, si bien creo que es criticable en algunos puntos (como queda claro en la segunda parte de esta investigación), muestra cómo es posible que distintos individuos, que posean distintas doctrinas comprehensivas, pueden estar en condición de aceptar la validez de una misma teoría de la justicia siempre y cuando reconozcan algunos puntos de vista mínimos compartidos (como reconocer los elementos moralmente relevantes para la decisión).

Si Rawls es capaz de lograr este objetivo, entonces las limitantes argumentativas que parece asumir en Liberalismo Político perjudican más el desarrollo y justificación de la justicia como imparcialidad de lo que la ayudan. La idea de la razonabilidad, que Rawls considera que está presente al menos

\footnotetext{
${ }^{3}$ John Rawls, $A$ Theory of Justice. xi
} 
implícitamente desde Teoría de la Justicia, puede reconocerse como un requisito mínimo (siempre que hablemos de personas razonables como aquellas que "están listas para proponer principios y estándares como términos justos de cooperación y a actuar conforme a ellos voluntariamente, dada la seguridad de que otros lo harán igual." ${ }^{4}$ ) y probablemente suficiente para realizar una justificación de la justicia como imparcialidad que no dependa necesariamente de la idea del consenso traslapado. En este contexto, la exigencia del consenso traslapado que propone Rawls se encuentra en lo que me parece un error fundamental: Rawls asume que en una sociedad liberal en donde se respeten los poderes morales de los individuos, imponer una concepción de la justicia sin el consentimiento de los ciudadanos (razonables) es ilegítimo en todos los casos. No parece que exista una contradicción en la posible imposición de una concepción de la justicia que sea efectivamente justa, aun cuando no cumpliera con las condiciones del consenso traslapado.

El error de Rawls proviene de que trabaja con una simplificación ideal, de algún modo utópica, que no se corresponde con la realidad del ciudadano. Aun cuando pudiera ser cierto que la mayoría de los ciudadanos desean que su sociedad esté regida por una concepción de la justicia que sea, de hecho, justa y aceptable para todos, esto no es, en modo alguno, una condición necesaria. El consenso, en la política real, puede existir en muchas ocasiones alrededor de virtudes (o vicios) que no son la justicia $y$, en ese término, puede terminar legitimando, si el consenso es la clave de la legitimidad, regímenes injustos. Dado que puede existir consenso a favor de un régimen como el Nazi en la Alemania del siglo pasado, difícilmente podríamos afirmar que el consenso es la característica que legitima la imposición de una concepción de la (in)justicia. El consenso, como afirma Joseph Raz, no ofrece las condiciones de legitimidad, aunque pueda extender los poderes de un régimen legítimo. ${ }^{5} \mathrm{El}$ consenso ni garantiza legitimidad política ni, del mismo modo, refleja la justicia (o falta de) de la concepción de la justicia hacia la que se ordena. La consideración sobre la justicia de una concepción determinada debe provenir de algo más que el consenso emanado de una cultura de fondo, como propone Rawls con el giro político.

Asumiendo que Rawls fuera capaz de justificar la justicia como imparcialidad desde una línea pragmatista y no en función de una hipótesis conservadora de la cultura o a una antropología necesariamente individualista (como fue criticado por su neokantismo en Teoría), estaría en posibilidad de

\footnotetext{
${ }^{4}$ Rawls, Political Liberalism. 49

${ }^{55}$ Cfr. Joseph Raz, Morality of Freedom (Oxford: Oxford University Press, 1986), 93.
} 
sostener que el único prerrequisito mínimo necesario para ser parte de una sociedad liberal, que se ordene en función de la justicia como imparcialidad, es únicamente el ser un individuo razonable, al margen de si acepta la concepción por ser parte del consenso traslapado o por un simple modus vivendi.

Podrían existir personas que sostuvieran que exigir la razonabilidad como una característica mínima implica una violación a ciertos valores o identidad cultural. Después de todo existen culturas que no reconocen el valor de la razonabilidad aunque sí de la obediencia y presumen que, dado que las diversas culturas son inconmensurables, no es legítimo asumir la razonabilidad pues estaríamos obligando un modo de ser particular (presumiblemente liberal), lo que sería injusto. A esos individuos Rawls podría responder que la idea misma del costo de oportunidad, tan popular en el ámbito económico, supondría que en el ámbito político la elección de una concepción de la justicia, la que sea, supone la negación de todas aquellas que sean incompatibles. La ventaja de una concepción de la justicia liberal frente a alguna otra opción no liberal es que esta (de la que suponemos por ahora, siguiendo el desarrollo de Teoría, la justicia como imparcialidad es la formulación que sería elegida bajo condiciones de imparcialidad) es la que tiende a permitir la mayor cantidad posible de "mundos" coexistiendo ordenadamente (en la medida en que es el liberalismo es mucho más tolerante a la diferencia, aunque no absolutamente tolerante a la diferencia).

En Teoría de la Justicia Rawls asume que una característica positiva de la justicia como imparcialidad, que la hace una mejor candidata como la concepción de la justicia mejor justificada, proviene de la necesidad de tener un procedimiento adecuado que nos permita hacer una distribución correcta (justa) de los bienes primarios. Lo que permitía afirmar la justificación de la justicia como imparcialidad no era que fuera el objeto de un consenso (aniquilando así las diferencias políticas de los ciudadanos), más bien lo que la justificaba era el hecho de que era útil y razonable como sistema de justicia distributiva. El hecho de que la justicia como imparcialidad podía ser justificada, como Rawls lo pensaba, a cualquier individuo que esté dispuesto a razonar con imparcialidad, permitía que fuera una concepción racionalmente defendible incluso ante ciudadanos que poseen una concepción de la justicia distinta. Parte del argumento en favor de la validez de la justicia como imparcialidad es elaborado en función de que sería la opción que mejor cumpliría con las necesidades de justicia de la sociedad (de ahí viene, por ejemplo, la crítica de Rawls al utilitarismo o al liberismo que se presentan como opciones alternativas a la justicia como imparcialidad). Esto 
permitía construir el argumento de la obligatoriedad de la justicia como imparcialidad no sólo como una concepción razonable, sino como una racional.

En este sentido, la idea de la justicia como imparcialidad como una concepción de la justicia procedimental imperfecta es compatible con la idea de la sociedad liberal que Dewey propone. La sociedad en general, para Dewey, corresponde a la organización de lo público a través de oficiales que representan los intereses de los ciudadanos. En la sociedad liberal de Dewey, después de todo, "los hombres no obedecen la ley porque piensen que las leyes están de acuerdo a un esquema de derechos naturales. Obedecen la ley porque creen, correcta o incorrectamente, que las consecuencias de obedecerlas son en general mejores que las consecuencias de desobedecerlas." ${ }^{6}$ Esta creencia puede referirse a la idea de que romper la ley trae consecuencias negativas en un sentido individual (ir a la cárcel por ejemplo) o porque una ley concreta se piensa como la mejor opción disponible.

Aun cuando parte de la justificación de la justicia como imparcialidad en Teoría proviene del neokantismo de Rawls, una de las premisas en el texto es que la justicia como imparcialidad debe ser aceptada, al menos siendo este un requisito, siempre que pueda funcionar como una concepción de justicia procedimental. Es cierto, como busqué exponer en la parte dedicada al análisis de Teoría, que la justificación deontológica de la justicia como imparcialidad tiende a contradecir los postulados de la filosofía pragmatista, en especial la de Dewey; sin embargo, considero que siempre que se justifique de acuerdo a su funcionalidad es posible realizar una lectura eminentemente pragmática dejando de lado el neokantismo o, para el caso, cualquier otro postulado metafísico, aun cuando se pueda seguir justificando desde una metafísica de modo distinto para distintas personas.

Decir que la verdad es justificación, que sería la propuesta pragmática de Dewey, no tendría que implicar necesariamente que sólo podemos hablar de verdad en función de la justificación (que podría considerarse un tipo de enunciación sobre la metafísica, o no existencia de ella, del mundo) y que por lo mismo negáramos necesariamente la existencia de otro tipo de verdades (como las reveladas o algún tipo de realismo metafísico) cuando las condiciones existieran. Lo que implicaría, más bien, es que en muchos casos hablamos de verdad en función la justificación (que para Dewey y otros pragmatistas, como Rorty, no existan verdades de otro tipo no implica que tenga que ser necesariamente aceptado para aceptar el método de justificación pragmático para la concepción de

\footnotetext{
${ }^{6}$ Dewey, Liberalism and Social Action. 27
} 
la justicia política). Esto querría decir que la justificación pragmática de la justicia como imparcialidad no intenta ser la única justificación existente, simplemente es la que procura servir como justificación válida cuando nos encontramos con el hecho del pluralismo.

Me parece que ese es el intento del giro político de Rawls, aunque por las razones que ya he mostrado no es exitoso: desarrollar un mecanismo de justificación de la justicia como imparcialidad que no dependa de una metafísica, en particular de su neokantismo tan criticado por los comunitaristas, que pueda ser aceptada por diversas doctrinas comprehensivas. El producto del giro político termina generando más problemas que soluciones y no contribuye a la estabilidad de una sociedad democrática y, sobre todo, liberal, pues Rawls termina quedando desarmado para justificar la justicia como imparcialidad a doctrinas comprehensivas que no son liberales. En cambio, si fuéramos capaces de hacer una lectura y justificación eminentemente pragmática, en especial una de naturaleza deweyana, de la justicia como imparcialidad, considero que los problemas de estabilidad podrían ser enfrentados de un modo más satisfactorio siempre que reconozca la naturaleza conflictiva de la política al tiempo que entiende la justicia como imparcialidad no como una concepción para desvanecerla o desaparecerla sino, por el contrario, para arbitrarla. Una lectura pragmática deweyana nos permite reconocer los riesgos a la estabilidad pero, de igual modo, nos permite desarrollar las herramientas necesarias para contrarrestarlos de un modo más efectivo que en la formulación original de la concepción de la justicia. Esto implica que será necesario hacer algunas concesiones en el planteamiento de la justicia como imparcialidad, entre ellos abandonar la idea del antiperfeccionismo (que puede ser planteado de un modo que no conduzca a todas las consecuencias negativas que preveía Rawls), el reconocimiento de la idea de verdad como justificación dentro de la arena pública y la apertura de la razón pública a argumentos de ámbitos diversos además del meramente político. Sobre esto y otros cambios hablo en esta parte.

Como vimos en el primer capítulo, para Dewey el uso del poder político se justifica ya que permite alcanzar un estado en el que las diferencias entre los individuos, es decir el conflicto, no conduzcan a caos o violencia abierta; en una sociedad democrática y liberal, este manejo del conflicto adecuado se torna en un mecanismo de desarrollo y progreso. En este punto Dewey parece estar haciendo uso de un criterio con ciertos rasgos utilitaristas, aunque es importante mostrar que dicho utilitarismo sería una especie de agregado, ya que el fin primero que busca Dewey no es, en modo alguno, utilitarista: en la medida en que cada 
individuo desarrolla sus capacidades, tiende a un mayor grado de perfección en sentido práctico del que hablé en el capítulo primero; este progreso individual conduce, en tanto los individuos viven en sociedad y participan de su cultura, a un progreso social en general (ese ha sido el camino de la ciencia por ejemplo, un individuo piensa en la solución a un problema y su solución contribuye al desarrollo de todo un campo).

Desde los presupuestos pragmáticos, democráticos y liberales, podríamos afirmar que, asumiendo que la sociedad debe permitir las diferencias entre los individuos, deberá ser responsable de garantizar las herramientas necesarias para que puedan actuar libremente (quizá, haciendo una lectura pragmática de Rawls, podríamos afirmar que aquí se encuentra contenido su igualitarismo democrático); de lo contrario difícilmente podríamos afirmar que realmente permite las diferencias. Del mismo modo, la sociedad permitirá las diferencias entre los individuos siempre y cuando el ejercicio de su libertad, aunque esté en conflicto directo con la de los demás, no se convierta en una imposición ilegítima sobre otros individuos. En este punto el liberalismo de Dewey es consistente con la tradición liberal, al menos a grandes rasgos, como puede ser representada con el siguiente fragmento de Brian Barry:

Los liberales deben sostener los derechos de aquellos que quieren perseguir sus metas individuales de desarrollo propio. Al contrario, sin embargo, de lo que usualmente se afirma, los liberales no están comprometidos con erradicar todos los modos de vida tradicionales para apoyar algún ideal de autonomía personal acultural. El punto aquí es simplemente que el reclamo realizado por los liberales no es en contra del objetivo de permanecer fiel a alguna cultura ancestral, sino contra la coerción de aquellos que no comparten dicho objetivo. Si esa posición hace al liberalismo "inhóspito a la diferencia", no es algo de lo que deba avergonzarse. Desde Eslovaquia a Singapur, es claro que las instituciones liberales no están seguras en estados en que el mantenimiento de una (supuesta o actual) cultura tradicional es aceptada como parte de la agenda política. ${ }^{7}$

La lectura pragmática de la justicia como imparcialidad, que retoma su valor como una concepción de justicia procedimental imperfecta, permite vincular la importancia de generar las condiciones sociales adecuadas (que están contenidas en buena medida en el segundo principio de la justicia como imparcialidad) así como la asignación de libertades y derechos (contenidos en el primer principio). De este modo la justicia como imparcialidad sirve como la concepción de la justicia que nos permite resaltar la importancia, como mantiene permanentemente Rawls en toda su obra, de una estructura básica ordenada que tienda a generar

${ }^{7}$ Barry, Culture and Equality. 66 
instituciones bien ordenadas: si la justificación de la concepción de la justicia responda a su funcionalidad, y siempre que la justicia como imparcialidad sea la más justificada, podremos asumir que la ordenación de la estructura básica y de la sociedad en un contexto más amplio estará ordenada. Este argumento es fácilmente rastreable, originalmente, a Teoría de la Justicia en donde, como insistí durante la segunda parte de esta investigación, conviven justificaciones pragmáticas y neokantianas de la justicia como imparcialidad. El argumento, al que Rawls regresa en el Liberalismo Político ${ }^{8}$ (aunque distanciándose, en mi opinión, de su foco pragmatista por causa del giro político) es el que se centra en la idea de la publicidad de la concepción de la justicia. En Teoría Rawls afirma que, "por tanto podemos explicar la aceptación del sistema social y los principios que satisface por la ley psicológica que las personas tienden a amar, cuidar y apoyar lo que sea que afirma su propio bien. Ya que el bien de todos se afirma, todos adquieren las inclinaciones para sostener el esquema." ${ }^{9}$

Este mecanismo de justificación, que me parece claramente pragmático, no cumple con las condiciones del giro político en la medida en que implica, al menos, una familia de ideas de corte liberal. Es fundamental recordar que, en el caso del argumento pragmático, el peso de las razones que demos para la justificación está necesariamente condicionado por los resultados previstos (o que de hecho hayamos obtenido) con el proceso de indagación. Es decir, si nuestra hipótesis es que la justicia como imparcialidad es la más justificada, esto sólo puede ser sostenido si los resultados de la conformación de una estructura básica regulada por los principios de la justicia son, de hecho, preferibles a las alternativas. Si nos mantenemos dentro de los márgenes del giro político, los argumentos para justificar que dichos resultados son de hecho deseables se nos escapan. Por el contrario, desde un argumento pragmático es posible afirmar que dichos resultados (la ordenación de la sociedad de acuerdo a la justicia como imparcialidad) son preferibles, y por lo mismo cumplirán con las condiciones de publicidad que mencioné antes, en tanto que satisfacen ciertos requisitos liberales como los del beneficio mutuo, la igual libertad y el apoyo al autorespeto de los individuos. ${ }^{10}$

Por lo tanto, la condición de estabilidad de las instituciones se da, al menos desde la perspectiva de Rawls, en función del impacto de la concepción de la justicia en el desarrollo de las instituciones a través de su influencia al informar la

\footnotetext{
8 John Rawls, Political Liberalism. 66-77

${ }^{9}$ John Rawls, Theory of Justice. 154-155

${ }^{10}$ Cfr. Ibid. 156
} 
estructura básica. Sin embargo, esta lectura nos conduce a caminos que Rawls, con el giro político, parece no querer transitar. Reconociendo que la exigencia "esquizofrénica" que implicaba Rawls para algunos (la de asumir que sean políticamente liberales aunque pudieran no serlo en lo privado) no se corresponde necesariamente con la circunstancia de la mayoría de las personas razonables (aunque puedan existir personas con doctrinas comprehensivas suficientemente inconsistentes en su contenido, no es deseable argumentar a favor de una concepción de la justicia en un hecho que podría no ocurrir), tendremos que conformarnos con que el impacto de la concepción de la justicia en la conformación de las ideas del bien será mucho mayor de lo que inicialmente se había planteado. $\mathrm{Si}$ aceptamos que las personas tienden a preferir concepciones de la justicia consistentes con sus ideas del bien, parecería importante afirmar que el desarrollo de una sociedad estable exige que las ideas del bien de los ciudadanos tiendan a ser consistentes respecto de sus concepciones de la justicia. En palabras de Dewey:

El problema de la libertad de individualidades que cooperan debe por tanto ser analizado desde el contexto de la cultura. El estado de la cultura es el de la interacción de muchos factores, siendo los principales la ley y la política, la industria y el comercio, la ciencia y la tecnología, el arte expresivo y la comunicación y la moral, o los valores que los hombres ponen a las cosas y los medios en que los evalúan; finalmente, aunque indirectamente, el sistema general de ideas usados por los hombres para justificar y criticar las condiciones fundamentales bajo las que viven, su filosofía social. ${ }^{11}$

Para Rawls, los alcances del liberalismo que propone Dewey podrían ser exagerados. Aunque se puede fácilmente argumentar que así era desde Teoría, los límites de la concepción de la justicia son la estructura básica y, posteriormente, los temas de esenciales constitucionales. El argumento de Dewey, sin embargo, es sugerente si reconocemos que aun cuando las personas poseen creencias inconsistentes (y por eso se explica que una persona liberal pueda tener opiniones no liberales respecto a algunos temas concretos), esa inconsistencia normalmente tiende a no ser tan extrema como Rawls considera posible. La única manera para tratar el problema de la libertad y la defensa de la justicia como imparcialidad, que parece ser la mejor elaboración de una concepción de la justicia dadas ciertas condiciones de imparcialidad (como lo muestra el experimento de la posición original), es promoviendo una cultura liberal que sostenga el trato imparcial entre los ciudadanos y que trascienda el ámbito meramente político.

\footnotetext{
${ }^{11}$ Dewey, Freedom and culture, 25
} 
Siguiendo la idea de Dewey, Rawls probablemente consideraría que la concepción de la justicia elegida, así fuera la justicia como imparcialidad, estaría infringiendo la libertad ya que llevaría a que el desarrollo de la idea del bien de los ciudadanos estuviera influenciada, directa o indirectamente, por una concepción liberal de la justicia. Si aceptáramos que no todas las doctrinas comprehensivas de la sociedad bien ordenada de Rawls son liberales, esta diversidad de doctrinas puede, en el largo plazo, convertirse en un riesgo para la estabilidad si no están bajo algún tipo de control. Desde Dewey, podemos afirmar que una sociedad bien ordenada puede "darse el lujo" de permitir que existan concepciones del bien y de la justicia no liberales dentro de ella (al final del día la existencia de la iglesia bautista de Westboro, de la que he hablado en capítulos anteriores, no pone en riesgo la viabilidad de los Estados Unidos de América). Sin embargo, este tipo de asociaciones deben ser contenidas (por ejemplo, mientras se mantengan dentro del marco de la ley, no permitiendo que propaguen sus ideas a personas que merezcan la protección de la sociedad, como podría suceder, por ejemplo, con los menores de edad) y, en cierto sentido, desincentivadas sin violentar sus derechos y garantías, incluidos en la concepción de la justicia gobernante, siempre ellos mismos no violenten las leyes o pongan en riesgo la constitución y la estabilidad social. Un poco más adelante argumento, esbozando a partir de la filosofía educativa de Dewey, algunos de los modos en que este ejercicio de estabilización puede suceder.

Para que el pensamiento pragmatista de Dewey pudiera ayudar a solucionar los problemas de estabilidad de la justicia como imparcialidad sería necesario incluir la idea de progreso, pues este es el producto del ejercicio de la libertad cuando utilizamos la razón en nuestras indagaciones. La idea de progreso, como he mostrado, no está libre de críticas. En algunos casos se asume que el progresismo (el de Dewey o cualquier otra de sus formas) rechaza ilegítimamente la tradición, como sucede con algunos conservadurismos. Del mismo modo, existen críticas que niegan el valor del progresismo en tanto que la idea misma de progreso está vinculada a una doctrina comprehensiva particular y, por lo mismo, no toma en cuenta al pluralismo de doctrinas comprehensivas (esta es en buena medida la postura de Rawls y, al mismo tiempo, de algunos comunitaristas).

Retomando lo dicho en el pasaje anterior de Barry, buscando dar respuesta a los dos tipos de críticas, no es que, incluso asumiendo una postura deweyana, el liberal esté en contra de una cultura ancestral sólo porque es ancestral; de hecho no hay necesidad de que esté contra ella en lo absoluto. Si una sociedad liberal procura debilitar o desaparecer una cultura ancestral lo hará únicamente si su permanencia limita el desarrollo libre de los individuos. Es fundamental tener 
claro que el desarrollo de los individuos no implica, desde el pensamiento liberal de Dewey, un camino determinado de acción, la idea del desarrollo se refiere, en este caso, a un perfeccionismo en sentido práctico, el perfeccionamiento de las prácticas existentes. Como vimos en el primer capítulo, cuando hablamos de perfeccionismo en sentido práctico, no estamos necesariamente suponiendo un modo de ser como el mejor, lo que sí suponemos es que hay ciertos modos de actuar (entendiendo actuar de un modo muy amplio) que son simplemente injustificables pues no responden a las necesidades y circunstancias en las que los individuos se desarrollan; conforme desaparezcan esos modos, tenderemos hacia la perfección en el sentido que establece Dewey.

Desde la perspectiva de Rawls, una vez dado el giro político, debido a que no hay un criterio para juzgar la justificación de una concepción de la justicia ya que cada justificación de cada doctrina comprehensiva debe de ser considerada irreductible la una a la otra, el único criterio para determinar lo adecuado de la concepción es el acuerdo mayoritario; ${ }^{12}$ en particular un acuerdo fundado en una cultura compartida que encarna las instituciones públicas de una sociedad democrática y liberal. El problema con esta aproximación es que, como ya he mencionado, Rawls, con su confianza en la posibilidad del consenso traslapado, se mantiene alejado de la realidad política y social histórica pues la cultura democrática y liberal, insisto en que así sucede cuando es efectivamente liberal, genera cambios en la cultura en tanto que los individuos puedan libremente decidir por ellos mismos y ejerzan efectivamente su libertad. Si el consenso es la clave para ver qué acciones, creencias y manifestaciones culturales son aceptables, Rawls termina dejando al "capricho de las masas" una de las tareas fundamentales de la justicia, discriminar quiénes pueden ser sujetos de un trato justo (vivir en una sociedad regida por la justicia como imparcialidad).

Al mismo tiempo, realizar una lectura pragmática de la justicia como imparcialidad nos permite retomar algunas de las ideas básicas del contractualismo, aunque estoy consciente que Dewey era un crítico del mismo, lo

\footnotetext{
${ }^{12}$ Cabe mencionar que Rawls, en la introducción a la edición Paperback del Liberalismo Político, supone la necesidad de ciertas instituciones para garantizar la estabilidad de la democracia liberal como la entiende. Considero desafortunado que Rawls enfatice la importancia de dichas instituciones en dicha introducción en la medida en que, su reconocimiento, puede terminar implicando cambios amplios en la estructura de justicia como imparcialidad. Más adelante se verá cómo podrían afectar algunas de esas instituciones, al desarrollo de la concepción de la justicia. Mientras tanto, es oportuno mencionar que dichas instituciones mínimas que, como menciona Rawls sirven como condiciones materiales mínimas, son: el financiamiento público de elecciones, igualdad de oportunidades (en educación y entrenamiento), distribución de ingreso y riqueza decente, la sociedad como empleador en el último caso y sistema de salud básico para todos. (Cfr. Rawls, Political Liberalism. lvi-lvii)
} 
que permitiría justificar de mejor manera la obligatoriedad de la concepción de la justicia. Si somos capaces de reconocer, al modo que terminó haciendo Rawls después de la publicación de Teoría, que la teoría contractual no está intentando desarrollar una propuesta antropológica y que no procura, en modo alguno, hacer una descripción sociológica del orden social, es posible evadir la crítica de Dewey al supuesto del contrato social. El centro de la crítica al contractualismo, desde el pensamiento de Dewey, proviene del reconocimiento de que, por un lado, el contractualismo es una teoría que explica la formación de la sociedad en función de una especie de agencia (como si la sociedad se hubiera creado en un punto específico de la historia por una fuerza determinable) y, al mismo tiempo, que el contractualismo tiende a antagonizar los intereses de los individuos y de la sociedad haciéndolos, en último término, irreconciliables. Una ventaja de buscar hacer una lectura pragmatista-deweyana de la justicia como imparcialidad es que, ya que el contractualismo es un mecanismo de representación que no intenta ilustrar el origen de la sociedad en modo alguno, sino que más bien es una herramienta que nos ayuda a identificar los elementos moralmente relevantes para la evaluación y desarrollo de una concepción de la justicia, permite hacer una elaboración de la concepción que escapa a algunas de las críticas comunitaristas en su origen. Sin embargo, y de esto proviene en cierta medida la utilidad del contractualismo desde una perspectiva pragmática, creo justificable suponer que, cuando las condiciones en las que se lleva a cabo el contrato hipotético tiendan a ser aceptables para personas razonables, las conclusiones a las que llegaremos serán, como consideraba Rawls en Teoría, ejecutables incluso a aquellos que no necesariamente estén de acuerdo con ellas (lo que podría suceder por diversas razones, incluso porque su doctrina comprehensiva no esté abierta a razonar con imparcialidad o no sea razonable en general).

Es fundamental recordar que el pragmatismo de Dewey no está en contra de la reflexión teórica o hipotética por sí misma, este tipo de reflexión es el camino de la ciencia por excelencia. Si los frutos de la reflexión, sin importar que tan hipotética sea, pueden ser justificables dadas las condiciones concretas, podrán ser aceptados y, en ese sentido, consistentes con los criterios de Dewey. En Teoría de la Justicia Rawls buscaba abordar los problemas de las diferencias de un modo que, aunque postulaba algunas condiciones poco justificables para la posición original (en especial algunos límites a la motivación y al conocimiento), pudiera efectivamente desarrollar una concepción de la justicia procedimental imperfecta que permitiera tratarlas de modo justo, como afirma Barry: "El punto es simplemente que, más allá de desear desaparecer la diferencia, Rawls construye 
una estructura bajo la idea de que la principal labor de una teoría de la justicia es lidiar con la diferencia de un modo que pueda ser mostrado como justo." ${ }^{13}$ Este proyecto constructivista, basado en la idea del contrato hipotético, puede ser compatible con una lectura pragmatista que supere los problemas de estabilidad que el mismo Rawls reconoce en su obra.

Lo que Rawls planteaba en Teoría de la Justicia era en parte un argumento que sentaba las bases necesarias para realizar un proceso de selección imparcial de quiénes pueden, de hecho, ser ciudadanos. La justicia como imparcialidad, como concepción de la justicia, no sólo define la manera en que los bienes primarios deben de ser distribuidos sino, al mismo tiempo, genera las condiciones para establecer quiénes pueden ser parte de dicha sociedad bien ordenada. Esta lectura nos permite plantear a la justicia como imparcialidad como una concepción que puede, de hecho, funcionar en una sociedad real. Contrario a lo que sucede con el planteamiento en el Liberalismo Político, cuando afirmamos la conveniencia y utilidad de la justicia como imparcialidad con un enfoque pragmático como una concepción de justicia procedimental, es posible argumentar que responde a algunas de las necesidades básicas de las democracias plurales, que implican, como afirma Chantal Mouffe, el continuo conflicto. ${ }^{14}$ No solo la justicia como imparcialidad nos permite saber cómo solucionar los conflictos distributivos en función de un procedimiento racional justo, sino que también nos permite comprender quiénes están en condiciones de ser ciudadanos y, por tanto, de entender qué exigencias son realmente legítimas.

Una vez que podemos reconocer que la aceptación y argumentación de la justicia como imparcialidad puede ser realizada de un modo pragmático, y que Rawls es el que genera el precedente en Teoría de la Justicia, se sigue el reconocimiento de que, si es racional y razonable, además de útil y estable, vivir en una sociedad ordenada por una concepción del bien liberal, será necesario que la mayoría de los integrantes de dicha sociedad compartan modos de vida liberales si es que tenemos alguna expectativa en mantener dicha concepción de modo estable en el tiempo. Una vez que reconocemos que todas las sociedades sientan bases de exclusión, es tan sólo normal reconocer que una sociedad liberal requerirá de la capacidad de controlar, limitar y en algunos casos excluir modos de vida que no sean adecuados para garantizar su estabilidad. Como ya mencioné, el liberalismo tiende a permitir una mayor cantidad de modos de vida, o variedades de ideas del bien y concepciones de la justicia, dado que "(L)os modos de vida liberales deben

\footnotetext{
${ }^{13}$ Barry, Culture and Equality, 69

${ }^{14}$ Mouffe, "The limits of John Rawls' Pluralism". 9
} 
de ser definidos simplemente como aquellos modos de vivir, cualesquiera que sean, que no son incompatibles con la existencia de instituciones liberales." ${ }^{15}$

Pensemos en una nación multicultural que no esté gobernada por instituciones liberales y democráticas; para hacerlo sólo tendríamos que recordar algunas de las naciones que, por ejemplo, participaron en la denominada primavera árabe. Bahréin es un ejemplo. Ali Aldairy, periodista e intelectual bahrení, plantea el reto de la revolución del siguiente modo:

En su núcleo, la revolución de Bahréin es sobre dos cosas: estado y sectas. ¿Cómo es que una secta puede hacer una transición a un estado? ¿Cómo es que un estado se convierte en un sistema de gobierno capaz de incorporar un cierto número de grupos sectarios con diferentes (si no es que abiertamente contradictorias) culturas, intereses y narrativas históricas? Este es el reto que Bahréin enfrentó el 14 de febrero, y ahora ese día es parte del viaje del país de una secta a un estado, de una tribu a un país. ${ }^{16}$

Bahréin es una nación monárquicamente gobernada por una familia, la familia Al Khalifa, donde los intereses de los grupos son claramente representados de modo desigual y por tanto, existe una amplia discriminación a uno de los grupos étnicos más grandes, la población Shia. Suponiendo que, de hecho, el movimiento de liberación del 2011 hubiera tenido el apoyo suficiente para derrocar al régimen de la familia Al Khalifa, que no lo tuvo, nos quedaría la pregunta de cómo podría gobernarse dicha nación. Si aceptáramos un análisis de la política en su sentido más simple, como hace Dewey antes de buscar la justificación de la democracia liberal, tendríamos que decir que, dadas las condiciones del país, parece razonable suponer que el grupo que cuente con el mayor poder político podrá hacer valer sus intereses a futuro; si la población Shia accede al poder a través de un movimiento revolucionario, tendrá los medios para imponer su autoridad y, probablemente, revertir las condiciones sociales de modo que sean injustamente beneficiados.

Si negamos que es posible ofrecer razones que pueden ser verdaderas (al menos en un sentido de justificación pragmática), el devenir político de una nación como Bahréin no puede ser juzgado como justo o injusto por sociedades que tengan doctrinas comprehensivas distintas más allá de una mera opinión. Si esto es así, y los shias decidieran imponer un régimen totalitario, no tendríamos realmente manera de generar una condena a dicho acto. El giro político en Rawls conduce a esta dirección pues, en la medida en que la concepción de la justicia se desarrolla

\footnotetext{
${ }^{15}$ Barry, Culture and Equality. 130

${ }^{16}$ Ali Aldairy, "Coming down from the Tower (Bahrain)"; en Diaries of an unfinished revolution (Nueva York: Penguin, 2013), 131-132.
} 
en función de la cultura política dominante, parecería inaceptable el que buscáramos juzgar a una sociedad con una cultura política en función de la justicia como imparcialidad. Por otra parte, el problema no queda, en cualquier caso, resuelto si asumiéramos una perspectiva neokantiana únicamente; si la única alternativa para afirmar la justicia como imparcialidad fuera a través de un argumento deontológico neokantiano, como el que se desarrolla en partes de Teoría de la Justicia, sería necesario reconocer que las críticas comunitaristas son capaces de mostrar que dicha justificación difícilmente puede ser reconocida por sociedades y culturas distintas. Después de todo fue en parte por esta crítica que Rawls realiza el giro político.

Por el contrario, la fortaleza del argumento en favor de la justicia como imparcialidad desde una base pragmatista-deweyana es que, cuando se reconoce que la razón para justificar la concepción de la justicia es su utilidad procedimental y que es, al mismo tiempo, la concepción que mejor sirve para garantizar una distribución imparcial, puede servir para juzgar concepciones distintas pues utilidad y eficacia parecen ser criterios trascendentes entre la mayoría de las doctrinas comprehensivas. El argumento pragmático es sugerente, en especial en circunstancias como las de Bahréin, porque la justicia, independientemente de qué tan ambiguo pueda ser el término por sí mismo, se refiere a condiciones concretas y materiales; una concepción de la justicia, la que fuera, que no pudiera ser aplicada, no tiene validez en tanto concepción de la justicia. Si la justicia como imparcialidad puede ser justificada en base a su eficacia y utilidad, que como concepción de justicia procedimental nos permite ordinariamente obtener resultados justos en las distribuciones de bienes, y es capaz de hacerlo de mejor modo que las otras concepciones "en competencia", entonces podemos afirmarla como la mejor opción y desechar las otras opciones. Esta perspectiva, por tanto, regresa el carácter civilizatorio al liberalismo que Rawls le quitó con el giro político como lo interpretó Habermas. ${ }^{17}$

Para poder sostener una versión pragmática, al modo del pragmatismo de Dewey, de la justicia como imparcialidad es necesario responder al menos dos cuestiones: por un lado, (i) alguien podría objetar que las condiciones y límites en la posición original no permiten una reflexión adecuada y, por lo mismo, discriminan injustamente a algunas doctrinas comprehensivas; por otro, (ii) podría ser posible que alguien negara la premisa de que desde un razonamiento imparcial es posible obtener una concepción de la justicia válida para una sociedad concreta.

${ }^{17}$ Hice amplia referencia a esta crítica en la nota 17 del capítulo anterior. 
El primer argumento es complejo, de hecho durante el segundo capítulo busqué mostrar cómo es que algunos de los límites al conocimiento y condiciones en la posición original que impone Rawls son inaceptables (por ejemplo la aversión al riesgo o, del mismo lado, su comprensión de los contenidos de la ciencia). En este sentido considero que el argumento está abierto a ser mejorado y a que, en caso de que las condiciones de la posición original cambiaran, podrían darse algunos ajustes a la concepción de la justicia como imparcialidad. Este hecho es consistente con el pensamiento falsacionista y pragmático con el cual procuro justificar la justicia como imparcialidad pues reconoce que no tenemos información perfecta y, en esa medida, conforme nuestros datos cambian, tendríamos que ser capaces de cambiar nuestras conclusiones. Dicho esto, la crítica podría estar en contra de la forma actual del argumento aunque no necesariamente en contra del procedimiento; nada impediría que pudiéramos recoger los elementos moralmente relevantes en alguna formulación posterior (bajo el supuesto que en efecto hubiera un problema con la formulación de Rawls).

Por otra parte, sobre el segundo argumento, considero que quien estuviera en contra de la justicia como imparcialidad porque considera que la imparcialidad no es una perspectiva adecuada para formular una concepción de la justicia, simplemente podemos reconocer que no es un individuo que pueda vivir dentro de una sociedad democrática dado que la negación de la imparcialidad supone, en último término, la negación de la igualdad moral de los individuos; no podríamos pensar que esa es una persona razonable, por tanto no es candidata para vivir en una sociedad democrática y liberal en lo absoluto. La democracia implica, necesariamente, una comprensión igualitaria de los individuos (entendida como igualdad moral) ya que, al menos en el tipo de democracia que estamos considerando, todos los ciudadanos tienen iguales derechos (aunque materialmente no tengan la misma capacidad) para influir en el proceso político.

En la medida en que sea posible justificar la justicia como imparcialidad desde una perspectiva eminentemente pragmática, es necesario reconocer que tendrán que existir cambios en la presentación de dicha concepción de la justicia alejándola de su formulación original (aunque en general cambiará más respecto a la versión de Liberalismo Político). En particular abordo tres temas que me parecen particularmente relevantes: (i) la razón pública, (ii) el rol de la educación en la sociedad (que por sí mismo es un tema que Rawls no aborda con profundidad y que, por el contrario, es central en el pensamiento pragmático de Dewey) y (iii) el antiperfeccionismo rawlsiano. Esta lista de cambios no es exhaustiva en sentido 
alguno, más bien intenta dar una idea de lo que dicha reformulación implicaría para la justicia como imparcialidad.

\section{La razón pública conforme al giro pragmático}

El concepto de la razón pública es particularmente relevante para poder comprender el giro político en Rawls. En el Liberalismo Político la razón pública juega un papel fundamental para garantizar la estabilidad en la comunidad pues, al ser la razón compartida por todos los ciudadanos, establece los criterios adecuados de discusión y solución de problemas. A modo de recordatorio es pertinente mencionar las dos partes que constituyen la razón pública: por un lado están los principios de la justicia, mismos que ordenan la estructura básica (en el caso de la justicia como imparcialidad nos referimos a los dos principios de la justicia); por otro lado, la razón pública está constituida por las guías de investigación (principios de razonamiento, reglas de evidencia y las políticas concretas con las que se llevan a cabo las "investigaciones"). Además, el sujeto propio de la razón pública es el "bien público". Esto quiere decir que los temas de razón pública son aquellos propios de la esfera pública; en especial los que se refieren a la concepción política de la justicia.

La razón pública permite a Rawls continuar con la tradición liberal de evitar que la fuerza del Estado pueda terminar sirviendo para imponer una moral particular. Dado que los contenidos de la razón pública se limitan a la existencia de los principios de la concepción de la justicia, no permite que otros principios, provenientes algunos de doctrinas comprehensivas, puedan servir para ordenar la estructura básica y para darle forma a temas de esenciales constitucionales. En la medida en que Rawls realiza el giro político, e intenta aislar la esfera pública alejándola de argumentos metafísicos y morales de las doctrinas comprehensivas, es que, o al menos es lo que intenta, puede desarrollar una idea de la razón pública que renuncie a argumentos del orden privado. Sin embargo, el éxito de la razón pública, al modo en que está planteada en Liberalismo Político, depende en buena medida de la posibilidad de realizar el giro político; como he intentado mostrar hasta ahora, el giro político no se puede sostener en la realidad.

Uno de los problemas con el giro político está en que supone una sociedad conservadora a la vez que genera las condiciones de libertad y progreso que tienden a negar la existencia de ese tipo de sociedades. Siempre que se respeten los 
dos principios de la justicia, la posibilidad de que se pueda mantener la concepción de la justicia política en función de su origen histórico (es decir ser parte de la cultura política de una sociedad democrática y liberal) parece poco razonable en un tiempo prolongado (dado que Rawls no ofrece un argumento a favor de ello más allá del requisito de ser parte de la cultura política). Dicho lo anterior, hay al menos dos posibilidades para justificar la imposición de la concepción para procurar un régimen estable en el tiempo: por un lado podría ser justificada mediante la tradición o, por otro, que se pudiera demostrar su verdad o pertinencia dadas las condiciones sociales del momento. La primera opción es inaceptable dada la capacidad de los seres humanos de exigir y ofrecer razones. La imposición de la concepción de la justicia en función de la tradición es inaceptable ya que no respeta a los seres humanos (con sus poderes morales y racionales) y no sienta bases reales de cooperación libre y, en el caso de la justicia como imparcialidad, se volvería una contradicción en sí misma.

La segunda opción, que implica que la concepción de la justicia debe de mostrarse como verdadera (o justificada), nos conduce al centro mismo del problema del giro político y la posibilidad de realizar una lectura pragmática de la justicia como imparcialidad. Es posible desarrollar un argumento, al modo en que Rawls realizó en Teoría de la Justicia, mediante el cual se pueda probar la conveniencia, utilidad y eficacia de la justicia como imparcialidad como un ejemplo de justicia procedimental imperfecta, para que sea la concepción que personas racionales y razonables elegirían en condiciones de imparcialidad (con circunstancias de escasez moderada). Considerando que dicha justificación pueda ser realizada, es posible mantener que la justicia como imparcialidad podría ser estable en una sociedad donde se garantizara la libertad y las condiciones sociales necesarias para su existencia. Dado que la libertad social conduce a la variedad de opiniones (entre ellas sobre cuál debe de ser la concepción de justicia adecuada), la justicia como imparcialidad se mantendrá estable siempre que pueda justificarse como la concepción más justa entre diversos candidatos. La apuesta de un giro pragmático sería que, de hecho, la justicia como imparcialidad sí se justifica como la más justa y, por lo mismo, puede ser impuesta sin ser una contradicción.

Si esta posibilidad de justificarse es plausible, implicaría, desde la postura pragmática que intento plantear, que los contenidos de la concepción de la justicia deben estar abiertos a revisión continua. Si la concepción de la justicia no estuviera abierta a revisión, difícilmente podríamos afirmar que es la más justificada dado que las condiciones materiales (políticas, sociales, ecológicas, culturales o de cualquier otra índole) pueden haber cambiado lo suficiente para considerar que la 
justicia como imparcialidad no es ya, como sí lo fue en algún momento, la mejor candidata. ${ }^{18}$ Asumiendo que requerimos de la justificación de la concepción de la justicia y que su revisión debe de ser un ejercicio libre, es posible darse cuenta de que la razón pública se vuelve una herramienta inútil, al menos en la manera en que es presentada por Rawls.

Si los contenidos de la razón pública son la concepción de la justicia, así como los métodos de indagación, la cuestión de cómo podríamos evaluar o cuestionarnos sobre la justificación de la concepción misma se vuelve irresoluble desde la razón pública misma. Para entender a lo que me refiero podría plantear el hecho en términos de las revoluciones científicas, como explica Thomas Kuhn. En la Estructura de las Revoluciones Científicas, Kuhn afirma el desarrollo del conocimiento científico mediante revoluciones que cambian lo que denomina la “ciencia normal" ${ }^{19}$ La "ciencia normal" está constituida por el cúmulo de hipótesis que permiten responder a las interrogantes presentes en un área del conocimiento científico; en la medida en que la "ciencia normal" sea capaz de explicar suficientemente la realidad (y es importante mencionar que en ocasiones el paradigma no puede explicar completamente el por qué acontecen algunos hechos $^{20}$ ) será aceptada. Cuando la "ciencia normal" no pueda seguir explicando la realidad, surgen hipótesis nuevas que terminarán desembocando, después de que suficientes hipótesis sean estructuradas, en una nueva "ciencia normal". Para que estos cambios ocurran es necesario que nueva información (sea gracias a una mejor capacidad de observación, cambio de circunstancias, o nuevas hipótesis de otros campos) esté disponible; siempre que las condiciones y la información sean estables, presume Kuhn, la "ciencia normal" se mantendrá pues no es preciso desarrollar una nueva hipótesis.

En una sociedad que esté abierta a la revisión de su concepción de la justicia, que reconozca el papel de la razón pública que considera Rawls, es importante afirmar que, si el contenido de ésta son los principios de la justicia, y sólo es

\footnotetext{
18 Podemos afirmar que, además, si ese fuera el caso, no hay ninguna razón para querer una concepción de la justicia como el fundamento del orden social que no fuera la mejor candidata posible. En este sentido Rawls no intentaría afirmar que justicia como imparcialidad debe ser inmune a revisión, si lo fuera, implicaría que Rawls es un conservador que no estaría realmente abierto a las cargas del juicio, contrario a lo que él mismo muestra.

19 Thomas Kuhn, La estructura de las revoluciones científicas (Buenos Aires: Fondo de Cultura Económica, 2004), 51.

20 Un ejemplo de cuando esto sucede es, por ejemplo, con la astronomía aristotélica, que era incapaz de explicar consistentemente por qué algunos planetas mantenían órbitas irregulares (esto era especialmente evidente conforme los instrumentos de medición iban mejorando) aunque seguía siendo la explicación normal del orden del cosmos hasta que Galileo demostró materialmente la hipótesis copernicana.
} 
posible argumentar desde ellos usando la razón pública (pues los asume como un hecho dado), entonces no queda claro cómo podría ser posible realizar la revisión de la concepción de la justicia desde una razón pública compartida. Dicho de otro modo, asumiendo que el contenido de la razón pública acepte los principios de la concepción de la justicia injustificadamente (pues parece que, desde Rawls con el giro político, no le corresponde a la razón pública el justificar los principios de la justicia), el acto de discusión sobre el contenido de la concepción política de la justicia termina siendo, en mi consideración, un acto estéril. Al final, parece que Rawls asume, en el Liberalismo Político, que dicha discusión, en caso de que ocurriera, debería de suceder en la cultura de fondo (background culture):

Esta es la cultura de la sociedad civil. En una democracia esta cultura no está, por supuesto, guiada por una idea central o principio, sea político o religioso. Sus muchas y diversas agencias y asociaciones con su vida interna residen dentro de un marco de ley que asegura las libertades familiares de pensamiento, expresión y el derecho a la asociación libre. La idea de la razón pública no aplica a la cultura de fondo con sus muchas formas de razón no pública ni medios de ningún tipo. Algunas veces aquellos que aparentan rechazar la idea de la razón pública realmente buscan afirmar la necesidad de una discusión abierta y completa de la cultura de fondo. Con esto el liberalismo político está completamente de acuerdo. ${ }^{21}$

La referencia anterior termina siendo problemática para la estabilidad del proyecto rawlsiano. En cuanto la concepción de la justicia se concibe de acuerdo a la cultura política, la razón pública termina estando en el largo plazo condicionada en su contenido por los postulados mayoritarios de la cultura de fondo. De nuevo, una vez analizados los límites de la razón pública, parece que la sociedad bien ordenada depende de una sociedad profundamente conservadora para existir. Dado que hay una escisión entre el ámbito político y el privado, la reflexión privada parece que no puede ser condicionada por la política en modo alguno.

En este punto Rawls termina generando un riesgo desproporcionado. Cuando asume que el ámbito político (a través de la razón pública) debe de abstenerse de intervenir en la discusión sobre la cultura de fondo (ique es la que conforma la concepción de la justicia!), parece que la condición para que se mantenga la estabilidad podría ser una de las dos siguientes: (i) los ciudadanos en una sociedad bien ordenada, que actúan en completa libertad, tienden a no tener un impacto en la cultura de fondo con sus actos y, por tanto, la concepción de la justicia política no tenderá a cambiar, o (ii) asumiendo que, por el contrario, los actos de los ciudadanos sí impactan la cultura de fondo y podrían conducir a un

${ }^{21}$ Rawls, Political Liberalism. 443-444 
cambio en la concepción política de la justicia, los oficiales, jueces y candidatos a puestos de elección popular (quienes son aquellos que deben principalmente dialogar con la razón pública, lo que quiere decir que deben de ser los que principalmente razonan en función de la concepción de la justicia ${ }^{22}$ ) mantendrán la concepción de la justicia como el criterio ordenador independientemente de lo que diga la cultura política.

La segunda opción creo que sería inaceptable para Rawls pues haría una burla de la idea del consenso traslapado e implicaría la imposición de una concepción de la justicia que no está, según el giro político, justificada. Sobre la primera posibilidad me parece que es la que informa el conservadurismo rawlsiano del que he hablado y se sostiene por una idea incorrecta de lo que es la cultura. Si reconocemos que no hay una razón para que se mantenga dicho conservadurismo en una sociedad liberal, nos vemos en la necesidad de reconocer que los límites en el contenido a la razón pública que propone Rawls terminan siendo, en buena medida, insatisfactorios. En este sentido, creo adecuado citar a Benjamin Barber sobre la posibilidad de desarrollar una democracia en una sociedad:

Cuando consideramos una democracia en una sociedad emergente, por tanto, es vital establecer las condiciones educativas y cívicas necesarias para cultivar ciudadanos comprometidos antes de construir una constitución de arriba hacia abajo, que de hecho sólo puede funcionar adecuadamente cuando es cuidada por un cuerpo de ciudadanos competente. Madison advirtió que una carta de derechos era sólo un parapeto desde el que la democracia no podía ser defendida de ausencia de ciudadanos informados y participativos. Los fundadores sabían suficientemente bien, en palabras de John Adams, que una nación que espera ser "ignorante y libre... espera lo que nunca sucederá" ${ }^{23}$

Este punto debe ser central para la existencia de una concepción de la justicia en una sociedad de modo estable. Si la razón pública es algo que deben tener los ciudadanos, pero que sólo se le debe exigir a unos pocos a razonar en función de ella, ¿cómo podríamos garantizar la estabilidad de social?

Considero que una lectura pragmática de la justicia como imparcialidad reconoce que la razón pública no debe renunciar a la indagación sobre la concepción de la justicia misma, de modo que pueda mudarla (en parte o en su totalidad) en caso de ser necesario. Esto implica que sería necesario reconocer que

\footnotetext{
${ }^{22}$ Cfr. Ibid. 444

${ }^{23}$ Benjamin Barber, Strong democracy, participatory politics for a new age (Berkeley: University of California Press, 2003), xvii.
} 
la razón pública debe asumir la concepción de la justicia y sus principios como fundamentos justificados para analizar cuestiones que los competen pero, al mismo tiempo, que debe estar en disposición de analizar si la concepción misma y sus principios son adecuados dadas las circunstancias de la sociedad. Si este uso de la razón pública es razonable, entonces deberemos afirmar que, incluso entre ciudadanos, en una conversación privada, los argumentos mejor justificados que traten temas públicos (incluyendo la pertinencia de la concepción de la justicia misma) serán aquellos que se elaboren en función de la razón pública, dado que ésta se refiere a un método de reflexión apropiado para la vida política; del mismo modo que, aun entre legos en la materia, tendemos a asumir que una explicación naturalista está mejor justificada (siempre y cuando esté realmente justificada por supuesto) que una sobrenatural para un fenómeno del mundo natural. Es más: sostengo que es necesario permitir a la razón pública, que funciona de acuerdo a un método de investigación, el indagar no sólo sobre la materia que delimita Rawls y la concepción misma sino, al mismo tiempo, la totalidad de la vida de los individuos siempre que sus actividades tengan algún tipo de repercusión pública; lo que no significa que sea el único, quizá ni siquiera el más relevante, punto de vista para analizar las acciones de las personas.

La lectura pragmática de la justicia como imparcialidad conduce a que la aplicación de la razón pública, y por tanto de la concepción de la justicia, no puede limitarse al mero ámbito político en los términos que Rawls había definido. Considerando que la distinción entre público y privado que hace Rawls parece no reconocer la íntima vinculación entre ambos (sin afirmar, lo que sería falso, que son indistinguibles), una comprensión pragmática de la justicia como imparcialidad permite reconocer cómo es que esta concepción liberal de lo justo no se limita únicamente a la estructura básica ni a los esenciales constitucionales, aun cuando estos fueran sus sujetos fundamentales. Dewey, como si hubiera previsto el planteamiento eminentemente político de Rawls, afirmaba:

Ya no es fácil mantener la esperanza que dadaa la libertad política como la única cosa necesaria todas las demás con el tiempo se le agregarán -y por tanto a nosotros. Ya que ahora sabemos que las relaciones que existen entre las personas, afuera de las instituciones políticas, las relaciones de la industria, de comunicación, de ciencia, arte y religión, afectan las asociaciones diarias y por tanto afectan profundamente las actitudes y hábitos expresados en el gobierno y las reglas de ley. Si es cierto que lo político y legal actúan para moldear otras cosas, es aún más cierto que las instituciones políticas son un efecto, no una causa. ${ }^{24}$

\footnotetext{
${ }^{24}$ Dewey, Freedom and culture. 13
} 
Es importante comprender, como parece ser que Rawls no hace, que las diversas esferas de la vida de las personas tienden a tocarse; así como un mismo hecho puede ser juzgado en función de su moralidad, su impacto político, económico o estético, hay algunas que, aunque aparentemente están desvinculadas los unos de los otros, tienen consecuencias entre ellos. Si asumimos que las diversas áreas pueden ser perfectamente separables, como parece hacerlo Rawls en el Liberalismo Político respecto de la política, es complicado garantizar la estabilidad de una sociedad liberal. Sólo pensando de este modo, en la acción humana como una serie de compartimentos perfectamente distinguibles y con principios de conocimiento y argumentación completamente independientes, es que podríamos suponer que un individuo posea una concepción política de la justicia liberal y, al mismo tiempo, una idea del bien dogmática. Por el contrario, la realidad parece evidenciar que la experiencia política (que puede ser valorada en buena medida en función de la justicia) es relevante en la vida del hombre, incluso en su acción no política (o al menos en la que no es eminentemente política) si reconocemos que la afirmación del ser humano como un zoon politikon es, más que una afirmación metafísica, una descripción de la realidad humana. Si el hombre es naturalmente un ser social, como evidentemente es, eso implica que parte de su vida (quizá la más importante) supone la interacción con otros seres humanos; esas interacciones, en muchas ocasiones, pueden ser juzgadas desde el punto de vista de la política en general y de la justicia en particular. Siempre que esto ocurre, es innegable que la concepción de la justicia tiene un papel fundamental.

Esta línea de pensamiento acarrea algunos riesgos. Reconocer la importancia de la política en la vida de los individuos puede conducir a una confusión sobre los ámbitos públicos y privados con consecuencias perniciosas para ambos. Sin embargo, del reconocimiento de este riesgo no se sigue una acción concreta ya que, sólo si estamos en disposición de discutir públicamente, usando la razón pública para analizar todo tipo de aseveraciones e ideas, incluso las de orden moral, podremos aplicar la inteligencia en la ordenación de la sociedad y, al hacerlo, mantener contenidos a individuos o grupos que busquen cambiar la cultura de fondo de modo que atente contra la estabilidad.

La razón pública no puede quedar, si es que es la herramienta necesaria para determinar la concepción de la justicia y su aplicación en la sociedad, limitada a un ámbito de especulación tan restrictivo como el que propone Rawls si va a cumplir con su objetivo: servir como una herramienta para garantizar la estabilidad de la sociedad bien ordenada. La idea de la democracia de Barber es distinta al ideal liberal de Rawls, sin embargo, el planteamiento sobre la 
importancia de la racionalidad en la arena pública (que, insisto, implica más que la mera ordenación de la estructura básica así como la discusión sobre esenciales constitucionales) es adecuado por parte de Barber, en particular si es posible desarrollar una lectura pragmática de la justicia como imparcialidad: "El lenguaje es siempre el campo de batalla crucial; conserva o liquida la tradición, pone a prueba o promueve los paradigmas de poder establecidos y es el cristal con el que se mira toda visión futura. Si el lenguaje está vivo, la sociedad puede crecer; si es dialéctico, la sociedad puede reconciliar sus partes (...)." ${ }^{25}$

En la medida en que Rawls exenta a la razón pública de la tarea de analizar la cultura política y a la concepción de la justicia, piensa que puede levantar un muro que garantiza su estabilidad; sin embargo, sucede todo lo contrario. Si comprendemos que el lenguaje, es decir la razón y el diálogo, es, como afirma Barber, el campo de batalla en el cual la tradición se juega su supervivencia, es necesario reconocer que la concepción de la justicia (que es parte de una tradición en una sociedad) se mantendrá si es que, junto con las condiciones materiales pertinentes por supuesto, es posible justificarse racionalmente. Al dejar la crítica de la cultura de fondo sin un estándar metodológico, Rawls termina poniendo en riesgo la tradición misma que quiere defender. Si nos remitimos a Teoría de la Justicia es fácil reconocer que Rawls consideraba que sí era posible realizar ese tipo de crítica cultural de modo que pudiera terminar justificando la justicia como imparcialidad. Criticar el perfeccionismo, el utilitarismo y el liberismo, por nombrar algunas de las comprensiones sociales a las que Rawls les dedica tiempo en Teoría, reconocía la existencia de bases racionales para realizar dicho análisis.

La razón pública, desde una lectura pragmática de la justicia como imparcialidad, debe entenderse como un método falibilista preocupado por juzgar la justicia y, en ese sentido, abierto a definir el contenido mismo de la idea de lo justo, dentro de la existencia social completa, incluso más allá de ámbito de la estructura básica y los esenciales constitucionales. Una de las tareas fundamentales, si no es que la más relevante, de la razón pública es la de juzgar los criterios de justificación censurando, al mismo tiempo, aquellos que sean improcedentes.

La preocupación de Rawls al postular la idea de la razón pública parece ser que, si en la sociedad existe el hecho del pluralismo, es necesario compartir un lenguaje; entiéndase por esto un modo de razonar, que permita a los individuos llegar a acuerdos:

${ }^{25}$ Barber, Strong democracy. 197 
Los ciudadanos se dan cuenta de que no pueden alcanzar acuerdos, o siquiera llegar a una comprensión mutua en base a sus doctrinas comprehensivas irreconciliables. En vista de esto, ellos deben considerar qué tipos de razones pueden razonablemente dar los unos a los otros cuando las preguntas fundamentales están en juego. Propongo que en la razón pública las doctrinas comprehensivas de la verdad o lo correcto sean reemplazadas por la idea de los políticamente razonable que se refiere de ciudadanos a ciudadanos.

Central a la idea de la razón pública es que ni critica ni ataca una doctrina comprehensiva, religiosa o no religiosa, excepto en tanto esta doctrina sea incompatible con los esenciales de la razón pública y la vida democrática. ${ }^{26}$

Desde una perspectiva pragmatista como la de Dewey, la objeción contra la idea de la razón pública en Rawls no proviene de su objetivo fundamental: el desarrollar un modo de argumentación que permita construir acuerdos. Es posible hablar de la razón pública como una aplicación falsacionista de la razón referida al ámbito público, en particular al de la justicia en la repartición de bienes dados los intereses de los individuos. No habría nada de incorrecto en afirmar que una doctrina comprehensiva, religiosa o no, es falsa dados los criterios de justificación públicos si, por ejemplo, asumiera que el calentamiento global causado por el hombre es una conspiración china, a pesar de la clara evidencia que prueba su existencia, sólo porque su doctrina comprehensiva no valora de un modo adecuado la evidencia científica.

Una lectura pragmática de la justicia como imparcialidad implica, para realmente ser tal, la entrada de la verdad en el ámbito político (lo que no implica una verdad metafísica). Si bien es cierto que no todos los temas o aseveraciones deben considerarse como verdaderos o falsos (pues algunos simplemente se sancionen como convenientes, como por ejemplo podría ocurrir con la imposición de límites de velocidad), hay otras que, siempre que estén bien justificadas, serán referidas en términos de verdad. En palabras de Joshua Cohen:

La razón por la que el concepto de verdad no tenga lugar no puede ser que las aseveraciones hechas por una concepción política no sean aptas para ser referidas como verdaderas; esas aseveraciones deben de ser aptas a ser verdaderas, aun si la concepción política rechaza el concepto de verdad. Deben de serlo si es que va a existir un lugar común para discutir bajo condiciones de desacuerdos doctrinales. Negar la aptitud a la verdad de las aseveraciones por causa de la razón pública ofendería los esenciales mismos de la idea de la razón pública. ${ }^{27}$

${ }^{26}$ Rawls, Political Liberalism. 441

${ }^{27}$ Joshua Cohen: "Truth and public reason"; Philosophy \& Public Affairs, col. 37 no. 1 (2009), 17-18. 
La recuperación de la idea de la verdad en el ámbito público es necesaria si es que el liberalismo tiene alguna posibilidad de ser estable. La preocupación del gro político, de generar las condiciones adecuadas para un consenso traslapado, dadas las condiciones de libertad en una sociedad democrática, en donde se permite y dentro de ciertos límites se promueve el pluralismo, mediante un acercamiento al conservadurismo alejándose de un liberalismo moral es insuficiente. La razón pública debe de funcionar de modo que permita el diálogo entre diversas doctrinas comprehensivas y no me queda claro cómo las consecuencias de dicho diálogo se pueden volver justificadamente vinculantes de las acciones de los hombres si están basadas únicamente en función del consenso. Si no hay un modo de hablar de las conclusiones de la razón pública en términos de verdad, ¿no tendríamos que concluir que al final del día la razón de que tengamos una concepción determinada se remite, en último término, a la imposición de la mayoría?

La preocupación de Rawls, en el momento en que afirmamos la importancia de hablar en términos de verdad al utilizar la razón pública, sobre la imposibilidad de construir consensos a partir de un diálogo de doctrinas comprehensivas, morales y religiosas, que afirman poseer la verdad aunque tengan posturas contrarias, es un reto a enfrentar. Una razón pública fundada en una perspectiva pragmática supone que un diálogo entre ciudadanos que sostengan doctrinas comprehensivas distintas se efectúa en base a justificaciones que sean aceptables a las distintas partes siendo congruentes con la tradición liberal. Un argumento elaborado desde una doctrina comprehensiva particular, en función de premisas que no son aceptables para otros individuos razonables, carece se fuerza justificatoria.

Un ejemplo típico al respecto es la búsqueda de la imposición de la moral por parte de algún grupo determinado. Hart, en Ley, Libertad y Moralidad, analiza la relación entre los tres conceptos que titulan su obra y el modo en que, cuando la ley procura satisfacer las necesidades de la moral, la libertad es la que sufre. Al respecto, analiza el modo en que algunos de los argumentos típicos en la defensa de la moral a través de la ley:

Por tanto, Lord Devlin basa su respuesta afirmativa a la cuestión en el principio general de que es permisible para cualquier sociedad el llevar a cabo los pasos necesarios para preservar su propia existencia como una sociedad organizada, y piensa que la inmoralidad -aun la inmoralidad sexual privada- puede, como la traición, ser algo que pone en riesgo la existencia de la sociedad. ${ }^{28}$

${ }^{28}$ H. L. A. Hart, Law, liberty and Morality (Stanford: Stanford University Press, 1963), 19. 
Es por argumentos como el delineado por Hart que Rawls promueve la idea de la razón pública del modo en que lo hace. Aceptando que limita a los individuos que forman parte del proceso de ordenación de la estructura institucional a pensar sólo en función de los principios de la justicia, desvanece el argumento en favor de la moral de un grupo en particular. Sin embargo, al hacerlo, excluye a aquellos que sostienen ideas del bien antiliberales a intentar justificarlas frente al resto de los ciudadanos y reconocer su alcance y su adecuación a una concepción de la justicia presumiblemente liberal; más bien permite a dichos grupos suponer que sus ideas están más allá de la crítica y del escrutinio de la justicia y la razón pública.

Si interpretamos la razón pública desde una vertiente pragmática, seríamos capaces de abrir el diálogo a ideales no liberales, como el de imponer una moral particular a través de la ley a individuos que no comparten dichos ideales. Al hacerlo se verían obligados a responder cuestiones como: ¿en qué sentido la no obligación de este principio moral (el que fuera) pone en riesgo la existencia de la sociedad si, por ejemplo, el acto es eminentemente privado?, ¿en qué sentido es socialmente preferible la persecución de una minoría que no ocasiona un daño a un tercero (en la medida en que fuera un acto eminentemente privado e que se quisiera limitar) a una sociedad tolerante? Hay quienes, ante preguntas como las anteriores, procuran defender la causa intolerante y conservadora de su moral pública; en ese sentido, gracias a la razón pública, dichos individuos pueden ser abiertamente criticados y evidenciados en su intolerancia. El rechazo al diálogo abierto, ${ }^{29}$ sea basándonos en la razón pública o por cualquier otra razón, termina obstaculizando el análisis crítico de posturas políticas, algunas legítimas y otra no, que escapan al escrutinio público y, en esa medida, pueden no cobrar la relevancia que desearíamos o seguir existiendo cuando no lo desearíamos (cuando dichas posturas e ideas plantean una idea de la sociedad más injusta).

El liberalismo de Rawls, en particular desde el giro político, se mantiene en contra de la idea de una moral social, pública y obligatoria. Sin embargo, dado que la razón pública se encuentra limitada, como ocurre en el giro político, termina sentando las bases para que dicha moral pueda terminar desarrollándose en un formato incompatible con una concepción liberal en el devenir histórico y real, en el que Rawls en ocasiones parece no interesarse. La importancia del diálogo abierto

\footnotetext{
${ }^{29}$ El tema de los límites a la libertad de expresión tiene que estar contemplado en esta idea del diálogo abierto. Me parece que se deben de garantizar condiciones mínimas de diálogo para que verdaderamente pueda ser considerado como tal. Una de estas es un cierto respeto y reconocimiento moral entre las partes. Es decir, si una de las partes incurre en lo que se denomina, normalmente, como "hate speech", no está permitiendo que existan las condiciones mínimas de diálogo y, por lo mismo, podría ser razonable limitar su participación en la esfera pública.
} 
la pone el mismo Hart en evidencia, en las conclusiones del breve texto ya citado, en el cual se refiere particularmente a las leyes que prohibían la homosexualidad en Inglaterra hasta la segunda mitad del siglo XX, a causa de la inmoralidad:

El verdadero solvente de la moral social, como ha mostrado un crítico de Lord Devlin, no es el fallo de la ley para apoyar sus restricciones con castigos legales, sino la discusión crítica libre. Es esto -o la autocrítica que genera- lo que separa el mero rechazo de la condena moral. Si en nuestro día la "gran mayoría moral" se ha dividido o ha dudado sobre muchos temas de moralidad sexual, los principales catalizadores han sucedido cuando la libre discusión de la moral sexual, a la luz de los descubrimientos de la antropología y la psicología han llamado la atención. Estos hechos son muy diversos: incluyen el carácter indefenso de la mayoría de las desviaciones sexuales, la variedad de distinciones morales sexuales en distintas sociedades, la conexión entre la moral sexual restrictiva y la represión dañina. ${ }^{30}$

Con lo dicho hasta ahora se puede ver cómo es que la razón pública presenta dos tipos de problemas: por un lado, (i) niega la posibilidad de preguntarnos por la naturaleza de la concepción de la justicia y su justificación, haciéndola así justificable principalmente en términos de la tradición y la idea de la cultura política (que como sabemos, aunque Rawls parece no reconocer, es cambiante en el tiempo), y, por otro, (ii) al limitar a la razón pública en sus contenidos del modo en que lo hace Rawls, no permitiendo el diálogo abierto entre doctrinas comprehensivas, desaparece la posibilidad de retar ideas y concepciones del bien en referencia a su valor en tanto justas; esto es un serio inconveniente pues dichas ideas del bien terminan influenciando la cultura política de fondo y, en el largo plazo, pueden ser factores claves para la estabilidad de la justicia como imparcialidad.

Una razón adicional para repensar la razón pública en función de un giro pragmático, aceptando la idea de la verdad como una característica de las aseveraciones de ese tipo de razón, es que las razones por las que los individuos tienen diferencias políticas no se limitan a diferencias en doctrinas comprehensivas; probablemente no son, siquiera, la razón fundamental de sus desacuerdos políticos. ${ }^{31}$ Asumiendo que la idea de los bienes primarios es correcta, en la medida en que todas las doctrinas comprehensivas querrán, por lo regular, una cantidad de bienes mayor que menor, los conflictos políticos serán principalmente sobre cuál es la distribución justa de dichos bienes. Las discusiones sobre esas distribuciones difícilmente serán mejor conducidas distanciadas de la idea misma de la verdad como justificación al modo pragmático.

\footnotetext{
${ }^{30}$ Ibid. 68

${ }^{31}$ Cohen, "Truth and public reason". 7
} 
Un ejemplo de lo anterior lo podemos encontrar en el debate que surge en función de programas de redistribución de riqueza mediante becas en efectivo. En general tiende a haber una división de opiniones respecto a si, como estrategia para el combate a la pobreza y la promoción de la igualdad de oportunidades, la colecta de impuestos a los individuos con más recursos y su posterior distribución a los que menos tienen cumple su objetivo. Entendiendo que Rawls asume que la verdad no tiene lugar en las discusiones de la razón pública, su argumento no parecería ser capaz de ofrecer una solución adecuada a problemas de este tipo. Este tipo de conflictos tienen una solución real basada en la verdad (entendida desde una perspectiva pragmática); asumiendo que la sociedad acepta la idea de la igualdad de oportunidades como parte de su concepción de la justicia procedimental justificada de modo que es reconocida como la mejor opción, no hay una razón en la que no pueda existir un estudio que muestre qué cantidad de redistribución del ingreso es necesaria (si es que alguna es, de hecho, necesaria) para mejorar los índices de oportunidades para una población determinada. Si estos temas pueden ser estudiados con rigor científico y las conclusiones son convincentes y claras, la única razón para que dichos resultados no sean reconocidos en general tienden a ser ideológicos; con el uso de una razón pública pragmática dichas motivaciones deberían ser evidenciadas como falsas e inadecuadas para resolver el conflicto. Este hecho, que parecería ser de sentido común, se muestra como una realidad continua cuando reconocemos que los debates de política pública se dirigen más en términos de postulados ideológicos que en cuanto a la evidencia científica.

Existirán temas en que las soluciones no sean perfectamente claras, sin embargo, en cuanto la razón pública opere bajo un criterio pragmático se mantendrá alejada de propuestas de solución que no son realmente tales. Un ejemplo de una pseudosolución a los problemas sociales es, a mi entender, el discurso anarquista como solución a problemas de distribución (entendiendo el anarquismo desde una perspectiva social ideal en la que el Estado se vuelve una realidad innecesaria, muy al estilo de la economía del laissez faire); no es necesario ser un científico social para reconocer que, dado el estado de cosas en las sociedades actuales, el anarquismo no presenta una solución a los problemas, del mismo modo que no lo hace el comunismo platónico (si es que se puede llamar comunismo adecuadamente) o la economía planificada al modo comunista soviético. Dialogar los problemas sociales en clave de algunas de las ideas anteriores refleja una incapacidad de centrar la indagación en hechos reales; por el contrario, quienes así lo hacen se mantienen en planos teóricos (a veces existentes 
sólo dentro de la lógica de su doctrina comprehensiva) que no se refieren a los problemas concretos. Este modo de proceder fracasa desde una perspectiva pragmática.

Por otro lado, dado que Rawls parece considerar que el conflicto que surge de las diferencias en ideas morales del bien son irresolubles en tanto que la verdad sea un valor relevante en la esfera pública (y por lo tanto es mejor sacarla por completo), termina renunciando a la posibilidad progresista que Dewey sostiene y que, debo agregar, comparte la tradición liberal, al menos en algunos de sus exponentes más relevantes:

Lo que es más, el conflicto doctrinal no es sólo un problema. Como Mill y otros han observado, puede funcionar como base del aprendizaje social, en la medida en que juntamos la información obtenida de las variedades de la experiencia humana, y reflexionamos a la luz de los pensamientos y los patrones de conducta que no hubiéramos considerado de otro modo. Así, el conflicto doctrinal puede ser visto como poseedor de un cierto atractivo, como una expresión del alcance de las posibilidades humanas. ${ }^{32}$

Una razón pública que esté abierta a tratar el tema de la verdad no garantiza la eliminación del conflicto, ni siquiera podríamos afirmar que garantiza la cooperación entre todos los individuos, sin embargo, si el liberalismo rawlsiano tiene un futuro estable, como lo tiene con la lectura pragmática-deweyana, tampoco deberíamos buscar erradicar el conflicto o suponer que la sociedad en general tiende a la cooperación de modo perfecto. La razón pública pragmatizada de este modo, como he intentado esbozar, no es una herramienta para desaparecer el conflicto. Esta razón hace que del conflicto podamos obtener las soluciones más productivas dadas las condiciones en las que nos encontremos. Con el paso del tiempo, aquellas soluciones que pasen las pruebas de la razón continúan encausando la acción humana $y$, por otro lado, aquellas que reprueben sean rechazadas.

La aplicación de una racionalidad pragmática a la razón pública implica la restauración de la idea de la verdad, pero no esa verdad metafísica-realista que parece suponer Rawls. La verdad que propongo para la esfera pública es una verdad llena de matices, que permite, antes que identificar la aseveración verdadera, mostrar todas aquellas que son falsas; que reconoce que las circunstancias son fundamentales para su mantenimiento y que siempre está abierta a ser refutada. Una verdad que reconoce que no puede solucionar todas las

${ }^{32}$ Cohen, "Truth and public reason". 7 
disputas y que, en ocasiones (no pocas), deben resolverse en función de lo meramente conveniente y posible. La aplicación de una lectura pragmática al liberalismo de Rawls implica la aplicación de una visión científica-falibilista de la razón pública, antidogmática y progresista.

Una vez desarrollado este esbozo queda la siguiente cuestión: ¿cómo es posible desarrollar, materialmente, este tipo de racionalidad en la sociedad? Al final del día la estabilidad de una sociedad depende de su capacidad de promover valores (la racionalidad y la perspectiva científica pueden ser entendidas como valores) en la ciudadanía. La educación tiene un papel central en el establecimiento de una sociedad democrática y liberal, ya que supone la participación, más o menos activa, de todos los ciudadanos. A continuación trato el tema de la educación en una sociedad liberal gobernada por la justicia como imparcialidad.

\section{La educación liberal}

El tema de la educación en el contexto del liberalismo político es particularmente complejo. El segundo principio de la justicia, de igualdad democrática, supone la importancia de la educación como un bien relevante que genera igualdad de oportunidades para los ciudadanos. La sociedad tiene la obligación de garantizar dicho bien siempre que sea necesario para que los individuos puedan perseguir su propia idea del bien. Si bien es cierto que la idea de la educación en Teoría de la Justicia no ocupa un lugar central, la realidad es que todo parece indicar que en esa presentación de la justicia como imparcialidad Rawls considera que la educación tiene un papel relevante en la sociedad pues ayuda a garantizar la libertad en su justo valor; la educación tiene un papel como bien primario que es necesario para permitir el desarrollo libre de los poderes morales de los individuos. Rawls tiende a reconocer el derecho de las familias a educar ${ }^{33} \mathrm{y}$, en lo que respecta a la educación impartida por la sociedad, parece referirse a ella en términos más bien de medio para la adquisición de bienes. Parece haber implícitamente una comprensión de la educación en Rawls que lo lleva a hacer una distinción entre la educación que se refiere al desarrollo de las capacidades morales de los individuos (que sería la educación que tiende a impartir la familia por ejemplo) y la educación que sirve como mecanismo igualador de oportunidades, es decir una especie de educación referente a la formación profesional de los ciudadanos (cabe decir que,

\footnotetext{
${ }^{33}$ Más adelante muestro cómo esto es así.
} 
en este ámbito de la educación como un bien igualador, Rawls incluye en el Liberalismo las virtudes políticas necesarias para sostener la concepción política de la justicia, sobre ellas hablo con más detalle un poco más adelante).

Esta actitud respecto a la educación puede conducir, en el mediano y largo plazos, a un proceso de inestabilidad en el que la sociedad sea incapaz de reproducir los patrones culturales para garantizar su existencia a futuro pues, como he intentado mostrar, los valores necesarios para el buen funcionamiento político son más que la capacidad técnica profesional y los valores políticos considerados a raíz del giro político.

Rawls parece dar por sentado, y esto lo hace por igual en Teoría de la Justicia que en Liberalismo Político, que la transmisión de lo que denomina "cultura de fondo" ocurre en mayor o menor medida sin problemas; en este punto Dewey es mucho más consciente de la importancia de la educación en cualquier proyecto de civilización:

La sociedad existe a través de un proceso de transmisión similar al de la vida biológica. Esta transmisión ocurre por medio de los hábitos de comunicación de la acción, el pensamiento y el sentir de los más viejos a los más jóvenes. Sin la comunicación de ideales, esperanzas, expectativas, estándares y opiniones de aquellos miembros de la sociedad que están saliendo del grupo a aquellos que están entrando, la vida social no podría existir. Si los miembros que componen a una sociedad vivieran continuamente, podrían educar a los nuevos miembros que llegaran, pero sería una tarea dirigida por el interés personal más que una necesidad social. Ahora es el trabajo de la necesidad.

(...) Las diferencias en edades, el hecho de que algunos nacen y otros mueren, hace posible mediante la transmisión de ideas y prácticas la renovación del fundamento social. Sin embargo esta renovación no es automática. A menos que se lleven a cabo trabajos para que exista una genuina transmisión, el grupo más civilizado recaerá en el barbarismo y después en el salvajismo. ${ }^{34}$

Si buscamos el mantenimiento estable de una concepción de la justicia por un tiempo prolongado (al menos mientras sea funcional y justa dadas las condiciones de la sociedad), no puede dejarse, al menos no a ojos de Dewey, al devenir social accidental. En tanto somos capaces de reconocer la importancia de la educación en la transmisión de la cultura y los hábitos sociales, no es complicado prever que una sociedad bien ordenada, para poder serlo de modo estable, tiene la responsabilidad de garantizar que la educación cumpla con sus fines. Este problema, en el liberalismo rawlsiano, es poco abordado.

${ }^{34}$ John Dewey, Democracy and Education (Dehli: Aakar, 2013), 14-15. 
Lo que es más, cuando de hecho es tratado, la postura rawlsiana termina generando problemas adicionales en el ámbito de la educación y de la transmisión de la concepción de la justicia y de los mecanismos de razonamiento que se deben fomentar para el ejercicio adecuado de la razón pública. Con el giro político, como ya he analizado con cierta amplitud, Rawls procura establecer un liberalismo que no esté fundamentado en una visión moral del mundo; busca desarrollar un liberalismo político que pueda ser aceptable para distintas doctrinas comprehensivas razonables que puedan tener contenidos distintos. Para alcanzar este objetivo, Rawls termina definiendo la sociedad y al ciudadano en lo que él considera términos meramente políticos, justificados por la cultura de fondo de la sociedad bien ordenada. La cuestión sobre la justicia no es una, dicho esto, que interese porque sirva para determinar la adecuada distribución de bienes entre seres humanos cualesquiera que habiten en la sociedad; el tema de la justicia en el liberalismo político interesa si buscamos la concepción adecuada para “(...) ciudadanos libres e iguales, que son miembros cooperadores de una sociedad durante toda una vida $(. . .)^{\prime \prime 35}$ Rawls no intenta comprender el problema de la justicia, a partir del giro político, como un problema de distribución entre personas, es sólo entre ciudadanos cooperadores.

Un problema con esta idea del ciudadano, que tiene implicaciones respecto al tema de la educación, es el de la extensión. En la medida en que la idea del ciudadano con la que trabaja el liberalismo político, como lo exige la idea de razón pública propuesta por Rawls, no pueda ser entendida más allá de "miembros cooperadores de una sociedad durante toda una vida", los derechos y obligaciones de la sociedad con aquellos que no son miembros no son claros, están profundamente abiertos al debate $\mathrm{y}$, probablemente, podría justificarse, haciendo uso de la razón pública, que la sociedad no tiene responsabilidades con ellos en lo absoluto. El problema de la extensión tiene repercusiones serias respecto a la educación. Si Dewey tiene razón al respecto, este es un problema relevante pues, si la sociedad es negligente en la educación de sus ciudadanos, corre el riesgo de caer en algún modo de barbarismo. El problema de la extensión de la concepción de la justicia nos deja sin los mecanismos para entender qué responsabilidad y deberes debe tener la sociedad respecto de los individuos que, aun cuando no sean actualmente ciudadanos, sí lo serán en un futuro. Los menores de edad no cumplen con las características de extensión que supone Rawls y, en esa medida, parecen no ser sujetos a ser tratados con justicia (al menos en los confines de la concepción política de la justicia). Si el liberalismo político debe estar

${ }^{35}$ Rawls, Political Liberalism. 3 
fundamentado en conceptos de la cultura política democrática, como pretende hacerlo Rawls, y por tanto determina que dicha concepción sirve para informar la estructura básica de la sociedad en donde los individuos se aceptan en ella en tanto que son ciudadanos (cooperadores durante toda su vida), desde la razón pública es imposible reconocer derechos y responsabilidades de la sociedad con individuos que no pertenezcan a dicho grupo.

Sobre este tema, la lectura pragmática-deweyana presenta, de igual modo, una mejora a la comprensión de la justicia como imparcialidad que el giro político. Desde una perspectiva pragmatista es posible reconocer derechos y obligaciones de la sociedad con grupos como los menores de edad de un modo en que el liberalismo político simplemente no puede. Esta distinción permitiría reconocer no sólo el derecho de un futuro ciudadano a recibir una educación, que como defiendo en esta sección tiende a ser parcial hacia una comprensión del mundo liberal (por esto me refiero humanista, falsacionista y moralmente liberal), así como la necesidad de la sociedad de concretar dicho proceso educativo si quiere contar con una herramienta para procurar su estabilidad. La diferencia de la comprensión pragmática de la política con el liberalismo político es que la primera no está obligada a determinar, ex ante, quiénes son los individuos que merecen ser considerados por la concepción de justicia. En el liberalismo político parte del problema proviene de que no existen las herramientas necesarias para matizar grados de participación, que pueden ir desde la dependencia (como en el caso de un menor de edad muy joven o una persona con discapacidad grave) hasta la plena cooperación (como ocurre con un ciudadano adulto) entendiendo que existen puntos intermedios (por ejemplo un(a) joven de 17 años, con plenas capacidades, que en algunos casos puede ser considerado un adulto y en otros un menor). La lectura pragmática de la justicia como imparcialidad presenta incluso ventajas a la presentación hecha en Teoría, en donde el neokantismo rawlsiano tendía a excluir, igualmente, a ciertos grupos de individuos de los cálculos de la justicia.

Si bien concuerdo con Rawls en que la concepción de la justicia tiende a centrarse en el impacto que tenga con los ciudadanos, ya que son ellos quienes gozan de la mayor parte de derechos y responsabilidades así como son los principales sujetos con intereses reconocibles públicamente, una concepción de la justicia adecuada para las necesidades de las sociedades reales no puede omitir al resto de seres involucrados en la sociedad que no gozan de plena ciudadanía. Esta reinterpretación implica un reto a la formulación de la justicia como imparcialidad ya que en la posición original, que he defendido como mecanismo de 
representación correcto para justificar la justicia como imparcialidad al modo en que lo hizo Rawls en Teoría de la Justicia, la "discusión" la llevan a cabo individuos que esperan una situación de igualdad una vez que salgan de la posición. Lo anterior implica que en la posición original no se encuentran previstos menores de edad ni personas con discapacidades graves.

Asumiendo que en la posición original los contratantes tuvieran conocimiento de la existencia de personas sin la capacidad de ser miembros igualmente cooperativos con la sociedad, no existe una razón por las que no puedan ser contemplados sus intereses en su justa medida. Considero razonable la existencia de una cláusula que suponga que la sociedad debe generar las instancias, al modo en que lo hace el segundo principio, de igualdad democrática con quienes se considera que son individuos capaces de utilizar sus poderes morales, para que aquellos que no se encuentren en condición de desarrollar una idea del bien y poseer una concepción de la justicia actualmente puedan con el tiempo ejercer sus libertades, participar políticamente si es su deseo y, en pocas palabras, convertirse en ciudadanos. Dicho acuerdo sería razonable dadas las condiciones de imparcialidad impuestas en la posición original; después de todo, los grupos de personas con discapacidades, así como de menores de edad, son parte de la sociedad irremediablemente. Reconociendo el hecho de que son sujetos de intereses que se relacionan con los de otros individuos, no importa que sus poderes morales no estén del todo desarrollados, deberían ser tomados en cuenta en una circunstancia como la posición original pues serán irremediablemente actores políticos, sin importar que lo fueran de una clase distinta a los ciudadanos con plenos derechos.

Esta previsión promovería el desarrollo de una sociedad que tienda a ser más incluyente con quienes Rawls ha dejado afuera del contrato o del consenso y, al mismo tiempo, tendería a garantizar su estabilidad al mediano y largo plazo ya que procuraría los medios para que los ciudadanos del futuro pudieran mantener su concepción de la justicia y desarrollen ideas del bien compatibles con ella.

La lectura pragmática que propongo de la justicia como imparcialidad (al menos en este caso) asume que los individuos son sujetos con intereses (no importa cómo o de dónde se obtengan) y que cuando nos planteamos la vida en sociedad, todas las personas que vivan en ella los tendrán, independientemente de su edad o su condición (suponiendo que un interés es tal independientemente de que se tenga conciencia de él o no). Dado que interactuarán con otros miembros de la sociedad, o la sociedad en su conjunto para el caso, pueden ser juzgadas desde la 
perspectiva de lo justo y lo injusto dependiendo de cómo se relacionan esos intereses. La idea de que los individuos poseen intereses está en consonancia con el fundamento contractual de la justicia como imparcialidad.

El reconocimiento de la tesis comunitaristas, por parte de Rawls, que supone que la sociedad afecta la conformación de la personalidad humana a través de la cultura, es claro en el Liberalismo Político cuando afirma que: "Todos reconocen que la forma institucional de la sociedad afecta a sus miembros y determina el tipo de personas que quieren ser así como el tipo de personas que son. La estructura social también limita las ambiciones personas y las esperanzas en distintos modos." ${ }^{36}$ Aceptado este hecho, que supone que la concepción de la justicia influye en la estructura de la sociedad y en el tipo de personas que habitan en ella, Rawls termina asumiendo que el proceso formativo de los individuos debe ser confiado a la influencia descontrolada de la sociedad dado que la concepción de la justicia política es parte de la cultura básica de la sociedad y por tanto tendría que ser transmitida de una generación a la otra. Aun cuando desde el giro político pudiera ser justificable la obligación de la enseñanza de ciertas virtudes cívicas necesarias, la cuestión es totalmente insuficiente si reconocemos el papel central de la educación en la estabilidad social.

Hay una deficiencia crítica en esta idea de Rawls. Mientras afirma el liberalismo político como medio de justificar la justicia como imparcialidad, parece ser incapaz de reconocer que, como he mostrado ya, no existe una distinción concreta entre el ámbito político y el moral para los individuos; al menos esto no es un hecho plenamente generalizable a todos los ciudadanos. Las obligaciones educativas de una sociedad que procure justificar un régimen liberal y democrático no pueden delegarse al ámbito privado pues la distinción cultural que propone Rawls, entre la de cultura política y el resto de la cultura, es una que sirve meramente para analizar el fenómeno de la vida social de los seres humanos. Asumiendo que las instituciones afectan el modo en que los individuos forman sus ambiciones y esperanzas no hay razón para suponer que sus intereses no afectarán, de igual modo, sus instituciones. Por qué la relación causal tendría que ser en una sola dirección es una cuestión que Rawls no puede responder. Así, aun cuando reconoce la importancia de utilizar la educación para formar las virtudes cívicas necesarias para conservar las instituciones, una pregunta relevante es el por qué la educación debería mantenerse limitada al campo de las virtudes cívicas (aun

\footnotetext{
${ }^{36}$ Rawls, Political Liberalism. 269
} 
cuando, como mostré, para Gutmann es un ideal inalcanzable en cualquier caso). La cuestión se refiere, más bien, a responder la cuestión que plantea Dewey:

No podemos seguir manteniendo la idea de que la naturaleza humana por sí misma, cuando se libera de restricciones externas arbitrarias, tenderá a producir instituciones democráticas que funcionarán exitosamente. Debemos afirmar ahora el problema desde el otro lado. Debemos ver que la democracia significa la creencia que la cultura humanística debe prevalecer; hay que ser francos y abiertos en nuestro reconocimiento que la proposición es una moral.

(...) No importa que tan uniforme y constante sea la naturaleza humana en lo abstracto, las condiciones desde las que y hacia las que opera han cambiado tanto desde que la democracia política fue establecida entre nosotros, que la democracia no puede depender ahora, o ser expresada únicamente, en instituciones políticas. No podemos si quiera estar seguros que ellas y sus acompañamientos legales son realmente democráticos en el tiempo presente -pues la democracia es expresada en actitudes de los seres humanos y es medida por las consecuencias que produce en sus vidas. ${ }^{37}$

El fragmento anterior fue escrito bajo un contexto particular, John Dewey, al hablar de la cultura y la libertad, se encuentra en un momento en el que el totalitarismo ha surgido en Europa con gran fuerza (Freedom and Culture fue publicado en 1939). En ese contexto es posible reconocer cómo instituciones democráticas, como las demarcadas por la constitución de la República de Weimar, permitieron, por vía democrática, el crecimiento del partido Nazi en Alemania al final de la década de los veinte y principio de los treinta. El argumento de Dewey es fundamental. Si Rawls asume la influencia de la cultura e instituciones políticas en los individuos, no puede negar la importancia del resto de los ámbitos de la vida de los ciudadanos en la cultura e instituciones políticas. En esa medida, la búsqueda de la estabilidad de una concepción de la justicia para una sociedad democrática debe llevarse a cabo desde los diversos ámbitos de la vida de los ciudadanos.

El proyecto educativo de la sociedad cobra una relevancia fundamental no sólo justificado desde una perspectiva política sino, igual de importante, desde una perspectiva moral. El liberalismo como estructura social tiene el fin de desarrollar las libertades de los individuos, es decir la promoción de las libertades en su justo valor y eso, últimamente, supone el desarrollo de una cultura que promueva valores morales y culturales de libertad en todos los ámbitos de la vida de los ciudadanos.

\footnotetext{
37 Dewey, Freedom and culture. 97
} 
El tipo de educación que propone Dewey supone obligaciones en la comprensión de la responsabilidad de la sociedad respecto a sus ciudadanos, en especial respecto a aquellos que están en la fase formativa de su identidad (que en general tienden a ser menores de edad pero que no se limita a ellos, al final del día la identidad se construye durante toda una vida); sobre un sistema de educación de este tipo, referido en particular a los menores de edad, afirma Barry: "Las implicaciones serán, si estoy correcto en lo que esto es, que los niños deberían recibir una educación que los equipará para el éxito práctico y les permitirá vivir vidas satisfactorias al introducirlos a las artes, las humanidades y las ciencias." 38

Con lo dicho hasta ahora parece que el planteamiento de educación que propongo queda abierto a una crítica similar a la que Teoría recibió en su momento. En pocas palabras, un comunitarista tendería a criticar la posibilidad de impartir contenidos que trasciendan el mero ámbito político y que promuevan una educación liberal (en la que se promuevan cierto tipo de valores especiales) pues implicaría, según dice la crítica, una discriminación ilegítima a culturas que no comparten los contenidos morales del liberalismo. El origen de dicha crítica proviene de que parecería que, si reconocemos que las distintas doctrinas comprehensivas son inconmensurables en buena parte de su contenido moral, no tenemos un criterio claro para preferir una moral liberal frente a otras siempre y cuando las doctrinas comprehensivas estén en disposición de respetar la concepción de la justicia; esto representaría una discriminación injusta. En parte la respuesta debe realizarse (a la espera de que justificaré por qué ciertos contenidos deberían de tener preferencia desde una lectura pragmática de la justicia como imparcialidad y, para el caso, de la tradición liberal en términos más generales) en función de la idea del paternalismo y su relación con la sociedad.

La idea de una sociedad paternalista ha desarrollado profunda aversión en nuestros tiempos, pues se asume que la sociedad no está legitimada a tratar a su población como menores de edad. El liberalismo surge en parte como una respuesta a la sociedad paternalista que tiende a no reconocer los límites a su acción política. Cuando pensamos que una nación es paternalista suponemos que es una que no respeta los poderes morales de su población dado que asume cuáles ideas del bien deben de motivar la vida de sus ciudadanos y, al hacerlo, lleva acciones concretas que limiten el actuar de los individuos. Dicha sociedad es irreconciliable, se asume, con una concepción de la justicia liberal como lo muestra Rawls en Teoría de la Justicia.

\footnotetext{
${ }^{38}$ Barry, Freedom and Culture. 224
} 
Supongamos, sólo para efectos de la respuesta (aunque un poco más adelante los justifico con más detalle), que es posible reconocer justificadamente que ciertos contenidos en la educación son preferibles frente a otros. Si esto fuera posible cabe preguntarnos por qué los participantes en la posición original podrían estar en contra de que dichos contenidos fueran enseñados a los menores de edad. La posición original asume que las personas, al estar bajo el velo de la ignorancia, tienden a apostar por la imparcialidad de la sociedad y la garantía de perseguir su propia idea del bien. La pregunta que me interesa explorar en este punto es, ¿aceptarían que ese mismo criterio de imparcialidad se cumpliera con aquellos que no han desarrollado sus poderes morales lo suficiente como para afirmar una idea del bien suficientemente acabada? Dicho de otro modo, el criterio de aplicación de la educación de modo paternalista respecto de los menores de edad es producto del pensamiento imparcial y completamente compatible con el liberalismo en general y con justicia con imparcialidad en específico. Si es posible ofrecer un criterio imparcial (que sería la compatibilidad de los contenidos de la educación con la concepción de la justicia de modo que promueva su estabilidad), no hay razón para que no prefirieran impartir dicha educación a individuos que todavía no son sujetos plenos de derechos.

Uno de los beneficios de entender a los miembros de la comunidad política como algo más que meros ciudadanos, es decir, verlos como individuos con intereses, es que facilita reconocer que hay más que ciudadanos en la sociedad y que su interacción puede y debe ser analizada en función de la justicia. En esa medida es posible reconocer que un menor de edad es un sujeto con intereses pero con poderes morales insuficientes, además de límites físicos para formarlos por sí mismo así como para perseguirlos. Si en la posición original se reconoce la existencia de dichos individuos, ¿qué razón puede existir en contra de que la sociedad procure su acceso a los bienes necesarios para su óptimo desarrollo (asumiendo que la educación es uno de esos bienes y que, como hice el supuesto aun no mostrado, es posible justificar que ciertos contenidos son preferibles a otros)? Recordemos que la posición original impide a los participantes saber cuál es su doctrina comprehensiva, por lo tanto no pueden conocer de antemano cuál es su ideal familiar; un participante de la posición original no podría saber si prefiere la educación en casa o la educación escolarizada, religiosa o secular, científica o mística, ¿por qué, bajo ese contexto, preferiría exponer al menor de edad a una educación insuficiente contrario a buscar garantizar su bienestar? Asumiendo que los participantes reconozcan en la educación uno de los mecanismos más importantes de estabilidad social, así como uno de los medios de desarrollo 
individual, parece difícil suponer que una decisión imparcial asuma el perjuicio de los individuos más desprotegidos. Lo que no implica que, si alguien con mayoría de edad decide vivir una vida contraria a la moralidad liberal (siempre en que respete la concepción de la justicia), la sociedad vaya a hacer algo para evitarlo.

El principio paternalista, que puede ser invocado en este punto, asume que hay casos en que los individuos no están facultados a tomar una decisión racional y por tanto la sociedad puede hacerlo por ellos. Aun cuando la tradición liberal pueda cuestionar el paternalismo para adultos conscientes, racionales, libres y en uso pleno de sus facultades, no hay una razón para que ese mismo rechazo al paternalismo pueda ser aplicable a individuos que no cumplan con esas características. Un ejemplo particularmente ilustrativo sobre la importancia del principio paternalista es el de una asociación civil norteamericana llamada NAMBLA (Asociación Norteamericana del Amor entre un Hombre y un Niño por sus siglas en inglés). NAMBLA es una asociación que aboga por el cambio en la legislación existente en Estados Unidos respecto a los límites de edad para las relaciones sentimentales entre adultos y menores de edad (ellos promueven que no debería de existir ese límite de edad). En su sitio de internet afirman que "sabemos que las diferencias en edad no limitan la mutua y amorosa interacción entre personas. NAMBLA se opone firmemente a las leyes de consentimiento basadas en la edad y toda otra restricción que niegue a los hombres y a los niños el pleno disfrute de sus cuerpos y el control sobre sus propias vidas." ${ }^{39}$

La necesidad de la aplicación del principio paternalista se justifica en casos tan evidentes como el de NAMBLA. Supongamos que un miembro de NAMBLA tiene un hijo $y$, dadas sus preferencias sexuales, permite que este hijo, siendo menor de edad, sea seducido por un adulto (aunque no es difícil asumir que esto pueda ocurrir aunque los padres no sean miembros de una organización así de siniestra). Si no existiera una idea paternalista de la sociedad, que le garantiza un poder sobre el menor mayor al que tiene el mismo padre en ciertos casos, el menor podría asumir que al dar su consentimiento para una relación con un adulto está legitimado para hacerlo. El objeto del paternalismo en este caso es que asume, como debería de hacerlo, que el menor no está en condiciones (en buena medida por su estado de desarrollo) para dar su consentimiento; al no estarlo, la sociedad asume el papel de protector para que, aun si su familia no se interesara, no sea víctima de un depredador.

${ }^{39} \mathrm{http}: / /$ nambla.org/welcome.html 
Con esto dicho, tendríamos que preguntarnos en qué sentido aplica el principio del paternalismo a la educación. Si comprendemos que un menor de edad es un individuo que es parte de la sociedad, aunque no con plenos derechos dado que no es cooperador con poderes morales y racionalidad completamente desarrollados, se sigue del mismo modo, en que la seguridad a su integridad personal (como asumimos en el caso del abuso físico y emocional) es un bien necesario para su desarrollo y por tanto debe de ser garantizado siempre que sea posible, que la educación es un bien necesario para su productividad futura y el mayor disfrute posible de su vida. Un ejemplo de esto lo cita Brian Barry en Cultura e Igualdad sobre una familia fundamentalista cristiana en Estados Unidos, la familia Mozert. Los Mozert decidieron demandar a su condado local en Tennessee por el derecho de prohibir a sus hijos educación que estuviera en contra de su religión:

Entre los hechos a los que se oponían eran 'un cuento describiendo un asentamiento católico en la medida en que enseñaba catolicismo' y 'un ejercicio de lectura que hablaba de un niño preparando pan tostado mientras una niña le leía ("Par lee a Jim. Jim cocina. El gran libro le ayuda a Jim. Jim se divierte.")' Ellos afirmaban que esto "denigra la diferencia entre los sexos" que afirma la Biblia. Los Mozert también se quejaban sobre un 'fragmento del Diario de Anna Frank porque Anna Frank escribe en una carta a una amiga que las creencias no ortodoxas en Dios pueden ser mejores que la falta de creencias absoluta' y un 'texto que describe la idea central del Renacimiento como una "creencia en la dignidad y el valor de los seres humanos" porque esa creencia es incompatible con su fe' ${ }^{\prime 40}$

El ejemplo de los Mozert es, al igual que el caso de NAMBLA, un caso extremo de un posible perjuicio a un menor de edad. En este caso es evidente que permitir a los Mozert el limitar la educación de sus hijos del modo que deseaban implicaba un serio perjuicio. En palabras de Barry: "Si los Mozert hubieran deformado los cuerpos de sus hijos restringiendo su habilidad para moverse con libertad nadie (con la posible excepción de Chandran Kukathas) hubiera tenido duda alguna de que alguna agencia pública tenía el deber de intervenir para proteger a los niños del abuso. En la exacta misma manera, los padres no deberían de tener la posibilidad de limitar sus mentes en el modo en que los padres Mozert deseaban hacerlo." $^{41}$

Si es cierto que el acceso, o en este caso la limitación, a la educación puede constituir un caso de abuso a un menor de edad, el principio paternalista estaría legitimado y justificado en la justicia como imparcialidad desde una perspectiva

\footnotetext{
${ }^{40}$ Barry, Culture and Equality. 245-246

${ }^{41}$ Ibid. 246
} 
pragmática-deweyana; esto debido a que los menores de edad deberían ser considerados sujetos con intereses legítimos (la buena educación y la integridad física y psicológica es en su interés, aun cuando ellos pudieran no reconocerlo en el momento) y deberían de ser tomados en cuenta en la posición original dado que implica la búsqueda de una concepción de la justicia para una sociedad bien ordenada.

El argumento anterior descansa en la posibilidad de que seamos capaces de justificar que de hecho existen mejores contenidos que otros. Como mencioné anteriormente, si asumimos que las doctrinas comprehensivas son inconmensurables entre sí, como parece hacerlo Rawls, aparentemente no tendremos un criterio para justificar qué contenidos impartir. La importancia de este esclarecimiento depende del reconocimiento que en la posición original sería deseable garantizar a los menores de edad, para quienes podemos justificar el principio paternalista, una educación en sentido amplio y no meramente político. Todo esto se sostiene si podemos reconocer que el fin de la educación es más que simplemente otorgar una herramienta para ser económicamente productivo; de lo contrario, dentro de los bienes primarios se debe contar sólo la educación técnica, que permite a los individuos obtener medios suficientes para su manutención. La educación, sin embargo, tiene un fin liberador en el sentido en que el desarrollo de las capacidades del individuo supone el desarrollo de la libertad y ese parecería ser uno de los fines de una sociedad liberal: promover, y no sólo no obstaculizar, el ejercicio de la libertad de los miembros de la sociedad.

Antes de continuar considero relevante regresar a la posición de liberalismo político de Rawls respecto a la educación. De acuerdo con la formulación de la justicia como imparcialidad posterior al giro político, la educación no necesita promover el desarrollo de los menores en función de virtudes morales y algunas intelectuales, ya que, piensa Rawls, no es un requisito necesario para convertirlos en ciudadanos:

Pero el liberalismo político tiene un objetivo distinto y requiere menos. Pedirá que la educación de los niños incluya cosas como el conocimiento de sus derechos civiles y constitucionales para que, por ejemplo, sepan que la libertad de conciencia existe en su sociedad y que la apostasía no es un crimen legal, esto para asegurar que su pertenencia continuada a una religión cuando alcancen la edad adecuada no esté basada simplemente en la ignorancia de sus derechos básicos o el miedo al castigo para ofensas que sólo son consideradas como tales en su secta religiosa. Su educación debe también de prepararlos para ser miembros completamente cooperativos de la sociedad y de permitirles mantenerse a sí mismos; debería 
también promover las virtudes políticas para que puedan honrar los términos justos de cooperación social en relación al resto de la sociedad. ${ }^{42}$

Es claro que para Rawls la educación liberal es una enfocada sólo a las virtudes políticas y al mantenimiento-sustento personal (como un modo de mantener el segundo principio de la justicia). Esta idea es consistente con la idea del liberalismo político ya que se niega a tomar partido por un modo de educación concreto para la sociedad. Esta neutralidad no sólo es inconveniente, en el sentido en que en el largo plazo tiende a generar inestabilidad, sino que es prácticamente inviable (como la objeción de Chantal Mouffe muestra), en el sentido en que poseer valores morales y políticos discordantes al nivel que supone Rawls parece poco probable (o al menos mentalmente saludable) y, en caso de que fuera posible, injusta, ya que no garantiza las condiciones para que individuos que requieren de la protección de la sociedad en tanto son ciudadanos con todos los derechos puedan vivir sus libertades en su justo valor.

Dicho así, si bien el liberalismo político estaría en contra de la educación que la familia Mozert esperaba para sus hijos, no sería porque, ni siquiera en parte, terminarían limitando las posibilidades cognitivas de sus hijos privándolos del pleno ejercicio de sus capacidades de acuerdo a las opciones que ofrecía la segunda mitad del siglo XX. El problema que tendría Rawls, o más bien el liberalismo político, porque tengo la convicción de que Rawls argumentaría por el error de dicha familia en términos morales, sería que ese tipo de educación podría conducirlo a no tener suficientes medios para vivir. Si la familia Mozert ha sabido conducirse dentro el marco de la ley, y no tenemos razones para pensar que no lo han hecho cumpliendo con sus obligaciones ciudadanas, no hay razón por las que, piensa Rawls, no pudieran obligar a sus hijos a estar aislados del mundo, siempre y cuando le enseñen que no existe una ley civil que impida que se integren a un mundo lleno de pecadores condenados al infierno, según ellos.

Asumiendo esto, Rawls se equivocaría gravemente en este punto. En la medida en que el liberalismo político renuncia a la verdad y a una visión moral del mundo, es incapaz de reconocer, debido a que parece no haber criterios objetivos para juzgar, que los intereses de los padres pueden ser irreconciliables con los de los hijos, aun cuando acepten los criterios educativos del liberalismo político. Pues, como bien afirma Brian Barry: “Al preguntarnos cuánto derecho tienen los padres de opinar sobre la educación de los hijos, debemos de tomar como un hecho

42 Rawls, Justice as Fairness, a restatement. 156 
axiomático que los intereses de los padres y de los niños son distinguibles y potencialmente conflictivos." ${ }^{\prime 3}$

El fin de la educación de una sociedad liberal, al menos para los menores de edad, debe de ser el de promover el pensamiento crítico y autónomo. Este tipo de pensamiento lo mantiene en contacto con un mayor número de influencias (sociales, científicas, políticas, morales, religiosas, etc.) y, cuando esto ocurre así, la persona puede decidir con mayor libertad y hacerse responsable de su decisión ejerciendo sus poderes morales efectivamente. ${ }^{44}$ Un poco más adelante explicaré cómo es que se puede justificar que esto es mejor desde la posición original, o sea desde un juicio imparcial.

Es fácil quedar perplejo ante la incapacidad de Rawls para comprender que una política liberal exige construir activamente una sociedad liberal y que, dicha sociedad, necesita de una educación liberal que promueva el pensamiento, la crítica y se revele contra el dogmatismo. He asumido que Rawls piensa que los individuos pueden mantener ideas del bien incompatibles con la concepción de la justicia. Si esto pudiera ocurrir, terminaría defendiendo en lo privado condiciones antiliberales de vida. Eso sería, considero, inaceptable para el mismo Rawls dadas las opciones que Dewey considera que existirían:

Las objeciones que se hacen contra el liberalismo ignoran el hecho de que sus únicas alternativas a la dependencia en la inteligencia son o la deriva y la improvisación causal, o el uso de la fuerza coercitiva simulada por la emoción no inteligente y el dogmatismo fanático -este segundo siendo intolerante por su propia constitución. ${ }^{45}$

Una educación liberal está encaminada al desarrollo y ejercicio de las libertades: a una mejor capacidad de pensar para hacer un mejor uso de los bienes primarios que socialmente compartimos. Permitir que los individuos puedan escoger, llegado el momento adecuado, qué vida desean vivir después de haber realizado un análisis racional sobre las opciones que se presentan es el objetivo de la educación liberal. Esto no implica, por supuesto, que tengan que elegir una opción determinada pues, como bien afirma Harry Brighouse, como es citado por Barry: “(..) una educación que facilita la autonomía 'no intenta asegurar que sus estudiantes utilicen la autonomía en sus vidas en mayor medida que las clases de Latín están diseñadas a asegurar que los estudiantes utilicen Latín en sus vidas.

\footnotetext{
${ }^{43}$ Barry, Culture and Equality. 202

${ }^{44}$ Cfr. Dewey, Ethics. 436

${ }^{45}$ Dewey, Liberalism and social action. 56
} 
Más bien busca permitirles vivir autónomamente en caso de que lo deseen.'" ${ }^{46} \mathrm{Si}$ después de haber recibido una educación liberal en su niñez un adulto desea incorporarse a la Iglesia Bautista de Westboro, mientras no quebrante la ley, puede hacerlo libremente. Esto no implica que, una vez que comience su viuda en dicha agrupación, tenga el derecho de prohibir a su hijo, en caso de que lo tenga, el acceso a la educación que le permita elegir, si desea, una vida racional y que pudiera ser caracterizada de liberal.

Como una afirmación que podría ayudar a calmar algunas de las críticas comunitaristas, podríamos decir que una sociedad liberal, que sostenga a la justicia como imparcialidad como su concepción de la justicia, tiene la obligación de enseñar el estilo de vida que la libertad presupone (un estilo de vida que supone estar abierto a la crítica, tanto para recibirla como para hacerla, que reconoce que hay diferencias entre las doctrinas comprehensivas que no pueden ser conciliadas pero que, siempre que se toleren, no implican necesariamente vivir en conflicto, que cuando existe el conflicto la solución justa es la que ofrece una solución imparcial y materialmente posible, que la sociedad tiene la responsabilidad de promover el ejercicio de la libertad de los individuos que por sí mismos no están en condiciones de ejercerla actualmente y de respetar las decisiones, siempre y cuando sean razonables, de aquellos que sí están en condiciones), aunque no implica necesariamente que un ciudadano tenga que vivir de acuerdo con ella en sus actos privados. Si el liberalismo se afirma en bases pragmáticas como un concepción procedimental de justicia imperfecta, como he intentado proponer como justificación de la justicia como imparcialidad, aquellos que no estén de acuerdo con el estilo de vida liberal y la concepción de la justicia liberal (aunque puedan vivir con ella) que no sean capaces de ofrecer un sustituto que ofrezca mejores resultados (una concepción más efectiva en la distribución de la justicia), tendrán que aceptar, si son racionales y razonables, que la justicia como imparcialidad es la concepción aceptada por la sociedad y vivir de acuerdo a ella al menos bajo un esquema de modus vivendi.

La democracia liberal exige una cierta uniformidad. Como ya he mencionado antes, no todas las doctrinas comprehensivas tienen cabida en una sociedad liberal. Aun cuando el liberalismo es la concepción de la justicia que permite mayor diversidad, simplemente es imposible que la diversidad sea absoluta: un dogmático terrorista, por ejemplo, no tiene cabida en una sociedad liberal. Si reconocemos que la neutralidad que propone Rawls es implausible por

\footnotetext{
${ }^{46}$ Barry, Culture and Equality. 224
} 
razones que ya he mencionado ampliamente, Dewey presenta un buen complemento para la justicia como imparcialidad pues supone un sistema educativo que promueve el pensamiento liberal y democrático y puede entender la idea del consenso en valores y principios democráticos solo que, a diferencia de Rawls, no puede entenderlos desvinculados del resto de la cultura de la sociedad:

\begin{abstract}
Más que tratar las escuelas públicas como terrenos neutrales en el que los niños de distintos orígenes pudieran enfrentarse y aprender el mínimo "código" liberal de civismo, Dewey argumentaba que las escuelas públicas deberían de constituir una cultura competitiva que era menos parroquial y más democrática y, por tanto, mejor que cualquiera de las que los niños pudieran provenir. Poniendo menos fe en las instituciones, procedimientos e incluso derechos que los liberales anteriores habían hecho, Dewey argumentó que la genuina democracia requería -o más bien era- el compartir valores similares. Pero estos valores no podían ser ciegamente aceptados por la tradición. ${ }^{47}$
\end{abstract}

Dewey suponía que, dada la posibilidad de educar a la sociedad en los métodos de la indagación falsacionista (que es el método del pragmatismo que mostré en el primer capítulo), los individuos terminarían negando el dogmatismo y la tradición irracional. Si bien esto no es necesariamente así, sí es un mecanismo de estabilidad adicional pues es una característica necesaria para cumplir con algunos de los objetivos de la sociedad liberal, que es permitir que los individuos puedan elegir libremente (entendiendo que eso implica que la libertad exige de medios para desarrollarse) su idea del bien y tiendan a aceptar la concepción de la justicia; ser obligado mediante la tradición irracional a elegir un bien dogmáticamente preseleccionado no es, en modo alguno, un ejercicio de libertad. Aun reconociendo que hay casos en que las personas pueden decidir vivir una vida antiliberal aun cuando recibieran una educación liberal, es razonable suponer que esto sucede en mucho menor medida bajo una educación liberal a que si parte de la población recibe una educación conservadora y dogmática, como algunos comunitaristas probablemente desearían que sucediera.

Para resumir, antes de presentar la idea de educación escolarizada de Dewey como modelo de educación liberal, es posible argumentar en favor de la importancia de una educación que promueva la autonomía desde dos perspectivas distintas: por un lado como un medio para que la sociedad pueda facilitar su estabilidad en el tiempo y, por otro, en función de un principio paternalista que entiende que los intereses de los menores de edad deben ser vigilados por la sociedad.

\footnotetext{
${ }^{47}$ Richard Ruderman y Keneth Godwin: "Liberalism and parental control of education"; The Review of Politics, vol. 62 no. 3,(2000) 514.
} 
El primer argumento asume que si la estabilidad de la concepción de la justicia es una circunstancia deseable, suponiendo que nos encontremos en una sociedad democrática, o que al menos reconozca la importancia del principio de "legitimidad liberal", dicha concepción tiene que ser libremente aceptada por los ciudadanos en una buena proporción. En la medida en que la concepción de la justicia afecta las instituciones de la sociedad, reconocemos, del mismo modo que lo hace Rawls, que afecta la identidad de los individuos. La distinción que hago con Rawls, y para esto me apoyo en el pensamiento de Dewey, es que considero que, así como la concepción de la justicia influye en otros ámbitos de la vida de los ciudadanos, esos otros ámbitos tienden a influir en la concepción de la justicia que cada uno de ellos posee. Si es aceptable este hecho, entonces la idea de que la única educación que la sociedad debe obligar es aquella que promueva virtudes políticas y enseñe derechos, como pretende Rawls, es insuficiente para garantizar la estabilidad de la concepción. Siempre que la educación promueva una vida liberal (que por sí misma sólo implica la búsqueda del desarrollo libre de las facultades humanas al modo en que cada persona prefiera siempre y cuando sea compatible con las instituciones liberales que lo permiten), generará las condiciones necesarias para la estabilidad social.

El segundo argumento, el del paternalismo, es un tanto más complejo ya que requiere que reconozcamos que hay ciertos contenidos mejores que otros. $\mathrm{Si}$ utilizamos un criterio pragmático el argumento en favor del paternalismo nos conduce a preguntarnos cuál es el fin de la educación. Si el fin de la educación es la sumisión a una doctrina, la educación liberal es un medio completamente errado. Pensemos en el concepto de educación que podría tener un fundamentalista religioso. Probablemente éste consideraría que la educación supone el obligarmostrar a una persona la importancia de creer en un canon sin criticarlo, asumiendo que es conocimiento que está más allá de toda crítica.

La compatibilidad entre el pensamiento pragmático y la posición original como mecanismo de justificación para la justicia como imparcialidad es particularmente relevante en el reconocimiento de la educación como un bien. Para las partes que están en la posición original, y se encuentren cubiertas por el velo de la ignorancia, parecería razonable suponer que todas ellas desearán, dado que la educación es un bien irrenunciable (no se puede elegir no educar, se puede elegir educar de diversos modos, bien o mal, pero la opción de no educar en lo absoluto no existe en pues eso condenaría a la persona a no contar con los medios necesarios para poder desarrollar sus capacidades morales absolutamente $y$, si radicalizamos la idea, probablemente suponga una condena de muerte), garantizar una 
educación que permita elegir libremente la doctrina comprehensiva que sea preferible. La opción por permitir que la familia sea la responsable única de educar al menor (no se puede negar la participación de la familia en la educación de los individuos por razones evidentes mientras la estructura familiar siga existiendo en la sociedad) supondría la posibilidad de negar a las personas la posibilidad de elegir con libertad el ejercicio de sus poderes morales en el futuro. Esto es claro una vez que entendemos el papel del entorno social en la formación de nuestras capacidades de juicio y de nuestra habilidad de analizar las opciones:

Un grupo social pequeño con hábitos fijos, un clan, una pandilla, una secta pequeña, un grupo dogmático restringirá la formación de poderes críticos -por ejemplo, de la conciencia moral reflexiva. Pero un individuo que realmente se convierte en miembro de la sociedad moderna, con sus múltiples ocupaciones, sus facilidades de relacionarse, su libre movilidad, su riqueza en recursos de arte y ciencia, tendrá muchas oportunidades para el juicio reflexivo y la valuación personal y de sus preferencias. Los mismo hábitos de la iniciativa moral, de la crítica personal, del orden existente y del proyecto privado de un orden mejor, a los cuales los individualistas morales apuntan como pruebas de la naturaleza moral "interior", son en sí mismos efectos de un orden social variable y complejo. ${ }^{48}$

Es posible reconocer que las características cognitivas que Dewey reserva para los miembros de una sociedad moderna podrían no ser aceptables para muchos grupos razonables, sin embargo, también es posible reconocer que cualquier otra opción (una educación que no promueva la "iniciativa moral") sería mucho menos aceptable para aquellos que no compartieran las creencias dogmáticas de aquellos en posición de imponerse. Si aceptamos la posición original como un experimento mental que nos permite pensar en términos de imparcialidad, podríamos cuestionarnos qué es preferible desde la perspectiva de un grupo minoritario con una idea moral del mundo dogmática, dar prioridad a una educación que al menos abra la puerta a que mi doctrina comprehensiva pueda ser aceptada por un individuo libre (aunque existan pocos individuos libres que la acepten) o a una educación dogmática que limite las posibilidades de los individuos a, al menos, considerar mi doctrina comprehensiva como una posibilidad.

Es posible justificar que una educación que promueva la autonomía es preferible a una que promueva el dogmatismo desde un punto de vista imparcial, como lo pretende ser la posición original. Es importante enfatizar que el argumento no puede ser construido en términos absolutos pues eso implicaría que existe la verdadera educación y las demás son, simplemente, mentiras o errores.

${ }^{48}$ Dewey, Ethics. 434 
Cuando reconocemos la validez del pragmatismo de Dewey, la posibilidad de afirmar una verdad de ese estilo queda completamente invalidada. Sólo es posible afirmar que, si deseamos vivir bajo una sociedad donde los individuos puedan desarrollar sus poderes morales, entonces es necesario que la educación que reciban esos individuos mientras sus poderes morales no están plenamente desarrollados debe promover el ejercicio de dichos poderes (admitiendo, al mismo tiempo, que su desarrollo tiende a estar vinculado al desarrollo de las capacidades intelectuales en su conjunto). La necesidad de que sea la sociedad la que garantice que esto suceda emana de la aplicación de un principio paternalista que reconoce que, como afirma Barry, los intereses de padres e hijos son independientes (aunque puedan ser convergentes en algunos casos) y, por lo mismo, la sociedad debe de garantizar que los intereses de los menores sean respetados dado el reconocimiento de sus intereses aun en una circunstancia como la posición original.

El papel de la cultura liberal en sentido amplio en una sociedad gobernada por una concepción de la justicia liberal es algo a lo que Rawls no hace justicia con el giro político. Una sociedad democrática y liberal alberga, a causa del pluralismo, doctrinas comprehensivas que no son necesariamente liberales en sí. Los Estados Unidos, nación de la que Rawls hablaba en el Liberalismo Político, alcanzaban en la década de los noventa casi los 250 millones de habitantes, suponer que dentro de esos millones todos los individuos serán unos perfectos liberales es un delirio (no supongo que Rawls lo afirmaría por supuesto). Lo que es más, no importa qué tipo de programa educativo se llevara a cabo, el dogmatismo, la intolerancia y el conservadurismo, que se oponen a una sociedad liberal, seguirán existiendo en cualquier Estado nación contemporáneo. Considero, tomando en cuenta todo lo que ya he dicho hasta ahora, que la pregunta por la estabilidad no puede centrarse en cuál es el modo de presentar una concepción de la justicia liberal que todos los ciudadanos, con sus doctrinas comprehensivas ya formadas, puedan aceptar; más bien la cuestión de la estabilidad se centra en cómo podemos construir una sociedad más liberal y, en el contexto de la justicia como imparcialidad, más justa para todos los miembros de dicha sociedad (sean ciudadanos con plenos derechos o no lo sean) a pesar de que nunca vaya a ser aceptada por todas las doctrinas comprehensivas.

Si el pragmatismo de Dewey tiene sentido como una herramienta para justificar y comprender la justicia como imparcialidad de un mejor modo, suponiendo que mejore su expectativa de estabilidad a la vez que se sostiene como una concepción justa justificable para cualquier persona razonable dadas las 
circunstancias de la posición original, entonces la cuestión del progreso de la libertad es ineludible. A continuación planto, con la intención de finalizar este esbozo de lo que un giro pragmático de la justicia como imparcialidad significaría, la íntima relación entre liberalismo, progreso y, en última instancia, una cierta idea de perfección que puede ser compatible con la justicia como imparcialidad, sin caer en contradicción con las razones por las que Rawls estaban en contra del perfeccionismo desde Teoría, aunque pueda sonar imposible.

\section{La justicia como imparcialidad, progreso y perfección}

Si bien el progreso es un ideal formativo típico, aunque no necesario, de la política liberal norteamericana del siglo XX, su tratamiento intelectual amerita cuidado. Un problema con el concepto del progreso en el pensamiento político, como considero que identificó Rawls adecuadamente, es que el progreso supone, en muchos casos, ${ }^{49}$ un estado final al que se debe llegar y por lo mismo se puede considerar legítimo, si no tenemos una idea del mismo de carácter fundamentalmente liberal, censurar las doctrinas comprehensivas que no contemplen dicho ideal dentro de sus ideas del bien políticos. Rawls, sosteniendo su postura antiperfeccionista, deja de lado la idea del progreso (aunque como explico a continuación intenta justificar, fallidamente, una cierta idea de bien en la sociedad política) y su importancia para una sociedad bien ordenada pues no es claro cómo podrían ser compatibles las ideas de progreso y de imparcialidad.

¿Por qué el ideal perfeccionista es rechazado por Rawls?, ¿está vinculada la idea de progreso a la de perfección?, ¿qué problema hay con hablar de los logros de la sociedad en términos de progreso o atraso?, ¿es la idea del progreso realmente compatible con una visión liberal de la justicia? Para Rawls el problema del perfeccionismo, desde Teoría de la Justicia, se encuentra en el presunto hecho de que, siempre que una sociedad mantenga una idea de perfección como el objetivo de su actuar político, que influya en la concepción de la justicia, es parcial respecto otras ideas de perfección, o de doctrinas comprehensivas que no contemplen la perfección como un fin, y en ese sentido es injusta con ellas pues no las trata con imparcialidad. Asumiendo que fuera imposible mantener una idea de perfección y desarrollo para la sociedad que pueda justificarse en términos de imparcialidad,

\footnotetext{
${ }^{49}$ La noción de progreso que defiendo, que está relacionada con la idea de perfección en sentido práctico de Dewey, no supone un estadio final para poder justificarse, del mismo modo en que la evolución por selección natural tampoco lo necesita.
} 
parecería ser necesario renunciar a dicho ideal pues su imposición sería inaceptable en la posición original. La sociedad bien ordenada de Rawls, que existe bajo la condición del pluralismo razonable, no podría adoptar una concepción de la justicia que discriminara injustamente ideas del bien de la sociedad (es decir la idea de perfección en la sociedad) y, por lo tanto, tendríamos que rechazar simplemente la idea del perfeccionismo en general.

Contrario a los que probablemente eran los deseos de Rawls, la noción de progreso como mecanismo para evaluar el desempeño de las sociedades no ha menguado con el tiempo. Lo que es más, es posible afirmar que en general existe un consenso internacional de lo que implica el progreso ampliamente aceptado, no sólo por múltiples naciones con tradiciones liberales, sino por organismos internacionales que tienden a evaluar dicho fenómeno en diversas naciones del mundo. Podemos hablar de progreso también como desarrollo. El Banco Mundial utiliza una serie de indicadores que abarcan una amplia gama factores, algunos de ellos se refieren a circunstancias bastante diversas; ${ }^{50}$ por ejemplo, en ocasiones se habla de países desarrollados o en vías de desarrollo apelando al estado de su industria y tecnología, también es posible hablar de desarrollo en función de la aceptación y respeto por los derechos de las mujeres (participación política, estado del campo laboral para las mujeres, expectativa de vida, etc.), el estado de la educación, investigación científica, facilidad para hacer negocios, estado y cuidado del medio ambiente, incluso es posible encontrar acceso a internet y a otros medios de comunicación, entre otros, como criterios de desarrollo.

Los criterios anteriores de desarrollo pueden ser despreciados por algunas personas como ejemplos de mejoramiento social: uno de los ejemplos más claros al respecto sería el del desarrollo de la participación pública de la mujer. En muchas naciones es clara la resistencia a permitir a las mujeres una participación activa en la vida económica y política de la comunidad. Suponiendo que aceptemos, como hace Rawls, que no hay una idea de perfección que sea compartida por todos, parece que nos veríamos en la circunstancia de negar que dichos criterios de desarrollo de hecho son muestras de desarrollo y progreso y no sólo características, más bien arbitrarias, de las diversas concepciones de la justicia que podemos encontrar en el mundo. Empero, aun cuando viviéramos en una sociedad ordenada por la justicia como imparcialidad, hablar de desarrollo o progreso respecto a la participación de las mujeres en la vida pública, el acceso a la información o el avance tecnológico y científico no debería de ser hecho, si nos

${ }^{50} \mathrm{Cfr}$. http://wdi.worldbank.org/tables 
mantenemos en la trinchera antiperfeccionista de Rawls, en términos de desarrollo o perfección; el avance en dichos indicadores puede representar en términos, aunque tendríamos que ver que realmente se conformen en función de la concepción de la justicia en su ejecución concreta, de la construcción de una sociedad más justa según una concepción de la justicia determinada. Una sociedad más justa, tanto en términos procedimentales como desde la perspectiva del giro político, no implica necesariamente una transición o un cambio a un estado más desarrollado; esto es, al menos, lo que Rawls deja ver en su obra.

Esta comprensión antiperfeccionista de Rawls termina promoviendo, sostengo, la incapacidad de la sociedad liberal de reconocer su responsabilidad civilizatoria. ${ }^{51}$ Aun cuando es cierto que imponer un ideal de perfección social puede implicar una imposición ilegítima sobre las personas, me parece que, desde la perspectiva de la sociedad liberal, dicho ideal perfeccionista es irrenunciable ya que el liberalismo mismo, contra lo que Rawls esperaba en el Liberalismo Político y he intentado mostrar hasta ahora, supone una familia de ideas del bien (aquellas que no estén en oposición a los valores liberales) que permiten evaluar la sociedad en términos de desarrollo.

En cualquier caso, el reto de plantear el ideal perfeccionista en una sociedad liberal es grande. En el momento en que buscamos dar contenido a la idea de la perfección nos encontramos con la posibilidad de convertirnos en aquello contra lo que Rawls se opone (quienes quieren imponer su visión comprehensiva de la sociedad ilegítimamente). Sin embargo, la comprensión pragmática de la justicia como imparcialidad, como se ve reflejado particularmente en el tema de la educación que traté antes, supone una cierta noción de proyecto civilizatorio que es, de hecho, compatible con la concepción de la justicia liberal. En este sentido Dewey afirma que: "El liberalismo está comprometido con un fin que es al mismo tiempo duradero y flexible: la liberación de los individuos para que la realización de sus capacidades pueda ser la ley de su vida. Está comprometido con el uso libre e la inteligencia como método para dirigir el cambio." ${ }^{52}$

\footnotetext{
${ }^{51}$ Esta afirmación no implica, necesariamente, que Rawls rechace cualquier tipo de acción coordinada hacia un fin inspirada por los principios de la justicia. La tendencia a la igualdad democrática, como predispone el segundo principio de la justicia, es, en cierto sentido, un objetivo político que conduce a este tipo de acción coordinada. Sin embargo, dicho igualitarismo, en especial con el giro político, carece de justificación moral y de, si el planteamiento rawlsiano de la justicia como imparcialidad es correcto, esta responsabilidad civilizatoria pues en sí mismo no contiene un ideal moral para la sociedad liberal. En la medida en que es un principio distributivo político, su razón de existir está fundada en la imparcialidad.

${ }^{52}$ Dewey, Liberalism and Social Action. 61
} 
Una posible objeción de la lectura pragmática-deweyana del liberalismo de Rawls podría considerar que dicha lectura es incompatible, y de hecho de un espíritu completamente contrario, a la noción de un liberalismo que reconociera el papel de la imparcialidad en la estructuración y elaboración de la concepción de la justicia que sería elegida en la posición original. Considero que la idea de que el liberalismo político tenga un fin ulterior a la mera ordenación de la sociedad es una violación a la idea del giro político de la justicia como imparcialidad. En este punto identifico una tensión profunda dentro del pensamiento rawlsiano, en específico posterior al giro político.

Cuando en el Liberalismo Político Rawls lleva a cabo el análisis sobre el bien de la sociedad política, ${ }^{53}$ parecería que abre la puerta para que la sociedad bien ordenada por la justicia como imparcialidad, asumiendo el giro político, tenga fines ulteriores al mero orden. Cuando Rawls habla de una sociedad bien ordenada incluye la idea de cooperación y, en ese sentido, parece que se encuentran implícitos, incluso desde ese momento, algunas ideas de bienes dentro de concepción de la justicia (la idea de la cooperación parece suponer un objetivo ulterior y, a menos que Rawls sólo se interesara por el orden por sí mismo, podemos legítimamente esperar algún otro bien distinto). El problema, el origen de la tensión, se evidencia, a mi parecer, en que en el mismo apartado Rawls afirma que "la justicia como imparcialidad efectivamente abandona el ideal de comunidad política si por ese ideal se significa una sociedad política unida por una (parcial o completa) doctrina comprehensiva religiosa, filosófica o moral. (...) Como hemos visto, el liberalismo político concibe la unidad social en un modo distinto: específicamente, como el producto de un consenso traslapado en una concepción política de la justicia adecuada para un régimen constitucional." ${ }^{54}$ Aunque la idea del abandono de la idea de comunidad merecería un estudio a mucha mayor profundidad, ${ }^{55}$ quiero centrarme en la tensión entre la posibilidad de plantear fines para la sociedad política con el giro político. El problema de definir bienes al modo en que lo hace en el Liberalismo Político es que, con los límites del giro político, considero que Rawls difícilmente puede justificarlos distanciándose de una comprensión moral de la justicia como imparcialidad:

\footnotetext{
53 Cfr. Rawls, Political Liberalism. 201

${ }^{54}$ Idem

${ }^{55}$ Algo que sería importante aclarar, antes de continuar en la explicación de la tensión en el pensamiento de Rawls, es que efectivamente, si reconocemos la realidad del pluralismo, la posibilidad de que una doctrina comprehensiva, parcial o total, en cualquiera de sus modalidad, sea el punto de unión de la totalidad de la comunidad es, efectivamente, una imposibilidad. Sin embargo, como espero ya haber mostrado, las condiciones del consenso traslapado, en tanto niega el consenso fundado en un modus vivendi, es igualmente una imposibilidad.
} 
Con estos asuntos asumidos, la sociedad bien ordenada de justicia como imparcialidad es buena en dos modos. El primero es como un bien para las personas individualmente, y esto por dos razones. Una es que el ejercicio de los dos poderes morales se experimenta como un bien. Esto es una consecuencia de la psicología moral usada en la justicia como imparcialidad. Y que este ejercicio puede ser un bien importante, y lo será para muchas personas, es claro por el papel central de estos poderes en la concepción política de los ciudadanos como personas. (...)

Una segunda razón por la que la sociedad política es un buen para los ciudadanos es que asegura para ellos el bien de la justicia y las bases sociales para el respeto mutuo. $^{56}$

La idea de que Rawls puede justificar los bienes en su concepción política del ciudadano es un error. Por ejemplo, cuando habla de la psicología moral en el pasaje recién citado, Rawls refiere un comentario, en la nota al pie, en la que habla de cómo esa psicología usa el principio Aristotélico, tratado en Teoría de la Justicia. Dicho principio difícilmente está distanciado de una doctrina comprehensiva parcial. Lo que es más, cuando afirma que el ejercicio de dicha psicología, no fundada en un argumento político, es un bien, no tiene realmente razones políticas para hacerlo. Afirmar que sólo porque es parte de la definición del ciudadano la posesión de los poderes morales su ejercicio es un bien es simplemente una conclusión injustificada. De hecho, la idea de que el ejercicio de los poderes morales es un bien está vinculado a un principio liberal y moral de autonomía que Rawls está cargando de contrabando al argumento.

Rawls intenta, al plantear el bien en la sociedad política, estirar los límites del giro político más allá de lo que el argumento es capaz de dar. Si uno de los factores fundamentales del consenso no es una comprensión moral del liberalismo, entonces las ideas del bien liberales (que son eminentemente morales) no pueden servir para justificar el liberalismo político si este, efectivamente, no requiere de una justificación moral (como sostiene Rawls que sucede con el giro político). Así, si la sociedad bien ordenada tiene fines que no pueden ser justificados desde el giro político de modo estricto, podemos suponer que dicha sociedad es compatible con un progresismo que está, irremediablemente, condicionado por ideas morales que se extienden más allá del ámbito político. Si esta tensión está presente, como sostengo que lo está, entonces la posibilidad de sostener la distribución de bienes desde justificaciones puramente políticas es inoperante.

En último término el liberalismo, al menos en la formulación de la justicia como imparcialidad desde una lectura pragmática-deweyana, se justifica en la

56 Ibid. 202-203 
"naturaleza humana" (que es un concepto irremediablemente perteneciente a una doctrina comprehensiva), en la existencia de los poderes morales de los individuos que implican la capacidad deliberativa y racional, y por eso parecería ser razonable afirmar que de hecho tiene el fin de promover el uso de la inteligencia ya que ésta implica el ejercicio de los poderes morales y, como intenté mostrar en el apartado pasado, el ejercicio de la inteligencia debe de ser formado responsablemente por la sociedad. Suponiendo que la promoción de la inteligencia sea uno de los fines del liberalismo, el progreso, y en esa medida el perfeccionismo, es una de las consecuencias de la aplicación de una concepción liberal de la justicia a la estructura básica de la sociedad.

La relación entre liberalismo y progreso es necesaria desde la perspectiva del pensamiento pragmatista de Dewey. Encuentro justificado afirmar que la vinculación de conceptos como democracia, libertad y progreso es necesaria: la única manera de ser libres es viviendo en una democracia, donde los individuos sean responsables de hacerse cargo de su vida y su sociedad y, al mismo tiempo, ese estado democrático y liberal implica, necesariamente, un avance progresivo en el bienestar y la realización de los individuos; esto dado que la libertad es condición del progreso humano (como sucede en el campo de las ciencias, en donde un tendencia falsacionista requiere de libertad para elaborar hipótesis nuevas y experimentar). En la medida en que los individuos gocen en su vida ordinaria de libertad, tenderán a generar progreso en un sentido pragmático. En este sentido la sociedad más avanzada, al menos desde un proyecto civilizatorio liberal, no es una en la que todos se comporten igual por la coacción de un agente externo a ellos (sea el gobierno o algún otro poder político como pueden ser el sector industrial o de comunicación por ejemplo), sino aquella que permita que todos los proyectos de vida, o comprensiones del bien, compatibles con la concepción de la justicia liberal sean "puestos a prueba" y se encuentren abiertos a la crítica y evaluación de la sociedad.

Considero relevante afirmar que, en esta lógica, no hay ninguna condición necesaria para que una sociedad liberal tienda a mantener el pluralismo actualmente presente en nuestras sociedades contemporáneas en tanto que, con el paso del tiempo, ciertas ideas del bien terminan cayendo en desuso debido a su inferioridad como mecanismos de desarrollo; la diferencia con otro tipo de concepciones de la justicia no liberales es que éstas limitan el pluralismo mediante el uso de la fuerza y en una sociedad liberal podría limitarse (de nuevo, no creo que sea un proceso necesario) simplemente mediante la elección libre de ciudadanos que prefieren otros proyectos de vida para sí. En cualquier caso 
también queda la posibilidad, dado que no sabemos cómo cambian bajo condiciones de libertad los individuos y sus doctrinas, de que el pluralismo incremente y que las diferencias se hagan más evidentes (aunque sean diferencias compatibles con el ideal liberal).

El progresismo liberal de Dewey no está definido por un estilo de vida particular o un tipo de modelo final (lo que considero que es la gran preocupación de Rawls respecto del perfeccionismo). El progreso liberal no puede ser comprendido como una meta ya que no existe un estilo de vida arquetípico del liberal más allá del de una persona que utiliza su razón para definir los proyectos de vida que satisfacen sus necesidades dadas sus condiciones vitales. Este estilo de liberalismo conduce al progreso de un modo similar en que la evolución por selección natural lo ha hecho, desechando las opciones inviables manteniéndose abierto a las posibilidades del futuro. El futuro de la sociedad liberal no puede ser identificado con una meta final determinada, la sociedad liberal se resiste a ser pensada en términos de utopía pues está compuesta por personas que son capaces de pensarse y pensar su mundo de un modo distinto y autónomo y, de esta manera, cualquier utopía representa la idea de bien de cada uno de ellos.

El fin de la sociedad liberal ordenada por la justicia como imparcialidad es en este sentido pragmático deweyano; permitir que todas las personas tengan igual oportunidad de ejercer sus poderes morales y el uso de su inteligencia del modo más libre que la sociedad misma pueda plantear. Para poder permitir este desarrollo de poderes morales y de inteligencia debe, al mismo tiempo, ser capaz de enfrentar el conflicto de un modo productivo, contrario a lo que Rawls tiende a buscar en particular con el giro político donde parecía buscar su desaparición, generando, últimamente, progreso y perfeccionamiento en un sentido pragmático.

El tipo de perfeccionamiento del que estoy hablando se fundamenta en la idea de desarrollo continuo cuasi evolutivo. El hecho que la sociedad apunte al perfeccionamiento de sí misma mediante el desarrollo de sus ciudadanos implica que éstos serán capaces de comprender los estándares que dictaminan la acción en los distintos ámbitos de su sociedad (es decir que podrán evaluar críticamente las acciones y sus principios) y, al hacerlo, estarán en condición de afirmarlos o superarlos dependiendo de sus circunstancias: "El estándar siempre es reformulado con base en la experiencia presente aunque formulado con base en la experiencia pasada." ${ }^{57}$ Siempre que los miembros de la sociedad puedan actuar de este modo, el progreso y el perfeccionamiento de la sociedad, en un sentido de

${ }^{57}$ Dewey, Principles of Instrumental Logic. 87 
claro mejoramiento, deberá ser la consecuencia. Lo que podríamos anticipar es que, en una sociedad abierta al pensamiento crítico, los ciudadanos se mantienen abiertos al diálogo y reconocen (aunque no ocurra en todos los casos por supuesto) que las aseveraciones deben de estar justificadas. A dónde nos llevará eso, es imposible de anticipar.

El proceso que intento plantear es similar al de "destrucción creativa" que Schumpeter acuñó para explicar el mecanismo de operación del capitalismo. Para Schumpeter la razón por la que el capitalismo ha sido tan exitoso históricamente (Schumpeter sostiene que el capitalismo ha sido, al menos hasta 1950, el sistema económico que ha garantizado el mayor crecimiento económico año con año frente a las opciones socialistas o comunistas ${ }^{58}$ ) es su capacidad destructiva de los medios productivos que se convierten, con el paso del tiempo, en opciones anticuadas. ${ }^{59}$ Un ejemplo de destrucción creativa es la entrada de la iluminación con luz eléctrica, de la que Tomas Edison fue pionero, y la desaparición de la industria de las lámparas de keroseno; claramente la luz eléctrica se presentaba como una opción más segura y eficiente que las lámparas de keroseno. Esto implicó que una industria completa desapareciera y se perdieran empleos directos e indirectos; sin embargo estos costos, afirmaría la idea de Schumpeter, se deberían compensar con las nuevas industrias y mejoras en la economía. Este tipo de dinamismo, destrucción creativa, ha sido el motor del progreso económico pues se fundamenta en un proceso evolutivo que responde a las condiciones ambientales (situación concreta en la que se encuentra la sociedad) y, al mismo tiempo, genera sus nuevas condiciones (mediante la formación de nuevos mercados, nueva organización industrial, nuevos métodos de producción) ${ }^{60}$ Lo que es más, desde la óptica de Schumpeter el capitalismo es la causa de fondo de las circunstancias mismas del liberalismo como un fenómeno social y político:

No sólo la planta moderna y mecanizada y el volumen de producción que emana de ella, no sólo la tecnología moderna y la organización económica, sino todas las características y logros de la civilización moderna son, directa o indirectamente, productos del proceso capitalista. Deben de ser incluidos en cualquier hoja de balance para poder analizar sus ventajas y desventajas. ${ }^{61}$

Una lectura pragmática del liberalismo de Rawls, que como he intentado justificar sería compatible con la idea del perfeccionismo, se identifica con la idea de la

\footnotetext{
${ }^{58}$ Cfr. Joseph Schumpeter, Capitalism, Socialism and Democracy (Nueva York: Harper Perennial, 2008), 63-71.

${ }^{59}$ Cfr. Ibid. 83

${ }^{60}$ Cfr. Ibid. 82-83

${ }^{61}$ Cfr. Ibid. 125
} 
destrucción creativa pero la transfiere al ámbito social. Las diferencias entre Schumpeter y Dewey sobre esto se encuentran en una comprensión distinta del origen de la motivación de los actos humanos. Parece que Schumpeter considera que los beneficios propios del capitalismo, entre ellos la posibilidad de acumulación de capital, es la causa originaria de la sociedad contemporánea. Por su parte, Dewey, quien era un crítico abierto del capitalismo, tiende a considerar que el progreso de la sociedad moderna no tiene como única causa la motivación capitalista de origen (la acumulación de capital). Si es posible hablar de progreso a partir de la existencia de la sociedad moderna (y creo que con lo dicho hasta este punto en la investigación sí es posible hacerlo), para Dewey la causa de este no se encuentra en el sistema económico sino en las características personales que coexisten con dicho sistema económico pero que no encuentran en él su origen necesariamente:

\begin{abstract}
Una objeción aun más seria al argumento es que concede a la iniciativa, el vigor y la independencia exclusivamente en términos de su manifestación menos significativa. Están limitadas a su ejercicio en el área económica. El significado de su ejercicio en conexión con los recursos culturales de la civilización, en temas aquellos como la compañía, la ciencia y el arte, están prácticamente ignorados. Es en este último punto en particular que la crisis del liberalismo y la necesidad para su reconsideración en términos de genuina liberación de los individuos es más evidente. $^{62}$
\end{abstract}

Dewey acierta en su consideración pero yerra en la evaluación de la importancia del área económica. Considero cierto que el ejercicio de la independencia, iniciativa y de la acción autónoma (que es tan preciada para el proceso de destrucción creativa) no sólo se explican por la dimensión económica. Aunque, como afirma Schumpeter, "[E]l liberalismo robusto de Galileo era el individualismo de la naciente clase capitalista", ${ }^{63}$ eso no implica necesariamente que ese individualismo sea fruto única o principalmente del sistema económico. El naciente capitalismo es en parte causante del individualismo, quizá una de las más importante, sin embargo no es la causa única.

La lectura de Dewey permite plantear el problema de la destrucción creativa desde una perspectiva mucho más amplia. Si asumiéramos, con Schumpeter, que el origen de los valores del individualismo provienen del desarrollo del capitalismo, parecería que una sociedad liberal, ordenada por una concepción de la justicia liberal, tiende a proteger sólo las diferencias que puedan en último término

\footnotetext{
62 Dewey, Liberalism and Social Action. 46

${ }^{63}$ Schumpeter, Capitalism, Socialism and Democracy. 124
} 
contribuir al desarrollo económico; esto sería un liberalismo flaco, tanto para Dewey como para Rawls. El problema de dicha ordenación es que tendería a tratar injustamente a las ideas del bien que no reconozcan el incentivo económico como la razón de su quehacer; por el contrario podría tratar con una ventaja injusta a las ideas del bien que sí lo hagan. Ideas del bien liberales que no necesariamente reconocen el quehacer económico como central no sólo se refieren a un tipo de vida ascética, sino también pueden ser algunas dedicadas a la investigación científica, al desarrollo del arte o la filantropía por ejemplo; todas ellas compatibles con una comprensión pragmática de la justicia como imparcialidad y, en esa medida, una acción deliberada en su detrimento estaría injustificada dados los parámetros de la justicia procedimental que he intentado perfilar.

Si bien es cierto que Teoría de la Justicia, obra fundamental en el planteamiento de la justicia como imparcialidad, debe mucho al neokantismo de Rawls, es posible plantear el hecho que puede ser consistente con el pragmatismo de Dewey. Cuando Rawls se propone descubrir cuáles son los elementos moralmente relevantes para evaluar una concepción de la justicia, y al hacerlo elabora la posición original con todas sus condiciones, está desarrollando un método compatible con la comprensión de la política de Dewey. Esta comprensión no puede ser ajena a la idea del perfeccionismo dado que éste es intrínseco a la posición liberal en tanto se entienda en su dimensión pragmática, cercana aunque no idéntica, a la idea de la destrucción creativa de Schumpeter. Un tipo de perfeccionismo que no se sostiene por un arquetipo final y que, por eso mismo, es coexistente con el hecho del pluralismo razonable de un modo natural. Reconociendo la existencia del conflicto, la imposibilidad de erradicarlo, pero la posibilidad de manejarlo de un modo inteligente de manera que, en último término, permita a los individuos desarrollarse y, al mismo tiempo, desarrollar la sociedad liberal

en

$\mathrm{su}$ conjunto. 


\section{Conclusiones}

¿Cuál debería ser el papel de la historia, la sociología, la economía y el análisis de las instituciones políticas existentes en la indagación en la filosofía política? La primera respuesta que viene a la cabeza es que debería de ser predominante, fundamental y constitutivo. Imaginar una filosofía política que no mantuviera como eje los diversos ámbitos de análisis de la realidad social y política no es una tarea del todo simple. Sin embargo, eso es lo que Sheldon Wolin considera sobre el pensamiento de Rawls:

A pesar de sus continuas referencias al concepto de "lo político", lo que hace falta en mayor medida en el Liberalismo [Liberalismo Político] es un análisis de las circunstancias políticas y los prospectos del liberalismo mismo. El Liberalismo necesita comenzar en un punto como la pregunta fundamental del ensayo Experiencia, de Emerson: ‘¿Dónde nos encontramos?' ${ }^{1}$

Sobre la posición original, en particular, afirma:

La omisión más crítica de la posición original es cualquier tipo de reconocimiento de que una sociedad política inevitablemente conlleva una carga histórica como parte de su identidad, que la compromete con las injusticias pasadas, cuyos remanentes aun definan a muchos de sus miembros. Rawls, en contraste, nos ofrece una imagen de una comunidad expiada que ha resuelto sus injusticias en términos que simplemente deben ser recordados, como en las enmiendas antiesclavistas de la constitución. $^{2}$

En esta investigación he intentado mostrar las ocasiones en las que, a mi parecer, Rawls en efecto parece olvidar algunas de las circunstancias en las que la realidad política y las circunstancias como las teoriza son en cierto sentido incompatibles. Una de estas circunstancias, que Wolin considera igualmente relevante, es la relevancia del conflicto en la arena pública. Me he enfocado en este punto en la segunda y tercera partes y con especial detenimiento en el quinto capítulo. Igualmente traté el tema de cómo el concepto de la razón pública, especialmente en el Liberalismo Político, genera condiciones irrealizables pues la expectativa de que los individuos hagan uso de dicha razón parece un ideal inalcanzable. Otro punto que critiqué, que está relacionado al aparente olvido de la realidad por parte de

\footnotetext{
${ }^{1}$ Sheldon Wolin, "The liberal/democratic divide", en Fugitive Democracy and other essays (Princeton University Press: Nueva Jersey, 2016). 277

${ }^{2}$ Ibid. 279
} 
Rawls, es la dificultad de considerar que el argumento de la posición original puede justificar una noción de justicia a partir de la naturaleza noumenal de los individuos, esto en Teoría de la Justicia.

Reconocer que Rawls desarrolla argumentos que pueden ser sujetos a esta crítica no implica, como lo hace Wolin, que "el resultado es una construcción que se denomina una sociedad libre de presupuestos pero que es, en realidad, una utopía en el sentido peyorativo, un proyecto ideológico cuyo autor no se da cuenta que ha diseñado un engaño y no una solución." ${ }^{3}$ Por el contrario, una vez que reconocemos la validez de algunas de las premisas cognitivas del pragmatismo de Dewey, es posible reconocer cómo el producto de abstracción que presenta Rawls es, si no perfecto, sí defendible y útil.

La conclusión que luego será alcanzada está anticipada aquí para servir como una guía en lo que siga en la discusión. (1) El objeto de la ciencia y sus procedimientos provienen de los problemas y métodos del sentido común, de los usos prácticos y su disfrute y (2) reacciona a este de un modo que lo refina, expande y libera de sus contenidos y agencias que están a la disposición del sentido común. ${ }^{4}$

Es conveniente mencionar en este punto que el sentido común de Dewey se refiere al conocimiento no científico en general. Dicho esto, el procedimiento rawlsiano, al menos en su lectura pragmatista, permite plantear los elementos esenciales de la vida política haciendo un trabajo de abstracción que, como afirma Dewey, "refina, expande y libera de contenidos y agencias", en la medida de lo posible, el conocimiento político. La crítica, me parece, debería enfocarse en si el trabajo de abstracción es de hecho adecuado, no si el esfuerzo de abstracción es en sí mismo correcto.

En el capítulo cuarto mostré como la idea de ciencia en Rawls es deficiente. En Teoría de la Justicia supone que el conocimiento científico tiene cualidades epistémicas que, como supone el falibilismo (pieza clave de la actitud científica contemporánea), son incorrectas. Esto conduce a Rawls a pensar que las verdades de la economía, por ejemplo, deben de estar disponibles para los participantes en la posición original bajo un estatuto de verdades. Esta idea es incorrecta y no hay disciplina científica en donde sea más evidente que en las ciencias humanas: la sociología, la política, la antropología y la economía, que tiende a ser la más abstracta de todos, mantienen estándares de justificación altos pero, al mismo tiempo, deben reconocer que, dada la materia de la que tratan, los niveles de

\footnotetext{
${ }^{3}$ Ibid. 280

${ }^{4}$ John Dewey, Logic (Nueva York: Saerchinger Press, 2007), 110
} 
abstracción son menores que en otras ciencias y, por lo mismo, las hacen más sensibles al falibilismo (que no está exento en ninguna otra disciplina humana que trabaje con la indagación).

La crítica que plantea Wolin nos conduce a pensar en los límites de la ciencia política en general y de la filosofía política en particular. ¿Qué significa hacer teoría política? ¿Cuál es el modo en que debemos abordar la filosofía política? Cualquier esbozo de respuesta tendría que reconocer que no hay un solo modo de hacer filosofía pues, como probablemente afirmaría Dewey, los modos de indagar serán distintos dependiendo los problemas que nos interesen desde nuestra perspectiva particular. Es decir, el modo en que realizamos nuestra investigación dependerá de nuestros objetivos. Jeremy Waldron, en el prefacio a su libro Political Political Theory, resume este punto de modo sumamente sintético: "Espero que la totalidad de esta obra motive a los teóricos de la política más jóvenes a entender que hay vida más allá de Rawls, vida más allá de la comprensión abstracta de la libertad, la justicia y el igualitarismo -no que esos temas no sean importantes." ${ }^{5}$

En la cita anterior hay una idea fundamental, que Wolin no parece considerar en su crítica a Rawls, y es que la indagación abstracta cumple una función en la teoría política que no puede ser simplemente desechada como un engaño o una tendencia hacia al pensamiento utópico inservible. No sólo eso, la filosofía política abstracta, como la de Rawls, no puede ser entendida, como parece hacerlo Wolin, como si fuera una especie de ejercicio de ficción que no tiene relación con la sociedad norteamericana en la que vivió Rawls. No sólo Rawls afirma que la sociedad en la que está pensando es básicamente los Estados Unidos en el Liberalismo Político, sino que la relevancia de los temas que trata muestra una comprensión de su realidad política profunda.

A pesar de que Dewey estaría en contra de afirmar una concepción de la justicia desde un argumento de tipo kantiano, estoy seguro que podría aceptar la validez de una concepción de la justicia en términos pragmáticos como hace también Rawls. Lo que es más, en la medida en que la justicia es un concepto que está abierto a nuevas reconceptualizaciones de acuerdo a las circunstancias históricas en las que nos encontramos, me parece que la necesidad de desarrollar argumentos de orden pragmáticos para dar contenido a la principal virtud política es una necesidad. Esa indagación requiere un cierto grado de abstracción que nos conduce a reconocer el método rawlsiano en su utilidad y validez. El problema de la abstracción en ciencias sociales lo plantea Dewey del siguiente modo:

${ }^{5}$ Jeremy Waldron, Political Political Thought (Harvard University Press: Cambridge, 2016), ix. 
Pero la conversión de las situaciones investigadas en problemas concretos, que pueden ser inteligentemente atendidos, demanda una formulación objetiva e intelectual de las condiciones; esta formulación demanda, por su parte, una completa abstracción de las cualidades del pecado o virtud [righteousness], de vicio o motivos virtuosos, que son tan fácilmente atribuibles a individuos, grupos, clases, naciones. ${ }^{6}$

Por supuesto en Teoría de la Justicia y en Liberalismo Político es ineludible la presencia de las virtudes; el tema, después de todo, es un análisis sobre la justicia. Sin embargo, en ambos textos es posible encontrar un esfuerzo para encontrar las condiciones fundamentales del fenómeno político y el modo en que la justicia podría mediar en ellos. Más allá de las críticas concretas que se puedan hacer a la obra de Rawls, me parece que la estrategia es la correcta. Es por esta razón que la crítica de Wolin está fuera de lugar. Lo que es más, creo que Wolin simplemente no comprendió la intención (en el sentido pragmático del que hablé en el primer capítulo) de la indagación rawlsiana.

Si el pensamiento de Rawls procurara dar una explicación del origen de la democracia representativa, la separación de poderes o la estructura de las revoluciones sociales, el argumento en contra de la posición original de Wolin podría ser correcto; pues esos objetos de indagación no pueden plantearse en el nivel de abstracción que plantea Rawls. Sin embargo, en tanto que Rawls está intentando abordar una cuestión particular, encontrar una concepción de la justicia que pueda servir en sociedades plurales, el ejercicio de abstracción me parece en general correcto del modo en que está planteado.

La comprensión del pragmatismo como método de indagación permite comprender las fortalezas del modo de argumentación rawlsiano a la vez que permite replantear algunos de sus problemas. El objetivo es sumamente ambicioso y la hipótesis es interesantísima: es posible desarrollar una concepción de la justicia enfocándonos en los elementos más fundamentales de la socialización humana contemporánea. Es decir, la indagación de la justificación de la justicia como imparcialidad desde sus premisas pragmáticas nos conduce a preguntarnos si es posible desarrollar una concepción de lo justo que, dada la condición humana, sea la mejor opción posible para el mayor número posible de personas.

Si es posible desarrollar una concepción de la justicia, situada en ciertas condiciones históricas, pero que sea capaz de justificarse, al menos en parte, en una hipótesis justificable de la naturaleza de los seres humanos, entonces será una

${ }^{6}$ John Dewey, Logic. 772 
concepción que será justa en más circunstancias que una que dependiera de una idea del bien determinada y parcial. La idea de la concepción política de la persona, que está en el Liberalismo Político, plantea un nivel de abstracción de los ciudadanos para la dimensión política que está, considero, en esos términos. ${ }^{7}$

La posibilidad de desarrollar una concepción de la justicia en términos pragmáticos, como lo hace Rawls, con las contribuciones que es posible hacer a la justicia como imparcialidad desde el pragmatismo de Dewey, nos da las herramientas para pensar en algunos problemas políticos fundamentales que tienen implicaciones políticas relevantes. En ese sentido Rawls comprendió perfectamente la importancia de que la concepción de la justicia tenga como objeto la estructura básica pues ésta termina afectando a realidad política casi en su totalidad. Para concluir esta investigación quisiera hacer una revisión muy breve de algunos temas que considero especialmente relevantes por las implicaciones que tienen en las sociedades contemporáneas. Antes de hacerlo, quisiera hacer una aclaración. El planteamiento de esta investigación, antes de haber iniciado con la redacción de la misma, busqué enfocarlo en la comparación del pensamiento liberal de dos autores, en especial respecto a la posibilidad de plantear una justificación pragmática del liberalismo y las implicaciones que dicha justificación supondría, de modo que pudiera hacer un balance de sus contribuciones y sus límites haciéndoles justicia del mejor modo. He intentado hacerlo del mejor modo, sin embargo, creo que el lector podría no pensar lo mismo dada la desproporcional atención que di a la obra de Rawls (como parece evidenciar la cantidad de tinta dedicada a él frente a la dedicada específicamente a Dewey). A pesar de haberme centrado mucho más en la explicación de la justicia como imparcialidad, en sus dos presentaciones más importantes, el pensamiento pragmático de Dewey, así como algunos de los factores fundamentales de su idea de democracia liberal, se encuentran de fondo. Como bien señala Dewey, la manera en que abordamos la indagación está determinada por nuestros presupuestos y, al menos en ese sentido, el pensamiento de Dewey está claramente presente en toda la investigación. Las ideas del falsacionismo, de la importancia de la capacidad previsora de la indagación y la noción de verdad como aseveración justificada, que rechaza cualquier tipo de intuicionismo o realismo metafísico, están presentes, o al menos eso espero, en todo el texto.

Con esto en mente, las ideas finales a las que quiero dedicarles un espacio son: (i) las características moralmente relevantes para determinar una concepción

${ }^{7}$ Cfr. John Rawls, Political Liberalism (Nueva York: Columbia University Press, 2005). 29-35 
de la justicia y su relación con el hecho del pluralismo y (ii) la relación entre democracia y liberalismo. Del segundo de ellos hablé en distintos momentos durante la investigación. Sobre la posibilidad de encontrar los elementos moralmente relevantes para la determinación de una concepción de la justicia dediqué mi atención en la segunda parte de la investigación. El hecho del pluralismo, que está presente en prácticamente la totalidad de la investigación, lo trato especialmente al exponer el Liberalismo Político en la tercera parte. La relación entre ambos es bastante evidente, al menos la intuición de que, si la posibilidad de encontrar las características moralmente relevantes en la posición original (como ejercicio de reflexión) es real, hay serias implicaciones para la existencia del pluralismo. Este tema, en estos tiempos, me parece que es particularmente vigente por las razones que explico a continuación. Por su parte, el tema de la relación entre la democracia y el liberalismo está en esta investigación lo trato brevemente en el último capítulo. Sin embargo, de ninguna manera lo agoto y algunos de los problemas fundamentales sólo están sugeridos; a continuación intento problematizarlo un poco más con el fin de demostrar la relevancia del tema.

\section{Las características moralmente relevantes para la justicia y el hecho del pluralismo}

La pregunta sobre cuáles son las características moralmente relevantes para configurar una concepción de la justicia es muy importante. Como afirmó Dewey, existe la posibilidad de trasladar conceptos de otras épocas, en especial en el ámbito moral y político, sin contrastarlos con las nuevas condiciones sociales del momento; de hecho tendemos a hacer esto continuamente. Este es uno de los puntos en que el acuerdo de Rawls y Dewey me parece más evidente. No es conveniente mantener una concepción de la justicia que no sirva para los propósitos de nuestra sociedad concreta pues, como consecuencia, no sería justa. La cuestión sobre qué es moralmente relevante, está condicionada por las condiciones de la indagación.

La relevancia de tener un concepto funcional y adecuado de la justicia para una sociedad determinada no puede ser menospreciada. Negarla en nuestras sociedades implicaría, probablemente, que la única regla a la que podríamos razonablemente apelar es a la del poder. La justicia es la condición de la paz duradera para una sociedad que no busque imponer una idea del bien limitando la 
libertad de los individuos injustificadamente. El poder es capaz de imponer, pero el poder no se justifica por sí mismo y, en sociedades donde se dan las "condiciones de la justicia", la mejor manera de justificar el uso del poder político es a través de la justicia. Si la justicia es el criterio principal para justificar el uso del poder político, la cuestión sobre qué es la justicia es fundamental para cualquiera $\mathrm{y}$, especialmente, para el que se dedique a pensar en política.

La relación del hecho del pluralismo y la necesidad de una concepción de la justicia adecuada a las necesidades de las sociedades occidentales es tratada por Rawls con una insistencia atípica en la tradición filosófica. El hecho de que las sociedades contemporáneas están constituidas irremediablemente de modo plural (en sociedades de millones de personas y acceso a diversos medios de comunicación parece imposible, a menos que exista un ejercicio de poder injustificable, desaparecer dicho pluralismo) conduce a poner en duda la justificación posible de concepciones de la justicia a partir de ideas del bien particulares. La obra de Rawls es, en este aspecto, profundamente ambiciosa. Cuando se plantea cuáles son los elementos moralmente relevantes para formular una concepción de la justicia y se centra principalmente en la igualdad moral de los individuos (con sus poderes morales) hace un reconocimiento de la importancia del pluralismo y las implicaciones que tiene en cada individuo en particular.

La crítica comunitarista, que supone que la justicia como imparcialidad no toma en cuenta las diferencias culturales con la seriedad que debería, es, en la medida en que entendemos los objetivos de Rawls, completamente inadecuada. A pesar de que en esta investigación he procurado mostrar que Rawls no reconoce algunas de las implicaciones que una idea del bien puede en los individuos (esto en tanto supone que los ciudadanos serán capaces de reconocer la verdad de sus doctrinas comprehensivas en lo privado pero no en lo público), el hecho de que intente formular una concepción de la justicia de orden político es, justamente, porque entiende la relevancia que las doctrinas comprehensivas tienen en la vida de las personas. Después de todo, las consecuencias históricas que han existido cuando un régimen obliga una idea del bien, así como una concepción de la justicia dependiente de ella, a una parte de la población que no la comparte, tiende a generar conflictos sociales graves.

Del mismo modo, la crítica de Benjamín Barber a la idea de elaborar una concepción de la justicia que sea útil para una sociedad contemporánea estaría equivocada. Barber, en un argumento similar al de Wolin, afirma que: 
Lo que requerimos en cualquier caso en el mundo político real no son verdades reflexivas conseguidas a través del equilibrio reflexivo sino el desarrollo de normas desarrolladas en medio de problemas concretos comunes; no la certeza absoluta sino la convicción relativa; no la incorregibilidad de la filosofía sino el acuerdo práctico; no el conocimiento último sino fines compartidos, valores comunes, estándares comunitarios y bienes públicos en un mundo donde el conocimiento final puede ser inconseguible. Por tanto, la democracia puede existir completamente sin fundamentos morales; puede ser la respuesta política a la incertidumbre moral. ${ }^{8}$

El esfuerzo de desmantelar las complejidades y los conflictos de la realidad política del momento, con la finalidad de encontrar los elementos fundamentales de la justicia, permite a Rawls pensar si las condiciones más fundamentales de la vida política pueden establecer las condiciones de justicia (como procura hacer desde la posición original). En caso de que lo logre, Rawls podría afirmar que, aunque "la democracia puede existir completamente sin fundamentos morales", dicha democracia será justa sólo en la medida en que pueda tenerlos. En el intento de encontrar estas condiciones y sus implicaciones nos jugamos la posibilidad de existir en sociedades libres y plurales de modo justo.

Ya que el pluralismo es un hecho inescapable para las sociedades actuales, las alternativas al objetivo rawlsiano son, por un lado, un replanteamiento fundamental de las estructuras sociales para que el pluralismo desaparezca y todos puedan ser libres y estar de acuerdo al mismo tiempo (quizá refundando las sociedades en unidades más pequeñas y homogéneas en contra de la existencia del Estado nación moderno y la tendencia a la globalización contemporánea) o, por otro, desaparecer las libertades y limitar, más allá de lo justificable en condiciones de imparcialidad, la libertad de aquellos que no compartan la idea del bien de aquellos que estén en el poder. La primera opción parecería ser poco probable; considero que sería necesario realizar un cambio radical a la organización de los Estados y, como bien muestra la historia, esos procesos no dependen de un acto planeado de ese tipo. La segunda opción, que podría ser la de algunos comunitaristas, representa el conservadurismo que en su modo menos dañino sería benevolente aunque contrario al pluralismo y, en el peor, sería opresor mediante la violencia.

En el caso en que la indagación realizada por Rawls pueda ser llevada a una conclusión justificada, las dos alternativas a una sociedad liberal como esa, como

\footnotetext{
${ }^{8}$ Benjamin Barber, Strong democracy, participatory politics for a new age (Berkeley: University of California Press, 2003). 65
} 
las que planté atrás, son inaceptables. Como lo expliqué en la tercera y cuarta partes, sin embargo, esto no significa que tenga la capacidad de dar cabida a todas las doctrinas comprehensivas en la sociedad (pues es imposible que integre a todas las doctrinas pues, como reconoce Rawls, existen algunas que no son razonables y no pueden coexistir). Es decir, es una condición histórica que existan doctrinas comprehensivas que sean incompatibles con una concepción de la justicia aun cuando ésta estuviera argumentada desde los elementos moralmente relevantes. A esas doctrinas, aun cuando sean capaces de vivir en una sociedad bien ordenada por un consenso fundado en un modus vivendi, tendríamos que definirlas como doctrinas intrínsecamente injustas. Por tanto, la condición de reconocer dicha concepción de la justicia es el requisito de aceptación para las doctrinas comprehensivas en una sociedad justa.

Lo que intenté mostrar en esta investigación es que, si la argumentación pragmática es correcta, es posible plantear una concepción de la justicia que esté justificada en criterios no dependientes de una idea específica de bien. Esto no quiere decir, como espero haber mostrado también, que una concepción de la justicia liberal, incluso una como la justicia como imparcialidad, sea independiente de una cierta idea del bien.

La ventaja de este tipo de concepción de la justicia es que, al justificarse haciendo uso de los elementos moralmente relevantes, es capaz de ser mucho más incluyente que cualquier otra opción existente. Una objeción a la propuesta rawlsiana podría suponer que todas las doctrinas comprehensivas, incluso las que no reconozcan la validez de la justicia como imparcialidad, suponen que los elementos que toman en cuenta para su concepción de la justicia son los moralmente correctos. Considero que ese es el gran uso de la posición original como mecanismo de representación y, por tanto, la objeción sería correcta sólo en la medida en que pueda justificar sus concepciones de la justicia bajo las condiciones de imparcialidad.

La búsqueda de las características moralmente relevantes, además, es parte fundamental de la lectura pragmatista que hago de la justicia como imparcialidad. Esta selección de factores se asemeja al proceso científico en la medida en que sea capaz de encontrar cuáles son los elementos constitutivos del fenómeno político que nos permitan, dado que le tipo de justicia en el que estamos pensando es uno de tipo procedimental, generar las condiciones de justicia deseadas en las diversas interacciones relevantes al proceso. Esta lectura pragmatista, como mostré a partir de la segunda parte de esta investigación, está mejor representada en el trabajo 
anterior al Liberalismo Político por parte de Rawls. En Teoría de la Justicia, a pesar de que dicho pragmatismo convive con el neokantismo, el que tuvo un papel mucho más protagónico, tanto en el texto como en las reacciones de sus lectores, es posible encontrar una justificación de la concepción de la justicia fundamentada en conceptos tales como la objetividad, que supone que la relevancia epistémica de la concepción de la justicia está en la condición de poder ser compartida entre los diversos participantes. $\mathrm{Si}$, como afirma Dewey, las indagaciones son en sí mismas intencionales, el criterio de objetividad para la elaboración de una concepción de la justicia para una sociedad plural es una condición pragmática para la estabilidad de cualquier concepción que pudiera ser elegida.

Del mismo modo, en Teoría de la Justicia el pragmatismo está presente en uno de los conceptos más estudiados de Rawls, el del equilibrio reflexivo. El concepto del equilibrio reflexivo presupone que los individuos tendrán juicios considerados sobre cuál consideran que debería ser la concepción de la justicia que informe la estructura básica. En el proceso para alcanzar dicho equilibrio es fundamental ser capaz de comparar las alternativas entre sí, en sus mejores versiones, para que, una vez que lleguemos a una conclusión nos hayamos quedado con la mejor opción posible: "la justicia como imparcialidad puede ser entendida como que afirma que los dos principios antes mencionados serían elegidos en la posición original siendo preferidos a las otras concepciones de la justicia tradicionales, por ejemplo, aquellas de la utilidad y el perfeccionismo; y que estos principios son más compatibles con nuestros juicios considerados, después de reflexionarlo, que esas alternativas mencionadas." ${ }^{9}$

Este proceso de enfrentar las opciones en su funcionalidad, en especial con algunas de nuestras ideas de lo que constituye condiciones justas de cooperación, es fundamentalmente pragmático. John Dewey, por ejemplo, supone que una de las tareas de la educación es, en un sentido parecido, encargarse de enfrentar las diversas creencias que sostienen los individuos en la sociedad para que, mediante un proceso de evolutivo (como si fuera de selección natural), seamos capaces de desechar aquellas que no son útiles.

Este modo de aproximarse a la elección de la concepción de la justicia, aunado a todas las demás razones que ya exploré en esta investigación, permiten hacer una lectura pragmática de la justicia como imparcialidad como fue presentada en Teoría de la Justicia. La ventaja que presenta el hacer este tipo de lectura desde ese texto y no, como algunos pragmatistas lo han hecho (como

\footnotetext{
${ }^{9}$ Rawls, Theory of Justice. 43
} 
Richard Rorty), desde el Liberalismo Político, es que no necesitamos renunciar a criterios objetivos para demostrar, es decir justificar, que es la mejor opción disponible (hasta que no lo sea porque tengamos alguna otra). Además de esto, la lectura pragmática desde Teoría de la Justicia cumple con una característica de las indagaciones que el giro político es incapaz de cumplir. El proceso indagatorio, según el pragmatismo deweyano, puede cumplir la función de desarrollar planes de acción para cambiar las condiciones presentes. El giro político, por su parte, asume que la sociedad que sea ordenada por la justicia como imparcialidad es en sí misma una sociedad democrática y liberal en la que todos los ciudadanos están en consenso traslapado. Asumiendo las condiciones del giro se cumplieran en la realidad, ¿cómo podrían los individuos que viven en naciones no liberales aspirar a construir una sociedad bien ordenada por la justicia como imparcialidad? Si mi lectura pragmática es adecuada, entonces el tipo de razones que desarrolló Rawls en Teoría, las de orden pragmático, podrían servir para convencer a suficientes individuos de participar en dicho consenso, ya fuera uno pleno o, del mismo modo, fundamentado en un mero modus vivendi. Del mismo modo, cuando conducimos la lectura pragmática hacia consecuencias que el mismo Rawls quería evitar, como es reconociendo la compatibilidad de un cierto tipo de perfeccionismo (perfeccionismo en sentido práctico deweyano), podemos pensar en los mecanismos que podrían ayudar a mejorar los prospectos de estabilidad de la concepción.

Este ejercicio, que como mostré no es perfecto $\mathrm{y}$, al contrario, debe ser continuamente revisado, contiene en sí la intención ilustrada y civilizatoria que permite plantear seriamente la posibilidad de convivir y cooperar en un sistema social naturalmente plural en condiciones de justicia. Un problema adicional, dadas las condiciones de pluralismo en las sociedades reales contemporáneas es, en el caso de las sociedades democráticas, la posibilidad de que las doctrinas comprehensivas no liberales intenten, por vía democrática, deshacerse de la concepción de la justicia liberal. Ese es el siguiente tema que quisiera analizar.

\section{La relación entre democracia y liberalismo}

La relación entre la democracia y el liberalismo es un tema que en Dewey es poco claro y en el pensamiento de Rawls poco tratada. Por un lado, para Dewey, no parece haber una distinción entre democracia y liberalismo. Es complicado 
identificar cuál es la diferencia entre una y otra. Los conceptos son intercambiables, lo que nos conduce a pensar que cuando Dewey habla de democracia no está necesariamente hablando de la democracia representativa electoral sino, más bien, de una cultura en la que la libertad y la representación de intereses de todos los grupos e individuos esté asegurada.

Por su parte, para Rawls es claro que la sociedad en la que está pensando es una sociedad democrática, así lo afirma repetidamente en su obra. Ahora bien, cuando toca el tema del objeto de la justicia como imparcialidad, nos deja ver que la concepción de la justicia liberal tiene prioridad sobre la democracia. Esta relación, en la que la concepción de la justicia es anterior y en cierto sentido independiente de las decisiones democráticas merecería mucha más atención de la que Rawls le dio.

Hay pensadores democráticos que intuyen que los liberalismos como el rawlsiano tienen una idea de la democracia en la que la justificación del uso del poder político, en última instancia, no reside en el pueblo. Si la concepción de la justicia es la que da forma a la estructura básica y, por tanto, a todas las instituciones políticas fundamentales de la sociedad, parecería que es anterior, en importancia y probablemente en el tiempo, a los valores democráticos fundamentales. Esta idea es adjudicada a los liberalismos constitucionales en general y parece provenir de un temor por los excesos de la democracia, como lo resume, críticamente, Benjamín Barber:

Ha sido parte de la sabiduría convencional del pensamiento democrático liberal de occidente -o lo que hemos llamada la teoría de la democracia "delgada" - que muchas de las patologías más dañinas de nuestra era han derivado de los excesos de la democracia (...). En cada caso, el cargo es que la democracia, cuando no es controlada por el liberalismo, se convierte en una democracia descontrolada, que el gobierno popular lleva en sí la semilla del despotismo totalitario que puede ser prevenido de desarrollarse sólo mediante la aplicación judicial del herbicida constitucional compuesto por doses iguales de libertad individual, derechos naturales, propiedad privada y capitalismo de mercado. ${ }^{10}$

Barber piensa que el proyecto liberal fracasa pues supone que es capaz de controlar los impulsos negativos de la democracia, sin embargo esta idea, sostiene, es irreal dadas las condiciones de la política y los Estados existentes:

La política no descansa en la justicia y la libertad; es la que las hace posibles. El objetivo de la democracia no es aplicar abstracciones sin sustento en los hechos a situaciones concretas sino, más bien, extrapolar abstracciones funcionales de

${ }^{10}$ Ibid. $93-94$ 
situaciones concretas. En otras palabras, la política no es la aplicación de la Verdad al problema de las relaciones humanas sino la aplicación de las relaciones humanas al problema de la verdad. ${ }^{11}$

La crítica anterior podría ser atinada (aunque no necesariamente correcta) para la justificación de la justicia como imparcialidad que realiza Rawls en Teoría de la Justicia, en términos neokantianos, aunque me parece que no funciona para la argumentación en bases pragmáticas. El modo en que el argumento pragmático de la justicia como imparcialidad permite escapar a estas críticas está, en parte, en la idea del consenso traslapado. Si dicho consenso es una posibilidad real, entonces la justificación de la concepción de la justicia es en bases democráticas. Es por esto que desarrollar una concepción en función a los factores moralmente relevantes es tan importante. Si la concepción de la justicia de Rawls puede superar la prueba de verdad de Dewey, es decir ser la concepción más justificada, entonces no es necesario hablar de, como afirma Barber, la política como "la aplicación de la Verdad al problema de las relaciones humanas". La idea del consenso traslapado no requiere de una Verdad así, con mayúsculas, pues exige sólo una verdad pragmática.

El consenso traslapado supone la afirmación democrática de la concepción de la justicia. El supuesto de que dicho consenso tenga que ser total es irreal; después de todo no existe un consenso absoluto respecto a ninguna idea en un Estado nación moderno, no importa cuál sea. Los consensos democráticos no necesitan ser absolutos para ser legítimos. Considero que, si se llevan a cabo las acciones necesarias para garantizar su estabilidad, como algunas de las que traté en el capítulo siete, tener un consenso traslapado suficiente sobre la concepción de la justicia es una posibilidad real.

Aun cuando la idea del consenso traslapado permita defender la naturaleza democrática de la justicia como imparcialidad, espero haber podido mostrar que dicho consenso no puede ser alcanzado dadas las condiciones antiperfeccionistas que mantiene Rawls para la justicia como imparcialidad en la totalidad de su obra. Sobre este tema Rawls parece tener una comprensión de la cultura, y los consensos que surgen de ella, sumamente estática; es decir, una vez que los individuos tienen un consenso traslapado sobre la concepción de la justicia, parece que la guerra está prácticamente ganada. En este sentido las contribuciones de Dewey son particularmente iluminadoras de este problema y el modo en que puede ser abordado con la educación de la sociedad. No sólo nos ofrece las herramientas

11 Ibid. 64 
para entender qué sería necesario para alcanzar dicho consenso sino que, de igual modo, nos ayuda a comprender qué implicaría mantenerlo (por ejemplo los mecanismos educativos de una sociedad liberal).

Este tema nos lleva al centro del espíritu liberal. Si la justicia como imparcialidad está fundamentada en el consenso democrático y, consecuentemente, su mantenimiento exige el desarrollo y mantenimiento de una cultura y sociedad liberal, ¿dónde deberíamos poner los límites entre el espacio público y privado?, ¿en qué momento la promoción de la cultura pública puede constituir una violación a la privacidad de los ciudadanos?, ¿qué partes de la vida privada no deben ser llevadas al espacio público? Estas son cuestiones difíciles de resolver y que probablemente no tengan una respuesta única (pues dependan del tiempo y la sociedad concreta en la que nos encontremos). Sin embargo, siguiendo algunas de las intuiciones de Rawls y de Dewey me parece que podemos comenzar a plantear soluciones útiles y adecuadas manteniendo el objetivo de construir una sociedad justa.

Propuestas liberales como la de Rawls y la de Dewey, reconociendo sus enormes diferencias, tienen particular relevancia en la actualidad con el resurgimiento de las políticas de la identidad. El esfuerzo por desarrollar una concepción de la justicia, ya sea la justicia como imparcialidad o el ideal democrático de Dewey, justificado por las condiciones más fundamentales de la dimensión política de la sociedad, permite enfrentar el reto de la política de la identidad de conducir la totalidad de los reclamos de los individuos a la arena pública. Este reclamo, que puede ser identificado con el argumento de que "lo personal es político", tiende a ser incapaz de diferenciar la sociedad en un sentido amplio y la sociedad como entidad política, en donde, como Rawls afirma, la justicia es la primera virtud. Los pensamientos liberales de Rawls y de Dewey nos permiten considerar sociedades en donde las reglas de la política apliquen igual para todos los individuos y que, al mismo tiempo, permitan su desarrollo en el espacio privado del modo en que ellos decidan. La indagación sobre la posibilidad de una sociedad democrática y liberal fundada en una idea de la justicia imparcial, hasta que no sea mostrada como falsa, vale la pena pues en ella encontramos algunas de las características e ideales más preciosos de la civilización ilustrada.

Dicho lo anterior cabe decir que, aunque las diferencias entre ambos autores son clarísimas, desde el rechazo al contractualismo de Dewey o el neokantismo rawlsiano, indudablemente ambos son parte de una tradición liberal típicamente americana. Contrario a lo sucede con el liberalismo europeo, aunque no estoy 
afirmando que no sea un tema existente en dicha tradición, el liberalismo norteamericano fue fundado y se ha centrado siempre en la importancia de la Unión. La guerra civil norteamericana fue, contrario a como ocurrió en otros lugares en donde los conflictos civiles iniciaron por demandas religiosas o de justicia distributiva, fundamentalmente una guerra para mantener la Unión, como lo mencioné en el capítulo segundo. Esta preocupación ha estado presente en el pensamiento político norteamericano desde su génesis, incluso desde la publicación de los ensayos del Federalista: "La conclusión del décimo ensayo del Federalista es familiar: Contrario al conocimiento convencional que afirma que los gobiernos populares sólo pueden existir en ciudades pequeñas y homogéneas, sólo en una república extendida, con una amplia variedad de grupos, y con un "esquema de representación" puede curar los efectos del defecto mortal del gobierno popular, la "facción". "12

El mantenimiento de la Unión, que está amenazada por la facción, supone algunos de los conceptos que están presentes en esta tradición liberal de la que Rawls y Dewey son parte. Por un lado, debido a la historia de persecuciones y migraciones europeas, que dieron origen a las Colonias, supone la existencia del pluralismo religioso y cultural. Del mismo modo, dan por sentado, en ambos casos, la adecuación de la democracia representativa (aunque en Dewey el concepto es mucho más rico no deja de incluir la representación) como la manera en la que los intereses de las facciones puedan ser controlados. Otro factor importantísimo, presente en la tradición americana (dentro de esta no cuento a la escuela neoliberal de Chicago, en la medida en que ésta es heredera directa de la tradición liberal económica austriaca), es un cierto igualitarismo pues, como menciona Epstein: "La mayoría de los interpretes se han enfocado en las facciones que se movilizan por intereses económicos. Mientas que estas son, de hecho, las "más comunes y durables" facciones en los regímenes liberales modernos, Madison describe una categoría separada de facciones movilizadas por su apasionada adhesión a opiniones falibles." ${ }^{13}$ En este análisis se ven dos características típicas de los liberalismos de Rawls y de Dewey: por un lado la preocupación por la desigualdad económica (no únicamente por sus implicaciones respecto a las divisiones internas que genera sino, en mayor medida, por la injusticia que implican dicha desigualdad) $\mathrm{y}$, por otro, un cierto falibilismo, presente en la naturaleza

\footnotetext{
${ }^{12}$ David Epstein, The Political Theory of The Federalist (The University of Chicago Press: Chicago, 1984). 59

${ }^{13}$ Ibid. 60
} 
pragmática del pensamiento de Dewey y, en el caso de Rawls, en las cargas del juicio.

Intentar capturar la esencia del liberalismo americano en unas pocas líneas sería imposible. Afirmar que la totalidad de sus conceptos relevantes están presentes en Dewey y en Rawls sería un error. Sin embargo, ambos pensadores son parte de esta tradición. Una tradición que reconoce que la verdad puede ser un valor menos relevante en el ámbito político que la utilidad; que se interesa por el igualitarismo porque, desde el principio, la Unión se definió como un lugar donde todos los hombres son iguales y las facciones tienden a surgir con el trato desigual (aunque la sombra de la esclavitud se mantenga siempre presente); y que está abierta al progreso y a la posibilidad de pensar cómo construir una mejor sociedad. 


\section{Bibliografía}

Alejandro, Roberto. The Limits of Rawlsian Justice. Baltimore: Johns Hopkins University Press, 1998.

Arendt, Hannah. La condición humana. Barcelona: Paidós, 2007.

Barber, Bejamin. “Justifying Justice: Problems of Psychology, Measurement, and Politics in Rawls", The American Political Science Review vol 69 no 2 (1975). 664

- - Strong democracy, participatory politics for a new age. Berkeley: University of California Press, 2003.

Barry, Brian. The Liberal Theory of Justice. Londres: Oxford University Press, 1973.

- - "John Rawls and the Search for Stability"; Ethics, vol. 105 no. 4 (1995).

- - . Culture and Equality. Cambridge: Harvard University Press, 2001.

Brooks, Thom y Freyenhagen, Fabian. The Legacy of John Rawls. Londres: Continuum, 2005.

Callan, Eamon. "Political Liberalism and Political Education"; The Review of Politics, vol. 58 no. 1 (1996).

Carbonell, Miguel. Una historia de los derechos fundamentales. México: Porrúa 2010.

Cohen, Joshua. "Truth and public reason"; Philosophy E Public Affairs, col. 37 no. 1 (2009).

Dahl, Robert. On Democracy. Londres: Yale University Press, 2000.

- - . A preface to democratic theory. Chicago: The university of Chicago press, 2005.

Davis, Ryan. "Justice: Metaphysical, After All?"; Ethical Theory and Moral Practice vol. 14 no. 2 (2011).

Dewey, John. Ethics. Nueva York: Henry Holt and Company, 1908.

- - . Freedom and Culture. Nueva York: Prometheus Books, 1989.

- - . Logic. Nueva York: Saerchinger Press, 2007.

- - Principles of Instrumental Logic, editado por Donald Koch. Carbondale: Southern Illinois University Press, 1998.

- - "Beliefs and Realities", The Philosophical Review vol. XV no. 2 (1906): 113.

- - "What Does Pragmatism Mean by Practical?", The Journal of Philosophy, Psychology and Scientfic Methods vol. 5 no. 4 (1908): 93.

- - " Progress", International Journal of Ethics vol. 25 no. 3 (1916).

- - "Common Sense and Science: Their Respective Frames of Reference", The Journal of Philosophy vol. 45 no. 8 (1948). 
- -. "Perception and Organic Action", The Journal of Philosophy, Psychology and Scientific Methods vol. 9 no. 24 (1912).

- -. "The Realism of Pragmatism", The Journal of Philosophy, Psychology and Scientific Methods vol. 2 no. 12 (1905).

- -. "The Subject-Matter of Metaphysical Inquiry", The Journal of Philosophy, Psychology and Scientific Methods vol. 12 no. 13 (1915).

- -. "The Experimental Theory of Knowledge", Mind, New Series vol. 15 no. 59 (1906).

- -. "Propositions, Warranted Assertibility, and Truth", The Journal of Philosophy vol. 38 no. 7 (1941).

- -. "Reality as Experience", The Journal of Philosophy, Psychology and Scientific Methods vol. 3 no. 10 (1906).

- -. "The Ambiguity of 'Intrinsic Good'", The Journal of Philosophy vol. 39 no. 12 (1942).

- -. The Public and its Problems. Atenas Ohio: Swallow Press y Ohio University Press, 1954.

- - . Liberalism and Social Action. Reno: Frederick Ellis.

- - . Experience E Education. Nueva York: Touchstone, 1997.

- - Democracy and Education. Dehli: Aakar, 2013.

Enslin, Penny. "Education and the Limits of Political Liberalism"; Theoria: A Journal of Socail and Political Theory, no. 90 (1997).

Epstein, David. The Political Theory of The Federalist. Chicago: The University of Chicago Press, 1984.

Fesmire, Steven. John Dewey \& Moral Imagination. Bloomington: Indiana University Press, 2003.

- -. "Dramatic Rehearsal and The Moral Artist: A Deweyan Theory of Moral Understanding", Transactions of the Charles S. Pierce Society, vol. XXXI no. 3 (1995).

- - . "Morality as Art: Dewey, Metaphor, and Moral Imagination", Transactions of the Charles S. Pierce Society vol. 35 no. 3 (1999).

Freeman, Samuel. Rawls. Nueva York: Routledge, 2007.

- - . Justice and the Social Contract. Nueva York: Oxford University Press, 2007.

Fromm, Erich. El miedo a la libertad. Barcelona: Paidós, 1964.

Fukuyama, Francis. "The End of History?"; The National Interest, no. 16 (1989).

- - . The end of History and the Last Man. Nueva York: The Free Press, 1992.

Garrison, Jim. Recontextualizing Dewey. Albany: State University of New York Press, 2008. 
George, Robert P. "Public Reason and Political Conflict: Abortion and Homosexuality"; The Yale Law Journal, vol. 106 no. 8 (1997)

Geuss, Raymond. Philosophy and Real Politics. Princeton: Princeton University Press, 2008.

Gutmann, Amy. "Civic Education and Social Diversity"; Ethics, vol. 105 no. 3 (1995).

Habermas, Jurgen. "Reconciliation Through the Public use of Reason: Remarks on John Rawls's Political Liberalism"; The Journal of Philosophy, vol. 92 no. 3 (1995)

Hardin, Russell. Liberalism, Constitutionalism, and Democracy. Oxford: Oxford University Press, 1999.

Harsanyi, John. "Can the Maximin Principle Serve as a Basis for Morality? A Critique of John Rawls Theory"; The American Political Science Review vol. 69 no 2 (1975).

Hart, H. L. A. Law, liberty and Morality. Stanford: Stanford University Press, 1963.

Hedick, Rodd. Rawls and Habermas; Reason, Pluralism and the Claims of Political Philosophy. Stanford: Stanford University Press, 2010.

Hobbes, Thomas. Leviathan. Indianápolis: Hackett Publishing, 1994.

Kirk, Russell. The Conservative Mind, From Burke to Eliot. Washington: Regnery Publishing, 1985.

Kuhn, Thomas. La estructura de las revoluciones científicas. Buenos Aires: Fondo de Cultura Económica, 2004.

Larmore, Chaels. The Autonomy of Morality. Cambridge: Cambridge University Press, 2008.

Lewis, David. Justice or Tyranny. Londres: Kennikat press 1979.

- - . Iliberal Justice. Columbia: University of Missouri Press, 2007.

Lister, Andrew. "Public Reason and Moral Compromise"; Canadian Journal of Philosophy, vol. 37 no. 1 (2007).

Mandle, Jon. Rawl's A Theory of Justice, an introduction. Cambridge: Cambridge University Press, 2009.

Mouffe, Chantal. "The Limits of John Rawls' Pluralism"; Theoria: A Journal of Social and Political Theory, vol. 56 no. 118 (2009).

Nagel, Thomas. "Rawls: sobre la justicia" en Otras mentes. Barcelona: Gedisa, 2000.

Nell, Onora. "A Theory of Justice", Journal of Economic Issues vol. 7 no. 4 (1973): 665.

Nussbaum, Martha. The fragility of goodness. Nueva York: Cambridge University Press, 1986.

- - Libertad de conciencia, trad. Alberto Álvarez y Araceli Benítez. México: Tusquetes Editores, 2009. 
Nozick, Robert. Anarchy, State, And Utopia. Oxford: Blackwell Publishers, 1974.

O'Neill, Daniel. "Multicultural Liberals and the Rushdie Affair", The Review of Politics vol. 61 no. 2 (1999).

Olson, Kevin. "Legitimate Speech and Hegemonic Idiom: The Limits of Deliberative Democracy in the Diversity of its Voices", Political Studies vol. 59 (2011).

Pogge, Thomas. Realizing Rawls. Ithaca: Cornell University Press, 1989.

- -. John Rawls; His Life and Theory of Justice. Oxford: Oxford University Press, 2007.

Posner, Richard. Law, Pragmatism, and Democracy. Cambridge: Harvard University Press, 2003.

Putnam, Hilary. El desplome de la dicotomía hecho-valor, trad. Francesc Forni Argimon. Barcelona: Paidós, 2004.

- - . El Pragmatismo. Sevilla: Gedisa, 2006.

- - . Ethics without Ontology. Cambridge: Harvard University Press, 2004.

- -. "Meaning and Reference", The Journal of Philosophy vol. 70 no. 19 (1973).

- -. "Reply to Two Realists", The Journal of Philosophy vol. 79 no. 10 (1982).

Rawls, John. "Justice as Fairness"; The Philosophical Review, vol. 67 no. 2 (1958).

- -. "Réplica a Habermas", en Debate sobre el liberalismo político, ed. Fernando Vallespín. Barcelona: Paidós, 1998.

- - . A Theory of Justice. Cambridge, Harvard University Press, 1999.

- - Justice as Fairness, a restatement, ed. Erin Kelly. Estados Unidos de América: Harvard University Press, 2001.

- - Political Liberalism. Nueva York: Columbia University Press, 2005.

- - . The Law of Peoples. Cambridge: Harvard University Press, 1999.

- - . Collected Papers. Cambridge: Harvard University Press, 1999.

Raz, Joseph. Morality of Freedom. Oxford: Oxford University Press, 1986.

Rodríguez Zepeda, Jesús. La política del consenso, Una lectura crítica de El liberalismo político de John Rawls. Barcelona: Anthropos, 2003.

- - El igualitarismo liberal de John Rawls. México: Miguel Ángel Porrúa, 2010.

Rorty, Richard. "Charles Taylor en torno a la verdad", en Verdad y progreso, trad. Ángel Faerna García. Barcelona: Paidós, 2000.

- -. "Hilary Putnam y la amenaza del relativismo", en Verdad y progreso, trad. Ángel Faerna García. Barcelona: Paidós, 2000.

- - Consequences of Pragmatism. Minneapolis: University of Minnesota Press, 1982.

- -. "La justicia como lealtad ampliada" en Filosofía y Futuro. Barcelona: Gedisa 2002. 
- -. "Is Truth a Goal of Enquiry?", The Philosophical Quarterly vol. 45 no. 180 (1995)

- -. "Putnam on Truth", Philosophy and Phenomenological Research vol. 52 no. 2 (1992)

Ruderman, Richard y Godwin, Richard: "Liberalism and parental control of education"; The Review of Politics, vol. 62 no. 3, (2000).

Ryan, Alan. John Dewey and the high tide of American Liberalism. Norton: Nueva York, 1997.

- - . The Making of Modern Liberalism. Princeton: Princeton University Press, 2012.

Sandel, Michael. "On Republicanism and Liberalism”, entrevista por Leif Wenar y Ching-Min Hong, The Harvard Review of Philosophy, Primavera (1996).

- - . El liberalismo y los límites de la justicia, trad. María Luz Melon. Barcelona: Gedisa, 2000.

Savage, Daniel. John Dewey's Liberalism. Southern Illinois University Press: Illinois, 2002.

Schumpeter, Joseph. Capitalism, Socialism and Democracy. Nueva York: Harper Perennial, 2008.

Searle, John. Libertad y neurobiología, trad. Miguel Candel. Barcelona: Paidós, 2005.

Shklar, Judith. "Liberalism of Fear", en Political Thought \& Political Thinkers, ed. Stanley Hoffman. Chicago: The University of Chicago Press, 1998.

- -. "Montesquieu and the New Republicanism", en Political Thought \& Political Thinkers.

Shook, John t Margolis, Joseph. A Companion to Pragmatism. Oxford: Blackwell, 2006.

Stiglitz, Joseph. El precio de la desigualdad. México: Taurus 2012.

Taylor, Charles. "Paralelisms between Heidegger and Wittenstein", en Philosophical Arguments. Cambridge: Harvard University Press, 1995.

- -. Sources of the Self. Cambridge: Harvard University Press, 1989.

Tiles, J. E. Dewey. Londres: Routledge, 1988.

Vanderveen, Zach. "Pragmatism and Democratuc Legitimacy: Beyond Minimalist Accounts of Deliberation", Journal of Speculative Philosophy vol. 21 no. 4 (2007).

Welchman, Jennifer. "Dewey's Moral Philosophy" en The Cambridge Companion to John Dewey, ed. Molly Cochran. Nueva York: Cambridge University Press, 2010.

Williams, Bernard. "In the Beginning Was the Deed", en In the Beginning Was the Deed. Princeton: Princeton University Press, 2005. 
LIBERALISMO Y PRAGMATISMO: UNA LECTURA DE LA JUSTICIA

COMO IMPARCIALIDAD DESDE EI

PRAGMATISMO DE JOHN DEWEY

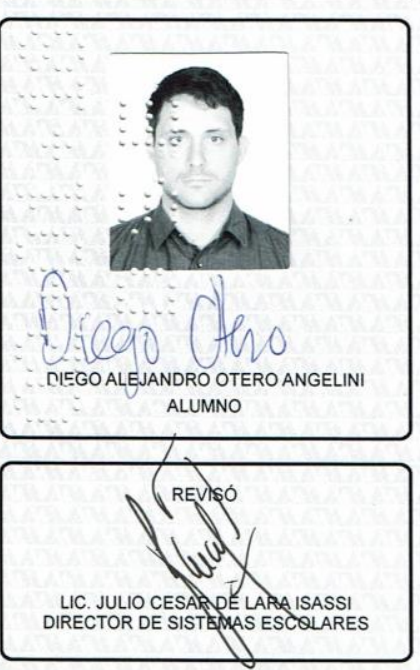

Bajo la Presidencia de la primera y con carácter de Secretario el último, se reunieron a la presentación de la Disertacion Publica cuya denominación aparece al margen para la obtención del grado de:

DOCTOR EN HUMANIDADES (FILOSOFIA)

DE: DIEGO ALEJANDRO OTERO ANGELINI

de acuerdo con el artículo 78 fracción IV del Reglamento de Estudios Superiores de la Universidad Autónoma Metropolitana, los miembros del jurado resolvieron:

\section{Grobae}

Acto continuo, la presidenta del jurado comunicó al interesado el resultado de la evaluación y, en caso
aprobatorio, le fue tomada la protesta.
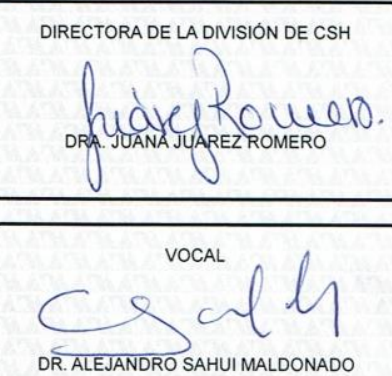
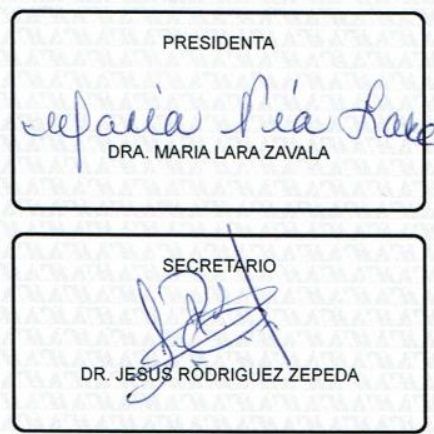